\title{
L'Europe dans le monde du football
}

Genèse et formation de I'UEFA (1930-1960)

Philippe Vonnard

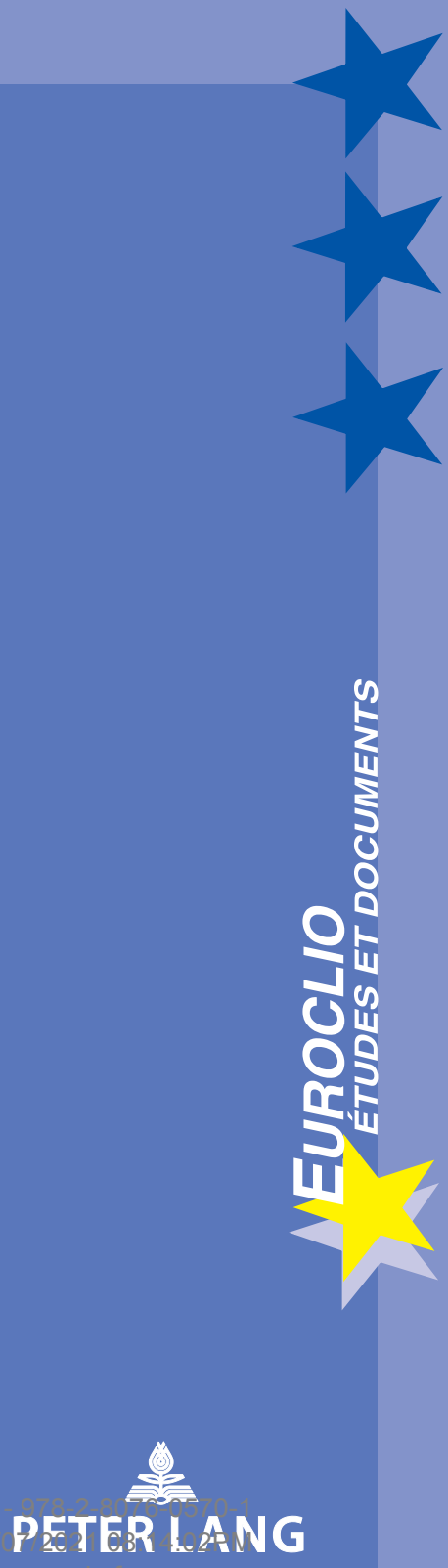


Comment expliquer la popularité du football à l'échelle européenne ? Une des pistes pour répondre à cette question est d'étudier le rôle de l'Union des associations européennes de football (UEFA) qui n'a eu de cesse d'agir en vue de renforcer les échanges footballistiques au niveau européen. À partir du dépouillement d'archives inédites, ce livre répond à un vide historiographique en proposant de retracer la genèse et la formation de I'UEFA dans une perspective globale et qui privilégie le long terme. Nous défendons ici la thèse que la mise en place de cette organisation au milieu des années 1950 est un tournant dans I'histoire du football européen.

Trois axes principaux complémentaires sont développés tout au long de cet ouvrage. Le premier traite du rôle de la FIFA (Fédération internationale de football association), puis de I'UEFA dans le développement d'une dynamique européenne du jeu. Le deuxième questionne la possibilité qu'ont les dirigeants du football de créer un organisme qui transcende les barrières de la Guerre froide (à sa fondation, I'UEFA compte une trentaine de pays européens). Finalement, le troisième interroge les raisons de la constitution de l'UEFA durant les années 1950 ainsi que le modèle d'organisation choisi par ses promoteurs.

Philippe Vonnard est Docteur ès sciences du sport et de l'éducation physique de I'Université de Lausanne. Ses recherches portent sur l'histoire transnationale des sports. II a publié plusieurs articles scientifiques sur cette thématique et récemment coordonné Building Europe with the Ball (2016) et Beyond Boycotts. Sport during the Cold War in Europe (2017). Chercheur associé à I'Institut für Europäische Sportenwicklung und Freizeitforschung (IESF) de la Deustche Sporthochschule de Cologne et de l'Institut des sciences du sport de l'Université de Lausanne (ISSUL), il est un membre actif du d'études des relations internationales sportives (RERIS). 


\section{L'EUROPE DANS LE MONDE DU FOOTBALL}

\section{GENÈSE ET FORMATION DE L'UEFA (1930-1960)}

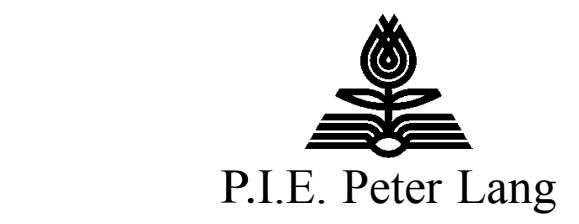

Bruxelles $\cdot$ Bern $\cdot$ Berlin $\cdot$ New York $\cdot$ Oxford $\cdot$ Wien

Philippe Vonnard - 978-2-8076-0570-1

Téléchargé de PubFactory à01/07/2021 08:14:02PM 
EUROCLIO est un projet scientifique et éditorial, un réseau d'institutions de recherche et de chercheurs, un forum d'idées. EUROCLIO, en tant que projet éditorial, comprend deux versants : le premier versant concerne les études et documents, le second versant les instruments de travail. L'un et l'autre visent à rendre accessibles les résultats de la recherche, mais également à ouvrir des pistes en matière d'histoire de la construction/intégration/unification européenne.

La collection EUROCLIO répond à un double objectif : offrir des instrumentsde travail, de référence, à la recherche ; offrir une tribune à celle-ci en termesde publication des résultats. La collection comprend donc deux séries répondant à ces exigences : la série ÉTUDES ET DOCUMENTS et la série RÉFÉRENCES. Ces deux séries s'adressent aux bibliothèques générales et/ou des départements d'histoire des universités, aux enseignants et chercheurs, et dans certains cas, à des milieux professionnels bien spécifiques.

La série ÉTUDES ET DOCUMENTS comprend des monographies, des recueils d'articles, des actes de colloque et des recueils de textes commentés à destination de l'enseignement.

La série RÉFÉRENCES comprend des bibliographies, guides et autres instruments de travail, participant ainsi à la création d'une base de données constituant un «Répertoire permanent des sources et de la bibliographie relatives à la construction européenne ».

Sous la direction de

Éric BUSSIÈRE, Université de Paris-Sorbonne (France), Michel DUMOULIN, Louvain-la-Neuve (Belgique), \& Antonio VARSORI, Universitá degli Studi di Padova (Italia) 


\title{
L'EUROPE DANS LE MONDE DU FOOTBALL
}

\section{GENÈSE ET FORMATION DE L'UEFA (1930-1960)}

Philippe Vonnard

Euroclio

\author{
Vol. 105
}

Philippe Vonnard - 978-2-8076-0570-1

Téléchargé de PubFactory à01/07/2021 08:14:02PM 
Imprimé avec le soutien de la Fondation de I'UNIL, du Fonds des publications de l'UNIL, de la Société académique vaudoise, du LabEx EHNE et de I'Union des associations européennes de football associations (UEFA).

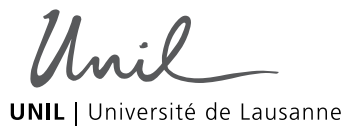

Société Académique Vaudoise

\section{$\left\{\begin{array}{l}\text { FONDATION } \\ \text { POUR L'UNIVERSITÉ } \\ \text { DE I.ALSANNE }\end{array}\right.$}

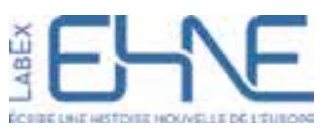

Cette publication a fait l'objet d'une évaluation par les pairs. Toute représentation ou reproduction intégrale ou partielle faite par quelque procédé que ce soit, sans le consentement de l'éditeur ou de ses ayants droit, est illicite.

Tous droits réservés.

(C) P.I.E. PETER LANG S.A.

Éditions scientifiques internationales

Bruxelles, 2018

1 avenue Maurice, B-1050 Bruxelles, Belgium

www.peterlang.com; brussels@peterlang.com

ISSN 0944-2294

ISBN 978-2-8076-0564-0

ePDF 978-2-8076-0569-5

ePUB 978-2-8076-0570-1

MOBI 978-2-8076-0571-8

DOI 10.3726/b13912

D/2018/5678/43

«Die Deutsche Bibliothek » répertorie cette publication dans la « Deutsche Nationalbibliografie »; les données bibliographiques détaillées sont disponibles sur le site http://dnb.ddb.de. 
À mes parents

Philippe Vonnard - 978-2-8076-0570-1

Téléchargé de PubFactory à01/07/2021 08:14:02PM

via free access 
Philippe Vonnard - 978-2-8076-0570-1

Téléchargé de PubFactory à01/07/2021 08:14:02PM

via free access 


\section{Table des matières}

Listes des abréviations majeures

Avant-propos et remerciements

Préface

Introduction générale

\section{Partie 1}

GENÈSE DE L'UEFA (1930-1949)

\section{Chapitre 1. L'affirmation du pouvoir de la FIFA} sur le football mondial (1930-1938) 45

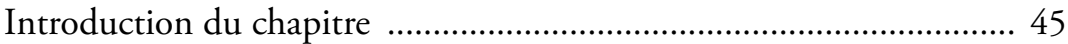

1.1. Une organisation européenne du football ? ............................... 47

1.1.1. Une plateforme d'échanges ........................................... 48

1.1.2. Dynamiser les échanges et définir un territoire européen ... 55

1.1.3. En dehors de l'Europe. Le cas des Britanniques et des Soviétiques ............................................................... 64

1.1.4. Réunir les Européens ? Les matchs de la FIFA de 1937 et 1938 .............................................................. 72

1.2. Créer une "Société des nations sportives " ................................. 79

1.2.1. Jules Rimet : l'autre Coubertin ? ..................................... 80

1.2.2. Développer les échanges footballistiques internationaux : sociographie de l'élite dirigeante ............ 86

1.2.3. Construire une " autonomie " sur la scène internationale ... 92

1.2.4. Prôner l'apolitisme et le consensus .................................. 98

1.3. Quelle place pour «l'autre continent du football » ? .................. 105

1.3.1. L'Europe comme épicentre .......................................... 106

1.3.2. Une première contestation de l'hégémonie européenne ... 111 
Chapitre 2. La souveraineté de la FIFA remise en cause (1939-1948) ............................................................... 123

Introduction du chapitre ............................................................... 123

2.1. L'élargissement du territoire européen ..................................... 124

2.1.1. La persistance des échanges footballistiques européens durant la guerre ............................................ 125

2.1.2. Le retour des associations britanniques .......................... 132

2.1.3. L'intégration de l'URSS ................................................... 137

2.1.4. Le match de la FIFA (1948) : le symbole de l'unité européenne ? .......................................................... 142

2.2. Une position en péril sur la scène internationale ....................... 144

2.2.1. Faire face à l'Europe sportive des forces de l'Axe ............ 144

2.2.2. Entre oubli et réécriture de l'histoire .............................. 154

2.2.3. De la gestion de la guerre à l'entrée en Guerre froide ..... 162

2.3. L'émergence d'un contre-pouvoir américain .............................. 171

2.3.1. La structuration de la Confédération sud-américaine ..... 172

2.3.2. Créer une contre-organisation ? ..................................... 178

Conclusion de la partie ……………………………………......... 187

\section{Partie 2 \\ FORMATION DE L'UEFA (1949-1960)}

ChAPITRE 3. La continentalisation de la FIFA (1949-1953) ......... 193

Introduction du chapitre ............................................................... 193

3.1. Réorganiser le football européen ? ............................................. 194

3.1.1. Une nouvelle phase de l'européanisation du jeu ............. 194

3.1.2. La prise d'importance du trio Barassi, Rous, Thommen ... 201

3.1.3. La mise sur pied d'un " petit Conseil de l'Europe du football " ..................................................... 211

3.2. Entre internationalisation et Guerre froide ................................. 221

3.2.1. Une deuxième phase de mondialisation .......................... 221

3.2.2. S'accorder sur une réorganisation .................................... 229

3.2.3. Les revendications du bloc soviétique ............................. 234 
3.3. Suivre le modèle sud-américain ..................................................... 244

3.2.1. Un match Europe-Amérique du Sud ............................ 244

3.2.2. Le « compromis Thommen " .......................................... 256

Chapitre 4. La création de l'UEFA (1954-1960) .......................... 263

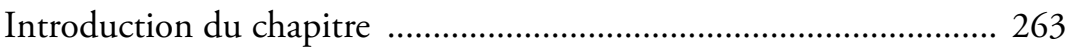

4.1. Dynamiser le football européen ............................................... 265

4.1.1. Un organe faitier pour le football européen .................... 265

4.1.2. Quelles sont les frontières du football européen ? ........... 281

4.1.3. Le succès de l'Europe des clubs ....................................... 289

4.1.4. La difficile émergence de l'Europe des nations ............... 298

4.2. Un nouvel acteur européen ...................................................... 304

4.2.1. L'ombre de la Guerre froide ............................................ 305

4.2.2. "Accord et désaccord » avec la FIFA ................................ 317

4.2.3. Neutraliser les concurrences ........................................... 326

4.2.4. Interagir avec d'autres organisations européennes .......... 333

4.2.5. Un acteur " atypique " de la coopération européenne .... 341

4.3 Un modèle pour les autres groupements continentaux ? ........... 347

4.3.1. La continentalisation effective de la FIFA ...................... 348

4.3.2. Un « effet retour » sur la Confédération sud-américaine ... 356

Conclusion de la partie …………………………………………. 363

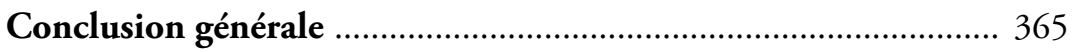

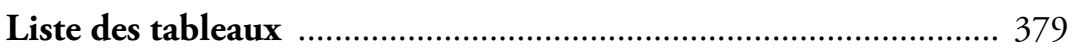

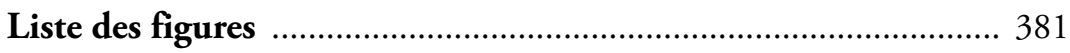

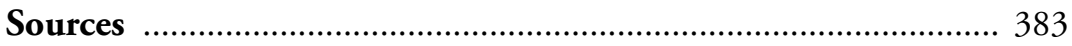

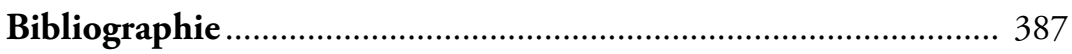

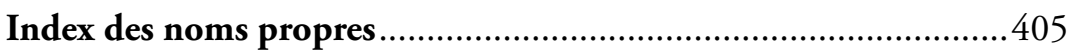


Philippe Vonnard - 978-2-8076-0570-1

Téléchargé de PubFactory à01/07/2021 08:14:02PM

via free access 


\section{Listes des abréviations majeures}

$\begin{array}{ll}\text { AELE } & \text { Association européenne de libre-échange } \\ \text { ASF } & \text { Association suisse de football } \\ \text { CECA } & \text { Communauté européenne du charbon et de l'acier } \\ \text { CEE } & \text { Communauté économique européenne } \\ \text { CIO } & \text { Comité international olympique } \\ \text { CONMEBOL } & \text { Confederación sudamericana de fútbol } \\ \text { DFB } & \text { Deutsche Fussball Bund } \\ \text { FA } & \text { Football Association } \\ \text { FFF (3F) } & \text { Fédération française de football } \\ \text { FIFA } & \text { Fédération internationale de football association } \\ \text { IB } & \text { International Board } \\ \text { ONU } & \text { Organisation des Nations unies } \\ \text { SDN } & \text { Société des Nations } \\ \text { UEFA } & \text { Union des associations européennes de football } \\ \text { UER } & \text { Union européenne de radio } \\ \text { URBSFA } & \text { Union royale belge des sociétés de football association }\end{array}$


Philippe Vonnard - 978-2-8076-0570-1

Téléchargé de PubFactory à01/07/2021 08:14:02PM

via free access 


\section{Avant-propos et remerciements}

Ce livre est un remaniement de ma thèse de doctorat intitulée "Genèse du football européen. De la FIFA à l'UEFA (1930-1960) ", préparée à partir d'octobre 2010 à l'Université de Lausanne (UNIL) et défendue au sein de cette même institution en décembre 2016. Cet ouvrage a en outre bénéficié de nouvelles réflexions effectuées dans le cadre d'une recherche postdoctorale débutée en février 2017 au sein de l'Institut des sciences de la communication du CNRS (ISCC) de Paris et financée par le Fonds national suisse de la recherche scientifique (FNS). Dans le courant de l'été 2017, Marion Beetschen a effectué une patiente relecture sur le fond qui a amené à de nombreux ajustements. Ce fut une coopération très enrichissante et je me permets ici de la remercier chaleureusement pour son excellent travail.

La présente publication n'aurait pu être réalisée sans le soutien financier de différentes organisations. Â ce titre, je remercie sincèrement la Fondation et le Fonds des publications de l'UNIL, le LabEx «Écrire une histoire nouvelle de l'Europe » (EHNE), la Société académique vaudoise et l'Union des associations européennes de football (UEFA) pour leur soutien envers ma démarche. J'en profite également pour remercier l'éditeur, P.I.E. Peter Lang, d'avoir accepté de publier ce manuscrit dans sa collection "Euroclio ", ce qui constitue une entreprise quasiment pionnière puisque, sur les 100 numéros y étant déjà parus, un seul jusqu'ici avait été consacré au domaine sportif (Le continent basket publié en 2015). À ce titre, ma gratitude va particulièrement à Éric Bussière, membres du comité de rédaction de la collection, pour son intérêt envers mon travail ainsi qu'à Thierry Waser pour sa constante disponibilité tout au long du processus d'édition. Par ailleurs, je remercie Sylvain Schirmann, qui m'a fait la grande gentillesse d'accepter de préfacer l'ouvrage.

Ce livre n'aurait pu aboutir sans le concours et le soutien de nombreuses personnes ${ }^{1}$, qui ne pourront toutes être indiquées dans ces quelques lignes. Je remercie sincèrement mes deux directeurs de thèse, Nicolas Bancel et Thomas David, pour leur constant soutien, leurs précieux conseils et leur suivi continu. Ce fut indéniablement une grande chance d'être suivi par ces deux professeurs. Je remercie également les membres du jury de ma

1 Dans ce livre, l'emploi du masculin préyaut pour le féminin etele masculin 
thèse, à savoir Jürgen Mittag, Fabien Ohl et Sandrine Kott pour leurs relectures attentives et leurs pertinents commentaires.

Un salut tout particulier à Nicolas Bouchet, documentaliste à l'UEFA, pour sa disponibilité, sa gentillesse ainsi que son constant intérêt pour mes recherches. De même, je remercie Dominik Petermann, collaborateur à la Fédération internationale de football association (FIFA), qui m’a toujours agréablement reçu et mis dans de bonnes conditions pour réaliser mes recherches, ainsi qu'Andreas Huber de l'Association suisse de football (ASF) et Filip Strubbe, des Archives générales du Royaume de Belgique (AGRB).

Sur différents aspects de cet ouvrage, je suis redevable à Clément Astruc, Jérôme Berthoud, Xavier Breuil, Paul Dietschy, Yannick Deschamps, Sylvain Dufraisse, William Gasparini, Lorenzo Jalabert D'Amado, Claire Nicolas, Kevin Tallec Marston, Sébastien Moreau, Nicola Sbetti, Manuel Schotté, Albrecht Sonntag et Quentin Tonnerre pour les intéressants échanges, leurs précieux conseils et autres relectures. J’adresse un salut amical également à Léonard Laborie et Christian Wenkel pour les discussions soutenues que nous entretenons depuis le début de l'année 2017 dans le cadre du projet LabEx EHNE. Et je n'oublie pas la précieuse aide de André Vieli - collaborateur au service de presse de l'UEFA de 1982 à 2012 et qui a écrit le livre commémoratif des 60 ans de l'UEFA - qui m'a fait le grand plaisir de relire entièrement ma thèse et de me faire part de ses commentaires et autres questionnements.

Pour conclure, j'adresse mes pensées à quatre personnes. Tout d'abord, un immense merci à Grégory Quin, avec qui je partage cette passion pour l'histoire contemporaine depuis le printemps 2010. Je ne compte plus les colloques auxquels nous avons pris part ensemble, ni les voyages effectués, ni même les nombreux coups de main ou conseils avisés reçus de sa part. Ensuite, je souhaite embrasser tendrement mes exceptionnels parents, qui m'ont toujours soutenu dans mes démarches et dont la maison est un havre de paix et de réconfort. Enfin, mon ultime, mais aussi ma première, pensée va à, Luz Yenny Romero Rodriguez. Merci, Luz, de m’avoir ouvert l'esprit sur le monde, de m'avoir donné le goût des langues étrangères, de me pousser à davantage me décentrer. Merci du fond du cœur d'être là. Te quiero muchissimo!

Paris, février 2018

Philippe Vonnard 


\section{Préface}

L'histoire de la construction européenne a largement privilégié l'étude de la genèse et des développements ultérieurs de l'Europe communautaire. Elle en a fixé les rythmes, à travers une succession de crises et de relances bien connue. Si cette historiographie a dominé la production académique, progressivement des histoires sectorielles des coopérations existantes en Europe ont permis d'affiner un processus d'européanisation qui s'est accéléré depuis la Seconde Guerre mondiale. Les milieux économiques, leurs interactions ont par exemple été étudiés dans leurs rapports à l'Europe. Ces travaux ont montré combien ces coopérations et ces hommes d'affaires ont non seulement influencé les projets politiques européens, mais également combien ils avaient conscience d'une nécessité d'Europe face à d'autres parties de la planète.

Ces coopérations existent également avec le même impact dans d'autres secteurs, ce qui fait qu'il faut parler d'Europes plurielles : une Europe de la technologie, une Europe de la culture, une Europe du syndicalisme. Depuis maintenant trois décennies, l'histoire du sport a, à son tour, approché l'Europe à travers les coopérations entre ses acteurs. Philippe Vonnard s'inscrit avec cet ouvrage dans cette dynamique impulsée par les travaux pionniers d'Alfred Wahl, de Pierre Lanfranchi ou plus récemment d'un Paul Dietschy. Il se penche sur «l'Europe dans le monde du football » des années 1930 aux années 1960, une période charnière pour l'affirmation de l'Europe footballistique.

Le travail est riche par les convergences qu'il met en exergue. La première phase, avant la Deuxième Guerre mondiale, est marquée par une double évolution : la structuration du football est internationale d'un côté, et l'émergence par touches d'affirmation d'une coopération européenne se fait de l'autre. Si la FIFA domine l'organisation internationale du football, s'affiche comme organisatrice du spectacle sportif, des initiatives européennes existent. Ces dernières, si elles sont infrarégionales en matière de compétition, n'en intéressent pas moins un public plus large que celui des seuls participants, comme le montrent les rencontres de la Mittel Europa Cup. Mais cela ne débouche pas sur une institutionnalisation européenne du football. Contexte et organisation de la FIFA l'expliquent pour une large part. À l'époque des nationalismes agressifs, dans le sport comme ailleurs, des organisations européennes avaient peu de chances de voir le 
jour. Mais surtout, l'internationalisme se confond avec l'européanisme, tant les organisations internationales gouvernementales ou non sont dominées par les Européens. C'est également le cas du mouvement sportif dans son ensemble, et du football en particulier.

L'immédiat après-guerre offre une fenêtre d'opportunité. L'Europe n'est plus le centre du monde, mais surtout n'est plus libre de son destin. La guerre froide le rappelle, et dès lors les milieux européens réfléchissent à d'autres structurations du continent. Mais il faut aussi faire face à d'autres régionalismes plus affirmés. Sur le plan politique la Conférence panaméricaine est largement antérieure à des organisations paneuropéennes. Dans le domaine du football, les élites latino-américaines sont les premières à faire émerger une fédération régionale du football et à contester la domination européenne au sein de l'instance internationale. Davantage encore, il y a des opportunités nouvelles qui s'offrent progressivement. Les miracles économiques conditionnent le développement des transports, la construction des stades, leur équipement et la diffusion de l'information relative au football. Ils favorisent l'émergence d'un espace public européen du football. C'est dans ce contexte que naît l'UEFA.

Philippe Vonnard en présente la genèse dans une perspective de longue durée, montrant par là qu'à travers la construction d'une Europe du football, on traverse les grandes problématiques de l'histoire des constructions européennes. Cela lui permet à l'évidence de souligner également les traits originaux de l'Europe du football. Les dirigeants du football choisissent la grande Europe, englobant la Russie et la Turquie, enjambant le rideau de fer. Ils se démarquent d'autres régionalismes, comme celui du continent sud-américain, pour continuer à peser sur le football international, comme d'autres réseaux et acteurs européens essaient, à travers leur coopération sectorielle d'exister à l'échelle internationale. L'Europe est ainsi le nouveau vecteur de l'influence internationale pour des élites, y compris les élites du football. L'introduction de l'échelon européen dans l'organisation et la diffusion du football complexifie les relations au sein de l'espace footballistique. Il faut faire coexister les acteurs locaux (clubs, fédérations régionales), les acteurs nationaux, l'acteur européen et l'organisation internationale. Un jeu multi-scalaire se met ainsi en place, comme pour d'autres sports, ou encore d'autres domaines d'activités en Europe.

C'est donc à la mise en place d'une organisation politique internationale que nous invite Philippe Vonnard. Politique, elle l'est car elle tente de neutraliser les conflits entre ses membres ; car elle occupe un espace public de plus en plus vaste ; car elle mobilise des moyens étatiques pour l'organisation d'un spectacle privé. Politique, elle l'est par la diplomatie 
interétatique qu'elle permet; par les opinions publiques qu'elle mobilise. Mais elle est également lieu d'hybridation pour des élites qui viennent d'autres mondes : mondes économiques, monde des médias (dont le nouveau vecteur contemporain de l'UEFA : la télévision), monde du journalisme, supporters, etc.

Le mérite de Philippe Vonnard c'est d'avoir mis en scène, grâce à l'emploi d'une importante et inédite documentation, cette Europe du football, riche de sa diversité, à travers le récit de sa genèse. Une genèse inscrite de plein pied dans les débats européens d'alors! Un pari réussi !

Sylvain Schirmann 
Philippe Vonnard - 978-2-8076-0570-1

Téléchargé de PubFactory à01/07/2021 08:14:02PM

via free access 


\section{Introduction générale}

Chaque saison, plus de trois cents clubs de football masculin et féminin ${ }^{1}$, issus des quatre coins de l'Europe, prennent part aux compétitions européennes. Ces échanges entraînent l'organisation de plus de cinq cents rencontres. S'ajoute à ces chiffres la dizaine de parties officielles ou amicales disputées annuellement par les équipes nationales, ainsi que la phase finale de l'Euro (le Championnat d'Europe pour les équipes nationales) qui est organisé tous les quatre ans. Par ailleurs, une bonne partie de ces rencontres draine des milliers de supporters qui n'hésitent pas à faire des centaines de kilomètres pour voir jouer leurs clubs ou leur équipe nationale, participant ainsi à l'existence d'un véritable tourisme footballistique. Notons encore que le football professionnel n'est pas seul concerné par cette circulation de personnes car d'innombrables échanges footballistiques ont lieu tout au long de l'année au niveau des jeunes et des clubs amateurs. En outre, signalons la retransmission en direct de la plupart de ces rencontres et les nombreuses émissions de télévision, quasiment quotidiennes, traitant du football d'élite européen. Enfin, pour clore ce bref et non exhaustif tableau, de juin à août et de décembre à janvier, le marché des transferts (mercato) implique une circulation intense des joueurs et entraîneurs mais aussi de capitaux ainsi que des données sur les joueurs (dans les médias ou par des organismes de statistiques privés). C'est donc peu dire que les échanges européens en matière de football sont conséquents.

Ces différents éléments permettent à Manuel Schotté d'indiquer que "si l'échelon national prime historiquement dans la structuration du football en Europe, le niveau européen est progressivement devenu un espace important $»^{2}$. Cette place du football à l'échelle européenne a conduit des auteurs à se questionner sur l'hypothétique rôle du ballon

1 Ce livre s'intéresse uniquement au football masculin. Pour des réflexions sur le football féminin européen, voir : Breuil X., Histoire du football féminin en Europe, Paris, Nouveau Monde, 2011 ; Williams J., Globalising Women's Football: Europe, Migration and Professionalization, Bern, Peter Lang, 2013.

2 Schotté M., "La structuration du football professionnel européen. Les fondements sociaux de la prévalence de la "spécificité sportive" ", Revue française de socio-économie, vol. $13, \mathrm{n}^{\circ} 1,2014$, p. 14. 
rond dans la formation d'une identité européenne ${ }^{3}$ ou d'un espace public européen ${ }^{4}$, voire de considérer les compétitions européennes de football des clubs (telle la Ligue des champions) comme des «lieux de mémoire européens $»^{5}$.

\section{Pourquoi étudier le rapport entre le football et l'Europe?}

Il est intéressant de souligner que les scandales qui touchent régulièrement le domaine $\mathrm{du}$ football européen (violences entre supporters, paris truqués, corruption, transferts illégaux de joueurs, achats de rencontres ou d'arbitres, etc.) ne semblent pas avoir de conséquences sur la popularité des rencontres européennes et surtout ne remettent aucunement en question l'organisation de ces échanges continentaux. Ce constat paraît surprenant, d'autant qu'il contraste avec le contexte actuel d'une pensée plutôt sceptique vis-à-vis de la construction européenne dans les différents pays du Vieux Continent ${ }^{6}$.

Comme l'avait déjà étudié au début des années 2000 Andy Smith, le fait de suivre les compétitions européennes n’implique aucunement de souscrire à l'idée de la création d'une communauté politique à l'échelle

3 Sonntag A., Les identités du football européen, Grenoble, Presses universitaires de Grenoble, 2008, pp. 247-271. Le concept d'identité européenne est sujet à de nombreux débats. Pour une réflexion critique, voir : Duchesne S., "L'identité européenne, entre science politique et science fiction ", Politique européenne, vol. 30, $\mathrm{n}^{\circ} 1,2010$, pp. 7-16.

4 Kennedy P., «Using Habermas to crack the European football championships ", Sport in Society, vol. 20, $\mathrm{n}^{\circ} 3$, 2017, pp. 355-369. Pour une discussion récente sur le concept d'espace public européen, voir : Doria C., Raulet G. (dir.), L'espace public européen en question. Histoire et méthodologie, Bruxelles, P.I.E. Peter Lang, 2015.

5 Groll M., "UEFA football competition as European site of memory - cups of identity ", dans Pyta W., Havemann N. (eds.), European Football and collective memory, Basingstoke, Palgrave Macmillan, 2014, pp. 63-84. Sur les lieux de mémoire européen, voir : Bussière E., Moradiellos E. (dir.), Mémoires et lieux de mémoire en Europe, Bruxelles, P.I.E. Peter Lang, 2012.

6 Pour une réflexion historique sur ce sujet, voir : Wassenberg B., Clavert F., Hamman P. (dir.), Contre l'Europe? Anti-européisme, euroscepticisme et alter-européisme dans la construction européenne de 1945 à nos jours : acteurs institutionnels, milieux politiques et société civile, Stuttgart, Franz Steiner, 2010. De même, voir deux numéros de la revue Politique européenne coordonnée par Christophe Bouillaud : vol. 34, n 1, 2011 ; vol. 43, n $1,2014$. 
géographique européenne ${ }^{7}$. Par ailleurs, William Gasparini a rappelé il y a peu qu'il fallait prendre des précautions sur le rôle du football dans le rapport entretenu à l'Europe chez ses citoyens ${ }^{8}$. Il n'empêche que ces nombreux échanges footballistiques font vivre, plusieurs fois dans l'année, l'idée d'un continent uni et doivent donc être pris en compte dans les études sur la construction européenne. Et ce d'autant plus que nous savons désormais que les processus d'intégrations ont été « à la fois plus nombreux et très différents des grands projets politiques d'après-guerre tels que, par exemple, la Communauté européenne " ${ }^{9}$. C'est d'ailleurs pourquoi Laurent Warlouzet propose plutôt d'évoquer, à la place du terme de construction européenne, l'histoire des coopérations européennes afin de rendre " justice au profond renouvellement de l'histoire de l'intégration européenne lors des deux dernières décennies ${ }^{10}$.

Notre intérêt pour l'histoire du football européen s'inscrit justement dans ce renouvellement de perspective. Si ce jeu paraît digne d'intérêt, c'est qu'à notre sens il recèle trois caractéristiques - qui ne lui sont pas totalement propres - qui rendent cet objet particulièrement intéressant à étudier dans le cadre de l'histoire des coopérations européennes. Premièrement, il faut souligner la popularité du football dans quasiment tous les pays européens et la régularité des rencontres disputées à l'échelle européenne. En ce sens, le jeu concerne une grande partie des citoyens européens. Mais ce sont aussi les ressorts de ces échanges européens qui sont relativement bien connus, compris et surtout investis, en particulier par les couches populaires. C'est du moins ce que suggère la conclusion d'une étude réalisée par le sociologue Pierre-Édouard Weil parue en 2011 sur le rapport à l'Europe chez des populations de jeunes issus de l'immigration de

7 Smith A., La passion du sport : le football, le rugby et les appartenances en Europe, Rennes, Presses universitaires de Rennes, 2001. En 2012, Andy Smith est brièvement revenu à nouveau sur le sujet : Smith A., "Conclusion. L'Europe, le football et la sociologie politique. Quelques remarques ", Politique européenne, vol. 36, n 1, 2012, pp. 149-157.

8 Gasparini W., "Sport et football “européens”. Genèse d'une nouvelle catégorie de l'action publique ", dans Gasparini W. (dir.), L'Europe du football. Socio-histoire d'une construction européenne, Strasbourg, Presses universitaire de Strasbourg, 2017, pp. 25-49.

9 Madsen M.R., " "Europe United”. La Ligue des champions comme construction européenne », dans Cohen, A., Dezalay Y., Marchetti D., "Esprits d'États, entrepreneurs d'Europe ", Actes de la recherche en sciences sociales, vol. 166-167, n 1-2, 2007, p. 9.

10 Warlouzet L., " Dépasser la crise de l'histoire de l'intégration européenne ", Politique europenne, vol. 44, $\mathrm{n}^{\circ}$ 2, 2014, p. 116. 
la banlieue parisienne ${ }^{11}$. Ce point est important à souligner car il contraste avec l'espace européen qu'essaient de construire les institutions basées à Bruxelles, à savoir principalement l'Union européenne ou le Conseil de l'Europe, un espace européen souvent perçu comme un processus obscur, manquant de légitimité auprès des populations, voire qui concerne avant tout les élites ${ }^{12}$. En ce sens, le football fait partie de ces domaines, comme ceux des techniques ${ }^{13}$ ou de la culture ${ }^{14}$, qui arrivent à toucher quasiment de manière quotidienne une grande partie des populations du continent.

La deuxième caractéristique du football concerne le cadre compétitif dans lequel le jeu s'est rapidement structuré à l'échelle supranationale. Si les tournois, pour les clubs et les nations, créés pour la plupart dans les années 1920, se présentent rapidement comme des lieux propices à l'exacerbation des nationalismes et offrent ainsi de formidables occasions pour les États de montrer leur puissance sur la scène internationale ${ }^{15}$, la confrontation footballistique ne peut toutefois se réaliser que lorsque des règles ont été préalablement acceptées par les participants. C’est pourquoi l'affrontement nécessite de trouver des accords entre les adversaires afin de jouer ensemble. Ce point est en particulier défendu par différents promoteurs (dirigeants sportifs, journalistes, voire acteurs politiques) de ces échanges footballistiques internationaux qui imaginent que le sport peut aider à créer des rapprochements entre les populations ${ }^{16}$. Même si cette ambition peut paraitre utopique, force est de constater que le

11 Weill P.-É., " "Plutôt l'UEFA que l'UE !" : (dés-)enchantement de l'identification à l'Europe des jeunes de milieux populaires issus de l'immigration ", Politique européenne, vol. 30, n 1, 2011, pp. 107-130.

12 Sur les différentes représentations de l'Europe qu'ont ses citoyens, voir en particulier : Gaxie D. et al., L'Europe des Européens. Enquête comparative sur les perceptions de l'Europe, Paris, Economica, 2010. Et pour une réflexion contemporaine sur ce sujet, voir par exemple : Olivier C., Magnette P. (dir.), Une Europe des élites ? Réflexions sur la fracture démocratique de l'Union européenne, Bruxelles, IEE, 2007.

13 Badenoch A., Fickers A. (eds.), Materializing Europe. Transnational Infrastructure and the project of Europe, Basingstoke, Palgrave Macmillan, 2010. Pour d'autres publications sur ce rapport entre Europe et domaine technique, voir la série « Making Europe. A new European history " coordonnée par Johan Shot et Phil Scranton chez Palgrave Macmillan.

14 Fleury A., Jilek L. (dir.), Une Europe malgré tout, 1945-1990, Bruxelles, P.I.E. Peter Lang, 2009. Pour d'autres ouvrages sur le domaine culturel et l'Europe, nous renvoyons à la bibliographie de fin de livre.

15 Voir notamment : Archambault F., Beaud S., Gasparini W. (dir.), Le football des nations. Des terrains de jeu aux communautés imaginées, Paris, Publications de la Sorbonne, 2016.

16 Kissoudi P., «Antidote to war: the Balkans Games », dans Mangan J.A. (ed.), Militarism, Sport, Europe. War Without Weapons, London, Frank Cass, 2003-2por 142-165.-1 
football offre indéniablement de nombreuses opportunités d'organiser des parties entre des clubs, ou des équipes nationales, issus de pays éloignés géographiquement et parfois opposés dans les relations politiques internationales ${ }^{17}$.

Troisièmement, le football est administré sur la scène européenne par des acteurs non étatiques, qui prennent de l'importance au fil des années. Il s'agit en premier lieu de la Fédération internationale de football association (FIFA), créée en $1904^{18}$. La FIFA autorise, ou non, les échanges internationaux entre les équipes nationales et pose un cadre réglementaire contraignant sur l'organisation de ces rencontres. Cette situation a pour conséquence majeure que les États - qui investissent le jeu durant l'entredeux-guerres ${ }^{19}$ - doivent tenir compte de cet acteur qui dicte les règles dans le domaine du football international. Certes, la FIFA est composée d'une association nationale par pays dont certaines pourraient être tentées de l'instrumentaliser à leurs profits - surtout si celle-ci dépend d'un pays dans lequel sévit un régime autoritaire. Cependant, l'élite de la FIFA ${ }^{20}$ puis également de l'Union des associations européennes de football (UEFA), fondée en 1954 - pense son action en dehors des contraintes de la politique internationale. Ainsi, ses membres souhaitent avant tout dynamiser les échanges internationaux au travers du jeu et comme dit cidessus, certains d'entre eux vont même jusqu'à estimer que les nombreux échanges footballistiques peuvent, à terme, favoriser les rapprochements entre les peuples. Par ailleurs, ces organisations internationales, qui sont à placer dans celles de type non gouvernemental, constituent des arènes qui permettent aux associations nationales de se rencontrer, de discuter, voire, en certaines circonstances, de créer des alliances atypiques au regard de ce qui se passe sur la scène internationale.

17 Pour une réflexion préliminaire sur ce type d'échanges, voir : Vonnard P., Marston K., "Building bridges between separated Europeans: the role of UEFA's competitions in East-West exchanges (1955-1964) ", dans Vonnard P., Sbetti N., Quin G. (eds.), Beyond boycotts. Sport during the Cold War in Europe, Berlin, De Gruyter Oldenbourg, 2017, pp. 85-109.

18 Sur l'histoire de la FIFA, voir notamment : Eisenberg C. et al., FIFA 1904-2004. Le siècle du football, Paris, Cherche Midi, 2004.

19 Pour une synthèse sur l'investissement du football par les États, voir : Macon B., "The politization of football: the European game and the approach to the Second World War ", Soccer and Society, vol. 9, n 4, 2007, pp. 532-55.

20 Nous considérons l'élite dirigeante de manière positionnelle : elle comprend toutes les personnes faisant partie du comité exécutif des organisations considérées dans cet ouvrage. Pour un bref propos sur l'emploi du terme élite, voir : Genieys W., " Nouveaux regards sur les élites du politique ", Revue française de science politique, vol. 56, $\mathrm{n}^{\circ} 1,2007$, pp. 121-147. 
Au regard de tous ces éléments, il paraît donc intéressant d'étudier plus précisément les ressorts de cette place particulière que détient le football à l'échelle géographique européenne. En d'autres termes, dans ce livre il s'agit de s'interroger sur le côté quasiment " naturel » des échanges européens en football. Nous proposons ici de revenir sur une période charnière dans l'établissement de cet ancrage du football à l'échelle géographique européenne : les années 1930 aux années 1960.

\section{L'Europe et le football : perspectives historiques}

Depuis une vingtaine d'années, plusieurs historiens ont insisté sur l'ancienneté des échanges continentaux en football. À ce titre, Pierre Lanfranchi a été l'un des premiers à souligner le cosmopolitisme des premiers pratiquants qui s'attellent à diffuser le jeu sur le continent européen dans le premier quart du $\mathrm{XX}^{\mathrm{e}}$ siècle $^{21}$. À sa suite, d'autres chercheurs ont développé des études sur les trajectoires transnationales des acteurs du football (principalement les joueurs et les entraineurs) ${ }^{22}$. Dans le sillage de ces recherches, plusieurs aspects européens du jeu ont commencé à être analysés, en particulier la création et le développement des compétitions supranationales - comme la Mittel-Europa (Mitropa) Cup pour les clubs et la Coupe des Balkans ou la Coupe internationale pour les nations - qui voient le jour dès l'entre-deux-guerres ${ }^{23}$. Ces différents tournois offrent un cadre régulier d'échanges aux clubs et aux associations nationales de football, entités pour la plupart créées entre la fin du XIX ${ }^{\mathrm{e}}$ et la première décennie du $\mathrm{XX}^{\mathrm{e}}$ siècle. En outre, ces compétitions favorisent le déplacement des acteurs du jeu, au sens large du terme (joueurs, entraîneurs, journalistes, voire de supporters). Enfin, leur précoce et large médiatisation - que ce soit par la presse spécialisée qui connaît un développement durant les années 1920 ou par la presse généraliste -

21 Lanfranchi P., "Football, cosmopolitisme et nationalisme ", Pouvoir, vol. 101, 2002, pp. 15-25.

22 Par exemple : Poli R., "L'Europe à travers le prisme du football. Nouvelles frontières circulatoires et redéfinition de la nation ", Cybergeo: European Journal of Geography, vol. 294, 2004, pubié en ligne ; Taylor M., "Football's engineers? British football coaches, migration and intercultural transfer, c.1910-c.1950's ", Sport in History, vol. $30, \mathrm{n}^{\circ} 1,2010$, pp. 138-163.

23 Pour un aperçu général du processus : Mittag J., "Europa und der Fussball. Die Europäische Dimension des Vereinsfussballs vom Mitropa-Cup bis zur Champions League ", dans Mittag J., Nieland J.-U. (eds.), Das Spiel mit dem Fussball. Interessen, Projektionen und Vereinnahmungen, Essen, Klartext, 2007,pp 155-176. 
accroît la popularisation du jeu dans l'espace public national autant qu'elle participe à la diffusion d'informations au niveau supranational. Ainsi, la Mitropa Cup, disputée de 1927 à 1938, principalement entre des clubs autrichiens, hongrois, italiens et tchèques (des formations roumaines, suisses et yougoslaves y prennent occasionnellement part), est relayée par des journaux sportifs de pays n'ayant pourtant pas de représentants dans la compétition, par exemple l'Allemagne, la Belgique, la France ou les Pays-Bas. Tenant compte de l'épaisseur historique de ces échanges européens en football, Paul Dietschy évoque l'existence d'une « Europe du football ", dont les prémices se repéreraient durant la Belle Époque déjàa ${ }^{24}$ et qui s'affirmerait pendant l'entre-deux-guerres ${ }^{25}$. S'il n'emploie pas cette terminologie, Christian Koller présente aussi la période qui va de 1919 à 1939 comme charnière dans l'établissement d'échanges footballistiques de différents types - économiques, institutionnels, voire politiques - à l'échelle continentale ${ }^{26}$.

Certes, de nombreux échanges en football existent à l'échelle européenne depuis le premier quart du siècle dernier, toutefois des analyses préliminaires nous poussent à postuler qu'un nouveau palier est franchi dans cette dynamique européenne du football durant les années $1950^{27}$. En effet, ce moment correspond notamment à la fondation d'une entité européenne du football, à savoir l'UEFA. Le football s' inscrit ainsi dans le processus $d^{\prime}$ " Europe-organisation ${ }^{28}$, c'està-dire la création d'organisations supranationales dans de très nombreux domaines (culture, économie, politique, science, sport, technique, etc.) qui favorisent les échanges à l'échelle géographique européenne. Très diverses de par leur nombre de membres, leur géographie, leurs objectifs et leur portée sur la société, ces organisations témoignent d'une ère favorable aux échanges européens. En football, c'est en 1954 que l'UEFA

24 Dietschy P., "Football during the Belle-Époque: The first "Europe du football" (1903-1914) ", dans Vonnard P., Quin G., Bancel N. (eds.), Building Europe with the ball. Turning points in the Europeanization of Football (1905-1995), Oxford, Peter Lang, pp. 21-51.

25 Dietschy P., "Did a "Europe of footbal” exist in the 1930's ? ", Sport in History, vol. 35, $\mathrm{n}^{\circ}$ 4, 2015, pp. 515-530.

26 Koller C., "Einleitung: Europäischer Fussball im Zeitalter der Katastrophen », dans Koller C., Brändle F. (eds.), Fussball zwischen den Kriegen, Zürich, Lit Verlag, 2010, pp. 1-22.

27 Vonnard P., La genèse de la Coupe des clubs champions. Une histoire du football européen (1920-1960), Neuchâtel, CIES, 2012.

28 Frank R., "Les débats sur l'élargissement de l'Europe avant l'Élargissement ", dans Pécout G. (dir.), Penser les frontières de l'Europe du XIX au XX $X^{e}$ siècle. Élargissement et union : approches historiques, Paris, PUF, 2004 , pp 180-1,81 1 - $1878-2-8076-0570-1$ 
voit le jour. Force est de constater que cette organisation va rapidement s'affirmer comme un "acteur clef $"{ }^{29}$ de la dynamisation des échanges européens dans le football.

Lors de ses cinq premières années, l'UEFA invente des compétitions européennes pour les clubs (Coupe des clubs champions européens ; Coupe des vainqueurs de coupe européenne), les nations (Coupe d'Europe des nations) ou les jeunes (Tournoi international des juniors). Contrairement aux épreuves disputées durant l'entre-deux-guerres, ces tournois convoquent désormais la grande majorité des pays européens. En outre, ils connaissent un fort engouement de la part du public, renforcé par leur intense médiatisation, des rubriques spéciales à leur sujet étant rapidement créées dans les grands journaux sportifs. De plus, ces épreuves commencent à être télédiffusées dans la seconde partie des années 1950 par le biais du réseau Eurovision de l'Union européenne de radio (UER), créé en $1954^{30}$. Au travers de l'organisation de ces tournois, l'UEFA dynamise le nombre de matchs disputés à l'échelle géographique européenne. Mais son activité ne se résume pas à l'organisation de compétitions et, comme le note William Gasparini

l'UEFA structure progressivement l'espace européen du football [...] en élaborant un règlement et des réglementations, et en offrant des formations pour entraîneurs et arbitres. Elle s'impose progressivement comme l'interlocuteur privilégié des États européens et des institutions européennes dès lors que le football se retrouve à l'agenda des États membres de l'UE mais également du Conseil de l'Europe ou, plus tardivement, de la Commission et du Parlement européen ${ }^{31}$.

Il semble donc qu'il y ait un avant et un après la création de l'UEFA, celle-ci correspondant in fine à une nouvelle phase de développement du football européen.

29 Ce postulat s'inspire des réflexions développées par Barbara Keys au sujet de l'internationalisation du sport durant l'entre-deux-guerres. Keys B., Globalizing sport. National rivalry and international community in the 1930s, London, Harvard University Press, 2006, p. 5.

30 Meyer J.-C., "La fondation du "Grand Stade". De la triomphale retransmission en direct de la Coupe du monde 1954 et de ses avatars dans les pays membres de l'Eurovision (1954-1958) ", Traverse. Revue d'histoire, vol. 23, n 1, 2016, pp. 49-59.

31 Gasparini W., "En guise de conclusion. Le football dans la construction européenne : de la nation à l'illusio européiste ", dans Archambault F., Beaud S., Gasparini W. (dir.), Le football des nations, op. cit., pp. 250-251 1ilippe Vonnard - 978-2-8076-0570-1 


\section{Études historiques sur l'UEFA : état de l'art}

Si une littérature relativement abondante existe sur l'UEFA, elle est surtout le fruit d'économistes, de juristes, de spécialistes en gestion du sport ou encore de sociologues du sport qui ont abordé différents aspects de l'Union pour la période allant des années 1990 à nos jours ${ }^{32}$. $\mathrm{Au}$ contraire, rares sont encore les historiens qui se focalisent sur cette organisation, une situation qui s'explique sans doute en raison du nombre limité de travaux consacrés au football européen sur la période qui court des années 1950 aux années 1980. En outre, les chercheurs qui se sont intéressés à ces décennies ont jusqu'ici plutôt considéré le développement de l'UEFA comme un acte secondaire et ont surtout proposé des textes consacrés à la création des compétitions européennes ${ }^{33}$.

Pourtant, comme nous l'avons récemment montré pour le cas de la Coupe des champions européens ${ }^{34}$ - première épreuve organisée par l'UEFA dès la saison 1955-1956 -, le rôle tenu par l'Union dans le tournant européen des épreuves créées durant les années 1950 est considérable. En effet, si l'idée initiale de la création de la Coupe des champions provient de journalistes de L'Équipe, l'apport de l'UEFA est décisif. Premièrement, c'est elle qui finalise le projet, fonde l'épreuve et permet sa pérennisation. Deuxièmement, la reprise de l'organisation du tournoi par l'Union renforce son pôle européen, puisque des associations non invitées par les journalistes français (comme celles de l'Allemagne de l'Est, de la Bulgarie ou de la Roumanie) demandent immédiatement l'inscription de leur champion national dans l'épreuve. Troisièmement, par ses actions, l'UEFA

32 Pour un état de l'art, nous renvoyons à la bibliographie générale qui se trouve à la fin de : Vonnard P., Quin G., Bancel N., Building Europe with the ball, op. cit., pp. 231-243. Voir aussi les contributions dans : Niemann A., Garcia B., Grant W. (eds.), The transformation of European Football: Towards the Europeanisation of the national Game, Manchester, Manchester University Press, 2011.

33 Mittag J., Legrand B., "Towards a Europeanization of football? Historical phases in the evolution of the UEFA football championship ", Soccer \& Society, vol. 11, n 6, 2010, pp. 709-722 ; Vonnard P., La genèse de la Coupe des champions, op. cit ; Marston K.T., " "Sincère camaraderie": professionalization, politics and the pursuit of the European idea at the International Youth Tournament, 1948-57 ", dans Vonnard P., Quin G., Bancel N., Building Europe with the ball, op. cit., pp. 137-161; Dietschy P., "L'Euro de l'européisme à la commercialisation de la Nation ", Pôle Sud, vol. 47, n 4, 2018, pp. 25-39.

34 Vonnard P., "How did UEFA govern the European turning point in Football? UEFA, the European champion clubs' cup and the Inter-cities fairs cup projects (1954-1959) ", dans Vonnard P., Quin G., Bancel N., Building Europe with the ball, op. cit., pp. 165-185. 
favorise la popularité de l'épreuve, notamment en acceptant - certes, au départ, encore a minima - la rapide télédiffusion des rencontres. Ainsi, ses dirigeants et ceux de l'UER se rencontrent, dès 1956, au sujet de la médiatisation de l'épreuve par le biais du réseau Eurovision ${ }^{35}$. Ce bref exemple révèle que, quelques mois après sa création, et alors qu'elle reste une entité très modeste (elle ne dispose pas de siège fixe ni de secrétaire rémunéré à plein temps), l'UEFA joue déjà un rôle prépondérant dans l'organisation et la popularisation du football européen.

Hormis les trois livres réalisés à l'occasion d'anniversaires de l'Union ${ }^{36}$, ouvrages qui permettent déjà de donner des éléments factuels sur le développement de l'organisation, nous pouvons mentionner quatre recherches qui ont traité de son cas. En premier lieu, il faut indiquer un article généraliste et basé sur la lecture des ouvrages commémoratifs de l'UEFA écrit en 2007 par Laurent Barcelo ${ }^{37}$. Ce papier est plutôt descriptif et n'offre dès lors que peu de pistes d'explication sur les raisons de la création de l'Union et sur les raisons de son rapide développement. Pour autant, il a l'avantage, non négligeable, de souligner l'existence d'une organisation européenne de football et d'inviter à s'y intéresser de plus près. En deuxième lieu, des informations sur l'Union peuvent être collectées dans un intéressant mémoire de fin d'étude réalisé, en 2009, par un étudiant en sciences politiques de l'Université de Strasbourg, Antoine Maumon de Longevialle ${ }^{38}$. Cet étudiant souligne en particulier un fait important, à savoir que l'Union transcende, dès sa création, la Guerre froide puisqu'elle est constituée autant de pays de l'Est que de l'Ouest de l'Europe. De même, il aborde des questions relatives au territoire de l'UEFA et traite brièvement de l'adhésion de la Turquie, en convoquant pour l'occasion des archives issues de la FIFA. En troisième lieu, il faut mentionner le travail mené par Grégory Quin dans le cadre de la bourse de recherche de l'UEFA 2011-2012 ${ }^{39}$. S'il n’a pas traité spécifiquement de

35 Mittag J., Nieland J.-U., "Auf der Suche nach Gesamteuropa: UEFA und EBU als Impulsgeber der Europäisierung des Sports ", dans Bertling C., Mertin E. (eds.): Freunde oder Feinde? Sportberichterstattung in Ost und West während des Kalten Kriegs, Gütersloh, Medienfabrik Gütersloh, 2013, pp. 208- 229.

36 Rothenbühler R., Les 25 ans de l'UEFA, Berne, UEFA, 1979 ; Rothenbühler R., UEFA. 50 ans, Nyon, UEFA, 2005 ; Vieli A., Les 60 ans de l'UEFA, Nyon, UEFA, 2015.

37 Barcelo L., "L'Europe des 52 : l'Union Européenne de Football Association (UEFA) ", Guerres mondiales et conflits contemporains, vol. 228, $\mathrm{n}^{\circ} 4,2007$, pp. 119-133.

38 Maumon de Longevialle A., "La construction de l'Europe du football ", mémoire de $4^{\mathrm{e}}$ année d'I.E.P. réalisé sous la direction de Justine Faure, Université de Strasbourg, 2009.

39 Quin G., Une première élite du football européen (1904-1956), ou les prémices d'un champ footballistique européen, dossier réalisé dans le cadre de l'UEFA Research Grant Programme 2011-2012. 
l'Union, son étude se terminant en 1954, soit l'année de sa création, Grégory Quin y développe des éléments intéressants sur la structuration de la FIFA durant l'entre-deux-guerres (en analysant ses finances, en traitant à nouveaux frais de la création de la Coupe du monde ou encore en apportant quelques brefs propos sur son élite dirigeante). En outre, il postule que cette dernière peut être considérée comme une " pré-organisation " du football européen car elle dynamise les échanges entre ses associations membres. Sa recherche invite donc à élargir la focale temporelle et à davantage relier la création de l'UEFA avec le développement que connaît la FIFA durant les années 1920 et 1930. Enfin, il faut indiquer l'étude réalisée en 2014 par Jürgen Mittag, titulaire de la Chaire Jean Monnet sur le sport et la politique à la Deutsche Sporthochschule de Cologne. En effet, ce chercheur s'interroge sur la particularité de l'UEFA à transcender la Guerre froide et s'est notamment demandé comment son élite dirigeante a négocié cette situation ${ }^{40}$. De plus, Jürgen Mittag s'attelle également à replacer les premiers développements de l'UEFA dans la trame plus générale de la coopération européenne. À ce propos, l'auteur soutient l'hypothèse que les dirigeants du football suivent des objectifs sportifs mais aussi plus politiques, c'est-à-dire qu'ils utilisent le football pour rapprocher les pays européens divisés par la Guerre froide.

L'article du chercheur allemand a été produit dans le cadre d'une publication du Football research in an enlarged Europe (FREE). Conduit de 2011 à 2015 par neuf universités européennes, ce projet avait pour but d'étudier le développement de nombreux aspects du football européen sur le long terme tout en favorisant une perspective interdisciplinaire ${ }^{41}$. Constatons néanmoins que, mise à part l'étude de Jürgen Mittag, aucune autre des nombreuses contributions publiées dans les ouvrages qui ont suivi les différentes conférences du projet FREE n'a abordé spécifiquement des éléments de l'histoire de l'UEFA. Ce projet a cependant eu le grand mérite de susciter de nouvelles réflexions et, en parallèle, d'autres conférences ont

40 Mittag J., "Negotiating the Cold War? Perspectives in memory research on the UEFA, the early European football competitions and the European nations Cups ", dans Pyta W., Havemann N., European Football and collective memory, op. cit., pp. 40-63. Nous avons continué ses réflexions avec ce chercheur et notamment récemment co-écrit un article sur ce sujet : Mittag J., Vonnard P., «The role of societal actors in shaping a pan-European consciousness. UEFA and the overcoming of Cold War tensions, 1954-1959 ", Sport in History, vol. 37, n 3, 2017, pp. 332-352.

41 Sonntag A., "Grilles de perception et dynamiques identitaires dans l'espace européen du football. Le projet FREE (7 PCRD, 2012-2015) ", Politique européenne, vol. 36, $\mathrm{n}^{\circ} 1,2012$, pp. 185-192. Pour les résultats de ces différents échanges, voir également la série "FREE » coordonnée par Albrecht Sonntag et David Ranc chez Palgrave Macmillan. 
été organisées autour de la thématique du développement du football à l'échelle géographique continentale. Durant ces échanges scientifiques, des réflexions ont émergé sur le cas de l'UEFA ${ }^{42}$, ouvrant le champ à une exploration plus approfondie sur son histoire.

Dans le cadre de cet ouvrage, nous souhaitons poursuivre, mais aussi élargir, ces réflexions, démarche qui viendra combler un vide historiographique important et qui permettra de mieux comprendre un double mouvement, d'une part, le développement du football à l'échelle géographique européenne; d'autre part, le processus qui a mené à ce fort ancrage européen du jeu. Outre de bénéficier des développements précités de l'histoire des coopérations européennes et de l'histoire du football international, cette recherche est également inspirée par les nouvelles réflexions proposées dans le champ des études de l'histoire des relations internationales sur les thématiques de la culture ${ }^{43}$ et du sport ${ }^{44}$. Par ailleurs, elle s'appuie aussi sur des études qui abordent différents aspects

42 Ce fut notamment le cas lors d'un congrès organisé en janvier 2015 à Strasbourg par William Gasparini et Jean-Michel de Waele dans le cadre d'un projet d'Excellence "Europe " de l'Université de Strasbourg dont les résultats ont été publiés dans : Gasparini W. (dir.), L'Europe du football, op. cit. De même, en février 2015, avec Grégory Quin, nous avons invité une dizaine de spécialistes de l'histoire du football à débattre de l'européanisation de ce sport dans une perspective à long terme. Ces échanges ont été publiés dans : Vonnard P., Quin G., Bancel N., Building Europe with the ball, op. cit.

43 Voir par exemple : Dulphy A. et al. (dir.), Les relations culturelles internationales au XXe siècle, Bruxelles, P.I.E. Peter Lang, 2010. Et pour un état des lieux de la littérature : Mikkonen S., Suutari P., «Introduction to the Logic of East-West Artistic Interactions ", dans Mikkonen S., Suutari P. (eds.), Music, Art and Diplomacy. EastWest Cultural Interactions and the Cold War, London, Routledge, pp. 1-13 ; Gilabert M., "Diplomatie culturelle et diplomatie publique : des histoires parallèles ", Relations internationales, vol. 169, $\mathrm{n}^{\circ}$ 1, 2017, pp. 11-26.

44 Pour un état de la littérature voir : Keys B., "International relation ", dans Pope S., Nauright J. (eds.), Routledge Companion to Sports History, London \& New York, Routlege, 2010, pp. 248-267 ; Dichter H., "Sport history and diplomatic history ", H-Diplo, vol. 122, 2014, publié en ligne : http://h-diplo.org/essays/PDF/ E122.pdf; Sbetti N., Tulli U., « La fine di una reciproca negazione: riflessioni sullo sport nella storia delle relazioni internazionali ", Ricerche di storia politica, vol. 193, $\mathrm{n}^{\circ}$ 2, 2016, pp. 193-202. Pour des réflexions plus théoriques, voir : Beacom A., "Sport in International Relations: a Case for Cross-disciplinary Investigation ", The Sports Historian, vol. 20, $\mathrm{n}^{\circ}$ 2, 2000, pp. 1-23 ; Murray S., "The Two Halves of Sports-Diplomacy ", Diplomacy \& Statecraft, vol. 23, 2012, pp. 575-592 ; Frank R., "Internationalisation du sport et diplomatie sportive ", dans Frank R. (dir.), Pour l'histoire des relations internationales, Paris, Presses universitaires de France, 2012, pp. 387-405 ; Rofe S., "Sport and Diplomacy: A Global Diplomacy Framework ", Diplomacy and Statecraft, vol. 27, n², 2016, ph 212-230. 
de l'histoire et de la sociologie des organisations internationales ${ }^{45}$. C'est donc une recherche qui se veut à la croisée de différentes historiographies, et qui n'hésite pas à mobiliser des travaux issus de différentes disciplines (en particulier la sociologie et les sciences politiques), que nous proposons dans les lignes qui vont suivre.

Plusieurs questions seront explorées dans le cadre de ce livre, certaines ayant pour but de préciser des points déjà abordés dans les travaux présentés ci-dessus, d'autres cherchant à explorer de nouvelles pistes : d'où vient l'idée de la création de l'UEFA ? Pourquoi celle-ci est-elle créée au milieu des années 1950 ? Qui en sont les promoteurs et quels sont les objectifs qu'ils poursuivent en s'investissant activement dans le développement du football continental ? Quelles sont leurs sources d'inspiration pour développer l'entité ? Comment ont-ils pu créer une organisation à la configuration si atypique en comparaison de la très grande majorité des organisations européennes précitées ? Quel est l'impact de la Guerre froide au sein de l'Union et comment ses dirigeants ont-ils pu le négocier ? Comment expliquer son rapide développement ? Autant de questionnements qui impliquent de revenir sur la mise en place de l'UEFA. C'est pourquoi, dans cet ouvrage, nous faisons le choix de nous focaliser sur la genèse et la formation de cette entité.

\section{Longue durée, gouvernance et perspective globale. Problématiques de la recherche}

Ce livre s'intéresse à la construction de l'Europe dans le monde - ou la planète - football. Le terme "monde » recèle l'avantage de faire double emploi. D'une part, il permet de souligner qu'il existe un domaine du football avec ses propres organisations, ses règles et ses codes ${ }^{46}$. Ce monde n'est bien évidemment pas clos et ses acteurs ont des liens avec ceux évoluant

45 En particulier : Kott S., "Les organisations internationales, terrains d'étude de la globalisation. Jalons pour une approche socio-historique ", Critique internationale, vol. 52, n 3, 2011, pp. 9-16 ; Sluga G., "Editorial. The Transnational History of International Institutions ", Journal of Global History, vol. 6, n 2, 2011, pp. 219-222; Herren M. (ed.), Networking the International System. Global Histories of International Organization, Cham, Springer, 2014. Et pour un état de la littérature ainsi que des réflexions théoriques, voir : Smouts M.-C., Devin G., Les organisations internationales, Paris, Armand Colin, 2011.

46 Cette vision s'inspire du concept sociologique de "champ " développé par Pierre Bourdieu ou de celui d'" espace " mobilisé par Jacques Lagroye et qui a notamment été utilisé par William Gasparini et Jean-Francois Polo pour le ças du football européen 
dans d'autres domaines, jouent eux-mêmes un rôle dans d'autres sphères (économique, politique). Toutefois, ils essaient de se réserver une certaine autonomie. À noter que celle-ci n'est pas figée, mais qu'elle se construit au fil du temps et, selon le contexte international, peut être sérieusement mise à mal. D'autre part, le terme " monde » rappelle que l'échelle géographique européenne doit être mise en rapport avec l'échelle internationale. En ce sens, il faut relier la mise en place de l'UEFA avec le développement du football hors d'Europe, et en particulier en Amérique du Sud ${ }^{47}$.

La période étudiée ici débute en 1930, année qui correspond à une réforme de la structure de la FIFA, avec la création d'un secrétariat et l'engagement d'un secrétaire permanent. En outre, l'invention de la Coupe du monde lors de cette même année marque une étape importante dans l'affirmation de l'organisation en matière d'administration du football mondial, lui permettant de consolider ses finances ainsi que de dynamiser les échanges entre les pays européens, qui sont alors encore largement majoritaires en son sein. L'étude se termine en 1960, lorsque l'UEFA dispose d'un siège fixe et d'un secrétaire rémunéré à temps plein. C'est aussi en 1960 que s'organise la première phase finale de Coupe d'Europe des nations, qui va progressivement devenir une compétition phare de l'Union.

Notre recherche poursuit trois axes de questionnement. Le premier se focalise sur le rôle des organismes footballistiques, tout d'abord la FIFA puis l'UEFA, dans le développement du football international. En effet, ces organisations - qui agissent elles-mêmes dans un contexte footballistique mouvant - permettent un accroissement du nombre de matchs de football à l'échelle géographique européenne, en particulier par le biais de l'établissement de compétitions supranationales. De même, elles offrent des opportunités aux dirigeants du football de se rencontrer régulièrement et peuvent être comprises comme des lieux d'échanges dans lesquels les dirigeants présents discutent et prennent des décisions en vue de dynamiser le football continental. Au fil des ans, elles créent / favorisent / contribuent à établir un réseau serré de dirigeants du football européen dont l'objectif avéré consiste à développer le jeu sur le continent, voire même à créer et maintenir - des liens entre les pays européens, et ce indépendamment

contemporain : Gasparini W., Polo J.-F., «L'espace européen du football. Dynamiques institutionnelles et constructions sociales ", Politique européenne, vol. 36, n 1, 2012.

47 Pour des réflexions préliminaires sur cet aspect, voir : Dietschy P., « Making football global? FIFA, Europe, and the non-European football world, 1912-74 ", Journal of Global History, vol. 8, 2013, pp. 279-298. Et plus spécifiquement pour une influence sur la création de l'UEFA : Vonnard P., Quin G., « Did South America Foster European Football?: Transnational Influences on the Continentalisation of FIFA and the creation of UEFA, 1926-1959 ", Sport in Society, pol 20, no nonnàp. 1424-1439. 
de la situation politique internationale. La question principale que nous souhaitons poser concerne le rôle que jouent la FIFA, puis l'UEFA dans la dynamisation des échanges européens en football. Notre hypothèse est que si la FIFA pose déjà, durant les années 1930, un cadre d'échanges footballistique à l'échelle européenne, la création de l'UEFA marque une nouvelle étape car cet organisme prend des décisions qui permettent, à terme, de renforcer cette dynamique et ainsi de progressivement établir la « naturalité " du cadre européen dans le football.

Le deuxième axe questionne les rapports entre les dirigeants du football (principalement ici l'élite dirigeante de la FIFA, puis de l'UEFA) et la politique. Pour le dire autrement, il s'agit d'explorer la capacité que les dirigeants ont à proposer des échanges qui contrastent avec le contexte politique international et, plus globalement, à se réserver une autonomie, certes relative, sur la scène internationale. Aussi, il est nécessaire de comprendre comment ces dirigeants ont fait pour affirmer le pouvoir de leur organisation sur la scène internationale. Il s'agit donc ici d'étudier un double mouvement. Tout d'abord, il est nécessaire de décrire les stratégies de gouvernance créées par les dirigeants au sein de la FIFA et qui persistent sur le long terme ainsi que les compromis momentanés négociés au regard de la situation internationale. Ces éléments sont cruciaux car ils permettent de renforcer la cohésion interne de leur organisation, condition sine qua non pour exister sur la scène internationale. Puis, il faut étudier la politique que les dirigeants développent afin de positionner leur organisation sur la scène internationale dans le but d'altérer les possibles concurrences extérieures qui pourraient remettre en question l'autorité de leur organisation. La question principale peut être décrite comme suit : de quelle manière les dirigeants de la FIFA et de l'UEFA parviennent-ils à se réserver une autonomie relative sur la scène internationale? Notre hypothèse est que l'élite dirigeante de l'UEFA s'inspire largement de ce que nous nommons des stratégies de gouvernance développées, puis rediscutées, depuis les années 1930, au sein de la FIFA (en particulier par les membres de son élite). Celles-ci ont pour but de lui conférer une place particulière sur la scène internationale permettant à l'organisation de se soustraire, en partie, au contexte de la politique internationale et ainsi de poursuivre son but premier : le développement du jeu à l'échelle supranationale.

Le troisième axe de cette recherche consiste à s'interroger autant sur les raisons de la formation de l'UEFA dans la seconde partie des années 1950 que sur la structure d'organisation choisie par ses promoteurs. Ici, nous pensons le développement de l'organisation européenne en termes globaux, c'est-à-dire en tenant compte d'acteurs non européens. Cet aspect est d'autant plus important à étudier dans le cadre du football car-comme 
c'est le cas d'autres sports ${ }^{48}$ - celui-ci est conduit par une géopolitique particulière. En effet, des années 1930 aux années 1960, les puissances footballistiques sont principalement issues de deux continents : l'Amérique du Sud et l'Europe. Or des dirigeants des associations nationales de football sud-américaines commencent, dans les années 1930, à contester l'hégémonie européenne au sein de la FIFA et vont militer en vue de décentraliser la structure de l'organisation en groupements continentaux (prenant comme modèle leur association continentale, la Confédération sud-américaine, première confédération continentale existante au sein de la FIFA). La question que nous nous posons ici est : comment expliquer la mise en place de l'UEFA au milieu des années 1950 ? Notre hypothèse est qu'il faut penser la mise en place de l'organisme européen dans une perspective globale et prendre en compte les oppositions mais aussi les transferts d'idées qui existent entre les dirigeants européens et sudaméricains, des années 1930 aux années 1960.

Ces trois questionnements s'enchevêtrent tout au long d'un récit proposé au lecteur sous forme diachronique et qui a pour but principal de retracer les étapes menant à la mise en place (genèse et formation) de l'UEFA.

\section{Mobiliser les « archives du football »}

La présente étude s'appuie sur une documentation, en bonne partie inédite, issue de ce qu'Alfred Wahl a nommé « les archives du football » ${ }^{49}$, à savoir des documents provenant essentiellement d'organismes footballistiques. Il s'agit donc de s'inscrire dans une dynamique, par la suite continuée en particulier par des chercheurs comme Paul Dietschy et Grégory Quin, qui vise à collecter et utiliser la riche documentation conservée par les organismes sportifs ${ }^{50}$. Dans le cadre de cette recherche,

48 Pour une illustration de cette géopolitique du sport, voir : Ravenel L., Gillon P., Grosjean F. (dir.), Atlas du sport mondial. Business et spectacle : l'idéal sportif en jeu, Paris, Autrement, 2010. Voir également les publications de Pascal Boniface. Si ces dernières offrent de nombreuses informations sur cette géopolitique du sport, elles restent néanmoins de l'ordre de la description et n'amènent donc que peu de visée explicative sur les raisons de celle-ci.

49 Wahl A., Les archives du football. Sport et société en France (1880-1990), Paris, Gallimard, 1989.

50 Pour des réflexions sur ce point, voir : Johnes M., "Archives and Historians of Sport ", International Journal of the History of Sport, vol. 32, $\mathrm{n}^{\circ}$ 15, 2015, pp. 1784-1798; Quin G., "Writing Swiss Sport History: A Quest for Original Archives ", The International Journal of the History of Sport, vol. 34, n $\mathrm{P}_{\mathrm{P}}$ - 6 , 2017 , $\mathrm{pp}_{\mathrm{p}}$. 432-436. 
nous avons mobilisé deux corpus d'archives principaux. Tout d'abord, il s'agit des archives de l'UEFA, qui se trouvent à son siège de Nyon (en Suisse) et qui n'avaient jusqu'ici jamais été utilisées dans le cadre d'un travail académique. Puis, celles de la FIFA ${ }^{51}$, qu'il est possible de consulter au siège de l'organisation à Zurich. Si ces dernières ont déjà été mobilisées par plusieurs auteurs, nous mettons ici au jour une documentation encore largement inédite.

Dans un premier temps, nous avons dépouillé les documents officiels (procès-verbaux) des différentes commissions et des assemblées générales de l'UEFA et de la FIFA, les rapports annuels tenus par leurs secrétaires généraux ainsi que les bulletins officiels des deux organismes. Ces documents permettent de dresser une chronologie du développement des deux organisations, de repérer les sujets développés en leur sein, les réalisations qu'elles concrétisent ainsi que d'identifier les principaux dirigeants qui œuvrent à leur développement respectif. Dans un deuxième temps, ce riche corpus a été complété par des informations issues de plusieurs dossiers de correspondance. À noter qu'en ce qui concerne l'UEFA, pour la période étudiée, il n'existe pas de dossiers de correspondances spécifiques entre l'UEFA et les associations nationales (les dossiers commencent à partir des années 1970). Ce sont donc les dossiers de correspondance de la FIFA qui sont mobilisés dans cette recherche. Tout d'abord, des documents sont issus des boîtes de correspondances entre la FIFA et l'UEFA pour les années 1950, dans lesquelles il est possible de retrouver des documents non conservés par l'organisme européen, ainsi que celles entre la FIFA et la Confédération sud-américaine pour les années 1930 à 1960, qui offre autant des informations sur la volonté des dirigeants sud-américains de décentraliser la FIFA que sur le développement de leur organisme continental. Puis, nous avons passé au crible la correspondance entre la FIFA et les associations nationales pour la période étudiée ${ }^{52}$. Cette

51 Pour un détail du fonds, voir : Dietschy P., «Une plongée dans les archives du football mondial : faire l'histoire de la Fédération Internationale de Football Association (FIFA) ", dans Bosman F., Clastres P., Dietschy P. (dir.), Images de sport : de l'archive à l'histoire, Paris, Nouveau Monde, 2004, pp. 319-332.

52 Les associations ont été choisies selon cinq critères : 1) le nombre de délégués envoyés par le pays lors des congrès annuels de la FIFA ; 2) la continuité observée dans la présence des délégués de ces pays lors des congrès de la FIFA ; 3) le nombre de ressortissants des pays dans le comité exécutif et plus généralement dans les commissions permanentes de l'organisation ; 4) le nombre de matchs internationaux disputés par le pays, situation qui n'est pas sans incidence sur la FIFA puisque celle-ci prélève un montant financier sur la recette brute des matchs internationaux. Dès lors, plus le pays joue de rencontres, plus la FIFA a l'opportunité (cela dépend encore des affluences lors des rencontres) d'encaisser des montants importants ; 5p p'appartenance du paysà un regroupement 
documentation renseigne autant sur la politique institutionnelle de la FIFA que sur les étapes qui mènent à la constitution d'un organisme européen de football.

Nous avons également consulté les boîtes de correspondances personnelles des dirigeants du comité exécutif de la Fédération internationale. Cette documentation permet de connaître le positionnement des dirigeants sur de nombreux sujets et éclaire les décisions prises lors des séances du comité exécutif ou de l'assemblée générale, complétant avantageusement les documents officiels préalablement consultés. En outre, il est aussi possible de recueillir des appréciations personnelles qui aident à brosser le profil des dirigeants concernés par notre recherche. De plus, ces lettres permettent d'esquisser les liens qui les unissent et aident à comprendre l'établissement d'un réseau de dirigeants européens. Pour en savoir davantage sur la trajectoire et le profil sociologique de ces dirigeants, nous avons récolté des articles nécrologiques dans les journaux ainsi que consulté les Who's Who nationaux et des dictionnaires biographiques ${ }^{53}$. S'il est possible d'y collecter des informations sur la majorité des dirigeants de notre étude, mentionnons que les indications sont parfois succinctes et très liées aux activités sportives. De plus, ajoutons que ces dirigeants n'ont pas laissé beaucoup de traces ${ }^{54}$. En conséquence, le constat tiré, il y a près de vingt

géographique puisque, dès les années 1920, différents blocs régionaux apparaissent au sein de la FIFA. Toutefois, afin de croiser les données, nous avons sélectionné au minimum deux pays par bloc géographique. Pour ce qui est de l'Europe (par ordre alphabétique) : Allemagne, Angleterre, Autriche, Belgique, Danemark, Espagne, France, Hongrie, Italie, Pays-Bas, Roumanie, Suède, Suisse, Tchécoslovaquie, Union soviétique et Yougoslavie. Concernant l'Amérique du Sud (par ordre alphabétique) : Argentine, Brésil, Chili et Uruguay. En raison des thématiques traitées, pour certaines périodes, d'autres pays ont également retenu notre attention (par ordre alphabétique) : Chypre, Égypte, Israël-Palestine et Turquie.

53 Nous avons notamment utilisé la base de données disponible en ligne "World Biographical Information System ", gérée par l'éditeur De Gruyter et qui regroupe plus de 8 millions de notices biographiques.

54 Seul le dirigeant anglais Stanley Rous a rédigé une autobiographie : Rous S., Football worlds. A lifetime in Sport, London, Faber, 1978. De même, au crépuscule de sa vie, le président de la FIFA (1919-1954) Jules Rimet a brièvement couché sur papier sa vision de l'apport du sport à la société internationale et a également profité d'un livre retraçant la création de la Coupe du monde pour donner quelques éléments biographiques le concernant. Rimet J., "Le football et le rapprochement des peuples ", Bulletin de la FIFA, édition spéciale, 1954 ; Rimet J., Histoire merveilleuse de la Coupe du monde, Paris, Union Européenne d'Éditions, 1954 
ans, par Alfred Wahl sur les difficultés à se procurer des informations sur les acteurs des organisations sportives reste d'actualité ${ }^{55}$.

Dans le but de corroborer, questionner, voire élargir le propos sur certains points, nous avons aussi eu recours à une documentation complémentaire. D'un point de vue archivistique, la riche documentation récoltée à l'UEFA et à la FIFA a été étoffée par d'autres documents issus des fonds de la fédération allemande (ex-Est et Ouest), belge, anglaise, française et suisse, choix qui s'explique en raison de l'accessibilité de leurs archives et aussi du fait que ces associations étaient parmi celles sélectionnées dans l'étape précédente. Le recours à ces archives devait nous permettre non seulement de mieux saisir les enjeux des discussions qui se déroulent au sein de la FIFA et de l'UEFA mais aussi de recueillir de nouvelles informations.

Nous avons également effectué deux autres types de démarches : la lecture de périodiques et des entretiens avec des acteurs footballistiques importants de la période étudiée. L'emploi de journaux spécialisés s'avère un complément utile car les journalistes assistent aux réunions officielles et ne se privent pas de donner des éléments sur la manière dont se sont déroulés les débats, ce qui contraste avec le côté policé des documents officiels des organisations. De plus, les rédacteurs de journaux sont souvent proches des dirigeants sportifs et, à ce titre, sont relativement bien informés. C'est pourquoi ils n'hésitent pas à émettre des hypothèses, notamment les jours précédant les réunions, sur les décisions qui pourraient être prises au sein de l'organisation. Sur certains aspects, des journaux généralistes français et suisses ont aussi été consultés.

En ce qui concerne les entretiens avec des acteurs clés du football de la période étudiée, ceux-ci ont été conduits sous une forme semi-directive. Deux rencontres ont été réalisées avec le journaliste Jacques Ferran. Entré à L'Équipe en 1948, Ferran va y rester quarante ans et en devient le rédacteur en chef durant les années 1970. Nous avons également eu l’opportunité de nous entretenir avec Pierre Delaunay, secrétaire général de l'UEFA de 1955 à 1959 puis membre de son comité exécutif de 1960 à 1962. Parallèlement secrétaire général de la Fédération française de 1955

55 Wahl A., "Les dirigeants du monde sportif français et allemand au XX $\mathrm{XX}^{\mathrm{e}}$ siècle. Un aperçu ", dans Wahl A., Football et histoire, Metz, Centre de recherche histoire et civilisation, 2004, pp. 193-208. À ce jour, peu d'études biographiques existent sur les dirigeants qui ont officié dans l'élite de la FIFA et de l'UEFA concernant notre période. Pour un bref aperçu, voir : Vonnard, P., « Euvrer en faveur du football européen. Jalons biographiques sur les précurseurs de l'UEFA (1920-1960) ", dans Gasparini W. (dir.), L'Europe du football, op. cit, pp. 107-121. 
à 1968, il était donc aux premières loges pendant la création de l'UEFA, et ce d'autant plus qu'il est le fils d'Henri Delaunay, premier secrétaire de l'Union et dirigeant influent du football européen des années 1920 aux années 1950. Nous nous sommes aussi entretenus avec Hans Bangerter. Contemporain de Delaunay, Bangerter a été secrétaire général adjoint de la FIFA de 1953 à 1959, puis secrétaire général de l'UEFA de 1960 à 1989. À la tête du secrétariat durant près de trente ans, il a vécu et participé à son développement. Enfin, cette recherche bénéficie d'entretiens réalisés dans le cadre d'autres recherches sur le football européen des années $1950-1970^{56}$.

\section{Plan du livre}

L'ouvrage est scindé en deux parties, chacune composée de deux chapitres. La première partie traite de la genèse de l'UEFA : il s'agit de comprendre le processus qui va mener à la création de l'Union au milieu des années 1950, mais aussi de saisir les raisons qui expliquent sa structure ainsi que les buts principaux de ses promoteurs.

Dans le premier chapitre, il s'agit de retracer le développement du football européen durant les années 1930 et en particulier d'insister sur le rôle de la FIFA dans ce processus. Si une dynamique européenne existe indéniablement, nous montrons que celle-ci reste malgré tout concurrencée par des connexions de type régional. De plus, il s'agit de mettre au jour les différentes stratégies développées par l'élite dirigeante de la FIFA dans le but de neutraliser les conflits au sein de l'organisation mais aussi en vue de se réserver une place relativement autonome sur la scène internationale. Cette volonté est notamment émise par son président, le Français Jules Rimet, qui reste à la tête de l'organisation de 1919 à 1954 et l'imprègne

56 En particulier avec des dirigeants du football helvétique à l'occasion d'une recherche sur le professionnalisme dans le football suisse : Berthoud J., Quin G., Vonnard P., Le football suisse. Des pionniers aux professionnels, Lausanne, PPUR, 2016. Par ailleurs, nous avons longuement conversé avec André Vieli, qui est entré en 1982 au service communication de l'UEFA. Outre les nombreux articles qu'il a publiés dans le Bulletin officiel de l'Union, UEFA direct, André Vieli a aussi écrit le livre des 60 ans de l'UEFA. À ce titre, il connaît extrêmement bien l'histoire de l'institution ainsi que ses archives. De même, nous avons rencontré à deux reprises Gerhard Aigner, qui entre au secrétariat de l'UEFA en 1969 et en devient le secrétaire général de 1989 à 2002. Par ailleurs, lors de notre séjour de recherche au sein de l'Union qui a duré trois mois au printemps 2012, nous avons eu l'occasion de discuter avec de nombreux collaborateurs, ce qui nous a permis de mieux comprendre le fonctionnement de l'organisation ainsi que ses récents développements. 
fortement de ses idéaux. Enfin, nous montrons que des contestations existent vis-à-vis de l'européocentrisme de l'élite de la FIFA dès le milieu des années 1930. Ce sont principalement des dirigeants officiant dans la Confédération d'Amérique du Sud - créée en 1916 - qui commencent à demander davantage de place dans la gouvernance de l'organisation et, à ce titre, envisagent déjà une décentralisation de la Fédération internationale.

Le deuxième chapitre s'intéresse à la période de la Deuxième Guerre mondiale ainsi qu'à ses conséquences pour la FIFA. Contrairement au premier conflit mondial, le football européen ne connaît pas un arrêt total et des rencontres continuent à se disputer, ce qui explique en partie leur perpétuation rapide au sortir du conflit. Mais si les échanges footballistiques reprennent rapidement après la guerre, c'est aussi parce que la FIFA a réussi à faire face à la pression des Allemands durant les premières années de guerre. Au sortir du conflit, son élite dirigeante doit néanmoins négocier au mieux les ressentiments dus à la guerre ainsi que les conséquences de l'arrivée de l'Union soviétique et au retour des associations britanniques qui avaient quitté la FIFA en 1927. En effet, en raison de leur statut sur la scène footballistique, mais aussi politique, internationale, un changement dans la composition du comité exécutif est décidé afin de permettre à un Soviétique et à un Britannique d'y figurer. Ces changements préfigurent ceux qui auront lieu au début des années 1950 et qui seront notamment impulsés par la Confédération sud-américaine. Car, dans les premières années de la décennie - le continent étant moins directement touché par la guerre-, cette confédération connaît une phase de structuration qui lui permet de mieux porter la voix de l'Amérique du Sud au sein de la FIFA. Au sortir du conflit, une alliance est même créée entre les confédérations d'Amérique centrale - fondée en 1938 - et d'Amérique du Nord - qui voit le jour en 1946. Elle doit permettre de dynamiser le football dans les Amériques mais aussi d'éventuellement créer une position panaméricaine au sein de la FIFA dans le but d'obtenir davantage de considération.

La deuxième partie aborde plus directement la formation de l'UEFA et s'attelle à décrire, avec précision, sa création et ses premiers développements.

Le troisième chapitre revient sur les actions qui débouchent sur la décentralisation de la FIFA. Au début des années 1950, le contexte semble plus propice à la création d'une entité continentale. Tout d'abord, des idées sont développées par plusieurs acteurs du football européen (dirigeants d'associations nationales, dirigeants de clubs, journalistes) qu'il faudrait créer davantage de synergies à l'échelle continentale. Ainsi, l'idée de fonder une organisation continentale est soulevée par une nouvelle génération de dirigeants œuvrant dans les associations nationales et arrivant sur le 
devant de la scène au sein de la FIFA (en particulier le trio Ottorino Barassi, Stanley Rous et Ernst Thommen). Toutefois, à cette période, ces projets concernent principalement les associations d'Europe de l'Ouest, la Guerre froide, dans un moment particulièrement chaud avec le déclenchement de la Guerre de Corée, ne permettant plus d'échanges réguliers entre les associations footballistiques de l'Est et de l'Ouest. Parallèlement, les associations sud-américaines passent à l'offensive et proposent un réagencement de la structure de la FIFA. Il s'agirait de créer des confédérations continentales - sur le modèle de la Confédération d'Amérique du Sud - qui administreraient le football sur le continent. Après trois ans de discussions, cette question va être réglée lors d'un congrès extraordinaire de la FIFA qui se déroule à Paris en novembre 1953.

À la suite de cette assemblée, la décision est prise que les dirigeants du comité exécutif de la Fédération internationale devront être choisis par chaque continent. Ceci implique quasiment implicitement la création d'organisations continentales, sujet qui est traité dans le quatrième chapitre. Alors qu'un réchauffement Est-Ouest s'opère progressivement (ce que les historiens ont appelé le « Dégel »), les associations européennes se réunissent et créent, en juin 1954, un Groupement européen, qui est renommé UEFA en octobre de la même année. S'inscrivant dans un contexte propice aux échanges footballistiques continentaux (pour la première fois de l'histoire, des projets de compétitions véritablement européennes sont lancés), l'UEFA va rapidement reprendre à son compte ce dynamisme et le soutenir. En moins de cinq ans, elle va se profiler comme l'organisme principal du football européen. Ce développement rapide s'opère en particulier parce que ses dirigeants tentent de négocier le fait que l'organisation est composée d'associations qui proviennent des blocs de l'Est et de l'Ouest. Reprenant et adaptant les stratégies développées au sein de la FIFA durant l'entredeux-guerres, ils vont réussir à construire un monopole de l'UEFA dans la gestion du football européen, que ce soit vis-à-vis de l'intérieur du monde du football (face à la FIFA notamment) et de l'extérieur (comme face à l'Union européenne de radio). En outre, ses compétitions (comme la Coupe des clubs champions européens) vont permettre de créer, ou de maintenir, des liens réguliers entre des pays politiquement divisés. Ainsi, l'UEFA se profile comme la principale confédération de la FIFA. Car, dans cette seconde partie des années 1950, la Fédération internationale se continentalise avec la création d'autres confédérations (en Afrique et en Asie). Jusqu'ici, la Confédération sud-américaine était le modèle à suivre, mais, en raison de son rapide développement, l'UEFA devient également un acteur majeur de cette continentalisation ainsi qu' une source d'inspiration pour les autres continents. 


\section{Partie 1}

\section{GenÈse De L'UEFA (1930-1949)}


Philippe Vonnard - 978-2-8076-0570-1

Téléchargé de PubFactory à01/07/2021 08:14:02PM

via free access 
ChAPITRE 1

\section{L'affirmation du pouvoir de la FIFA sur le football mondial (1930-1938)}

\section{Introduction du chapitre}

Ce premier chapitre, qui couvre la période de 1930 à 1938, a pour but de montrer que la politique de dynamisation du football européen rapidement développée par l'UEFA et la configuration particulière de son territoire ainsi que sa formation durant les années 1950 trouvent leurs racines dans les modifications structurelles que connaît la FIFA à partir des années 1930. En outre, ce retour en arrière a aussi comme avantage de bien souligner la nouveauté qu'implique, pour le football européen, la création de l'UEFA dans la seconde partie des années 1950.

Dans ce chapitre, nous décrivons premièrement la manière dont la FIFA accentue, durant les années 1930, les échanges de football (matchs internationaux, rencontres entre leurs dirigeants) entre les associations européennes. C'est notamment par l'entremise de la Coupe du monde, créée en 1930, que ces connexions plus étroites sont réalisées mais également qu'une géographie européenne du jeu se dessine progressivement. Toutefois, à cette époque, des associations considérées comme européennes, en particulier par les journalistes sportifs, ne sont pas sous la juridiction de la FIFA. C'est le cas des quatre associations britanniques et de l'Union soviétique. Malgré ces acteurs qui restent en dehors de son giron, au fil des années, la Fédération internationale pose des bases solides en matière de réunion des différents acteurs (dirigeants des associations nationales, dirigeants de clubs, journalistes) du football européen comme en témoignent les deux matchs de la FIFA de 1937 et 1938.

Deuxièmement, nous nous attelons à décrire la manière dont l'élite de la FIFA développe une politique visant à conférer à l'organisation une autonomie relative sur la scène internationale, démarche qui doit lui permettre de ne pas suivre strictement les configurations des relations politiques internationales. Cette vision correspond à celle défendue par le président de l'organisation, Jules Rimet, qui, sur un modèle s'inspirant des idéaux de Pierre de Coubertin, vise à « rapprocher les peuples par le ballon 
rond ». Durant les années 1930, le président Rimet est entouré d'une petite dizaine de dirigeants qui officient dans le comité exécutif de la FIFA. Si l'élite de la FIFA ne partage pas forcément l'ambition politique de Rimet, elle est mue par la volonté farouche de mener à bien le but de l'organisation : développer le football à l'échelle internationale. Sous cet angle, les dirigeants de la FIFA s'accordent donc sur la nécessité de renforcer la position de leur organisation sur la scène internationale, démarche qui doit in fine leur permettre de se réserver un monopole en matière d'administration du jeu à l'échelle internationale. Pour réaliser cette politique - renforcée par le fait qu'ils restent longtemps en poste et qu'ils partagent des visions proches $\mathrm{du}$ monde -, ils développent différentes stratégies, comme celle qui consiste à neutraliser la politique au sein de l'organisation ou, pour le dire autrement, à mener une "politique de l'apolitisme ». Dans cette optique, l'élite de la FIFA prend différentes mesures : renforcer les possibilités d'autofinancement de la FIFA pour limiter les ingérences extérieures, élire des dirigeants habiles et diplomates à la tête de la Fédération ou encore décider de ne pas intervenir dans les affaires internes des associations nationales. Ce dernier point permet d'éviter de se confronter aux patriotismes de ces associations - le football connaissant une politisation croissante durant l'entre-deux-guerres - et en particulier un investissement des États sur la scène internationale. De plus, le comité exécutif de la FIFA essaie au maximum de limiter les conflits au sein de l'organisation, plébiscitant par exemple la création de petites commissions dans lesquelles les sujets délicats seront traités. De même, il décide de nommer un secrétaire général dynamique, en l'occurrence Ivo Schricker, qui privilégie le dialogue et qui puisse s'entretenir linguistiquement parlant avec la majorité des dirigeants.

Troisièmement, nous prenons en compte l'aspect global de la FIFA. Certes, comme beaucoup d'autres organisations internationales de l'époque, la Fédération internationale reste largement dominée par les associations du Vieux Continent. Ce contexte implique une politique européocentrée de la part de son comité exécutif. Cette situation va néanmoins poser des problèmes car, dès les années 1920, de plus en plus d'associations extra-européennes deviennent membres de l'organisation. C'est notamment le cas des associations sud-américaines dont les plus grandes (Argentine, Brésil et, dans une moindre mesure, Chili et Uruguay) comptent des milliers d'adhérents. Ainsi, leurs représentants lors des congrès de la FIFA commencent à émettre des revendications en vue de disposer de davantage de reconnaissance au sein de l'organisation ainsi que de places fixes dans son comité exécutif. À ce titre, ils proposent, dès le milieu des années 1930, de décentraliser la FIFA. Une solution préconisée serait d'entamer sa régionalisation, en d'autres termes de créer des entités continentales - sur le modèle de la Confédération sud- 
américaine créée en 1916 - qui s'occuperaient de la gestion du football dans chaque continent. Des discussions - assez houleuses - s'engagent donc sur cette question au sein de la FIFA et débouchent, en 1938, sur une première réforme de la composition du comité exécutif avec une place fixe réservée à un représentant directement nommé par l'entité sud-américaine.

\subsection{Une organisation européenne du football ?}

La FIFA est créée en 1904 à Paris avec comme objectif principal « de régler et de développer le football international et de prendre à cour les intérêts de ses fédérations affiliées " ${ }^{1}$. Mais c'est surtout à partir des années 1920 qu'elle commence à prendre de l'importance. Administrant désormais le tournoi des Jeux olympiques, dont l'édition de 1924 marque un tournant ${ }^{2}$, la Fédération voit aussi constamment augmenter le nombre de ses membres ${ }^{3}$.

Malgré ces développements, à la fin des années 1920, la FIFA reste encore une organisation aux prérogatives limitées. En effet, elle n'organise pas sa propre compétition; ne dispose pas d'un siège ni d'un secrétariat puisque le siège se trouve au domicile de Carl Hirschman - membre fondateur et secrétaire général de l'organisation ; enfin, les associations britanniques considérées encore comme les « Masters of the Game » par les continentaux sont en dehors de son giron, ce qui peut paraitre problématique puisque, suite à la création de l'International Board (IB) ${ }^{4}$ en 1885 , les associations britanniques sont les garantes des lois du jeu. Au regard de ces éléments, les années 1930 marquent une nouvelle étape du développement de la FIFA qui permet de la considérer comme un organe pré-régulateur du football européen (la majorité de ses membres provenant encore de ce continent).

Anonyme, Statuts de la FIFA [édition de 1904], art. 2. Archives de la Fédération internationale de football association (FIFA), statuts, 1904-1981.

2 Charroin P., Waquet A., " Paris 1924 : l'universalisme professionnalisant du football contre l'amateur internationaliste des Jeux olympiques ", dans Terret T. (dir.), Les Paris des Jeux Olympiques de 1924, Biarritz, Atlantica, 2004, pp. 445-490.

3 En 1927, la FIFA compte quarante-quatre membres selon le Handbook de l'organisation paru cette même année.

4 L'International Board se veut l'organisme qui gère les Lois du jeu et, pour tout changement sur celles-ci, il faut l'approbation de la majorité de ses membres. À cette période, il est composé d'un membre des quatre associations britanniques (Angleterre, Écosse, Irlande du Nord et Pays de Galles) et de deux représentants de la FIFA. Sur la création de l'International Board, voir : Brown T., The Football Association 1863-1883: A source book, Nottingham, Soccer DataPhiblication, 2011. 


\subsubsection{Une plateforme d'échanges}

Dans un livre récemment publié, Éric Anceau, Jacques-Olivier Boudon et Olivier Dard abordent le cas des nombreuses "internationales " créées au $\mathrm{XIX}^{\mathrm{e}}$ et au $\mathrm{XX}^{\mathrm{e}}$ siècle ${ }^{5}$. Si leur ouvrage ne mentionne aucune internationale sportive, gageons qu'un article sur la FIFA aurait pu y avoir sa place. En effet, l'organisation se profile véritablement comme une internationale, regroupant différents acteurs du football européen et poursuivant comme but principal de « développer et de contrôler le football association international et de veiller à l'application de ses statuts et règlements ${ }^{6}$.

Afin de mener à bien cette mission, les promoteurs de la FIFA ont, dès le départ, décidé de calquer la structure de leur organisation sur celle d'autres organisations internationales créées, comme elle, dans le "moment internationaliste " du début du siècle dernier. Un organe législatif, l'assemblée générale - appelée également congrès -, se réunit de manière annuelle. Le lieu de la réunion est choisi lors de l'assemblée précédente et il est de coutume qu'il ne peut être le même deux fois de suite. Des représentants des associations nationales de football ${ }^{8}$ composent l'assemblée et discutent, puis parfois statuent, sur des questions relatives aux nouvelles adhésions, aux changements dans les règlements de la FIFA ou encore sur des sujets ayant trait à différents aspects du jeu (compétitions internationales; football professionnel et amateur ; relations avec l'IB ; discussions sur les Lois du jeu ; relations avec d'autres organismes comme le $\mathrm{CIO}$ ). À noter qu'au contraire de plusieurs autres organisations, les dirigeants de la FIFA ont opté pour deux règles spécifiques : d'une part, une seule association nationale par État peut être membre de l'organisation ; d'autre part, chaque association nationale dispose d'une seule et unique voix lors des votations, ce qui les place de facto sur un pied d'égalité.

Entre les assemblées générales, la gestion de la FIFA est confiée au comité exécutif dont les membres sont élus par l'assemblée générale pour un mandat de trois ans renouvelable aussi longtemps qu'ils le souhaitent.

Anceau É., Boudon J.-O., Dard O. (dir.), Histoire des internationales. Europe, XIX'eXXe siècles, Paris, Nouveau Monde, 2017.

6 Anonyme, Statuts de la FIFA [édition de 1929], art. 2 [des statuts]. FIFA, statuts, 1904-1981.

7 Rasmussen A., "Tournant, inflexions, ruptures : le moment internationaliste ", Mil neuf cent. Revue d'histoire intellectuelle, vol. 19, $\mathrm{n}^{\circ} 1,2001$, pp. 27-41.

8 En Europe, ces entités voient le jour entre la fin du XIX ${ }^{\mathrm{e}}$ siècle et les deux premières décennies du XX $\mathrm{X}^{\mathrm{e}}$ siècle. 
Afin de pouvoir être élu au sein du comité, le dirigeant qui se présente doit - règle tacite sur laquelle nous reviendrons plus loin - avoir un poste au sein du comité exécutif d'une association nationale et ne pas être rémunéré pour des activités dans le football. En conséquence, les secrétaires généraux des associations nationales, qui commencent à disposer de contrats à temps plein depuis les années 1910, ne peuvent se présenter pour ce type de poste.

Au début des années 1930, le comité exécutif est composé d'un président et de sept vice-présidents ainsi que d'un secrétaire, qui fait également office de trésorier. Nous pouvons considérer que les dirigeants qui font partie de cet organe constituent l'élite de la FIFA. À noter que, sur des sujets considérés comme sensibles ou devant être traités rapidement, un comité d'urgence comprenant le président et le secrétaire-trésorier peut se réunir entre les séances du comité exécutif.

Depuis sa création en 1904, la FIFA ne connaît pas beaucoup de changements structurels. Certes, une première réorganisation des statuts a eu lieu au milieu des années 1920 , toutefois celle-ci n’a pas énormément changé la structure de l'organisation. Au début de la décennie suivante, une partie des dirigeants des associations nationales estiment que celle-ci n'est plus en phase avec le développement croissant du football. En ce sens, ils préconisent une réorganisation de la FIFA. Ce sont notamment l'Italien Giovanni Mauro et l'Autrichien Hugo Meisl qui portent cette volonté devant l'assemblée de 1930. Leur idée se couple autant d'une envie de renforcer la position de la FIFA dans le champ sportif que d'une ambition personnelle, à savoir entrer dans son comité exécutif ${ }^{\circ}$. Acteurs disposant d'une écoute certaine auprès de nombreux autres dirigeants des associations nationales européennes, leurs doléances trouvent un écho au sein de l'élite de la FIFA. Toutefois, si des discussions ont lieu en son sein, aucune décision n'est prise de manière immédiate, sans doute en raison de la difficulté de la question à traiter.

Cependant, un élément va forcer le comité exécutif à finalement agir. En effet, l'organisation va se retrouver dans la tourmente car, suite à de mauvais placements - déroute encore amplifiée par la dévaluation de la livre qui suit le krach boursier de 1929 -, le secrétaire-trésorier de la FIFA, Carl Hirschman, se retrouve en faillite personnelle ${ }^{10}$. Or, signe d'un certain amateurisme dans la gestion de l'organisation, il n'avait pas

9 "MM. Mauro et Meisl entrent en scène ", Football, 6 août 1931.

10 Schricker I., Procès-verbal de la réunion du comité exécutif de la FIFA du 12 décembre

1931, n.d. FIFA, comité exécutif (procès-verbaux 1927-1932). 
dissocié ses comptes de ceux de la FIFA. Conséquence immédiate de cette situation, l'avenir financier de la Fédération internationale est directement menacé. Un match de secours est rapidement organisé entre la Belgique et les Pays-Bas - cette dernière se sent en effet responsable de la faute de son représentant - afin de collecter des fonds. La rencontre sauve effectivement la FIFA d'une déroute financière. Par contre, elle oblige Hirschman à démissionner, ce qu'il fait en automne $1931^{11}$. Cette situation est instrumentalisée par Mauro et Meisl, qui l'utilisent comme argument en faveur d'une réorganisation de la FIFA et ainsi mettent une pression supplémentaire sur son comité exécutif afin qu'il agisse.

Dès septembre 1931, l'élite de la FIFA prend la décision de déléguer le travail de réorganisation à une commission spéciale ${ }^{12}$. Ce procédé permet d'éviter que les conflits n'éclatent lors de l'assemblée générale et il a même l'avantage d'éventuellement les prévenir. Par ailleurs, il offre la possibilité de discuter dans un petit organisme, au sein duquel les différentes forces de la FIFA sont représentées. En effet, nous retrouvons dans la commission l'Italien Mauro, représentant des associations de l'Europe centrale, et l'Allemand Félix Linnemann, deux dirigeants favorables à une réorganisation. La composition est complétée par le Suédois Johanson, représentant des pays du Nord, et du Tchèque Rudolf Pelikan. Ce dernier peut aussi être considéré comme un dirigeant de l'Europe centrale. Toutefois, il semble plus modéré sur la réorganisation que ses collègues Meisl ou Mauro, probablement en raison du fait qu'il occupe déjà une place dans le comité exécutif de la FIFA. Enfin, le Belge Rodolphe Seeldrayers officie en qualité de président de la commission. Celle-ci se réunit à plusieurs reprises, ce qui permet aux dirigeants de s'accorder sur un projet de réorganisation. Finalement, les propositions sont présentées lors de l'assemblée générale de 1932 et sont bien accueillies par les congressistes.

La réforme tend à augmenter les prérogatives du comité exécutif. Par exemple, les congrès se tiendront dorénavant tous les deux ans, disposition qui renforce le leadership de l'élite de la FIFA. De plus, la structure de l’organisation évolue, avec un comité exécutif dont le nombre de membres augmente (voir le tableau 1). Il sera désormais composé d'un président, de deux vice-présidents et de six membres.

11 "Le comité exécutif de la FIFA s'est réuni samedi à Paris ", Football-association, 17 décembre 1931.

12 Hirschman C.A.W., Procès-verbal de la réunion du comité exécutif de la FIFA du 26 septembre 1931, n.d. FIFA, comité exécutif (procès-verbaux 1927-1932) 
Pour déterminer la première composition du comité, les délégués présents choisissent de faire une élection uniquement pour les deux places de vice-présidents. Sans doute, mais nous n'avons pas de preuve formelle à apporter sur la question, la situation a-t-elle été négociée en amont, et de manière non officielle, entre les associations présentes. De plus, une interruption de séance précède cette élection, afin de sceller les dernières alliances. Ce procédé démontre la volonté d'effectuer la transition en douceur et de limiter d'éventuelles tensions au sein de l'organisation. Finalement, Rodolphe Seeldrayers et Giovanni Mauro sont élus comme vice-présidents et les six vice-présidents restants sont proposés à l'assemblée pour occuper les six postes de membres ${ }^{13}$.

\section{Tableau 1. Ancienne et nouvelle composition du comité exécutif}

\begin{tabular}{|l|c|l|c|l|}
\hline Fonction & $\begin{array}{l}\text { Nombre } \\
\text { (statuts 1929) }\end{array}$ & Élection & $\begin{array}{l}\text { Nombre } \\
\text { (dès 1932) }\end{array}$ & Élection \\
\hline Président & 1 & congrès & 1 & congrès \\
\hline Vice-président & 7 & congrès & 2 & congrès \\
\hline Membres & 0 & congrès & 6 & congrès \\
\hline $\begin{array}{l}\text { Secrétaire- } \\
\text { trésorier }\end{array}$ & 1 & congrès & 1 & comité exécutif \\
\hline
\end{tabular}

Afin d'être plus efficient, il est décidé que le comité se réunira moins souvent que par le passé, soit dorénavant deux à trois fois par année. Dans l'intervalle, il sera suppléé par le comité d'urgence, dont la composition est revue. Feront désormais partie de cet organe le président et les deux membres les plus anciens du comité exécutif ${ }^{14}$. Par ailleurs, la durée du mandat est étendue d'une année et passe de trois à quatre ans, ce qui permet une plus grande stabilité et offre la possibilité aux dirigeants du comité de conduire plus aisément les projets, d'autant qu'ils sont souvent réélus. Dans les mois qui suivent, le pouvoir de l'élite de la FIFA va encore être renforcé. En décembre de la même année, il est décidé que "dorénavant aucune commission n'aura le droit de se réunir [sans son] autorisation préalable ou éventuellement du comité d'urgence ${ }^{15}$.

13 Schricker I., Procès-verbal de l'assemblée générale de la FIFA des 13 et 14 mai 1932, n.d. FIFA, XX-XXIV congrès ordinaires (1931-1938, rapport d'activité).

14 Auxquels il faut également ajouter le secrétaire général.

15 Schricker I., Procès-verbal de la réunion du comité exécutif de la FIFA du 10 décembre 1932, n.d. FIFA, XX-XXIV congrès ordinaires (1931-1938 rapport d'activité). 
Ces nouvelles prérogatives conférées au comité exécutif de l'organisation doivent permettre de mener une politique plus directrice et ainsi d'affirmer le monopole de la Fédération internationale sur le jeu, suivant en cela les souhaits émis par Meisl et Mauro.

Lors de l'assemblée générale de 1932, les congressistes prennent encore deux décisions qui vont dans ce sens. Premièrement, ils fixent un siège pour l'organisation. Deuxièmement, ils créent un poste de secrétaire général. Comme le notent Eisenberg et al., les changements opérés en 1932 permettent à la FIFA de consolider sa structure administrative ${ }^{16}$. Dès la nomination du nouveau secrétaire général, Ivo Schricker, les documents sont plus systématiques et davantage structurés que par le passé. De même, le nouveau secrétaire met en place une comptabilité double, avec un compte " $\mathrm{A}$ » qui contient le capital de la FIFA et un compte « $\mathrm{B}$ » qui est le compte courant pour le service financier. Ce système doit permettre à l'organisation de tenir plus sérieusement ses comptes.

Figure 1. Structure de la FIFA en 1932

Organe exécutif

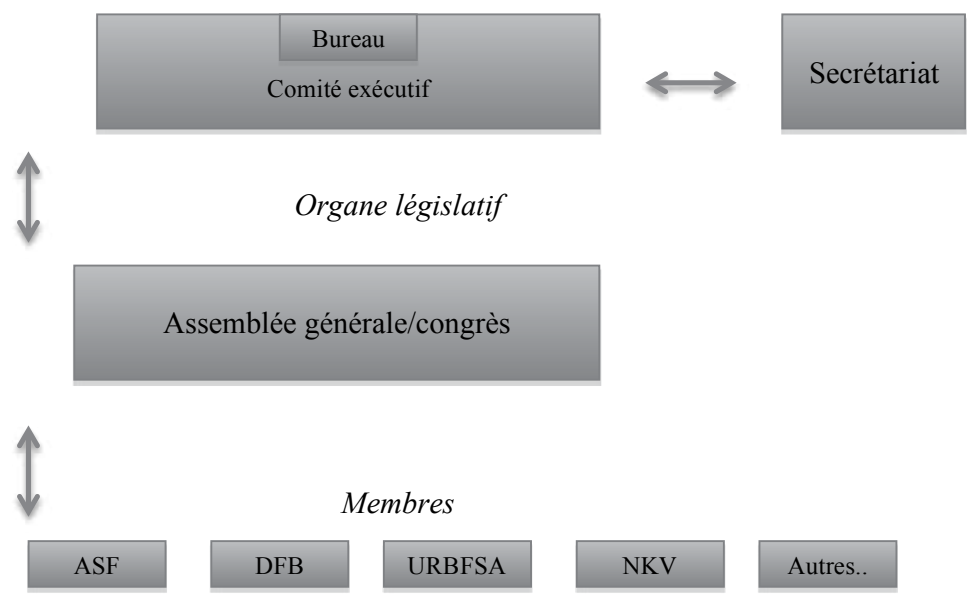

Légende : le bureau est formé du président, du premier vice-président et du secrétaire général.

16 Eisenberg C. et al., FIFA 1904-2004, opp citîpp. 74́. V́nnard - 978-2-8076-0570-1 
La FIFA dispose désormais d'une structure plus solide pour effectuer sa mission ${ }^{17}$. Durant les années 1930 , le comité exécutif étend ses prérogatives et s'attelle à traiter de nombreux sujets. Nous pouvons les regrouper en huit sous-ensembles :

1) Administration (questions relatives au secrétariat et aux différentes commissions de la FIFA).

2) Sujets relatifs aux compétitions.

3) Relations avec le $\mathrm{CIO}$ et les autres fédérations internationales.

4) Discussions sur les modifications de statuts et du règlement de la FIFA.

5) Discussions sur les Lois du jeu et les relations avec l'IB.

6) Questions financières (rapports financiers, placements, pourcentage sur les matchs internationaux).

7) Cas de joueurs (suspension ou litige sur les transferts de joueurs).

8) Relation avec les associations nationales et les associations nationales non affiliées à la FIFA (comme les associations britanniques ou l'Union soviétique).

De même, la FIFA diffuse des informations sur elle-même, et plus largement sur le développement du football, par l'entremise d'un Bulletin officiel d'information, créé durant les années 1920 . Un pas supplémentaire est effectué lorsqu'un mensuel, intitulé World's Football, est mis sur pied à la fin de la décennie. Jusqu'au milieu des années 1930, celui-ci va être publié et distribué aux associations nationales, voire à des particuliers, à un rythme soutenu avec presque un numéro par mois. Cette entreprise de propagande ${ }^{18}$ permet aux lecteurs d'être au courant des décisions prises lors des congrès de la FIFA, de connaître tous les résultats des rencontres internationales, mais aussi de disposer d'articles sur le football dans différents pays. Bien que le titre du journal indique le terme "monde ", celui-ci fait surtout la part belle au continent européen puisque le football en dehors d'Europe est certes traité, mais avec parcimonie et souvent sous des titres génériques comme le football " en Amérique du Sud ». $A$ contrario, les articles sur le football européen sont plus nombreux et

17 À côté du comité exécutif, trois autres organismes s'occupent de sujets précis : la commission des Lois du jeu, la commission de la Coupe du monde et la commission de l'amateurisme.

18 Le terme " propagande » est couramment utilisé à cette époque et n'a pas la connotation négative que nous lui connaissons aujourd'hui. 
souvent, le jeu est abordé à l'échelon national comme le football " en Pologne ", " aux Pays-Bas » ou " en Roumanie ».

Mais la FIFA ne fait pas que traiter ou diffuser des informations au sujet du football. Comme la grande majorité des organisations internationales, elle permet d'œuvrer au regroupement de nombreux acteurs du football européen (élite de la FIFA, dirigeants des associations nationales et parfois des dirigeants de clubs ou encore des journalistes), en particulier lors de ses assemblées générales.

De 1932 à 1938, les congrès réunissent une trentaine d'associations nationales, dont une bonne partie envoie systématiquement des délégués aux assemblées ${ }^{19}$. Tout au long de cette période, une assemblée générale de la FIFA convoque entre 70 et 80 dirigeants (entre un et quatre délégués par association nationale). Autour de l'élite de la FIFA, c'est donc une petite communauté européenne qui se réunit tous les deux ans. Ainsi, des dirigeants d'associations nationales comme les Autrichiens Eberstaller et Meisl, les Belges Verdyck et Jouveneau, le Danois Oestrup, l'Espagnol Cabot, les Français Delaunay et Chevallier, les Hongrois Fodor et Kenyeres, le Luxembourgeois Jacquemart, le Portuguais Ribeiro dos Reis, le Néerlandais Kips, le Norvégien Eie, le Polonais Mallow ou encore les Suisses Henninger et Gassmann participent à la grande majorité des congrès des années 1930 .

Ces dirigeants, qui partagent une passion sincère pour le développement du football - ce sont souvent d'anciens joueurs - et disposent de profils sociologiques proches (parlant plusieurs langues et ayant une trajectoire souvent internationale) ne font pas que de discuter de jeu durant les deux ou trois jours que dure l'assemblée générale. En effet s'ajoutent aux sessions de discussion plusieurs moments de sociabilité. Outre d'assister à une partie de football international qui se joue dans la ville - toujours une grande capitale européenne - où se tient le congrès, un jour est souvent réservé pour des excursions culturelles (visite de "hauts lieux " historiques ou de musées). Par ailleurs, la manifestation se conclut systématiquement par un grand banquet dans un restaurant bien coté, auquel les journalistes sont souvent conviés. Par exemple, lors de l'assemblée générale de 1924 à Paris, le programme suivant est proposé aux congressistes. Le premier soir, ils assistent à une cérémonie à l'opéra Garnier. Le lendemain, ils sont conviés à une

19 En particulier (par ordre alphabétique) : Allemagne, Belgique, Danemark, Finlande, Hongrie, Irlande, Italie, Luxembourg, Norvège, Pays-Bas, Pologne, Roumanie, Suède, Suisse, Tchécoslovaquie et Yougoslavie. 
visite du château de Versailles ${ }^{20}$. Enfin, le dernier jour est le théâtre du traditionnel banquet de gala. Ces différentes activités doivent créer, ou maintenir, les liens entre les dirigeants. En certaines occasions, la FIFA continue à fortifier cette solidarité en dehors des assemblées officielles. Ainsi, lors du décès de l'Autrichien Hugo Meisl en 1938, le secrétaire général, Ivo Schricker, s'adresse aux associations nationales en vue de créer un fond d'assistance qui permettra à ses trois enfants de toucher un petit capital à leur majorité.

Durant les années 1930, la FIFA peut être considérée comme une "plateforme d'échanges $"{ }^{21}$, aidant à diffuser de l'information sur le football mais aussi œuvrant au renforcement des liens entre les dirigeants des associations nationales, voire permettant d'en créer de nouveaux. Avec la création de la Coupe du monde en 1930, cet aspect se renforce encore, l'épreuve permettant de dynamiser les échanges footballistiques entre les pays européens. Par ailleurs, la compétition permet aussi d'inventer une frontière et de délimiter les associations nationales qui font partie du continent européen et celles qui se tiennent en dehors de celui-ci.

\subsubsection{Dynamiser les échanges et définir un territoire européen}

Il faut s'arrêter ici quelque peu sur la création de la Coupe du monde, dont la première édition est organisée en 1930. Même si le terme "monde " apparaît dans son titre, le tournoi doit être plutôt appréhendé comme une compétition entre les associations du Vieux Continent. En effet, les éditions de 1934 en Italie et de 1938 en France s'apparentent à des championnats d'Europe, en raison de leur participation très largement européenne. Sous le régime de Mussolini, douze participants sur seize proviennent d'Europe ${ }^{22}$. Quatre ans plus tard, l'épreuve disputée dans l'Hexagone du Front populaire concerne uniquement trois pays extraeuropéens, à savoir le Brésil, Cuba et les Indes néerlandaises. Le cas de

20 Hirschman C.A.W., "Congress », 15 avril 1924, FIFA Official Communications, $\mathrm{n}^{\circ} 3$, p. 1. Voir également : "Les congrès internationaux ont eux aussi leurs histoires ", Football, 12 août 1936.

21 Maurel C., "L'Unesco : une plate-forme pour les circulations transnationales de savoirs et d'idées (1945-1980)", Histoire@Politique. Politique, culture, société, vol. 15, 2014, publié en ligne.

22 À savoir (par ordre alphabétique) : Allemagne, Autriche, Belgique, Espagne, France, Hongrie, Italie, Roumanie, Suède, Suisse, Pays-Bas et Tchécosloyaguię 
cette épreuve est néanmoins intéressant à développer car celle-ci permet non seulement d'accentuer les échanges entre les associations européennes mais aussi de déterminer les frontières géographiques de l'Europe dans le football.

La création de la Coupe du monde en 1930 est désormais bien connue et a notamment été abordée dans ses grandes lignes par Alfred $\mathrm{Wahl}^{23}$. Dans un texte publié en 2013, Grégory Quin est revenu plus précisément sur les discussions qui se déroulent sur le sujet, au sein de la FIFA, à la fin des années 1920. Sa recherche a permis de montrer que différents positionnements existent chez les acteurs européens du football, entre ceux qui préconisent une Coupe du monde et ceux qui défendent l'idée d'un Championnat d'Europe. Après plusieurs mois de discussions, notamment dans le cadre d'une commission spécialement mise sur pied pour traiter de la question, le congrès de 1929 opte en faveur d'une Coupe du monde, dont la première édition sera organisée en Uruguay ${ }^{24}$. C'est donc la vision " universaliste " défendue par les dirigeants français Jules Rimet et Henri Delaunay ${ }^{25}$ qui prévaut sur la solution plus européenne souhaitée, en particulier, par l'Autrichien Hugo Meisl.

Certes, l'attribution de la Coupe du monde à l'Uruguay peut être perçue comme une opportunité de créer davantage de liens avec les associations extra-européennes et en premier lieu avec les Sud-Américains. Toutefois, dans les faits, cette tentative se solde par un échec. En effet, alors que la majorité des congressistes avaient voté en faveur de l'Uruguay, seules quatre équipes nationales européennes font le déplacement, à savoir (par ordre alphabétique) la Belgique, la France, la Roumanie et la Yougoslavie. Pour expliquer leur non-participation, les associations nationales européennes évoquent le coût du long voyage pour se rendre à Montevideo (près d'un mois en bateau) et de l'entretien financier de l'équipe durant près de deux mois. Cependant, comme le note Lorenzo Jalabert d'Amado, c'est aussi un argument d'ordre sportif qui semble freiner la plupart des associations européennes. En effet, le haut niveau de jeu présenté par l'équipe uruguayenne lors du tournoi olympique de

23 Wahl A., Histoire de la Coupe du monde de football : une mondialisation réussie, Bruxelles, P.I.E. Peter Lang, 2013.

24 Hirschman C.A.W., Procès-verbal de l'assemblée générale de la FIFA des 17 et 18 mai 1929, n.d. FIFA, XII-XIX congrès ordinaires (1923-1930, rapport d'activité).

25 Dietschy P., "French sport: caught between universalism and exceptionalism ", European Review, vol. 19, n 4, 2011, pp 509-525. 5. 
1928 - qu'elle remporte facilement - semble ne donner que peu de chance de victoire aux équipes nationales européennes ${ }^{26}$.

De plus, la participation des quatre associations européennes qui acceptent de traverser l'Atlantique n'a été obtenue qu'in extremis. En Belgique, celle-ci fait suite à l'énergie déployée par le diplomate uruguayen, Enrique Buero ${ }^{27}$. Ministre de l'Uruguay dans le pays, Buero contacte le gouvernement belge à la suite du refus de l'Union belge d'accéder à sa demande d'envoyer une équipe. Finalement, le gouvernement intervient auprès de la Fédération de football, qui accepte bon gré mal gré de former une sélection ${ }^{28}$. La situation n'est guère plus positive en France et, à la fin du mois de mai 1930 - soit un peu plus de deux mois avant le début de l'épreuve -, L'Auto mentionne que la Fédération française " ne s'est pas encore prononcée pour la participation à la Coupe du monde $»^{29}$.

Outre le déplacement des équipes en Amérique du Sud, l'organisation d'une autre compétition, la Coupe des nations, disputée en juin 1930 à Genève constitue une sérieuse concurrence à l'épreuve mondiale. Soutenu par la Société des intérêts de Genève, en partenariat avec le club local, le Servette, le tournoi disputé sur les bords du lac Léman convoque des clubs renommés (et donc potentiellement des joueurs qui auraient pu être sélectionnés dans leur équipe nationale) d'une dizaine de pays ${ }^{30}$. En raison du peu de documentation à disposition pour cette période conservée au siège de la FIFA, nous ne savons pas exactement quelle est la position de la Fédération internationale vis-à-vis de la Coupe des nations. Toutefois, les organisateurs ont pris la précaution de placer le président de la FIFA, Jules Rimet, dans le comité d'honneur. Est-ce une manière d'éviter l'ingérence ou la non-acceptation du tournoi par la FIFA ? Par ailleurs, il faut aussi

26 Jalabert D’Amado L., “"Montevideo 1930” ou l'amnésie européenne. Étude d'une Coupe du monde ignorée ", Mémoire de master II réalisé sous la direction d'Olivier Compagnon, Université de Paris III, 2014, p. 139.

27 En fait, Enrique Buero mène de nombreuses actions vis-à-vis des associations de football, mais aussi de plusieurs gouvernements européens. Celles-ci sont relatées dans un document imprimé après l'épreuve, intitulé Negociaciones internacionales.

28 Anonyme, Procès-verbal de la réunion du comité exécutif de l'Union belge du 23 avril 1930. Archives générales du Royaume de Belgique (AGRB), Union royale belge des Sociétés de Football-Association (URBSFA), dossier : comité exécutif (procès-verbaux du 7 avril 1928-25 mars 1931).

29 "La FFFA ne s'est pas encore prononcée pour la participation à la Coupe du monde ", L'Auto, 28 mai 1930.

30 Lüscher L., La Coupe des nations 1930. Une compétition "européenne " dans la Genève internationale, Mémoire de fin d'études réalisé sous la direction de Nicolas Bancel, Université de Lausanne, 2015. 
souligner que malgré le terme " nations » utilisé dans la dénomination de l'épreuve, il s'agit ici d'une compétition pour les clubs. Or, à cette époque, la FIFA n'entretient pas de liens avec les clubs et n'a que des connexions avec les associations nationales. Une chose est néanmoins sûre, la Coupe des nations est perçue par de nombreux acteurs du football européen, et en particulier par les journalistes, comme un tournoi très important. Ainsi, le journal allemand Kicker n'hésite pas à la définir comme la « Genfer Kleine Olympiade ». De même, le journal L'Auto met sur pied, en collaboration avec la Compagnie des wagons-lits, un voyage spécial pour les lecteurs qui souhaiteraient se rendre à Genève ${ }^{31}$. Ce tournoi semble donc être la principale attraction de l'été footballistique et éclipse l'épreuve mondiale ${ }^{32}$.

Malgré la faible participation des Européens à cette première édition de la Coupe du monde, la compétition est reconduite pour l'année 1934, notamment en raison du fait que la première édition a apporté une nouvelle source de financement à la FIFA. Dans les années qui suivent, le tournoi va participer à une nouvelle étape dans l'affermissement des rencontres internationales entre les équipes européennes de football. Ce type de rencontres existe depuis le début du siècle et certaines confrontations, comme Autriche-Hongrie, Belgique-Pays-Bas, Suisse-Italie, DanemarkSuède, constituent de véritables traditions footballistiques entretenues de manière annuelle. À partir de la seconde moitié des années 1920, des compétitions régionales s'ajoutent à ces matchs dits « amicaux » et renforcent les liens entre les associations nationales voisines. En effet, en s'inspirant des championnats britannique qui se disputent entre l'Angleterre, l'Ecosse, l'Irlande du Nord et le Pays de Galles depuis 1885, diverses épreuves sont créées (par ordre de leur création) : Championnats scandinave (Danemark, Finlande, Norvège et Suède) ; Coupe internationale (Autriche, Hongrie, Italie, Suisse et Tchécoslovaquie) ${ }^{33}$; Coupe des Balkans (Bulgarie, Grèce, Roumanie et Yougoslavie $)^{34}$. De même, des idées de nouvelles compétitions sont régulièrement lancées - comme celle que présente le Tchèque Rudolf Pelikan à ses collègues du comité exécutif de la FIFA en novembre 1936, entre la Roumanie, la Tchécoslovaquie et la Yougoslavie - sans toutefois être réalisées. Durant la même période, le football des clubs est aussi

31 "La Coupe des Nations. Un train spécial avec séjour à Genève », L’Auto, 7 juin 1930.

32 Celle-ci est malgré tout traitée, mais de manière différée. Par exemple, Le Sport suisse consacre de longs articles sur l'épreuve du mois d'août au mois d'octobre 1930.

33 Quin G., «La Coupe de l’Europe centrale (1927-1938), une compétition internationale oubliée ? ", Stadion. Revue internationale d'histoire du sport, vol. 37, n ${ }^{\circ}$ 2, 2013, pp. 285-304.

34 Breuil X., Constantin P.N., "The Balkan cups as a vector of European Integration ", Sport History, vol. 35, n 4, 2015, pp. 591-603. 
marqué par de nombreux matchs internationaux - les équipes des pays d'Europe centrale, en premier lieu celles basées à Budapest et à Vienne, faisant de véritables tournées afin de récolter des fonds permettant de financer leurs joueurs professionnels ${ }^{35}$. Des tournois commencent aussi à être organisés de manière régulière, telle la Mitropa (Mittel-Europa) $\mathrm{Cup}^{36}$ - qui à son apogée convoque quatre équipes issues de cinq à six pays -, ou de manière occasionnelle, comme la Coupe des nations ou le tournoi qui se dispute en 1937 durant l'Exposition universelle de Paris.

Cette importance du cadre régional s'explique pour plusieurs raisons. Tout d'abord, il faut souligner les limites induites par les conditions de transport. Certes, les connexions sont en amélioration constante, en particulier entre les grandes villes d'Europe de l'Ouest. Ainsi, en 1933, l'avion permet désormais de relier Paris à Berlin en 4 heures $25 \mathrm{de} \mathrm{vol}^{37}$. Toutefois, cinq ans plus tard, il faut encore plus de 14 heures pour faire ce trajet en train de nuit ${ }^{38}$. De plus, il reste toujours difficile de rallier d'autres villes du Sud ou du Nord de l'Europe. Par ailleurs, c'est aussi l'habitude des échanges qu'il faut ici relever. En effet, comme dans d'autres domaines ${ }^{39}$, les liens privilégiés s'établissent avant tout sur un plan régional. C'est pourquoi l'entre-deux-guerres peut être perçu comme l'« âge d'or " en ce qui concerne les échanges footballistiques régionaux ${ }^{40}$.

35 Suivant le modèle britannique, le professionnalisme est adpoté au milieu des années 1920 par les associations nationales de l'Autriche, de la Hongrie et de la Tchécoslovaquie. Au début des années 1930, l'Espagne, la France et la Suisse franchissent à leur tour leur Rubicon. En Italie, si le professionnalisme n'est pas officiellement toléré, les joueurs sont de facto des professionnels et sans doute les mieux payés d'Europe. Toutefois, la pratique professionnelle est encore délicate à mettre en œuvre dans beaucoup de clubs. Dans le cas de la France, des auteurs ont postulé qu'il fallait plutôt parler de "professionnalisme marron ». De même, l'association suisse fait marche arrière à la fin des années 1930 et interdit la pratique professionnelle.

36 Marschick M., " Mitropa: representations of "Central Europe" in football ", International Review for the Sociology of Sport, vol. 36, n 7, 2001, pp. 7-23.

37 Studeny C., Linvention de la vitesse. France, XVIII $-X X^{e}$ siècle, Paris, Gallimard, 1995 , p. 348.

38 Information donnée dans une publicité du journal L'Auto du 2 mai 1938 en vue d'un déplacement pour assister au match de football Allemagne-France à Berlin.

39 Pour une synthèse sur les espaces régionaux de cette période, voir : Dumoulin M., "La réflexion sur les espaces régionaux en Europe à l'aube des années trente ", dans Schirmann, S. (dir.), Organisations internationales et architectures européennes 1929-1939, Metz, Université de Metz, 2003, pp. 17-33.

40 Quin G., "Central Europe rules European Football. The "golden age” of regional connections in European Football (1926-38) ", dans Vonnard P., Quin G., Bancel N., Building Europe with the ball, op. cit pppp 53-73. 
Au regard de cette configuration géographique, la Coupe du monde propose une première rupture, car le tournoi mondial permet de créer des confrontations encore inédites et qui dépassent le cadre géographique régional. Si nous tenons compte de toutes les rencontres internationales disputées entre 1923 et 1934 par les équipes nationales européennes prenant part à la Coupe du monde 1934, nous constatons que leurs principaux adversaires sont effectivement leurs voisins directs ou des pays géographiquement proches. Durant cette période, il n'y a par exemple aucun match entre la Belgique et des pays comme la Bulgarie ou la Roumanie. De même, la Suisse ne rencontre jamais la Grèce tandis que la Pologne n'entretient pas de relations footballistiques avec l'Espagne.

\section{Tableau 2. Matchs internationaux (1923-1930) des participants européens à la Coupe du monde 1934}

\begin{tabular}{|l|c|l|l|l|}
\hline Pays/adversaires & $\begin{array}{l}\text { Nb de } \\
\text { Matchs }\end{array}$ & ${\text { Adversaire } \mathbf{n}^{\circ} \mathbf{1}}$ & ${\text { Adversaire } \mathbf{n}^{\circ} \mathbf{2}}$ & ${\text { Adversaire } \mathbf{n}^{\circ} \mathbf{3}}$ \\
\hline Allemagne & 41 & Suisse (8)* $^{*}$ & Pays-Bas (5) & Norvège, Suède (5) \\
\hline Autriche & 57 & Hongrie (16) & $\begin{array}{l}\text { Tchécoslovaquie } \\
(9)\end{array}$ & Suède, Suisse (6) \\
\hline Belgique & 59 & Pays-Bas (19) & France (10) & Angleterre (7) \\
\hline Espagne & 28 & Italie (8) & Portugal (5) & France (3) \\
\hline France & 51 & Belgique (10) & Angleterre (6) & Portugal, Suisse (5) \\
\hline Hongrie & 58 & Autriche (16) & $\begin{array}{l}\text { Tchécoslovaquie } \\
(9)\end{array}$ & Suisse (6) \\
\hline Italie & 52 & Espagne (8) & Suisse (7) & $\begin{array}{l}\text { Hongrie, } \\
\text { Tchécoslovaquie (6) }\end{array}$ \\
\hline Pays-Bas & 52 & Belgique (19) & Allemagne (6) & Suède (6) \\
\hline Roumanie & 27 & Yougoslavie (8) & Bulgarie (5) & Turquie (4) \\
\hline Suède & 74 & Danemark (8) & Finlande (8) & Norvège (8) \\
\hline Suisse & 55 & Allemagne (8) & Autriche (7) & Italie (7) \\
\hline Tchécoslovaquie & 54 & Hongrie (9) & Yougoslavie (9) & Italie (6) \\
\hline
\end{tabular}

Légende : ${ }^{*}$ nombre de matchs joués.

Sous cet angle, la Coupe du monde propose de nouveaux rapprochements entre des associations nationales n'entretenant pas, ou peu, de relations footballistiques. Dès la deuxième édition de 1934, les équipes qui s'inscrivent à la compétition doivent, dans un premier temps, 
disputer une phase qualificative dont le but est de permettre la sélection des seize meilleures équipes. Dans un deuxième temps, ces formations se rencontrent lors de la phase finale, disputée sous la forme d'une coupe, c'est-à-dire dans des matchs à élimination directe ${ }^{41}$. Ainsi, entre 1933 et 1934, trente-deux équipes, dont dix-huit pays européens, sont réparties dans douze groupes de qualification ${ }^{42}$. Afin de rendre la phase qualificative plus facile à organiser (notamment en limitant les coûts de transport), le comité exécutif de la FIFA choisit de tenir compte « le plus possible de [la] situation géographique [des participants] ${ }^{43}$. Il est dès lors décidé d'utiliser les matchs des compétitions régionales (Coupe des Balkans, Coupe internationale et Championnat scandinave) comme épreuve qualificative. Cependant, cette manière de procéder est, dans certains cas, problématique. En effet, l'élite de la FIFA estime que les meilleures équipes européennes ne doivent pas se rencontrer dans la phase de qualification, car leur élimination aurait pour conséquence de prétériter l'attractivité de la phase finale. Cette situation implique de créer des regroupements artificiels, procédé permettant notamment de réserver un statut préférentiel aux meilleures équipes. Dès lors, les groupes européens sont constitués de la manière suivante :

Espagne et Portugal (1 finaliste) ; Italie et Grèce (1 finaliste) ; Autriche, Hongrie et Bulgarie (2 finalistes); Tchécoslovaquie et Pologne (1 finaliste); Yougoslavie, Suisse et Roumanie (2 finalistes) ; Pays-Bas, Belgique et Irlande (2 finalistes), Allemagne, France et Luxembourg (2 finalistes) ${ }^{44}$.

Dans la plupart des cas, les relations régionales sont respectées et, afin de favoriser les grandes équipes, certains groupes bénéficient de deux places qualificatives pour la phase finale. La phase de qualification permet néanmoins l'organisation de quelques confrontations inédites. Ainsi, elle offre une première opposition entre la Suisse et la Roumanie, ainsi qu'entre la Suisse et la Yougoslavie. De même, jusqu'alors la Bulgarie n'avait rencontré qu'à une seule reprise l'Autriche et jamais la Hongrie. Un constat analogue peut être réalisé au sujet de la Grèce et de l'Italie, pays qui n'avaient jamais joué l'un contre l'autre. En ce sens, la Coupe du monde

41 Hirschman C.A.W., Procès-verbal de la réunion du comité exécutif de la FIFA du 19 avril 1931, n.d. FIFA, comité exécutif (procès-verbaux 1927-1932).

42 Schricker I., Rapport du secrétaire général de la FIFA (1932-1934), n.d. FIFA, XX-XXIV congrès ordinaires (1931-1938, rapport d'activité).

43 Schricker I., Procès-verbal de la réunion du comité exécutif de la FIFA des 22-23 avril 1933, n.d. FIFA, comité exécutif (procès-verbaux 1933).

44 Schricker I., Procès-verbal de la réunion du comité exécutif de la FIFA du 26 juin 1933, n.d. FIFA, comité exécutif (procès-verbaux 1933). 
de 1934 permet une extension du cadre des échanges entre les associations européennes. En outre, elle ancre aussi des représentations géographiques de la zone Europe. Ainsi, pour les dirigeants de la FIFA, le territoire du Vieux Continent s'étend de l'Irlande à la Turquie, de l'Est à l'Ouest, et de la Scandinavie à la Grèce, du Nord au Sud.

Pour l'édition de 1938, le même modus operandi est appliqué. La zone Europe compte cette fois huit groupes de qualification et, comme quatre ans plus tôt, propose des rencontres inédites. Par exemple, l'Autriche rencontre deux pays baltes contre lesquels elle n’a jamais joué. De même, la Hongrie se voit proposer une opposition inédite face à la Grèce, et la confrontation Pologne-Irlande est aussi une première.

Par l'entremise de la Coupe du monde, la FIFA favorise indéniablement les échanges entre les différents acteurs du football du Vieux Continent. En effet, il faut souligner ici que les parties internationales dépassent le cadre du terrain et doivent servir à maintenir, voire développer, l'amitié entre les associations footballistiques nationales (d'où l'emploi du terme " amical " lorsque la rencontre ne se déroule pas dans le cadre d'une compétition officielle). En conséquence, les matchs internationaux disputés lors des qualifications de la Coupe du monde offrent des occasions aux dirigeants des associations nationales concernées de se rencontrer et d'échanger, souvent de manière informelle, sur des sujets du football européen et mondial. À ce titre, et comme lors des assemblées générales de la FIFA, des banquets sont organisés le plus souvent à la suite de la rencontre, auxquels participent les deux équipes mais aussi les dirigeants des deux fédérations concernées.

Par ailleurs, l'épreuve qualificative de la Coupe du monde délimite aussi les associations nationales qui font partie du territoire européen et celles qui en sont exclues. Ce territoire est d'autant plus légitime qu'il est ensuite largement repris par d'autres acteurs du football qui prennent de plus en plus d'importance : les journalistes. En effet, les rencontres sportives internationales connaissent, depuis le début des années 1920, une médiatisation croissante de la presse sportive ${ }^{45}$. À celle-ci s'ajoute progressivement une attention grandissante de la part de la presse écrite généraliste, puis de la radio ${ }^{46}$, envers les matchs internationaux. Lors des déplacements à l'étranger, les journalistes qui couvrent l'événement

45 Pour un propos général sur l'essor de la presse sportive à cette époque, voir : Tétart P., "Spectacle sportif, médias et représentations sociales ", dans Terret T., Froissart T. (dir.), Le sport, l'historien et l'histoire, Reims, Epure, 2012, pp. 149-191.

46 Sur la radio et le football durant l'entre-deux-guerres voir : Isola G., "Les hérauts du foot : l'invention du reportage sportif à la radio italienne", Sociétés et keptéssentations, 
voyagent souvent avec les joueurs et les dirigeants de la fédération nationale qui les accompagnent, formant pour l'occasion une véritable délégation. Cette situation permet de créer des liens de proximité, prolongés par le fait que les membres de la presse participent au dîner de gala qui suit le match et, souvent, dorment dans le même hôtel que les joueurs et les dirigeants. Cette importance de la presse se repère lors de l'épreuve finale. Ainsi, à l'occasion du tournoi qui se dispute en Italie en 1934, L'Auto indique que 249 journaux européens ont envoyé des reporters en Italie. Le décompte se présente comme suit (par nombre) : Italie (65 journaux) ; France (27); l'Allemagne (23) ; Tchécoslovaquie (19), la Suisse (18), Pays-Bas (16); Belgique, Espagne, Hongrie (12), Yougoslavie (9) ; Suède (7); Autriche (6) ; Roumanie (5) ; Luxembourg (2) ; Angleterre, Bulgarie, Pologne, Turquie, Vatican et Pologne $(1)^{47}$. Les journalistes ne font pas que relayer de l'information, ils participent aussi activement à brosser les contours de cette Europe footballistique. Au travers de ces différentes rencontres internationales, ils opposent en effet régulièrement le "football européen " à un autre continent où le football est également très populaire : l'Amérique du Sud. Ainsi, leurs discours s'ajoutent à ceux de la FIFA et permettent d'affirmer les contours géographiques du football européen.

Enfin, dernier aspect qu'induit la Coupe du monde : le renforcement de l'échelle internationale dans les échanges footballistiques. Si, comme nous l'avons indiqué, les rencontres au niveau supranational sont déjà importantes avant la création du tournoi, celui-ci les dynamise encore davantage. Et ce d'autant plus qu'au travers de ces parties, les journalistes inventent des hiérarchies entre les équipes à partir des statistiques de matchs et n'hésitent pas à faire des rappels historiques sur les oppositions qui ont précédé la future opposition. En conséquence, ils légitiment l'existence, mais aussi l'importance de l'échelle internationale - ici principalement européenne - dans le football. Ces rencontres participent à la popularisation croissante du football car les matchs internationaux drainent, dans la plupart des pays européens, des milliers de spectateurs. De même, un petit nombre d'entre eux commencent à se déplacer pour voir jouer leur équipe nationale à l'étranger, propension qui augmente avec

vol. 7, 1998, pp. 295-307 ; Haynes R. «"Lobby"and the formative years of radio sports commentary, 1935-1952 ", Sport in History, vol. 29, n 1, 2009, pp. 25-48.

47 "Chronique de la Coupe du monde ". L'Auto, 25 mai 1934. Sur la médiatisation de la Coupe du monde de 1934 : Chisari F., "Une organisation parfaite" : la Coupe du monde de football de 1934 selon la presse européenne ", dans Mourlane S., Gastaud Y. (dir.), Le football dans nos sociétés. Une culture populaire. 1914-1998, Paris, Autrement, 2006, pp. 174-189. 
la portée de l'événement ${ }^{48}$. À ce titre, soulignons que les journaux sportifs comme L'Auto commencent à proposer des publicités pour des voyages d'accompagnement de l'équipe nationale de leur pays.

Tenant compte de cette importance des rencontres internationales, de nombreux auteurs ont justement montré que ces rencontres participent à la création de l'identité nationale ${ }^{49}$. Le propos présenté ici se veut différent et insiste plutôt sur l'importance prise, durant l'entre-deux-guerres, par ces parties entre les pays européens. Par l'entremise de la création de la Coupe du monde, qui connaît une rapide médiatisation, la FIFA participe grandement à les légitimer, voire à les naturaliser. Pour toutes les raisons évoquées dans les lignes ci-dessus, nous pouvons souligner qu'avec la création de la Coupe du monde, la FIFA œuvre à l'établissement d'une communauté footballistique européenne formée, en premier lieu, de dirigeants, de journalistes, voire de joueurs (bien que ces derniers ne participent finalement que peu à la création de ces échanges). Toutefois, pendant les années 1930, les limites géographiques de cette Europe du football ne sont pas totalement arrêtées et des associations nationales restent à la marge de celles-ci, ce qui s'explique, en partie, par leur nonappartenance à la FIFA.

\subsubsection{En dehors de l'Europe. Le cas des Britanniques et des Soviétiques}

C'est notamment le cas des associations britanniques de football, qui ont quitté la FIFA en 1928, et de l'Union soviétique, dont l'activité sportive internationale est surtout réalisée au travers de l'Internationale rouge communiste créée au début des années $1920^{50}$. Quelle est donc la place de ces associations dans la communauté footballistique qui s'instaure progressivement en Europe?

En ce qui concerne les associations britanniques, constatons que celles-ci ont un statut d'exception puisque, malgré leur non-affiliation, il leur est possible de jouer contre une association nationale membre de la

48 Lors de la Coupe du monde de 1934, environ 10000 Suisses font le déplacement de Milan à l'occasion du huitième de finale disputé entre les Pays-Bas et la Suisse.

49 Une riche littérature existe sur ce sujet. Voir en particulier le numéro spécial de la revue Vingtième siècle, "Le foot, du local au mondial ", coordonné par Paul Dietschy en 2011. Pour un panorama général, voir également Archambault F., Beaud S., Gasparini W. (dir.), Le football des nations, op. cit.

50 Sur cette organisation : Gounot A., Die Rote Sportinternationale, 1921-1937. Kommunistische Massenpolitik im europäisshen Arbeitersport, Münster Lit Verlag, 2002. 
FIFA $^{51}$. Ainsi, une année après leur retrait de la FIFA, l'équipe d'Espagne reçoit l'équipe nationale anglaise à Madrid. Puis, dans les années qui suivent, ce sont les meilleures formations européennes, respectivement l'Autriche et l'Italie, qui font le déplacement à Londres. Ces rencontres montrent que le départ des Britanniques n'a pas altéré totalement leurs relations avec les associations membres de la Fédération internationale. En fait, des connexions se perpétuent entre la FIFA et les associations britanniques, mais en dehors de toute adhésion ${ }^{52}$ et il y a assurément une volonté de part et d'autre de ne pas couper totalement les liens. Tout d'abord, du côté de la FIFA, indiquons que ses deux représentants à l'IB ne sont sans doute pas choisis par hasard puisqu'il s'agit de l'Allemand Peco Bauwens, membre important du comité exécutif du DFB, et du Français Henri Delaunay, secrétaire de $\mathrm{FFF}^{53}$. Ces deux acteurs importants du football européen semblent avoir le profil pour entretenir de cordiales relations avec les Britanniques. Les deux dirigeants sont d'anciens arbitres et sont littéralement passionnés par les Lois du jeu - ils sont membres de la Commission des Lois du jeu de la FIFA. Des deux hommes, Delaunay est sans doute celui qui est le plus proche des dirigeants d'outre-Manche. Anglophile convaincu - ses collègues de la Fédération française, dont il est le secrétaire depuis 1919, le surnomment Sir Henry pour caractériser ce trait $^{54}$-, il est admiratif du football anglais qu'il a connu lors de son adolescence alors qu'il effectuait un stage commercial à Londres ${ }^{55}$. S'exprimant parfaitement dans la langue de Shakespeare, il est donc un atout pour la FIFA en vue de perpétuer de bonnes relations avec les associations britanniques. Côté anglais, les premières années de la décennie 1930 sont certes marquées par une certaine distance avec la FIFA, situation qui agace plusieurs des membres de son comité exécutif. C'est le cas par exemple du Belge Seeldrayers qui s'exclame en 1932 que «l'état actuel ne

51 Selon l'article 14, ce type de relation est normalement prohibé sauf si le comité exécutif confere une autorisation spéciale. Anonyme, Statuts de la FIFA [édition de 1929], art. 14 [des statuts]. FIFA, statuts, 1904-1981.

52 La décision fait suite à une réunion qui a eu lieu entre les quatre associations britanniques en date du 7 janvier. Lettre de T. Robbins à C.A.W. Hirschman, 10 février 1931. FIFA, correspondance avec les associations nationales: Angleterre (1927-1955), dossier : 1928-1947.

53 Hirschman C.A.W., Procès-verbal de l'assemblée générale de la FIFA des 17 et 18 mai 1929, n.d. FIFA, XII-XIX congrès ordinaires (1923-1930, rapport d'activité).

54 Paul Dietschy a réalisé une brève notice bibliographique sur Henri Delaunay qui a été publiée sur le site wearefootball : http://www.wearefootball.org/PDF/henri-delaunay. pdf (consulté le 28 septembre 2015).

55 Entretien avec Pierre Delaunay réalisé le 19 septembre 2012 à̀ Versailles. 
peut pas durer et qu'il n'est pas digne de la Fédération " ${ }^{56}$. Prenant sans doute conscience qu'il leur est de moins en moins possible de rester isolés, à partir du milieu des années 1930, les Britanniques, et en premier lieu les Anglais, commencent à rediscuter davantage avec la FIFA.

Il faut ici signaler que si une partie des acteurs du football britannique prônent l'isolationnisme, cette posture n'est pas communément partagée. Dans plusieurs recherches, Matthew Taylor a notamment montré que, dès les années 1910, de nombreux Anglais - il en a répertorié cent un pour la période de 1910 à 1940 - officient en tant que joueurs ou entraîneurs dans différents pays européens. Cet auteur affirme également que, durant l'entre-deux-guerres, plusieurs dirigeants de la FA ainsi que des journalistes s'intéressent au football continental et, à ce titre, se tiennent au courant des résultats des matchs entre les équipes nationales européennes, mais aussi des décisions prises lors des congrès de la FIFA ${ }^{57}$. De ce point de vue, la nomination de Stanley Rous au poste de secrétaire général de la FA va jouer un rôle particulièrement important dans le renforcement des liens entre Britanniques et Européens.

Engagé au poste de secrétaire de la Football Association (FA) en 1934 en remplacement de Sir Frederik Wall qui se retire pour des raisons de vieillesse, Rous est beaucoup plus enclin à créer des liens avec les dirigeants continentaux que son prédécesseur. Passionné de football, il se tourne vers l'arbitrage en raison de nombreuses blessures qui l'empêchent d'envisager une carrière de joueur professionnel. Dans ce domaine, il connaît une ascension fulgurante et devient arbitre international en 1927, ce qui lui permet d'effectuer plusieurs voyages en Europe. En effet, les continentaux font souvent appel à des arbitres britanniques, car ils sont considérés comme les plus aptes à faire respecter les règles du jeu. Ainsi, Rous est convié lors de matchs internationaux à enjeux ou de grands rendez-vous, comme lors de la Coupe des nations de Genève en 1930. Ces voyages lui permettent de rencontrer de nombreux acteurs du football européen (journalistes ou dirigeants) et développent en lui le goût pour les voyages. " $E \hat{t r e}$ un arbitre et voir le monde" aurait pu être mon slogan " ${ }^{58}$, écrit-il dans son autobiographie au sujet de cette période de sa vie. Matthew Taylor le décrit comme faisant partie des Anglais qu'il définit comme " europhiles ", à savoir « des hommes portés par le voyage, intéressés à s'informer au sujet

56 Schricker I., Procès-verbal de la réunion du comité exécutif de la FIFA des 27 et 28 février 1932, n.d. FIFA, comité exécutif (procès-verbaux 1927-1932).

57 Taylor M., "England and the "Continent” reconsidered (1920-1960) », dans Vonnard P., Quin G., Bancel N., Building Europe with the ball, op. cit., pp. 75-97.

58 Rous S., Football worlds, op. cit., p. 30. 
du football hors d'Angleterre et qui ont pris fait et cause pour des liens plus proches avec le "continent" "59. Cette posture lui permet assurément de se montrer plus ouvert que ses prédécesseurs quant à un rapprochement du football britannique vis-à-vis de la FIFA et semble même constituer un atout dans sa nomination au poste de secrétaire général de la FA en 1934. En effet, dans son livre Scoring for Britain, Peter Beck indique brièvement que l'arrivée de Rous à ce poste fait suite à une pression exercée sur leur fédération nationale par des acteurs du football anglais plutôt tournés vers l'Europe (comme le célèbre journaliste Capel-Kirby ou l'entraîneur globe-trotter Jimmy Hogan). Ceux-ci critiquent le côté statique du jeu anglais qui aura comme conséquence à terme de déboucher sur une perte de supériorité des Anglais face aux équipes continentales. Ce risque est d'autant plus grand que, comme ils le soulignent, le niveau de jeu des équipes nationales progresse à grands pas sur le continent ${ }^{60}$. Le fait que le principal animateur de la plus importante association britannique en termes de membres soit plutôt favorable à un rapprochement avec les Européens est sans aucun doute un facteur décisif dans le rétablissement de liens plus fermes entre la FIFA et les associations britanniques. Signe que Rous incarne une plus grande ouverture avec le continent, sa nomination au poste de secrétaire de la FA est très bien perçue par le secrétaire de la FIFA Ivo Schricker. Ce dernier lui écrit immédiatement pour le féliciter de sa nomination et lui indiquer qu'il espère que les relations amicales entre les organisations pourront continuer, voire se renforcer, dans le futur ${ }^{61}$. Ce souhait semble partagé par l'intéressé, car Rous répond rapidement par l'affirmative au secrétaire et demande que Schricker lui fasse parvenir le dernier numéro de World's Football afin d'être tenu " au courant [des] affaires du [football] continental ${ }^{62}$.

Dans la seconde partie des années 1930, ces nouveaux liens se prolongent sur le terrain puisque l'équipe nationale anglaise entreprend différentes tournées en Europe, comme celle effectuée en Scandinavie en 1937. Une année plus tard, c'est du côté de l'Europe centrale que l'équipe nationale anglaise projette de se rendre. Cependant, en raison de l'invasion de l'Autriche par l'Allemagne (l'Anschluss), la tournée est annulée, l'équipe

59 Taylor M., "Four nations against the world: Britain, "Britishness" and World Cup ", dans Wahl A., Histoire de la Coupe du monde de football, op. cit., p. 68.

60 Beck P.J., Scoring for Britain: international football and international politics, 1900-1939, London, F. Cass, 1999, p. 164.

61 Lettre de I. Schricker à S. Rous, 18 août 1934. FIFA, correspondance avec les associations nationales : Angleterre (1927-1955), dossier : 1928-1947.

62 Lettre de S. Rous à I. Schricker, 22 août 1934. FIFA, correspondance avec les associations nationales : Angleterre (1927-1955) dossier : 1928-1947 Vonnard -978-2-8076-0570-1 
nationale anglaise disputant néanmoins un match à Zurich contre la Suisse. Suivant l'exemple anglais, l'Écosse commence aussi à développer des échanges avec les associations continentales. Dès 1936, son équipe nationale se rend en Allemagne, partie qui est ensuite suivie d'autres confrontations contre l'Autriche et la Tchécoslovaquie. En juin 1937, Peco Bauwens se félicite que la réunion annuelle de l'IB se soit déroulée " dans une atmosphère très amicale ${ }^{63}$. Quelques mois plus tard, une décision importante est prise par les associations britanniques, qui confirment le rapprochement en train de s'opérer avec la FIFA. En effet, en raison de la Coupe du monde de 1938, les Britanniques acceptent que la réunion de l'IB soit transférée d'Irlande du Nord à Paris. De plus, cette démarche s'accompagne d'une présence officielle de la Football Association et de la Fédération écossaise au dîner de gala de la Coupe du monde ${ }^{64}$. Deux ans plus tôt, les quatre associations britanniques avaient déjà pris une décision importante qui soulignait leur loyauté relative envers la FIFA, en refusant d'autoriser leurs clubs à jouer contre des clubs soviétiques ${ }^{65}$.

En effet, depuis le début de la décennie, il apparaît que l'URSS souhaite reprendre la place occupée par la Russie tsariste dans la FIFA ${ }^{66}$, ambition qui correspond à l'ambition nouvelle du régime soviétique de désormais concurrencer les pays "bourgeois " en matière sportive. Cette démarche s'explique aussi par les échecs de l'Internationale rouge sportive car, comme l'indique Sylvain Dufraisse dans sa thèse de doctorat, l'IRS reste " une organisation marginale, sans beaucoup d'argent, piètrement organisée. Les athlètes soviétiques n'y trouvent pas d'adversaires à leur hauteur. L'absence d'organisations ouvrières dans certains pays voisins contraint les Soviétiques à collaborer avec les organisations "bourgeoises" de certains pays $"{ }^{67}$.

63 Anonyme, Procès-verbal de la réunion du comité exécutif de la FIFA du 19 juin 1937, n.d. FIFA, comité exécutif (procès-verbaux 1937).

64 Beck P.J., " Going to War, peaceful co-existence or virtual membership? Bristish Football and FIFA, 1928-46 ", The International Journal of The History of Sport, vol. 17, $\mathrm{n}^{\circ} 1,2000$, p. 124

65 Lettre de G. Graham à I. Schricker, 15 juin 1936. FIFA, correspondance avec les associations nationales : Russie/URSS (1932-1983), dossier : 1932-1936.

66 La Russie tsariste est membre de la FIFA et il est à constater qu'aucune demande de démission n'a été transmise à la FIFA par l'URSS. Schricker I., Procès-verbal de la réunion du comité exécutif de la FIFA du 10 décembre 1932, n.d. FIFA, comité exécutif (procès-verbaux 1927-1932).

67 Dufraisse S., Les “Héros du sport”. La fabrique de l'élite sportive soviétique (1934-1980), thèse réalisée sous la direction de Marie-Pierre Rey, Université Paris 1-PanthéonSorbonne, 2016, p. 65. 
À partir de 1934, la participation des Soviétiques aux échanges footballistiques internationaux se fait plus précise en raison d'un double mouvement. Premièrement, un changement s'opère dans la politique internationale soviétique, qui est la conséquence de l'arrivée au pouvoir des nazis. Désormais, le fascisme est considéré comme le premier ennemi et l'URSS tente de créer de nouvelles alliances sur la scène internationale, notamment en adhérant à la Société des Nations. Cette nouvelle donne favorise donc l'établissement de liens dans différents domaines et notamment dans le champ sportif. Deuxièmement, le football connaît une nouvelle étape de structuration en Union soviétique ${ }^{68}$. Le niveau de jeu s'améliore et permet, d'une part, aux équipes soviétiques d'envisager de rivaliser davantage avec leurs homologues continentales; d'autre part, que les dirigeants de clubs des grandes capitales européennes les considèrent comme des adversaires potentiels, le match pouvant connaître un certain succès financier notamment en raison du mystère qui plane autour de l'URSS, considérée alors comme « lointaine " (autant géographiquement que politiquement). Signe de ce changement, le comité exécutif de la FIFA reçoit des demandes concrètes des associations de Bulgarie et de Tchécoslovaquie ${ }^{69}$ afin que des clubs de leurs fédérations respectives puissent jouer contre leurs homologues soviétiques. Pour l'élite de la FIFA, la situation est toutefois délicate, car conférer une autorisation à ses associations membres risque de créer des vagues en son sein, l'organisation sportive russe entretenant " des relations avec les organisations sportives ouvrières, existant dans beaucoup de pays affiliés à la FIFA dont l'opposition prononcée contre les associations de la FIFA est connue ${ }^{70}$. Face à ce dilemme, les dirigeants de la Fédération internationale optent néanmoins pour le choix de l'ouverture et acceptent provisoirement la tenue de ces rencontres. Ils expliquent cette position en argumentant que le rôle de la FIFA est avant tout d'encourager les relations internationales sportives.

En date du 19 octobre 1934, une circulaire est envoyée par la FIFA aux associations nationales pour leur indiquer la possibilité provisoire de

68 Une transition vers une pratique professionnelle s'opère sous l'impulsion de grands clubs moscovites. Pour un aperçu, voir : Edelman R., " Le football sous Staline. Le Spartak au Goulag, 1937-1945 ", dans Bensoussan G. et al., Sport, corps et sociétés de masse. Le projet d'un homme nouveau, Paris, Armand Colin, 2012, pp. 135-145.

69 Schricker I., Circulaire 36, n 3, septembre 1934. FIFA, comité exécutif (procèsverbaux 1934).

70 Anonyme, Procès-verbal de la réunion du comité d'urgence de la FIFA du 7 octobre 1934, n.d. FIFA, comité exécutif (procès-verbaux 1934). 
jouer contre les Soviétiques ${ }^{71}$. À la même période, d'autres organisations sportives internationales, telle la Fédération internationale d'athlétisme (IAAF), prennent des décisions analogues. Dans les mois qui suivent, les échanges s'accélèrent, le secrétaire de la FIFA pouvant indiquer qu'entre le 30 août et le 11 septembre 1935, cinq matchs opposant des clubs continentaux à des formations soviétiques ont été joués. Le Tchèque Pelikan - membre du comité exécutif de la FIFA -, qui a assisté à des rencontres en Union soviétique, se montre très enthousiaste auprès du secrétaire général Schricker et souligne que ces rencontres se sont très bien déroulées et sans influence politique ${ }^{72}$. En 1935 et 1936, de nouvelles demandes sont transmises au secrétariat, provenant cette fois de Suède, d'Autriche, de France et de Roumanie. Des matchs ont notamment lieu à Paris entre des clubs français (Red Star, Racing Club de Paris) et des formations soviétiques et il semble que Jules Rimet, président de la FIFA mais aussi de la Fédération française de football, essaie de favoriser - de manière non officielle - ce type d'échanges ${ }^{73}$. Malgré les ouvertures de la FIFA vis-à-vis des Soviétiques, ces derniers ne font pas mine de vouloir s'affilier à la Fédération. Selon Barbara Keys, les dirigeants du sport soviétique ${ }^{74}$ considèrent que la FIFA est conduite par des dirigeants fascistes qui ont montré une "attitude négative à propos de l'URSS " ${ }^{75}$, c'est pourquoi il n'est pas question pour eux d'entrer dans la Fédération internationale. André Gounot ajoute que le refus de l'URSS d'adhérer à la FIFA se nourrit par la présence d'un secrétaire général allemand ${ }^{76}$. Estimant qu'ils ont fait assez de concessions aux Soviétiques, l'élite de la Fédération internationale réagit et interdit, dès

71 Schricker I., Circulaire n 38, 19 octobre 1934. FIFA, comité exécutif (procès-verbaux 1935-1936).

72 Anonyme, "Relations sportives avec la Russie ", Annexe II.3 de la réunion du comité exécutif du 5 octobre 1935, 5 octobre 1935. FIFA, comité exécutif (procès-verbaux 1935-1936).

73 Un dossier conservé aux archives de la préfecture de police de Paris recèle des informations à ce sujet. À la veille du congrès de la FIFA d'août 1936, le journal Football relaie une information officieuse au sujet d'une possible entrée des Soviétiques dans l'organisation. "Les Russes sont-ils à la veille d'entrer à la FIFA ? ", Football, 5 août 1936. Nous remercions Yannick Deschamps pour cette information.

74 La Fédération de football est intégrée dans un organisme étatique qui s'occupe du domaine sportif.

75 Keys B., Globalizing sport, op. cit., p. 171.

76 Gounot A., "Vom "Rotsport” zur FIFA. Der Sowjetfußball und seine internationalen Kontakte, 1922-1946 ", dans Dahlmann D., Hilbrenner A., Lenz B. (eds.), Überall ist der Ball rund. Zur Geschichte und Gegenwart des Fußballs in Ost-und Südosteuropa, vol. 2, Essen, Klartext, 2007, p. 277. 
mai 1936, les matchs contre des équipes soviétiques. Finalement, les liens entre les deux parties s'interrompent et, plus globalement, l'idée d'une affiliation de l'URSS dans les fédérations internationales est abandonnée par l'organe soviétique des sports. À la fin des années 1930, l'URSS reste donc en dehors du giron de la FIFA et en marge des relations footballistiques européennes.

Les cas des associations britanniques et soviétiques sont intéressants à mettre en parallèle car ils soulignent la manière dont la FIFA gère les relations avec des acteurs du football qui ne sont pas dans son giron. Tout d'abord, il faut mentionner que, dans les deux cas, la Fédération internationale fait preuve de souplesse et tente, sous l'impulsion notamment de son président, Jules Rimet, de réunir la grande famille du football européen sous son aile. En ce sens, elle donne des autorisations à ses associations membres de jouer contre ces fédérations non affiliées à la FIFA, démarche qui va à l'encontre de ses statuts. Toutefois, ces deux cas soulignent aussi que la Fédération internationale se profile comme l'organe suprême du football et souhaite se faire respecter. Sous cet angle, et voyant qu'aucune démarche n'est entreprise par les Soviétiques, la FIFA se montre finalement stricte et annule les possibilités de jouer contre eux. Au contraire, dans le cas britannique, l'amélioration des relations au fil des années 1930 permet une plus grande ouverture. Ainsi, à la fin de la décennie, il est possible d'envisager un retour des associations britanniques dans le giron de la Fédération internationale. Dans un texte paru en 2000, Peter Beck mentionnait déjà que les associations britanniques peuvent être considérées comme "des membres virtuels $"{ }^{77}$ de la FIFA dans les années 1930. Il soulignait notamment qu'elles entretiennent des liens étroits avec la FIFA et que celle-ci reste représentée par deux dirigeants aux réunions de l'International Board. À la vue des nouveaux éléments présentés ci-dessus, nous pouvons donc corroborer ces propos et indiquer que, si elles ne sont pas membres de la FIFA, les associations britanniques - en premier lieu les associations anglaises et écossaises - peuvent être englobées dans cette communauté européenne de football. Toutefois, il faut préciser que c'est véritablement autour des années 1937-1938 que cette situation se réalise, comme le confirment les matchs de la FIFA de 1937 et 1938.

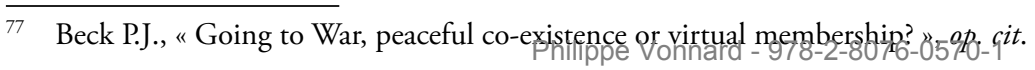




\subsubsection{Réunir les Européens ? Les matchs de la FIFA de 1937 et 1938}

À la fin des années 1930 prévaut une dynamique favorable à l'émergence de différents projets visant à rapprocher les Européens, que ce soit en vue de créer une entité supranationale ou de favoriser les coopérations intergouvernementales ${ }^{78}$. Sur le plan politique, les plus ambitieux sont les projets du Hongrois Coudenhove-Kalergi, avec son idée de PanEurope, et du Français Aristide Briand qui, à la fin des années 1920, évoque l'idée de mettre sur pied les États-Unis d'Europe. Les organisations internationales créées après la Première Guerre mondiale, et en premier lieu la Société des Nations (SDN) et l'Organisation internationale du travail (OIT), favorisent des actions s'opérant à l'échelle européenne - ces organismes sont composés en majorité de pays européens - ou aident à la création de réseaux d'experts dans les domaines économiques ${ }^{79}$, juridiques ${ }^{80}$ ou intellectuels ${ }^{81}$. En fait, dans de très nombreux domaines, la problématique européenne tend à se profiler progressivement comme digne d'intérêt. Joan Schot et Vincent Lagendijk évoquent par exemple le projet de l'Italien Piero Puricelli visant à créer un réseau européen d'autoroutes ${ }^{82}$ qui est, au début des années 1930, discuté au sein de l'OIT et soutenu par le directeur de son bureau, Albert Thomas. Léonard Laborie et Suzanne Lommers ont travaillé quant à eux sur l'élaboration des concerts européens qui sont diffusés par de nombreuses radios nationales à partir de 1931 avec le concours de l'Union internationale de radio (UIR). À ce sujet, ces deux auteurs ont proposé la jolie formule de "métaphore diplomatique » car outre des objectifs techniques et financiers, les promoteurs des concerts poursuivent également un objectif plus diplomatique, à savoir « donner corps [à] un idéal de paix européenne, qui, après la Grande Guerre et avec les nouveaux moyens de communication qui [s'offrent] à la société,

78 Sur l'idée d'Europe durant l'entre-deux-guerres, voir : Chabot J.-L., Aux origines intellectuelles de l'Union européenne. L'idée d'Europe unie de 1919 à 1939, Grenoble, Presses universitaires de Grenoble, 2005.

79 Clavin P., Securing the world economy. The reinvention of the League of Nations, 1920-1946, Oxford, Oxford University, 2013.

80 Decorzant Y., La Société des Nations et la naissance d'une conception de la régulation économique internationale, Bruxelles, P.I.E. Peter Lang, 2011.

81 Renoliet J.-J., L'Unesco oubliée. La Société des Nations et la coopération intellectuelle (1919-1946), Paris, Publications de la Sorbonne, 1999.

82 Schot J., Lagendijk V. «Technocratic internationalism in the Interwar years: building Europe on motorways and electricity networks ", Journal of Modern European History, vol. 6, n 2, 2008, pp. 196-217. 
[semble] devoir ou pouvoir passer par la quête d'une forme d'unité respectueuse de la diversité, un "rapprochement", une vie internationale concertée ${ }^{83}$.

L'élite de la FIFA participe également au développement de ces synergies continentales. En premier lieu, et d'un point de vue réglementaire, la Fédération internationale publie des directives sur les Lois du jeu et " chaque année [elle doit adresser] une copie [des Lois du jeu] conforme à chaque association $»^{84}$. De même, elle contrôle leur bonne application lors des rencontres internationales et n'hésite pas, comme le montrent les correspondances entre le secrétariat et les fédérations nationales, à les interpeller en cas d'infraction. Par ailleurs, elle régule aussi les transferts de joueurs internationaux, les associations nationales devant lui demander l'autorisation pour qu'un joueur puisse changer de club. Ainsi, la Fédération crée une sorte d'homogénéisation de la pratique du ballon rond sur le continent et joue son rôle dans l'européanisation du jeu.

De plus, elle organise des événements qui convoquent, l'espace d'un temps donné, une grande partie des acteurs footballistiques européens. Outre la Coupe du monde, il faut citer les matchs dits de la FIFA, de 1937 et 1938. Le premier, qui a lieu en juin 1937, oppose l'Europe de l'Est à l'Europe de l'Ouest. Le deuxième, joué en octobre 1938, met aux prises l'Angleterre au Continent. À ce jour, ces deux parties n'ont pas vraiment fait l'objet d'investigations dans l'historiographie. Il s'agit ici de revenir plus précisément sur ces deux rencontres en soulignant qu'elles participent à l'établissement de connexions plus fermes à l'échelle continentale entre les associations nationales.

Lidée de faire jouer un match entre l'Europe de l'Est et l'Europe de l'Ouest est évoquée au sein de la FIFA depuis 1933 déja $^{85}$, mais c'est en 1936 que le projet est véritablement lancée ${ }^{86}$. Durant l'entre-deux-guerres, l'idée qu'il existe "deux Europe " n'est pas propre à l'élite de la FIFA et

83 Laborie L., Lommers S., «Les concerts européens à la radio dans l'entre-deux-guerres. Mise en onde d'une métaphore diplomatique ", Le Temps des médias, vol. 11, 2008, p. 119.

84 Anonyme, Statuts de la FIFA [édition de 1929], art. 19 [des statuts]. FIFA, statuts, 1904-1981.

85 Anonyme, Procès-verbal de la réunion du comité exécutif de l'Union belge, 5 janvier 1933. AGRB, URBSFA, dossier : comité exécutif (procès-verbaux du $1^{\text {er }}$ janvier 1931-3 mars 1933).

86 Anonyme, Procès-verbal de l'assemblée générale de la FIFA des 13 et 14 août 1936, n.d. FIFA, XX-XXIV congrès ordinaires(1.931-1938, rapport d'activité) 
plusieurs auteurs écrivent sur la question ${ }^{87}$. En football, une distinction peut être également faite car les associations de l'Est sont passées plus tôt à la pratique professionnelle et leurs clubs sont mieux structurés qu’à l'Ouest. Dès lors, leur football (nommé « football danubien " par les chroniqueurs) est considéré comme l'exemple à suivre pour les associations nationales de l'Ouest.

Lorganisation de la partie s'explique notamment par son enjeu financier, la rencontre apparaissant comme un moyen de pérenniser la santé financière de la FIFA ${ }^{88}$. En effet, la FIFA touchera un pourcentage de la recette brute du match. Au sein de son comité exécutif, c'est le Néerlandais Karel Lotsy qui prend en charge l'organisation de la rencontre. Lotsy va s'atteler à rendre la partie la plus attractive possible, condition nécessaire en vue d'optimiser les gains de la rencontre. Il réussit tout d'abord à insérer la partie dans le cadre de la journée annuelle olympique néerlandaise, ce qui permet de recueillir une publicité supplémentaire pour l'événement. De même, il préconise de contacter le plus de journalistes possible et de les convaincre d'évoquer cette rencontre avec bienveillance (notamment en relayant les informations sur la composition des équipes, afin d'intéresser au maximum le public). En outre, il souhaite assurer la présence des meilleurs joueurs européens car, comme il l'indique à ses collègues du comité exécutif de la FIFA, seule « la collaboration de ces "stars" pourra assurer un succès complet de ce match ${ }^{89}$. Cette volonté de publicité exerce un impact sur la composition des équipes, les nations de faible niveau footballistique n'étant pas conviées à la fête. Ainsi, la formation de l'Europe de l'Est est composée uniquement de joueurs provenant d'Autriche, d'Italie, de Hongrie et de Tchécoslovaquie, soit les pays dominants du football de l'Europe de l'Est. La Suisse, par exemple, qui participe pourtant à l'épreuve phare du football « danubien ", à savoir la Coupe internationale, n'est pas invitée à envoyer des joueurs. De même pour l'Europe de l'Ouest, dont l'équipe est composée de footballeurs issus d'Allemagne, de Belgique, de France et des Pays-Bas ${ }^{90}$. Les joueurs des associations balkaniques et scandinaves, qui sont les plus faibles sur le plan

87 C'est notamment le cas de Francis Delaisi qui publie en 1929 un livre intitulé Les Deux Europes dans lequel il fait une distinction de type économique entre l'Europe du cheval de fer (Ouest) et l'Europe du cheval de trait (Est).

88 Anonyme, Procès-verbal de la réunion du comité exécutif de la FIFA du 14 mars 1937, n.d. FIFA, comité exécutif (procès-verbaux 1937).

89 Schricker I., Circulaire n 21 (13 avril) et $n^{\circ} 23$ (29 avril) de l'année 1937. FIFA, comité exécutif (procès-verbaux 1937).

90 Schricker I., Rapport du secrétaire général de la FIFA (1936-1937), n.d. FIFA, XX-XXIV congrès ordinaires (1931-1938, rapport d'activité). 
footballistique, ne sont donc pas sélectionnés pour disputer la rencontre. Quant à la non-présence de joueurs britanniques, elle s'explique par le fait que si des rapprochements ont lieu entre les associations britanniques et la FIFA, celles-ci ne sont pas officiellement membres de l'organisation. Enfin, signalons que la Fédération espagnole, qui aurait pu alimenter l'équipe d'Europe de l'Ouest par quelques bons éléments, n'est pas contactée en raison de la Guerre civile qui fait rage dans le pays.

L'Europe proposée sur le terrain est donc limitée géographiquement. Cependant, l'idée de créer davantage de synergies à l'échelle continentale au travers de cette rencontre existe réellement. Tout d'abord, comme le note le journaliste Lucien Gamblin, le match réunit tous les acteurs influents qui officient dans le football européen, auxquels s'ajoutent des dirigeants de la FA, comme Stanley Rous. De plus, les joueurs doivent témoigner de cette unité continentale, ce qui se perçoit dans l'organisation même de leur séjour. En effet, Gamblin ajoute que si les joueurs des deux équipes prennent leur repas de manière séparée à l'établissement, il s'agit de "la seule démarcation qu'on ait faite entre les deux formations " ${ }^{91}$ car ils logent dans le même hôtel en compagnie des dirigeants du comité exécutif de la FIFA. Cette volonté de créer des liens est aussi l'apanage des journalistes qui, curieux, sont venus en nombre. Dès lors, en marge de la partie, l'Association des journalistes sportifs de la capitale des Pays-Bas décide d'offrir " un petit souper aux principaux journalistes étrangers $"{ }^{92}$.

C'est sans doute pourquoi, pour de nombreux chroniqueurs, cette rencontre recèle un caractère exceptionnel et semble même préfigurer de futurs regroupements continentaux. Un journaliste du Sport suisse indique que ce match « représente un pas de plus dans la voie de la concentration des forces du football, de la formation de blocs de plus en plus étendus. Le prochain pas sera un match Europe-Asie ou Europe-Amérique $"{ }^{93}$. De même, Pierre Gosset du quotidien généraliste français $C e$ soir n'hésite pas à écrire que "la rencontre d'Amsterdam est une des plus grandes qui se soient jamais déroulées dans le domaine de la balle ronde " ${ }^{94}$. Par l'entremise de cette rencontre, la FIFA dynamise donc les échanges entre les acteurs européens du football et, in fine, matérialise l'existence d'un territoire européen du football.

91 "Aujourd'hui à Amsterdam. Le pronostic impossible : Europe de l'Ouest-Europe centrale ", L'Auto, 20 juin 1937.

92 Schricker I., Circulaire $\mathrm{n}^{\circ} 35,11$ juin 1937. FIFA, comité exécutif (procès-verbaux 1937).

93 "Échos de partout », Le Sport suisse, 23 juin 1937.

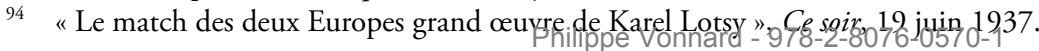


L'opération semble d'autant plus réussie que le match rencontre un bel engouement, se jouant devant 70000 spectateurs. Il permet de récolter 80000 florins, un montant qui solidifie les finances de la FIFA et pose les jalons de la création d'un fonds d'assistance en vue de soutenir des projets footballistiques divers. La rencontre offre donc l'illusion d'un continent pour le moins uni puisque la rencontre propose un agencement inédit entre des joueurs issus de huit pays différents et cette situation contraste avec la situation politique tendue dans laquelle plonge le continent. En effet, l'Allemagne et l'Italie viennent de sceller un an plus tôt l'Axe Rome-Berlin, alliance qui fait peser de graves menaces sur la paix en Europe.

Une année après la partie de 1937, une autre rencontre tout aussi exceptionnelle est organisée, opposant cette fois l'Angleterre au Continent. Cette rencontre doit toutefois être considérée sous un angle quelque peu différent car son initiative ne provient pas directement de la Fédération internationale mais de l'association anglaise ${ }^{95}$. En effet, le match doit permettre de fêter les soixante-quinze ans d'existence de la FA, tout en s'inscrivant dans la volonté d'améliorer les relations entre les dirigeants de la FIFA et les associations britanniques. Le comité exécutif de la Fédération internationale se montre enthousiaste vis-à-vis de l'idée et s'accorde pour opposer une équipe continentale à l'équipe nationale anglaise ${ }^{96}$. Outre cet aspect commémoratif, la rencontre recèle également un objectif financier, puisquil est prévu que la FIFA touche $30 \%$ des recettes nettes de l'événement ${ }^{97}$. Paul Dietschy souligne - en se basant sur une phrase de l'autobiographie de Stanley Rous - que la rencontre a aussi été organisée pour supporter les coûts du grand banquet lié à la soirée de gala (de nombreux dirigeants d'associations européennes sont invités à y participer) qui suit la rencontre ${ }^{98}$. L'objectif financier semble toutefois passer au second plan tant cette rencontre comporte, comme celle de l'année précédente, une forte portée symbolique.

Cette symbolique s'entrechoque néanmoins avec une autre : celle de faire bonne figure face aux Anglais, toujours considérés comme

95 Anonyme, Procès-verbal de la réunion du comité exécutif de la FIFA des 6-7 novembre 1937, n.d. FIFA, comité exécutif (procès-verbaux 1937).

96 Cette décision souligne l'européocentrisme de l'élite de la FIFA puisque, d'un point de vue de qualité sportive, nous aurions pu imaginer qu'ils proposent d'opposer aux Anglais une équipe composée également de joueurs des associations de l'Amérique du Sud.

97 Lettre de S. Rous à I. Schricker, 3 mai 1938. FIFA, correspondance avec les associations nationales : Angleterre (1927-1955), dossier : 1928-1947.

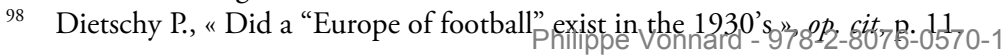


la meilleure équipe du monde. Or l'élite de la FIFA et de nombreux journalistes continentaux craignent qu'une médiocre prestation ne constitue une mauvaise publicité pour le football européen. Ce point peut paraître anecdotique, mais pour le comité exécutif de la FIFA il est très important. En effet, dans le cadre de cette recherche de légitimité constante vis-à-vis des Anglais - si de nets rapprochements ont eu lieu, il faut rappeler que ces derniers ne sont toujours pas membres de l'organisation -, il est important que l'équipe de la FIFA puisse donner le change aux Anglais. C'est pourquoi, quelques mois avant la rencontre, Rodolphe Seeldrayers rappelle à ses collègues du comité exécutif de la Fédération internationale : " [Si l'] équipe, qui, sur le papier, représentera le football continental tout entier est battue, il en résultera pour [le football continental] et pour la FIFA une diminution considérable de prestige $^{99}$. En conséquence, il s'agit pour la FIFA de former la meilleure équipe possible. C'est pourquoi, afin de procéder à la sélection des joueurs, elle met en place une commission ad hoc. Celle-ci comprend plusieurs commissaires techniques de fédérations : l'Allemand Herberger, le Français Barreau, le Hongrois Dietz, l'Italien Pozzo accompagnés de dirigeants de la FIFA. Cette commission se réunit à deux reprises, respectivement le 22 septembre et le 12 octobre 1938, dans le but de déterminer les quinze ou seize joueurs de l'équipe européenne. Il est décidé de confier les destinées de l'équipe durant le match au sélectionneur italien Vittorio Pozzo. Double champion du monde à la tête de la sélection italienne, il a aussi le bénéfice d'avoir tenu tête aux Anglais sur leur sol en 1934 lors de la "bataille de Highbury " (défaite trois buts à deux). En outre, Pozzo connaît bien le jeu anglais puisqu'il a entretenu une correspondance soutenue avec le célèbre manager anglais Chapman jusqu'à son décès en $1934^{100}$. La représentation italienne au sein de l'équipe est forte puisque cinq joueurs en font partie, situation " qui doit inspirer confiance », selon le journaliste suisse Émile Birnbaum ${ }^{101}$. Ils sont accompagnés de deux Allemands et d'un Hongrois, alors qu'un Belge, un Français et un Norvégien font partie des cinq attaquants. De fait, les postes les plus stratégiques ont été confiés aux Allemands et aux Italiens et l'équipe européenne peut même être perçue comme une transposition footballistique de l'axe Rome-Berlin, et ce d'autant plus que la rencontre fait suite à la signature des Accords de Munich.

99 Lettre de I. Schricker au comité exécutif de la FIFA, 13 juillet 1938. FIFA, comité exécutif (procès-verbaux 1938).

100 "Les Napoléons du football ", Football, 15 juin 1933.

101 "Le match de l'année. Angleterre ? Continent ?" Le Sport syisse-219octobre 1938. 
Au premier abord, la composition de l'équipe remet donc quelque peu en question la deuxième symbolique du match, à savoir que celui-ci doit servir à l'affirmation d'un rapprochement des peuples européens par l'entremise du football. Cet aspect est souligné par le président de la FIFA, Jules Rimet. Ce dernier n'hésite pas à écrire dans le Bulletin officiel de la FIFA que la rencontre dépasse largement le cadre du football et doit être perçue comme " un symbole de l'amitié internationale établie sous l'égide du sport, de la communauté spirituelle qui englobe les joueurs de balle à travers le monde ${ }^{102}$. En fait, si sur le terrain, la représentation européenne est limitéeà noter que des joueurs hongrois, suisses ou scandinaves accompagnent l'équipe en qualité de remplaçants ${ }^{103}$-, de nombreux dirigeants d'associations font le déplacement pour venir commémorer l'anniversaire de la Football Association. Quelques jours avant les festivités, Stanley Rous indique à Ivo Schricker que les associations continentales suivantes lui ont confirmé leur présence (par ordre alphabétique) : Allemagne, Belgique, Finlande, France, Hongrie, Italie, Luxembourg, Norvège, Pays-Bas, Suède et Yougoslavie ${ }^{104}$. De plus, la rencontre mobilise l'attention de nombreux autres acteurs européens du jeu. Ainsi, la veille du match, le journaliste Jacques de Riswyck note que " le hall du Central Hôtel est ce soir très animé et l'on peut y entendre à peu près toutes les langues du continent, car si les joueurs enfouis dans ces profonds fauteuils attendent tranquillement l'heure du coucher, dirigeants et journalistes sont arrivés en nombre aujourd'hui » ${ }^{105}$. Lors de la partie, dans la tribune officielle, les dirigeants de la FA côtoient bien entendu ceux du comité exécutif de la FIFA. S'ajoutent à cette cohorte, de nombreux autres importants dirigeants du football européen comme l'Italien Ottorino Barassi, le Luxembourgeois Gustave Jacquemart, les Français Henri Delaunay et Pierre Pochonet. De même, de nombreux dirigeants de clubs sont également présents. Une grande partie de ce beau monde se retrouve le soir lors du banquet qui suit la partie ${ }^{106}$.

Alors que l'équipe de la FIFA - appelée "Équipe du continent » ou équipe du "Reste de l'Europe " par les Britanniques - a été surclassée par les Anglais (trois buts à zéro), au terme de la partie, le sélectionneur Pozzo souligne que ce n'est pas le résultat qu'il faut retenir de ce match (sous cet angle, l'expérience ne serait pas à renouveler) mais bien le fait qu'il

102 Rimet J., "Un match symbolique ", Football World, n 1, 1938, p. 1.

103 Aucun changement de joueurs en cours de match n'est alors autorisé par l'IB.

104 Lettre de S. Rous à I. Schricker, 20 octobre 1938. FIFA, correspondance avec les associations nationales : Angleterre (1927-1955), dossier : 1928-1947.

105 "Les Anglais favoris de tous et d'eux-mêmes ", L'Auto, 26 octobre 1938.

106 "Le stade, la table et... le départ ", L'Auto 27 octobre $1938_{9}$ 
permet de commémorer l'amitié qui existe entre les associations nationales du continent et leur homologue anglaise. Comme la Coupe du monde, il n'est pas usurpé de penser que les deux parties de 1937 et 1938 permettent de renforcer l'existence de cette communauté sportive européenne. Il faut bien prendre la mesure de cet objectif puisqu'il est affiché par une partie de l'élite de la FIFA. En effet, pour des dirigeants comme le président Jules Rimet, il ne s'agit pas seulement de renforcer la dynamique internationale du jeu mais aussi de proposer des échanges qui se réalisent en dehors de toute ingérence politique.

\subsection{Créer une « Société des nations sportives »}

C'est en ces termes que le secrétaire-trésorier de la FIFA, Carl Hirschman présente l'organisation. Cette idée d'apparenter la Fédération internationale de football à la SDN témoigne d'une volonté affichée de jouer un rôle dans les échanges diplomatiques qui s'opèrent sur la scène internationale. Ce souhait nécessite toutefois que deux éléments complémentaires soient réalisés. Premièrement, il faut que la FIFA se présente comme une organisation forte et unie. Or, en son sein, les associations européennes de football sont amenées à aborder de nombreux sujets relatifs au football dont certains sont parfois hautement problématiques. Ainsi, dans les années 1920, des discussions sur la légalisation de la pratique professionnelle ont provoqué de sérieux remous en interne. De fait, comment faire pour régler ces différends sans qu'ils ne créent de fortes dissensions au sein de la FIFA, ce qui aurait pour risque de pénaliser son action en faveur du développement du football. Deuxièmement, la FIFA doit faire face à la politisation croissante du football. En effet, en raison de sa popularité, le football - comme d'autres sports est désormais investi par les gouvernements. Ceux-ci tentent de contrôler le jeu au niveau national, avec néanmoins un degré d'investissement qui varie selon le régime de l'État, autoritaire ${ }^{107}$ ou démocratique ${ }^{108}$. De même,

107 De nombreuses études ont été réalisées sur l'emploi du football par l'Italie faciste et l'Allemagne nazie sur la scène internationale. Sur le cas allemand, voir en particulier : Havemann N., Fußball unterm Hakenkreuz. Der DFB zwischen Sport, Politik und Kommerz, Francfort, Campus-Verlag, 2005 ; Herzog M., Bahro B. (eds.), Die "Gleischschaltung" des Fussballsports im Nationalsozalististischen Deutschland, Stuttgart, Kohlhammer, 2016. Pour un aperçu sur la " querelle des historiens " qui a éclaté autour de la position des dirigeants du DFB vis-à-vis du régime nazi, voir : Pfeil U., "Le football allemand sous le national-socialisme ", dans Bensoussan G. et al., Sport, corps et sociétés de masse, op. cit., pp. 117-133. Et sur le cas italien : Martin S., Football and Fascism. The National Game Under Mussolini, Berg, Oxford, 2004.

108 Beck P.J., Scoring for Britain, op. cit. 
les gouvernements surveillent ou se tiennent au courant des rencontres internationales disputées par la sélection nationale car ces échanges peuvent constituer autant une occasion de démontrer sa puissance qu'une bonne manière d'entretenir des relations diplomatiques, en particulier avec des États considérés comme ennemis ${ }^{109}$. En conséquence, le risque n'existe$\mathrm{t}$-il pas que des États essaient d'influencer la politique de la Fédération internationale ? Il faut d'ailleurs rappeler qu'à la fin de la Première Guerre mondiale, la FIFA a failli connaître une scission puisque les associations britanniques, accompagnées de la Belgique et de la France, avaient demandé l'exclusion de l'Allemagne, de l'Autriche et de la Hongrie, se calquant sur la politique menée par leur gouvernement. Or cette décision était contestée par les pays scandinaves ainsi que par les Pays-Bas et la Suisse ${ }^{110}$.

Durant les années 1930, l'élite dirigeante de la FIFA va mettre en place différentes stratégies permettant de limiter les tensions en interne et de conférer à l'organisation une autonomie sur la scène internationale. Pour bien saisir les raisons de ces décisions, arrêtons-nous tout d'abord sur l'élite dirigeante de la FIFA et en premier lieu sur le président de la FIFA, Jules Rimet. Se focaliser sur le cas de Rimet est très important puisque, tout au long de ses 34 années de mandat à la tête de la FIFA, il va imprégner l'organisation de la manière dont il faut gérer le football international, voire essayer d'y développer certains idéaux.

\subsubsection{Jules Rimet : l'autre Coubertin ?}

Au début des années 1920, le Français entame un mandat qu'il achèvera en 1954, ce qui en fait encore aujourd'hui le président qui est resté le plus longtemps en place à la FIFA ${ }^{111}$. Comment expliquer cette longévité à la tête de la FIFA ? Par ailleurs, quels buts Rimet vise-t-il au travers de son investissement dans le football ? Enfin, quelle est la vision de la Fédération internationale défendue par ce dirigeant français?

Jules Ernest Séraphin Valentin Rimet est proche de ses cinquante ans (il est né en 1873) lorsqu'il accède à la présidence de la FIFA, ce poste venant couronner une carrière déjà longue dans les arcanes du football français. Celle-ci commence tôt, plus précisément à l'âge de vingt-quatre

\footnotetext{
109 Macon B., "The politization of football ", op. cit.

110 Onyestak N., "Boycott, exclusion or non-participation? Hungary in the years of the 1920 and 1984 Olympic games ", The International Journal of the History of Sport, vol. 27, n 11, 2010, pp. 1920-1941.

111 La deuxième place est occupée par le Brésilien João Havelange qui est resté vingt-quatre ans en poste, soit de 1974 à 1998. 
ans lorsqu'il participe activement à la création d'un club de la région parisienne, le Red Star ${ }^{112}$, dont il devient rapidement le président. Dans la première décennie du siècle dernier, l'action de Rimet dépasse le cercle parisien et s'inscrit à l'échelle nationale. Il commence à tisser autour de lui un réseau de dirigeants également animés par la volonté de développer le football en France. Ses appartenances au camp catholique lui permettent de se rapprocher de deux autres dirigeants qui ont préalablement œuvré au développement du jeu dans les patronages catholiques, Charles Simon ${ }^{113}$ et Henri Delaunay. Un événement va jouer en la faveur de ces trois hommes : l'exclusion de la FIFA, en 1907, de l'Union des sociétés françaises de sports athlétiques (USFSA) - fédération multisportive qui contrôle le football en France ${ }^{114}$. En effet, l'USFSA prône avant tout la pratique du football amateur et, en ce sens, souhaite favoriser les rapprochements avec l'association anglaise de football amateur. Or la FIFA ne reconnaît pas cette organisation comme légitime, puisque la représentation anglaise est déjà assurée en son sein, par la Football Association. L'USFSA n'entend toutefois pas les menaces de la FIFA qui lui interdit d'entretenir des relations avec cet organisme et, en conséquence, se voit finalement exclue de la Fédération internationale. Cette situation est problématique puisque la France ne dispose dès lors plus de représentants au sein de la Fédération internationale, mais elle constitue une aubaine pour Rimet et ses collègues. Profitant de la situation, ils mettent en place une structure nommée le Comité français interfédéral (CFI) qui reprend le dialogue avec la FIFA. Par l'entremise des actions du CFI, la France est rapidement réintégrée dans le giron international. Le Comité interfédéral prend ainsi progressivement le leadership de l'organisation du football dans l'Hexagone. Pour Jules Rimet, il s'agit d'une première consécration et il se profile comme l'un des principaux dirigeants du ballon rond en France.

La Première Guerre mondiale met toutefois un frein à l'engagement de Rimet dans le football et c'est après le conflit qu'il prend une part active à la relance des activités footballistiques en France. En compagnie d'Henri

112 Club réunissant surtout des individus appartenant aux classes moyennes en émergence (fonctionnaires, commerçants, hommes de loi) et qui, en raison d'enjeux immobiliers, déménagent, en 1909, dans la "banlieue rouge ", plus précisément à Saint-Ouen. Sur le football à Paris de cette époque, voir : Sorez J., Le football dans Paris et ses banlieues. Un sport devenu spectacle, Rennes, Presses universitaires de Rennes, 2013.

113 Sur Charles Simon, voir : Munoz L., "L'itinéraire abrégé d'un fondateur du sport français, Charles Simon, 1882-1915 ", dans Robène L. (dir.), Le sport et la guerre. XIX et $X X^{e}$ siècles, Rennes, Presses universitaires de Rennes, 2012, pp. 399-410.

114 Hirschman C.A.W., Procès-verbal de l'assemblée générale de la FIFA des 19 et 20 mai 1907 , n.d. FIFA, I-XI congrès ordinaires_1904-1914 rappgrt d'activité) 
Delaunay, il participe, en 1919, à la fondation de la Fédération française de football dont il devient le premier président ${ }^{115}$. Dans les années qui suivent, Rimet va affirmer sa position de dirigeant incontournable du football français, et, plus largement, d'acteur majeur du sport en France. Durant les années 1920, il devient vice-président puis président du Comité national des sports - organisme qui doit coordonner les actions des sports au niveau national. Il occupe également le poste de membre du Conseil supérieur des sports au ministère de l'Éducation nationale. Durant cette période, Jules Rimet développe des liens étroits avec de nombreuses personnalités du sport hexagonal (dirigeants et journalistes). Signe d'une certaine notoriété, il a notamment la possibilité de publier facilement dans L'Auto, journal phare de la presse sportive française à cette époque. De même, il prend part au lancement du journal sportif L'Équipe, au sortir de la guerre, en devenant actionnaire de sa société éditrice, la SOPUSI. Son emprise sur le football français est telle que lorsqu'il est battu aux élections pour la présidence de la FFFA en 1949 par Emmanuel Gambardella, le journal France football n'hésite pas à titrer qu'il s'agit d'un " Hiroshima du football $" 116$.

C'est en 1920 que Rimet débute son long mandat à la présidence de la FIFA. Or, contrairement à la majorité de ses collègues du comité exécutif de la FIFA, le Français n'officie pas en tant que joueur de haut niveau pendant sa jeunesse. D'après ses propres aveux, il ne serait pas très doué pour le jeu ${ }^{117}$. De plus, les lettres de sa correspondance personnelle conservée à la FIFA n'abordent, au contraire d'autres membres de l'élite de la Fédération internationale ${ }^{118}$, que rarement la joute footballistique en tant que telle. Dès lors, au regard de cette moindre passion pour le jeu, comment expliquer le très fort investissement de Rimet pour le football ?

Son implication est animée par plusieurs raisons. Premièrement, le jeu peut lui permettre de réaliser une ambition personnelle, celle de gravir les échelons de la société et ainsi d'acquérir une certaine notoriété. Issu d'un milieu relativement modeste - son père est un petit commerçant dans le quartier populaire du Gros-Caillou à Paris -, le jeune homme est ambitieux, ce qui se reflète dans son parcours professionnel. En effet, il entreprend des études, suivant des cours du soir, ce qui lui permet d'obtenir un baccalauréat, puis une licence en droit. Ce diplôme lui offre la possibilité d'intégrer un cabinet de contentieux de la place parisienne,

115 Sur la création de la 3F, voir : Wahl A., Les archives du football, op. cit., pp. 107-121.

116 "Hiroshima du football ", France football, 26 juillet 1949.

117 Rimet J. (1954), "Le football et le rapprochement des peuples », op. cit., p. 25.

118 Comme Andrejevic, Mauro ou Seeldraysrsilippe Vonnard - 978-2-8076-0570-1 
plus précisément le comptoir fiduciaire de Paris (cabinet de contentieux et de recouvrement). Il va y faire carrière et progressivement intégrer la bourgeoisie parisienne ${ }^{119}$. Sous cet angle, ses actions dans le football local, national puis international peuvent servir ce parcours mais aussi, en retour, lui offrir une renommée. Témoin de cette volonté, à la fin de sa vie, il espère que ses actions dans le domaine du football, en particulier à l'échelle internationale, lui permettront d'être candidat au prix Nobel de $1955^{120}$.

Deuxièmement, le football lui offre l'opportunité de réaliser un projet plus politique. En effet, Rimet est attiré par le domaine politique et, en avril 1928, il franchit le Rubicon et déclare sa candidature à la députation $\mathrm{du} 7^{\mathrm{e}}$ arrondissement de Paris. Se présentant sur la liste des indépendants, son engagement dans l'administration du sport est un argument central de sa campagne. Cependant, sa candidature est un échec et restera comme une unique tentative. En conséquence, c'est au travers du football que, durant toute sa vie, Rimet va faire " de la politique sans en avoir l'air " ${ }^{121}$. Car, dès sa jeunesse, Jules Rimet développe l'ambition d'améliorer la société, en fervent adepte des idées du catholicisme social, un courant dont les promoteurs critiquent les ravages du libéralisme et visent à instaurer une société plus juste. Si des améliorations doivent être faites, il n’est par contre pas question de révolution. Au contraire, les tenants de ce courant sont des conservateurs qui proposent des réformes de la société en vue de maintenir l'équilibre social ${ }^{122}$. Jules Rimet œuvre tout d'abord dans le Cercle catholique ouvrier du Gros-Caillou. Puis, en compagnie de son père qui semble jouer un grand rôle de socialisation, il participe à la création de l'Union sociale du $7^{e}$ arrondissement, qui a pour but d'aider les plus démunis à obtenir une assistance médicale et sociale. Très actif, il aide

119 À ce titre, il faudrait aussi se pencher sur le statut social de l'épouse de Jules Rimet, démarche que nous n'avons pas entreprise.

120 Lettre de J. Rimet à P. Bauwens, 17 février 1955. Archives du Deutsche Fussball Bund (DFB), Korrespondenz Peco Bauwens, dossier Korrespondenzen [28]. Le prix Nobel n'est finalement pas attribué lors de l'année 1955.

121 Sur cette thématique, voir : Le Gali L., Offerle M., Ploux F. (dir.), La politique sans en avoir l'air. Aspects de la politique informelle, XIX'e-XXI' siècle, Rennes, Presses universitaires de Rennes, 2012.

122 À la fin du XIX ${ }^{\mathrm{e}}$ siècle, le catholicisme social prend de l'essor et connaît en France une phase d'intense développement. En effet, l'Association catholique de la jeunesse française passe de 15000 à 140000 membres entre 1898 et 1913. Cette expansion s'accompagne, en 1901, de la création de la Ligue des femmes françaises, puis de la Ligue patriotique française une année plus tard. Sur ce développement, voir : Hilaire P.-Y., "Un siglo de catolicismo social en Francia desde una perspectiva Europea ", dans Pazos A.M. (ed.), Un siglo de catolicismo social en Europa 1891-1991, Pamplona, Ediciones Universitad de Navarra, 1991 p pp. 93-119. 
ensuite à la fondation d'un journal intitulé La Revue en 1898 qui, deux ans plus tard, est incorporé dans Le Sillon de Marc Sangnier, l'un des leaders du catholicisme social en France.

Au début du siècle, c'est par l'intermédiaire du football qu'il va continuer son action, le jeu lui permettant d'incarner un rapport à la modernité qui le détache sans doute quelque peu du mouvement - des études supplémentaires devraient être conduites pour confirmer ce point. En effet, il semble saisir le potentiel du football comme un "instrument de civilisation » et un vecteur privilégié des idéaux du catholicisme social, la pratique sportive favorisant la tempérance, le dévouement, mais aussi une acceptation des hiérarchies sociales existantes et qui sont, dans la compétition, naturalisées. Tout au long de sa carrière de dirigeant, Rimet va rappeler avec force cette utilité du football pour améliorer la société. Ainsi, le $1^{\text {er }}$ janvier 1935, il écrit une longue tribune dans le journal L'Auto, dans laquelle il tente de démontrer que le sport peut constituer un remède contre les maux (il parle de crise économique, sociale et morale) qui touchent alors la société française. Selon lui, les sportifs échappent à l'apathie générale et sont des exemples au regard de l'optimisme dont ils témoignent, car ils sont à la recherche constante de progrès (ce dont témoigne bien la recherche des records). En définitive, les regroupements sportifs, les clubs ou les équipes donnent un exemple à la société, puisqu' une équipe c'est " une réunion d'hommes qui, s'étant perfectionnés individuellement, harmonisent leurs efforts en vue d'atteindre le même but, qui obéissent à une autorité librement acceptée, font tout ce que celle-ci leur impose et ne font que cela ${ }^{123}$.

Troisièmement, et comme beaucoup de ses contemporains, Rimet est fortement marqué par les horreurs de la Première Guerre mondiale. Patriote, il part au front alors qu'il a dépassé l'âge obligatoire d'engagement. En raison de son action et de sa bravoure, voire de son ingéniosité - il invente, en 1915, un appareil balistique nommé le "télémire »-, il reçoit trois citations à la Croix de Guerre. Pourtant, au sortir du conflit, il s’agit pour lui de dépasser les antagonismes créés par celui-ci et de recréer une société internationale harmonieuse et pacifique. Or le football semble constituer un moyen de surpasser les tragiques événements et, sous cet angle, Rimet semble ici être inspiré par des idéaux de type courbertien ${ }^{124}$. Ceux-ci sont

123 "L'idée sportive", L'Auto, $1^{\text {er }}$ janvier 1935. Texte intégralement reproduit dans Leblond R. (dir.), Le journal de Jules Rimet : le récit rare du fondateur de la Coupe du monde de football, Paris, First, 2014, p. 142.

124 Clastres P., "Inventer une élite : Pierre de Coubertin et la "chevalerie sportive" ", Revue

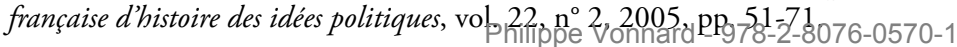


d'ailleurs des sources d'inspiration pour une nouvelle élite qui sévit dans le sport international durant l'entre-deux-guerres ${ }^{125}$. Dans l'article qu'il écrit pour le livre commémoratif célébrant les vingt-cinq ans de la Fédération internationale, Rimet évoque les sportsmen comme des « chevaliers des temps modernes ». Vingt-cinq ans plus tard, alors qu'il vient de quitter son poste et qu'il est immédiatement élu par le congrès comme président d'honneur, il réitère sa vision dans une sorte de testament politique intitulé « Le football et le rapprochement des peuples ". Ce document discute, sur une quinzaine de pages, de l'apport du football dans la paix. Dès les premières lignes, le ton est donné, l'auteur indiquant : « Le sport [a] une mission internationale, celle de favoriser la compréhension réciproque des peuples, leur réconciliation voire, peut-être, dans un avenir plus ou moins proche, l'abolition du hideux et stupide fléau de la guerre ${ }^{126}$. Et il ajoute plus loin que son expérience de trente-cinq années à la tête de la FIFA a « renforcé [sa] conviction que les hommes sont plus près les uns des autres qu'on ne le croit généralement. Et "la paix sur terre", depuis si longtemps promise "aux hommes de bonne volonté" je crois qu'il est dans le destin du football d'en faciliter beaucoup, un jour ou l'autre, l'avènement tant souhaité. ».

Si Jules Rimet dispose d'une longue expérience de dirigeant au sein du football français, lorsqu'il accède à la tête de la FIFA au début des années 1920, il n’a toutefois pas toutes les ressources nécessaires pour exercer au niveau international. En effet, comme évoqué ci-dessus, ce n'est pas un ancien joueur et sa passion pour le jeu paraît modérée. De plus, ses ressources pour être écouté à l'échelle internationale sont limitées puisqu'il ne parle que le français, là où, comme nous allons le décrire dans le souschapitre suivant, ses collègues sont polyglottes. En outre, il ne semble pas avoir énormément voyagé dans sa jeunesse, a contrario de la majorité des autres membres de l'élite de la FIFA qui ont un capital cosmopolite plutôt bien développé. Selon nos analyses, outre une capacité oratoire reconnue de tous ${ }^{127}$, c'est surtout le sens de la diplomatie de Jules Rimet même si, lors de ses allocutions lors des congrès il peut aussi se montrer offensif contre les possibles adversaires de sa politique -, son réseau de connaissances à l'extérieur de la sphère footballistique et sa volonté farouche d'utiliser le football comme un instrument de paix sur la scène

125 Pour un autre exemple : Artiaga L., "Jeux de pouvoir aux premiers temps de la Fédération internationale de basket-ball ", dans Archambault F., Artiaga L., Bosc G., Le continent basket. L'Europe et le basket-ball au XX' siècle, Bruxelles, P.I.E. Peter Lang, 2015, pp. 47-65.

126 Rimet J., "Le football et le rapprochement des peuples ", op. cit., p. 1.

127 "Gens de revue et... corrigés ", L'Auto, 18 piliptobre 1938. 
internationale qui expliquent sa longévité à la tête de la FIFA. Choisi lors d'un congrès officieux qui se déroule à Anvers durant les Jeux olympiques, la nomination de Rimet porte elle-même, selon Paul Dietschy, "l'abandon progressif d'une politique radicale à l'égard des vaincus » ${ }^{128}$. Tout au long de son mandat, il va s'atteler à prôner le consensus au sein de la FIFA car, comme il le souligne dans le livre commémoratif des vingt-cinq ans de l'organisation, ce qui importe est de renforcer « la confiance réciproque entre les associations nationales, le sacrifice des intérêts particuliers, l'abnégation de soi-même, le dévouement à la cause commune " ${ }^{129}$. C'est pourquoi Jules Rimet n'hésite pas à faire de nombreux voyages (pour les réunions de la FIFA mais aussi en qualité de représentation, le président de la FIFA assistant à de multiples événements footballistiques en Europe et, parfois, en Amérique du Sud) afin d'entretenir cette " grande famille du football mondial ", comme il aime à le rappeler lors de ses allocutions au début des congrès de la FIFA. Renforcer l'amitié entre les associations nationales de football devient un but à atteindre qui est inséré dans les statuts de la Fédération internationale à partir de $1938^{130}$.

Au regard de ces différents objectifs, Rimet paraît être davantage que "le missionnaire du jeu ", brièvement décrit par Alan Tomlinson ${ }^{131}$. En fait, il peut être considéré comme un diplomate du sport international qui tente, au travers de son action au sein de la FIFA, de proposer des échanges entre des pays parfois politiquement divisés. Si cet objectif n'est pas forcément partagé - ou du moins formellement affiché - par ses collègues du comité exécutif, ceux-ci ont également l'ambition de développer la FIFA en dehors de tout conflit.

\subsubsection{Développer les échanges footballistiques internationaux : sociographie de l'élite dirigeante}

Lors d'une étude réalisée dans le cadre de la bourse de recherche de l'UEFA 2011-2012, Grégory Quin a évoqué l'émergence d'une élite du football européen durant l'entre-deux-guerres, développant une proposition

128 Dietschy P., « Histoire du football » op. cit., p. 159.

129 Rimet J., "La Chevalerie des temps modernes ", dans Anonyme, Fédération internationale de football-association 1904-1929, Amsterdam, J.H. de Bussy-FIFA, 1929, p. 3.

130 Anonyme, Statuts de la FIFA [édition de 1938], art. 2. [des statuts]. FIFA, statuts, 1904-1981.

131 Tomlinson A., "FIFA and the men who made It ", Soccer and Society, vol. 1, $\mathrm{n}^{\circ}$ 1, 2000, pp. 55-71. 
faite par Pierre Lanfranchi au début des années $1990^{132}$. Sans qu'il ne donne de définition précise du mot "élite ", nous comprenons aisément, à la lecture de son travail, que le terme est utilisé pour traiter des principaux dirigeants du football européen et notamment ceux qui officient dans les diverses commissions permanentes de la FIFA. Grégory Quin a souligné notamment que cette élite du football européen est " polyglotte, cultivée, engagée dans les associations nationales, proches des journalistes et [se côtoie] régulièrement autour des rencontres internationales $"{ }^{133}$.

Dans les lignes qui suivent, nous souhaitons revenir plus précisément sur le profil des membres de l'élite de la FIFA c'est-à-dire, pour rappel, les dirigeants qui composent exclusivement le comité exécutif de la Fédération internationale. Comme pour le président Rimet, la majorité de ces dirigeants restent de longues années en place (entre dix et vingt ans) et sont donc capables d'imprégner l'orientation de l'organisation. Ainsi, se focaliser sur ces acteurs est important pour comprendre le développement de la FIFA mais aussi la politique de consensus menée en son sein. Deux questions principales nous intéressent. Premièrement, il s'agit de comprendre les raisons de la longue présence de ces dirigeants dans le comité exécutif de la FIFA.

Tableau 3. Composition du comité exécutif de la FIFA (1930-1938)

\begin{tabular}{|c|c|c|c|c|c|}
\hline $\begin{array}{l}\text { Positions/ } \\
\text { Années }\end{array}$ & $1930-1931^{*}$ & 1931-1932* & 1932-1934* & 1934-1936* & 1936-1938* \\
\hline Président & Rimet & Rimet & Rimet & Rimet & Rimet \\
\hline $\begin{array}{l}\text { Vice- } \\
\text { président et } \\
\text { membres }\end{array}$ & $\begin{array}{l}\text { Bonnet, } \\
\text { Seeldrayers, } \\
\text { Fischer, } \\
\text { Schricker, } \\
\text { Ferretti, } \\
\text { Buero }\end{array}$ & $\begin{array}{l}\text { Seeldrayers, } \\
\text { Fischer, } \\
\text { Schricker, } \\
\text { Buero, } \\
\text { Pelikan, } \\
\text { Mauro }\end{array}$ & $\begin{array}{l}\text { Seeldrayers, } \\
\text { Mauro, } \\
\text { Fischer, } \\
\text { Buero, } \\
\text { Pelikan, } \\
\text { Bauwens, } \\
\text { Johanson, } \\
\text { Lotsy }\end{array}$ & $\begin{array}{l}\text { Seeldrayers, } \\
\text { Mauro, } \\
\text { Fischer, } \\
\text { Pelikan, } \\
\text { Bauwens, } \\
\text { Johanson, } \\
\text { Lotsy, } \\
\text { Garcia- } \\
\text { Duran }\end{array}$ & $\begin{array}{l}\text { Seeldrayers, } \\
\text { Mauro, } \\
\text { Fischer, } \\
\text { Pelikan, } \\
\text { Bauwens, } \\
\text { Johanson, } \\
\text { Lotsy, } \\
\text { Garcia- } \\
\text { Duran }\end{array}$ \\
\hline Secrétaire & Hirschman & $\begin{array}{l}\text { Hirschman/ } \\
\text { Schricker }\end{array}$ & Schricker & \begin{tabular}{|l|} 
Schricker \\
\end{tabular} & Schricker \\
\hline
\end{tabular}

Légende : * nous avons découpé les périodes suivant les congrès car, lors de ceux-ci, des élections peuvent faire évoluer la composition du comité exécutif.

132 Lanfranchi P., «Fussball in Europa 1920-1938: die Entwicklung eines Internationalen Netzwerkes ", dans Horak R., Reiter W. (eds.), Die Kanten des Runden Leders. Beitrage zur Europäischen Fussballkultur, Vienna, Promedia, 1991, pp. 163-172.

133 Quin G., Une première élite du football européen (1904-1956) 8pp cito ct6-0570-1 
Au regard du tableau ci-dessus, l'élite de la FIFA est composée d'une petite dizaine de membres (par ordre alphabétique) : le Belge Rodolphe Seeldrayers, les Allemands Peco Bauwens et Ivo Schricker, le Hongrois Mor Fischer, l'Italien Giovanni Mauro, le Néerlandais Karel Lotsy, le Tchèque Rudolf Pelikan auxquels il faut bien entendu ajouter le président, Jules Rimet. Savoir pourquoi ces acteurs sont choisis par leurs collègues des associations nationales pour faire partie du comité exécutif de la FIFA et connaître les raisons de leur longue présence dans les arcanes de la Fédération internationale impliquent de saisir les dispositions qui leur permettent d'officier à la tête de la FIFA. En effet, pour être présent à l'international, il est nécessaire que les dirigeants possèdent des dispositions particulières ou, en d'autres termes, des " capitaux " spécifiques ${ }^{134}$.

Le premier capital de l'élite de la FIFA est d'ordre footballistique et concerne leur rapport au jeu ${ }^{135}$ et à son administration. Si ce trait peut paraitre banal, Manuel Schotté a montré, dans un texte récent sur les présidents de clubs de l'élite du football français, que pour ces dirigeants, la pratique sportive - si ce n'est la passion pour le jeu - n'allait pas forcément de soi ${ }^{136}$. Soulignons que les dirigeants qui officient à la tête de la FIFA ont un passé de joueur de ballon rond et souvent à un niveau international. Lorsque cela n'est pas le cas, comme pour Giovanni Mauro, ils ont un passé dans l'arbitrage. Mais cette proximité avec le jeu n'est pas une caractéristique suffisante pour arriver au sommet de la FIFA et doit être couplée à une carrière d'administrateur dans le football national. Comme dans les autres organisations sportives internationales, les membres de l'élite de la FIFA ont ainsi occupé, souvent pendant plusieurs années, des fonctions exécutives - non rémunérées - dans leurs associations nationales

134 Deux textes ont particulièrement inspiré notre démarche : Miercejewski S., El Boujoufi T., "Le recrutement socio-professionnel du personnel enseignant des instituts régionaux d'éducation physique (1927-1939) ", Staps, vol. 75, n 1, 2007, pp. 9-24 ; Genin V., « Recrutement et réseaux des représentants diplomatiques belges auprès du royaume d'Italie (1861-1911), dans Dumoulin M., Lanneau C. (dir.), La biographie individuelle et collective dans le champ des relations internationales, Bruxelles, P.I.E. Peter Lang, pp. 131-154.

135 En particulier, leur rapport presque passionnel au football. Dans leurs correspondances personnelles, il n'est pas rare de retrouver des échanges sur les rencontres qui viennent de se dérouler. Par ailleurs, comme évoqué plus haut, les congrès et les réunions du comité exécutif sont très souvent organisés au même moment qu'une rencontre internationale, ce qui permet à ces dirigeants de profiter d'une récréation sous la forme d'une partie de football.

136 Schotté M., "Monter en première division. Trajectoires de notabilisation des présidents de clubs de football professionnel (1960-1999), Politix, vol. 114, $\mathrm{n}^{\circ} 2$, 2016, pp. 99-120. 
respectives avant d'entrer au sein de l'organisation. En conséquence, ce sont des dirigeants aguerris aux discussions sur le football et qui disposent d'une expérience certaine dans la conduite des affaires footballistiques. Le capital footballistique paraît donc une condition indispensable pour pouvoir œuvrer à la tête de la Fédération internationale.

D'autres capitaux se superposent néanmoins à celui-ci, et notamment le capital cosmopolite. Si nous suivons la proposition d'André Mach, Thomas David et Félix Bühlmann, ce capital "renvoie à la capacité [du dirigeant] d'évoluer dans un contexte international ${ }^{137}$. Dans le cadre d'une organisation internationale, ce trait paraît particulièrement important car, pour y officier, il est souvent nécessaire de parler plusieurs langues. De plus, le milieu international nécessite un apprentissage particulier de codes et de normes (manière de se tenir, de communiquer et de prendre la parole en public). C'est pourquoi ces dirigeants ont souvent étudié à l'étranger, voire ont fait de multiples voyages dans leur jeunesse puisque, comme le souligne Anne-Catherine Wagner, " au-delà des langues, les voyages dotent de compétences sociales et relationnelles internationales. Les enfants se familiarisent avec la diversité des codes sociaux et des normes de sociabilité d'un pays à l'autre, ils apprennent à retrouver rapidement leurs repères dans les milieux nationaux, sociaux et culturels les plus divers et ils acquièrent des compétences d'interaction précieuses $"{ }^{138}$. Par ailleurs, une éducation internationale et les voyages permettent de disposer d'une grande ouverture d'esprit, qui est d'autant plus nécessaire dans une organisation internationale où des acteurs du monde entier se côtoient et doivent tenter de se comprendre par-delà leurs différences.

Dans le cas de l'élite de la FIFA, nous pouvons constater que plusieurs de ses membres ont vécu quelques années hors de leur pays natal, que ce soit pendant leurs études ou plus tard, pour des raisons professionnelles. C'est notamment le cas de l'Allemand Ivo Schricker, qui travaille plusieurs années dans une banque en Égypte. De même, après avoir fini ses études en ingénierie, Mor Fischer vit à Londres où il gagne de l'expérience en matière de gestion du trafic ferroviaire. La pratique du football, les matchs internationaux de leur équipe nationale puis les quelques congrès de la FIFA avant leur nomination - auxquels ils participent en tant que

137 Mach A., David T., Bühlmann F., «La fragilité des liens nationaux. La reconfiguration de l'élite du pouvoir en Suisse, 1980-2010 ", Actes de la recherche en sciences sociales, vol. 190, n 5, 2011, p. 83.

138 Wagner A.-C., "La place du voyage dans la formation des élites ", Actes de la recherche en sciences sociales, vol. 170, $\mathrm{n}^{\circ} 5,2007, \mathrm{~B}_{\mathrm{h}} 60$. 
représentants de leur association nationale - leur ont permis de continuer à voyager. Enfin, soulignons qu'ils parlent, voire écrivent, dans plusieurs langues (souvent les langues officielles de la FIFA : allemand, anglais et français) comme en témoignent leurs correspondances personnelles conservées dans les archives de la FIFA. Ce trait s'explique en premier lieu par leurs études supérieures (de niveau universitaire) ou par leur profession (ils officient souvent dans des professions de type libéral) qui les amènent à jongler avec plusieurs langues. Brossons brièvement la trajectoire d'un dirigeant qui illustre bien ce profil transnational : le Néerlandais Karel Lotsy. Né aux États-Unis (à Baltimore), il suit ensuite sa famille en Indonésie où son père, un biologiste renommé, a trouvé une opportunité professionnelle. Après quelques années, il est envoyé par ses parents dans un collège en Angleterre afin de parfaire son éducation. Ce séjour lui permet de découvrir les vertus du football et, plus globalement, des sports modernes. Puis il rejoint ses parents aux Pays-Bas, où son père a obtenu un poste fixe dans une université. Ce parcours lui permet de maîtriser plusieurs langues et lui offre également la possibilité d'être rapidement baigné dans une ambiance cosmopolite.

Ces informations, bien que relativement sommaires, nous permettent de construire un idéal-type du dirigeant de la FIFA des années 1930. Il a entre quarante et cinquante ans, bénéficie d'un niveau d'études supérieures et officie soit dans une profession libérale, soit en tant que professeur ou entrepreneur. Son activité professionnelle lui laisse le temps, et les ressources financières, de pouvoir s'investir dans des organismes footballistiques. Sa position au sein de l'élite de la FIFA s'explique, tout d'abord, par une forte passion pour le football et la conviction de le développer. Une trajectoire transnationale dès le jeune âge lui apporte des ressources lui permettant d'œuvrer à l'échelle internationale. Ce parcours lui permet d'être plus ouvert vis-à-vis de la diversité et de faire preuve de suffisamment de tact et de diplomatie dans un contexte globalisé. En fait, il est à l'aise à l'échelle internationale puisqu' il parle souvent plusieurs langues. Cependant, avant d'entrer au sein du comité exécutif de la FIFA, le dirigeant doit faire ses preuves. C'est pourquoi il dispose d'une expérience de plusieurs années au niveau de sa fédération nationale et participe, préalablement, à quelques congrès de la FIFA, démarche qui lui permet notamment d'être socialisé aux us et coutumes de la Fédération.

Notre deuxième question vise à comprendre les rapports qu'entretiennent les membres de l'élite de la FIFA entre eux. Comme nous l'avons indiqué, de par leur passion pour le jeu, leur formation et leur profession, ils partagent des visions relativement similaires de la société et, sans aucun doute, une certaine foi dans le libéralisme comme source de 
progrès et de paix. Sur l'échiquier politique, nous les placerions plutôt du côté des sociaux-démocrates ou des démocrates-chrétiens, même si sur ce point des études supplémentaires sont à mener ${ }^{139}$.

Leurs activités à la tête de la FIFA renforcent ces liens car les membres du comité exécutif se rencontrent entre trois et six fois par année. En outre s'ajoutent aux réunions de travail qui se tiennent dans de grandes capitales européennes, la présence à des rencontres internationales de football mais aussi des visites culturelles et des dîners. Ces activités sociales permettent donc aux dirigeants d'éprouver leur fort internationalisme et de découvrir de nouveaux endroits. Nous pouvons supposer qu'outre les discussions sur le football, ils abordent également d'autres domaines relatifs à la culture (musique, cuisine ou arts) ${ }^{140}$. De plus, ces rencontres se superposent aux retrouvailles lors des matchs internationaux, aux banquets organisés à l'occasion d'événements spéciaux (match de la FIFA ou match commémoratif pour fêter les vingt ou vingt-cinq ans d'une association nationale), voire des discussions informelles tenues pour aborder un sujet précis. Malgré cette proximité, tous ne sont pas des amis proches et les connexions les plus intenses sont celles qui existent entre les dirigeants de pays voisins. Toutefois, il y a assurément une entente cordiale entre eux, qui se remarque dans les moments difficiles comme lors de la maladie d'un des leurs ${ }^{141}$ ou d'un décès ${ }^{142}$.

139 Au sujet du secrétaire général de la FIFA, Ivo Schricker, Henri Wahlig a indiqué qu’il était un "libéral-conservateur ", concept qui nous semble particulièrement fécond et qui mériterait d'être développé. Wahlig H., " Dr. Ivo Schricker: Ein Deutscher in Diensten des Weltfussballs ", dans Peiffer L., Schulze-Marmeling D. (eds.), Hakenkreuz und Rundes Leder. Fussball im Nationalsozialismus, Göttingen, Verlag die Werkstatt, 2008, pp. 197-206.

140 Dans un article du journal Football, le Hongrois Mor Fischer est décrit comme un voyageur incessant, polyglotte et qui s'intéresse de près à de nombreux domaines culturels. Selon le journaliste, il donne des conférences lors de ses voyages à l'étranger sur l'histoire artistique ou politique de son pays. "Un autre grand voyageur... L'ingénieur Fischer ", Football, 3 juillet 1930.

141 Schricker fait par exemple parvenir du tabac à Lotsy afin de l'aider à surmonter une longue hospitalisation au début des années 1950. Lettre de K. Lotsy à I. Schricker, 21 décembre 1950. FIFA, membres du comité exécutif, dossier individuel : correspondance K. Lotsy (1.1.49-31.12.50).

142 "Avec Mr. Pelikan un ami personnel dont [il gardera] toujours le souvenir d'un ami dans le meilleur sens du mot ", écrit Ivo Schricker en apprenant la mort de Rudolph Pelikan. Lettre de I. Schricker à la Fédération tchèque de football, 20 mai 1946, FIFA, correspondance avec les associations nationales : Tchécoslovaquie (1938-1998), dossier : 1939-1950. 
Ces éléments nous permettent d'avancer que ces dirigeants forment un noyau dur qui officie dans le comité exécutif de la FIFA durant de longues années. Fortement liés les uns, ils vont œuvrer au renforcement du rayonnement de la Fédération internationale. Il est difficile de savoir s'ils partagent l'ambition de Jules Rimet d'utiliser le football pour le rapprochement des peuples. Par contre, comme lui, ils ont un profil de diplomate et souhaitent éviter les conflits au sein de l'organisation. En outre, ils ont également pour but que la FIFA développe toujours davantage les liens entre les associations européennes de football, et ce en passant outre les antagonismes qui existent entre les États sur la scène internationale.

\subsubsection{Construire une " autonomie » sur la scène internationale}

Dans un texte paru en 1995, Jacques Defrance a développé une réflexion intéressante autour de l'autonomisation du champ sportif ${ }^{143}$. En complément de quelques travaux réalisés sur l'autonomie des organisations non gouvernementales ${ }^{144}$, les propos de Defrance nous offrent la possibilité de réfléchir sur l'autonomie que se construit la FIFA durant les années 1930 vis-à-vis des acteurs étatiques sur la scène internationale. Dans cette perspective, nous nous attachons à décrire les actions des dirigeants du comité exécutif de la FIFA en vue de consolider la position de leur organisation sur la scène internationale.

Afin de construire l'autonomie de leur organisation, les dirigeants mettent en place différents mécanismes de gouvernance que nous pouvons qualifier de permanents. L'un des plus importants mécanismes permanents consiste dans la recherche d'une autonomie financière. En effet, garantir son propre financement est crucial pour la FIFA car ce procédé limite l'ingérence de bailleurs de fonds externes, en particulier des États. Sous cet angle, la création de la Coupe du monde est très importante. En effet, dans le règlement établi pour le tournoi de 1934, il est prévu qu' elle touche $5 \%$ de la recette brute sur les rencontres jusqu'aux demi-finales, puis $10 \%$ des demi-finales et enfin $20 \%$ de la finale ${ }^{145}$. Selon Heidrun Homburg,

143 Defrance J., «L'autonomisation du champ sportif. 1890-1970 », Sociologie et sociétés, vol. 27, n 1, 1995, pp. 15-31.

144 Par exemple : Denéchère Y., "Diplomatie privées et autonomisation des ONG humanitaires dans l'espace de la cause des enfants ", Monde(s), vol. 5, n 1, 2014, pp. 119-135.

145 Schricker I., Procès-verbal de la réunion du comité exécutif de la FIFA des 8 et 9 octobre 1932, n.d. FIFA, comité exécutif (procès-verbaux 1927-1932), 
la première épreuve rapporte 38805 francs suisses, montant qui passe à 59963 pour la troisième édition ${ }^{146}$. Cette somme n'est pas négligeable et elle correspond à près de $40 \%$ du chiffre d'affaires de la Fédération ${ }^{147}$. Ainsi, la compétition permet à la FIFA de combler un déficit de quatre années et lui assure une relative sécurité financière.

Parallèlement, la Fédération internationale perçoit aussi un pourcentage sur les matchs internationaux disputés entre ses associations membres. Pour l'année 1935, durant laquelle aucune Coupe du monde n'est disputée, la FIFA touche 17300 francs suisses de la part des associations nationales. Ce chiffre correspond à $59 \%$ de ses recettes pour l'année. En 1937, celui passe même à plus de $81 \%$ en raison de l'augmentation du nombre de matchs qui fait suite à l'adhésion de nouvelles associations nationales. Dans le dernier tiers de la décennie, la situation financière de la FIFA est au beau fixe, comme le montre le tableau ci-dessous.

Tableau 4. Résumé des recettes et dépenses de la FIFA en 1938 (en francs suisses)

\begin{tabular}{|l|l|l|l|}
\hline \multicolumn{2}{|c|}{ Recettes } & \multicolumn{2}{c|}{ Dépenses } \\
\hline $\begin{array}{l}\text { Cotisations des associations } \\
\text { membres }\end{array}$ & 11531,55 & Total dépenses & 56187,52 \\
\hline $\begin{array}{l}\text { Pourcentage reçu sur les matchs } \\
\text { internationaux et transmis par } \\
\text { les associations membres }\end{array}$ & 44356,54 & & \\
\hline Divers & 4309,30 & & 4009,87 \\
\hline Sous-total & $\mathbf{6 0 1 9 7 , 3 9}$ & Sous-total & $\mathbf{6 0 1 9 7 , 3 9}$ \\
\hline $\begin{array}{l}\text { Recettes nettes de la Coupe du } \\
\text { monde }\end{array}$ & 52697,65 & & \\
\hline & & & $\mathbf{1 1 2} \mathbf{8 9 5 , 0 4}$ \\
\hline Total & $\mathbf{1 1 2} \mathbf{8 9 5 , 0 4}$ & & \\
\hline
\end{tabular}

Grâce aux résultats financiers de la Coupe du monde, à l'augmentation des pourcentages reçus sur les matchs internationaux et à une meilleure

146 Homburg H., « Financial aspects of FIFA's World cup or the structural challenges of growth ", dans Wahl A., Histoire de la Coupe du monde de football, op. cit., pp. 157-209.

147 Schricker I., Rapport financier 1938, n.d. FIFA, comité exécutif (procès-verbaux 1938). 
gestion des finances - dès les années 1932-1933, un membre de l'élite de la FIFA est chargé de contrôler la gestion financière de la Fédération -, les dirigeants du comité exécutif peuvent constater avec satisfaction, en mars 1938, que " pour la première fois depuis [sa] fondation [la FIFA connaît] un excédent assez considérable de recettes sur les dépenses $"{ }^{148}$.

Au fil des années, la FIFA se constitue un capital. Ainsi, en date du 4 novembre 1938, le secrétaire général Schricker fait parvenir à ses collègues du comité exécutif un relevé sur l'état de la situation des avoirs de la Fédération. Cette dernière dispose désormais de trois comptes qui contiennent au total 170000 francs suisses d'obligations de premier ordre. En effet, la FIFA a souscrit des obligations entre 3 et $4 \%$ des chemins de fer fédéraux et de plusieurs cantons suisses (Bâle, Berne, Grisons, SaintGall, Soleure, Tessin Valais et Zurich $)^{149}$. Cette nouvelle donne financière permet à l'organisation, d'une part, de soutenir sa politique consistant à favoriser le développement du jeu et donc de renforcer sa position en tant qu'administrateur du football mondial ; d'autre part, de consolider son autonomie sur la scène internationale car cette posture confirme sa position en tant qu'organisation internationale non gouvernementale ${ }^{150}$.

Remarquons néanmoins que son autonomie financière vis-à-vis des États n'est pas totale, car la politisation croissante du football a pour conséquence un rattachement direct de certaines fédérations nationales à leur État, comme c'est le cas en Allemagne ou en Italie. Or rappelons que la Coupe du monde de 1934 se joue en Italie et que ces deux équipes nationales comptent parmi celles qui jouent le plus de rencontres dans la seconde partie des années 1930. Ainsi, ces deux pays participent activement au financement de la FIFA, ce qui leur confere une position importante en son sein (ils disposent chacun de deux représentants de leur fédération nationale au sein du comité exécutif de la FIFA). En conséquence, cette autonomie financière n'est pas suffisante pour garantir l'autonomie à la FIFA sur la scène internationale et se retrouve doublée d'autres mécanismes permanents qui doivent permettre à la Fédération de se prémunir des possibles soubresauts de la politique internationale.

148 Anonyme, Procès-verbal de la réunion du comité exécutif de la FIFA des 5-6 mai 1938, n.d. FIFA, comité exécutif (procès-verbaux 1938).

149 Lettre de I. Schricker au comité exécutif de la FIFA, 4 novembre 1938. FIFA, comité exécutif (procès-verbaux 1938).

150 Pour une réflexion sur le statut de la FIFA, voir : Eisenberg C., "FIFA et politique. 1945-2000 ", dans Mourlane S., Gastaud Y. (dir.), Le football dans nos sociétés, op. cit., pp. 119-134. 
Parmi ceux-ci, la place du siège de l'organisation a son importance et dans le cadre de la réorganisation de la FIFA qui s'opère entre 1931 et 1932, des discussions ont lieu sur l'idée de créer un secrétariat fixe pour la Fédération. En effet, jusqu'ici, la FIFA ne dispose pas d'un véritable siège et ses archives sont domiciliées au bureau du secrétaire-trésorier, Carl Hirschman. Il ressort des premiers échanges sur la question entre les dirigeants du comité exécutif de la FIFA que le futur siège devrait se trouver " dans une des villes du centre de l'Europe, disposant de bonnes communications par chemins de fer et située par préférence dans un pays dont les combinaisons politiques et la constitution ne peuvent pas causer des difficultés $"{ }^{151}$. Deux endroits sont préconisés. Premièrement, Paris est plébiscitée par Rodolphe Seeldrayers et Jules Rimet. Cité de villégiature du président de la FIFA, la présence de plusieurs autres organisations sportives telles que certaines Fédérations internationales sportives (aéronautique, automobiles, bobsleigh et tobogganing, cyclisme, gymnastique, hockey ou encore tennis) ${ }^{152}$ plaide largement en sa faveur. Deuxièmement, les dirigeants de l'Europe centrale, soutenus par le dirigeant allemand Félix Linnemann, souhaitent plutôt que le siège de la FIFA soit placé sur le territoire de la Confédération helvétique. Plusieurs arguments sont avancés pour expliquer le choix de la Suisse. Tout d'abord, Rimet semble avoir eu des difficultés à ouvrir un compte dans une agence bancaire parisienne pour la FIFA, car " étant une organisation internationale [elle] n'a pas de siège social avec des signatures autorisées en France ${ }^{153}$. A contrario, grâce à son système bancaire en plein développement - option à laquelle s'ajoute la stabilité du franc suisse -, ouvrir un compte en Suisse est plus facilement envisageable pour une organisation comme la FIFA. Par ailleurs, ce pays accueille également de nombreuses organisations internationales, dont les plus connues sont la SDN, la Croix-Rouge et, élément sans doute d'importance, le $\mathrm{CIO}^{154}$, avec qui il serait ainsi plus facile de communiquer.

151 Anonyme, Appendice à l'ordre du jour de la réunion du comité exécutif de la FIFA du 14 mars 1931, n.d. FIFA, comité exécutif (procès-verbaux 1927-1932).

152 Dietschy P., Clastres P., Sport, société et culture en France du XIXe siècle à nos jours, Paris, Hachette, 2006, p. 116.

153 Schricker I., Procès-verbal de la réunion du comité exécutif de la FIFA du 15 mai 1932, n.d. FIFA, comité exécutif (procès-verbaux 1927-1932).

154 Sur l'implantation du CIO à Lausanne, voir : Morath P., Le C.I.O. à Lausanne. 1939-1999, Yens-sur-Morges, Cabédita, 2000. Cette relation avec le CIO peut s'avérer importante car des divergences ont eu lieu entre les deux organisations durant les années 1920, en particulier autour de la question du professionnalisme. Sur ce point, voir : Carpentier F., « Le conflit entre le CIO et la FIFA dans l'entre-deux-guerres. Les Jeux olympiques contre la Coupe du monde de football ", Staps, vol. 68, n 2, 2005, pp. 25-39. 
De plus, d'un point de vue géographique, la Suisse se trouve au centre de l'Europe. Or, comme la majorité de ces associations proviennent d'Europe, il sera plus facile pour les dirigeants des associations nationales de se rendre à son siège, que ce soit pour les éventuelles sessions des différentes commissions de la FIFA ou lors de rencontres informelles avec le futur secrétaire général - ces discussions sur le siège se couplent aux discussions sur la nomination d'un secrétaire général permanent, sur lesquelles nous revenons ultérieurement. Enfin, la Suisse est considérée comme étant neutre sur la scène internationale, même si la neutralité suisse de cette période n'est pas dite "intégrale ", le pays participant par exemple aux travaux de la SDN ${ }^{155}$. Dès lors, en cas de conflit, le siège de la FIFA se trouverait en sûreté, ce qu'a démontré la Première Guerre mondiale, le pays n’ayant pas été envahi. Certes, un nouveau conflit n'est pas encore d'actualité, mais les tensions ponctuelles qui opposent plusieurs États européens et la montée des fascismes, invitent sans doute à prendre quelques précautions.

La faillite du secrétaire-trésorier Hirschman ${ }^{156}$ rend nécessaire la création d'un siège, sujet qui est discuté lors de l'assemblée générale de 1932. Au terme des débats, les représentants présents décident par quatorze voix contre onze que le siège de la FIFA se trouvera en Suisse ${ }^{157}$. Certes, le scrutin est serré mais la décision témoigne d'une volonté manifeste de plusieurs dirigeants de placer le siège de la Fédération dans un endroit sûr et éloigné du pouvoir présidentiel (ce qui permettra au secrétaire général de disposer d'une certaine indépendance pour réaliser son travail). Quelques semaines plus tard, le comité exécutif opte pour la ville de Zurich ${ }^{158}$, où un bâtiment est loué à la Bahnofstrasse. L'emplacement au centre de la ville, à proximité de la gare, est idéal pour accueillir des visiteurs étrangers. Malgré cela, peu de réunions se déroulent à Zurich. En fait, jusqu'en 1939, la majorité des réunions se déroulent à Paris, soit dans la ville du président. La décision prise en 1932 par les congressistes va surtout s'avérer cruciale durant la Deuxième Guerre mondiale, car, nous le verrons, la place du siège à Zurich va permettre au secrétaire Schricker de disposer d'une certaine sécurité lui donnant la possibilité de continuer son travail.

155 Pour un exemple de négociation de cette neutralité dans l'arène internationale, voir : Vonèche Cardia I., Neutralité et engagement : les relations entre le Comité international de la Croix-Rouge (CICR) et le gouvernement suisse, 1938-1945, Lausanne, Société d'histoire de la Suisse romande, 2012.

156 Infra 1.2.4.

157 Schricker I., Procès-verbal de l'assemblée générale de la FIFA des 13-14 mai 1932, n.d. FIFA, XX-XXIV congrès ordinaires (1931-1938, rapport d'activité).

158 Schricker I., Procès-verbal de la réunion du comité exécutif de la FIFA du 15 mai 1932, n.d. FIFA, classeur : comité exécutif (procès-verbaux 1927-1832). 
Au début des années 1930, les dirigeants du comité exécutif de la FIFA envisagent également une autre stratégie devant permettre de garantir l'autonomie, à savoir d'inscrire cette neutralité de la FIFA dans le droit international. À ce titre, ils engagent des discussions avec la SDN. Il faut tout d'abord souligner que l'organisme basé à Genève n'est pas totalement étranger au domaine sportif, comme le montrent des correspondances avec l'Union cycliste internationale ${ }^{159}$ ou l'intérêt pour la question des activités physiques dans le cadre de sa commission d'hygiène (qui traite de questions très diverses relatives à la santé des populations ou à la salubrité). Ainsi, pour la Fédération internationale de football, entreprendre des démarches auprès de la SDN s'apparente autant à contacter un interlocuteur qui pourrait être sensible à sa requête qu'à contrôler les éventuelles actions en matière footballistique qu'il pourrait développer. Car des rapprochements initiaux entre la SDN et le domaine du football se sont déjà réalisés à l'occasion de la Coupe des nations, organisée à Genève en juin 1930. En effet, les promoteurs de la compétition contactent la Société des Nations pour inviter son secrétaire général à faire partie du Comité d'honneur de la manifestation. De même, il semble qu'une visite du Palais des Nations ait été organisée pour les joueurs des équipes participantes.

Les premiers échanges entre la FIFA et la SDN datent de l'été 1931 et sont établis par le Tchèque Rudolf Pelikan. Ceux-ci ont avant tout un but informatif, car il s'agit pour la FIFA de savoir quelle est la teneur des discussions sportives des membres de la commission d'hygiène de la $\mathrm{SDN}^{160}$. Toutefois, si cette démarche est enregistrée par l'organisme basé à Genève, aucun lien concret n'est établi. Une année plus tard, la FIFA contacte à nouveau la SDN avec, cette fois, l'idée que cette dernière peut l'aider à consolider son autonomie sur la scène internationale en lui conférant un statut juridique particulier. Afin de traiter de cette question complexe, un avocat suisse du nom de Streuli est contacté. Parallèlement, un petit rapport est réalisé par le vice-président Seeldrayers, avocat de formation, et soumis à un juriste de la SDN du nom de Nisot. C'est l'Uruguayen Enrique Buero, vice-président de la FIFA et dont le frère, Juan-Antonio, y officie alors en qualité de conseiller juridique, qui se charge de transmettre le dossier. Le comité exécutif fait donc fonctionner

159 Par exemple, nous avons retrouvé dans ces archives des échanges entre la SDN et l'Union cycliste internationale. Archives de la Société des nations (SDN), 5A International Bureaux Général, 1928-1932, dossier (11713) : Union cycliste internationales (correspondances et documents divers).

160 Lettre de C. Hirschman à la Société des Nations, $1^{\text {er }}$ juin 1931. SDN, 8A Santé divers Healt, dossier (29252) : Éducation physique. Correspondance avec la Fédération Internationale de Football Association. 
ses réseaux afin de plaider sa cause auprès de la SDN. Quelques semaines plus tard, Nisot indique que la question est complexe et que seule la Croix-Rouge dispose en fait d'un tel statut sur la scène internationale ${ }^{161}$. Si ces démarches au sujet du statut juridique de la FIFA n'aboutissent pas, elles révèlent que les dirigeants de son comité exécutif recherchent différents moyens pour garantir l'autonomie de la Fédération sur la scène internationale.

Les actions de l'élite de la FIFA décrites dans les lignes précédentes doivent in fine permettre à l'organisation de réussir au mieux sa mission : développer, toujours et encore, les échanges footballistiques internationaux. Dans ce but, il est très important que l'entité dispose également d'une forte cohésion en interne. En ce sens, et sous la conduite de Jules Rimet, ses principaux dirigeants vont œuvrer à neutraliser au maximum les conflits au sein de la FIFA et développer une politique visant à créer du consensus.

\subsubsection{Prôner l'apolitisme et le consensus}

Garante de la gestion du football mondial, la Fédération internationale doit néanmoins faire face aux associations nationales, jalouses de leurs prérogatives sur leur territoire. Par ailleurs, en raison de la politisation croissante du football, la FIFA peut également être le théâtre de tensions entre des pays divisés sur la scène internationale. En conséquence, il est très important pour son élite dirigeante de trouver des moyens afin de maintenir la politique en dehors de la FIFA ${ }^{162}$. Dans son Histoire $d u$ football, Paul Dietschy s'est questionné sur l'influence de la politisation croissante du football durant l'entre-deux-guerres sur la FIFA. Selon lui, pendant cette période, la Fédération internationale entretient « un rapport ambivalent avec le monde politique. D'un côté, elle [copie] d'une certaine manière la Société des Nations, ses congrès annuels constituant le pendant sportif des rendez-vous de septembre au bord du lac Léman. De l'autre, elle se [proclame] apolitique tout en considérant que la géographique du football [doit] épouser celle des États ${ }^{163}$."

Nous savons depuis les travaux pionniers de Jacques Defrance sur la " politique de l'apolitisme " des dirigeants sportifs que l'apolitisme

161 Schricker I., Procès-verbal de la réunion du comité exécutif de la FIFA du 10 décembre 1932, n.d. FIFA, comité exécutif (procès-verbaux 1927-1932).

162 Sur ces stratégies dites de dépolitisation ou de refoulement du politique, voir le numéro spécial de la revue Critique internationale, "La (dé)politisation des organisations internationales ", coordonné par Franck Petiteville en 2017.

Dietschy P., Histoire du football, op. cit., B. 223. 
peut être considéré comme une stratégie développée par les acteurs du domaine afin de se préserver de l'ingérence des États ${ }^{164}$. Manuel Schotté a repris cette thèse et en a précisé les contours, car le propos de Defrance était d'ordre général et théorique. À partir d'un cas contemporain étudié empiriquement, celui des principaux dirigeants du football européen (dirigeants du comité exécutif de l'UEFA et présidents de grands clubs), Schotté relève que cette manière d'agir est une «façon de [faire] prévaloir [la] centralité dans la gestion des affaires sportives et de mettre à distance d'autres modes de régulation ${ }^{165}$. Nous souhaitons nous inspirer de cette analyse et postulons que l'apolitisme des dirigeants est avant tout une stratégie devant permettre d'assurer le développement des activités de la FIFA.

Tout d'abord, la posture apolitique est régulièrement présente dans le discours de l'élite dirigeante de la FIFA. Par exemple, en septembre 1932, lors d'une discussion au sein du comité exécutif sur le cas soviétique, Jules Rimet souligne que la FIFA «ne fait pas de politique " ${ }^{166}$. De même, dans le livre commémoratif de 1929, Ivo Schricker n’hésite pas à écrire un petit texte intitulé "Sport et politique " ${ }^{167}$ dans lequel il insiste sur l'importance des liens que le football crée entre les dirigeants, permettant ainsi de dépasser les antagonismes de la politique internationale. Il existe plusieurs autres exemples de ce type de discours, en particulier des publications parues dans le Bulletin de la FIFA. Cette posture apolitique implique pour les dirigeants du comité exécutif de la FIFA de ne pas s'y intéresser dans le cadre de leurs activités footballistiques. L'une des postures mises en œuvre par l'élite de la FIFA consiste donc à ne pas s'occuper des affaires internes à ses associations membres. Ce procédé est discuté dans le cadre de la réorganisation de la FIFA du début des années 1930. Un journaliste de L'Auto résume en affirmant, quelques jours avant le congrès de 1932, que le changement préconisé à ce sujet " tend à donner à la FIFA le caractère d'une confédération, alors que les textes actuels, trop strictement interprétés, pourraient lui faire jouer le rôle d'une superfédération ${ }^{168}$. Quelques jours plus tard, les congressistes suivent effectivement cette voie et décident à l'unanimité que la FIFA doit être avant tout une

164 Defrance J., "La politique de l'apolitisme. Sur l'autonomisation du champ sportif ", Politix, vol. 50, n 2,2000 , pp. 13-27.

165 Schotté M., "La structuration du football professionnel européen ", op. cit., p. 13.

166 Hirschman C.A.W., Procès-verbal de la réunion du comité exécutif de la FIFA du 26 septembre 1931, n.d. FIFA, comité exécutif (procès-verbaux 1927-1932).

167 Anonyme, Fédération internationale de football-association 1904-1929, op. cit., p. 55.

168 "Le $21^{\text {e }}$ congrès de la FIFA doit prendre, à Stockholm des décisions importantes ", L'Auto, 11 mai 1932. 
union d'associations «qui se gouverne elle-même sans interférence de la [FIFA] " ${ }^{169}$. C'est donc une politique non interventionniste qui est décidée par les congressistes. Cette disposition a l'avantage d'éluder, au sein de la FIFA, toutes les questions relatives à la possible ingérence des États dans les affaires des fédérations nationales. La non-interférence avec les affaires des fédérations nationales permet de limiter les tensions en interne, d'autant que la Fédération internationale est composée de pays entretenant parfois des relations tendues sur la scène internationale. Les dirigeants sportifs de ces pays pourraient dès lors être tentés d'utiliser l'arène footballistique internationale pour faire passer des messages d'ordre politique ${ }^{170}$.

Dans les années qui suivent le congrès de 1932, plusieurs décisions prises par le comité exécutif de la FIFA confirment cette posture de neutralité. En février 1934, l'Irlande fait par exemple part à l'élite de la Fédération internationale de ses grandes difficultés à organiser des rencontres contre les associations britanniques. En effet, le pays n'entretient aucune relation sportive avec ces dernières ${ }^{171}$, situation qui s'explique en raison des relations politiques tendues entre les deux camps depuis que l'Irlande s'est détachée de la Grande-Bretagne en 1922. L'association irlandaise souhaiterait que l'assemblée générale autorise "dorénavant [la FIFA] à arranger deux matchs inter-nations par année pour l'État Libre d'Irlande " ${ }^{172}$. Il s'agit donc d'un appel envers la FIFA pour qu'elle endosse un rôle d'arbitre dans cette situation. Malgré une sympathie affichée pour la requête irlandaise, le comité exécutif refuse de présenter officiellement cette demande aux associations membres de la FIFA et se contente de signifier à l'association irlandaise qu'il va essayer d'encourager, de manière informelle, ce type de rencontres. Le cas des deux fédérations espagnoles durant la Guerre d'Espagne constitue un autre exemple, beaucoup plus significatif en raison de la situation politique du pays concerné, du comportement apolitique de la FIFA. À partir du déclenchement de la Guerre civile en 1936, l'Espagne connaît une querelle footballistique qui voit deux fédérations concurrentes s'affronter. La première poursuit le travail de l'organisme qui existait sous

169 Schricker I., Procès-verbal de l'assemblée générale de la FIFA des 13 et 14 mai 1932, n.d. FIFA, XX-XXIV congrès ordinaires (1931-1938, rapport d'activité).

170 Laqua D., "Internationalisme ou affirmation de la nation ? La coopération intellectuelle transnationale dans l'entre-deux-guerres, Critique internationale, vol. 52, $\mathrm{n}^{\circ} 3,2011$, pp. 51-67.

171 Sur les relations sportives entre l'Irlande et la Grande-Bretagne, voir : Liston K., Maguire J., "Sport, Empire, and diplomacy: "Irleand" at the 1930 British empire games ", Diplomacy \& Statecraft, vol. 27, n² 2, 2016, pp. 314-339.

172 Schricker I., Procès-verbal de la réunion du comité exécutif de la FIFA des 24-25 février 1934, n.d. FIFA, comité exécutif (procès-verbaux 1934). 
la République alors que la seconde se place sous la coupe des nationalistes du général Franco. Pendant plusieurs mois, chaque entité écrit tour à tour à la FIFA pour gagner la légitimité d'y représenter le pays. Dans un article récemment paru qui retrace brièvement l'histoire de la sélection espagnole, Juan Antonio Simón indique que «le camp des Nationaux [parvient] à être reconnu en 1937 par la FIFA comme son représentant en Espagne ${ }^{173}$. Cet auteur base son argumentaire sur un article du journal $A B C$ paru le 13 novembre 1937. Ce journal d'obédience monarchiste, donc proche du camp nationaliste, détourne en fait le propos en faveur des partisans de Franco. Au vu des archives de la FIFA, cette affirmation nous paraît erronée. Au contraire, la documentation indique que les dirigeants de la FIFA ne prennent pas position, considérant qu'il s'agit d'une "affaire domestique ${ }^{174}$. En fait, ils choisissent de ne pas choisir pour un camp ou l'autre et d'attendre que la situation se règle. Dès 1939 , la collaboration avec la Fédération espagnole, désormais sous le joug du régime franquiste, est reprise comme si rien ne s'était passé. Dernier exemple qui témoigne de cette politique de non-intervention, le simple enregistrement administratif effectué lors de l'incorporation de la Fédération autrichienne dans celle de l'Allemagne, à la suite de l'incorporation du pays dans le Troisième Reich (Anschluss). Ce changement s'opère suite à une lettre reçue par Schricker de la part de l'organisme autrichien expliquant la nouvelle situation politique du pays ${ }^{175}$. Constatons que ni le comité exécutif ni l'assemblée générale ne statuent sur cette question qui implique pourtant la disparition d'une des plus importantes associations membres de la FIFA. Pourtant, des protestations ont lieu dans le monde footballistique. Par exemple, en signe de contestation, le célèbre attaquant autrichien Matthias Sindelaar réalise une courbette face aux représentants nazis présents dans la tribune pour célébrer un but lors de l'ultime match joué par l'équipe d'Autriche (disputé contre l'Allemagne $)^{176}$. Mais, dans les arcanes de la FIFA, la nouvelle donne semble - officiellement du moins - ne poser aucun problème. Paul Dietschy corrobore cette vision des faits puisqu'il note à ce sujet que

173 Simón, J.A., « De la furia espagnole au tiki-taka. Football et construction identitaire en Espagne (1920-2015) ", dans Archambault F., Beaud S., Gasparini W., Le football des nations, op. cit., p. 79.

174 Anonyme, Procès-verbal de la réunion du comité exécutif de la FIFA des 6-7 novembre 1937, n.d. FIFA, comité exécutif (procès-verbaux 1937).

175 Lettre de la Fédération autrichienne de football au secrétaire général de la FIFA, 28 mars 1938. FIFA, correspondance avec les associations nationales : Autriche (1935-1963), dossier : 1935-1950.

176 Marschick M, "Wiener Melange: Fussball in Österreich 1918-1939 », dans Koller C., Brändle F., Fussball zwischen den Kriegen pop citp pit, Ponnar 262 
"l'Anschluss footballistique fut enregistré par une lettre-circulaire " ${ }^{177}$. Ces exemples montrent que le comité exécutif de la FIFA prend le parti de ne pas intervenir dans les affaires internes de leurs associations membres. Et lorsque le contexte est véritablement tendu, nous pouvons considérer que l'élite de la FIFA ferme volontairement les yeux face à certaines situations, alors même que leurs correspondances personnelles montrent que ses membres sont bien informés et qu'ils s'intéressent de près à la politique internationale.

Cette politique sur la scène extérieure s'accompagne d'une politique interne visant à favoriser le consensus. À ce titre, les dirigeants de la Fédération internationale développent, depuis sa création, un corpus réglementaire conséquent - en 1929, il comporte déjà cinquante-deux pages. Le document est scindé en deux parties. La première, intitulée "Statuts ", est composée de vingt-trois articles qui traitent de manière générale de l'activité de l'organisation. La seconde, nommée "Règlement ", est formée de cinquante-deux articles qui précisent plusieurs points des "statuts ». Cette réglementation n'est pas statique mais, au contraire, sujette à de constantes modifications qui sont discutées lors des séances du comité exécutif et votées pendant les congrès. S'ajoutent à ce corpus réglementaire des stratégies plus informelles qui doivent renforcer l'unité au sein de la FIFA. Dans un texte portant sur la négociation des conflits au sein d'une organisation internationale, l'anthropologue Birgit Müller étudie la capacité de ces entités " à gommer les contradictions et à normaliser le comportement des États et des individus ${ }^{178}$. Cette remarque nous inspire et il s'agit de montrer qu'une sorte de " coutume " - rien n'étant formellement écrit dans les statuts de la FIFA à ce sujet - existe au sein de la FIFA. Par exemple, les débats durant les congrès montrent que des regroupements régionaux existent au sein de la Fédération internationale. Lors de l'assemblée de 1936, le Roumain Luchidy se permet de souligner que " les associations du Sud-Est de l'Europe n'ont jamais eu un représentant au comité exécutif ${ }^{179}$, raison pour laquelle il propose la candidature du Yougoslave Andrejevic. Bien que non retenue, cette proposition montre que des discussions préliminaires ont eu lieu entre les pays de cette région, probablement entre des dirigeants de la

177 Dietschy P., Histoire du football, op. cit., p. 223.

178 Müller B., "Comment rendre le monde gouvernable sans le gouverner : les organisations internationales analysées par les anthropologues ", Critique internationale, vol. 54, $\mathrm{n}^{\circ} 1$, 2011, p. 14.

179 Schricker I., Procès-verbal de l'assemblée générale de la FIFA du 3 juin 1938, n.d. FIFA, XX-XXIV congrès ordinaires (1931-1938, rapport d'activitéé) 
Bulgarie, de la Grèce, de la Roumanie et de la Yougoslavie. De même, en mars 1938, le secrétaire général reçoit, en vue du prochain congrès de la FIFA, un courrier signé des présidents des associations du Nord, respectivement le Danemark, la Finlande, la Norvège et la Suède, sur la question des remplacements des joueurs blessés ${ }^{180}$. Les statuts de la FIFA interdisent formellement l'existence des blocs en son sein. En effet, l'article 14 de l'édition de 1929 indique que "sans autorisation spéciale de la Fédération, les Associations nationales affiliées ne sont pas autorisées à former des groupes entre elles ${ }^{181}$. Cependant, le comité exécutif de la FIFA doit tenir compte de l'existence d'affinités particulières entre les pays. Ainsi, des accords tacites se créent entre les dirigeants du comité exécutif, voire avec une partie des représentants des associations nationales, souvent avant les congrès ou alors pendant des réunions informelles ayant lieu en marge des séances. Le but est de réserver des places aux différents blocs dans les commissions permanentes de la FIFA. En conséquence, un jeu subtil se met en place qui consiste à faire coexister les différentes forces au sein de la FIFA ${ }^{182}$, tout en évitant de conférer trop de place à l'une d'elles. Par exemple, en 1934, lors du remplacement de l'Uruguayen Buero dans le comité exécutif - Buero se retire car il retourne en Amérique du Sud pour des raisons professionnelles -, Giovanni Mauro signale à ses collègues que «lui et ses amis [souhaitent] proposer le Dr. Eberstaller ${ }^{183}$. Toutefois, force est de constater que sa requête renforcerait le pouvoir du bloc de l'Europe centrale puisqu'il s'agirait de son quatrième représentant au sein de l'élite de la FIFA, Eberstaller étant autrichien. C'est sans doute pourquoi il souhaite sonder le terrain et demande l'avis de ses collègues, et en particulier celui du président Rimet. En fait, ses collègues du comité exécutif ne sont pas favorables à cette idée et souhaitent plutôt que la fonction soit à nouveau occupée par un dirigeant sud-américain. Dès lors, même si la candidature d'Eberstaller est maintenue devant l'assemblée générale, il n'est pas élu, obtenant d'ailleurs le plus faible résultat des

180 Lettre des présidents des associations du Danemark, de la Finlande, de la Norvège et de la Suède à I. Schricker, 16 mars 1938. FIFA, correspondance avec les associations nationales : Danemark (1932-1974), dossier : 1935-1950.

181 Anonyme, Statuts de la FIFA [édition de 1929], art. 14. [des règlements]. FIFA, statuts, 1904-1981.

182 Il est possible de repérer trois blocs en Europe : l'Europe centrale (ou Europe danubienne), les pays du Nord et les pays des Balkans, qui s'y ajoutent à la fin des années 1930. À noter également que les associations britanniques forment un groupe en dehors de la FIFA.

183 Schricker I., Procès-verbal de la réunion du comité exécutif de la FIFA du 23 mai 1934, n.d. FIFA, comité exécutif (procès-verbaux 1934) 
suffrages ${ }^{184}$. Le poste échoit finalement à l'Espagnol Garcia Duran. Nous pouvons penser que, dans l'esprit des congressistes présents, ce dirigeant a comme avantage d'être celui qui représente des pays plus latins et qui pourrait donc faire office de porte-parole des Sud-Américains.

Enfin, dernier volet de la volonté de neutraliser les conflits au sein de la FIFA, le traitement de sujets délicats. Dans le cas de la réorganisation de 1931-1932 dont nous avons déjà parlé, les discussions ont lieu au sein d'une commission ad hoc représentant les différentes forces au sein de la FIFA. Ce procédé a comme avantage d'éviter de trop longues discussions, et un possible conflit, durant l'assemblée générale. De même, il est intéressant de s'arrêter brièvement sur l'engagement d'un secrétaire général au début des années 1930 . Cette décision fait suite aux souhaits de réorganisation portés par Mauro et Meisl dont un des points était de créer un secrétariat ${ }^{185}$ et devient effective au moment de la démission de Carl Hirschman qui intervient en automne 1931. Dans un premier temps, l'Allemand Ivo Schricker, vice-président depuis 1927, fait office de secrétaire ad interim. Cependant, en mai 1932, Schricker est finalement choisi comme secrétaire général de la FIFA $^{186}$, et ce au détriment de la centaine de personnes ayant postulé. Le profil de Schricker correspond parfaitement au poste tel qu'il est imaginé par Rimet ou Seeldrayers. Premièrement, c'est un diplomate qui travaillera en étroite collaboration avec le président. Au contraire, Meisl - également candidat déclaré au poste - est considéré comme un acteur plutôt dirigiste et qui souhaite avant tout appliquer ses idées. Dans ses mémoires, le dirigeant anglais Stanley Rous - qui deviendra deux ans plus tard secrétaire de la Fédération anglaise - le surnomme le "dictateur du football autrichien ${ }^{187}$. Meisl peut donc être perçu comme une menace pour la stabilité de l'organisation. Deuxièmement, Ivo Schricker parle et écrit dans plusieurs langues (allemand, anglais, français et, dans une moindre mesure, espagnol) et en ce sens répond aux besoins de la Fédération internationale. Troisièmement, il connaît extrêmement bien l'organisation du jeu tant sur le plan national (il a été secrétaire de la Fédération d'Allemagne du Sud) qu'international et

184 Schricker I., Procès-verbal de l'assemblée générale de la FIFA des 24 et 25 mai 1934, n.d. FIFA, XX-XXIV congrès ordinaires (1931-1938, rapport d'activité).

185 Schricker I., "Bericht über die Anträge auf Reorganisation der FIFA », n.d. FIFA, comité exécutif (procès-verbaux 1927-1932).

186 Schricker I., Procès-verbal de la réunion du comité exécutif de la FIFA du 15 mai 1932 ", n.d. FIFA, comité exécutif (procès-verbaux 1927-1932).

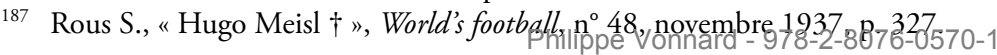


possède assurément les compétences pour mener le travail administratif de la FIFA. Quatrièmement, vice-président de la FIFA depuis 1927, il est déjà intégré dans le comité exécutif et fait donc partie de la "famille ", ce qui facilitera son intégration.

La gestion de la nomination du nouveau secrétaire général de la FIFA révèle différents aspects de la gouvernance qui est en train de se mettre en place à la tête de la FIFA. Tout d'abord, comme dans le cas de la réorganisation, les dirigeants tentent de limiter les conflits, agissant avec tact et discrétion. Quelques jours avant le congrès de 1932, durant lequel Schricker va être confirmé dans ses fonctions, un journaliste de L'Auto fait remarquer que si l'Allemand est pressenti pour le poste, " il serait prématuré d'indiquer un favori, car une discrétion diplomatique règne à ce sujet dans les milieux internationaux ${ }^{188}$. De plus, Schricker illustre le profil type du secrétaire qui va désormais agir dans les arcanes de la FIFA. Proche des dirigeants influents, mais sachant rester à sa place, le secrétaire est l'homme à tout faire, mais aussi l'homme de confiance du président. Son dynamisme va permettre à la FIFA de connaître une phase de développement dans les années à venir mais aussi de faire face à un conflit qui couve depuis le début des années 1930 entre la Fédération internationale et la Confédération sud-américaine de football.

\subsection{Quelle place pour « l'autre continent du football »?}

Comme beaucoup d'autres organisations estampillées « internationales " de l'époque ${ }^{189}$, la FIFA est gouvernée majoritairement par des Européens, qui y mènent une politique européocentrée, et son véritable terrain d'action est l'Europe. Or, depuis les années 1910, plusieurs pays extraeuropéens font leur entrée au sein de l'organisation et, en premier lieu, les associations nationales sud-américaines.

Fabien Archambault a eu raison de nommer l'Amérique du Sud « le continent du football ${ }^{190}$ car le ballon rond y connaît un développement

188 "Le $21^{\text {e }}$ congrès de la FIFA doit prendre à Stockholm des décisions importantes ", L'Auto, 11 mai 1932.

189 Laborie L., "De quoi l'universel est-il fait ? L'Europe, les empires et les premières organisations internationales ", Les Cahiers Irice, vol. 9, n 1, 2012, pp. 11-22.

190 Archambault F., "Le continent du football ", Cahiers des Amériques latines, vol. 74, 2014, pp. 15-35. 
constant, et ce dès la fin du XIX siècle $^{191}$. Par ailleurs, depuis 1915, un organisme continental y existe : la Confédération sud-américaine de football. Au début des années 1930, celle-ci regroupe toutes les associations nationales du continent (excepté la Colombie et le Venezuela) et paraît se profiler comme le garant du football sud-américain. Elle semble capable de fédérer une voix sud-américaine au sein de la FIFA qui a pour but de réclamer davantage de place dans les organes de la Fédération internationale. Avant d'expliciter ces requêtes et dans le but de les comprendre, il est nécessaire de décrire l'européocentrisme qui règne au sein de la FIFA.

\subsubsection{L'Europe comme épicentre}

Les revendications sud-américaines reposent sur le fait que les dirigeants à la tête de la FIFA mènent une politique européocentrée. En 1931, la FIFA est officiellement composée de quarante-six membres, dont vingthuit pays européens ${ }^{192}$. Si $40 \%$ des associations ne proviennent pas du Vieux Continent, durant les années 1930, toutes les réunions du comité exécutif - au nombre de quarante-deux - et les congrès annuels - il y en a treize $^{193}$ - sont organisés en Europe. Ces chiffres témoignent de l'emprise des Européens sur la gestion des affaires de la FIFA. Le tableau ci-dessous, qui aborde la participation lors des congrès de la FIFA de 1930 à 1938, confirme cette situation.

Tableau 5. Répartition continentale lors des congrès de la FIFA entre 1930 et $1938^{194}$

\begin{tabular}{|l|l|c|c|l|c|l|l|}
\hline Années & Lieu & Europe & $\begin{array}{l}\text { Amérique } \\
\text { du Sud }\end{array}$ & $\begin{array}{l}\text { Amérique } \\
\text { centrale/ } \\
\text { Amérique } \\
\text { du Nord }\end{array}$ & Afrique & $\begin{array}{l}\text { Asie/ } \\
\text { Océanie }\end{array}$ & $\begin{array}{l}\text { Total d'as- } \\
\text { sociations } \\
\text { nationales } \\
\text { présentes }\end{array}$ \\
\hline 1930 & Budapest & 21 & 5 & 1 & 0 & 0 & 27 \\
\hline 1931 & Berlin & 21 & 3 & 1 & 0 & 0 & 25 \\
\hline
\end{tabular}

191 Pour une synthèse sur le développement du football en Amérique du Sud, voir : Mason T., Passion of the People? Football in South America, London, Verso, 1995.

192 Hirschman C.A.W., Handbook 1931, Amsterdam, J.H. de Bussy, 1931, pp. 11-16.

193 Schricker I., Handbook 1950, Zürich, Buchdruckerei Lienberger, 1950, pp. 5-7.

194 Cette répartition est effectuée au regard de la continentalisation qui se produira au

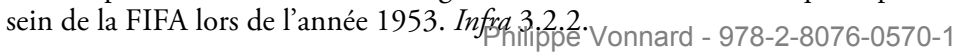




\begin{tabular}{|l|l|c|c|c|c|l|l|}
\hline Années & Lieu & Europe & $\begin{array}{l}\text { Amérique } \\
\text { du Sud }\end{array}$ & $\begin{array}{l}\text { Amérique } \\
\text { centrale/ } \\
\text { Amérique } \\
\text { du Nord }\end{array}$ & Afrique & $\begin{array}{l}\text { Asie/ } \\
\text { Océanie }\end{array}$ & $\begin{array}{l}\text { Total d'as- } \\
\text { sociations } \\
\text { nationales } \\
\text { présentes }\end{array}$ \\
\hline 1932 & Stockholm & 26 & 2 & 0 & 0 & 1 & 29 \\
\hline $1934^{*}$ & Rome & 22 & 1 & 2 & 1 & 1 & 27 \\
\hline 1936 & Berlin & 26 & 5 & 1 & 1 & 4 & 37 \\
\hline 1938 & Paris & 18 & 7 & 3 & 0 & 2 & 30 \\
\hline
\end{tabular}

Légende : * à partir de 1934, les congrès de la FIFA s'organisent tous les deux ans.

Durant ces huit années, les associations du Vieux Continent composent entre $60 \%$ (congrès de 1938) et $90 \%$ (congrès de 1932) des associations présentes. Hormis les Européens, les autres associations participant aux réunions proviennent surtout d'Amérique du Sud. La faible présence des régions asiatiques et africaines s'explique en raison du fait qu' elles restent largement sous domination coloniale ${ }^{195}$. Le congrès de 1938 montre malgré tout que la FIFA se mondialise progressivement puisque quatre associations asiatiques font le déplacement jusqu'à Paris. Un autre tableau peut être établi avec le nombre de dirigeants présents à ces assemblées, qui confirme la prédominance des Européens dans la FIFA.

Tableau 6. Pays et dirigeants présents durant les congrès de la FIFA de 1930 à 1936

\begin{tabular}{|l|l|l|l|l|l|}
\hline $\begin{array}{l}\text { Lieu du } \\
\text { congrès }\end{array}$ & Années & $\begin{array}{l}\text { Événements } \\
\text { en parallèle }\end{array}$ & $\begin{array}{l}\text { Nb de } \\
\text { dirigeants } \\
\text { présents* }\end{array}$ & $\begin{array}{l}\text { Nb de } \\
\text { dirigeants } \\
\text { européens } \\
\text { présents* }\end{array}$ & $\begin{array}{l}\text { Pourcentage } \\
\text { d'Européens au } \\
\text { congrès }\end{array}$ \\
\hline Budapest & 1930 & Non & 58 & 51 & $88 \%$ \\
\hline Berlin & 1931 & Non & 57 & 52 & $91 \%$ \\
\hline Stockholm & 1932 & Non & 67 & 62 & $93 \%$ \\
\hline Rome & $1934^{* *}$ & $\begin{array}{l}\text { Coupe du } \\
\text { monde }\end{array}$ & 62 & 54 & $87 \%$ \\
\hline
\end{tabular}

195 Pour un état de la situation coloniale à cette période, voir : Singaravélou P. (dir.), Les empires coloniaux, $X I X^{e}-X X^{e}$ siècle, Paris, Éditions Points 20133 


\begin{tabular}{|l|l|l|l|l|l|}
\hline $\begin{array}{l}\text { Lieu du } \\
\text { congrès }\end{array}$ & Années & $\begin{array}{l}\text { Événements } \\
\text { en parallèle }\end{array}$ & $\begin{array}{l}\text { Nb de } \\
\text { dirigeants } \\
\text { présents* }\end{array}$ & $\begin{array}{l}\text { Nb de } \\
\text { dirigeants } \\
\text { européens } \\
\text { présents* }\end{array}$ & $\begin{array}{l}\text { Pourcentage } \\
\text { d'Européens au } \\
\text { congrès }\end{array}$ \\
\hline Berlin & 1936 & $\begin{array}{l}\text { Jeux } \\
\text { olympiques }\end{array}$ & 97 & 79 & $81 \%$ \\
\hline Paris & 1938 & $\begin{array}{l}\text { Coupe du } \\
\text { monde }\end{array}$ & 78 & 59 & $76 \%$ \\
\hline
\end{tabular}

Légende : * : en tenant compte des membres du comité exécutif. ${ }^{* *}$ : à partir de 1934, les congrès de la FIFA s'organisent tous les deux ans.

À la vue de ce tableau, nous voyons clairement que la majorité des dirigeants (qu'ils représentent leur association nationale ou qu'ils fassent partie de l'élite de la FIFA) proviennent d'Europe. Ainsi, lors du congrès de Paris de 1938, ils constituent $75 \%$ de l'assemblée. Pour rappel, à cette période, chaque association a le droit d'envoyer trois de ses dirigeants à l'assemblée générale. Toutefois, ce sont uniquement les Européens qui utilisent ce droit, ce qui s'explique aisément en raison de l'organisation de la manifestation dans une ville de leur continent. A contrario, les associations extra-européennes ne sont souvent représentées que par un, parfois deux dirigeants. Cette situation n'est pas sans incidence sur les discussions car elle favorise indéniablement la mainmise du Vieux Continent sur l'organisation du football mondial. Il est en effet plus facile pour les dirigeants européens d'être actifs et attentifs - ils peuvent se relayer dans les discussions, voire se répartir les sujets ${ }^{196}$ - durant toute la durée des débats.

Le choix des lieux de congrès témoigne bien de ce que nous pouvons qualifier d'une hégémonie européenne sur l'organisation. En effet, les réunions sont toujours organisées sur le Vieux Continent, et ce en dépit de propositions visant à les délocaliser en dehors d'Europe. En 1930, un délégué égyptien, Youssof Mohamed, propose par exemple de tenir le congrès dans son pays, plus précisément au Caire ${ }^{197}$. Depuis 1924, il s'agit de la troisième candidature égyptienne soumise en vue de l'organisation de l'assemblée générale. Pour la majorité des dirigeants européens présents, il est cependant impensable de choisir cette option. Alors que le délégué

196 Déduction réalisée à partir des procès-verbaux du comité exécutif de l'Union belge de football et de la Fédération française.

197 Hirschman C.A.W., Procès-verbal de l'assemblée générale de la FIFA des 6 et 7 juin 1930, n.d. FIFA, XX-XXIV congrès ordinaires (1931-1938 rapport d'activité). 
autrichien Eberstaller se montre farouchement opposé à la possibilité d'organiser le congrès au Caire et que le Polonais Kuchar propose qu'il soit prochainement tenu à Varsovie, l'Allemand Linnemann se permet de rappeler quant à lui qu'il attend depuis trois ans que la ville de Berlin soit choisie par la FIFA. Finalement, par 19 voix contre 4 pour le Caire, Berlin est désignée pour accueillir l'assemblée générale de 1931. Constatons que les trois années d'attente de l'Allemagne ont pesé nettement plus lourd dans la balance que les trois propositions en faveur du Caire déposées depuis sept ans. Si l'argument qui consiste à évoquer le coût du transport pour ne pas se rendre en Égypte est sans doute recevable, il nous semble toutefois que cette décision révèle également les rapports de force qui existent au sein de la FIFA. En effet, l'association égyptienne n'y a que peu d'influence, ce qui s'explique avant tout par le manque de structuration de sa fédération et le faible niveau de jeu de son équipe nationale. Malgré d'autres tentatives, notamment en 1931 lorsque des villes comme New York et Le Caire sont à nouveau proposées comme lieu de réception du congrès ${ }^{198}$, aucune assemblée générale de la Fédération internationale ne s'organise en dehors de l'Europe durant les années 1930.

Cette hégémonie européenne se remarque dans la composition du comité exécutif de la FIFA car, jusqu'en 1938, ses membres proviennent uniquement d'Europe, à l'unique exception de l'Uruguayen Buero qui y siège entre 1928 et 1934 . Le comité exécutif conduit la politique de la FIFA et règle les questions ou litiges que lui soumettent les associations membres. Disposer d'un représentant dans l'élite de la FIFA est donc crucial pour un groupe d'associations qui souhaiterait y faire passer ses idées en matière d'organisation du jeu ou défendre sa position sur certaines thématiques. La lecture des procès-verbaux des séances nous montre que les problématiques abordées par le comité exécutif durant les années 1930 concernent principalement le football européen. Cette prédominance européenne sur la gouvernance de l'organisation est encore amplifiée par la composition dans les commissions permanentes de la FIFA. Comme les mandats dans les commissions ont une durée indéterminée, leur composition change peu. Ainsi, de 1930 à 1938, la commission des Lois du jeu et des arbitres, qui s'occupe de l'uniformisation des règles du jeu et met à jour une liste d'arbitres ayant l'aptitude d'officier lors des rencontres internationales, est composée de l'Allemand Peco Bauwens qui la préside, du Français Henri Delaunay qui en est le secrétaire, du Belge Albert Verdyck et de l'Italien Giovanni Mauro. La commission de l'amateurisme - renommée en 1935 la commission pour l'amateurisme

198 Ibid. 
et les transferts ${ }^{199}$ - est présidée par le Tchèque Rudolf Pelikan et sa composition est complétée par le Néerlandais Karel Lotsy, qui y officie comme secrétaire, par l'Autrichien Hugo Meisl et le Hongrois Mor Fischer. Enfin, aucune trace d'un non-Européen dans la Commission de la Coupe du monde, dans les commissions ad hoc (comme la commission qui s'occupe de la réorganisation de la FIFA en 1931) ou encore chez les vérificateurs de compte et du procès-verbal de l'assemblée générale qui sont élus durant celle-ci. Soulignons donc que toutes les places dans les organes de la FIFA sont occupées par des Européens.

Enfin, l'emprise du Vieux Continent sur la FIFA apparaît également dans les publications officielles de la FIFA. Dans le livre commémoratif des vingt-cinq ans de la FIFA paru en 1929, plusieurs acteurs ayant officié ou qui officient encore au sein la Fédération internationale signent une petite tribune (entre une et trois pages). Or aucune ligne n'est écrite par un dirigeant d'association extra-européenne. Seules les photos du viceprésident, Enrique Buero, et du conseiller ${ }^{200}$ pour l'Amérique du Sud, César Seoane, sont présentées sur une page ne comportant pas de texte hormis l'indication de leur fonction ${ }^{201}$.

De même, dans le Bulletin officiel d'information, puis dans World's Football, la part belle est faite au continent européen puisque le football en dehors d'Europe est certes traité, mais avec parcimonie et souvent sous des titres génériques comme le football " en Amérique du Sud " ce qui contraste avec les articles plus précis qui traitent des régions - voire de l'activité des associations nationales européennes - en Europe.

Durant les années 1930, la FIFA est une organisation avant tout européenne. Les informations données ci-dessus confirment dès lors les

199 Qui est " chargée d'étudier les questions de l'amateurisme, de l'examen des principes en vigueur dans les différentes Associations nationales, d'établir des rapports et de formuler des propositions à soumettre au congrès ". Anonyme, Statuts de la FIFA [édition de 1929], art. 49 [des règlements]. FIFA, statuts, 1904-1981.

200 Ce poste est créé au milieu des années 1920 afin d'établir des liens plus étroits entre le comité exécutif et les pays extra-européens. Ainsi, chaque continent, hormis l'Europe, dispose d'un conseiller. Si cette décision a pour but d'entretenir un dialogue plus étroit entre le comité exécutif de la FIFA et ces régions éloignées - un comité général, composé de représentants du comité exécutif et des conseillers, se réunit une à deux fois par année -, le système ne fonctionne pas très bien. En effet, le conseiller est parfois trop occupé par ses affaires professionnelles pour correctement gérer les affaires footballistiques de la région ou alors il n'est pas forcément bien intégré dans le réseau des dirigeants du football du continent qu'il est censé représenter (perçu comme trop proche du comité exécutif de la FIFA).

201 Anonyme, Fédération internationale de fogthall-association 1904-1929 gpo citos. p. 50. 
propos de Paul Dietschy qui, en 2015, soulignait : "Bien que la FIFA [donne] l'apparence d'opter pour un cadre de référence mondial, elle [est] menée en premier lieu par les Européens ${ }^{202}$. " Toutefois, durant cette décennie, l'hégémonie de l'Europe au sein de la FIFA commence à être contestée par les associations sud-américaines.

\subsubsection{Une première contestation de l'hégémonie européenne}

Alors que la Coupe du monde de 1930 est un succès pour le pays organisateur, l'Uruguay, les dirigeants des associations sud-américaines sont déçus du manque d'enthousiasme de leurs homologues européennes à y participer ${ }^{203}$. Quelques mois avant l'épreuve, un article du journal français Football soulignait les conséquences qu'impliquerait une nonparticipation massive des Européens à la compétition. Le journal notait que si un tel cas se présentait, il y aurait le risque de voir émerger un " "bloc sud-américain” dont les équipes se [refuseraient de] jouer contre les clubs des nations qui se sont désintéressées de la première épreuve mondiale de football ${ }^{204}$. Durant le tournoi, les associations sud-américaines présentes décident de créer davantage d'unité entre elles afin d'être mieux représentées au sein de la FIFA. Dans ce but, c'est la Confédération sudaméricaine qui se chargera de communiquer sur ce point avec le comité exécutif de la FIFA ${ }^{205}$.

Nous n'avons pas retrouvé les statuts de cet organisme pour la période étudiée. Cependant, nous pouvons nous baser sur ceux de 1939 car il ne semble pas y avoir de grands bouleversements dans la structure de l'organisation durant les années 1930 . Entité modeste ${ }^{206}$, la Confédération sud-américaine se donne deux objectifs principaux. Premièrement, elle a pour but d'unir les associations nationales sud-américaines, union qu'une possible opposition face aux Européens pourrait renforcer. Deuxièmement, de contrôler le football sur le continent sud-américain - ce dont témoigne

202 Dietschy P., "Did a "Europe of football” exist during the 1930's? ", op. cit., p. 13.

203 Supra 1.1.2.

204 "Les Sud-Américains se fâchent.... », Football, 20 mars 1930.

205 Anonyme, Confederación sudamericana de fútbol. Estatutos [édition de 1939], art. 48. FIFA, CSF statutes.

206 L'entité est dirigée par un comité exécutif composé du président, d'un vice-président et du secrétaire-trésorier. Celui-ci est désigné pour deux ans par l'assemblée générale, qui peut se réunir de manière ordinaire ou extraordinaire, si le sujet est urgent ou délicat, sans que des dates précises soient fixées. 
notamment l'organisation de la Copa America depuis 1916 - et, sous cet angle, se détacher de la tutelle de la FIFA lui permettrait de renforcer cet aspect.

Consciente du mécontentement des Sud-Américains, le comité exécutif de la FIFA tente de limiter l'impact négatif de la faible participation européenne à la première Coupe du monde. Il faut dire que le comité exécutif de la FIFA a tout intérêt à ménager les associations d'Amérique latine, en particulier parce que leur présence à la deuxième édition du tournoi mondial est " nécessaire pour démontrer le caractère universel et mondial de la FIFA et de sa grande compétition ${ }^{207}$. Mais, bien que le comité exécutif considère l'Amérique du Sud comme "la région la plus importante pour la FIFA [après l'Europe] », peu de gestes sont réalisés dans les faits en leur faveur. Lors de l'assemblée générale de la FIFA qui se déroule pendant la Coupe du monde de 1934, la discussion sur le siège occupé par l'Uruguayen Buero dans l'élite de la FIFA confirme une césure entre le comité exécutif et les associations sud-américaines. En effet, Buero est obligé de démissionner pour des raisons professionnelles ${ }^{208}$ et les congressistes se questionnent sur son remplacement. Des discussions ont préalablement lieu au sein du comité exécutif de la FIFA pour savoir s'il doit être remplacé par un de ses collègues sud-américains. Si cette idée semble préconisée a priori par ses membres, ceux-ci décident toutefois que deux points doivent être respectés par le futur représentant. Premièrement, ils considèrent que l'expérience d'un diplomate - pour rappel, Buero est ministre de l'Uruguay en Belgique - n'est plus souhaitable. Au contraire, il faudrait que le dirigeant dispose " de force et d'influence auprès des Associations [qu'il représente] ${ }^{209}$. Deuxièmement, il doit vivre en Europe. Ce souhait rappelle la vision européocentrée des dirigeants, car il indique que les futures réunions du comité exécutif s'organiseront uniquement sur le Vieux Continent. Mais il peut aussi s'agir d'un manque de réalisme de la part des dirigeants de la FIFA, car il semble peu crédible qu'un dirigeant influent du football sud-américain habite en Europe. En tous les cas, par cette décision, les membres du comité exécutif ne se montrent guère enclins à faire des concessions aux dirigeants sud-américains.

207 Schricker I., Procès-verbal de la réunion du comité exécutif de la FIFA des 24-25 février 1934, n.d. FIFA, comité exécutif (procès-verbaux 1934).

208 Schricker I., Procès-verbal de la réunion du comité exécutif de la FIFA du 7 octobre 1933, n.d. FIFA, comité exécutif (procès-verbaux 1933).

209 Schricker I., Procès-verbal de la réunion du comité exécutif de la FIFA du 23 mai 1934, n.d. FIFA, comité exécutif (procès-verbaux 1934). 
Lassemblée générale réunie à Rome décide finalement de nommer l'Espagnol Garcia Duran en remplacement de Buero ${ }^{210}$. Alors que l'Argentine et le Brésil sont les seuls pays d'Amérique du Sud à disputer la Coupe du monde de 1934, la décision prise dans la capitale italienne marque véritablement le début d'une discorde entre Sud-Américains et Européens. En effet, au même moment que le congrès de Rome, de l'autre côté de l'Atlantique, la Confédération sud-américaine organise un congrès extraordinaire durant lequel il s'agit notamment de traiter des rapports avec la FIFA. Pendant les discussions, des griefs sont adressés envers la Fédération internationale et l'idée d'une prise d'indépendance vis-à-vis de son autorité sur certains sujets est même évoquée. Par exemple, il s’agirait que la Confédération sud-américaine se charge elle-même de l'organisation des éliminatoires de la Coupe du monde. Par ses positions, les dirigeants présents n'hésitent donc pas à remettre en question la souveraineté de la FIFA. Il s'agit du début d'une fronde interne qui va prendre de l'ampleur dans les mois qui suivent. À noter que cette remise en question de l'hégémonie européenne correspond à un mouvement plus général de contestation au sein des organisations internationales dans lesquelles les Sud-Américains essaient de faire entendre leur voix - à l'OIT ${ }^{211}$ et à la Société des Nations ${ }^{212}$ entre autres exemples.

En novembre 1934, le conseiller pour l'Amérique du Sud auprès du comité exécutif, Bermudez, se fait le porte-parole des doléances émises lors du dernier congrès de la Confédération sud-américaine auprès du secrétariat de la FIFA. Il souligne que les associations sud-américaines regrettent le manque "de compréhension ou d'attention approfondie démontrée par la FIFA vis-à-vis du football panaméricain $»^{213}$. S'ajoute à cette critique un document intitulé "Question de la modification des Lois de la FIFA en ce qui concerne la représentation des groupements extra-européens ", qui doit ouvrir une discussion sur une meilleure

210 Schricker I., Procès-verbal de l'assemblée générale de la FIFA des 24-25 mai 1934, n.d. FIFA, XX-XXIV congrès ordinaires (1931-1938, rapport d'activité).

211 Stenger V., " "To Raise Awareness of Difficulties and to Assert their Opinion”. The International Labour Office and the Regionalization of International Cooperation in the 1930s ", dans McPherson A., Wehrli Y. (eds.), Beyond Geopolitics. New Histories of Latin America, Albuquerque, University of New Mexico Press, 2015, pp. 97-113.

212 Richard A.-I., "Competition and complementarity: civil society networks and the question of decentralizing the League of Nations ", Journal of Global History, vol. 7, $\mathrm{n}^{\circ} 2$ 2, 2012, pp. 233-256.

213 Anonyme, "Question d'un congrès et championnat pan-américain ", Annexe n II.5.B de la réunion du comité exécutif du 17 novembre 1934. FIFA, comité exécutif (procèsverbaux 1934). 
représentation des associations sud-américaines dans la Fédération internationale. Une transformation des statuts de la FIFA est préconisée, de sorte que son comité exécutif soit élu différemment. Il s'agirait de créer des groupes régionaux au sein de la FIFA, groupes qui disposeraient d'une " autonomie relative » et qui seraient " représentés dans la direction de la Fédération ${ }^{214}$. Le projet soumis par Bermudez est novateur puisqu' en invitant à la création d'organismes régionaux, il envisage une décentralisation de la Fédération mondiale.

Comment le comité exécutif de la FIFA réagit-il face à cette proposition pouvant être perçue comme une remise en question de la position hégémonique de la Fédération internationale sur le football mondial ? Tout d'abord, l'élite de la FIFA tente de minimiser l'impact de ces revendications en s'appuyant sur d'autres associations du continent américain. Ainsi, il est demandé au conseiller pour l'Amérique centrale, Campbell - dont les visions du football sont proches de celles défendues par l'élite de la FIFA - d'intervenir auprès des associations sud-américaines. Dans ce but, ce dernier va tenter de nouer des contacts entre les dirigeants sud-américains et ceux de l'Amérique centrale et du Nord. À cet effet, il propose de convoquer un congrès panaméricain en 1935 " pour discuter les intérêts mutuels des associations américaines et pour resserrer les liens entre ces associations et la FIFA ${ }^{215}$. Jouer sur l'échelle panaméricaine pourrait permettre de contrebalancer les velléités de la Confédération sud-américaine. De plus, une telle conférence correspond à l'air du temps car les échanges panaméricains se développent durant les années 1930, notamment sous l'influence de la politique de "bon voisinage " instaurée par le président américain Franklin Roosevelt. Ainsi, dans le domaine sportif, des Jeux panaméricains voient le jour en 1937 à Dallas ${ }^{216}$.

214 Anonyme, "Question de la modification des Lois de la FIFA en ce qui concerne la représentation des groupements extra-européens ", n.d. Annexe $n^{\circ}$ II. 4 b de la réunion du comité exécutif du 17 novembre 1934. FIFA, comité exécutif (procès-verbaux 1934).

215 Anonyme, Procès-verbal de la réunion du comité exécutif de la FIFA du 17 novembre 1934, n.d. FIFA, comité exécutif (procès-verbaux 1934).

216 Dyreson M., "The Original Pan-American Games? The 1937 Dallas Pan-American Olympics ", The International Journal of the History of Sport, vol. 33, ${ }^{\circ}$ 1-2, 2016, pp. 6-28. À noter que, dans un document datant de 1947 et qui retrace brièvement les étapes majeures de la constitution d'une confédération panaméricaine de football sur laquelle nous allons revenir plus loin -, son président, Luis Valenzuela, ne fait pas allusion à cette manifestation. Par contre, il souligne que des contacts ont eu lieu lors des Jeux d'Amérique centrale et des Caraïbes qui sont organisés depuis la seconde partie des années 1920. Des recherches sont donc à mener sur ce que signifie l'échelle panaméricaine en football à la fin des années 1930. 
Toutefois, le conseiller pour l'Amérique du Sud Bermudez ne se montre guère favorable à l'organisation de ce congrès car, selon lui, la réunion convoquerait trop de représentants, ce qui aurait comme conséquence de ne "pas [donner] de résultats pratiques ${ }^{217}$. Cet argument est sans doute techniquement recevable, mais les réserves apportées par ce dirigeant montrent peut-être également que les Sud-Américains préfèrent agir de leur côté : Campbell étant en lien étroit avec le comité exécutif de la FIFA, il pourrait court-circuiter l'idée de possibles réformes.

Suite à ce refus, le comité exécutif de la FIFA décide de ne pas répondre favorablement au projet présenté par Bermudez car il le juge dangereux pour l'autorité de la FIFA. En effet, comme le souligne Rodolphe Seeldrayers, une "fois réunies, ces associations, au premier conflit avec des fédérations européennes, feraient bloc et [les] menaceraient d'une scission ${ }^{218}$. Afin de disposer de davantage d'arguments sur la question, voire d'entamer éventuellement quelques réformes statutaires qui permettraient de répondre, en partie, aux souhaits des associations nationales sud-américaines, il est décidé de confier au Néerlandais Karel Lotsy la tâche d'étudier plus dans le détail cette question. Lotsy est un des plus jeunes membres de l'élite de la FIFA et, à ce titre, il semble être plus ouvert que certains de ses collègues à l'élaboration d'un plan visant à une décentralisation future de la FIFA. Dans le rapport qu'il établit à la suite de son étude, Lotsy ne se montre effectivement pas totalement hostile à l'idée de régionaliser la FIFA. Pour lui, l'important est que la FIFA agisse "par une influence morale, par l'autorité de son expérience et le poids de l'équité ${ }^{219}$ et non pas qu'elle se montre dirigiste sur certains sujets qui pourraient être administrés par des groupements continentaux. Cependant, conscient des risques que créerait une trop grande décentralisation, il confirme la position du comité exécutif, à savoir de rejeter la proposition de Bermudez. À ce stade, il préconise surtout d'améliorer le dialogue entre l'élite de la FIFA et les conseillers continentaux. En effet, écrit-il, "si l'on avait connu les intérêts [de la Confédération sud-américaine] et si l'on avait été disposé d'en tenir

217 Anonyme, "Question d'un congrès et championnat pan-américain ", n.d. Annexe $\mathrm{n}^{0}$ II. 5 de la réunion du comité exécutif du 17 novembre 1934. FIFA, comité exécutif (procès-verbaux 1934).

218 Anonyme, "Question de la modification des Lois de la FIFA en ce qui concerne la représentation des groupements extra-européens ", n.d. Annexe $n^{\circ}$ II. 4 c de la réunion du comité exécutif du 17 novembre 1934. FIFA, comité exécutif (procès-verbaux 1934).

219 Lotsy K., "Rapport de Mr. K.J.J. Lotsy ", Annexe n III.4 de la réunion du comité du 20 avril 1935. FIFA, comité exécutif (procès-verbaux 1935-1936) 
compte, on aurait probablement quelquefois pu éviter - par une petite modification ou par un petit supplément - des mécontentements et de l'amertume ${ }^{220}$.

En date du 20 avril 1935, et en suivant les recommandations de Lotsy, le comité exécutif de la FIFA propose une timide ouverture visà-vis de la Confédération sud-américaine puisqu'elle obtient le droit de nommer un représentant en son sein. Ce dernier pourra prendre part " [aux travaux] du comité [exécutif] chaque fois qu'il y aurait à prendre une décision concernant l'Amérique du Sud ${ }^{221}$. Cette proposition confirme, une fois encore, l'européocentrisme de l'élite de la FIFA. D'une part, le représentant sud-américain devra habiter en Europe. D'autre part, il ne pourra participer qu'aux discussions concernant le football de son continent et n'aura ainsi pas la possibilité de prendre position sur d'autres sujets, ce qui limitera fortement ses possibilités d'action sur la politique de la FIFA. De fait, il ne s'agit pas d'accepter que la Confédération sud-américaine nomme un membre à part entière du comité, mais plutôt un "super-conseiller ». La proposition du comité exécutif ne répond donc pas véritablement aux demandes transmises par les dirigeants sud-américains.

Dès lors, ceux-ci ne tardent pas à faire savoir leur mécontentement face à la position de l'élite de la FIFA. Lors d'un nouveau congrès extraordinaire de la Confédération sud-américaine organisé au printemps 1935, les dirigeants présents demandent à la FIFA que la Confédération sud-américaine puisse être reconnue comme l'organe s'occupant de la gestion du football amateur et professionnel en Amérique du Sud. Il s'agit pour eux de créer une force continentale qui doit tout bonnement leur permettre de se libérer "de l'oppression de la FIFA » ${ }^{222}$. Les mots sont forts et ils indiquent le sentiment de soumission ressenti par les dirigeants sudaméricains. Les divergences entre les deux camps vont donc en s'accentuant et les associations nationales les plus virulentes comme celles du Chili et du Pérou évoquent même ouvertement l'éventualité de quitter la Fédération internationale. Le comité exécutif de la FIFA se doit de réagir pour éviter l'éclatement d'un conflit. À la veille du congrès de la FIFA, qui doit se dérouler à Berlin en juin 1936 - soit pendant les Jeux olympiques -, il propose de réserver une place de vice-président à un dirigeant désigné par

\footnotetext{
220 Ibid.

221 Anonyme, Procès-verbal de la réunion du comité exécutif de la FIFA du 20 avril 1935, n.d. FIFA, comité exécutif (procès-verbaux 1935-1936).

222 Schricker I., "Congrès de Lima ", Annexe n III.5 de la réunion du comité exécutif du 20 avril 1935 à Paris, n.d. FIFA, comitée exécutif (procès-verbaux 1935-1936).
} 
la Confédération sud-américaine pour une période test de deux ans. Les congressistes acceptent cette proposition et, à la fin des débats, Jules Rimet profite de l'occasion pour faire preuve de son habituel sens de la diplomatie en soulignant qu' "il désire que les pays de l'Amérique du Sud emportent de ce vote l'impression que le congrès de la FIFA est animé du plus ardent esprit de collaboration entre tous les éléments qui la composent et du plus grand désir de voir régner l'harmonie la plus parfaite $"{ }^{223}$.

Si cette place provisoire confiée à un représentant de la Confédération sud-américaine au sein du comité exécutif peut faire office de pas en avant de la part de l'élite de la FIFA envers les Sud-Américains, cette décision est néanmoins largement occultée par deux autres qui vont en fait accentuer la tension entre les dirigeants des deux continents. Premièrement, il y a l'affaire du match Autriche-Pérou : lors du deuxième tour du tournoi olympique, l'équipe péruvienne voit sa victoire sur le terrain annulée après coup en raison de débordements causés par ses supporters. Refusant de rejouer le match comme le demande le jury d'appel du tournoi (uniquement composé d'Européens), les Péruviens quittent de suite les Jeux olympiques. Ils sont certes accompagnés de quelques athlètes sud-américains mais, grâce à l'intervention et à la diplomatie des hautes instances olympiques, un retrait massif des délégations des autres pays sud-américains est finalement évité ${ }^{224}$. Le congrès de la FIFA est fortement marqué par ce contexte. Dès les premières minutes de l'assemblée, des délégués sud-américains demandent de modifier l'ordre du jour et de traiter du cas de cette rencontre, proposition refusée par le président Rimet qui dirige les débats. La tension est palpable, ces discussions préliminaires durant plusieurs heures et retardant fortement l'avancée d'un congrès qui a été initialement prévu sur un seul jour ${ }^{225}$. Au moment d'aborder la question du match Autriche-Pérou, le délégué de l'Uruguay, Dupuy, déclare sans ambages qu'il y a une grande excitation au Pérou et plus généralement en Amérique du Sud. Les Sud-Américains ressentent la décision d'exclure l'équipe sud-américaine prise par le jury d'appel comme une injustice. Ils demandent donc que l'équipe du Pérou soit déclarée vainqueur et puisse jouer la demi-finale du tournoi. Après discussion, la majorité des congressistes décident de ne pas remettre en cause la décision du jury

223 Anonyme, Procès-verbal de l'assemblée générale de la FIFA des 13 et 14 août 1936, n.d. FIFA, XX-XXIV congrès ordinaires (1931-1938, rapport d'activité).

224 "Le Pérou s'est retiré des Jeux olympiques. Le comte de Baillet-Latour nous déclare que le CIO n'avait pas à intervenir ", L’Auto, 12 août 1936.

225 "Le congrès de la FIFA a été mouvementé et il n'est pas terminé ", L'Auto, 14 août 1936. 
d'appel du tournoi, mais afin de minimiser le conflit qui couve, ils demandent qu'une commission se réunisse immédiatement pour essayer de trouver une alternative aux requêtes des dirigeants des associations sud-américaines. Il ressort de ces échanges que les équipes d'Allemagne et d'Autriche se proposent chacune de disputer une rencontre contre le Pérou afin de financer les coûts du voyage de l'équipe. L'affaire se clôt sur cette proposition, mais l'amertume est palpable chez les dirigeants sud-américains.

Deuxièmement, les congressistes doivent discuter de l'organisation de la Coupe du monde de 1938. Après l'épreuve de 1934 disputée en Italie, les associations nationales sud-américaines souhaitent qu'une rotation continentale ait lieu et appuient fortement la candidature de l'Argentine. Disposant de plusieurs grands stades et d'une ferveur incontestable pour le ballon rond ${ }^{226}$, le pays semble à même d'organiser l'épreuve dans les meilleures conditions, ce que soulignent différents orateurs sud-américains. En outre, durant la discussion, Luis Dupuy mentionne qu'après l'épisode du match Autriche-Pérou, l'organisation de la Coupe du monde en Argentine " aurait une répercussion très favorable dans l'Amérique du Sud ${ }^{227}$. Malgré ces interventions, les congressistes présents décident, à une très grande majorité, d'attribuer l'organisation de la future épreuve à la France. Cette décision constitue une déconvenue supplémentaire pour les Sud-Américains et alimente leur rancœur vis-à-vis de la FIFA.

Quelques mois après la réunion de Berlin, un congrès extraordinaire de la Confédération sud-américaine se déroule dans une atmosphère tendue et révèle la rancœur des associations sud-américaine envers la FIFA. Le Pérou, appuyé dans sa démarche par le Chili, propose une résolution visant la "désaffiliation de l'Amérique du Sud de la FIFA " ${ }^{228}$. Si cette idée n'est pas acceptée par l'assemblée ${ }^{229}$, des décisions importantes (sept au total) sont prises. Connus sous le nom d' "Accords de Santiago ", ceux-ci soulignent la défiance des Sud-Américains vis-à-vis du comité exécutif de la FIFA. Parmi les décisions prises, il s'agit en particulier de « ne plus

226 Hémeury L., "Le pouvoir hors-jeu ? Football et péronisme en Argentine (1946-1955), Cahiers de l'Amérique latine, vol. 74, 2014, publié en ligne.

227 Anonyme, Procès-verbal de l'assemblée générale de la FIFA des 13-14 août 1936, n.d. FIFA, XX-XXIV congrès ordinaires (1931-1938, rapport d'activité).

228 Lettre de I. Schricker au comité exécutif de la FIFA, 21 novembre 1936. FIFA, comité exécutif (procès-verbaux 1935-1936).

229 Schricker I., Procès-verbal de la réunion du comité exécutif de la FIFA du 28 novembre 1936, n.d. FIFA, comité exécutif (procès-verbaux 1935-1936). 
participer [à des tournois] organisés par la FIFA ; aussi longtemps que la structure et la composition actuelle des jurys chargés de la direction et $\mathrm{du}$ règlement des conflits internationaux de caractère mondial ne seront pas modifiés $"{ }^{230}$. Une telle disposition permettrait d'instaurer davantage d'impartialité au sein de la FIFA et éviterait in fine des événements comme celui de la rencontre Autriche-Pérou. Une autre revendication émise par les congressistes consiste à revendiquer une autonomie en ce qui concerne la gestion des affaires footballistiques sur le continent sud-américain. En conséquence, l'organisme principal en matière de football sud-américain ne serait plus la FIFA mais la Confédération sud-américaine. Dans ce cas, c'est donc la souveraineté de la Fédération internationale qui est directement remise en cause. Dernier élément révélateur de la position d'obstruction des Sud-Américains vis-à-vis de la FIFA, il faut plusieurs mois pour que leur représentant continental au sein du comité exécutif de la Fédération internationale soit nommé. Le dirigeant finalement choisi est le diplomate Luis Dupuy, ambassadeur d'Uruguay en Allemagne puis, à partir de 1936, en Belgique.

Dupuy peut être perçu comme un successeur de Buero, autant au regard de sa position vis-à-vis du football sud-américain que de sa fonction professionnelle. Par contre, il se montre plus actif que son prédécesseur et, dès sa nomination, développe une politique offensive au sein du comité exécutif de la FIFA. Il appuie avec force les revendications portées par sa Confédération continentale en matière de composition des jurys d'appel lors des compétitions de football international. Leurs membres doivent désormais être issus de différents continents, ce qui permettra d'éviter "des cas fâcheux " ${ }^{231}$, propos faisant référence au match Pérou-Autriche de l'année précédente. De plus, en juin 1937, Dupuy propose la création d'une "Copa de Europa ", qui verrait le vainqueur de la Copa America affronter une association européenne choisie par la FIFA. Selon lui, cette coupe « serait un moyen excellent pour faire disparaitre certaines tensions existantes et pour amener un rapprochement entre les organisations sportives de l'Europe et de l'Amérique du Sud ${ }^{232}$. Toutefois, les dirigeants du comité exécutif de la FIFA rejettent l'idée, argumentant notamment qu'il y a déjà passablement de compétitions en Europe.

230 Lettre de I. Schricker au comité exécutif de la FIFA, 21 novembre 1936. FIFA, comité exécutif (procès-verbaux 1935-1936).

231 Anonyme, Procès-verbal de la réunion du comité exécutif de la FIFA des 6-7 novembre 1937, n.d. FIFA, comité exécutif (procès-verbaux 1937).

232 Anonyme, Procès-verbal de la réunion du comité exécutif de la FIFA du 19 juin 1937, n.d. FIFA, comité exécutif (procès-verbayx 1 1937) 
Si les deux camps maintiennent leurs positions dans un premier temps, la situation évolue véritablement durant l'année 1938. En janvier, un énième congrès extraordinaire de la Confédération sud-américaine poursuit les discussions sur les relations avec la FIFA. Tout d'abord, il est décidé de soumettre au prochain congrès de la Fédération internationale la proposition visant à nommer des dirigeants extra-européens dans les jurys d'appel des compétitions internationales gérées par la FIFA ${ }^{233}$. Mais les congressistes émettent aussi une idée plus ambitieuse en souhaitant "simplifier l'appareil administratif de la FIFA en le décentralisant ${ }^{234}$. Dans les faits, il s'agirait de créer cinq confédérations continentales représentant l'Afrique, l'Amérique, l'Asie, l'Europe et l'Océanie. Ces cinq groupements éliraient les membres du comité exécutif de la FIFA. Quatre ans après la proposition formulée par Bermudez, les associations sudaméricaines développent donc un nouveau projet, qui doit être soumis en vue d'une discussion lors du congrès de la FIFA de juin 1938, visant à la décentralisation de la Fédération internationale. Il faut signaler que, dans l'intervalle, une Confédération d'Amérique centrale de football a vu le jour en février 1938 sous les actions du Costaricain, Hector Beeche, ce qui renforce la proposition de la Confédération sud-américaine. Celle-ci remet directement en cause la domination européenne sur le monde du football puisque l'Europe est placée sur le même plan que des régions qui n'ont à ce jour aucun conseiller, comme l'Afrique, encore sous domination coloniale ${ }^{235}$, ou l'Océanie, région dont l'existence n'a jusque-là jamais été nommée au sein de la FIFA. Dans le courrier qui accompagne le projet, le secrétaire général de la Confédération sudaméricaine souligne à Schricker que "l'Amérique ne peut pas être une colonie de l'Europe en matière de football ${ }^{236}$. Le ton de la lettre révèle la détermination qui anime les dirigeants sud-américains, position qui

233 Tochetti Lespade F. « Proposition de la Confederación Sud-Americana concernant la composition des Comités et Jury d'appel des tournois organisées par la FIFA », Annexe $\mathrm{n}^{\circ}$ II.3.i de la réunion du comité exécutif du 5 mars 1938. FIFA, comité exécutif (procès-verbaux 1938).

234 Anonyme, «Proposition de la Confederación Sud-Americana concernant l'organisation de la FIFA par continents et la composition du comité exécutif ", Annexe n II.3.j de la réunion du comité exécutif du 5 mars 1938. FIFA, comité exécutif (procès-verbaux 1938).

235 Seuls l'Éthiopie et le Liberia ne sont pas sous domination coloniale. En football, l'Égypte dispose d'une certaine autonomie et, comme déjà signalé, est présente à la FIFA depuis les années 1920.

236 Dietschy P., Histoire du football, op. cit., B. 251 1. 
est d'ailleurs soulignée dans un article du journal L'Auto écrit à la veille de l'assemblée générale de $1938^{237}$.

La radicalité de cette position ne semble toutefois pas être partagée par toutes les associations sud-américaines, ce qui pénalise son impact au sein de la FIFA. Premièrement, à la fin de l'année 1937, l'Argentine s'est retirée de la Confédération sud-américaine, comme elle l'explique dans une lettre adressée à la FIFA en date du 29 décembre ${ }^{238}$. Lors du congrès de la FIFA de 1938, son délégué revient sur cette décision et précise que si son association nationale est d'accord avec la proposition concernant la modification de la composition des jurys d'appel lors des compétitions internationales, elle est par contre opposée aux propositions visant à la décentralisation de la FIFA. En effet, selon lui, la création de groupements continentaux risquerait de faire du tort au pouvoir de la FIFA et, par ailleurs, cette idée ne correspond pas à la volonté de " beaucoup de pays [lui] appartenant ${ }^{239}$. Il s'agit donc, pour cette association, de rester dans le giron de la Fédération internationale, qu'elle considère comme l'organe suprême en matière de football. Deuxièmement, le Brésil - seule association sud-américaine à avoir envoyé son équipe nationale en France pour y disputer la Coupe du monde - se montre également peu favorable aux volontés de la Confédération sud-américaine. A la suite de l'Argentin, le dirigeant brésilien déclare que si son association reste membre de l'entité continentale, par contre elle " ne reconnaît aucune restriction ni intervention de [sa] part et entend maintenir ses relations directes avec la FIFA ${ }^{240}$. Ces positionnements affaiblissent assurément la portée du projet porté au sein de la Confédération sud-américaine, car l'Argentine et le Brésil sont des pays très influents sur le plan du football continental au vu de la qualité de leurs équipes nationales respectives et du nombre de footballeurs qu'elles regroupent. En outre, ces interventions soulignent que, malgré l'existence d'un organisme continental, les associations sudaméricaines peinent à créer une voix unique au sein de la FIFA.

237 La veille du congrès, un article de L'Auto évoque les possibles discussions autour de cette réforme. "La FIFA deviendra-t-elle une Confédération ? La proposition déposée par les fédérations sud-américaines sera discutée au congrès de la FIFA qui s'ouvre aujourd'hui ", L'Auto, 3 juin 1938.

238 Lettre du président de l'Association d'Argentine à J. Rimet, 29 décembre 1937. FIFA, correspondance avec les associations nationales, Argentine (1934-1968), dossier : 1934-1950.

239 Schricker I., Procès-verbal de l'assemblée générale de la FIFA du 3 juin 1938 à Paris, n.d. FIFA, XX-XXIV congrès ordinaires (1931-1938, rapport d'activité).

240 Anonyme, Procès-verbal de la réunion du comité exécutif de la FIFA des 5-6 mars 1938, n.d. FIFA, comité exécutif (procès-verbaux 1938 ). 
En fins tacticiens, les membres de l'élite de la FIFA, Jules Rimet en tête, tentent de profiter de cette situation, sentant que les revendications sud-américaines en vue d'une décentralisation de la FIFA manquent de tranchant. Pour autant, Rimet ne choisit pas d'attaquer de front le projet de création de cinq fédérations continentales et discute en premier lieu de sa faisabilité. Comme il l'explique quelques semaines plus tôt à ses collègues du comité exécutif, les autres continents n'ont pas d'organisation comparable à la Confédération sud-américaine. Dès lors, selon lui, il n'est pas possible, pratiquement parlant, de mettre en œuvre cette idée. Par contre, les dirigeants du comité exécutif semblent conscients que, pour éviter que le conflit ne perdure entre la FIFA et l'Organisation sudaméricaine, ils doivent faire un geste en faveur de leurs homologues sudaméricains. En ce sens, il s'agit notamment de faire accepter par le congrès la proposition de la Confédération sud-américaine concernant les jurys d'appel. De même, ils préconisent que le délai test de deux ans soit accepté et que, dorénavant, la Confédération sud-américaine puisse élire un représentant fixe au sein du comité exécutif. Avec ces deux propositions, ils pensent pouvoir endiguer les revendications sud-américaines.

Ces deux points sont acceptés par les congressistes et, à la suite de ces décisions, le président Rimet peut indiquer à l'assemblée que les propositions de la Confédération sud-américaine de revoir la structure de la FIFA ont été retirées. Au sortir du congrès de 1938, une sérénité semble quelque peu revenue au sein de la FIFA, conformée dans les mois qui suivent par le fait que les associations nationales sud-américaines décident d'annuler les Accords de Santiago. La décision de permettre à la Confédération sud-américaine de choisir son représentant au sein de l'élite de la FIFA marque néanmoins un précédent. Ainsi, cette décision ouvre la porte à une possible décentralisation du comité exécutif et, par-delà, de la structure de la FIFA ${ }^{241}$. Les événements qui se déroulent dans la décennie suivante vont créer de nouvelles possibilités à cet égard.

241 Décisions qui sont reprises dans les statuts de la Confédération sud-américaine. Anonyme, Confederación Sudamericana de Fútbol. Estatutos [édition de 1939], art. 48. FIFA, CSF statutes. 


\section{CHAPITRE 2}

\section{La souveraineté de la FIFA remise en cause (1939-1948)}

\section{Introduction du chapitre}

Le chapitre 2 couvre la période allant de 1939 à 1948. Durant ces dix ans, les dirigeants de la FIFA vont devoir faire face à un contexte international difficile avec la Deuxième Guerre mondiale puis le début de la Guerre froide. À cela s'ajoute, même si cet aspect joue un moindre rôle dans le monde du football de cette époque, le début de la décolonisation. Par ailleurs, c'est aussi l'internationalisation croissante du football qui connaît une nouvelle phase, processus qui n'est pas sans impact sur la gouvernance de la Fédération internationale de football. Toujours dans l'optique de comprendre la création ainsi que la configuration particulière de l'UEFA dans les années 1950, ce moment est importante à étudier et nous soutenons l'idée que la volonté de créer des organismes continentaux en football émerge pendant cette période.

Tout d'abord, il faut souligner que malgré d'évidentes difficultés dues à la guerre, des matchs entre les équipes nationales européennes persistent entre 1939 et 1943, puis reprennent dès 1945. Ces échanges témoignent de l'ancrage des liens footballistiques qui s'opèrent à l'échelle géographique continentale depuis l'entre-deux-guerres. De plus, au sortir de la guerre, le territoire européen de juridiction de la FIFA s'agrandit avec le retour des associations britanniques et l'entrée de l'Union soviétique en son sein. Cet élargissement de l'organisation a pour conséquence une poursuite de la recomposition du comité exécutif, un vice-président étant désormais directement nommé par les quatre associations britanniques et un autre par l'organisme du sport de l'URSS. Cette union de l'Europe semble symbolisée par le match "Europe-Grande-Bretagne » organisé en 1948, qui convoque davantage d'associations nationales que celui organisé dix ans plus tôt.

En outre, cette décennie voit aussi l'élite de la FIFA fortifier la structure de l'organisation. Il faut souligner ici que, contrairement à d'autres fédérations internationales (boxe, escrime), la FIFA réussit à survivre aux 
volontés de contrôle des nazis, ce que révèle bien sa position particulière sur la scène internationale. À la fin des hostilités, et toujours autour du président Rimet, son comité exécutif prend des décisions visant à renforcer les mécanismes d'autonomie créés durant l'entre-deux-guerres. Cependant, la fin des années 1940 est marquée par un renouvellement progressif de l'élite de la FIFA, et ce dans un contexte qui voit désormais l'Est et l'Ouest être séparés par le Rideau de fer. Ainsi, la Fédération internationale entre dans une période de transition générationnelle.

Enfin, les années 1940 voient également la poursuite des volontés décentralisatrices émises par les associations sud-américaines. Alors que le continent européen est plongé dans les horreurs de la Seconde Guerre mondiale, l'Amérique du Sud est moins touchée par les hostilités et les échanges footballistiques à l'échelle continentale continuent à avoir lieu. Dans les premières années de la décennie, les associations sud-américaines décident de renforcer la structure de leur confédération continentale afin de créer une voix unie qui pourra ensuite leur permettre de défendre une position commune au sein de la FIFA. Par ailleurs, elles établissent aussi des alliances formelles avec les associations d'Amérique centrale, notamment au sein de la Confédération panaméricaine de football créée en 1946, dans l'objectif de créer des échanges footballistiques plus fermes à l'échelle panaméricaine mais aussi sans doute dans le but de soutenir la décentralisation de la Fédération internationale. Deux propositions en la matière sont finalement envoyées à la fin de la décennie à la FIFA en vue d'une discussion lors du congrès de 1950. Il s'agirait pour les associations sud-américaines d'obtenir davantage de places dans le comité exécutif de la FIFA, voire de soutenir une possible " continentalisation " de l'organisme.

\subsection{L'élargissement du territoire européen}

Durant l'entre-deux-guerres, la FIFA a œuvré aux rapprochements footballistiques entre les différentes associations européennes. Les années 1940 vont continuer ce processus, en particulier avec le retour des associations britanniques au sein de la FIFA ainsi que l'incorporation de l'Union soviétique dans l'organisation. Mais avant de traiter ces deux points, il faut se questionner sur l'impact de la guerre sur le travail de la FIFA, et plus généralement sur les échanges footballistiques européens.

Dans le rapport du secrétaire général de la Fédération internationale pour la période 1940-1941, Ivo Schricker mentionne les "grandes 
difficultés " ${ }^{1}$ que le conflit engendre pour l'organisation. En effet, à partir de 1940, en raison de la guerre, son comité exécutif ne peut plus se réunir et la correspondance entre le secrétaire général et les associations membres s'avère délicate. Les combats puis les contrôles effectués par les Allemands dans les zones occupées ralentissent fortement la transmission des informations et certains courriers mettent ainsi plusieurs mois à arriver à leur destinataire. De même, le congrès prévu en 1940 à Luxembourg n'est pas organisé. Malgré cette situation difficile, des échanges footballistiques persistent durant toute la durée des hostilités et l'activité de la FIFA ne s'arrête jamais totalement.

\subsubsection{La persistance des échanges footballistiques européens durant la guerre}

Le football est indéniablement touché par le conflit. On le perçoit notamment dans le fait que les épreuves régionales créées durant l'entredeux-guerres sont toutes arrêtées. Ainsi, la Mitropa Cup connaît une abrupte fin de parcours avec l'organisation d'un dernier tournoi en 1940. Seules huit formations issues de Hongrie, de Roumanie et de Yougoslavie y prennent part, ce qui contraste avec la grandeur de l'épreuve du milieu des années 1930, lorsque six pays envoyaient chacun quatre équipes se disputant le trophée sur plusieurs mois. Des projets de remplacement du tournoi, comme celui d'une coupe du Danube ${ }^{2}$, sont par la suite évoqués, sans toutefois être mis en œuvre. Les épreuves de l'espace balkanique connaissent un sort analogue. Ivo Schricker indique à ses collègues du comité exécutif en mai 1940 que la Coupe des Balkans a cessé de se disputer depuis le dernier tiers de la décennie précédente déjà ${ }^{3}$. De même, les championnats britannique et scandinave sont stoppés durant toute la durée de la guerre, même si les équipes nationales de ces régions continuent à maintenir des matchs entre elles.

Au niveau des parties entre les équipes nationales, le contexte de guerre est peu favorable aux déplacements et rend l'organisation de matchs compliquée. En outre s'ajoute une situation politique qui rend

Schricker I., Rapport du secrétaire général de la FIFA (1940-1941), n.d. FIFA, comité exécutif (procès-verbaux 1940-1946), p. 1.

2 Lettre du ministre des Sports hongrois à la FIFA, 13 décembre 1940. FIFA, correspondance avec les associations nationales : Hongrie (1937-1965), dossier : 1937-1950.

3 Lettre de I. Schricker au comité exécutif de la FIFA, 29 mai 1940. FIFA, comité exécutif (procès-verbaux 1939) 
impossible ce genre d'entreprise pour certaines fédérations nationales. C'est notamment le cas des associations de la Pologne, de la Tchécoslovaquie et de la Yougoslavie qui, en raison de l'invasion allemande de leur pays, sont rayées de la carte footballistique. Les autres pays occupés par l'Allemagne se trouvent également placés dans une sorte de silence footballistique sur la scène internationale. C'est notamment le cas de la Belgique, de la France ou encore des Pays-Bas qui ne disputent plus aucun match entre 1941 - intensification de la guerre avec le début de la campagne russe de la Wehrmacht - et 1944 - début du départ des armées allemandes des territoires occupés. Selon Simon Kuiper, les autorités allemandes interdisent ces rencontres internationales car elles craignent qu'elles ne soient de bonnes occasions de manifester des sentiments antigermaniques, voire, notamment en cas de match contre l'Allemagne, d'actes patriotiques ${ }^{4}$. Dans son très bel ouvrage Football with the Foe, qui aborde le cas du sport danois durant la Deuxième Guerre mondiale, Hans Bonde donne l'exemple d'un match opposant deux clubs, à savoir Admira Wacker - une formation viennoise - et une équipe de Copenhague, lors duquel une partie de la foule se confronte à des soldats allemands présents au stade 5 .

En fait, très peu d'associations nationales continuent à organiser des rencontres internationales et lorsqu'elles le font, c'est à une moindre fréquence que par le passé. Par exemple, la fédération italienne réduit drastiquement les oppositions footballistiques internationales de sa sélection nationale, puisque de huit matchs en 1939 elle passe à cinq matchs disputés une année plus tard et seulement deux en 1942 - il s'agira des derniers matchs joués jusqu’à la fin des hostilités. De même, la Suède et la Suisse, deux pays "neutres " et particulièrement prolixes en matière d'échanges footballistiques internationaux durant l'entre-deuxguerres, connaissent aussi une diminution du nombre de rencontres jouées par leur équipe nationale respective. Ainsi, les parties disputées correspondent grosso modo à la moitié des matchs auxquels elles ont pris part dans les quatre années précédentes. La seule association nationale qui ne semble pas être touchée par ce contexte est l'Allemagne, du moins pour

4 Kuiper S., Ajax, the Dutch, the war. Football in Europe during the Second World War, London, Orion, 2003, p. 93

5 Bonde H., Football with the Foe. Danish sport under the swastika, Odense, University Press of Southern Denmark, 2008, p. 135.

6 Durant la Deuxième Guerre mondiale, le gouvernement suisse entretient des relations avec les deux camps. Sur ce positionnement, voir par exemple les contributions présentes dans le numéro spécial de la revue Relations internationales « Entre guerres et ruptures, la protection dans les relations internationales - II ", coordonné par JeanMarc Delaunay et Daniel Bourgeois en 2010.0 
la période 1939-1943. En effet, comme l'écrit l'un des plus importants dirigeants du football allemand, Karl Kopehel, dans le Bulletin de la FIFA d'août et septembre 1939, le football allemand est " en marche! " . L'utilisation de ce vocabulaire, qui évoque une démarche militaire - très révélatrice du contexte ambiant puisqu'elle précède de quelques semaines l'envahissement de la Pologne par les troupes du Reich - n'est pas usurpée au regard du nombre de parties internationales disputées par l'équipe nationale allemande à cette époque.

Ainsi, l'équipe nationale allemande joue près du double de rencontres que la Suède ou la Suisse entre 1939 et 1943. De plus, le nombre de parties qu'elle dispute durant les quatre années du conflit n'est que légèrement inférieur à la période 1934-1938 et peut donc être perçu comme une sorte de continuité avec la période antérieure, ce qui n'est pas le cas des autres pays. Si la formation du III ${ }^{\mathrm{e}}$ Reich dispute autant de rencontres, c'est qu'elles servent à soutenir les actions politiques et militaires du gouvernement nazi, notamment en représentant l'Allemagne auprès des nouveaux pays qui ont été créés suite au passage de l'armée allemande. En effet, des associations nationales de football émergent par exemple en Slovaquie ou en Croatie et jouent rapidement contre l'équipe d'Allemagne, permettant par ce biais d'appuyer leur reconnaissance sur la scène internationale par le III $^{\mathrm{e}}$ Reich. Dans la même veine, l'équipe allemande joue à plusieurs reprises contre ses alliés que sont la Hongrie, la Bulgarie ou la Roumanie. Comme le note Nils Havemann, ces différents concours sportifs "[facilitent] les rapprochements parce qu'ils [offrent] aux responsables politiques la possibilité de mener des entretiens en marge des manifestations et de contribuer à instaurer un climat de confiance ${ }^{8}$.

Mais plus qu'un soutien aux actions du Reich, l'équipe allemande doit aussi symboliser son idéologie conquérante. Sous cet angle, Markwart Herzog a notamment étudié la controverse qui existe, durant les premières années de la guerre, entre le sélectionneur de l'équipe allemande, Joseph Herberger, et un dirigeant sportif bavarois, Karl Oberhuter. Ce dernier estime que le style de jeu de la Mannschaft devrait être davantage tourné vers l'attaque en s'inspirant - mais aussi devant refléter - la tactique

Koppehel K., "Le football allemand en marche! ", Bulletin de la FIFA, n 10-11, août-septembre 1939, pp. 9-10.

8 Havemann N., "Le sport dans l'Allemagne nationale-socialiste en guerre ", Guerres

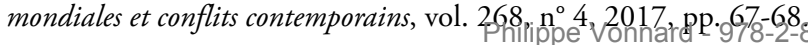


militaire de la guerre éclair (Blitzkrieg ${ }^{9}$ ), employée notamment dans la campagne de France. En fait, pour les principaux dirigeants nazis, l'équipe nationale doit correspondre à la grandeur du peuple allemand et, en ce sens, selon les mots de Hans Bonde, leurs joueurs sont " allergiques à la défaite $"{ }^{10}$. Au passage, soulignons que malgré la mise sur pied d'une "Grande Allemagne " ${ }^{11}$ renforcée, depuis 1938, par des joueurs autrichiens puis d'autres pays annexés - tel le buteur polonais Ernest Willimowski -, l'équipe nationale du Reich ne réussira que peu de coups d'éclat. Éliminée au premier tour de la Coupe du monde de 1938 face à la modeste équipe de Suisse ${ }^{12}$, elle enregistre également des défaites face aux deux équipes alors considérées comme les meilleures du monde, l'Angleterre (mai 1938) et l'Italie (mai 1940). Le football européen est donc en partie paralysé par les hostilités et, si les échanges continuent, ceux-ci sont organisés autour de l'activité de l'équipe allemande.

Malgré cette paralysie, le fait que des rencontres réussissent tout de même à être maintenues est important en vue d'une reprise rapide des échanges footballistiques en Europe après le conflit. Par ailleurs, ces matchs sont également cruciaux pour la FIFA car ils doivent lui permettre de se maintenir financièrement à flot. En effet, la non-organisation de la Coupe du monde en 1940 et en 1944, couplée à la baisse du nombre de matchs internationaux de manière générale, lui confère beaucoup moins de recettes. Des mesures d'économie sont d'ailleurs prises tout au long de la période, comme celle de réduire drastiquement le temps de travail de l'aide du secrétaire général, Rijnink. De plus, la situation oblige le secrétaire Schricker à puiser allègrement dans les réserves constituées durant la seconde partie des années 1930. En conséquence, les rentrées d'argent que la FIFA peut toucher de l'équipe allemande, et dans une moindre mesure des associations suédoise, suisse ou encore hongroise, sont cruciales pour sa survie.

9 Tactique offensive qui consiste à faire devancer les chars par l'aviation et qui permet une avancée rapide.

10 Bonde H., "Turn of the tide: nordic ideological change ", The International Journal of the History of Sport, vol. 16, $\mathrm{n}^{\circ}$ 10, 2009, p. 1508.

11 Surnom donné par des journaux sportifs, en particulier suisses, à l'équipe nationale allemande depuis l'incorporation de joueurs autrichiens en 1938.

12 Sur ce match, voir : Quin G., "La Suisse face à la Grande Allemagne (1933-1942). Éléments pour une histoire du football helvétique ", dans Attali M. (dir.), Sports et médias, XIX ${ }^{e}-X X^{e}$ siècles, Biarritz, Atlantiç,2010 pp. 761-770-89-2-8076-0570-1 
Tableau 7. Montant du pourcentage perçu (en francs suisses)
par la FIFA sur les matchs internationaux de 1939 à 1944

\begin{tabular}{|l|l|l|l|l|l|l|l|}
\hline Années & $\mathbf{1 9 3 8}$ & $\mathbf{1 9 3 9}$ & $\mathbf{1 9 4 0}$ & $\mathbf{1 9 4 1}$ & $\mathbf{1 9 4 2}$ & $\mathbf{1 9 4 3}$ & $\mathbf{1 9 4 4}$ \\
\hline Montant & 40984,49 & 27763,25 & 13578,55 & Inconnu & 22068,82 & 11364,49 & 3035,14 \\
\hline
\end{tabular}

Car la FIFA entend rester active durant les hostilités. Tout d'abord, dès l'entrée en guerre, ses principaux dirigeants écrivent une déclaration dans laquelle ils font "le vœu ardent de voir le conflit actuel se localiser et se terminer au plus vite ${ }^{13}$ et déplorent " que les efforts de tous ceux qui ont voué leur apostolat au sport pacifique aboutissent à cette catastrophe $»^{14}$. Tout au long du conflit, Ivo Schricker continue à rédiger des lettres ou des circulaires pour les associations nationales ainsi que des publications officielles. De même, il entretient une riche correspondance avec quelques membres du comité exécutif, et en premier lieu avec Rodolphe Seeldrayers. Alors que le temps est à la pénurie de papier, il n'hésite pas à relancer un Bulletin officiel en 1942, qui ne connaîtra toutefois que trois numéros.

Témoin de cette volonté de souligner l'activité de la Fédération internationale, dans son rapport du secrétaire pour les années 1942 et 1943, le secrétaire général se réjouit que l'organisation soit " à même de fonctionner presque normalement et de rester en contact régulier avec ses membres $"{ }^{15}$. Cet optimisme étonne au regard de la situation globale dans laquelle le continent européen est plongé. Dans un courrier datant du 26 mai 1944, Seeldrayers lui indique d'ailleurs qu'il ne partage pas son avis car, d'un " point de vue financier notamment [l'activité de la FIFA] est au 3/4 paralysée » et la plupart des matchs internationaux sont annulés ${ }^{16}$. Pour autant, la Fédération internationale continue effectivement d'exister et l'activisme de son secrétaire est indéniable. En outre, la FIFA ne connaît pas de membres démissionnaires, même si des adaptations vis-àvis de la situation politique des pays sont demandées par des associations nationales. C'est le cas par exemple de la Norvège, où la fédération

13 Lettre de I. Schricker à R.W. Seeldrayers, 31 mai 1940. FIFA, membres du comité exécutif, dossier individuel : correspondance R.W. Seeldrayers (1939-1950), dossier :

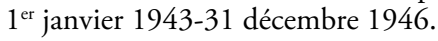

14 Ibid.

15 Schricker I., Rapport du secrétaire général de la FIFA (1942-1943), n.d. FIFA, comité exécutif (procès-verbaux 1940-1946), p. 1.

16 Lettre de R.W. Seeldrayers à I. Schricker, 26 mai 1944. FIFA, membres du comité exécutif, dossier individuel : correspondance R.W. Seeldrayers (1939-1950), dossier : $1^{\text {er }}$ janvier 1943-31 décembre 1946. 
nationale de football est désormais englobée dans un organisme étatique à la solde du nouveau gouvernement fasciste de Vickung Quisling. Suivant la politique développée durant l'entre-deux-guerres de ne pas intervenir dans les affaires des associations nationales afin de préserver sa neutralité ${ }^{17}$, la FIFA accepte le changement sans broncher.

Deux autres éléments peuvent encore être ajoutés, qui montrent que les échanges dans le football européen ne sont pas totalement au point mort durant la Deuxième Guerre mondiale. Premièrement, outre les parties entre les équipes seniors, des échanges persistent également entre les équipes nationales de réserve, comme le montre l'exemple des deux rencontres disputées en 1941 à Lyon et en 1942 à Lausanne, entre la Suisse et la France. L'enjeu de ces rencontres dépasse largement celui du football. En effet, lorsque l'équipe française se rend sur les bords du Léman, de nombreux discours de fraternité sont professés par les dirigeants du football ainsi que par des hommes politiques locaux, dans lesquels ils insistent sur l'amitié qui existe entre les deux pays. Deuxièmement, il faut aussi souligner qu'au sein des espaces nationaux, le jeu perdure ${ }^{18}$ et même parfois dans des conditions très peu favorables à la pratique du football, comme dans des villes polonaises, où le ballon rond est interdit par les Allemands ${ }^{19}$. Dans ces cas, jouer au football correspond à un moyen d'oublier, le temps d'une partie, les horreurs du conflit, voire représente une forme de résistance alternative face aux actions des Allemands.

Ces deux éléments, couplés à l'activité de la FIFA, expliquent pourquoi, dès que les hostilités cessent dans un pays, les parties internationales de football reprennent presque de manière instantanée. Par exemple, un peu moins de quatre mois après la libération de Paris, la ville accueille déjà la première partie officielle depuis 1941, dans laquelle s'opposent la Belgique et son voisin français. Lors du mois de juillet 1945, soit environ trois mois après la capitulation allemande, l'association suisse envoie également un courrier à toutes les fédérations nationales européennes dans le but " de reprendre les relations sportives par des matchs internationaux

\section{Supra 1.2.4.}

18 Pour des études de cas du football national durant la Deuxième Guerre mondiale, voir : Herzog M., Brändle F. (eds.), Europäischer Fussball im Zweiten Weltkrieg, Stuttgart, Kohlhammer, 2015. Et pour une vision plus générale : Dietschy P., " Football et guerre totale : le cas de la Seconde Guerre mondiale ", dans Gastaut Y., Mourlane S., Le football dans nos sociétés : une culture populaire, 1914-1998, Paris, Autrement, pp. 159-173.

19 Mazurkiewicz M., " "Forbidden goals" - Illegal football in occupied Poland (1939-1945) ", papier présenté au congrès annuel de la British Society of Sports History (BSSH), Université d'Édinbourg 2 irippeptembre 2016 
représentatifs ${ }^{20}$. Cette même année, l'équipe helvétique dispute cinq parties internationales, respectivement contre la France, le Portugal, l'Angleterre, l'Italie et la Suède. Les dirigeants de la FIFA insistent sur cette reprise rapide des activités de leur organisation et se montrent particulièrement optimistes quant à un retour à la normale, comme l'indique un document de synthèse écrit sur le football d'après-guerre : "Il n'y a pas de doute que les relations sportives entre nos membres reprendront bientôt leur étendue normale d'avant-guerre ; les matchs internationaux joués au courant de cette année [1945] ont fait preuve de la popularité énorme de notre sport ${ }^{21}$. L'année 1946 confirme la reprise des relations footballistiques internationales puisque la majorité des équipes nationales disputent cinq à six parties, même si pour des pays comme la Hongrie, les Pays-Bas ou la Yougoslavie, celles-ci sont principalement organisées contre leurs voisins, ce qui témoigne encore des difficultés rencontrées pour voyager plus loin sur le continent.

Certes, dans cet immédiat après-guerre, le nombre de parties internationales est quelque peu en deçà de la période d'avant-guerre. En effet, si 359 matchs sont joués entre les sélections nationales européennes entre 1937 et 1939, 299 parties seulement sont organisées en Europe entre 1945 et 1947. Ce chiffre doit néanmoins tenir compte des changements qui se sont produits sur la scène internationale, notamment l'incorporation des pays baltes dans l'Union soviétique, le retour de l'Espagne sur la scène footballistique internationale et bien entendu le fait qu'une Coupe du monde se dispute en 1938 - ce qui engendre davantage de matchs. Dès lors, nous pouvons en conclure qu'autour de l'année 1947, la tendance est à une normalisation des échanges tels qu'ils s'opéraient durant l'entredeux-guerres. Le football européen a certes subi les événements mais l'ancrage des liens footballistiques entre les associations européennes a aidé à surmonter cette situation.

La FIFA est certes touchée par le conflit mais, comme l'a justement relevé Grégory Quin, l'institution fait preuve d'une réelle robustesse au regard de la dureté de celui-ci ${ }^{22}$. En outre, fait important pour la

20 Lettre de J. Krebs et $\mathrm{H}$. Käser à l'Union belge des sociétés de football-association, 3 juillet 1945. FIFA, correspondance avec les associations nationales : Suisse (1938-1950), dossier : 1939-1950.

21 Anonyme, "Organisation du football d'après-guerre. Reprise complète de l'activité de la FIFA », n.d. FIFA, rapport d'activité durant la Guerre.

22 Quin G., "La reconstruction de la Fédération Internationale de Football Association (FIFA) après la Seconde Guerre mondiale (1944-1950). Jalons pour une histoire des

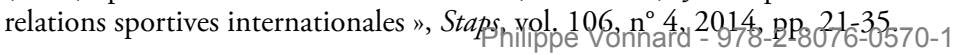


légitimité de l'organisation, au sortir de la guerre, son territoire européen de juridiction s'élargit avec le retour des associations britanniques dans son giron.

\subsubsection{Le retour des associations britanniques}

Nous avons vu qu'à la fin des années 1930, les associations britanniques se sont rapprochées de la FIFA. Quelques mois avant le début de la Deuxième Guerre mondiale, l'équipe anglaise se déplace à Rome pour y rencontrer l'Italie. Suite à ce match, Stanley Rous envoie un courrier au secrétaire de la Fédération internationale, Ivo Schricker, dans lequel il mentionne :

«Nous apprécions plus que nous pouvons dire la considération extraordinaire dont nous avons été l'objet et qui avait pour but d'assurer notre plaisir et notre confort. Nous sommes sûrs [d']avoir achevé le but principal de notre visite, c'est-à-dire de démontrer qu'un match international entre des équipes de l'Angleterre et des pays continentaux pourra bien être joué devant une nombreuse assistance dans un esprit de combat, mais tout de même d'amitié23.

Signe de l'importance de cette action, le secrétaire général s'empresse aussitôt de faire parvenir le courrier à la plupart des associations nationales européennes membres de la FIFA. La guerre vient néanmoins contrarier cet élan favorable au retour des Britanniques dans le giron de la FIFA. En effet, durant l'intégralité des hostilités, les quatre associations britanniques ne jouent de matchs que sur leurs îles et les acteurs du domaine footballistique sont aussi mobilisés pour l'effort de guerre ${ }^{24}$. De même, si leurs dirigeants décident de maintenir une fois par année les séances de l'International Board $^{25}$, celui-ci ne convoque plus les deux représentants de la FIFA. Dès lors, le football suit globalement la stratégie politique du repli sur soi instaurée par le gouvernement d'union nationale de Winston Churchill. Il faut dès lors attendre la fin du conflit pour que de véritables échanges

23 Lettre de I. Schricker au général G. Vaccaro, 6 juin 1939. FIFA, correspondance avec les associations nationales : Italie (1939-1957), dossier : 1939-1950.

24 En Angleterre, les joueurs professionnels doivent aider à maintenir la condition physique des troupes et jouent également des rencontres de charité en faveur de différents fonds créés pour soutenir la population civile, comme celui de la CroixRouge ou du Maire de Londres.

25 Anonyme, Procès-verbal de la réunion de l'IB du 8 juin 1940, n.d. FA, FA minutes 1939-43. 
formels reprennent entre les quatre associations britanniques et la FIFA. Quelles sont les motivations qui poussent les Britanniques à désormais franchir le Rubicon et à entrer dans la Fédération internationale ? Et comment ce retour s'effectue-t-il ?

Si les échanges entre la FIFA et les associations britanniques sont peu nombreux durant la guerre, les dernières années du conflit correspondent à de grandes réflexions au sein de la FA au sujet de la position à tenir dans les relations sportives internationales. Tout d'abord, il semble que les dirigeants britanniques maintiennent tout au long des hostilités des contacts avec les pays " neutres " comme la Suède et la Suisse ainsi qu'avec des associations d'Amérique centrale et d'Amérique du Sud ${ }^{26}$. Le retournement de la guerre en faveur des Alliés, qui commence à s'opérer durant l'année 1942 - notamment en raison de l'entrée en guerre des Américains en décembre 1941 aux côtés des Britanniques, puis de l'alliance conclue avec l'Union soviétique en 1942 - permet aux Anglais, en collaboration avec les Américains, d'élaborer des projets pour le futur de l'Europe ${ }^{27}$. Ces actions se retrouvent au sein de l'association anglaise de football. Dès 1943, un état des lieux (mémorandum) est établi afin d'aborder plusieurs thématiques du football d'après-guerre : les joueurs et entraîneurs, les infrastructures, les relations avec les autres organisations au niveau national (en particulier avec le Foreign Office), les arbitres, la propagande et la publicité. Dans ce tour d'horizon, qui doit permettre au domaine du football de reprendre rapidement l'activité footballistique d'avant-guerre, un point concerne les relations internationales. Ce travail de réflexion continue dans les mois qui suivent et, en 1944, huit souscommissions sont créées pour traiter des différentes thématiques. La question des relations internationales échoit à une sous-commission dans laquelle figurent de futurs dirigeants importants du football européen de la fin des années 1940 et de la décennie 1950, tel Arthur Drewry. Cette sous-commission suggère plusieurs dispositions, dont celle de jouer, dès la fin de la guerre, avec de nombreux clubs issus des territoires alliés et ceux qui seront occupés par l'armée anglaise. En effet, ces rencontres aideront à rétablir les relations entre les pays, mais également " à produire du divertissement et aussi à prélever des fonds pour rebâtir et financer

26 Brook Hirst A., Rapport du président de la FA (1942-1943), n.d. FA, minutes and proceedings from June 1943 to June 1945.

27 Kent J., "British postwar planning for Europe 1942-45 ", dans Varsori A., Calandri E. (eds.), The failure of peace in Europe, 1943-48, Basingstoke, Palgrave Macmillan, 2002, pp. 40-48. 
les associations de ces pays ${ }^{28}$. Ces décisions montrent que les Anglais souhaitent se positionner en tant que leader de la reconstruction du football en Europe. Afin de jouer ce rôle, le rapport recommande que la Football Association - et plus largement les associations britanniques reprenne sa place au sein de la FIFA.

À la suite de la capitulation allemande, cette question va être abordée par les deux parties, et ce dès le mois de juillet 1945 à l'occasion d'un match de l'équipe nationale anglaise en Suisse. Pendant celui-ci, Schricker et Rimet s'entretiennent avec Stanley Rous sur le contexte du football international et abordent aussi l'éventuelle réincorporation des associations britanniques dans la FIFA ${ }^{29}$. Le retour des Britanniques est vu d'un très bon œil par les dirigeants de la Fédération internationale. Témoin de cet état d'esprit, son secrétaire général n'hésite pas à faire parvenir à Stanley Rous - comme il l'a fait avec d'autres membres du comité exécutif - la page du futur rapport du secrétaire général 1944-1945 concernant les relations entre la FIFA et les associations britanniques $^{30}$. Ce procédé lui permet de recevoir des commentaires et des vérifications sur ses propos - Schricker ayant été globalement en manque d'informations sur les activités des associations nationales durant toutes les hostilités - mais c'est également un moyen d'amadouer les Anglais afin qu'ils reviennent rapidement dans le giron du football international. Pour la FIFA, le retour des Britanniques est en effet très important car il s'agit d'acteurs majeurs du football. Ainsi, à la suite de la période trouble de la guerre, leur présence constitue un gage de crédibilité pour la Fédération en vue de retrouver rapidement une place sur la scène footballistique internationale. En date du 24 septembre 1945, une lettre de Schricker à Seeldrayers confirme cet aspect. Le secrétaire relève ainsi que « la politique à suivre [...] est bien simple : activer les démarches pour arriver à un arrangement avec les associations britanniques. Une telle entente - ou fusion - aura l'effet de consolider et de fortifier énormément la position de la FIFA ${ }^{31}$.

28 Rous S., " Post war development - an interim Report, October 1944 », n.d. FA, minutes and proceedings from June 1943 to June 1945.

29 Lettre de I. Schricker à R.W. Seeldrayers, 20 juillet 1945. FIFA, membres du comité exécutif, dossier individuel : correspondance R.W. Seeldrayers (1939-1950), dossier :

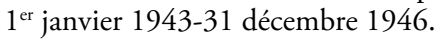

30 Schricker I., « Texte soumis à. Mr. Rous. Projet de Rapport 1944/45 concernant relations with the British Association ", n.d. FIFA, membres du comité exécutif, dossier individuel : correspondance J. Rimet (1945-1950), dossier : $1^{\text {er }}$ janvier 1945-31 décembre 1946.

31 Lettre de I. Schricker à R.W. Seeldrayers, 25 septembre 1945. FIFA, membres du comité exécutif, dossier individuel : correspondance R.W. Seeldrayers (1939-1950), dossier : $1^{\text {er }}$ janvier 1943-31 décembre 1946.6. 
Quelques mois plus tard, le rapprochement avec les Britanniques se précise puisque Drewry et Rous sont invités à participer à la première réunion du comité exécutif de la FIFA qui se déroule en novembre à Zurich $^{32}$. Le $1^{\text {er }}$ décembre 1945, Schricker fait mention à Rodolphe Seeldrayers d'une interview accordée par Rous au journal zurichois Sport dans lequel ce dernier s'est montré favorable au retour des Britanniques au sein de la FIFA ${ }^{33}$. Cependant, les autres associations britanniques vontelles emboîter le pas de la Football Association ? Le 18 juin 1946, Rous suggère à Schricker d'inviter des dirigeants des trois autres associations britanniques à participer en tant qu'observateurs au prochain congrès de la FIFA. L'Anglais précise qu'il ne sait pas "si les autres associations britanniques demanderont leur affiliation ${ }^{34}$, par contre il indique qu'elles accepteraient avec plaisir une invitation. Finalement, ces associations suivent les démarches de la Football Association et vont également se réaffilier lors du congrès de 1946. Pendant le printemps et l'été de cette même année, une quinzaine d'équipes britanniques jouent sur le continent $\mathrm{t}^{35}$, symbolisant cette volonté des associations britanniques de renouer, voire d'étendre, les liens avec leurs homologues continentaux. Le retour des associations britanniques à la FIFA nécessite néanmoins des négociations par les dirigeants de la Fédération internationale. En effet, dans l'optique de jouer un rôle dans la remise en route du football international, ces associations souhaitent occuper un rôle prépondérant au sein de la FIFA. Le comité exécutif semble conscient de cette situation et l'anticipe puisqu'il propose au congrès qu'un poste de vice-président leur soit réservé en raison "des immenses services rendus au sport par les associations britanniques ${ }^{36}$. De plus, les congressistes leur accordent le droit d'être exonérées du versement des pourcentages à la FIFA pour les rencontres des championnats britannique, une requête qui avait jusque-là toujours été refusée. C'est donc un tapis rouge que les associations

32 Drewry A., Rous S., "Report of the visit to the FIFA conference by the chairman of the international selection committee and the Secretary ", n.d. FA, FA council minutes 1945-1947.

33 Lettre de I. Schricker à R.W. Seeldrayers, $1^{\text {er }}$ décembre 1945. FIFA, membres du comité exécutif, dossier individuel : correspondance R.W. Seeldrayers (1939-1950), dossier : $1^{\text {er }}$ janvier 1943-31 décembre 1946.

34 Lettre de I. Schricker à J. Rimet, 18 juin 1946. FIFA, membres du comité exécutif, dossier individuel : correspondance J. Rimet (1945-1950), dossier : $1^{\text {er }}$ janvier 1945-31 décembre 1946.

35 Anonyme, Procès-verbal du comité exécutif de la FA du 11 mars 1946, n.d. FA, FA council minutes 1945-1947.

36 Schricker I., Procès-verbal de l'assemblée générale de la FIFA des 25-26 juillet 1946, n.d. FIFA, XXV-XXVII congrès ordinaires (1946-1952, rapport d'activité). 
membres de la Fédération internationale étendent devant les Britanniques. En comparaison, durant l'entre-deux-guerres, les Sud-Américains ont dû attendre près de vingt ans avant de disposer d'une place fixe au comité exécutif ${ }^{37}$.

Rapidement, les associations britanniques vont se montrer actives au sein de la FIFA, et en particulier participer à la pérennisation de ses finances. Par exemple, durant l'assemblée générale de 1948, l'assemblée accepte la proposition du comité exécutif de porter le pourcentage prélevé par la FIFA sur la recette brute des rencontres internationales de 1 à $1,5 \%$ et 0,5 à $0,75 \%$ pour les associations d'Amérique du Sud, celles-ci bénéficiant d'une exonération moindre puisque le pourcentage restant est reversé à la Confédération sud-américaine. À cette occasion, le délégué anglais, Brook Hirst, indique " qu'il veut faire plus que de soutenir la proposition du comité exécutif " $"$ "et soumet un amendement en vue d'une augmentation supplémentaire. Il s'agirait de passer à $2 \%$ sur tous les matchs internationaux et $1 \%$ pour ceux concernant les Sud-Américains. Cette proposition, qui va être retenue par l'assemblée, est soutenue par l'Écossais Graham, signe sans doute d'une consultation préalable entre les associations britanniques. Ces actions permettent donc à la FIFA de renforcer son autorité sur le football européen et mondial, et participent au retour des échanges internationaux en football. Certes, les associations britanniques jouent encore majoritairement entre elles, mais sur la trentaine de parties qu'elles disputent entre 1945 et 1948, l'Angleterre en joue une dizaine hors de ses frontières; quant à l'Écosse, elle s'oppose à la Belgique, à la France, au Luxembourg et à la Suisse.

Par ailleurs, le retour des associations britanniques au sein de la FIFA entame une nouvelle étape dans l'optique de décentraliser la Fédération internationale. En effet, quelques années après les associations d'Amérique $\mathrm{du}$ Sud, elles obtiennent aussi le privilège d'élire directement un viceprésident au comité exécutif. Cette démarche encourage la formation de groupements d'associations au sein de la Fédération. Or cette situation peut favoriser le développement d'idées chez des dirigeants souhaitant eux aussi bénéficier du même traitement et amener à une réflexion plus générale sur la structure de la FIFA. En outre, il faut souligner ici que des dirigeants britanniques, en premier lieu les Anglais Arthur Drewry et Stanley Rous, commencent à militer en faveur d'une réorganisation de la Fédération et d'une ouverture envers les pays extra-européens. Ces

\footnotetext{
Supra 1.3.2.
}

38 Anonyme, Procès-verbal de l'assemblée générale de la FIFA des 27-28 juillet 1948, n.d. FIFA, XXV-XXVII congrès ordinaires (1946-1952, rapport d'activité) 
démarches s'inscrivent dans le changement de la politique internationale de la Grande-Bretagne. En effet, au regard de sa position désormais secondaire sur la scène internationale par rapport aux États-Unis et à l'Union soviétique ainsi que des problèmes engendrés par les protestations de plus en plus actives et virulentes des mouvements d'indépendance dans ses colonies, le pays se retire progressivement de ses dernières possessions, comme en témoigne l'indépendance de l'Inde en 1948.

Le fait que des fédérations aussi puissantes que les associations britanniques commencent à envisager une décentralisation de la FIFA donne assurément du poids à cette éventualité. C'est d'autant plus le cas que, parallèlement, l'Union soviétique demande une position fixe de viceprésident au sein du comité exécutif comme condition à son adhésion.

\subsubsection{L'intégration de l'URSS}

Alors que des échanges préliminaires avaient eu lieu entre l'Union soviétique et la FIFA durant les années 1930, ceux-ci s'interrompent dès le début de la guerre. Cependant, des liens footballistiques entre les Soviétiques - qui hormis la guerre qu’ils mènent contre la Finlande restent en dehors des hostilités en raison de la signature du pacte de non-agression avec l'Allemagne en août 1939 - et leurs voisins perdurent dans les premiers temps du conflit. Ainsi, le 14 juin 1940, le Yougoslave Mihailo Andrejevic indique au secrétaire général Schricker qu'une rencontre footballistique est prévue entre l'Union soviétique et la Bulgarie, en août de la même année ${ }^{39}$. Toutefois, dans les mois qui suivent, l'attaque allemande dirigée contre l'Union soviétique durant l'été 1941 et la terrible guerre de l'Est qui s'ensuit paralysent les échanges internationaux du football soviétique jusqu'à la fin du conflit.

Au sortir de la guerre, l'URSS est, avec les États-Unis, la grande gagnante sur la scène internationale. Profitant du stationnement de l'armée rouge dans l'Est de l'Europe, elle étend sa zone d'influence. De plus, elle acquiert un prestige important sur la scène internationale : le courage de ses soldats et de sa population, qui a payé un lourd tribut aux combats - près de 25 millions de morts -, est relevé par ses alliés. L'Union soviétique s'affiche donc en tant que nouvelle interlocutrice potentielle dans les relations internationales et c'est dans ce contexte favorable - même

39 Lettre de M. Andrejevic à I. Schricker, 14 juin 1940. FIFA, membres du comité exécutif, dossier individuel : correspondance M. Andrejevic (1938-1982), dossier : 1939-1945. 
si des premières tensions avec les Américains se font sentir en particulier au sujet du futur gouvernement légitime en Pologne - qu'elle participe à la fondation de l'Organisation des Nations unies (ONU) en $1945^{40}$.

Un premier pas en vue de l'intégration de l'Union soviétique dans le giron du football international est réalisé avec la tournée à succès du Dynamo Moscou en Grande-Bretagne en automne $1945^{41}$. En outre, sur le chemin du retour, l'équipe soviétique semble également s'être arrêtée en Suède pour y disputer un match contre la formation de Norrköping. En décembre, le Dynamo effectue une autre tournée, cette fois en Yougoslavie. Quelques mois plus tard, ce sont les dirigeants du comité exécutif de l'Union belge de football qui évoquent la possibilité d'inviter une équipe soviétique à venir jouer en Belgique ${ }^{42}$. Au regard de ces échanges, l'adhésion de l'Union soviétique à la FIFA paraît de plus en plus plausible. Si au sein du CIO des discussions sur une probable adhésion de l'URSS à l'organisation n'aboutissent à aucun résultat ${ }^{43}$, par contre la Fédération internationale d'athlétisme tolère la participation des Soviétiques aux championnats du monde d'Oslo en août 1946. Cette décision ne laisse pas indifférents les dirigeants du comité exécutif de la FIFA ${ }^{44}$.

Les premières discussions officielles entre les Soviétiques et la Fédération internationale semblent avoir lieu durant le congrès de la FIFA de 1946. En effet, le spectre de l'Union soviétique plane sur l'assemblée générale puisqu'au début des discussions, la Pologne - au nom des associations d'Albanie, de Bulgarie, de Tchécoslovaquie et de Yougoslavie -dépose

40 Sur la participation de l'Union soviétique à la création des Nations unies, voir : Gaiduk I.V., Divided together. The United States and the Soviet Union in the United Nations, 1945-1965, Washington, Woodrow Wilson Center Press, 2012, pp. 43-82.

41 Porter D., Kowalski R., "Cold war football: British-European encounters in the 1940s and 1950s ", dans Wagg S., Andrews D. (eds.), East plays West: sport and the Cold War, London, Routledge, 2007, pp. 64-81.

42 Lettre de R.W. Seeldrayers à I. Schricker, 27 novembre 1945. FIFA, membres du comité exécutif, dossier individuel : correspondance R.W. Seeldrayers (1939-1950), dossier : $1^{\text {er }}$ janvier 1943-31 décembre 1946.

43 Sur l'arrivée de l'URSS au CIO, voir : Parks J., The Olympic Games, the Soviet Sports Bureaucracy, and the Cold War: Red Sport, Red Tape, Lanham, Lexington Books, 2017.

44 Lettre de I. Schricker à J. Rimet, 27 août 1946. FIFA, membres du comité exécutif, dossier individuel : correspondance J. Rimet (1945-1950), dossier : $1^{\text {er }}$ janvier 1945-31 décembre 1946. Dans un article de L'Équipe écrit en 1955, un journaliste note que l'ambassadeur soviétique alors en poste à Paris, M. Bogomolov, entreprend des démarches concrètes auprès de Jules Rimet en vue d'une adhésion de l'URSS à la FIFA. " M. Jules Rimet va abandonner non sans mélancolie le plus grand empire du monde ", L'Équipe, 16 juin 1954. 
une motion en vue d'une reconnaissance officielle de la langue russe au sein de l'organisation. Cette proposition n'est pas retenue par les congressistes, mais elle peut être perçue comme une préparation à l'arrivée des Soviétiques à la FIFA et révèle aussi que les pays qui soutiennent cette idée se trouvent désormais sous sa sphère d'influence. Durant le deuxième jour de l'assemblée, la présence de l'URSS se remarque plus précisément puisque Seeldrayers indique que la délégation yougoslave " a reçu une communication ${ }^{45}$ suivant laquelle l'organisme du football de l'URSS a exprimé sa décision de [rejoindre] la FIFA ${ }^{46}$. Pendant les discussions, le délégué yougoslave Andrejevic n'hésite pas à affirmer que si l'adhésion de l'URSS est acceptée, le congrès a l'assurance de recevoir la requête d'affiliation de l'URSS avant la fin des séances. Ce point de vue est soutenu par les délégués de la Tchécoslovaquie et de la Pologne. Cependant, l'Union soviétique se montre exigeante et souhaite disposer d'une place de vice-président au comité exécutif. Le but de cette requête est de lui permettre de jouer un rôle de premier plan dans la gouvernance de la Fédération. Les dirigeants de la FIFA se montrent plutôt favorables vis-à-vis de la demande, posture suivie par les congressistes qui acceptent un changement des statuts de la FIFA afin de faciliter l'arrivée de l'Union soviétique en son sein. Ainsi, comme c'est le cas pour les associations britanniques, le représentant soviétique dans le comité exécutif de la FIFA ne sera pas élu par le congrès, mais désigné par l'organisme qui dirige le football en Union soviétique. C'est donc un geste significatif en faveur de l'incorporation des Soviétiques qui est entrepris lors du congrès de 1946, mais aussi une nouvelle étape dans une possible future décentralisation de l'organisation.

Malgré les promesses faites par Andrejevic devant l'assemblée générale et un télégramme envoyé durant les discussions à la section de football de l'URSS pour lui annoncer l'avis favorable de la FIFA ${ }^{47}$, les Soviétiques ne donnent aucun signe de vie avant la fin des sessions du congrès. Ce silence va durer plusieurs semaines. En octobre, cette situation commence à créer un clivage au sein du comité exécutif de la FIFA qui illustre les tensions qui sont en train de se déclarer dans les relations politiques internationales, à savoir l'entrée progressive dans la Guerre froide. En

45 Selon un journaliste de L'Équipe, cette communication a été transmise dans la nuit entre la première et la deuxième journée du congrès. "Coup de théâtre à Luxembourg. La Russie désire adhérer à la FIFA », L'Équipe, 26 juillet 1946.

46 Schricker I., Procès-verbal de l'assemblée générale de la FIFA des 25-26 juillet 1946, n.d. FIFA, comité exécutif (procès-verbaux 1940-1946).

47 "Le congrès de la FIFA liquide ses travaux et nomme son nouveau comité exécutif. M. Rimet réélu président par acclamation ilip'Équipe, 27-28juillet 1946. 
effet, d'un côté, des dirigeants comme Andrejevic et Valousek soutiennent activement l'arrivée de l'URSS au sein de la FIFA ${ }^{48}$. De l'autre côté, des dirigeants plus proches du camp occidental, tels les Britanniques Drewry et Kirkwood, le Néerlandais Lotsy et le Belge Seeldrayers, qui s'agacent du silence soviétique et prônent le maintien de la position du comité exécutif des années 1936-1937. Pour eux, il ne sera possible de jouer contre l'Union soviétique que si elle soumet une demande d'affiliation à la FIFA. Entre ces positions fermes, le Suisse Krebs et le Chilien Bianchi se montrent plutôt favorables à une conciliation, situation qui rappelle, là aussi, la position de leurs pays sur la scène internationale. En effet, ils souhaitent que des permissions de jouer contre des équipes soviétiques soient accordées en attendant l'affiliation de l'URSS. S'ils défendent cette posture, c'est en raison du fait qu'ils estiment que cette affiliation est imminente. Le président Rimet se positionne, lui, plutôt de manière intransigeante, indiquant qu'accepter un compromis alors que l'Union soviétique a promis une affiliation devant l'assemblée générale de 1946 serait "une capitulation sans condition " ${ }^{49}$. Cette position ferme de Rimet doit se comprendre au regard des précautions réglementaires que prennent depuis la fin de la Deuxième Guerre mondiale les dirigeants de la Fédération internationale. En effet, il s'agit toujours de minimiser les tensions au sein de l'organisation, perspective qui lui permettra de réaffirmer son pouvoir sur le football mondial.

Au contour des mois de novembre et décembre 1946, le cas soviétique va néanmoins se régler. En date du 20 novembre, Schricker reçoit un télégramme du comité de culture physique et des sports de l'URSS qui l'informe que "la section de football de l'URSS désire [s'affilier à] la fédération $"$ et qu'elle s'engage à respecter la réglementation et les Lois du jeu de la FIFA. Le 11 décembre 1946, Rimet confirme au secrétaire de la FIFA qu'il vient de recevoir la demande d'affiliation de l'Union soviétique ${ }^{51}$. Le président, qui dans un courrier précédent avait indiqué au secrétaire que l'arrivée de l'URSS marquerait « l'unification mondiale

48 Anonyme, Procès-verbal de la réunion du comité exécutif de la FIFA du 23 octobre 1946, n.d. FIFA, comité exécutif (circulaire aux membres 1946-1957).

49 Lettre de I. Schricker au comité exécutif de la FIFA, 30 août 1946. FIFA, comité exécutif (circulaire aux membres 1946-1957).

50 Lettre de I. Schricker au comité exécutif de la FIFA, 22 novembre 1946. FIFA, comité exécutif (circulaire aux membres 1946-1957).

51 Lettre de J. Rimet à I. Schricker, 11 décembre 1946. FIFA, membres du comité exécutif, dossier individuel : correspondance J. Rimet (1945-1950), dossier : $1^{\text {er }}$ janvier 1945-31 décembre 1946. 
du sport-football ${ }^{52}$, se montre très satisfait. Cet enthousiasme doit être mis en perspective avec les actions Rimet opérées depuis plus de vingt ans dans le but d'élargir le nombre d'associations membres à la FIFA.

L'entrée de l'Union soviétique à la Fédération internationale de football constitue un nouveau pas important dans l'élargissement du territoire de juridiction de la FIFA. De plus, cette adhésion permet de poursuivre l'ambition de son élite de créer une organisation véritablement internationale en football ; d'autre part, elle élimine définitivement les risques d'une possible concurrence qui proviendrait de l'URSS (par exemple au travers de l'IRS). Enfin, sans doute qu'il s'agit aussi pour Rimet, plus idéaliste que ses collègues du comité exécutif, d'apporter une pierre de plus à la pacification des relations internationales par l'entremise du football (une démarche qui contraste avec les tensions entre l'Est et l'Ouest qui se font toujours plus visibles). L'année 1947 officialise définitivement l'arrivée de l'Union soviétique à la FIFA et, en date du 21 août, Ivo Schricker informe les membres du comité exécutif que l'URSS vient de nommer son représentant, Valentin Granatkine. Né en 1908, Granatkine est un jeune homme en comparaison des membres du comité exécutif de la FIFA, qui ont pour la plupart une soixantaine voire une septantaine d'années. Il partage bien quelques dispositions communes avec eux, comme le fait d'avoir été un joueur d'élite. Par contre, sa formation professionnelle est tout à fait différente puisqu'il est gradué de la haute école du parti communiste et membre de ce même parti depuis 1939. C'est donc un dirigeant qui s'insère dans la ligne politique du régime et contrebalance les aspirations libérales des autres membres du comité exécutif de la FIFA.

L'arrivée de l'Union soviétique offre de nouvelles possibilités d'élargissement des échanges footballistiques européens vers l'Ouest. Ainsi, le 7 janvier 1947, le journal L'Équipe demande, en première page, si un match entre l'équipe nationale française et son homologue soviétique sera prochainement organisé ${ }^{53}$. De même, en date du $1^{\text {er }}$ avril, la Fédération suisse envoie un courrier à Moscou afin de discuter de l'organisation d'une éventuelle rencontre contre une formation soviétique qui " pourrait avoir lieu dans le cadre d'une tournée [de cette équipe] dans les pays de l'Europe

52 Lettre de J. Rimet à I. Schricker, 26 novembre 1946. FIFA, membres du comité exécutif, dossier individuel : correspondance J. Rimet (1945-1950), dossier : $1^{\text {er }}$ janvier 1945-31 décembre 1946.

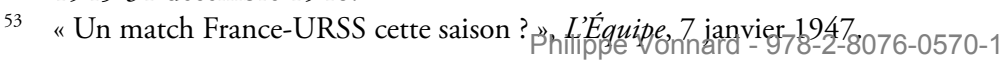


occidentale, soit en France, Belgique, Hollande ou en Italie ${ }^{54}$. Deux ans après la fin des hostilités, le football européen semble donc remis des affres de la guerre et, hormis le cas de l'Allemagne qui est encore en pleine discussion - nous y reviendrons plus loin -, tous les pays européens se montrent favorables à jouer les uns contre les autres.

\subsubsection{Le match de la FIFA (1948) : le symbole de l'unité européenne?}

Symbole de cette unité retrouvée, une nouvelle rencontre convoquant plusieurs joueurs d'association européenne est organisée sur le modèle de la rencontre de 1938, qui pour rappel a opposé l'équipe nationale anglaise à une sélection de la FIFA. Outre l'aspect commémoratif de la rencontre qui doit sanctionner le retour des Britanniques dans le giron de la FIFA, l'organisation de ce match a aussi pour but de permettre à l'organisation internationale de football d'améliorer ses finances, une partie des recettes lui étant reversée. Les premiers pourparlers semblent avoir eu lieu entre Rous et Schricker le 21 juillet 1945, à la suite de la rencontre AngleterreSuisse ${ }^{55}$.

Après de nouvelles discussions, le match est finalement fixé à Glasgow en mai 1947. L'avantage de la ville écossaise est qu'elle dispose de l'un des plus grands stades d'Europe pouvant contenir plus de 120000 spectateurs, ce qui permettra d'obtenir des fonds suffisants en vue de pérenniser les finances de la FIFA. Afin d'aguerrir l'équipe continentale, mais aussi pour compléter le dispositif visant à récolter un maximum de fonds, les dirigeants optent pour l'organisation d'un match d'entraînement à Amsterdam. Selon le journaliste Jacques de Ryswick, celui-ci « dépasse le cadre de la rencontre amicale car il réunit 65000 spectateurs et l'enceinte a été ornée des drapeaux de toutes les associations nationales affiliées à la FIFA $»^{56}$.

Reprenant la modalité de la rencontre de 1938, la partie doit aussi offrir une image d'un continent uni. Au sein de la Fédération internationale, une commission est créée pour sélectionner les joueurs continentaux,

54 Lettre de J. Krebs et H. Käser au président de l'organisme central du sport soviétique, $1^{\text {er }}$ avril 1947. FIFA, correspondance avec les associations nationales : Suisse (1938-1950), dossier : 1939-1950.

55 Lettre de I. Schricker à J. Rimet, 8 mars 1948. FIFA, membres du comité exécutif, dossier individuel : correspondance J. Rimet (1945-1950), dossier : $1^{\text {er }}$ janvier $1948-$ 31 décembre 1948.

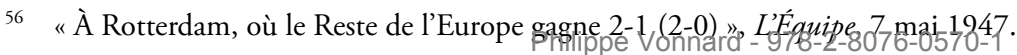


sous la présidence de Seeldrayers, de Frederiksen, Lotsy et Valousek. Il est intéressant de noter que, contrairement au match disputé dix ans auparavant, le comité de sélection est élargi puisqu'il est composé de membres représentant les associations du Nord (Frederiksen), le bloc soviétique (Valousek) et les pays du Benelux (Lotsy). Dès lors, si les membres du comité exécutif de la FIFA souhaitent que les joueurs sélectionnés soient ceux « ayant réellement la grande classe internationale et qui ont prouvé posséder cette qualité dans de grands matchs internationaux, contre des adversaires de grande classe $~_{57}$ - position qui se comprend afin d'assurer financièrement l'événement -, le niveau footballistique n'est pas le seul critère dans la sélection des joueurs. En effet, la partie recèle une portée symbolique plus forte que les rencontres organisées avant la guerre et doit permettre de dépasser les ressentiments issus du conflit. Cet objectif est en grande partie atteint. Malgré les difficultés rencontrées dans la sélection des joueurs de l'équipe continentale - il est par exemple impossible d'assurer le déplacement des joueurs autrichiens -, la formation est composée des joueurs issus de Belgique, du Danemark, de France, d'Irlande, d'Italie, des Pays-Bas, de Suède, de Suisse et de Tchécoslovaquie. Face à elle, une équipe composée de cinq Anglais, trois Écossais, un Gallois et un Irlandais du Nord. Au regard de la partie qui s’est déroulée en 1938, force est de constater que l'Europe présentée au public est plus étendue puisque treize associations européennes sont représentées sur la pelouse contre huit dix ans plus tôt. L'affiche présente sur le programme insiste sur cette situation, le joueur britannique donnant la main à son homologue européen, placé sur la Sibérie, leurs deux bras parcourant le territoire de l'Europe.

Le succès populaire de la manifestation est au rendez-vous puisque 120000 spectateurs assistent à la partie, ce qui permet de remettre la situation financière de la FIFA à un niveau "satisfaisant ${ }^{58}$, selon le mot du Suisse Jean Krebs. Ainsi, la Fédération internationale touche un montant net de 86598,50 francs suisses, ce qui correspond à près de $62 \%$ des recettes de la FIFA pour l'année 1948 (le match est comptabilisé sur les finances de 1948), qui s'élèvent à 140355,78 francs suisses ${ }^{59}$. Le succès financier de la rencontre s'ajoute à la recette du match d'entrânement préalablement disputé par l'équipe continentale à Amsterdam contre la

57 Brouillon d'une lettre de I. Schricker au comité exécutif de la FIFA, 8 janvier 1947. FIFA, membres du comité exécutif, dossier individuel : correspondance R.W. Seeldrayers (1939-1950), dossier : $1^{\text {er }}$ janvier 1947-31 décembre 1949.

58 Schricker I., Procès-verbal de la réunion du comité exécutif de la FIFA des 15-16 avril 1948 », n.d. FIFA, comité exécutif (procès-verbaux 1947-1950).

59 Anonyme, Rapport financier (1948), n.d. Annexe 3 de la réunion du comité exécutif du 29 juillet 1948. FIFA, comité exécutif (procès-verbaux 1947-1950) 
deuxième garniture de l'équipe des Pays-Bas. Toutefois, la somme due à la FIFA ne peut pas être versée par l'association des Pays-Bas, en raison des restrictions sur le transfert d'argent vers la Suisse qui sont en vigueur dans le pays. En conséquence, les dirigeants décident de garder la somme sur un compte bancaire dans ce pays et d'organiser les deux ou trois prochaines séances du comité exécutif à Amsterdam.

À la fin de l'année 1947, les échanges footballistiques européens semblent s'être remis des affres de la guerre. Si les associations nationales ont réussi à surmonter la Deuxième Guerre mondiale, c'est aussi en raison de la possibilité de la FIFA de faire face au conflit. Quelles sont les actions de son élite dirigeante qui ont permis à l'organisation de survivre à la guerre?

\subsection{Une position en péril sur la scène internationale}

Dans les années 1930, les dirigeants de la FIFA ont mis en place des mécanismes permettant de neutraliser l'influence du contexte politique international sur les activités de la Fédération internationale. Cependant, le déclenchement de la Deuxième Guerre puis l'entrée dans la Guerre froide risquent de les remettre en question en raison de la tension que ces contextes font peser sur la scène internationale.

\subsubsection{Faire face à l'Europe sportive des forces de l'Axe}

Comme signalé préalablement, le régime nazi investit les structures du football national dès son arrivée au pouvoir en 1933. Cette intervention politique dans les affaires du DFB a pour conséquence l'épuration progressive des clubs d'individus, comme les Juifs ${ }^{60}$, qui ne correspondent pas à l'idéal nazi. Sur la scène internationale, le Troisième Reich met rapidement une certaine pression sur la FIFA, comme il le fait d'ailleurs dans d'autres organisations internationales sportives ${ }^{61}$. Cette volonté du Troisième Reich de dominer la sphère sportive internationale se perçoit notamment avec l'organisation de manifestations d'envergure telles que les Jeux olympiques : après les Jeux d'hiver de Garmisch et surtout les Jeux de Berlin de 1936.

60 Wahlig H., Sport im Abseits. Die Geschichte der Jüdischen Sportbewegung im nationalsozialistischen Deutschland, Göttingen, Wallstein Verlag, 2015.

61 Teichler H.J., Internationale Sportpolitik im Dritten Reich, Schorndorf, K. Hofmann, 1991. 
À la fin des années 1930, l'Allemagne nazie figure parmi les associations les plus actives de la FIFA. Plusieurs exemples témoignent de cette situation, comme celui de la vente du Handbook de la Fédération internationale. En effet, dans un courrier adressé aux membres du comité exécutif datant de février 1939, le secrétaire Schricker fait le point sur les ventes du document paru en 1937. Sur un total de 291 ventes auprès des associations nationales, 116 exemplaires sont vendus en langue allemande contre 83 en français, 57 en espagnol et 35 en anglais. Quant aux ventes auprès du public, elles s'élèvent à 133 , dont 52 pour des ressortissants allemands. Ce chiffre est élevé comparé au deuxième pays à être représenté dans le classement, la Suisse, qui ne compte qu'une petite vingtaine de ventes. À noter que pour la plupart des autres pays, les ventes ne dépassent pas cinq exemplaires ${ }^{62}$. Autre exemple de cette influence grandissante de l'Allemagne dans les affaires de la FIFA, celle de l'attribution de la Coupe du monde de 1942. Durant le congrès de 1938 à Paris, le président du Fachamt Fussball - qui a remplacé le DFB à l'arrivée des nazis -, Felix Linnemann, présente la candidature de son pays en vue de l'organisation de la Coupe du monde $1942^{63}$. Rien n'est décidé lors du congrès parisien quant à l'attribution de la Coupe du monde, la décision finale étant reportée à l'assemblée suivante qui doit être organisée à Luxembourg en 1940. Pourtant, en date du 26 décembre 1939, le Bureau allemand d'information (Deutsches Nachrichten Büro) profite d'une réunion du comité exécutif de la FIFA pour diffuser une information sur le sujet. Il indique que l'organe dirigeant de la Fédération internationale vient de décider "définitivement de charger l'Allemagne de l'organisation de la Coupe du monde $1942 "{ }^{64}$. L'information est fausse, ce qui oblige Jules Rimet et Ivo Schricker à apporter un rapide démenti public.

Avec l'entrée en guerre, cette pression sur la FIFA s'accentue et accompagne la volonté du régime nazi de désormais contrôler, ou remplacer, les organisations internationales. En effet, dans son ambition totalitaire, le Troisième Reich tente de prendre le contrôle de tous les pans de la société civile européenne et d'instaurer un "nouvel ordre européen » ${ }^{65}$. Dans cette

62 Lettre de I. Schricker au comité exécutif de la FIFA, 13 février 1939. FIFA, comité exécutif (procès-verbaux 1939).

63 Schricker I., Procès-verbal de l'assemblée générale de la FIFA du 3 juin 1938, n.d. FIFA, XX-XXIV congrès ordinaires (1931-1938, rapport d'activité).

64 Lettre de I. Schricker à R.W. Seeldrayers, 26 décembre 1939. FIFA, membres du comité exécutif, dossier individuel : correspondance R.W. Seeldrayers (1939-1950), dossier : $1^{\text {er }}$ janvier 1943-31 décembre 1946.

65 Durant Y., Le nouvel ordre européen nazi (1938-1945), Bruxelles ${ }_{2}$ Complexe 1990. 
perspective, des organisations internationales sont largement investies, comme c'est le cas de l'OIT ${ }^{66}$, voire de nouvelles entités sont créées, telle la Fédération européenne des postes ${ }^{67}$.

À la suite des travaux pionniers de Hans Joachim Teichler, nous savons désormais que le domaine sportif n'échappe pas à cette emprise des nazis ${ }^{68}$. Aidée par ses alliés, l'Italie et la Hongrie, l'Allemagne nazie paralyse les actions du $\mathrm{CIO}^{69}$, reprend à son compte la gestion de la Fédération internationale d'escrime ${ }^{70}$ ou encore crée une nouvelle fédération de boxe ${ }^{71}$. Idée plus ambitieuse, le Reichsführer Hans von Tschammer und Osten développe le projet d'une Fédération européenne des sports qui regrouperait la plupart des organisations européennes ou internationales. Celle-ci serait dirigée par un président allemand, qui serait secondé par deux vice-présidents, un Italien et un Hongrois. Le projet est formellement discuté à l'été 1941, notamment lors d'une réunion à Berlin entre des dirigeants sportifs bulgares, croates, espagnols, finlandais, hongrois, italiens, néerlandais, norvégiens, roumains et slovaques, soit des pays faisant partie de l'Axe. Malgré d'autres discussions et un projet de conférence pour l'été-automne 1942, l'avancée de la guerre - en particulier les difficultés allemandes sur le front de l'Est et en Afrique du Nord retarde les travaux. Finalement, l'idée ne se concrétise pas et tombe en désuétude à la mort de von Tschammer und Osten, en 1943.

Dans la continuité de cette volonté des autorités nazies de contrôler les organisations sportives internationales, la FIFA est également l'objet de leur convoitise. Dès le début des années 1940, une ingérence allemande

66 Kott S., "Dynamique de l'internationalisation : l'Allemagne et l'Organisation internationale du travail (1919-1940) ", Critique internationale, vol. 52, n 3, 2011, p. 82 .

67 Laborie L., L'Europe mise en réseaux. La France et la coopération internationale dans les postes et les télécommunications (années 1850-années 1950), Bruxelles, P.I.E. Peter Lang, 2010 (voir les pages 332-340).

68 Teichler H.J., Internationale Sportpolitik im Dritten Reich, op. cit., pp. 328-354. Voir également : Bahro B., Der SS-Sport. Organisation, Funktion, Bedeutung, Paderborn, Ferdinand Schöningh Verlag, 2013, pp. 257-295.

69 Clastres P., " Neutralité politique, compromissions avec le régime nazi, continuité olympique. Les présidents successifs du CIO (1925-1972) au défi des Jeux de Berlin ", dans Bensoussan G. et al., Sport, corps et sociétés de masse, op. cit., pp. 211-228.

70 Ottogalli-Mazzacavallo C., Terret, T., « La Fédération internationale d'escrime en guerre : de la spoliation à l'épuration (1939-1948) ", Sport History Review, vol. 42, $\mathrm{n}^{\circ} 1,2011$, pp. 1-16.

71 Loudcher J.-F., Day D., "The International boxing union (1913-1946): a European sports and/or political failure? ", The International Journal of the History of Sport, vol. 30, n 17, 2013, pp. 2016-2030. 
dans ses affaires peut être constatée. C'est d'abord de l'extérieur que les nazis essaient de contrôler l'organisation. Grâce à leur victoire militaire sur la France en mai 1940, puis au repli des Britanniques qui s'opère dans les mois qui suivent, l'armée allemande contrôle la mobilité des populations sur le continent. Ainsi, l'organisation des réunions du comité exécutif de la FIFA est soumise au bon vouloir du gouvernement allemand car, pour se déplacer en territoire occupé, les dirigeants doivent obtenir une permission de la part des autorités allemandes. À partir de 1941, ces dernières font savoir au secrétariat de la FIFA que les futures réunions du comité exécutif devraient se tenir "soit en Allemagne, soit dans un des pays occupés " ${ }^{72}$. Parallèlement à ces pressions extérieures, c'est aussi de l'intérieur de la Fédération que les Allemands tentent de prendre le contrôle, et ce par l'entremise de son représentant au sein du comité exécutif, Peco Bauwens ${ }^{73}$.

En raison des alliances passées avec l'Italie, puis avec la Hongrie, dès l'entrée en guerre, le comité exécutif de la FIFA compte désormais trois représentants de l'Axe. Même si, en février 1940, Bauwens prône officiellement de continuer de jouer et de " rester unis dans l'amitié aussi longtemps que les circonstances le permettent $»^{74}$, il demande quelques mois plus tard à Ivo Schricker de permettre "l'installation d'un vice-président allemand $"{ }^{75}$ au sein du comité exécutif. Il justifie cette requête en raison de la puissance de la Fédération allemande dans la FIFA. Bien que la demande ne soit pas acceptée, elle confirme la tentative des nazis de pénétrer le cour même de la gouvernance de la FIFA. Cette quête se poursuit dans les mois

72 Lettre de R.W. Seeldrayers à I. Schricker, 12 septembre 1941. FIFA, membres du comité exécutif, dossier individuel : correspondance R.W. Seeldrayers (1939-1950), dossier : 1941-1942.

73 La position de Bauwens vis-à-vis du régime nazi nous semble très ambiguë. En effet, la poussée d'antisémitisme que connaît le pays depuis l'arrivée au pouvoir des nazis le concerne au premier plan puisque sa femme, Elisabeth Gidion, est juive. De fait, elle est suivie de près par la Gestapo. Harassée par cette situation, elle tombe en dépression et met fin à ses jours en septembre 1940. Sous cet angle, ce dernier peut être considéré comme une victime du nazisme. Toutefois, selon des historiens critiques comme Arthur Heinrich, cet argument n'est pas recevable car l'un de ses fils, Peter Franz, l'accuse d'être responsable de la mort de sa mère pour l'avoir délaissée. D'ailleurs, quelques mois plus tard, Bauwens se remarie. Après la guerre, il se présentera en victime du régime dans quelques courriers à ses collègues du comité exécutif et, en particulier, à son ami de longue date, Ivo Schricker, indiquant notamment à ce dernier qu'il fallait qu'il prenne conscience de ce qu'était la vie sous le nazisme.

74 Bauwens P., "Amitié même dans les temps difficiles ", Bulletin de la FIFA, n 15-16, février-mars 1940, pp. 2-3.

75 Wahlig H., "Dr. Ivo Schricker: Ein Deutscher in Diensten des Weltfussballs », dans Peiffer L., Schulze-Marmeling D. (eds.), Hakenkreuz und Rundes Leder. Fussball im Nationalsozialismus, Göttingen, Verlag die Willerkstatt, 2008, $\mathrm{p}$ P 200 
qui suivent avec la demande de Bauwens d'intégrer le comité d'urgence de la FIFA. Or, selon les statuts de la FIFA, cet organe est composé du président et des deux vice-présidents (à noter qu'un membre peut toutefois être désigné par le président si un vice-président ne peut se présenter $)^{76}$. En conséquence, il est formé de Mauro, Rimet et Seeldrayers. La demande de Peco Bauwens de faire partie de ce comité est acceptée par les trois dirigeants qui, faisant une accommodation de circonstance, vont ainsi à l'encontre de leur règlement. Durant la première partie de la guerre, Bauwens est incontournable dans les affaires de la FIFA. En effet, il fait souvent office de relais entre le secrétariat et les autres membres du comité d'urgence. Le dirigeant allemand dispose d'un avantage de taille vis-à-vis de ses collègues puisqu'il peut se déplacer facilement entre leurs différents lieux de résidence. Mais, et c'est toute l'ambiguïté d'une situation qui mêle un contexte politique international et des liens personnels très forts entre les individus, il profite de sa situation pour se montrer aussi bienveillant envers eux. Par exemple, il transporte des lettres personnelles ou des télégrammes écrits par Seeldrayers à sa fille qui réside aux États-Unis ${ }^{77}$. Ces gestes relèvent-ils d'une recherche de pouvoir ou d'un témoignage d'amitié sincère ? S'il est difficile de répondre à cette question, en tous les cas, et si nous suivons le raisonnement d'Alfred Wahl, l'entrée de Bauwens au sein du comité d'urgence n'est pour les Allemands qu'une première étape qui doit conduire à l'investissement total de la FIFA. Ce chercheur affirme en effet que Bauwens tente de prendre le contrôle de l'organisation. Il cite notamment le passage d'une lettre que ce dernier adresse au chargé de presse du Reichssportführer, Guido von Mengden, dans laquelle il écrit : "Si nous agissons habilement, nous pourrons placer l'actuelle FIFA totalement sous l'influence de l'Axe et l'isoler encore plus de l'Angleterre ${ }^{78}$. Force est néanmoins de constater que le régime nazi n'arrive finalement pas à ses fins.

Pour comprendre cet échec, il faut le remettre dans le contexte de la politique délicate mais habile que mène le secrétaire général Schricker, qui essaie de s'accommoder de cette ingérence allemande dans les affaires de la FIFA tout en essayant de maintenir indépendante l'activité de la Fédération internationale. Le traitement de l'adhésion des nouveaux pays qui voient le jour suite aux remaniements géopolitiques de la fin

76 Anonyme, Statuts de la FIFA [édition de 1938], art. 9 [des statuts]. FIFA, statuts, 1904-1981.

77 Lettre de R.W. Seeldrayers à P. Bauwens, 8 octobre 1941. FIFA, membres du comité exécutif, dossier individuel : correspondance R.W. Seeldrayers (1939-1950), dossier : $1^{\text {er }}$ janvier 1943-31 décembre 1946.

78 Wahl A., La seconde histoire du nazisme dans l'Allemagne fédérale depuis 1945, Paris, Armand Colin, p. 235 
des années 1930 témoigne bien de cette politique. Premier cas, celui de la Slovaquie. Créée à la suite du démantèlement de la Tchécoslovaquie, la Fédération slovaque de football demande de pouvoir entrer dans la Fédération internationale. Après un temps de réflexion, la FIFA reconnaît l'existence de l'association slovaque ainsi que celle du Protectorat de Bohême-Moravie ${ }^{79}$. Autre exemple, celui de la Croatie. Le passage des armées du Troisième Reich dans les Balkans en 1941 modifie une nouvelle fois la cartographie de cette région. Un État croate est proclamé sous l'égide d'un gouvernement mené par l'ultranationaliste Ante Pavelic. Le football semble avoir anticipé cette situation puisqu'une association croate de football s'est détachée, quelques mois plus tôt, de l'association yougoslave et son équipe nationale a déjà joué deux matchs contre la Suisse en $1940^{80}$. Au printemps 1941, elle demande à pouvoir adhérer à la FIFA. Des échanges ont lieu sur la question, en particulier entre Schricker et Seeldrayers. Rodolphe Seeldrayers se montre plutôt favorable et demande de suivre la même procédure qui a été employée vis-à-vis de la BohêmeMoravie $^{81}$. Quelques semaines plus tard, le 15 juillet 1941, la demande d'admission provisoire est confirmée par la FIFA. Ainsi, les membres du comité exécutif ne semblent pas avoir tenu compte du fait que le régime fasciste des Oustachis ${ }^{82}$ n'est pas reconnu par de nombreux pays.

Ces décisions montrent que la FIFA se plie à la nouvelle géopolitique instaurée par l'Allemagne nazie. Cependant, relevons que le comité d'urgence ne fait finalement que poursuivre ici la politique décidée durant les années 1930, à savoir de ne pas intervenir dans les affaires internes des associations nationales. De plus, l'organe a effectivement le droit de donner un aval positif au sujet d'une adhésion, aval qui n'est cependant en rien définitif puisqu'il devra être validé par l'assemblée générale. Selon nos analyses, l'acceptation de nouvelles fédérations permet finalement à la FIFA de continuer son activité.

79 La rapide mise sur pied d'une équipe nationale et la demande d'adhésion de la Slovaquie à la FIFA confirment l'importance acquise par le football comme vecteur de reconnaissance d'un pays sur la scène internationale. Anonyme, "Situation de l'Association de la Tchécoslovaquie ", Annexe $n^{\circ} 6$ de la réunion du comité exécutif du 16 décembre 1939. FIFA, comité exécutif (procès-verbaux 1939).

80 Quin G., Vonnard P., "Internationale Spiele der Schweiz im Zweiten Weltkrieg. Sport und Politik, Kontinuitäten und Traditionen ", dans Herzog M., Brändle F. , Europäischer Fussball im Zweiten Weltkrieg, op. cit., pp. 177-195.

81 Lettre de I. Schricker à R.W. Seeldrayers, 14 mai 1941. FIFA, membres du comité exécutif, dossier individuel : correspondance R.W. Seeldrayers (1939-1950), dossier : $1^{\text {er }}$ janvier 1943-31 décembre 1946.

82 Magaš B., Croatia through history: the making of a European state, London, Saqi Books, 2007 (voir les pages 555-566). 
En fait, tout au long du conflit, le secrétaire Schricker s'active pour que la Fédération internationale poursuive son action. Alors que la guerre vient d'éclater, il confirme par exemple aux associations membres que le prochain congrès, prévu en 1940, aura bel et bien lieu à Luxembourg. Il indique toutefois que si les circonstances du conflit devaient empêcher la bonne tenue de la manifestation dans cette ville, la Fédération internationale se réserve le droit de choisir une autre ville ${ }^{83}$. Au fil des mois et avec l'avancée des troupes allemandes vers l'Europe de l'Ouest, les dirigeants se rendent compte que le travail de la FIFA risque d'être compromis et le congrès de 1940 est finalement annulé. Malgré l'ampleur prise par la guerre, le secrétaire général essaie de maintenir le cap. Dans une circulaire datant de mai 1940, il indique aux associations membres de la FIFA que l'organisation "s'efforcera de conserver intacte, partout où elle le pourra, le patrimoine créé dans le monde entier par les grandes associations nationales. Elle demeurera en contact, autant que les circonstances le lui permettront, avec les Associations des pays envahis et leur apportera le réconfort qu'elles sont en droit d'attendre d'elle ${ }^{84}$. "Cette communication vise sans doute à rassurer les associations membres sur la capacité de la FIFA à faire face aux événements. Elle peut aussi être considérée comme une sorte de rappel vis-à-vis des forces de l'Axe contre une possible tentative d'ingérence de leur part dans la Fédération. Car, dans ces premiers mois de la guerre, le secrétaire général de la FIFA semble bien décidé à ne pas laisser l'organisation entre leurs mains.

En effet, la temporalité de la lettre correspond au moment où les Allemands semblent sur le point de remporter la bataille de France. Or, face à cette situation, Schricker songe à délocaliser le siège de la FIFA, en raison du fait qu'il ne met pas de côté le risque d'une invasion du territoire suisse par les armées du Reich. Cette situation aurait pour conséquence l'évacuation probable de la ville de Zurich, cette dernière se trouvant dans la zone de défense. Dans ce cas, le secrétaire devrait partir, laissant les affaires de la Fédération derrière lui, avec le risque qu'elles soient détruites lors de bombardements, voire même qu'elles tombent dans les mains des occupants. Un tel contexte signifierait l'arrêt du travail de la Fédération internationale. C'est pourquoi Schricker fait part à Rodolphe

83 Lettre de I. Schricker à l'Association argentine de football, 28 octobre 1939. FIFA, correspondance avec les associations nationales : Argentine (1934-1968), dossier : 1934-1950.

84 Lettre de I. Schricker à R.W. Seeldrayers, 31 mai 1940. FIFA, membres du comité exécutif, dossier individuel : correspondance R.W. Seeldrayers (1939-1950), dossier : $1^{\text {er }}$ janvier 1943-31 décembre 1946. 
Seeldrayers de son idée de transférer le secrétariat momentanément dans une petite localité près dans la région montagneuse du Rigi, qui aurait comme avantage de lui laisser l'opportunité « même en cas de danger [de continuer à] correspondre librement et aussi [de] partir pour une autre région si nécessaire ${ }^{85}$. Outre de préserver les activités de la FIFA, il y a cette volonté chez Schricker de perpétuer la posture apolitique développée durant les années 1930. En effet, dans un autre courrier écrit à Seeldrayers, il souligne qu'il est important que la FIFA reste " une organisation sportive dirigée absolument et exclusivement par des points de vue sportifs " ${ }^{86}$. Il semble donc conscient que, si la Fédération internationale tombe dans les mains des dirigeants du Troisième Reich, le risque est grand qu'elle soit totalement instrumentalisée par ce régime.

S'ajoute à cette politique une situation personnelle car, sur le plan politique, Schricker s'avère être plutôt hostile au régime nazi. Il est notamment président du Comité pro memoria Bensemann consacré au football des juniors, créé en mémoire de son ami de très longue date, Walther Bensemann, chassé d'Allemagne en 1933 en raison de ses origines juives et décédé en 1934 sur les bords du lac Léman (à Montreux) $)^{87}$. Ainsi, en cas d'invasion allemande, ne serait-il pas lui-même sous la menace d'une arrestation ? En ce sens, un déplacement au Rigi lui permettrait de se retirer dans un endroit sans doute moins visible que la ville de Zurich.

Quelques semaines plus tard, une autre mesure est discutée qui témoigne de cette volonté d'assurer la survie de la Fédération internationale. Il est cette fois question de mettre à l'abri les réserves financières de la FIFA. Cette action est imaginée par Rodolphe Seeldrayers en étroite collaboration avec le secrétaire. En effet, le dirigeant belge se demande s'il ne serait pas judicieux de transférer les fonds de la FIFA dans une banque à New York en ne gardant que le strict nécessaire sur le Vieux Continent. L'idée témoigne d'une certaine méfiance face à l'avenir de la situation politique générale et de la volonté d'éviter une éventuelle prise de contrôle des biens de la FIFA par les Allemands. Toutefois, l'idée est abandonnée, les plans d'invasion de la Suisse par les nazis n'étant finalement pas mis à exécution. Malgré la persistance du siège à Zurich, Schricker reste sur ses gardes tout

85 Lettre de I. Schricker à R.W. Seeldrayers, 20 mai 1940. FIFA, membres du comité exécutif, dossier individuel : correspondance R.W. Seeldrayers (1939-1950), dossier : $1^{\text {er }}$ janvier 1943-31 décembre 1946.

86 Lettre de I. Schricker à R.W. Seeldrayers, 31 juillet 1940. FIFA, membres du comité exécutif, dossier individuel : correspondance R.W. Seeldrayers (1939-1950), dossier : $1^{\text {er }}$ janvier 1943-31 décembre 1946.

87 "Le Tournoi Bensemann. Le 2 mai, à la_Pontaise. Le Sportsyisse, 24 avril 1940. 
au long du conflit, car il a conscience que les correspondances de la FIFA peuvent être soumises au contrôle du haut commandement de l'Armée allemande ${ }^{88}$. En fait, jusqu'au début de l'année 1945, où la défaite de l'Allemagne semble ne plus être qu'une question de temps, Schricker est conscient que le comité exécutif ne peut "se réunir complètement en toute liberté ${ }^{89}$. Malgré cette situation, il est important pour lui de montrer aux Allemands que la FIFA reste en activité.

Durant toute la guerre, il échange ainsi de nombreux courriers avec les dirigeants du comité exécutif, leur adressant des circulaires ou des lettres sur l'état du football. De même, il correspond avec les associations nationales pour leur donner régulièrement " un sommaire des activités de la [FIFA] $"{ }^{90}$ et essaie de maintenir de bonnes relations avec elles. En septembre 1943 par exemple, il félicite la Fédération argentine pour son cinquantième anniversaire et indique à son secrétaire que la FIFA lui a fait parvenir un souvenir pour commémorer cet événement ${ }^{91}$. Cette action symbolique peut paraître anecdotique à la vue du contexte international mais elle sert, sans doute, à rappeler l'existence de la FIFA auprès d'associations lointaines avec lesquelles les échanges sont difficiles. Dans cette volonté de maintenir l'activité de la FIFA à flot, Schricker relance même en 1942 la publication du bulletin officiel, qui avait cessé de paraître depuis le début des hostilités. Si cette tentative ne dure que quelques numéros, elle est à souligner car elle est entreprise alors que le conflit fait désormais rage sur le front de l'Est et que des restrictions en Suisse existent dans les fournitures de toutes sortes, en particulier du papier. De plus, tout au long des hostilités, Schricker continue à dresser les rapports annuels du secrétariat. Ces documents sont une occasion pour lui de montrer que la FIFA survit malgré le contexte de guerre. Par exemple, il conclut le document de 1941 comme suit : "Le comité a la volonté ferme de maintenir, comme par le passé, l'organisation mondiale

88 Il est fait mention dans une lettre du fait que celle-ci a été vérifiée par cet organisme. Lettre de I. Schricker à R.W. Seeldrayers, 21 août 1940. FIFA, membres du comité exécutif, dossier individuel : correspondance R.W. Seeldrayers (1939-1950), dossier : $1^{\text {er }}$ janvier 1943-31 décembre 1946.

89 Lettre de I. Schricker à R.W. Seeldrayers, 21 août 1940. FIFA, membres du comité exécutif, dossier individuel : correspondance R.W. Seeldrayers (1939-1950), dossier :

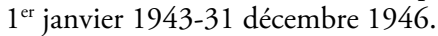

90 Anonyme, Procès-verbal du comité d'urgence pour temps de guerre de la FA du 14 mai 1943 , n.d. FA, FA minutes 1939-1943.

91 Lettre de I. Schricker à l'Association argentine de football, 18 septembre 1943. FIFA, correspondance avec les associations nationales : Argentine (1934-1968), dossier : 1934-1950. 
de notre sport, malgré toutes les difficultés de ces temps, et il compte, pour pouvoir accomplir sa noble tâche, sur la collaboration et l'appui de toutes les associations de la FIFA, afin qu'il soit à même de préparer la renaissance sportive à laquelle, la paix revenue, toutes les Associations viendront collaborer ${ }^{92}$."

En vue de préserver une certaine autonomie de la FIFA, la question financière est un point crucial à régler pour le secrétaire. En effet, les recettes de la Fédération internationale sont en constante diminution en raison du ressac des matchs internationaux et de l'annulation de la Coupe du monde de 1942. Dès lors, comment faire face à cette situation ? Il est impératif de trouver des solutions pour rester le plus possible indépendant de la Fédération allemande qui, ainsi que nous l'avons mentionné précédemment, apporte des sommes d'argent importantes à la FIFA. En outre, la survie économique de la FIFA est aussi cruciale pour Schricker lui-même. Âgé de plus de soixante ans, il doit faire face à des conditions de vie difficiles, en raison des pénuries - il signale par exemple le manque de chauffage lors de l'hiver $1942^{93}$ - et de l'inflation constante. De fait, il est nécessaire qu'il trouve des financements afin de conserver son poste de travail.

Tout d'abord, des mesures économiques sont prises. Ainsi, dès l'année 1941, le pourcentage du poste de secrétaire adjoint est réduit, puis même supprimé quelques mois plus tard. Rijnink, qui travaille pour la FIFA depuis les années 1920 et qui occupe alors ce poste, n'aide plus le secrétaire qu’une demi-journée par semaine. Durant l'année 1944, il semble même que le poste de secrétaire général soit discuté ${ }^{94}$. De plus, il est indispensable pour la FIFA de s'assurer de recevoir les recettes des matchs internationaux. En effet, malgré les hostilités, ces matchs perdurent en Europe jusqu'en 1943 et continuent à se jouer sur les autres continents. C'est pourquoi une grande partie de la correspondance de Schricker avec les associations nationales est liée à la réclamation des fonds qu'elles doivent à la Fédération. Son activisme va porter ses fruits, la FIFA recevant une partie des pourcentages que les associations doivent lui verser. Par ailleurs,

92 Schricker I., Rapport annuel du secrétaire général de la FIFA (1942-1943), n.d. FIFA, comité exécutif (procès-verbaux 1940-1946), p. 3.

93 Lettre de I. Schricker à R.W. Seeldrayers, 10 février 1942. FIFA, membres du comité exécutif, dossier individuel : correspondance R.W. Seeldrayers (1939-1950), dossier : $1^{\text {er }}$ janvier 1943-31 décembre 1946.

94 Information donnée par Bauwens à Schricker après la guerre, le premier indiquant au second qu'il s'est battu pour son poste. En raison de sa quête de rachat, nous prenons avec précaution cette information. Lettre de P. Bauwens à I. Schricker, 28 mars 1949. DFB, Wiederaufnahme des DFB in die FIFA [18] dossier : B/ZA/TT 
Schricker fait appel au Suisse Otto Eicher, qui a été nommé vérificateur des comptes au congrès de 1938, pour l'aider à tenir la comptabilité. Malgré quelques tensions entre les deux hommes ${ }^{95}$, Eicher va se montrer très rigoureux et réussir à préserver la santé financière de la FIFA. Si Schricker doit puiser dans les fonds de réserve de la FIFA pour maintenir à flot l'organisation, au sortir de la guerre, l'activité intense déployée par le secrétaire permet à la FIFA d'éviter la dissolution, au contraire d'autres organisations sportives.

L'activisme du secrétaire est indéniablement favorisé par la localisation du siège de la Fédération internationale en Suisse mais aussi par les mécanismes développés durant les années 1930 dans le but de réserver une autonomie de la FIFA sur la scène internationale. Ainsi, l'organisation a prouvé que, malgré un contexte politique hautement défavorable, elle pouvait se maintenir, dans la mesure du possible, en activité. Une fois la guerre passée, il va toutefois être nécessaire, pour la FIFA, de digérer les conséquences d'un conflit qui, en raison de sa longueur et de sa dureté, a laissé des traces.

\subsubsection{Entre oubli et réécriture de l'histoire}

Dans les mois qui suivent la fin de la Deuxième Guerre mondiale, la FIFA doit tout d'abord se positionner sur les cas des anciennes puissances de l'Axe et tout particulièrement sur ceux de l'Allemagne et de l'Italie. Condamnées au niveau international pour leurs agissements durant le conflit, des ressentiments existent au sein de la FIFA vis-à-vis de ces deux pays. Comment le comité exécutif de la FIFA négocie-t-il cette situation? La question mérite d'être posée puisque sa gestion risque de créer des tensions au sein de la Fédération internationale. L'élite de la FIFA va devoir faire preuve d'adresse et de tact car, pour eux, la question est délicate : avant la guerre, l'Allemagne et l'Italie comptent parmi les plus puissantes associations de l'entité et leur exclusion serait assurément une perte importante pour l'organisation. De plus, il s'agit de juger les actions de leurs principaux dirigeants, en d'autres termes, d'amis proches.

Arrêtons-nous tout d'abord sur le cas de l'Allemagne, car il semble plus facile à gérer pour le comité exécutif, un consensus se dégageant rapidement à ce sujet entre les associations membres de la FIFA. En

95 Lettre de I. Schricker à R.W. Seeldrayers, 25 juin 1944. FIFA, membres du comité exécutif, dossier individuel : correspondance R.W. Seeldrayers (1939-1950), dossier : $1^{\text {er }}$ janvier 1943-31 décembre 1946. 
novembre 1945, l'élite de la FIFA décide à l'unanimité des membres présents que "les associations affiliées, leurs clubs et leurs membres [n'entretiennent plus] de relations sportives avec les dirigeants ou des footballeurs allemands $"{ }^{96}$. Par ailleurs, les ressortissants allemands sont bannis des postes qu'ils occupaient à la FIFA et les arbitres allemands radiés de la liste des arbitres internationaux. Ainsi, Peco Bauwens est exclu du comité exécutif et, malgré ses demandes, n'est pas autorisé à venir s'expliquer officiellement devant ses (anciens) collègues. La FIFA poursuit donc la position défendue par les États qui excluent l'Allemagne de la scène politique internationale. En date du 13 août 1945, dans une lettre à Schricker, Seeldrayers souligne cet aspect et indique que "l'Allemagne est [mise] au banc des Nations et ne peut être admise à siéger dans aucun comité d'organisme international ${ }^{97}$. Pourtant, ce sont d'autres arguments qui sont avancés par le comité exécutif pour justifier leur position.

Tout d'abord, ils évoquent un argument d'ordre émotionnel, à savoir qu'il n'est plus possible pour eux d'entretenir des relations internationales amicales avec les Allemands. Ils basent néanmoins leurs propos sur l'article 2 des statuts de la FIFA, qui souligne la nécessité d'entretenir une bonne entente entre les associations membres, ce qui ne paraît plus être possible avec les Allemands dans cet immédiat après-guerre. Mais un deuxième argument est également évoqué. Celui-ci est implacable puisque les dirigeants invoquent l'article 6 des statuts de la FIFA qui indique que, pour entretenir des relations avec un pays, il est nécessaire que celui-ci dispose d'une association nationale ${ }^{98}$. Or l'Allemagne n'existe plus en tant qu'entité indépendante, son territoire étant divisé en quatre zones administrées par les Américains, les Anglais, les Français et les Soviétiques. En conséquence, tous les organismes de l'État sont dissous, processus auquel n'a pas échappé la fédération de football. L'avantage de cet argumentaire est donc de montrer que les dirigeants de la FIFA agissent avant tout selon les dispositions réglementaires de leur organisation et ne suivent pas des volontés politiques mais des enjeux proprement footballistiques. Ce procédé permet de réaffirmer leur stratégie apolitique, démarche devant in fine leur permettre de reconstruire progressivement l'autonomie de la FIFA sur la scène internationale. L'exclusion de

96 Schricker I., Procès-verbal de la réunion du comité exécutif de la FIFA des 10-12 novembre 1945, n.d. FIFA, comité exécutif (procès-verbaux 1940-1946).

97 Lettre de R.W. Seeldrayers à I. Schricker, 13 août 1945. FIFA, membres du comité exécutif, dossier individuel : correspondance R.W. Seeldrayers (1939-1950), dossier : $1^{\text {er }}$ janvier 1943-31 décembre 1946.

98 Anonyme, Statuts de la FIFA [édition de 1948], art. 6 [des statuts]. FIFA, statuts, 1904-1981. 
l'Allemagne de la FIFA est présentée par le comité exécutif lors du congrès organisé au Luxembourg en juillet 1946 et semble être acceptée sans problème, le procès-verbal ne mentionnant pas de discussions à ce sujet ${ }^{99}$. Si le cas allemand n'est finalement que peu l'objet de discussions au sein de la Fédération internationale, celui de la Fédération italienne est plus complexe, notamment en raison de la position de l'Italie à la fin du conflit.

Au sortir des hostilités, l'Italie fait partie des vainqueurs : dès 1943, un nouveau gouvernement mené par le général Badoglio succède à celui de Mussolini et opère rapidement un changement de camp en déclarant la guerre à l'Allemagne ${ }^{100}$. Toutefois, sur la scène internationale, le pays doit faire profil bas. En effet, des dirigeants politiques n'oublient pas qu'il a été sous la coupe fasciste durant plus de vingt ans ; c'est d'ailleurs la raison pour laquelle l'Italie ne participe pas à la création des Nations unies. Au sein de la FIFA, le ressentiment envers les Italiens est certes moins fort que celui auquel doivent faire face les Allemands, mais il est bel et bien présent. De plus, il faut souligner qu'il n'y a pas eu de véritable rupture au sein du football italien entre le fascisme et le nouveau régime, et tant Paul Dietschy ${ }^{101}$ que Fabien Archambault ${ }^{102}$ affirment que, dans les faits, une continuité s'observe. En effet, à la tête de la nouvelle Fédération italienne, créée dès 1943, nous retrouvons Giovanni Mauro qui exerce les fonctions de commissaire pour les relations avec les organisations internationales ${ }^{103}$. De même, le nouveau président est Ottorino Barassi, qui a été l'un des dirigeants du football les plus actifs sous le fascisme,

99 Anonyme, Procès-verbal de l'assemblée générale de la FIFA des 27-28 juillet 1947, n.d. FIFA, XXV-XXVII congrès ordinaires (1946-1952, rapport d'activité). Cette analyse est partagée par d'autres auteurs, en particulier : Dichter H., « Kiking around international sport: West Germany's return to the international community through football ", The International Journal of the History of Sport, vol. 30, $\mathrm{n}^{\circ} 17,2013$, pp. 2031-2051 ; Wahlig H., Ein Tor zur Welt. Der Deutsche Fußball und die FIFA 1945-1950, Göttingen, Verlag die Werkstatt, 2009.

100 Morgan P., The fall of Mussolini: Italy, the Italians, and the Second World War, Oxford, Oxford University Press.

101 Dietschy P., Histoire du football, op. cit., p. 34.

102 Archambault F., "Des continuités sans ruptures ? L'héritage du système sportif fasciste dans l'Italie libérée ", dans Bensoussan G. et al., Sport, corps et sociétés de masse, op. cit., pp. 197-209.

103 Lettre de I. Schricker à R.W. Seeldrayers, 11 septembre 1943. FIFA, membres du comité exécutif, dossier individuel : correspondance R.W. Seeldrayers (1939-1950), dossier : $1^{\text {er }}$ janvier 1943-31 décembre 1946. Le $1^{\text {er }}$ décembre 1943, le secrétaire mettra tout de même en doute cette information, signe que, durant la guerre, il est difficile pour Ivo Schricker de se tenir au courant précisément des affaires footballistiques mondiales. 
faisant notamment partie du comité d'organisation de la Coupe du monde de 1934. Quant à la sélection nationale, elle est toujours dirigée par l'entraîneur des succès acquis sous le régime du Duce, Vittorio Pozzo. Mais la véritable complexité du cas italien du point de vue de la FIFA est que, d'un point de vue réglementaire, rien ne s'oppose à la participation de l'Italie aux travaux de l'organisation. Pourtant, la présence de ce pays en son sein ne risque-t-elle pas d'attiser certains conflits ? Signalons que, dans d'autres fédérations internationales sportives ainsi que dans le Comité olympique, la présence de l'Italie fait également débat. À ce sujet, Nicola Sbetti a dressé une typologie des positionnements des organisations au sujet de la question italienne ${ }^{104}$. Selon lui, la FIFA se situe parmi les organisations les plus conciliantes vis-à-vis de l'Italie, ce qui s'explique pour plusieurs raisons. Tout d'abord, la force du football italien joue ici un grand rôle. Pays très actif dans les échanges footballistiques européens, il paraît difficile pour la Fédération internationale de se passer de cette association puisque le pays dispose assurément de soutien de la part d'autres associations membres de la FIFA. De plus, exclure l'Italie implique également de se priver des pourcentages sur les matchs internationaux que cette association pourrait lui fournir, démarche d'autant plus délicate en raison de l'exclusion de l'Allemagne, autre important bailleur de fonds. Enfin, les amitiés tissées durant l'entre-deux-guerres entre plusieurs dirigeants du comité exécutif et les leaders du football italien, comme Giovanni Mauro et Ottorino Barassi, expliquent sans doute une certaine complaisance. Pour les membres du comité exécutif de la FIFA, dont la plupart sont favorables au retour de l'Italie, il s'agit de gérer au mieux cette situation afin d'éviter d'éventuels conflits en interne ou des reproches provenant d'acteurs extérieurs (journaux, gouvernements).

La FIFA va cependant rapidement faire face à des pressions qui accélèrent sans doute le retour de l'Italie et favorisent sa cause. En effet, dès novembre 1945, la Suisse accueille l'équipe nationale italienne à Zurich. Rappelons que les deux pays entretiennent des relations footballistiques étroites depuis l'entre-deux-guerres ${ }^{105}$, qui se prolongent d'ailleurs en partie durant la guerre - en parallèle d'autres types d'échanges, notamment

104 Sbetti N., Giochi diplomatici. Sport e politica estera nell'Italia del secondo dopoguerra (1943-53), thèse de doctorat réalisée sous la direction de Giuliana Laschi, Université de Bologne, 2015 (voir les pages 259-408).

105 Quin G., Vonnard P., " "Par-delà le Gothard”. Les matches Italie-Suisse et la consolidation des champs footbalistiques italien et suisse dans l'entre-deux guerres ",

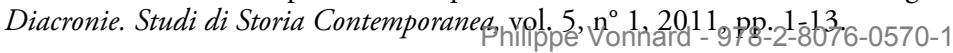


économiques $^{106}$. Signe de ces liens, Barassi et Mauro sont invités, en juillet 1945 , à venir fêter le jubilé de l'association suisse de football ${ }^{107}$. En outre, la Suisse fait un geste important en vue d'un retour prochain de l'Italie sur la scène footballistique internationale en l'invitant à disputer un match à Zurich en novembre 1945. Or la première session du comité exécutif se tient au même moment sur les bords de la Limmat. Ainsi, les dirigeants du comité exécutif de la FIFA se rendent au match Suisse-Italie. Outre d'assouvir leur passion pour le jeu et de partager un moment de sociabilité bienvenue après ces longues années de séparation, il s'agit aussi d'une bonne occasion pour le comité exécutif de la FIFA de rencontrer, de manière informelle, les dirigeants transalpins. Ce match œuvre aux rapprochements entre les deux camps et finalement, quelques mois plus tard, les dirigeants italiens sont bel et bien présents au congrès de 1946. Cependant, conscients sans doute que ce retour risque d'engendrer des mécontentements, il est demandé à Giovanni Mauro de se mettre " en congé » de sa fonction de vice-président de la FIFA. Le cas italien est emblématique de la façon dont les dirigeants à la tête de la FIFA tentent de neutraliser les conflits entre les associations membres. En effet, si l'Italie reste finalement membre de la FIFA, il est cependant nécessaire que les Italiens fassent profil bas en attendant que les ressentiments dus à la Deuxième Guerre mondiale s'atténuent, procédé qui a pour avantage d'éviter les tensions au sein de la FIFA.

Parallèlement à la gestion des cas allemand et italien, les dirigeants du comité exécutif s'attellent à éluder ou dépasser d'autres reliquats de la guerre. Quelques sujets sont en effet soulevés par des journalistes, sur lesquels les dirigeants du comité exécutif sont obligés de s'expliquer. Parmi ceux-ci, l'admission provisoire accordée à la Croatie semble leur être particulièrement reprochée. Outre la presse, ce cas intéresse également des gouvernements. Ainsi, dans une lettre à Schricker, Seeldrayers indique que les autorités politiques belges ont critiqué la manière dont la FIFA a géré l'affaire ${ }^{108}$. Selon ces contradicteurs, la Croatie était une alliée de l'Allemagne et son territoire n'a pas été reconnu officiellement par les Alliés. Dès lors,

106 Schneider J., " "Un moyen précieux de maintenir de bonnes liaisons" : la Suisse, puissance protectrice de l'Italie au cours d'une décennie tourmentée (1940-1949) ", Relations internationales, vol. 4, $\mathrm{n}^{\circ} 144,2010$, pp. 37-49.

107 Lettre de I. Schricker à R.W. Seeldrayers, 28 juin 1945. FIFA, membres du comité exécutif, dossier individuel : correspondance R.W. Seeldrayers (1939-1950), dossier :

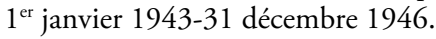

108 Lettre de R.W. Seeldrayers à I. Schricker, 6 décembre 1945. FIFA, membres du comité exécutif, dossier individuel : correspondance R.W. Seeldrayers (1939-1950), dossier : $1^{\text {er }}$ janvier 1945-31 décembre 1946. 
ce pays n'aurait pas dû obtenir une autorisation d'affiliation provisoire à la FIFA. Face à ces reproches, l'élite de la FIFA décide de faire la lumière sur cette affaire. Pour les têtes pensantes de l'organisation, il est crucial de savoir si le pays était déjà envahi par les troupes du Reich au moment de l'acceptation de sa fédération. Cette situation permettrait de montrer que la FIFA n'a pas anticipé de changements politiques - et n'a donc pas cautionné la politique nazie. Car, depuis les années 1930, il est de coutume que si un nouveau pays demande son affiliation, le comité d'urgence de la FIFA a le pouvoir d'accepter provisoirement le nouveau membre, tout en conditionnant l'affiliation définitive à l'approbation du congrès. Dès lors, si tel est le cas avec la Croatie, les dirigeants peuvent répondre qu'ils ont simplement suivi et appliqué le règlement de la Fédération internationale. Dans une lettre du 21 décembre 1945, Rodolphe Seeldrayers confirme ce point et indique à Ivo Schricker : "Tout ce qui m'intéresse, c'est de savoir si l'Allemagne avait déjà envahi la Yougoslavie au moment où nous avons admis la Croatie ${ }^{109}$. "Après recherches, il s'avère effectivement que l'affiliation provisoire donnée à la Croatie date de la seconde partie du mois de juillet 1941, après la prise de pouvoir du régime des Oustachis du mois de juin. Cela permet aux dirigeants de la FIFA de se dédouaner en partie, même si la question des deux matchs disputés par exemple par une équipe croate contre la Suisse en 1940 reste en suspens. Si l'unité vis-à-vis de l'extérieur doit prévaloir, des sujets aussi problématiques que celui-ci révèlent des tensions en interne entre les dirigeants du comité exécutif. Seeldrayers n'hésite par exemple pas à accuser les représentants des pays vaincus, et notamment Mauro, qui aurait facilité l'affiliation provisoire de la Croatie ${ }^{110}$.

Autre procédé utilisé pour minimiser les conflits sur des sujets épineux : les dirigeants n'hésitent pas à réécrire, ou simplifier, les événements passés. Cette stratégie est notamment employée au sujet de l'Autriche ou de la Norvège, pays occupés par l'Allemagne mais qui ont connu des gouvernements collaborationnistes. Afin d'éviter des questionnements qui pourraient engendrer des problèmes internes - l'association du Danemark demande par exemple que la FIFA prenne en considération le fait que la Norvège a été dirigée par un gouvernement collaborationniste -, il

109 Lettre de I. Schricker à R.W. Seeldrayers, 21 décembre 1945. FIFA, membres du comité exécutif, dossier individuel : correspondance R.W. Seeldrayers (1939-1950), dossier : $1^{\text {er }}$ janvier 1943-31 décembre 1946.

110 Lettre de R.W. Seeldrayers à I. Schricker, 8 janvier 1946. FIFA, membres du comité exécutif, dossier individuel : correspondance R.W. Seeldrayers (1939-1950), dossier : $1^{\text {er }}$ janvier 1943-31 décembre 1946. 
s'agit de considérer que ces pays n'ont pas coopéré volontairement avec les Allemands. Au contraire, le comité exécutif estime qu'ils ont subi une occupation de leur territoire et, en ce sens, doivent être perçus comme des victimes de la guerre. Dès lors, il est préconisé que les échanges reprennent comme si le conflit n'avait pas eu lieu et "les anciennes associations d'Autriche et de Norvège [...] seront considérées comme n'ayant point perdu leurs droits d'affiliation à la FIFA ${ }^{111}$. En d'autres termes, les dirigeants agissent dans ce cas comme si la guerre n'avait pas eu lieu. La stratégie qui vise à rapidement évacuer le passé a certes un but collectif, à savoir de pérenniser l'existence de la FIFA, mais elle permet aussi aux dirigeants de ne pas revenir sur leurs trajectoires personnelles durant le conflit. En effet, leur position face à l'Allemagne nazie n'a pas toujours été très claire. D'après La Gazzetta dello Sport par exemple, un journal communiste français indique, au sortir de la guerre, que Rimet aurait eu quelques accointances avec l'ennemi ${ }^{112}$. Certes, le commentaire est orienté politiquement car il figure dans un journal qui a une sympathie limitée pour un dirigeant plutôt conservateur comme Rimet, il ne semble toutefois pas totalement dénué de sens. Ainsi, dans une lettre d'août 1942 qu'il envoie à Seeldrayers, Schricker note que Rimet entretient « les meilleures relations ${ }^{113}$ avec le commissaire général des sports du régime de Vichy, le colonel Pascot ${ }^{114}$. De même, comme le montre l'historien Hans Bonde, le Danois Frederiksen n'a-t-il pas joué une sorte de "double jeu » durant le conflit ? S'opposant aux Allemands, il condamne toutefois les débordements du public à l'occasion de certains matchs de football contre l'occupant ${ }^{115}$. Enfin, rappelons que certains des dirigeants du comité exécutif ont directement participé aux actions des forces de l'Axe. Ainsi, en sa qualité de soldat de montagne, Mauro a combattu avec l'armée italienne dans les Alpes. Quant à l'Allemand Bauwens, il s'est fait complice du régime nazi en essayant de ramener la Fédération internationale dans son

111 Schricker, I., Procès-verbal de la réunion du comité exécutif de la FIFA des 10-12 novembre 1945, n.d. FIFA, comité exécutif (procès-verbaux 1940-1946)

112 "Attacchi al presidente della FIFA », La Gazzetta dello Sport, $1^{\text {er }}$ novembre 1945. Nous remercions Nicola Sbetti pour cette information.

113 Lettre de I. Schricker à R.W. Seeldrayers, 15 août 1942. FIFA, membres du comité exécutif, dossier individuel : correspondance R.W. Seeldrayers (1939-1950), dossier : 1941-1942.

114 Jep Pascot est le commissaire des sports du régime de Vichy de 1942 à 1944, en d'autres termes son ministre des Sports. Sur Pascot, voir : Lassus M., " Des pelouses de rugby aux salons de Vichy : le colonel Pascot, commissaire général aux Sports (avril 1942août 1944), dans Arnaud P. et al. (dir.), Le sport et les Français pendant l'occupation : 1940-1944, Paris, L'Harmattan, 2002, pp. 43-58.

115 Bonde H., Football with the Foe, op. cit.ppillips 135 
giron. À la vue de la documentation récoltée, il est toutefois difficile de déterminer exactement le positionnement de tous les membres du comité exécutif de la FIFA durant la guerre et des recherches sont assurément à mener sur ce point dans le futur.

Mais cette volonté de tourner rapidement la page de la guerre n'est-elle pas également une manière d'en rejeter les horreurs? Les correspondances personnelles conservées à la FIFA rappellent bien cet aspect. Certains dirigeants ont par exemple vu la mort de près. À son retour des combats en 1940, Mauro indique à Schricker avoir été proche de perdre la vie dans les combats qu'il a menés dans les Alpes françaises ${ }^{116}$. De même, Seeldrayers voit plusieurs membres de l'Union belge être déportés par les Allemands, dont son président, Oscar Vankesbeeck. À la fin du conflit, Seeldrayers se montre très heureux que lui et sa femme soient "sortis vivants de ces terribles cinq années, sans avoir été invités à goûter aux charmes de Buchenwald et de Dachau " ${ }^{117}$. Même s'il ne s'agit ici que d'affaires matérielles, dès le début de la guerre, Rimet a dû déplacer ses affaires commerciales à Lyon alors que Lotsy a vu les bureaux de son usine être détruits par des raids aériens. Enfin, les bombardements intenses que connaît la ville de Cologne durant l'année 1945 rasent entièrement la maison de Peco Bauwens ${ }^{118}$.

En novembre 1941, le secrétaire général se fend d'une confidence personnelle à un dirigeant autrichien, Joseph Gerö: «C'est toujours une bonne surprise, quand dans ces temps de troubles on reçoit aussi parfois une bonne nouvelle ${ }^{119}$. " Cette phrase relève bien l'état d'inquiétude constant dans lequel sont plongés ces hommes assurément marqués par les horreurs d'un conflit qui éclate seulement trente ans après la fin de la tragédie de 1914-1918 à laquelle - il faut le souligner - ils ont la plupart participé en tant que soldats. À la vue de tous ces éléments, il n'est sans doute pas usurpé de penser qu’à la fin de la guerre, le fait de

116 Lettre de I. Schricker à R.W. Seeldrayers, 15 juillet 1940. FIFA, membres du comité exécutif, dossier individuel : correspondance R.W. Seeldrayers (1939-1950), dossier : 1939-1940.

117 Lettre de R.W. Seeldrayers à I. Schricker, 15 mai 1945. FIFA, membres du comité exécutif, dossier individuel : correspondance R.W. Seeldrayers (1939-1950), dossier : $1^{\text {er }}$ janvier 1943-31 décembre 1946.

118 Autre exemple : le secrétaire de la Fédération luxembourgeoise, Gustave Jacquemart, apprend, le 17 mars 1945 que son fils, dont il était sans nouvelles depuis plusieurs mois, se trouve au camp de Dachau. Ces informations sont indiquées dans différentes lettres de la correspondance de Rodolphe Seeldrayers.

11 Lettre de I. Schricker à J. Gerö, 24 novembre 1941. FIFA, membres du comité exécutif, dossier individuel : correspondance M. Andrejevic(1938-1982), dossier:1939-1945. 
rediscuter rapidement de football, comme avant le conflit, constitue pour les dirigeants de la FIFA un bon moyen d'oublier ce qui vient de se passer et de ne pas attiser de possibles divergences personnelles.

\subsubsection{De la gestion de la guerre à l'entrée en Guerre froide}

Afin de relancer les activités de l'organisation, il est nécessaire pour l'élite de la FIFA de perpétuer la gouvernance développée durant l'entredeux-guerres, c'est-à-dire d'agir avec tact et en accord avec leur règlement dans le but d'éviter au maximum les conflits. Dans les années qui suivent la fin de la guerre, de nouvelles mesures sont décidées dans cette perspective. Dans un article paru en 2014, Grégory Quin a abordé la relance des activités de la FIFA après la guerre. Sous cet angle, il a brièvement insisté sur les nouvelles mesures administratives prises au sein de la FIFA qui, selon lui, ont pour but de " réaffirmer les principes organisationnels de l'institution - sa gouvernance reposant sur une assemblée générale (congrès), une compétition (la Coupe du monde) et l'affirmation d'un règlement $"{ }^{120}$. Dans les lignes qui suivent, nous souhaitons détailler quelque peu ces différents points.

Premièrement, le comité exécutif de la FIFA décide d'organiser rapidement une assemblée générale. Celle-ci se tient en juillet 1946 à Luxembourg. Le choix de la ville n'est pas anodin car la capitale du Grand-Duché avait déjà été choisie lors du congrès de 1938. Ainsi, c'est bien une continuité avec la période de l'avant-guerre qui est proposée aux associations membres de la FIFA par son comité exécutif. Outre discuter des affaires du football international, la manifestation a aussi une portée symbolique car elle doit permettre de "faire connaissance et renouer les anciennes amitiés ${ }^{121}$. C'est pourquoi le congrès est organisé sur cinq jours, ce qui est long - dans l'entre-deux-guerres, les assemblées générales n'excèdent que rarement trois jours. Afin de recréer des liens, les activités sociales sont nombreuses. Une soirée est prévue le jour précédent l'ouverture de la manifestation et le traditionnel banquet de clôture se tient l'avant-dernier jour. L'ultime journée est uniquement consacrée à une excursion qui mènera les participants dans les hauts lieux touristiques du Luxembourg. Par ailleurs, l'élite de la FIFA décide, pour ce congrès, de prendre des distances avec leur règlement en autorisant par exemple qu'un

120 Quin G., "La reconstruction de la Fédération Internationale de Football Association », op. cit., p. 28.

121 Lettre de I. Schricker au comité exécutif de la FIFA, 18 janvier 1946. FIFA, comité exécutif (circulaire aux membres 1946-1957.7). 
représentant anglais se fasse le porte-parole du Pays de Galles. De même, elle tolère que des diplomates en poste en Europe représentent certaines associations sud-américaines ${ }^{122}$.

Deuxièmement, le comité exécutif propose aux congressistes des mesures visant à renforcer l'harmonie au sein de la Fédération internationale. Ainsi, les représentants présents décident de suivre la proposition de l'élite de l'organisation visant à reconnaître officiellement la langue espagnole au sein de la FIFA. Cette décision répond au vœu qui avait déjà été formulé par les associations sud-américaines à de nombreuses reprises par le passé. Nous avons vu que les dernières années de la guerre sont marquées par une prise de distance des associations sud-américaines vis-à-vis de la FIFA. En ce sens, par cette décision les dirigeants du comité exécutif semblent vouloir faire un pas en vue d'un rapprochement avec leurs homologues sud-américains. De plus, les congressistes acceptent de porter le nombre de dirigeants au sein du comité exécutif de neuf à douze. Le but de cette augmentation est que tous les blocs régionaux soient davantage représentés au sein de l'organisme. Tout d'abord, le poste de vice-président conféré à la Confédération sudaméricaine par le congrès de 1938 est confirmé. La Confédération désigne Luis Aranha pour la représenter. De plus, un poste de vice-président est également créé spécialement pour les associations britanniques qui font leur retour dans le giron de la Fédération internationale. C'est Arthur Drewry qui est choisi par les quatre associations britanniques.

Dans le but d'éviter au maximum les conflits, il est à relever qu'aucune élection n'est réalisée durant le congrès de 1946 pour désigner les autres dirigeants du comité exécutif. Il faut souligner que s'ajoutent au contexte de la guerre deux pertes majeures pour le comité exécutif de la FIFA. En effet, le Hongrois Mor Fisher et le Tchèque Rudolph Pelikan décèdent, respectivement en 1945 et 1946, de cause naturelle. Il faut donc répondre à ces disparitions qui s’ajoutent aux départs forcés de Bauwens et Mauro. Afin de négocier au mieux cette transition, des discussions en interne ont lieu durant les semaines qui précèdent le congrès afin de nommer les dirigeants qui seront les plus consensuels et les plus représentatifs. Des démarches sont notamment entreprises par Eric von Frenckell. Le Finlandais est un dirigeant respecté dans les arcanes de la FIFA puisqu'il a été membre de son comité exécutif au début des années 1930 et qu'il est aussi membre du CIO. C'est donc un acteur important, et écouté, du sport international. En outre, il représente la Finlande, qui au regard de son histoire récente fait alors office de jonction entre l'Est et l'Ouest

122 Anonyme, Procès-verbal de la réunion du comité exécutif de la FIFA du 24 juillet 1946, n.d. FIFA, comité exécutif (procès-verbaux 1940-1946). 
de l'Europe ${ }^{123}$. Cette position conferre à von Frenckell des possibilités de discuter aisément avec la plupart des dirigeants européens du football. Après avoir " eu des conversations avec les délégués de différents pays " ${ }^{124}$, il propose à l'assemblée de choisir les huit dirigeants suivants : le Belge Seeldrayers et le Danois Frederiksen pour les deux postes de "viceprésidents ", puis le Yougoslave Andrejevic, le Chilien Bianchi, l'Écossais Kirkwood, le Suisse Krebs, le Néerlandais Lotsy et le Tchèque Valousek. Les congressistes acceptent cette proposition. Constatons que la nouvelle composition s'inscrit dans une continuité avec la FIFA des années 1930. En effet, autour du président Jules Rimet, qui est reconduit pour un nouveau mandat, et du secrétaire général Ivo Schricker, qui conserve son poste, Seeldrayers, Lotsy et Andrejevic conservent leur fonction. De même, le Tchèque Valousek peut être perçu comme le successeur de son compatriote Pelikan, qui vient de décéder. Quelques semaines plus tôt, Schricker avait d'ailleurs fait part à Jules Rimet du souhait de la Fédération tchèque de conserver un de ses ressortissants au sein du comité exécutif ${ }^{125}$. De même, Frederiksen prend la place jusque-là détenue par le Norvégien Eie et poursuit la représentation scandinave au sein du comité exécutif. L'unique changement consiste dans le non-remplacement du Hongrois Fischer, passé à trépas quelques mois plus tôt, par un dirigeant de son pays ou de sa région. Les trois autres dirigeants, le Chilien Bianchi, l'Écossais Kirkwood et le Suisse Krebs, sont nouveaux au sein du comité. En ce qui concerne Bianchi, c'est la première fois qu'un Sud-Américain est choisi. Sa présence vient compléter celle de Luis Aranha et souligne une volonté de conférer davantage de place aux associations sud-américaines en conformité avec leur vœu exprimé depuis les années 1930. Kirkwood provient d'une association faisant partie des vainqueurs de la guerre et vient renforcer la représentation des associations britanniques. Enfin, le Suisse Jean Krebs représente un pays politiquement " neutre » durant le conflit et s'inscrit dans la lignée des dirigeants suisses ayant occupé des postes à responsabilité dans le football international ${ }^{126}$.

123 Sur la position politique de la Finlande à cette période, voir : Rainio-Niemi J., The ideological Cold War: the politics of neutrality in Austria and Finland, New York, Routledge, 2014.

124 Schricker I., Procès-verbal de l'assemblée générale de la FIFA des 25-26 juillet 1946, n.d. FIFA, comité exécutif (procès-verbaux 1940-1946).

125 Lettre de I. Schricker à J. Rimet, 15 juillet 1946. FIFA, membres du comité exécutif, dossier individuel : correspondance J. Rimet (1945-1950), dossier : $1^{\text {er }}$ janvier 1945-31 décembre 1946.

126 Quin G., Vonnard P., "Switzerland, a stronghold in European football, 1930-1954 ? ”, Sport in History, vol. 35, n 4, 2015, pp $531-549$ 
Tableau 8. Comité exécutif de la FIFA en 1946

\begin{tabular}{|c|c|c|c|c|c|}
\hline Nom & Fonction & $\begin{array}{l}\text { Première } \\
\text { élection }\end{array}$ & Pays & Région & Élu par \\
\hline Rimet & Président & 1921 & France & Aucune & Congrès \\
\hline Seeldrayers & $\begin{array}{l}\text { Vice- } \\
\text { président }\end{array}$ & 1927 & Belgique & Benelux & Congrès \\
\hline Frederiksen & $\begin{array}{l}\text { Vice- } \\
\text { président }\end{array}$ & 1946 & Danemark & $\begin{array}{l}\text { Pays du } \\
\text { Nord }\end{array}$ & Congrès \\
\hline Drewry & $\begin{array}{l}\text { Vice- } \\
\text { président }\end{array}$ & 1946 & Angleterre & Britannique & Britannique \\
\hline Aranha & $\begin{array}{l}\text { Vice- } \\
\text { président }\end{array}$ & 1946 & Brésil & $\begin{array}{l}\text { Amérique du } \\
\text { Sud }\end{array}$ & $\begin{array}{l}\text { Amérique } \\
\text { du Sud }\end{array}$ \\
\hline Pas désigné* & $\begin{array}{l}\text { Vice- } \\
\text { président }\end{array}$ & $\begin{array}{l}\text { Pas } \\
\text { désigné }\end{array}$ & Union soviétique & Soviétique & $\begin{array}{l}\text { Union } \\
\text { soviétique }\end{array}$ \\
\hline Lotsy & Membre & 1934 & Pays-Bas & Benelux & Congrès \\
\hline Andrejevic & Membre & 1938 & Yougoslavie & $\begin{array}{l}\text { Balkans/ } \\
\text { Soviétique }\end{array}$ & Congrès \\
\hline Valousek & Membre & 1946 & Tchécoslovaquie & Soviétique & Congrès \\
\hline Bianchi & Membre & 1946 & Chili & $\begin{array}{l}\text { Amérique du } \\
\text { Sud }\end{array}$ & Congrès \\
\hline Kirkwood & Membre & 1946 & Écosse & Britannique & Congrès \\
\hline Krebs & Membre & 1946 & Suisse & Aucun & Congrès \\
\hline
\end{tabular}

Légende : * une place est réservée à l'Union soviétique qui, à cette période, n’a pas encore désigné de représentant car elle n'est toujours pas officiellement membre de la FIFA (voir : 3.1.2.).

Dans un souci de ne pas donner trop d'influence à un bloc régional ou un autre, les regroupements régionaux qui existent dans les années 1930 (Amérique du Sud, Balkans, Benelux, Britannique et Pays du Nord) sont tous représentés dans le comité après la guerre. Par ailleurs, Andrejevic et Valousek peuvent être considérés comme les représentants d'un nouveau bloc qui est en train d'émerger au sein de la FIFA : le bloc soviétique. Après la tragédie de la guerre, il s’agit plus que jamais pour le comité exécutif de se montrer uni. A ce titre, le secrétaire général invite les dirigeants siégeant dans les différentes commissions de la FIFA, ou qui la représentent dans d'autres organismes comme l'International Board, à être solidaires des décisions prises par le comité exécutif. Si Schricker se permet d'intervenir à ce sujet, c'est que ce n'est pas toujours le cas. Par exemple, le Norvégien 
Daniel Eie, nommé représentant de la Fédération à l'International Board en 1946, semble ne pas suivre les recommandations de vote transmises par le comité exécutif. Pour Schricker, cette situation est tout bonnement inadmissible ${ }^{127}$. Cette position n'est pas sans conséquence pour l'intéressé puisque, en 1948, Eie n'est pas réélu à son poste.

Troisièmement, l'élite de la FIFA poursuit sa politique non interventionniste vis-à-vis de ses associations membres. Ainsi, lorsque durant le congrès de 1946, l'association yougoslave demande l'exclusion de l'Espagne ${ }^{128}$, Jules Rimet coupe court à la discussion et souligne :

"Les délégués des Associations nationales se sont réunis à Luxembourg animés d'un esprit de solidarité et de camaraderie sportive qui doit exclure tous les sujets étrangers à l'ordre du jour [c'est pourquoi il] demande aux délégués de la Yougoslavie de ne pas insister pour que la question soulevée par eux soit discutée, ce qui constituerait un précédent extrêmement fâcheux pour l'avenir et risquerait de compromettre l'entente internationale [du football] " ${ }^{129}$.

Autre exemple de cette posture de neutralité, la gestion par la FIFA de la "soviétisation" des associations nationales des pays de l'Europe de l'Est. En effet, des partis communistes commencent à prendre le pouvoir dans plusieurs pays de l'Europe centrale et se trouvent désormais placés dans la sphère d'influence de l'URSS. Ce changement a des conséquences sur le système sportif de ces pays, qui se calque dès lors sur le modèle soviétique $^{130}$ : un organisme central dirigé par l'État englobe toutes les fédérations sportives. En date du 29 mars 1946, Schricker reçoit par exemple une lettre de la Fédération hongroise soulignant que celle-ci vient d'être réorganisée. Si plusieurs anciens membres conservent leur poste, dont le secrétaire, Arpad Kenyeres, l'organisme est désormais directement

127 Lettre de I. Schricker à J. Rimet, 31 mai 1948. FIFA, membres du comité exécutif, dossier individuel : correspondance J. Rimet (1945-1950), dossier : $1^{\text {er }}$ janvier 1948-31 décembre 1948.

128 La Fédération yougoslave se veut à la pointe du combat contre le fascisme - sur les lettres de cette époque envoyées au secrétariat de la FIFA, il est inscrit « Mort au fascisme. Liberté au peuple " - et souhaite combattre l'Espagne franquiste sur tous les terrains.

129 Schricker I., Procès-verbal de l'assemblée générale de la FIFA des 25-26 juillet 1946, n.d. FIFA, comité exécutif (procès-verbaux 1940-1946).

130 Pour une description du modèle soviétique d'organisation sportive, voir : Peppard V., Riordan J., Playing politics: Soviet sport diplomacy to 1992, Greenwich-London, Jai Press, 1992. Et pour un exemple de cette transition dans un pays satellite : Girginov V., "Bulgarian sport policy 1945-1989: A strategic relations approach ", The International Journal of the History of Sport, vol. 26, $\mathrm{n}_{\mathrm{P}}^{\circ} 4,2009 \mathrm{p}$, pp $515-538$. 
rattaché à l'État et se trouve être présidé par le ministre de la Justice, Etienne Ries ${ }^{131}$. De même en Pologne, l'ancien secrétaire, Mallow, qui a participé à plusieurs congrès de la FIFA durant l'entre-deux-guerres, est remplacé. Désormais, la fédération nationale est placée sous la coupe du ministère de la Défense ${ }^{132}$. Le 8 juin 1946, Schricker mentionne à Rimet que les associations bulgares et roumaines « se trouvent dans la zone d'influence russe ${ }^{133}$. Comme lors des années 1930 avec les partis fascistes, les officiels de la FIFA prennent simplement note de ces changements, considérant qu'il s'agit là d'affaires internes aux fédérations concernées.

Quatrièmement, le comité exécutif s'emploie à relancer l'activité de la Fédération. Sur ce point, un élément crucial est l'organisation d'une prochaine édition de la Coupe du monde. Signe de l'importance du sujet, il constitue l'un des points majeurs de l'assemblée générale de 1946. Les congressistes se montrent prudents dans le choix des futurs organisateurs : il s'agit notamment de ne pas choisir des pays qui ont participé trop activement à la dernière guerre afin d'éviter de possibles polémiques en interne. Pour la première compétition d'après-guerre, le congrès de 1946 décide que le tournoi se déroulera au Brésil. Tout d'abord, malgré le gouvernement dictatorial de Getulio Vargas et certaines positions ambiguës vis-à-vis de l'Axe durant la première partie du conflit, le Brésil s'est positionné du côté des Alliés en déclarant la guerre à l'Allemagne en 1942. De fait, il est considéré sur la scène internationale comme faisant partie des vainqueurs du conflit. Ce choix permet aussi de répondre aux attentes des Sud-Américains, qui souhaitent depuis l'édition de 1938 que la Coupe du monde se déroule sur leur continent. Ainsi, leur offrir l'organisation de l'épreuve permet de désamorcer un peu plus les tensions qui existent entre Sud-Américains et Européens au sein de la Fédération. Signe d'une volonté de remettre rapidement en route le tournoi, il est prévu qu’il ait lieu en 1947 déjà. Cependant, en raison de difficultés organisationnelles, l'épreuve est repoussée et une nouvelle discussion sur le sujet est prévue pour le congrès de $1948^{134}$. Finalement, les délégués présents décident que la compétition se déroulera en 1950. Ainsi, cinq ans

131 Lettre de A. Kenyeres à I. Schricker, 29 mars 1946. FIFA, correspondance avec les associations nationales : Hongrie (1937-1965), dossier : 1937-1950.

132 Fryc A., Ponczek M., "The Communist Rule in Polish Sport History ", The International Journal of the History of Sport, vol. 26, $\mathrm{n}^{\circ} 4$, 2009, pp. 501-514.

133 Lettre de I. Schricker à J. Rimet, 8 juin 1946. FIFA, membres du comité exécutif, dossier individuel : correspondance J. Rimet (1945-1950), dossier : $1^{\text {er }}$ janvier 1945-31 décembre 1946.

134 Schricker I., Procès-verbal de l'assemblée générale de la FIFA des 27-28 juillet 1948, n.d. FIFA, XXV-XXVII congrès ordinaires (1946-1952, rapport d'activité) 
après la fin du conflit international, la FIFA voit son épreuve phare être à nouveau organisée, ce qui va dans le sens d'un retour "à la normale " dans les affaires de la FIFA.

Cinquièmement, les dirigeants prennent des décisions en vue de développer la structure administrative du secrétariat. Il s'agit de permettre au secrétaire général d'être plus efficace dans son travail, mais aussi de contrôler davantage que par le passé les affaires de la FIFA. Tout d'abord, Seeldrayers demande désormais à Schricker que les circulaires « qui engagent la politique de la [FIFA] " ${ }^{135}$ soient soumises aux membres du comité exécutif ou au comité d'urgence, avant de les envoyer aux associations membres de l'organisation. Cette action permet d'avoir un plus grand contrôle sur les documents officiels de la Fédération internationale mais aussi d'offrir un discours lisse et uni tant vis-à-vis des associations membres de la FIFA que des acteurs extérieurs au domaine footballistique. Il est également demandé au secrétaire général de prendre des notes durant les séances, ce qu'il ne faisait pas avant la guerre. De même, Seeldrayers suggère qu'à l'avenir le procès-verbal soit " fait au fur et à mesure des débats et lu et approuvé à la fin de la dernière séance ${ }^{136}$. Ce type de démarche participe à la professionnalisation du secrétariat, schéma assez classique qui s'opère lorsqu' une organisation connaît un accroissement de ses tâches, comme l'ont montré plusieurs travaux de chercheurs s'intéressant à la problématique des groupes d'intérêts ${ }^{137}$. Si la gestion de l'après-guerre peut expliquer ces changements, ils s'inscrivent effectivement aussi dans le développement du travail du secrétariat. En effet, depuis 1945, la FIFA voit son nombre de membres augmenter chaque année, ce qui engendre des tâches de correspondance supplémentaires pour le secrétaire. C'est pourquoi, à partir des années 1947-1948, de nouveaux collaborateurs sont engagés. Tout d'abord, le secrétaire général dispose d'une nouvelle aide en la personne de "Mlle » Kurmann ${ }^{138}$. De même, un comptable, M. Tabord, est engagé. Signe de l'importance de cette nomination, Jules Rimet fait spécialement le déplacement pour l'introniser et écrit à Seeldrayers qu'avec

135 Lettre de R.W. Seeldrayers à I. Schricker, 3 octobre 1945. FIFA, membres du comité exécutif, dossier individuel : correspondance R.W. Seeldrayers (1939-1950), dossier :

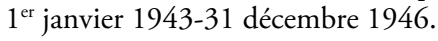

136 Lettre de R.W. Seeldrayers à I. Schricker, 27 février 1946. FIFA, membres du comité exécutif, dossier individuel : correspondance R.W. Seeldrayers (1939-1950), dossier :

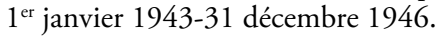

137 Mach A., Groupes d'intérêt et pouvoir politique, Lausanne, PPUR, 2015, pp. 31-45.

138 Dans les correspondances des dirigeants du comité exécutif de la FIFA, elle est appelée "Mlle ». Un bref article de France football lui est consacré lors de la Coupe du monde de 1950. «La petite histoire de la Coupedu monde \#, France fogtballb 12 juillet 1950. 
ces deux nouvelles personnes, la FIFA aura «maintenant une comptabilité correcte et à jour ${ }^{139}$. Ces améliorations réjouissent le secrétaire général Schricker, qui écrit à son président qu'un vent nouveau souffle sur le secrétariat. Ainsi, les premières années qui suivent la sortie du conflit correspondent à une nouvelle étape du développement de l'administration de la FIFA.

Si la fin de la guerre paraît avoir été bien négociée par l'élite de la FIFA et a permis de relancer les activités de la FIFA, dans les années 1947-1948, ils doivent faire face à une nouvelle menace pour la stabilité de leur organisation : la Guerre froide. En effet, comme l'ont indiqué plusieurs chercheurs ${ }^{140}, 1947$ marque un moment de rupture entre l'Est et l'Ouest, en particulier avec la mise en place par l'URSS d'un bureau devant davantage fédérer les actions des partis communistes internationaux, le Kominform ${ }^{141}$. Lélite de la FIFA est directement touchée puisque le " coup de Prague " de février 1948, qui correspond à la prise de pouvoir définitive des communistes en Tchécoslovaquie, va entraîner la démission de Vaclav Valousek. En avril, il informe ses collègues du comité exécutif de la FIFA que des transformations ont eu lieu au sein de la Fédération tchèque et précise : "La composition [du] comité [exécutif] a été modifiée par une décision du gouvernement de créer dans toutes les fédérations sportives des comités d'action en attendant des élections qui auront lieu incessamment conformément aux statuts de l'Association ${ }^{142}$. "Ces événements lui ont fait perdre sa place à la tête de la fédération nationale et même s'il conserve un poste de conseiller aux affaires internationales, son opposition au communisme l'oblige finalement à quitter ses fonctions. Quelques semaines plus tard, il quitte son pays et s'installe en Suède. Cette influence du contexte de tension qui sévit entre les blocs de l'Est et de l'Ouest se confirme lors du congrès de la FIFA de 1948 qui a lieu durant les premiers Jeux olympiques de l'après-guerre à Londres - auxquels

139 Lettre de J. Rimet à R.W. Seeldrayers, 3 juillet 1948. FIFA, membres du comité exécutif, dossier individuel : correspondance R.W. Seeldrayers (1939-1950), dossier : $1^{\text {er }}$ janvier 1947-31 décembre 1949.

140 Berstein S., Milza P. (dir.), L’année 1947, Paris, Presses de Sciences Po, 2007. De même, dans son histoire de la Guerre froide, George-Henri Soutou affirme : " À la fin de l'année 1947, la Guerre froide était déclarée " : Soutou G.-H., La guerre de cinquante ans. Le conflit Est-Ouest, 1943-1990, Paris, Fayard, 2001, p. 189.

141 Sur la création du Kominform, voir : Pons, S., The global revolution. A history of international communism. 1917-1991, Oxford, Oxford University Press, 2014, pp. 155-167.

142 Lettre de V. Valousek au comité exécutif de la FIFA, 16 avril 1948. FIFA, correspondance avec les associations nationales : Tchécoslovaquie (1938-1998) dossier:1939-1950. 
l'URSS ne participe pas car elle n'est toujours pas membre du Comité olympique - et de manière concomitante aux premières aides issue du Plan Marshall ${ }^{143}$, qui termine d'achever la scission entre les deux blocs. Parmi la vingtaine de congressistes provenant des pays du bloc soviétique, seuls trois dirigeants (le Polonais Przeworski, le Tchèque Valousek, tout de même présent mais à titre personnel et le Yougoslave Andrejevic) ont déjà, par le passé, participé à ce genre de manifestations. L'Autriche, la Belgique, le Danemark, l'Espagne, la Finlande, la France, la Grèce, l'Irlande, l'Italie, le Luxembourg, la Norvège, les Pays-Bas et le Portugal sont au contraire tous représentés par au moins un dirigeant ayant déjà participé aux assemblées générales de la FIFA durant les années 1930. Le cas des associations des pays de l'Est est donc l'exception qui ne confirme pas la règle. Il est d'ailleurs à noter que, pour Przeworski et Valousek, il sagit de leur dernier congrès.

En outre, les congressistes prennent la décision de nommer un dirigeant de la Fédération des États-Unis en remplacement de Valousek. D'un point de vue footballistique, cette nomination interroge, car ce pays n'est pas un acteur majeur du ballon rond. Pourtant, dès septembre 1945, Seeldrayers indiquait au secrétaire général que si la Fédération des États-Unis n’est pas une puissance majeure de la FIFA, il fallait néanmoins tenir compte de son avis ${ }^{144}$. L'élection d'un dirigeant d'Amérique du Nord, en l'occurrence Randolph Manning, souligne bien la recherche du neutralisme portée par le comité exécutif de la FIFA, posture suivie par une majorité des congressistes de la FIFA. Car la présence d'un États-unien au sein de son élite permet de contrebalancer la présence d'un vice-président soviétique et ainsi de limiter ses possibilités d'action à la tête de l'organisation. Sous cet angle, un autre changement de taille se produit avec la non-réélection du Yougoslave Andrejevic. Actif dès les années 1930 au sein des arcanes de la FIFA et dans le comité exécutif depuis 1938, sa non-reconduction peut sembler une surprise. Toutefois, dans ce fameux jeu de balance, n'estelle pas une occasion de rendre un peu de change à l'URSS, ce pays étant désormais en lutte contre la Yougoslavie sur la scène internationale ${ }^{145}$ ? Fait intéressant, il est remplacé par Giovanni Mauro. Ce retour en grâce

143 Sur le Plan Marshall, voir : Schain M. (ed.), The Marshall plan: fifty years after, New York, Palgrave, 2001.

144 Lettre de R.W. Seeldrayers à I. Schricker, 17 mars 1945. FIFA, membres du comité exécutif, dossier individuel : correspondance R.W. Seeldrayers (1939-1950), dossier : $1^{\text {er }}$ janvier 1943-31 décembre 1946.

145 Cette dernière étant désormais mise au ban par les autres pays communistes. Sur les raisons du schisme, voir Kullaa R., Non-alignment and its origins in Cold War Europe. Yugoslavia, Finland and the Soviet Challenge Londres, I.B. Tauris, 2012 
du dirigeant italien permet de minimiser le possible mécontentement des Yougoslaves, car la Fédération italienne entretient des relations de proximité avec eux, et ce malgré quelques tensions momentanées autour de l'administration footballistique de la ville de Trieste ${ }^{146}$. Après ces élections, les pays du bloc soviétique n'ont donc plus qu'un vice-président comme représentant au sein du comité exécutif. Ces propos restent toutefois au stade de l'hypothèse car nous n'avons pas le détail des votes ni retrouvé des données dans les correspondances personnelles sur ce jeu de «chaises musicales ", qui permettraient d'appuyer ce propos.

Mais l'élection de Manning pose une autre question. N'est-ce pas aussi pour répondre aux rapports de force Europe-Amérique du Sud que ce dernier est élu ? En effet, en raison de sa trajectoire professionnelle et footballistique, Manning fait partie de la même génération que les dirigeants européens qui officient au sein du comité exécutif de la FIFA. Né en Europe, il a effectué ses études en Allemagne où il s'est notamment lié d'amitié avec Ivo Schricker. Parti pour les Etats-Unis, il a œuvré au développement du football dans son pays. Durant toutes ces années, il est resté en contact constant avec des dirigeants comme Rimet ou Schricker et partage des idées proches d'eux quant au développement du football, et en particulier de la FIFA. Dès lors, Manning ne soutient sans doute pas les volontés décentralisatrices des dirigeants sud-américains. Or la décennie 1940 correspond à une prise de distance des associations sud-américaines vis-à-vis de la FIFA et à une consolidation de leur entité continentale, de sorte que celle-ci puisse se faire la porte-parole de leur volonté de réorganiser la FIFA.

\subsection{L'émergence d'un contre-pouvoir américain}

À la fin des années 1930, les tensions aperçues entre Européens et Sud-Américains paraissent s'atténuer. En effet, dans le but de « resserrer les liens existants entre les associations de l'Amérique du Sud et la FIFA $»^{147}$, Jules Rimet entame, en 1939, un voyage en Amérique du Sud. Il est

146 Sur les tensions italo-yougoslaves autour de la ville de Trieste, voir : Archambault, Fabien, "Le football à Trieste de 1945 à 1954 ", Vingtième Siècle. Revue d'histoire, vol. 111, n 3, 2011, pp. 49-58. Et pour une étude davantage basée sur les aspects géopolitiques : Sbetti, N., "Playing at the border of the cold war: the case of the city of Trieste (1945-1948) ", dans Vonnard P., Sbetti N., Quin G., Beyond boycotts, op. cit., pp. 17-32.

147 Schricker I., Procès-verbal de la réunion du comité exécutif de la FIFA des 3-4 juillet 1939, n.d. FIFA, comité exécutif (procès-verbaux 1939). 
bien accueilli par les dirigeants sud-américains et, à son retour, indique à ses collègues du comité exécutif que son voyage a certainement resserré les liens entre la FIFA et l'Amérique du Sud. Signe de l'amélioration des relations entre les dirigeants des deux continents, les délégués sudaméricains annulent, quelques semaines plus tard, les Accords du Congrès de Santiago ${ }^{148}$. Mais cet apaisement n'est que passager et va être remis en cause par la guerre.

\subsubsection{La structuration de la Confédération sud-américaine}

Durant la Deuxième Guerre mondiale, le fossé entre l'Amérique du Sud et le secrétariat de Zurich se creuse. Les difficultés dans les liaisons postales ont pour conséquence de réduire les communications entre les associations sud-américaines et la FIFA ${ }^{149}$. Dès lors, même s'il essaie de maintenir l'autorité de la Fédération internationale sur le football en Amérique du Sud, le secrétaire Schricker n'a, en réalité, qu'un contrôle relatif sur les actions des dirigeants de la Confédération sud-américaine. En fait, il ne reçoit que peu d'informations sur ce qui se passe en Amérique du Sud sur le plan footballistique. Les demandes d'informations qu'il transmet tant auprès des associations nationales que de la Confédération sud-américaine restent le plus souvent sans réponse. Dès lors, il tente de se renseigner par ses propres moyens et utilise d'autres canaux. À ce titre, il se base notamment sur des informations paraissant dans des journaux européens spécialisés dans le football. Ce mode de fonctionnement témoigne des difficultés auxquelles le secrétaire fait face pour se procurer des informations sur ce qui se passe réellement sur ce continent.

Ces difficultés sont d'autant plus grandes que le représentant sudaméricain au comité exécutif, Luis Dupuy, ne joue pas son rôle de relayeur d'informations. En effet, à partir de 1940, il ne semble plus disposer d'assez de temps pour s'atteler à cette tâche. Diplomate en représentation auprès du régime de Vichy, il annonce même sa démission en 1941. Celle-ci n'est toutefois pas acceptée par la Confédération sud-américaine car ses dirigeants estiment le moment peu opportun. Il serait, en effet, difficile de trouver un représentant qui soit impliqué autant que Dupuy dans les affaires footballistiques. Cette décision soulage Schricker, car il considère

148 Lettre de I. Schricker au comité exécutif de la FIFA, 21 avril 1939. FIFA, comité exécutif (procès-verbaux 1939).

149 Lettre I. Schricker à E. Borrero, 28 février 1944. FIFA, correspondance avec les confédérations continentales : CONMEBOL (1941-1961), dossier:-1941-31-12,1950. 
l'Uruguayen comme une personne " énergique et intelligente " ${ }^{150}$, dotée d'un bon état d'esprit, ajoute-t-il à son sujet. De plus, il constitue une aide précieuse pour le secrétaire général de la FIFA, car si Schricker comprend l'espagnol, il n'en maîtrise pas toutes les subtilités. En conséquence, des propos dans les courriers qu'il reçoit peuvent, parfois, lui échapper. Mais Dupuy se montre de moins en moins présent, ce qui oblige Schricker à faire appel au secrétaire de la Fédération espagnole pour l'aider à traduire plusieurs lettres ${ }^{151}$. Finalement, en 1943, Luis Dupuy annonce une nouvelle fois sa démission, "son gouvernement ayant rappelé tous les fonctionnaires diplomatiques accrédités en France $"{ }^{152}$. Face à ce contexte, la Confédération sud-américaine n'a pas d'autres choix que de le libérer de ses fonctions. Ainsi, la FIFA se retrouve dans la même situation que dix ans auparavant avec Enrique Buero. Comme son prédécesseur, Dupuy est un fonctionnaire politique en place en Europe et il est, parfois, amené à changer de fonction. Cette situation n'est pas sans conséquence puisqu'elle limite l'établissement d'une relation continue et de confiance entre les dirigeants européens et leurs homologues sud-américains.

Or, au fil du conflit international, les associations sud-américaines prennent leurs distances vis-à-vis de la FIFA, certains matchs internationaux étant par exemple joués en ne suivant pas les règlements de la Fédération internationale ${ }^{153}$. Certes, les pays d'Amérique du Sud ne restent pas en dehors du conflit mondial, toutefois ces pays sont tout de même moins touchés par les hostilités que les pays européens. D’un point de vue footballistique, cela signifie que la guerre n'a que peu d'impact sur les échanges à l'intérieur du continent sud-américain. Pour la FIFA, qui doit faire face à des difficultés financières, les rentrées d'argent sur les rencontres entre les associations sud-américaines s'avèrent cruciales. Dès le début de la guerre, Schricker fait part à leur représentant au sein du comité exécutif de la FIFA, Luis Dupuy, de son souhait d'organiser des rencontres entre des associations sud-américaines (par exemple UruguayArgentine ou Brésil-Pérou) qui auraient comme avantage de soutenir les finances de la FIFA. En outre, Schricker mentionne que de tels matchs

150 Lettre de I. Schricker à E. Borrero, 17 mars 1943. FIFA, correspondance avec les confédérations continentales : CONMEBOL (1941-1961), dossier : 1941-31.12.1950.

151 Lettre du secrétaire de la fédération espagnole à I. Schricker, 19 mai 1941. FIFA, FIFA, correspondance avec les associations nationales : Espagne (1935-1963), dossier : $1935-1950$

152 Lettre de I. Schricker à E. Borrero, 17 mars 1943. FIFA, correspondance avec les confédérations continentales : CONMEBOL (1941-1961), dossier : 1941-31.12.1950.

153 Lettre de I. Schricker à E. Borrero, 17 décembre 1942. FIFA, correspondance avec les confédérations continentales : CONMEBOL (1941-1961), dossier:-1941-31-12,1950. 
permettraient de créer " une forte sympathie en Europe $" ~{ }^{154}$, qui pourrait compter au moment de l'attribution de la future Coupe du monde. Si Dupuy répond positivement à la requête de Schricker, le secrétaire doit néanmoins constater, quelques mois plus tard, qu'il n'a toujours pas reçu d'informations à ce sujet. Dans les mois qui suivent, ce dernier commence à se plaindre des difficultés que les associations sud-américaines ont à lui envoyer leur contribution financière. Dans ces temps financièrement difficiles pour la FIFA - un déficit de 12000 francs suisses est par exemple budgété pour l'année 1942 -, Schricker insiste pour qu'elles versent rapidement le pourcentage sur les recettes des rencontres internationales. Sur ce point, notre interprétation differe quelque peu de celle de Paul Dietschy qui, dans son article sur la mondialisation de la FIFA, indique que les associations sud-américaines restent loyales vis-à-vis de la FIFA sur le plan financier ${ }^{155}$. Certes, une partie des montants dus à la FIFA sont bel et bien versés par des associations sud-américaines durant le conflit ${ }^{156}$. Cependant, il nous semble que, de manière générale, celles-ci répondent difficilement aux sollicitations de Schricker. C'est pourquoi il contacte, à plusieurs reprises, le secrétaire de la Confédération sud-américaine, Effrain Borrero. Afin de le pousser à agir, Schricker lui indique que les associations des pays en guerre, à savoir les associations européennes, "qui sont dans une situation beaucoup plus difficile que les associations du continent sud-américain n'ont à aucun moment cessé de payer régulièrement, malgré toutes les difficultés causées par les prescriptions de l'Office de compensation pas seulement leurs cotisations, mais aussi les pourcentages de leurs matchs internationaux $"{ }^{157}$. La correspondance entretenue entre les pays européens et le secrétaire général de la FIFA montre que ce dernier leur transmet également plusieurs lettres de rappel. Cependant, celles-ci font fort souvent la sourde oreille aux demandes du secrétaire. De même, la Confédération sud-américaine rechigne à lui indiquer les résultats des championnats continentaux de 1939 et 1942, sur lesquels la FIFA a aussi le droit de percevoir un pourcentage. En outre, lors du congrès ordinaire de la Confédération sud-américaine de 1942, un représentant chilien

154 Lettre de I. Schricker à L. Dupuy, 13 février 1941. FIFA, correspondance avec les confédérations continentales : CONMEBOL (1941-1961), dossier : 1941-31.12.1950.

155 Dietschy P., " Making football global », op. cit, p. 287.

156 Par exemple, la FIFA reçoit en juillet 1942 un versement des associations de la Colombie, de l'Équateur, du Paraguay et du Pérou. Lettre de E. Borrero à I. Schricker, 5 juillet 1942. FIFA, correspondance avec les confédérations continentales : CONMEBOL (1941-1961), dossier : 1941-31.12.1950.

157 Lettre de I. Schricker à E. Borrero, 17 mars 1943. FIFA, correspondance avec les confédérations continentales : CONMEBOL (1941-1961), dgssier:-1941-31 12,1950. 
propose que les fédérations sud-américaines ne paient plus que la moitié du montant des cotisations annuelles dues à la FIFA. L'argument évoqué est la diminution des dépenses de la Fédération internationale, dont l'activité est ralentie à cause de la guerre ${ }^{158}$. Même si Borrero peut indiquer à Schricker, quelques mois plus tard, qu'au vu des délibérations, cette proposition n'a pas été adoptée, celle-ci montre bien qu'un détachement du pouvoir de la FIFA s'opère progressivement chez les dirigeants sud-américains.

Tableau 9. Charges de la FIFA en 1938 et en 1942 (en francs suisses)

\begin{tabular}{|l|c|l|c|}
\hline \multicolumn{2}{|c|}{ Charges 1938 } & \multicolumn{2}{c|}{ Charges 1942 } \\
\hline Postes & Montants & Postes & Montants \\
\hline Comité & 12196 & Comité & 2304,55 \\
\hline Salaire et Loyers & 28072,90 & Salaire et Loyers & 24916,35 \\
\hline Frais de postes & 8568,05 & Frais de postes & 4272,80 \\
\hline $\begin{array}{l}\text { Fournitures de bureau }+ \\
\text { imprimés }\end{array}$ & 1650,75 & $\begin{array}{l}\text { Fournitures de bureau + } \\
\text { imprimés }\end{array}$ & 2465,26 \\
\hline Annuaire & 2265,50 & & \\
\hline Organe officiel & 2558,10 & & 177,58 \\
\hline Divers & 876,22 & Divers & 35136,54 \\
\hline Total & 56186,52 & Total & \\
\hline
\end{tabular}

En fait, la guerre semble offrir une opportunité aux associations sud-américaines de s'affranchir de la tutelle de la FIFA. Mais, vu la situation chaotique de l'Europe, elles estiment aussi que ce sera à elles de reconstruire la FIFA après 1945. C'est pourquoi, durant les hostilités déjà, elles prennent des décisions sur le futur du football international. Ainsi, lors d'un congrès de la Confédération sud-américaine tenu en 1941, les représentants présents formulent le souhait que le premier congrès de la FIFA après la guerre se déroule en Espagne, remettant en question la décision prise lors de l'assemblée de 1938 lors de laquelle le Luxembourg avait été choisi ${ }^{159}$. Cette initiative devrait permettre de renforcer les liens de l'Amérique du Sud avec l'ancienne puissance coloniale en créant un bloc

158 Lettre de I. Schricker au comité exécutif de la FIFA, juillet 1942. FIFA, rapport d'activité durant la guerre.

159 Schricker I., Procès-verbal de l'assemblée générale de la FIFA du 3 juin 1938, n.d. FIFA, XX-XXIV congrès ordinaires (1931-1938, rapport d'activité 
de pays latins. De plus, c'est aussi un moyen pour les Sud-Américains de faciliter leur participation. Premièrement, il leur sera plus aisé d'y accéder par bateau. Deuxièmement, au regard des liens entretenus avec l'Espagne franquiste, le risque de tracasseries administratives pour obtenir les visas sera moins délicat. En outre, durant ce même congrès de 1941, il est décidé de créer une commission afin de statuer sur le cas de la prochaine Coupe du monde. Hormis le souhait qu'elle soit disputée en Amérique du Sud, ses membres chargent " le comité exécutif de la Confédération sud-américaine d'entreprendre par l'entremise de son délégué auprès de la FIFA des démarches ayant pour but de renvoyer la Coupe du monde à l'année $1942 \|^{160}$ et d'organiser la future épreuve dans les 18 mois après la fin du conflit en Europe. Ces décisions montrent que la Confédération sud-américaine tend à prendre des prérogatives qui sont, en temps normal, l'apanage de la FIFA.

À la fin de la guerre, le nouveau représentant de la Confédération sud-américaine dans le comité exécutif de la FIFA, Augustin Matienzo, poursuit cette politique et fait part à ses collègues européens des volontés de l'organisation qu'il représente. Fils d'un célèbre juriste argentin qui a participé à la création de l'État, Matienzo est un haut dignitaire de la Fédération argentine. Lui-même a emprunté la voie de son père puisqu'il est docteur en droit et enseigne à la Faculté de droit de l'Université de Buenos Aires. Fort de sa formation de juriste, en juillet 1945, il envoie un courrier à Schricker dans lequel il explique que le comité exécutif n'est plus légitime puisque les mandats des derniers membres sont terminés depuis $1942^{161}$. Selon lui, ce dernier n'a donc plus aucune faculté " pour se réunir et dicter des résolutions [en tant que] directeur de [la FIFA] " ${ }^{162}$. À la vue de cette situation, il indique que la Confédération sud-américaine se permet de reprendre le flambeau et souhaite convoquer un congrès qui se déroulera à Montevideo en 1946. Constatons que, dans un positionnement plus ferme, le lieu du futur congrès de la FIFA est finalement situé en Amérique du Sud plutôt qu'en Espagne. Cette proposition est novatrice, car la convocation du congrès est normalement l'apanage du secrétariat de la FIFA. De plus, ces manifestations se sont jusqu'ici toujours déroulées en Europe. Les Sud-Américains tentent donc de profiter de la confusion qui existe à la fin

160 Lettre de I. Schricker au comité exécutif de la FIFA, 25 janvier 1941. FIFA, rapport d'activité durant la guerre.

161 En effet, les mandats de la FIFA durent quatre années et comme le dernier congrès a eu lieu en 1938, le dirigeant en déduit qu'en l'absence d'assemblée générale leur mandat est échu en 1942.

162 Lettre de A.N. Matienzo à I. Schricker, 23 juillet 1945. FIFA, rapport d'activité durant la guerre. 
de la guerre pour prendre davantage de pouvoir au sein de la FIFA, voire se proposer comme une alternative. Il s'agit donc d'une attaque frontale vis-à-vis de l'autorité de la FIFA, la requête des dirigeants sud-américains reflétant bien l'air du temps de cette sortie de conflit qui voit, d'une part, le pouvoir des grandes puissances européennes être remis en question sur la scène internationale et, d'autre part, l'émergence des pays extra-européens comme de nouveaux acteurs de la politique internationale. L'importance croissante de l'Amérique du Sud au niveau international n'est pas visible que dans le domaine sportif. Eric Helleiner a souligné la présence de neuf pays sud-américains, quatre pays africains et cinq pays asiatiques lors des conférences qui débouchent sur la formation des organismes de Bretton Woods (Banque mondiale et Fonds monétaire international). Certes, il souligne que les États-Unis et la Grande-Bretagne doivent être considérés comme les leaders du projet, mais il relève que "l'influence [dans les discussions] des délégués d'Amérique du Sud et d'autres pays du Sud ne doit pas être sous-estimée ${ }^{163}$. Cet aspect se retrouve aussi d'une certaine manière dans un texte de Nadjib Souamaa dans lequel l'auteur indique brièvement qu'au sein de l'Organisation internationale du travail, des liens plus fermes sont tissés avec les Sud-Américains, et ce dès la sortie de la Deuxième Guerre ${ }^{164}$.

Les dirigeants du comité exécutif de la FIFA réagissent néanmoins vigoureusement à cette tentative d'ingérence latino-américaine. Seeldrayers, également juriste de profession, contredit les arguments juridiques avancés. S'il constate, comme Matienzo, que les mandats sont terminés, il indique qu' « il est de règle dans tous les organismes [et] dans tous les États qu'en attendant qu'il puisse être pourvu à leurs remplacements, [les membres] restent en fonction et doivent assurer l'expédition des affaires courantes ${ }^{165}$. En outre, il renforce son argumentaire par des références historiques et rappelle que, lors de la Première Guerre mondiale, c'est le secrétaire Hirschman qui avait convoqué un congrès à Anvers, raison pour laquelle cette tâche doit incomber à Ivo Schricker. Son explication historique est toutefois discutable car les événements sont beaucoup plus complexes en 1919, la FIFA étant passée tout près d'une scission interne. Sous cet angle, la position des Sud-Américains rappelle celle des

163 Helleiner E., Forgotten Foundations of Bretton Woods. International Developments and the Making of the Postwar Order, Ithaca, Cornell University Press, 2014, p. 15.

164 Souamaa N., "L'OIT d'un après-guerre à l'autre : entre modèle universel et régionalisme européen ", Les Cahiers Irice, vol. 9, n 1, 2012, pp. 23-46.

165 Lettre de R.W. Seeldrayers à I. Schricker, 3 octobre 1945. FIFA, membres du comité exécutif, dossier individuel : correspondance R.W. Seeldrayers (1939-1950), dossier : $1^{\text {er }}$ janvier 1943-31 décembre 1946. 
Britanniques qui avaient voulu prendre le leadership de l'organisation au sortir du premier conflit mondial. Le comité exécutif suit la position de Seeldrayers et refuse la proposition de la Confédération sud-américaine. Sans doute vexé par cette situation, Matienzo, pourtant invité ${ }^{166}$, ne se rend pas à la réunion du comité exécutif de novembre 1945. Cette absence renforce la position des Européens puisqu'ils peuvent décider à leur guise de la remise en route de la FIFA. Signe de cette conservation du pouvoir par les Européens, le congrès de la FIFA de 1946 se déroule bel et bien en Europe, et même au centre du continent, à Luxembourg. Par cette décision, les membres du comité exécutif se placent dans la continuité des décisions prises lors du congrès de 1938. Ce procédé a l'avantage de montrer que, malgré les six années terribles qui viennent de s'écouler, l'élite de la FIFA s'attelle à poursuivre le travail sur les bases décidées avant la guerre. Mais le lieu choisi sonne aussi comme une sanction vis-à-vis de l'attitude des Sud-Américains, la ville de Luxembourg ne possédant, en effet, aucune liaison aérienne ${ }^{167}$. Dès lors, pour s'y rendre, les associations qui proviennent de pays non européens vont devoir passer par un autre pays, ce qui implique des démarches administratives supplémentaires, notamment en matière de visa.

Cette décision n'offre pas les meilleures garanties d'un rapprochement entre les dirigeants sud-américains et européens. C'est d'autant plus le cas que, depuis le début de la guerre, l'idée de mettre sur pied un organisme panaméricain est discuté. Celui-ci créerait une agrégation d'une vingtaine d'associations qui pourrait permettre de concurrencer le pouvoir des Européens au sein de la FIFA.

\subsubsection{Créer une contre-organisation ?}

Dès la fin des années 1930, la Confédération sud-américaine a élargi son territoire de juridiction et concerne dorénavant tous les pays de son continent, excepté le Venezuela. En effet, en 1936, un élargissement

166 Anonyme, "Délégué de la Confédération sud-américaine auprès de la FIFA ", n.d. FIFA, rapport d'activité durant la guerre.

167 Lidée d'organiser le congrès dans la ville de Lisbonne, un temps évoquée au sein du comité exécutif, afin de faciliter la participation des associations sud-américaines, est finalement abandonnée. Cette décision témoigne sans doute de la volonté de ses dirigeants de répondre aux ambitions sud-américaines. Lettre de I. Schricker à R.W. Seeldrayers, 16 octobre 1945. FIFA, membres du comité exécutif, dossier individuel : correspondance R.W. Seeldrayers (1939-1950), dossier : $1^{\text {er }}$ janvier 1943-31 décembre 1946. 
s'opère avec l'adhésion de la Colombie. Puis, l'association d'Argentine y fait officiellement son retour en $1941^{168}$. Il est difficile de savoir les raisons qui expliquent que le retour de l'Argentine s'opère à ce moment-là, mais il constitue un élément important pour la légitimité de la Confédération sud-américaine, ce pays étant assurément l'une des principales fédérations de football du continent. De plus, l'Argentine entretient aussi des liens internationaux avec plusieurs associations, dont la fédération anglaise ${ }^{169}$. Le retour de l'Argentine s'inscrit dans un contexte qui voit la Confédération sud-américaine bénéficier d'une plus grande reconnaissance sur le continent, comme le montre la participation lors de la Copa America. En effet, les éditions disputées en 1942 et surtout en 1945 sont les tournois qui rassemblent le plus de participants de l'histoire. Il semble que la nomination d'un nouveau président à la tête de la Confédération sudaméricaine ne soit pas étrangère à cette situation. C'est en janvier 1939 que le Chilien Luis Valenzuela accède à ce poste. Président de la Fédération chilienne depuis la fin des années 1930, Valenzuela, qui commence ici un mandat de près de quinze ans, va marquer l'organisme de son empreinte, notamment en cherchant à renforcer les liens en interne mais aussi en créant des alliances avec des organismes extérieurs. Durant les mois qui suivent son élection, des décisions importantes sont prises dans le but de rapprocher les associations membres de la Confédération.

Tout d'abord, en 1941, il est question de créer un Jour du football sudaméricain, qui serait fixé au 9 juin. Cette date fait référence à l'obtention de l'organisation de la Coupe du monde par l'Uruguay. Aspect commémoratif certes, mais aussi une manière de rappeler aux Européens que le grand tournoi mondial a pu être lancé grâce aux actions des Sud-Américains. De même, dans le cadre des commémorations du $450^{\mathrm{e}}$ anniversaire de la découverte des Amériques par Christophe Colomb, qui se déroulent en 1942, le comité exécutif de la Confédération sud-américaine évoque l'idée d'organiser un match entre une sélection sud-américaine et une équipe espagnole. Nous pouvons supposer que l'invitation de l'Espagne permettrait de fortifier les relations latines au sein de la Fédération internationale. Signe de cette volonté de créer des rapprochements avec les anciens colonisateurs, le cas du Brésil est aussi étudié. En effet, conscients que le continent sud-américain connaît " des nations de race espagnole

168 Lettre de I. Schricker au comité exécutif de la FIFA, 8 juillet 1941. FIFA, rapport d'activité durant la guerre.

169 Brook Hirst A., Rapport annuel du président de la FA (1942-1943), n.d. FA, Minutes and proceedings from June 1943 to Juns 1944 
et portugaise ${ }^{170}$, les dirigeants de la Confédération envisagent d'inviter, quelques mois plus tard, l'équipe du Portugal à venir disputer un match analogue en Amérique du Sud. Cette démarche a pour but explicite de tisser des liens plus solides avec le Brésil, dont les dirigeants ont parfois pris, dans les années 1930, leurs distances vis-à-vis des positions de la Confédération. À notre connaissance, ces deux rencontres ne se sont toutefois pas disputées.

Dans le même temps, le congrès de 1941 décide de renforcer la structure de la Confédération sud-américaine. À ce titre, un tournus du siège de l'organisation est désormais établi. Celui-ci suivra la nationalité du secrétaire et sera donc transféré, à tour de rôle, dans les grandes villes de différents pays sud-américains. Suivant ces dispositions, au début de l'année 1940, le secrétaire Effrain Borrero met sur pied un siège à Barranquilla (Colombie). Quelques années plus tard, le siège se trouve en Bolivie, à Cochabamba. Cette manière de fonctionner limite sans doute la structuration de la Confédération puisqu'il n'y a pas de secrétaire permanent pouvant assurer une continuité de travail sur le long terme. Par contre, elle a comme avantage de concerner toutes les associations membres, puisque chacune d'elle pourra à l'avenir potentiellement accueillir le siège de l'organisation. Ces mécanismes sont créés afin de renforcer le pouvoir de la Confédération en interne. Outre de permettre de nouvelles collaborations en football à l'échelle continentale, ces actions ont également comme but de montrer aux dirigeants de la FIFA que désormais ils ont face à eux une organisation mieux structurée et pouvant défendre la voix de l'Amérique du Sud dans la Fédération internationale. Afin d'être plus efficiente sur ce point, la Confédération sud-américaine envisage des alliances avec les associations se trouvant en Amérique centrale.

À la fin des années 1930, le football connaît un développement croissant dans cette région. Par exemple, si lors des Jeux de l'Amérique centrale et des Caraïbes disputés en 1938 seuls cinq pays (la Colombie, le Costa Rica, le Mexique, le Panama et le Salvador) prennent part à l'épreuve de football, cinq ans plus tard, un tournoi de football organisé au Salvador voit la participation de treize équipes (Colombie, Costa Rica, Curaçao, Guatemala, Haïti, Honduras, Jamaïque, Nicaragua, Panama, Puerto Rico, Saint-Domingue, Salvador et Venezuela) ${ }^{171}$. En conséquence,

170 Lettre de I. Schricker au comité exécutif de la FIFA, 8 juillet 1941. FIFA, rapport d'activité durant la guerre.

171 Lettre de I. Schricker à R.W. Seeldrayers, 23 novembre 1943. FIFA, membres du comité exécutif, dossier individuel : correspondance R.W. Seeldrayers (1939-1950),

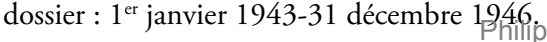


malgré l'influence culturelle nord-américaine, qui a tendance à favoriser le développement de sports comme le base-ball ou le basket-ball ${ }^{172}$, le football commence également à s'implanter durablement en Amérique centrale. Cette situation ne va pas sans poser des problèmes au secrétaire général de la FIFA, qui rappelle à la Fédération du Salvador que « les associations de Guatemala, Jamaïque, Nicaragua, Puerto Rico et Saint-Domingue ne sont pas affiliées à la FIFA ${ }^{173}$. En conséquence, il ne devrait pas être possible pour les associations membres de la Fédération internationale de jouer contre elles. Cette requête témoigne de la volonté de contrôler les actions des associations extra-européennes, mais elle montre aussi que le pouvoir de la FIFA n'est que faiblement exercé dans ces régions. Dans une lettre écrite en février 1943 à Seeldrayers, Schricker déplore le peu d'influence du conseiller pour l'Amérique centrale auprès de la FIFA, Campbell. Le secrétaire général note que celui-ci semble surtout être actif à Cuba et au Mexique et que son influence a encore diminué " depuis la constitution de la Confédération d'Amérique centrale ${ }^{174}$. Pour les dirigeants sudaméricains, créer des liens avec leurs homologues d'Amérique centrale permettrait de favoriser les échanges footballistiques avec leurs homologues plus au Nord mais aussi de possiblement créer une " voix de l'Amérique " au sein de la FIFA.

Idée déjà développée au début des années 1930, la formation d'une entité panaméricaine prend assurément du corps dans la décennie suivante. Ainsi, lors du congrès ordinaire de la Confédération sud-américaine de 1941, une volonté est clairement affichée de créer une Confédération panaméricaine qui se concrétise dans le nouvel article 50 des statuts de l'organisation sud-américaine qui mentionnent : "Les associations des trois Confédérations américaines uniformiseront leur opinion et agiront d'un commun accord dans un esprit de solidarité américaine dans les questions qui pourront se présenter dans la FIFA ${ }^{175}$.

172 Sur cette influence voir plusieurs contributions présentes dans : L’Hoeste H.F., Irwin R., Poblete, J., Anker R. (eds.), Sports and nationalism in Latin/o America, New York, Palgrave Macmillan, 2015.

173 Lettre de I. Schricker à R.W. Seeldrayers, 23 novembre 1943. FIFA, membres du comité exécutif, dossier individuel : correspondance R.W. Seeldrayers (1939-1950), dossier : $1^{\text {er }}$ janvier 1943-31 décembre 1946.

174 Lettre de I. Schricker à R.W. Seeldrayers, 9 février 1943. FIFA, membres du comité exécutif, dossier individuel : correspondance R.W. Seeldrayers (1939-1950), dossier : $1^{\text {er }}$ janvier 1943-31 décembre 1946.

175 Lettre de I. Schricker au comité exécutif de la FIFA, 22 août 1941. FIFA, rapport d'activité durant la guerre. 
Le nouvel organisme compterait une vingtaine d'associations nationales et pourrait dès lors contester l'hégémonie des Européens au sein de la FIFA. Cette menace est bien perçue par le secrétaire Schricker qui, ayant eu vent de l'affaire, écrit à Seeldrayers que " cette guerre a sûrement comme résultat le développement d'une pensée "panaméricaine", pas seulement dans le domaine du sport ${ }^{176}$. Les propos du secrétaire général ne sont pas dénués de sens, car les années de guerre permettent effectivement un rapprochement entre les pays du continent américain. Comme l'a relevé Olivier Compagnon dans un texte sur "les Amériques latines » pendant la Deuxième Guerre mondiale, la première partie des années 1940 correspond à un moment favorable dans l'élaboration de plusieurs projets à l'échelle latino-américaine. Compagnon note que les années de guerre peuvent être :

"Identifiées comme un tournant important dans l'histoire de la pensée latino-américaine en ce sens qu'elles [ont] stimulé l'émergence de théories et de paradigmes spécifiquement latino-américains dont la théorie de la dépendance, en matière économique ou la théologie de la libération, dans le domaine philosophico-religieux, ne [sont] que quelques-uns des avatars au cours des années $1960^{177}$ ".

Finalement, la confédération panaméricaine ne voit pas le jour durant la Deuxième Guerre mondiale mais l'idée n'est pas enterrée pour autant. En novembre 1945, le comité exécutif de la Fédération internationale discute d'une résolution prise - sessions durant lesquelles, pour rappel, aucun représentant sud-américain n'est présent -, lors du dernier congrès de la Confédération sud-américaine, sur l'éventuelle constitution d'un organisme panaméricain. Les dirigeants présents notent que « la Confederación Sud-Americana et la Confederación Centro-Americana existent depuis assez longtemps, et il serait inopportun d'entreprendre des démarches contre la fondation de la Confederación Panamericana $"{ }^{178}$. Souhaitant sans doute ne pas attiser davantage de conflits avec les dirigeants du football sud-américains, l'élite de la FIFA décide de ne pas agir mais souligne qu'il faut surveiller ces démarches.

176 Lettre de I. Schricker à R.W. Seeldrayers, 28 juillet 1941. FIFA, membres du comité exécutif, dossier individuel : correspondance R.W. Seeldrayers (1939-1950), dossier : $1^{\text {er }}$ janvier 1943-31 décembre 1946.

177 Compagnon O., " En marge de la guerre ? Les Amériques latines ", dans Aglan A., Frank R. (dir.), 1937-1947. La guerre-monde, tomes 1 et 2, Paris, Gallimard, p. 590.

178 Schricker I., Procès-verbal de la réunion du comité exécutif de la FIFA des 10-12 novembre 1945, n.d. FIFA, comité exécytif (procès-verbaux 1940-1946) 
En janvier 1946, lors d'un entretien privé, le vice-président de la Fédération argentine, Duco, confirme à Jules Rimet que « la création de la confédération panaméricaine semble en bonne voie ${ }^{179}$ et témoigne d'un moment particulièrement favorable à l'établissement de structures panaméricaines dans différents domaines ${ }^{180}$. Cette action se concrétise finalement le 22 décembre 1946, lors d'un meeting qui réunit les délégués de la Confédération sud-américaine, de la Confédération d'Amérique centrale ainsi que de la Confédération des associations d'Amérique du Nord - créée entre le 16 et le 20 décembre à Cuba ${ }^{181}$.

Les dirigeants présents ne souhaitent pas se mettre en porte-à-faux par rapport à la FIFA et indiquent qu'ils reconnaissent son autorité suprême en matière de football mondial. De plus, ils décident de lui envoyer les statuts de la nouvelle entité pour approbation, démarche réalisée dans le courant de l'année 1948. Dans ce document, il est stipulé que les associations doivent préalablement être membres de la Fédération internationale pour adhérer à la Confédération panaméricaine. Par ailleurs, il est aussi mentionné que l'organisation respecte les Lois du jeu telles qu'elles sont édictées par la FIFA. Tenant compte de ces dispositions, qui ne vont pas contre l'autorité de la FIFA, son comité exécutif accepte de ratifier les statuts de l'entité en juillet $1948^{182}$.

Si l'ambition de l'organisation n'est pas de remettre en question le monopole de la Fédération internationale, c'est tout de même un nouveau contre-pouvoir qui se dessine. Car, dans les statuts transmis à Ivo Schricker, nous pouvons constater que certains buts poursuivis par la Confédération panaméricaine sont, en fait, des prérogatives de la Fédération internationale. Par exemple, ses dirigeants souhaitent créer des compétitions internationales, un projet étant d'ailleurs développé dans

179 Lettre de I. Schricker au comité exécutif de la FIFA, n.d. FIFA, rapport d'activité durant la guerre.

180 Il faut par exemple relever la fondation, en 1948 à Bogota, de l'Organisation des États américains qui a pour but, en effet, de créer des objectifs communs (à cette époque, il s'agit notamment de lutter contre une possible prolifération du communisme). Olivier Compagnon considère cet immédiat après-guerre comme « le climax du Panaméricanisme ». Compagnon O., "En marge de la guerre ? ", op. cit., p. 590.

181 Valenzuela L.H., "Fundación de la Confederación Pan-americana de football ". Anonyme, Statuts de la Confédération sud-américaine [édition de 1947]. FIFA, CSF statutes.

182 Anonyme, Procès-verbal du comité exécutif de la FIFA du 29 juillet 1948, n.d. FIFA, comité exécutif (procès-verbaux 1947-1950). 
les mois qui suivent ${ }^{183}$, avec une épreuve recouvrant un territoire très large et intercontinental. En ce sens, le futur tournoi se pose comme une concurrence sérieuse envers la Coupe du monde de la FIFA. Plus important, les membres de la Confédération panaméricaine se donnent pour objectif de " résoudre, en dernière instance, les conflits qui se dérouleraient entre les associations affiliées aux différentes confédérations ${ }^{184}$. Il s'agit donc de la captation d'une prérogative importante de la FIFA sur le territoire américain. Par ailleurs, au vu du contexte de tensions régulières qui existent entre les associations sud-américaines et les Européens, nous pouvons présumer que la création de la Confédération panaméricaine répond au désir de créer un lieu où les associations américaines pourront se concerter sur les décisions à prendre lors des congrès de la FIFA.

En 1948, la Confédération panaméricaine est composée d'une vingtaine d'associations nationales. Dans un courrier adressé au secrétaire de la FIFA datant du mois de mars 1948, le secrétaire et le président de la Confédération précisent la composition de la nouvelle Confédération ${ }^{185}$ :

Amérique du Nord (3) : Cuba, Mexique et les États-Unis.

Amérique centrale (8) : Costa Rica, Curaçao, Guatemala, Honduras, Panama, République dominicaine, Salvador, Venezuela.

Amérique du Sud (9) : Argentine, Bolivie, Brésil, Colombie, Chili, Équateur, Paraguay, Pérou et Uruguay.

L'organisation réunit donc vingt pays et constitue ainsi assurément une force au sein de la FIFA. En effet, l'agrégation des voix de tous ses dirigeants permettrait de faire véritablement pression lors des congrès et de peser sur la gouvernance de l'organisation et donc de remettre en cause l'hégémonie européenne. Car il semble également qu'un objectif de la création de la Confédération panaméricaine réside dans l'idée de favoriser, à moyen terme, une réorganisation de la FIFA. Durant l'entretien qu'il a avec Rimet en 1946, le dirigeant argentin Duco souligne explicitement

183 Anonyme, "Projecto de reglamento para el primer Campeonato Pan-Americano de football ", 26 octobre 1948. FIFA, correspondance avec les confédérations continentales : CONMEBOL (1941-1961), dossier : 1941-31.12.1950.

184 Lettre de C.M. Hoyos et L.H. Valenzuela à J. Rimet, 30 mars 1948. FIFA, correspondance avec les confédérations continentales : CONMEBOL (1941-1961), dossier : 1941-31.12.1950.

185 Anonyme, "Nomina de associaciones afiliadas a la Confederación Pan-Americana de football », 30 mars 1948. FIFA, correspondance avec les confédérations continentales : CONMEBOL (1941-1961), dossier : 1941-31.12.1950. 
au président de la FIFA que « le projet consisterait dans la fondation de Confédérations continentales ayant chacune une assez grande autonomie et groupées dans une FIFA qui deviendrait un groupement de Confédérations ${ }^{186}$. La création de l'entité panaméricaine parait donc être un moyen pour les dirigeants sud-américains de soutenir leurs volontés de changement de l'architecture de la Fédération internationale. C'est sans doute pourquoi ceux-ci sont particulièrement présents dans le comité exécutif de l'organisation panaméricaine, qui se compose comme suit : Président : Chili ; Vice-présidents : États-Unis, Argentine ; Membres : Chili, Pérou, Honduras, Mexique ${ }^{187}$.

Cette composition montre que la Confédération est dominée par les Sud-Américains. D'une part, elle est dirigée par le Chilien Luis Valenzuela, qui cumule donc les postes de président de la Confédération sud-américaine et de la Confédération panaméricaine. D’autre part, sur les sept membres que compte l'organe directeur, quatre proviennent de pays faisant partie de la Confédération sud-américaine, ce qui indique bien la force qu'occupe cette région au sein de l'organisme.

À la fin des années 1940, les associations américaines semblent armées pour passer une offensive auprès du congrès de la Fédération internationale en vue de créer un débat sur la décentralisation de l'organisation. Cette situation a d'autant plus de sens qu'au sortir de la Deuxième Guerre mondiale, la FIFA connaît une nouvelle phase d'internationalisation avec l'arrivée d'une vingtaine de nouveaux membres, en majorité extraeuropéens. Ce processus n'est pas sans conséquence sur la Fédération internationale. D'une part, ces pays proposent, à terme, de réorganiser l'entité afin de pouvoir mieux soutenir le développement du football dans leur région ; d'autre part, pour le secrétaire général de la FIFA, cette situation implique de nouveaux problèmes (connaissance de la situation politique de nombreux pays, manque de connaissances en matière de géographie, peu de compréhension pour la pratique du football dans des pays dont le climat est différent de l'Europe) qui rendent assurément sa tâche plus complexe.

186 Lettre de I. Schricker au comité exécutif de la FIFA, n.d. FIFA, rapport d'activité durant la guerre.

187 Lettre de C.M. Hoyos et L.H. Valenzuela à J. Rimet, 30 mars 1948. FIFA, correspondance avec les confédérations continentales : CONMEBOL (1941-1961), dossier : 1941-31.12.1950. 
Philippe Vonnard - 978-2-8076-0570-1

Téléchargé de PubFactory à01/07/2021 08:14:02PM

via free access 


\section{Conclusion de la partie}

Cette partie a permis de retracer la genèse de l'UEFA. Tout d'abord, par le biais d'indicateurs quantitatifs et qualitatifs, nous avons souligné la forte hégémonie européenne qui existe, durant les années 1930, au sein de la Fédération internationale. Nous avons également indiqué que, par l'entremise de certaines actions comme la Coupe du monde - dont les éditions de 1934 et 1938 s'apparentent à de véritables championnats d'Europe - et les rencontres de la FIFA de 1937 et 1938, la FIFA dynamise indéniablement le football continental durant les années 1930. Enfin, nous avons relevé que ses congrès annuels font office de plateformes d'échange entre les dirigeants européens, ces événements permettant non seulement des discussions sur le football mais aussi le partage de nombreux moments de sociabilité. Au fil des années, l'élite dirigeante de la Fédération internationale, composée d'une dizaine de membres issus d'associations européennes, peut s'apparenter à un réseau transnational de dirigeants œuvrant pour le développement du football, et en premier lieu sur le Vieux Continent. Dès lors, nous avons confirmé, mais aussi précisé, les analyses de Grégory Quin et Paul Dietschy évoquées plus haut et qui soulignaient le fait que la FIFA peut être considérée comme une pré-organisation du football européen.

En outre, nous avons montré que l'élite de la FIFA met en place, durant les années 1930, différentes stratégies qui permettent de neutraliser les conflits en interne, élément indispensable pour établir une organisation forte ayant le monopole en matière d'administration du football. Pour ce faire, des règles - écrites ou tacites - sont élaborées, comme celles de convoquer les différents blocs régionaux qui existent au sein du comité exécutif de la Fédération. De même, l'organisation élit des dirigeants qui sont plutôt diplomates et agissent avant tout pour l'organisation. Enfin, l'élite de la FIFA mène une politique non interventionniste, à savoir de ne pas interférer dans les affaires internes des associations nationales. Par ailleurs, ses membres agissent dans le but de construire l'autonomie de l'organisation sur la scène internationale. À ce titre, il s'agit notamment de limiter les ingérences politiques. Outre une rhétorique constante soulignant que le football et la politique sont deux domaines séparés, l'élite de la FIFA prend aussi des décisions en matière de structure de l'organisation. Par exemple, il s'agit d'assurer son autofinancement, de recruter à sa tête des 
dirigeants qui font consensus ainsi que de placer le siège de la FIFA dans un pays neutre. Ces décisions permettent à la Fédération d'être considérée comme une organisation non gouvernementale sur la scène internationale. Afin de saisir les raisons qui expliquent la mise en place de cette politique, mais aussi de comprendre son succès, nous nous sommes focalisés sur l'élite dirigeante de l'organisation. Nous avons montré que ses membres sont animés par des objectifs analogues en matière de développement de la FIFA, disposent tous d'importantes ressources en matière de capitaux footballistiques, cosmopolites et sociaux qui leur permettent d'évoluer à l'échelle internationale. Ainsi, nous avons montré qu'un réseau d'une dizaine d'individus porte cet " internationalisme footballistique " durant les années 1930. En outre, nous avons signalé que certains dirigeants poursuivent aussi un but plus politique, à savoir que le football peut être un vecteur de rapprochement des peuples. C'est notamment le cas de Jules Rimet, qui prône souvent cet aspect en s'inspirant - sans pour autant le nommer - des idéaux de Coubertin quant au rôle des sports dans la pacification des peuples.

Ces formes de gouvernance créées par les dirigeants de la FIFA sont cruciales pour le développement mais aussi pour la pérennisation de l'organisation. En effet, elles permettent à la Fédération internationale de résister en partie à l'ingérence allemande durant la Deuxième Guerre mondiale. Cette situation est à souligner puisque d'autres fédérations internationales, comme celles de boxe ou d'escrime, ne parviennent pas à continuer leurs activités durant le conflit. Par ailleurs, ce sont aussi ces stratégies qui permettent de négocier au mieux la sortie de guerre. Nous avons néanmoins relevé que celles-ci ne sont pas figées mais doivent être renégociées au fil du développement des contextes footballistiques et internationaux.

Enfin, nous avons aussi souligné que l'hégémonie européenne au sein de la FIFA est remise en question depuis les années 1930 par les associations sud-américaines, qui préconisent notamment une décentralisation de l'organisation. Face aux tensions qui découlent de cette décision, il est décidé, en 1938, de réserver une place à un dirigeant sud-américain au sein du comité exécutif. Cette décision est suivie de celle, au sortir de la guerre, de réserver une place à un dirigeant sud-américain supplémentaire. Mais, ce n'est toujours pas suffisant pour les dirigeants sud-américains. L'internationalisation du football dans la seconde partie des années 1940 va toutefois offrir un terreau favorable aux volontés des associations sudaméricaines. En effet, après 1945, la FIFA voit le nombre de ses membres augmenter constamment. Ces arrivants, qui profitent du contexte naissant de la décolonisation, amènent de nouvelles problématiques pour 
le secrétariat, tant en termes de développement du jeu que du point de vue de leurs situations politiques sur la scène internationale. Enfin, avec l'entrée de l'URSS à la FIFA en 1947, un bloc soviétique se crée au sein de la Fédération internationale. Désormais, le réseau de dirigeants européens qui s'est développé pendant les années 1930 connaît une rupture entre les pays d'Europe de l'Ouest et de l'Est. Ainsi, la domination des Européens semble contestée, et c'est peut-être également pourquoi les Sud-Américains développent leurs revendications à ce moment précis, en pouvant compter sur l'appui des associations d'Amérique centrale. Tenant compte de ce contexte de tensions, un trio de dirigeants, composé de l'Italien Ottorino Barassi, de l'Anglais Stanley Rous et du Suisse Ernst Thommen, de plus en plus influent sur la scène footballistique internationale, commence à imaginer une restructuration de l'architecture de la FIFA. Il s'agit pour eux autant de répondre au développement du football et de contenter les Sud-Américains que de se profiler, par leurs actions, comme les futurs leaders de la FIFA. Ainsi, au début des années 1950, le contexte semble favorable à un débat sur une réorganisation de la FIFA qui se concrétiserait par sa régionalisation. 
Philippe Vonnard - 978-2-8076-0570-1

Téléchargé de PubFactory à01/07/2021 08:14:02PM

via free access 


\section{Partie 2}

\section{FORMATION DE L'UEFA (1949-1960)}


Philippe Vonnard - 978-2-8076-0570-1

Téléchargé de PubFactory à01/07/2021 08:14:02PM

via free access 
ChaPITRE 3

\section{La continentalisation de la FIFA (1949-1953)}

\section{Introduction du chapitre}

Ce chapitre, qui couvre la période de 1949 à 1953, a pour but d'étudier la manière dont s'effectue la régionalisation de la FIFA. Car le Groupement des associations européennes de football de la FIFA- renommé UEFA en octobre 1954 - est directement créé après une décision de recomposer le comité exécutif de la FIFA prise lors d'un congrès extraordinaire de la FIFA organisé à Paris en novembre 1953.

Premièrement, nous soulignons qu'au début des années 1950, le contexte du football européen paraît plus favorable que par le passé à la création d'un organisme gérant spécifiquement le football continental. En effet, en dépit d'un arrêt des rencontres entre l'Est et l'Ouest entre 1949 et 1951 à cause de la Guerre froide, le football européen connaît une nouvelle phase de développement. Des projets de compétitions supranationales plus ambitieux pour les clubs sont élaborés, comme celui de la Coupe des Grasshopper de 1952. Par ailleurs, de nouveaux dirigeants d'associations nationales du football européen, dont certains prennent de l'importance au sein de la FIFA (particulièrement Ottorino Barassi, Stanley Rous et Ernst Thommen), estiment qu'il serait bénéfique de discuter de manière commune sur différents sujets (par exemple en vue d'établir un calendrier annuel des matchs de football international). À ce titre, la création d'une organisation continentale pourrait s'avérer opportune et des premières discussions ont lieu à ce sujet au printemps 1952.

Deuxièmement, nous nous focalisons sur la manière dont les délégués présents lors du congrès de la FIFA de 1950 s'accordent pour débuter le travail de réorganisation. Dans cette perspective, nous étudions les différentes positions qui existent au sein de la FIFA sur cette question. Face à cette situation - complexifiée par le contexte tendu de la Guerre froide -, les dirigeants du comité exécutif doivent s'employer, une fois encore, à minimiser l'impact de ces positionnements car ils pourraient venir troubler la bonne conduite de la politique de la FIFA. 
Troisièmement, nous revenons plus précisément sur l'influence des associations sud-américaines dans la réforme de la FIFA. En effet, celles-ci sont à la base de la discussion sur la réorganisation de l'organisation et, tout au long des trois ans que dure le travail sur sa réforme, leurs délégués dans la commission d'étude mise sur pied pour discuter de celle-ci défendent l'idée de créer des groupements continentaux. Finalement, une entente ( le compromis Thommen ») est trouvée avec les associations de l'Europe de l'Ouest lors d'un congrès extraordinaire de la FIFA organisé à Paris en 1953.

\subsection{Réorganiser le football européen ?}

Dans la première partie des années 1950, les échanges entre les pays européens connaissent un nouveau développement, suivant en cela les initiatives prises dans d'autres sports comme le cyclisme, où l'idée d'un tour cycliste européen est évoquée ${ }^{1}$, ou le judo, qui voit la création d'une organisation européenne en 1948.

\subsubsection{Une nouvelle phase de l'européanisation du jeu}

Au début des années 1950, le football européen semble en ébullition, de nombreux projets de compétitions étant lancés. Pour le football des équipes nationales, nous pouvons mentionner la Coupe de la Méditerranée qui, dans le sillage des premiers Jeux méditerranéens de 1951, propose des rencontres entre les équipes nationales $B$ françaises et italiennes et les équipes nationales égyptienne, grecque et turque ${ }^{2}$. Par ailleurs, il semble que les Britanniques envisagent d'ouvrir le championnat qu'ils disputent entre eux à d'autres associations nationales européennes ${ }^{3}$.

$\mathrm{Au}$ sujet des épreuves pour les clubs, de nouvelles compétitions sont également créées, comme la Coupe latine. Lancée à la fin des années 1940, celle-ci réunit chaque année, dans un mini-championnat disputé pendant une semaine en été, un club espagnol, français, italien et portugais ${ }^{4}$. En

"Le Tour d'Europe empêche l'élaboration définitive du calendrier routier français ", L'Équipe, 18 novembre 1953.

2 Des extensions sont envisagées vers d'autres pays bordés par la Méditerranée comme l'Espagne. "L'Italie sur la voie de la conquête de la suprématie européenne ", France football, 3 mai 1949 .

"Ainsi tourne la boule ", France football, 28 août 1951,

4 Mourlane S., "A Brief Moment of Latinity? France, Italy and the Latin Cup 1949-1957 ", Sport in History, 35, n 4, 2015, pp. 580-590 978-2-8076-0570-1 
outre, de nombreux matchs amicaux internationaux sont organisés, en particulier durant la période estivale. En 1951, l'association anglaise invente le "British festival ", joutes qui durent plusieurs jours et qui voient de nombreuses équipes britanniques de tous niveaux s'opposer à des formations issues de plusieurs pays continentaux. Dans ce cadre, il est à relever que des équipes britanniques jouent contre des formations allemandes. En effet, dès la fin des années 1940, s'opère la réincorporation de l'Allemagne de l'Ouest - dont l'État est créé en mai 1949 - dans le giron des relations internationales footballistiques. Il faut dire que, depuis octobre 1948 et les matchs disputés entre trois sélections de villes allemandes (se trouvant dans la zone d'occupation américaine) et suisses ${ }^{5}$, le comité exécutif de la FIFA est mis sous pression et de plus en plus d'associations nationales militent pour le retour de l'Allemagne au sein de la FIFA. Si le sujet reste sensible, dans les premiers mois de l'année 1949 l'élite de la Fédération internationale commence à sérieusement envisager la réacceptation de la Fédération allemande. Ainsi, le 8 mars, Marc Hauguet, envoyé spécial de France football à Hambourg, relate les propos d'une haute personnalité du football de Hambourg, dont il ne donne pas le nom : "La création d'une Fédération de l'Allemagne de l'Ouest, que nous espérons, pour l'an prochain, sera un premier pas vers la reprise des relations internationales, notre vœu le plus immédiat et le plus cher ${ }^{6}$ ! " Deux mois plus tard, en date du 6 mai 1949 - soit une vingtaine de jours avant la création formelle de la République fédérale d'Allemagne (RFA) -, le comité exécutif de la FIFA accepte que les associations membres de l'organisation rejouent contre des clubs allemands à la condition d'obtenir l'accord des autorités d'occupation. Cette décision légitime les actions de dirigeants comme Peco Bauwens qui s'attellent, depuis 1948, à recréer une fédération allemande dans les territoires occupés par les Américains, les Anglais et les Français ${ }^{7}$. Formellement créée en 1950, celle-ci se construit en fait sur les ruines de l'ancienne fédération allemande. Elle en reprend d'ailleurs le nom et Bauwens, dirigeant phare du football allemand de l'entre-deux-guerres, en devient le premier président. Rapidement, plusieurs associations nationales font part à la FIFA de leur souhait de rejouer contre l'équipe

5 Dichter H., "Kiking around international sport ", op. cit.

6 "Popularité, stades vétustes mais en reconstruction, jeu excellent, proches perspectives d'une Fédération et de la reprise des relations internationales ", France football, 8 mars 1949.

7 Un « comité de coordination du football » est mis en place dès 1948 et doit préparer la refondation du DFB. Anonyme, Procès-verbal de la réunion de fondation du comité de coordination du 10 avril 1948, n.d. FIFA, correspondance avec les associations nationales : Allemagne (1938-1950), dossier: 1949-31.12.1950 
nationale allemande et une mention en vue de la réintégration du pays est officiellement déposée pour le congrès de 1950 qui doit se dérouler au Brésil. C'est l'association suisse qui soutient cette requête, que les délégués acceptent à une très grande majorité ${ }^{8}$. Parallèlement, une autre association est admise comme membre de la FIFA : la Sarre. Territoire allemand administré par les forces françaises d'occupation, il dispose d'une certaine autonomie et souhaite donc jouir de la possibilité de présenter une équipe sur la scène internationale? A A noter que la non-présence des pays de l'Est, qui n'ont pas fait le déplacement - suivant en cela la position de l'URSS qui n'entretient pas de relations diplomatiques avec le Brésil -, facilite le vote puisque, sur la scène internationale, le bloc communiste s'oppose vigoureusement à la division de l'Allemagne ${ }^{10}$. En novembre de la même année, l'équipe nationale suisse officialise l'incorporation de l'Allemagne de l'Ouest au sein de la FIFA en effectuant le court déplacement jusqu'à Stuttgart, une démarche poursuivie ensuite par d'autres fédérations et notamment par la France, qui reçoit la RFA en 1952.

Cette réintégration des clubs de l'Allemagne de l'Ouest dans les échanges footballistiques internationaux est rapide. Elle constitue un fait important car les acteurs du ballon rond allemand comptent parmi les plus actifs d'Europe depuis l'entre-deux-guerres, ce qui se perçoit notamment au travers de l'ambitieux projet de compétition de clubs présenté par l'entraîneur allemand des Grasshopper Zurich, Willy Treml. Il s'agit de réunir des clubs provenant d'Allemagne, d'Autriche, d'Espagne, de France, d'Italie et de Suisse qui se rencontreraient en matchs aller-retour, sur une durée de deux saisons. Le tournoi comprend un volet financier détaillé, qui permettrait aux participants de rentrer dans leurs frais, voire d'espérer un gain financier sur les matchs disputés à l'extérieur qui s’additionnerait aux recettes des rencontres à domicile ${ }^{11}$. L'aspect financier du tournoi est très

8 Anonyme, Procès-verbal de l'assemblée générale de la FIFA des 22-23 juin 1950, n.d. FIFA, XXV-XXVII congrès ordinaires (1946-1952, rapport d'activité).

9 Sur l'indépendance prise par les dirigeants du football sarrois vis-à-vis de la France, voir : Lanfranchi P., "Le football sarrois de 1947 à 1952. Un contre-pied aux actions diplomatiques ", Vingtieme siècle. Revue d'histoire, vol. 26, 1990, pp. 59-66. Et pour davantage de détails sur le football sarrois : Reichelt B., Fußball im Deutschfranzösischen Grenzraum Saarland/Moselle 1900-1952. Eine transnationale Geschichte politischer Inszenierung und sportlicher Emanzipation, Stuttgart, Franz Steiner, 2014.

10 Filitov A., "Germany as a European problem in Soviet and French views (1940s-1950s years) ", dans Soutou G.-H., Robin-Hivert E. (dir.), L'URSS et l'Europe : de 1941 à 1957, Paris, Presses universitaires de la Sorbonne, 2007, pp. 311-331.

11 "La Coupe internationale des Grasshopper amorce d'un championnat d'Europe ", France Football, 5 février 1952. 
important pour les clubs et intéresse particulièrement leurs dirigeants, qui sont à la recherche de fonds supplémentaires. En effet, dans ces premières années de la décennie 1950, le professionnalisme connaît un nouvel essor dans plusieurs pays et les footballeurs espagnols et italiens - pays où le professionnalisme est le plus développé - gagnent désormais d'importantes sommes d'argent. Sous cet angle, la Coupe des Grasshopper répond donc à cette demande. Cette compétition est officiellement lancée en juin 1952 et peut être considérée comme la propédeutique à une future compétition européenne de clubs. Cependant, aucune équipe du bloc de l'Est n'y participe et alors même que, au regard de la composition géographique de l'épreuve et de la mémoire de la Mitropa Cup, nous aurions pu imaginer que des clubs hongrois et tchécoslovaques y prennent part. Cette absence doit se comprendre en raison des tensions dues à la Guerre froide sur la scène internationale. En effet, à la suite du blocus de Berlin de 1948-1949, puis du déclenchement de la Guerre de Corée en 1950, l’opposition entre les deux blocs est extrême. Ce contexte influence directement la conclusion de rencontres entre les pays d'Europe de l'Est et de l'Ouest.

Ainsi, la Coupe internationale, qui avait été relancée en 1946, est arrêtée trois ans plus tard car, comme le note un journaliste de France football en octobre 1950, il est devenu impossible pour les associations d'Europe de l'Ouest d'avoir des contacts assurés avec leurs homologues hongrois et tchécoslovaques ${ }^{12}$. En fait, si nous exceptons l'équipe yougoslave, dont le pays occupe toujours une position à part dans le bloc des pays communistes, quasiment aucun match Est-Ouest n'est organisé lors des années 1950 et 1951 . Un changement commence néanmoins à se produire à partir de l'année 1952. En février, des discussions reprennent au sujet d'une possible relance de la Coupe internationale - décision effective quelques mois plus tard -, les dirigeants hongrois et tchécoslovaques souhaitant à nouveau participer à la joute ${ }^{13}$. De même, lors du congrès de la FIFA qui se déroule à Helsinki, les congressistes approuvent quasiment à l'unanimité (seuls les délégués de l'Allemagne de l'Ouest s'abstiennent), l'adhésion de l'Allemagne de l'Est à la FIFA. Une année plus tard, la mort de Staline puis la fin de la Guerre de Corée favorisent ce que les historiens ont appelé le "Dégel " ${ }^{14}$, à savoir l'amélioration progressive des relations Est-Ouest.

\footnotetext{
12 "Ainsi tourne la boule", France football, 3 octobre 1950.

13 "Ainsi tourne la boule ", France football, 13 février 1952.

14 Sur le Dégel, voir notamment le numéro spécial de la revue Cahiers du Monde russe " Repenser le Dégel », coordonné par Eleonory Gilburd et Larissa Zakharova en 2006. Voir également des contributions dans le numéro spécial de la revue Vingtiène Siècle.
} 
Le football anticipe, certes de manière encore timide, ce renouveau, comme l'illustre le match de la FIFA de 1953. Cette rencontre, mise sur pied sur le modèle des rencontres de 1938 et 1948, oppose l'Europe et l'Angleterre afin de commémorer les quatre-vingt-dix ans de la Football Association. La sélection de l'équipe continentale est confiée à Karel Lotsy, accompagné de deux conseillers techniques, le Français Gaston Barreau et l'Autrichien Walter Neusch, qui choisissent des joueurs provenant uniquement des pays du bloc de l'Ouest. Le comité exécutif de la FIFA les charge de sélectionner les meilleurs joueurs possible ${ }^{15}$. Cependant, ils vont devoir faire avec certaines réticences, comme celle de la Fédération hongroise qui refuse de mettre à disposition ses meilleurs éléments. Malgré ces désagréments, et comme les précédents matchs de 1938 et 1948 , cette rencontre se veut un appel à une réunion des associations européennes. Sous cet angle, la présence de l'exilé hongrois László Kubala dans l'équipe du "Reste de l'Europe ", entouré de coéquipiers provenant d'Allemagne de l'Ouest, d'Autriche, d'Espagne, d'Italie, de Suède et de Yougoslavie, ne peut-elle pas être perçue comme un appel à une réunification footballistique Est-Ouest? Selon Jacques Ferran, le match dépasse d'ailleurs la solennité des rencontres précédentes ${ }^{16}$. Comme ses devancières, la partie permet à une grande partie de la communauté du football européen de se retrouver. Pas moins de deux cents journalistes font le déplacement à Londres.

Cependant, cette rencontre est quelque peu occultée par la venue dans la capitale anglaise, un mois plus tard, de l'équipe nationale hongroise. Le match entre "l'équipe d'or ${ }^{17}$, comme la surnomment de nombreux journalistes, et l'Angleterre constitue assurément le plus haut fait footballistique de l'année 1953. Outre le niveau de jeu des Hongrois (invaincus depuis plus d'une année), c'est aussi le caractère

Revue d'histoire intitulé "Le bloc de l'Est en question », coordonné par Sandrine Kott et Justine Faure en 2011. Enfin, pour une discussion sur le début du dégel, voir : Lipkin M., "Avril 1952, la conférence économique de Moscou : changement de tactique ou innovation dans la politique extérieure stalinienne ? ", Relations internationales, vol. 147, n 3, 2011, pp. 19-33.

15 Gassmann K., Procès-verbal de la réunion du comité exécutif de la FIFA des 27-28 mars 1953. Procès-verbal, 21 avril 1953, FIFA, comité exécutif (procès-verbaux 1953-1954).

16 "Angleterre contre reste du monde : une grande parade à valeur symbolique et commémorative ", France football, 20 octobre 1953.

17 Hadas M., "Stratégie politique et tactique sportive : esquisse d'une analyse sociohistorique du style de jeu de "l'équipe d'or" hongroise des années cinquante ", dans Hélal H., Mignon P. (dir.), Football: Jeu et Société, Paris, Institut national du sport et de l'éducation physique, 1999, pp. 85-99 
politique de la rencontre qui est à souligner. Véritable ambassadrice de son État à l'étranger ${ }^{18}$, à partir de septembre 1952, l'équipe hongroise effectue de nombreux déplacements par-delà le Rideau de fer et se déplace respectivement en Suède, en Suisse, en Italie et en Autriche. En Angleterre, elle choque le monde du football en devenant la première équipe étrangère à s'imposer contre l'équipe nationale anglaise dans son antre de Wembley ${ }^{19}$. Au travers de ses nombreux matchs, l'équipe hongroise maintient donc les liens entre l'Est et l'Ouest de l'Europe, d'autant plus qu'en raison de la qualité de ses joueurs, ses performances sont largement suivies dans la presse spécialisée de nombreux pays européens d'Europe de l'Ouest. La Hongrie est effectivement à la pointe de ces échanges Est-Ouest, comme le souligne également sa participation au tournoi international des juniors.

Créée en 1948 à l'initiative de Stanley Rous, la joute révèle le développement progressif des rencontres internationales pour les jeunes footballeurs. Après une première joute réussie, à laquelle participent huit associations nationales (Angleterre, Autriche, Belgique, Irlande, Irlande du Nord, Italie, Pays-Bas et Pays de Galles), l'organisation du tournoi est reprise par la FIFA, selon le souhait émis par Rous ${ }^{20}$. L'épreuve reçoit notamment le soutien du président de la FIFA, Jules Rimet. Ce dernier y perçoit tout l'intérêt éducatif mais aussi la possibilité de réunir au travers du football une jeunesse européenne meurtrie par la guerre. Cet objectif est d'ailleurs clairement poursuivi par Rous, comme l'a bien expliqué Kevin Tallec Marston ${ }^{21}$. Avec sa reprise par la FIFA, la joute connaît une officialisation qui permet d'assurer son développement. Ainsi, au fil des années, de plus en plus de pays européens y participent et le tournoi connaît un fort engouement populaire, les parties étant parfois suivies par des milliers de spectateurs.

18 Pour un aperçu de l'utlisation du football hongrois par le gouvernement, voir : Majtényi G., "Football et pouvoir dans la Hongrie communiste », dans Archambault F., Beaud S., Gasparini W., Le football des nations, op. cit., pp. 109-120.

19 Kowalski R., Porter D., «England's world turned upside down? Magical Magyars and British football », Sport in History, vol. 23, n 2, 2003, pp. 27-46.

20 Lettre de R.W. Seeldrayers à I. Schricker, 30 novembre 1948, FIFA, membres du comité exécutif, dossier individuel : correspondance R.W. Seeldrayers (1939-1950),

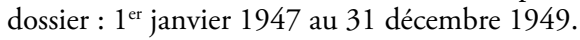

21 Marston K.T., " "Sincère camaraderie" "PPAllippe Vonnard - 978-2-8076-0570-1 
Tableau 10. Pays européens aux tournois internationaux des juniors de 1949 à 1954 (par ordre alphabétique)

\begin{tabular}{|l|l|l|l|l|l|}
\hline Pays & $\mathbf{1 9 4 9}$ & $\mathbf{1 9 5 0}$ & $\mathbf{1 9 5 1}$ & $\mathbf{1 9 5 2}$ & $\mathbf{1 9 5 3}$ \\
\hline Allemagne de l'Ouest & & & & & $\mathrm{X}$ \\
\hline Allemagne de l'Est & & & & & \\
\hline Angleterre & $\mathrm{X}$ & $\mathrm{X}$ & $\mathrm{X}$ & $\mathrm{X}$ & $\mathrm{X}$ \\
\hline Autriche & $\mathrm{X}$ & $\mathrm{X}$ & $\mathrm{X}$ & $\mathrm{X}$ & $\mathrm{X}$ \\
\hline Belgique & $\mathrm{X}$ & & $\mathrm{X}$ & $\mathrm{X}$ & $\mathrm{X}$ \\
\hline Bulgarie & & & & & \\
\hline Espagne & & & & $\mathrm{X}$ & $\mathrm{X}$ \\
\hline France & $\mathrm{X}$ & $\mathrm{X}$ & $\mathrm{X}$ & $\mathrm{X}$ & $\mathrm{X}$ \\
\hline Hongrie & & & & & $\mathrm{X}$ \\
\hline Irlande & & & & & $\mathrm{X}$ \\
\hline Irlande du Nord & $\mathrm{X}$ & & $\mathrm{X}$ & & $\mathrm{X}$ \\
\hline Italie & & & & & $\mathrm{X}$ \\
\hline Luxembourg & & $\mathrm{X}$ & & & $\mathrm{X}$ \\
\hline Pays-Bas & $\mathrm{X}$ & $\mathrm{X}$ & $\mathrm{X}$ & & $\mathrm{X}$ \\
\hline Pologne & & & & & \\
\hline Portugal & & & & & \\
\hline Roumanie & & & & & \\
\hline Sarre & & & & & $\mathrm{X}$ \\
\hline Suisse & & $\mathrm{X}$ & $\mathrm{X}$ & $\mathrm{X}$ & $\mathrm{X}$ \\
\hline Tchécoslovaquie & & & & \\
\hline Turquie & & & & & $\mathrm{X}$ \\
\hline Yougoslavie & & & & $\mathbf{1 6}$ \\
\hline Total & & & & \\
\hline
\end{tabular}

Légende $: \mathrm{X}=$ participation au tournoi.

Excepté le cas de la Hongrie, constatons néanmoins que les pays de l'Est - tout comme les pays scandinaves, où le football des jeunes est moins développé - restent encore en marge de la compétition.

Le développement du tournoi international des juniors n'est pas seulement le révélateur de cette nouvelle phase de développement du football européen, il est aussi le témoin du fait que la FIFA n'est sans doute 
plus forcément l'instance adéquate pour assurer la bonne marche du football continental. En effet, il n'existe pas de commission spécifique devant statuer sur le tournoi des juniors au sein de l'organisme international et, à plusieurs reprises, son secrétaire se plaint des difficultés en termes d'organisation que constitue l'épreuve. Durant l'un des entretiens que nous avons conduits avec lui, le journaliste Jacques Ferran nous a indiqué que la FIFA était " une association totalement sclérosée, qui ne demandait qu’à grandir, qu’à $s^{\prime}$ affirmer, à jouer un rôle et [qu'elle] ne le jouait pas $»^{22}$. Au milieu des années 1950, Jacques Ferran est un journaliste dynamique d'une trentaine d'années qui, dans le sillage de ses aînés Jacques de Ryswick, Gabriel Hanot et Jacques Goddet, n’hésite pas à proposer de nouvelles idées dans les colonnes de L'Équipe ou de France football pour dynamiser les échanges footballistiques européens. A contrario, la FIFA est effectivement dirigée par des individus relativement âgés qui paraissent quelque peu essoufflés par leurs années à la tête de la Fédération internationale et qui semblent dépassés par les transformations que connait alors le football. Hans Bangerter, engagé comme secrétaire adjoint de la FIFA en 1953, nous a signalé que, du haut de ses trente ans, il se sentait à son arrivée dans l'organisation comme un " junior ${ }^{23}$ en comparaison avec les autres membres du comité exécutif.

En fait, la Fédération internationale connaît une période de transition et son élite dirigeante commence à se renouveler. Cette transformation favorise une réforme de ses statuts ainsi qu'une réflexion sur la structure de l'organisation, les nouveaux dirigeants ayant en tête de l'adapter au nouveau développement que connait le football mondial.

\subsubsection{La prise d'importance du trio Barassi, Rous, Thommen}

Au début de l'année 1950, un changement de taille se produit à la tête de la FIFA puisque le secrétaire Ivo Schricker remet sa démission. À plus de septante ans, il semble fatigué de ses vingt années de travail au sein de la Fédération internationale. Dans un article de France football traitant de la succession du secrétaire général de la FIFA, le journaliste Maurice Pefferkorn se questionne sur son futur remplaçant. Il indique qu'Ottorino Barassi et Stanley Rous, deux dirigeants disposant déjà d'une certaine influence au sein de la FIFA durant l'entre-deux-guerres, pourraient être des candidats palpables en raison de leur forte personnalité et du rôle qu'ils

22 Entretien avec Jacques Ferran, réalisé le 19 septembre 2012 à Paris.

23 Entretien avec Hans Bangerter, réalisé le 1 hilipper obre 2012 à Bollingen 
jouent dans les différentes commissions de la FIFA depuis la seconde partie des années 1930. Mais, selon le journaliste, aucun des deux hommes n'est vraiment bien positionné pour reprendre le secrétariat de la FIFA : Rous a trop de travail au secrétariat de la Football Association pour pouvoir cumuler les deux fonctions et Barassi n'a pas vraiment le profil du poste étant "un homme d'action et un lutteur " ${ }^{24}$. Or, ainsi que nous l'avons déjà évoqué, le secrétaire doit être un fin diplomate. Dans son autobiographie, Stanley Rous revient brièvement sur ce moment et indique qu'il discute effectivement avec Arthur Drewry, président de la Football Association et vice-président de la FIFA, en vue d'une éventuelle reprise du poste de Schricker. Toutefois, selon ses dires, il renonce car il devrait quitter ses fonctions de secrétaire de la fédération anglaise en raison de la charge de travail que ce poste implique ${ }^{25}$. En fait, il semble qu'un certain flou règne autour de la succession de Schricker, comme en témoigne une lettre de Karel Lotsy au futur ex-secrétaire de la FIFA. Hospitalisé durant plusieurs semaines, le dirigeant néerlandais ne peut suivre que de loin les affaires de la Fédération internationale et s'interroge sur la succession de l'Allemand. Si lui non plus n'exclut pas que Barassi ou Rous reprennent le poste, il envoie tout de même la candidature de l'une de ses connaissances, Herman Wilhelm Glerum ${ }^{26}$. Par ailleurs, cette démarche montre aussi que la succession du secrétaire général est l'occasion pour les dirigeants du comité exécutif de la FIFA de se positionner, notamment pour les plus jeunes membres comme Karel Lotsy et les nouveaux arrivants, tel le Suisse Ernst Thommen, qui seront appelés à gérer les affaires de la FIFA dans le futur. Car les derniers membres de ce que nous pouvons nommer la vieille garde du comité exécutif, incarnée par Jules Rimet et Rodolphe Seeldrayers, sont en fin de carrière.

Or, pour qui souhaite jouer un rôle au sein du comité exécutif de la FIFA, être proche du secrétaire général est une condition sine qua non. Si Barassi et Rous ne se proposent finalement pas pour le poste, la succession de Schricker révèle néanmoins la prise d'importance progressive sur la gouvernance de la FIFA du trio qu'ils forment avec Ernst Thommen. Président de l'association suisse de football, ce dernier prend progressivement de l'importance au sein du football européen depuis la

24 "Qui succédera au docteur Schricker au poste de secrétaire général de la FIFA ? ", France football, 12 juillet 1950.

25 Rous S., Football worlds, op. cit., pp. 128-129.

26 Lettre de K. Lotsy à I. Schricker, 9 novembre 1950. FIFA, membres du comité exécutif, dossier individuel : correspondance K. Lotsy (1.1.49-31.12.50). Lotsy joint à ce courrier la lettre de motivation du candidat, M. Glérumg 
fin de la Deuxième Guerre mondiale et joue un rôle non négligeable dans l'affiliation de l'Allemagne de l'Ouest - à ce titre, il est d'ailleurs le premier étranger à recevoir le titre de membre d'honneur du $\mathrm{DFB}^{27}$. Cette position est confirmée par son élection au comité exécutif de la FIFA lors du congrès de Rio de 1950.

Durant plusieurs mois, les trois dirigeants forment un petit comité (nommé " délégation du bureau de la FIFA ») qui agit en parallèle au comité exécutif et qui s'attelle spécifiquement à la gestion administrative de la FIFA. Cette position leur donne des entrées aux réunions de l'élite de la FIFA et ce pour plusieurs années. Signe de leur position privilégiée, un journaliste de France football note en mars 1952 :

«On a été un peu étonnés d'apprendre qu’à la réunion du comité exécutif de la FIFA tenue récemment à Londres, assistaient deux personnalités, certes très importantes du football international, sir Stanley Rous et M. Barassi, qui ne sont cependant pas membres du comité. Ils étaient là comme conseillers. En fait, l'on doit considérer que l'influence qu'ils exercent dans les milieux du football international fait d'eux des membres officieux du comité exécutif. On ne peut négliger leur expérience et leur savoir quand se débattent des questions importantes de la FIFA ».

Afin d'assurer le fonctionnement du secrétariat, et en attendant la nomination d'un futur secrétaire général, les trois dirigeants se répartissent les tâches comme suit : Barassi et Rous se chargent du travail administratif alors que Thommen s'occupera plutôt de trouver le nouveau secrétaire général, choix qui devra ensuite être ratifié par le comité exécutif ${ }^{28}$.

Plus que sélectionner quelqu'un pour le poste, les trois hommes vont en fait redéfinir les tâches de la fonction et, plus largement, revoir le fonctionnement du secrétariat de la FIFA. Pour eux, le futur secrétaire général devra non seulement assumer toute la responsabilité de la gestion de la Fédération internationale, mais aussi " proposer des idées [et] étudier les questions soumises au comité »" ${ }^{29}$. Barassi propose même que, dans le futur, le secrétaire s'occupe de réaliser des enquêtes auprès des associations sur différents sujets (technique de jeu, professionnalisme, expérience des

27 «M. Thommen. Membre d'honneur du DFB », La Semaine sportive, 23 novembre 1950.

28 Anonyme, Procès-verbal de la réunion de la délégation du bureau de la FIFA du 29 décembre 1950, n.d. FIFA, comité exécutif (procès-verbaux 1947-1950).

29 Anonyme, Procès-verbal de la réunion entre E. Thommen, O. Barassi, S. Rous, I. Schricker et Mme Kurmann du 11 octobre 1950, 16 octobre 1950. FIFA, comité exécutif (procès-verbaux 1947-1950). 
associations). De plus, ils envisagent également l'engagement d'un chef de bureau capable d'épauler le secrétaire. Cette personne devra assurer le suivi des dossiers et, en conséquence, elle se doit de maîtriser les principales langues utilisées au sein de la FIFA (anglais, français et espagnol). Par ces mesures, il s'agit de professionnaliser le secrétariat de l'organisation afin qu'il puisse gérer au mieux le développement croissant du football à l'échelle géographique internationale ainsi que les transformations notamment médiatiques et commerciales - qui commencent à toucher la Coupe du monde.

En décembre 1950, et en attendant de trouver la personne adéquate, Ernst Thommen propose de placer quelqu'un au poste de secrétaire général de manière provisoire. Il faut dire que le travail est fastidieux et que les trois hommes, en raison de leurs occupations professionnelles respectives, ne peuvent lui consacrer qu'un temps partiel. Comme il le note à ses collègues, Ernst Thommen souhaiterait disposer des " services d'un personnage connaissant à fond le football et les travaux dans un secrétariat pareil " ${ }^{30}$. C'est pourquoi il a songé à Kurt Gassmann, qu'il a déjà rencontré à ce sujet et qui pourrait travailler en collaboration avec les deux autres employés du secrétariat. Gassmann est effectivement un secrétaire expérimenté qui connaît bien les affaires footballistiques. De plus, il a côtoyé de nombreux dirigeants du football européen puisqu'il a officié, de 1916 à 1942, en tant que secrétaire général de l'association suisse de football, ce qui lui a permis de participer à de nombreux congrès de la FIFA. C'est pendant cette période qu'il semble avoir tissé des liens étroits avec Ernst Thommen ${ }^{31}$. Sa compétence en matière d'administration est reconnue en dehors des cercles du football, car au sortir de la Deuxième Guerre mondiale, lorsque le $\mathrm{CIO}$ cherche à engager un nouveau chancelier (secrétaire général), il lance une enquête pour savoir si Gassmann pourrait être un bon candidat. Les conclusions de celle-ci soulignent son profil international ainsi que son honnêteté et son sérieux; il est ajouté que c'est un administrateur digne de confiance ${ }^{32}$. Gassmann dispose donc d'un profil proche de celui de Schricker et s'inscrit dans une certaine

30 Anonyme, Procès-verbal de la réunion de la délégation du bureau de la FIFA du 29 décembre 1950, n.d. FIFA, comité exécutif (procès-verbaux 1947-1950).

31 Dans un livre à caractère hagiographique réalisé par le journaliste Daniel Schaub sur la vie du dirigeant bâlois, Kurt Gassmann est présenté avec quelques autres dirigeants, sous la rubrique " amis et bienfaîteurs ». Schaub D., Ernst B. Thommen. Das bewegte Leben des grossen Schweizer Sportförderers, Basel, Rotweiss, 2013, p. 143.

32 Anonyme, "Renseignement confidentiel ", 6 mai 1946. Archives du Comité international olympique (CIO), correspondance du CNO de la Suisse, dossier : D-RM01-SUISS/006. Merci à Quentin_Tonnerre pour cette information $570-1$ 
continuité avec l'ancien secrétaire général. Barassi et Rous se montrent très satisfaits avec la proposition de Ernst Thommen, en indiquant toutefois qu'il leur paraît « utile et nécessaire que M. Gassmann [soit] présent tous les jours au bureau ${ }^{33}$. Finalement, après quelques mois de discussions et malgré les dizaines d'offres reçues pour le poste de secrétaire général, les trois hommes décident de continuer de collaborer avec le Suisse et de le proposer comme secrétaire général de la FIFA au comité exécutif. Cette solution est ratifiée par l'élite dirigeante de la Fédération internationale, qui accueille la proposition avec satisfaction ${ }^{34}$.

Avec la nomination de Kurt Gassmann, le trio Barassi-Rous-Thommen réussit à placer une personne de confiance à un poste clé de la Fédération internationale. De plus, les trois hommes sont certains d'avoir sa loyauté car cette nomination à la FIFA permet à Gassmann de reprendre une place dans le football international après une période relativement longue d'inactivité. En effet, durant la décennie précédente, Gassmann avait été mis sur la touche par les autorités du football suisse. En conséquence, la fonction de secrétaire général de la FIFA est pour lui une occasion de revenir sur le devant de la scène et de finir sa carrière d'administrateur sportif en beauté. Sous l'impulsion du nouveau secrétaire général, et comme l'avait souhaité le trio Barassi, Rous, Thommen, le secrétariat de la FIFA va se professionnaliser. Désormais, les documents officiels (les procès-verbaux des commissions et congrès ainsi que les circulaires) sont plus standardisés et précis, les dates de rédaction et le nom de l'auteur étant par exemple le plus souvent indiqués. De même, une modernisation de l'équipement intervient puisque, dès sa prise de fonction, Gassmann demande à acquérir du matériel neuf et en phase avec l'époque (machines à écrire et meubles de bureau). Il s'agit également de transmettre davantage d'informations aux associations nationales et l'idée de relancer un bulletin officiel ressurgit. Le but de cette publication, qui se concrétise quelques mois plus tard sous le titre de Bulletin de la FIFA, consiste à " publier toutes les décisions importantes et d'un caractère général, ainsi [qu’à] renseigner les associations sur le travail et les intentions des organes de la FIFA ${ }^{35}$.

33 Anonyme, Procès-verbal de la réunion du comité exécutif de la FIFA du 2 décembre 1950, n.d. FIFA, comité exécutif (procès-verbaux 1947-1950).

34 Dans un courrier, Seeldrayers indique à Gassmann : "Je saisis cette occasion, mon cher Gassmann, pour vous dire combien je suis heureux de votre bonne collaboration à la FIFA ». Lettre de R.W. Seeldrayers à K. Gassmann, 15 janvier 1951. FIFA, réorganisation 50-53,1. Commission d'étude et bureau, dossier : réorganisation séance des 29-30 mars.

35 Gassmann K., Procès-verbal de la réunion de la délégation du bureau de la FIFA des 16-17 août 1951, n.d. FIFA, comité exésutif (procès-verbaux 1951-1952) 
Autre changement de taille, Gassmann et Thommen s'attellent à trouver un siège pour la FIFA. En effet, le nouveau secrétaire général se plaint rapidement de l'étroitesse des bureaux de la Bahnhofstrasse ${ }^{36}$. Dès lors, au regard de l'activité croissante de l'organisation, les locaux existants commencent à devenir exigus, en particulier en matière de classement de documents. Si le sujet est discuté à plusieurs reprises au sein du comité exécutif, il semble difficile de trouver un lieu approprié (notamment en raison des coûts élevés de l'achat d'un immeuble). Des visites sont organisées dans la région zurichoise, mais également dans d'autres villes suisses comme Berne et Genève. En date du 25 septembre 1954, alors que la situation n'a pas évolué, Gassmann rappelle aux membres du comité d'urgence "l'état décidément insuffisant des bureaux actuels ${ }^{37}$. Quelques semaines plus tard, suite à une proposition d'Ernst Thommen et du secrétaire, le comité exécutif " décide à l'unanimité d'acheter la propriété Hitzigweg 11 à Zurich " ${ }^{38}$. Après plus de trois ans de discussion, la FIFA s'apprête donc à disposer d'un siège, qui devient opérationnel dans le courant de l'année 1955.

Enfin, dernier volet, l'engagement d'un secrétaire adjoint. Comme le note Kurt Gassmann dès sa prise de fonction, il faut que le travail puisse continuer en cas de maladie ou de vacances du secrétaire général. Ainsi, avant le congrès d'Helsinki de 1952, Thommen répond aux appels répétés du secrétaire en lui déléguant momentanément un employé du Sport Toto - l'organisme officiel de paris sportifs en Suisse - où il officie comme directeur, afin de l'aider à répondre à la charge de travail. Le dirigeant helvétique joue ensuite à nouveau les hommes providentiels puisqu'il "signale qu'une personne qualifiée serait disponible " ${ }^{39}$. Cet adjoint sera Hans Bangerter. Le Bernois, interrogé par nos soins, ne s'est pas montré très précis sur les raisons de son arrivée à la Fédération internationale, et a simplement indiqué : "J'avais travaillé à l'école fédérale de sport à Macolin, je me suis occupé des relations internationales surtout. Et j'ai

36 Lettre de K. Gassmann à J. Rimet, O. Barassi, S. Rous et E. Thommen, 18 mai 1951. FIFA, comité exécutif (procès-verbaux 1951-1952). Depuis 1931, la Fédération internationale ne dispose que de quelques bureaux situés sur la Bahnofstrasse de Zurich.

37 Gassmann K., Procès-verbal de la réunion du comité d'urgence de la FIFA du 25 septembre 1954, 5 octobre 1954. FIFA, comité exécutif (procès-verbaux 1953-1954).

38 Gassmann K., Procès-verbal de la réunion du comité exécutif de la FIFA du 18 novembre 1954, 29 novembre 1954. FIFA, comité exécutif (procès-verbaux 1953-1954).

39 Gassmann K., Procès-verbal de la réunion du comité exécutif de la FIFA des 8-9 septembre, 17 septembre 1952. FIFA, çmité exécutif (procès-verbaux 1951-1952). 
reçu évidemment les personnalités étrangères pour visiter Macolin et c'est là où j'ai fait la connaissance de dirigeants, notamment du foot et de la FIFA, et ils m'ont demandé de [venir] à la FIFA. C'est comme ça que j'ai commencé ${ }^{40}$."

Tous ces éléments indiquent que le trio Barassi, Rous et Thommen, accompagné de Kurt Gassmann, tente de moderniser la FIFA pour que sa structure soit adéquate au développement croissant du football mondial. En fait, la prise d'importance des trois dirigeants révèle plus globalement qu'une transition générationnelle est en train de se produire à la tête de la Fédération internationale. En effet, les dirigeants qui officiaient dans le comité exécutif durant les années 1930 se font de plus en plus rares et renoncent progressivement à leur fonction.

Le président Jules Rimet, par exemple, voit son aura au sein de la FIFA diminuer. En 1949, un " Hiroshima du football " ${ }^{41}$ s'est déjà produit lorsqu'il perd le poste de président de la Fédération française qu'il occupait depuis trente ans. Dans la première partie des années 1950, il connaît de sérieux problèmes de santé. Dès lors, s'il est tout de même reconduit pour un énième mandat pendant le congrès de 1952, à quatre-vingts ans, il est de plus en plus distant des travaux du secrétariat et informe d'emblée l'assemblée qu'il cessera ses activités en 1954. À ses côtés, Seeldrayers semble, lui, harassé tant par son travail professionnel que par la position qu'il occupe au Comité olympique depuis 1945, comme il l'indique dans plusieurs correspondances à Kurt Gassmann. De plus, il est plongé dans une affaire qui l'oppose à l'Union belge ${ }^{42}$ et qui nuit sans aucun doute à sa crédibilité. Enfin, lors du congrès de 1952, Barassi remplace son compatriote Giovanni Mauro, qui renonce à ses activités au sein du comité exécutif pour cause de maladie. Désormais, seul Karel Lotsy y a officié durant l'entre-deux-guerres. Une page semble donc progressivement se tourner au sein de l'élite de la FIFA.

Mais l'idée des nouveaux hommes forts n'est pas de tout révolutionner. D'ailleurs, ils entretiennent une certaine proximité avec plusieurs de leurs aînés qu'ils côtoient depuis les années 1930. Ainsi, Barassi et Mauro sont des amis proches. De même, Thommen semble bien s'entendre avec Seeldrayers, comme le montre une lettre de 1955 où le dirigeant belge

\footnotetext{
40 Entretien avec Hans Bangerter réalisé le $1^{\text {er }}$ octobre 2012 à Bollingen.

41 "Hiroshima du football ", France football, 26 juillet 1949.

42 Alfred Verdyck, secrétaire de l'Union belge durant près de trente ans a, semble-t-il, détourné de l'argent à son propre compte, ce qui l'oblige à démissionner en 1949. Il reçoit néanmoins le soutien de Seeldrayers, position qui lui vaut de nombreuses critiques au sein de l'Union belge de football.
} 
mentionne : "Quel dommage que tu n'aies pas pu venir à Londres. $\mathrm{Tu}$ aurais vu le vendredi soir au terrain de l'Arsenal une fantastique exhibition de Stanley Matthews ${ }^{43}$. " De plus, sociologiquement parlant, les nouveaux dirigeants ressemblent sous plusieurs aspects à leurs prédécesseurs. Premièrement, comme eux, ils disposent d'un important capital footballistique puisqu'ils bénéficient d'une longue trajectoire dans le domaine footballistique, comme joueurs (pour Thommen) et arbitres (pour Barassi et Rous). En outre, ils ont une trajectoire institutionnelle analogue puisqu'ils occupent préalablement des fonctions de direction au sein de leur fédération nationale respective pendant de nombreuses années. Barassi est secrétaire général de la Fédération italienne et participe activement à l'organisation de la Coupe du monde de 1934. C'est un des plus importants dirigeants du football italien sous le fascisme. Après la chute de Mussolini, il va œuvrer à remettre en place une fédération italienne de football, dont il devient le président. Comme nous l'avons déjà indiqué, Rous est le secrétaire général de la puissante Football Association depuis 1934 et s'active en vue du retour des associations britanniques dans le giron de la FIFA après la Deuxième Guerre mondiale. Thommen quant à lui est délégué puis président de la puissante branche des ligues inférieures au sein de l'association suisse de football. À ce titre, il élabore, à la fin des années 1930 le "Plan Thommen ", qui consiste à réorganiser les échelons inférieurs du football helvétique. Durant les années 1940, il prend du grade et, après y avoir officié en tant que vice-président, il accède au poste de président de l'association suisse de football en 1947.

Deuxièmement, des dirigeants comme le trio Barassi, Rous et Thommen ont aussi un capital cosmopolite bien développé. Tout d'abord, par l'entremise du ballon rond, ils ont eu l'occasion d'effectuer de nombreux voyages et sont rôdés aux us et coutumes du football international. Si Rous ne maîtrise que l'anglais, Barassi peut jongler avec l'italien, le français et l'anglais. Outre l'allemand qui est sa langue maternelle, Thommen peut également s'exprimer aisément dans la langue de Shakespeare et en français. Il y a indéniablement chez eux une posture transnationale qui se développe au fil des années avec leur investissement dans le jeu. C'est après la Deuxième Guerre mondiale, dans le contexte de relance des activités du football européen, qu'ils se montrent très actifs. Barassi prend par exemple part à la création et au développement de différentes épreuves

43 Lettre de R.W. Seeldrayers à E. Thommen, le 10 mai 1955. FIFA, membres du comité exécutif, dossier individuel : correspondance R.W. Seeldrayers (1939-1950), dossier : 1951-1955. 
supranationales ${ }^{44}$. Comme nous l'avons indiqué, Stanley Rous joue un rôle important dans la mise en place du tournoi international des juniors. Dans un texte publié en 2007 sur Ernst Thommen, Heidrun Homburg a décrit le dirigeant helvétique comme un acteur mû par la volonté de développer le football à l'échelle internationale ${ }^{45}$. Dans son papier, elle insiste en particulier sur ses actions en vue d'organiser la Coupe du monde de 1954 en Suisse ainsi que sur les fonctions que le dirigeant bâlois prend au sein du comité exécutif de la FIFA au début des années 1950.

Troisièmement, Barassi, Rous et Thommen évoluent également dans des milieux libéraux. L'Italien et le Suisse font des études d'ingénieur, le premier dirigeant ensuite une société industrielle de sidérurgie alors que le second travaille au département de construction de la ville de Bâle de 1921 à la fin des années 1930, avant de prendre la direction du Sport Toto. Quant à Rous, il suit une formation d'enseignant, puis professe durant quelques années avant d'entrer à la Football Association comme secrétaire général.

Si les différents éléments avancés ci-dessus montrent une certaine continuité avec leurs aînés, les trois dirigeants se démarquent néanmoins de leurs prédécesseurs sur quelques points. Tout d'abord, ils sont plus ouverts à la commercialisation du football. Il ne s'agit certes pas de laisser ce sport aux mains des industriels, mais plutôt de davantage coopérer avec eux afin de développer le jeu. Par exemple, ils estiment que les paris sportifs pourraient permettre de financer l'activité footballistique des associations et commencent à envisager la création de nouvelles épreuves. Par ailleurs, ils soutiennent l'idée qu'il faut faire une distinction plus nette entre le football amateur et le football professionnel. Si le premier doit retenir l'attention des fédérations nationales au détriment du second, il s'agit néanmoins de s'assurer d'un haut niveau de jeu dans les compétitions, et ce dans le but d'attirer du public. En ce sens, il est nécessaire que ce soit surtout les meilleures équipes qui participent aux épreuves, vision qui va à l'encontre de celle universaliste qu'a toujours prônée Jules Rimet. Or, lors de la Coupe du monde jouée au Brésil en 1950, Rous n’hésite pas à indiquer au journaliste Jacques De Ryswick qu'il faut revoir la formule du tournoi car «faire accomplir 20000 kilomètres à une équipe comme celle de la Suisse pour jouer deux matches et s'en retourner chez elle,

44 Il est notamment délégué de la Fédération italienne au sein du comité exécutif de la Coupe internationale puis il participe à la création de la Coupe latine et œuvre à la mise en place de la Coupe de la Méditerranée.

45 Homburg H., "Ernst Thommen, die Schweiz und der Weltfussball, 1946-1962", Basler Zeitschrift für Geschichte und Altertumskunde vol. 107-2007 pp 69-102. 
c'est absolument illogique ${ }^{46}$. Il préconise ainsi des éliminatoires dans chaque continent ainsi qu'une réduction du nombre de matchs dans la phase finale. C'est notamment ce qui est envisagé pour la Coupe du monde de 1954 pour laquelle Ernst Thommen officie en qualité de président du comité d'organisation. En effet, un journaliste de France football note que «l'épreuve de qualification semble devoir être très vaste, sinon décourageante pour quelques-uns. Mais l'on serait assuré ainsi de n'avoir en Suisse que l'élite du football mondial ${ }^{47}$. De par leurs actions, les trois dirigeants accompagnent et encouragent la nouvelle étape de professionnalisation du jeu qui se produit dans les années 1950.

Enfin, ils se démarquent de leurs aînés, et notamment de Rimet et Seeldrayers, par leur vision de la structure de la FIFA. Dans l'édition du Handbook de l'UEFA de 1963, Stanley Rous revient sur cet aspect et indique que lui et plusieurs de ses collègues (il ne précise toutefois aucun nom) sont, au début des années 1950, "d'avis que des changements parmi les membres et dans la constitution du Comité exécutif de la FIFA [s'avèrent] nécessaires étant donné qu'un plus grand nombre de pays [sont devenus] indépendants et [ont quitté] par conséquent l'association nationale à laquelle ils appartenaient auparavant ${ }^{48}$. Modifier la structure de la FIFA en créant des organismes continentaux permettrait de répondre aux revendications des dirigeants sud-américains, dont Barassi et Rous sont relativement proches. Mais ils souhaitent aussi réformer l'organisation afin de préserver l'hégémonie des Européens en son sein. Or leurs idées ont d'autant plus de chances d'être entendues que, au regard de leurs fonctions et actions de longue date dans le football européen, les trois hommes disposent d'un capital relationnel étendu ${ }^{49}$.

Nous pouvons donc considérer que le trio Barassi, Rous et Thommen se situe à la croisée entre deux générations de dirigeants du football européen. D’un côté celle des dirigeants plus âgés comme Mauro, Rimet et Seeldrayers, voire des acteurs encore actifs mais qui n'officient pas officiellement dans les arcanes du comité exécutif de la FIFA, comme Bauwens ou Delaunay. De l'autre côté, celle de dirigeants plus jeunes qui officient dans l'élite de la FIFA, comme Lotsy - et Andrejevic qui

46 "Sir, Stanley Rous. "Sportivement et économiquement la formule actuelle de la Coupe du monde est périmée...” ", L'Équipe, 21 juin 1950.

47 "Pour la Coupe du monde, Jules Rimet de 1954 », France football, 10 juin 1952.

48 Rous S., "Le rôle des confédérations ", dans Bangerter H., UEFA Handbook, Berne, UEFA, 1963.

49 Dans son autobiographie, Rous note qu’à la fin des années 1940, beaucoup de dirigeants du football européen le visitept régulièrement au gì̀ge de la FA 
y reviendra en 1954 - et d'autres qui commencent à être actifs lors des assemblées générales de la Fédération internationale, à savoir les Belges François Meert et José Crahay, le Danois Ebbe Schwartz, le Grec Constantin Constantaras ou encore le Suisse Gustav Wiederkehr. Au regard de leur position d'agents de liaison, Barassi, Rous, Thommen vont notamment œuvrer, au printemps 1952, à créer de nouveaux rapprochements entre les dirigeants européens.

\subsubsection{La mise sur pied d'un " petit Conseil de l'Europe du football »}

Dans un article de France football paru en avril 1949, Ottorino Barassi évoque l'idée de créer une "Confédération européenne " ${ }^{50}$ qui pourrait, entre autres, gérer une épreuve continentale pour les sélections nationales. Cette idée semble s'inspirer du modèle sud-américain et germe sans doute dans la tête de Barassi en raison des nombreux voyages qu'il effectue pour son travail en Amérique du Sud ${ }^{51}$. Trois ans plus tard, le dirigeant va développer plus précisément son projet. Profitant des discussions autour de la réorganisation de la FIFA sur laquelle nous allons revenir ultérieurement, dans le courant de l'hiver, Barassi entretient des discussions informelles avec des collègues belges et français. En mars, ceux-ci décident de s'arrêter sur une attitude commune à adopter lors du congrès de la FIFA de $1952^{52}$. Par ailleurs, et au regard de l'importance du sujet, les associations nationales belge, française et italienne pensent qu'il faudrait organiser une discussion plus générale avec d'autres fédérations nationales européennes pour évoquer la possible réforme de la Fédération internationale. Pour ce faire, il est décidé qu'ils actionnent leur réseau. Ainsi, les Belges entreront, par exemple, en liaison avec leurs homologues néerlandais et luxembourgeois. À la suite de la réunion franco-italo-belge, le vice-président de l'Union belge, François Meert précise à ses collègues du comité exécutif que l'idée de créer une coalition

50 «La Coupe internationale a-t-elle vécu ? L'Italie n’aura pas terminé son programme l'an prochain ", France football, 19 avril 1949.

51 Profitant de la présence de Barassi sur ce continent, le comité exécutif de la FIFA le charge souvent de discuter avec les dirigeants de la Confédération sud-américaine afin de régler certains problèmes. C'est par exemple le cas lorque l'association brésilienne met du temps à régler la somme qu'elle doit à la FIFA pour la Coupe du monde de 1950 .

52 Anonyme, Procès-verbal du comité exécutif de l'Union belge du $1^{\text {er }}$ mars 1952, n.d. AGRB, URBSFA, dossier : comité exécutif (procès-verbaux 51-52) 
supranationale "s'avère d'une grande utilité, tenant compte que les fédérations américaines se sont groupées en une entente semblable et forment un bloc homogène dont les délégués assistent au congrès avec mandat impératif $"$ "

C'est à la suite de ces discussions préliminaires qu'Ottorino Barassi prend l'initiative de convoquer une assemblée entre plusieurs fédérations européennes qui se tiendrait le 22 avril 1952 à Genève ${ }^{54}$. Fait important, le dossier présenté par le dirigeant italien à ses collègues européens ne contient pas seulement des informations sur la réforme de la FIFA mais également des éléments additionnels par rapport à ce qui avait préalablement été discuté avec les dirigeants belges et français. Ainsi, le bureau fédéral de la Fédération française note que la proposition de Barassi « diffère par son caractère et le nombre des pays invités à y participer de l'initiative qui avait été prise à Paris " ${ }^{55}$. L'Union belge mentionne aussi le changement au travers de son comité exécutif, qui souligne que l'objectif de la future réunion «a considérablement évolué depuis le moment où celle-ci fut envisagée ${ }^{56}$. Barassi semble donc avoir profité des discussions sur la réforme de la FIFA pour lancer une concertation générale sur l'établissement d'une confédération européenne de football.

Sans doute en raison de l'ambition du projet, les différentes associations concernées décident d'ajourner la réunion préalablement prévue le 22 avril et de la reporter à la fin mai. Ce laps de temps doit permettre de mieux étudier les propositions de Barassi. Quelques jours avant la réunion, qui est finalement fixée à Zurich le 28 mai, l'Italien envoie un nouveau courrier dans lequel il précise ses idées. Dans sa lettre d'accompagnement, l'Italien mentionne les droits particuliers déjà reconnus à certains groupements au sein de la FIFA - notamment les places réservées de vice-présidents dans le comité exécutif pour les associations sud-américaines et britanniques ainsi que pour l'URSS. Par ailleurs, il note qu'il y a un risque que des groupements continentaux se développent à l'avenir dans d'autres continents (comme en Asie), ce qui entraînerait une position délicate pour les associations qui resteraient

53 Anonyme, Procès-verbal du comité exécutif de l'Union belge du 29 mars 1952, n.d. AGRB, URBSFA, dossier : comité exécutif (procès-verbaux 51-52).

54 Anonyme, Procès-verbal du comité exécutif de l'Union belge du 19 avril 1952, n.d. AGRB, URBSFA, dossier : comité exécutif (procès-verbaux 51-52).

55 Delaunay H., Procès-verbal du bureau fédéral de la Fédération française du 25 avril 1952, n.d. Archives de la Fédération française de football (FFF), livre : procès-verbaux du Bureau fédéral $n^{\circ} 30$ (08.51-05.52).

56 Anonyme, Procès-verbal du comité exécutif de l'Union belge du 3 mai 1952, n.d. AGRB, URBSFA, dossier : comité exécutif (procès-verbaux $51-52$ ) 
isolées. Il souligne que, parmi celles-ci, il y a celles de l'Europe «qui ont pratiquement fondé la FIFA, en lui donnant soit des moyens financiers soit une activité continuelle [et] finiront par rester sans autorité et sans droits si la tendance des autres à se grouper devait augmenter ${ }^{57}$. Cette situation doit donc pousser les dirigeants européens à réagir et, peut-être, à créer un organisme défendant leurs intérêts au sein de la Fédération internationale. Enfin, il s'agit aussi de prendre en compte les récents développements du football international. La FIFA devenant une organisation mondiale ${ }^{58}$, il apparaît de plus en plus délicat qu' elle puisse traiter de sujets concernant le football au niveau européen. De plus, créer un groupement continental aurait donc comme avantage de régler des problèmes qui ne peuvent pas trouver une solution au sein de la FIFA mais qui, au contraire, pourraient " en trouver une satisfaisante dans un Groupement de fédérations géographiquement proches, avec une remarquable affinité de conditions de vie et mœurs " ${ }^{59}$. En outre, Barassi estime qu'une telle entité permettrait l'élaboration de projets communs du point de vue technique (arbitrage, entraînement), social (hygiène, santé), moral (amateurisme et professionnalisme) et organisationnel (calendrier international, tournoi européen). L'idée est ambitieuse et se calque assurément sur l'exemple de la Confédération sud-américaine, qui est alors la seule organisation qui ressemble au modèle proposé par le dirigeant italien. Ce dernier mentionne néanmoins que la future entité devra bien entendu collaborer avec la Fédération mondiale et qu'il s'agit de la placer sous l'égide de la FIFA.

Ottorino Barassi souligne la nécessité de coopérer avec la FIFA, il semble que des dirigeants majeurs de la Fédération internationale, comme le montre l'exemple de Rodolphe Seeldrayers, ne sont mis au courant que tardivement de cette réunion des associations européennes. En effet, dans une note adressée à Kurt Gassmann le 16 mai 1952, Seeldrayers indique qu'il ignorait que Barassi avait pris cette initiative à laquelle d'ailleurs il ne participera pas afin de garder la neutralité qui sied à sa fonction de président de la commission de réorganisation. Toutefois, il espère que d'autres dirigeants sauront modérer la teneur des débats. À ce titre, il note : "Je pense que Rous fera du bon travail dans la coulisse et [il] compte sur Crahay [le secrétaire de la Fédération belge] pour exercer une action

57 Annexe d'une lettre d'O. Barassi à R.W. Seeldrayers, n.d. FIFA, réorganisation 50-53.

1. Commission d'étude et bureau, dossier : réorganisation 50/52.

58 Infra 3.2.1.

59 Annexe d'une lettre d'O. Barassi à R.W. Seeldrayers, n.d. FIFA, réorganisation 50-53.

1. Commission d'étude et bureau, dossier i réorganisation $50 / 52$ 
modératrice ${ }^{60}$. Toutefois, à la vue des positions que vont occuper ces deux dirigeants dans les discussions, il semble que Seeldrayers n'est pas mis au courant de toutes les confidences sur le sujet.

Si Barassi semble notamment influencé dans ses démarches par le modèle de la Confédération sud-américaine, dans quelle mesure est-il aussi marqué par le contexte ambiant de la construction communautaire, qui prend une nouvelle tournure en ce printemps 1952 ? En effet depuis les années 1948-1949, des actes de coopération existent entre les pays de l'Europe de l'Ouest dans le domaine économique et militaire ${ }^{61}$. En 1949 , celle-ci prend une nouvelle forme avec la mise en place du Conseil de l'Europe, qui a pour but premier "de réaliser une union plus étroite entre ses membres afin de sauvegarder et de promouvoir les idéaux et les principes qui sont leur patrimoine commun et de favoriser leurs progrès économiques et sociaux " ". Malgré des difficultés dans la mise en route de cette organisation - dues au fait que « le Conseil de l'Europe tel qu'il est né à Londres ne fait de loin pas l'unanimité des parlements nationaux des pays fondateurs " ${ }^{63}-$, d'autres actions sont entreprises par des promoteurs de l'Europe au début des années 1950. Il s'agit notamment du lancement d'un ambitieux projet visant à établir une Communauté européenne du charbon et de l'acier (CECA) entre l'Allemagne et la France, à laquelle participeraient également les pays du Benelux et l'Italie ${ }^{64}$.

Cette proximité entre les démarches visant à la mise sur pied d'une conférence européenne du football et la création de la CECA est soulignée par Jürgen Mittag, qui pointe par ailleurs le fait que ces deux projets sont portés par des acteurs provenant des mêmes pays ${ }^{65}$. En fait, les liens entre le domaine du football européen et la politique européenne

60 Lettre de R.W. Seeldrayers à K. Gassmann, 16 mai 1952. FIFA, réorganisation 50-53. 1. Commission d'étude et bureau, dossier : réorganisation 50/52.

61 Avec la création de l'Organisation européenne de coopération économique (OECE) en 1948, puis de l'Organisation du traité de l'Atlantique Nord (OTAN) une année plus tard. Pour une synthèse sur ce processus, voir : Bitsch M.-T., Histoire de la construction européenne. De 1945 à nos jours, Bruxelles, Complexe, 2012 [1996].

62 Roussellier N., L'Europe des traités. De Schuman à Delors, Paris, CNRS Éditions, 2007, p. 34 .

63 Wassenberg B., Histoire du Conseil de l'Europe (1949-2009), Bruxelles, P.I.E. Peter Lang, 2012, p. 57.

64 Pour un aperçu de la création de la CECA voir : Bitsch M.-T., «La première institution supranationale. Du nouveau sur l'histoire de la Haute Autorité de la CECA », dans Bitsch M.-T., La construction européenne. Enjeux politiques et choix institutionnels, Bruxelles, P.I.E. Peter Lang, 2007, pp. 97-113. 
semblent plus étroits que nous pourrions le penser. Tout d'abord, la presse sportive se fait volontiers l'écho des projets européens en cours et avance même des idées de collaborations. En 1950, France football note ainsi que Strasbourg, en tant que ville d'accueil du siège du Conseil de l'Europe, pourrait être le lieu d'organisation d'un championnat d'Europe interclubs ${ }^{66}$. Parallèlement, des acteurs politiques envisagent d'utiliser le football comme un vecteur possible de propagande de leurs idées. Ainsi, à l'été 1952, le "Mouvement européen " pense à organiser des rencontres de football à l'échelle continentale ${ }^{67}$. Toutefois, de tels projets doivent trouver l'approbation des dirigeants des associations nationales de football. Or ceux-ci sont plutôt réticents à accepter de les cautionner car, comme l'argumente l'Union belge - qui refuse que ses clubs participent à des matchs patronnés par le "Mouvement européen »-, il n'est pas question de participer à des joutes organisées par une entité à " tendance politique $"{ }^{68}$. En ce sens, si ce contexte de coopération européenne a pu influencer l'action de Barassi, nous pouvons aussi émettre l'hypothèse que ces démarches en vue de rapprocher les associations nationales européennes de football n'ont pas uniquement comme but de développer les relations footballistiques continentales, mais qu'elles peuvent aussi avoir comme objectif de consolider le monopole des associations nationales en matière d'administration du jeu. Pour le dire autrement, l'existence d'un organisme footballistique européen aurait pour avantage de disposer d'un porte-parole du football continental vis-à-vis des autres organismes européens alors en construction.

La réunion entre les associations européennes se tient bien à la fin mai 1952 à Zurich et coïncide avec la rencontre qui se dispute entre la Suisse et

66 "Vers un Championnat d'Europe disputé à Strasbourg, "capitale”, France football, 22 août 1950. Selon ce journal, cette idée serait soutenue par le nouveau président du Conseil de l'Europe - et figure majeure de la construction européenne durant les années 1950 -, le Belge Paul-Henri Spaak, qui est décrit comme " un amateur éclairé de football ». Cet attrait de Spaak pour le football est confirmé par Michel Dumoulin : Dumoulin M., Spaak, Bruxelles, Racine, 1999.

67 Anonyme, Procès-verbal du comité exécutif de l'Union belge du 21 juin 1952, n.d. AGRB, URBSFA, dossier : comité exécutif (procès-verbaux 51-52). Parallèlement, Jean Monnet, alors président de la Haute Autorité gérant la CECA et jamais à court d'idées pour développer le projet européen, griffonne sur un bout de papier l'idée de mettre sur pied une équipe de football continentale "acier contre charbon ". Anonyme, Note de Jean Monnet, 4 février 1952. Archives de la Fondation Jean Monnet pour l'Europe. Document que nous a gentiment transmis par mail un des archivistes de la Fondation.

68 Anonyme, Procès-verbal du comité exécutif de l'Union belge du 7 mars 1953, n.d. AGRB, URBSFA, dossier : comité exécutif (procès-verbaux 51-52) 
l'Angleterre, à laquelle les congressistes assistent et qui permet de continuer les discussions dans un cadre plus informel. Relevons que si le courrier d'invitation est écrit par Barassi, c'est Ernst Thommen qui se charge de la logistique de la réunion. Cette action révèle que ce projet est en fait pensé de manière simultanée par plusieurs dirigeants du football européen, et en premier lieu par le trio Barassi, Rous et Thommen. Quelques heures avant la première réunion, le journaliste français Maurice Pefferkorn mentionne que le but essentiel de celle-ci est " de créer un embryon de Fédération européenne destiné à faire front à la coalition des Fédérations américaines " ${ }^{69}$.

Si Pefferkorn parle de fédérations européennes - propos repris dans les différents livres commémoratifs de l'UEFA -, il s'agit en fait d'une réunion des associations de l'Ouest de l'Europe uniquement. En effet, sont présents sur les bords de la Limmat (par ordre alphabétique) : Angleterre, Autriche, Allemagne, Belgique, Danemark, France, Pays-Bas, Italie, Luxembourg et Suisse $^{70}$. À noter que le Danemark parle au nom des associations scandinaves (Suède, Norvège et Finlande) tandis que la Suisse représente également l'Écosse, l'Espagne, le Portugal et la Yougoslavie. Au stade de nos recherches, il est difficile de savoir pourquoi les associations d'Europe de l'Est ne prennent pas part aux discussions. Dans le Handbook de l'UEFA de 1963, José Crahay précise que les associations nationales invitées sont celles qui ont préalablement "donné leur accord de principe lors des conversations préliminaires [tenues] avec M. Barassi » ${ }^{71}$. Entre les lignes, le dirigeant belge donne un autre indice puisqu'il signale que c'est durant ses voyages avec l'équipe nationale italienne que Barassi a évoqué son projet à plusieurs de ses collègues européens. Or, depuis le début des années 1950, l'équipe d'Italie ne joue aucune rencontre contre une équipe de l'Europe de l'Est - hormis un match contre la Yougoslavie en 1951. De fait, les possibilités d'échanges autour du projet entre le dirigeant transalpin et des membres de ces pays semblent plutôt réduites. En conséquence, les discussions initiales entre les dirigeants du football européen suivent les lignes de fracture du contexte politique de la Guerre froide et concernent avant tout des pays de l'Europe de l'Ouest. Malgré l'absence des associations du bloc communiste, la réunion propose déjà une configuration européenne élargie, en comparaison avec les six pays qui forment la CECA. Les journalistes de France football ne s'y

69 "Deux événements européens à Zurich : entretiens européens et Suisse-Angleterre ", L'Équipe, 25 mai 1952.

70 Lettre de H. Käser à K. Gassman, 7 janvier 1952. FIFA, Réorganisation 1950-1953, 1. Commission d'étude et bureau, dossier : conférence du 27 mai 1952 à Zurich.

71 Crahay J., "Des origines de l'UEFA », dans Rothenbuehler R., Les 25 ans de l'UEFA, UEFA, 1979, p. 19. 
trompent pas et décrivent d'ailleurs l'assemblée comme un " petit Conseil de l'Europe du football ${ }^{72}$.

Durant le premier jour, les congressistes discutent avant tout de la réforme de la FIFA. Afin d'avancer sur le projet, une commission permanente est créée, composée de l'Italien Barassi, du Belge Crahay et du Français Delaunay. Celle-ci permet de pérenniser les échanges et implique qu'un travail de fond va être conduit dans les prochaines semaines vis-àvis du nouveau projet de statuts présenté par le comité exécutif FIFA et devant être discuté lors du congrès de 1952. Ces trois dirigeants sont choisis car ils sont à la base du mouvement et ont, en outre, l'avantage d'avoir été - c'est le cas de Barassi - ou d'être encore - c'est le cas de Crahay et Delaunay - secrétaires de leur association nationale respective; il s'agit donc de dirigeants aguerris à la rédaction de dossiers. Enfin, à eux trois, ils sont capables d'écrire dans plusieurs langues, en particulier l'anglais, l'allemand et le français, ce qui facilitera les échanges avec les associations nationales. Il est donné pour mission aux trois dirigeants de coucher sur papier les remarques des associations européennes sur le projet de statuts de la FIFA préparé par la commission de réorganisation. Sur ce sujet, l'assemblée zurichoise semble avoir été bénéfique puisque des accords sont trouvés entre les associations européennes participant au projet et qu’il est décidé de fixer une nouvelle réunion quelques jours avant le congrès d'Helsinki. Par contre, l'idée proposée par Barassi de créer une confédération européenne de football, qui est discutée dans la matinée du deuxième jour ${ }^{73}$, ne fait pas forcément consensus. Quelques jours après la réunion, le comité exécutif de l'Union belge constate que "le principe de la création d'une entente européenne (ou d'une amicale des fédérations européennes) n'est pas encore définitivement mis au point ${ }^{74}$. Lidée de créer un organisme continental reste donc en latence. Sans doute que les dirigeants présents estiment qu'une telle démarche est prématurée et préfèrent donc attendre la tournure que prendra la réorganisation de la FIFA avant de se prononcer sur cette question.

L'éventualité de fonder un organisme européen du football est à nouveau discutée lors de la nouvelle assemblée qui se déroule en date du 27 juin 1952 à Paris. Ce sont cette fois dix-huit dirigeants qui sont présents dans la capitale française, représentant onze organisations

72 "À Zurich, les représentants de 13 nations jettent les bases d'une entente européenne ", L'Équipe, 28 mai 1952.

73 "Les "treize" ont terminé leurs travaux et nommé leur Bureau ", L'Équipe, 29 mai 1952.

74 Anonyme, Procès-verbal du comité exécutif de l'Union belge du 7 juin 1952, n.d. AGRB, URBSFA, dossier : comité exécutif (procès-verbaux $51-52$ ) 
nationales (Allemagne de l'Ouest, Belgique, Écosse, Espagne, France, Italie, Luxembourg, Pays-Bas, Portugal, Suisse et Yougoslavie ; l'Angleterre et l'Autriche se sont excusées). Contrairement à la première réunion, la Yougoslavie est présente, ce qui rappelle sa position à part au sein du bloc communiste. La continuité avec la première assemblée est respectée et nous constatons que la grande majorité des dirigeants qui vont jouer un rôle majeur dans le football européen de la seconde partie des années 1950 sont là (par ordre alphabétique) : Andrejevic, Barassi, Crahay, Delaunay, Graham, Lotsy, Meert ou encore Wiederkehr. Ernst Thommen ne peut participer aux débats, mais il envoie un petit mot à l'assemblée en vue d'encourager la poursuite des discussions entamées à Zurich ${ }^{75}$. Par ailleurs, l'assemblée convoque aussi des dirigeants plus âgés que nous pouvons considérer comme des " revanchards", tels Bauwens ou Delaunay ${ }^{76}$. Si les associations du bloc de l'Est ne participent pas aux discussions, il n'est pas à exclure qu'elles n'aient tout simplement pas répondu à l'invitation envoyée puisque, dans le procès-verbal de la réunion rédigé par le délégué suisse, Helmut Käser, il est indiqué que plusieurs associations ne se sont pas manifestées suite au courrier envoyé le 20 juin par Ottorino Barassi.

Lors de l'assemblée, les dirigeants présents se mettent d'accord pour défendre une vision européenne du nouveau projet de statuts de la FIFA. C'est à la commission permanente, formée de Barassi, Crahay et Delaunay, qu'échoit la rédaction finale de ce texte, intitulé "Projets d'additifs ou d'amendements aux derniers projets de modifications aux statuts et règlements élaborés par la commission d'étude de la FIFA ${ }^{77}$. Celui-ci est ratifié par les dix-huit associations européennes ${ }^{78}$.

75 Käser, H., Bericht über die Tagung der Europäischen FIFA. Verband in Paris, Rue de Londres 22, 27. Juni 1952. FIFA, réorganisation 1950-1953. 1. Commission d'étude et bureau/révision, dossier : conférence du 27 mai 1952 à Zurich.

76 Bauwens ambitionne, à terme, de pouvoir récupérer sa place au sein du comité exécutif de la FIFA. Quant à Delaunay, la position qu'il occupe depuis l'entre-deux-guerres en tant que secrétaire dans la commission des Lois du jeu est en effet mise en danger par le projet de réforme.

77 Barassi O., Crahay J., Delaunay H., « Projets d'additifs ou d'amendements aux derniers projets de modifications aux statuts et règlements élaborés par la commission d'étude de la FIFA », 27 juin 1952. FIFA, réorganisation 1950-1953, 3. Propositions et projets, dossier : propositions.

78 Par ordre alphabétique : Allemagne, Angleterre, Autriche, Belgique, Danemark, Espagne, Écosse, France, Grèce, Irlande, Italie, Luxembourg, Pays-Bas, Portugal, Sarre, Suède, Suisse et Yougoslavie. 
Figure 2. Pays ayant ratifié la proposition de modification des statuts de la FIFA

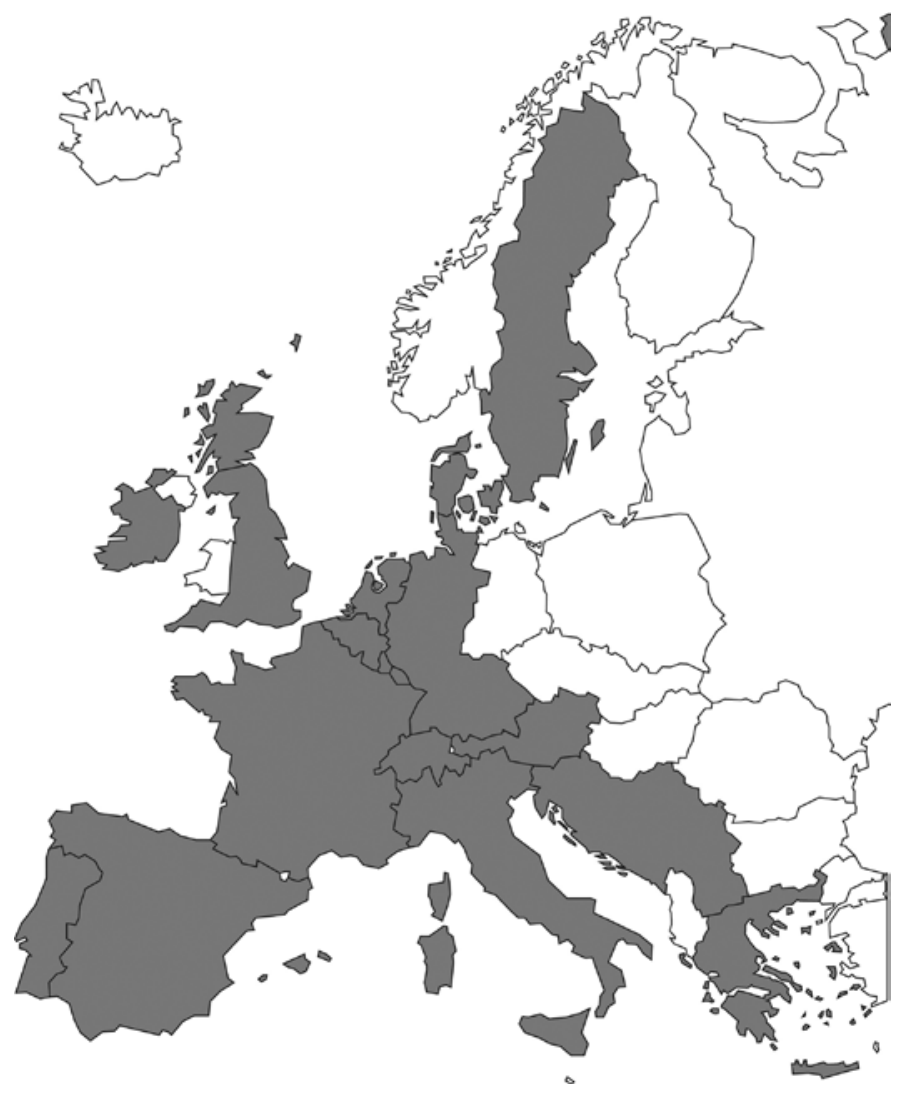

Légende : en gris, pays co-signataires de la proposition européenne de modification des statuts.

Les actions entreprises entre la fin mai et la fin juin par les dix-huit associations européennes marque un changement dans la manière d'aborder les congrès de la FIFA, une voix européenne semblant désormais pouvoir se créer à cette occasion. Ce type d'action semble d'ailleurs amené à perdurer puisque dans la lettre qui accompagne le document écrit par la commission permanente, Barassi mentionne qu'une prochaine réunion est d'ores et 
déjà fixée le 22 juillet suivant ${ }^{79}$, soit en marge des sessions du congrès de la FIFA. En mai-juin 1952, plusieurs associations européennes décident donc d'entamer une coopération. Par contre, leurs délégués présents aux réunions n'ont pas souhaité créer une organisation. Dans le petit mot qu'il adresse à ses collègues présents à Paris, Ernst Thommen résume bien le sentiment général. En effet, le dirigeant helvétique affirme son soutien à l'idée de former un groupement de fédérations européennes, afin de sauvegarder les intérêts des associations nationales du Vieux Continent. Il souligne néanmoins que la FIFA :

"Doit rester une entité regroupant des associations nationales et si une entente d'associations nationales continentales peut permettre de multiplier les échanges sur les discussions d'ordre interne, ce qui ne manquera pas de fortifier la FIFA, il ne faut pas se hâter sur la question, car le risque serait in fine de donner à cette entente un sens ou une direction qui ne serait pas voulue. ${ }^{80}$ "

C'est pourquoi le dirigeant suisse préconise la création d'une "Entente ", ce qui a pour avantage de permettre une réunion entre des associations ayant des intérêts communs, sans pour autant sceller une alliance trop ferme. Cette vision est finalement partagée par Barassi qui, quelques jours plus tard, écrit au secrétaire de l'association suisse que les deux réunions de Zurich et Paris ont eu un " caractère amical et pas du tout impératif ${ }^{81}$.

Si les dirigeants d'Europe de l'Ouest n'entérinent donc pas l'idée de créer un groupement continental, les réunions de Zurich et Paris, puis d'Helsinki à la veille du congrès de la FIFA de 1952, sont cependant à souligner. En effet, elles engagent une nouvelle manière de procéder, à savoir la convocation d'une assemblée élargie entre les associations européennes d'Europe de l'Ouest afin de discuter des sujets relatifs aux congrès de la FIFA, et plus largement des problèmes du football européen. Comme nous allons le voir, ce procédé va se répéter dans le futur et notamment à la veille du congrès extraordinaire de la FIFA de 1953. Car le facteur décisif qui va finalement permettre à terme la création d'une

79 Lettre de O. Barassi à H. Käser, 10 juillet 1952. FIFA, réorganisation 1950-1953, 4. Propositions et projets, dossier : propositions.

80 Käser H., Bericht über die Tagung der Europäischen FIFA. Verband in Paris, Rue de Londres 22, 27. Juni 1952. FIFA, réorganisation 1950-1953. 1. Commission d'étude et bureau/révision, dossier : conférence du 27 mai 1952 à Zurich.

81 Lettre de O. Barassi à H. Käser, 10 juillet 1952. FIFA, réorganisation 1950-1953, 4. Propositions et projets, dossier : propssitions. 
entité européenne va se jouer au sein de la Fédération internationale et doit être mis en perspective avec la réforme de sa structure.

\subsection{Entre internationalisation et Guerre froide}

La volontéde régionaliser-ou décentraliser-la Fédération internationale n'est pas nouvelle et nous avons déjà indiqué que les associations sudaméricaines font part de ce souhait dès les années $1930^{82}$. La coalition entre les associations d'Amérique centrale et du Sud et l'ouverture progressive à une décentralisation de la FIFA chez des dirigeants comme Barassi, Rous et Thommen forment un contexte favorable pour débuter un travail en vue d'une réforme des statuts de l'organisation. S'ajoute à ces éléments l'internationalisation croissante que connaît la FIFA après la Deuxième Guerre mondiale, qui rend son administration plus délicate et plaide pour une adaptation de sa structure.

\subsubsection{Une deuxième phase de mondialisation}

Dès la fin de la Deuxième Guerre mondiale, la FIFA connaît une nouvelle phase de mondialisation due en premier lieu à la décolonisation ${ }^{83}$. Les nouveaux pays indépendants souhaitent participer activement aux travaux des organisations internationales et l'une de leurs premières actions est de demander leur adhésion à l'Organisation des Nations unies. Dans la même perspective, et en raison de la place désormais incontournable prise par le sport sur la scène internationale, ils demandent à incorporer les organisations sportives internationales, et en premier lieu le CIO et la FIFA. Entre 1946 et 1950, cette dernière connaît une forte croissance de ses membres avec l'adhésion d'une vingtaine de nouvelles associations, dont seize sont extra-européennes ${ }^{84}$. Sur les quatorze associations extra-

82 Supra 1.3.2.

83 Dès les années 1946-1947, les Britanniques et les Français se voient contraints de quitter leurs possessions - non sans violences - au Proche-Orient. La décolonisation de l'Inde en 1948 marque un premier tournant dans le processus et semble signifier la fin de l'Empire britannique. Pour un propos général, voir : Michel M., Décolonisations et émergence du tiers monde, Paris, Hachette, 1993.

84 Par ordre d'arrivée et alphabétique : Guatemala et Syrie (1946) ; Afghanistan, Burma, Canada, Corée du Sud, Chypre, Gold Coast, Honduras, Iran, Nouvelle-Zélande, Pakistan, Pays de Galles et Soudan (1948) ; Irak et Nicaragua (1950). Les six nouveaux arrivants européens sont les quatre associations britanniques et l'Union soviétique en 1946 ainsi que la Sarre en 1950. 
européennes qui entrent à la FIFA, sept proviennent d'Asie - huit, si nous y intégrons, comme les dirigeants de l'époque, la Nouvelle-Zélande -, trois d'Amérique centrale, deux d'Afrique et une d'Amérique du Nord. En moins de cinq ans, le nombre d'associations membres de la FIFA augmente ainsi de près de $30 \%$ pour se fixer au nombre de septante et un. Le territoire de l'organisation s'étend de plus en plus en dehors de l'Europe et, signe de cette extension géographique, un premier congrès est organisé hors du Vieux Continent. Il se tient à Rio de Janeiro au Brésil en 1950, durant la Coupe du monde. De même, l'idée de délocaliser hors d'Europe les réunions du comité exécutif commence à être sérieusement évoquée en son $\operatorname{sein}^{85}$.

Figure 3. Nombre d'associations membres de la FIFA de 1904 à 1950

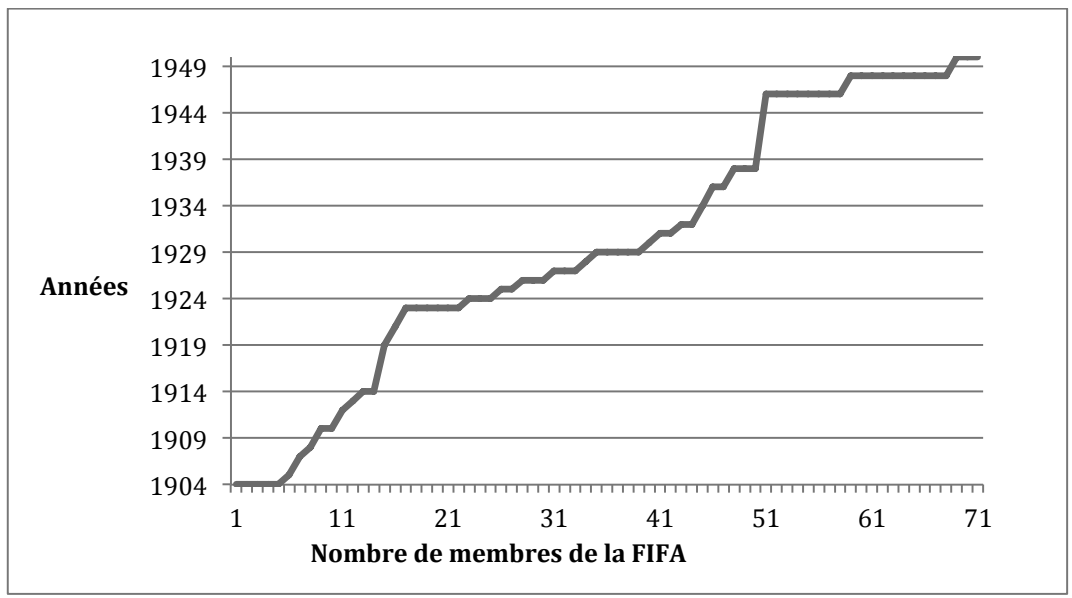

Cette situation a plusieurs conséquences pour la FIFA. Premièrement, elle complique la tâche au comité exécutif et au secrétariat. En effet, les associations entrantes amènent avec elles de nouvelles problématiques à gérer, qui souvent sont connectées à des revendications d'ordre politique. Par exemple, en 1946, « la Fédération Libanaise de FA demande l'autorisation d'organiser un championnat du Proche et Moyen-Orient avec le concours

85 Au début de l'année 1951, une réunion du comité exécutif à New York est envisagée. Cette idée n'est finalement pas réalisée en raison des coûts de transport qu'elle engendrerait, la plupart des membres provenant d'Europe. Gassmann K., Procèsverbal de la réunion du comité exécutif de la FIFA des 6-7 octobre 1951, n.d. FIFA, comité exécutif (procès-verbaux 1951-1952). 
des équipes arabes de Palestine ${ }^{86}$. Le comité exécutif refuse d'entrer en matière, car la Fédération de la Palestine ne représente pas tout le territoire du pays, étant en concurrence avec un autre organisme regroupant les clubs juifs. De même, dès 1948, l'Égypte proteste ouvertement contre l'affiliation du Soudan car elle estime que certains des territoires soudanais lui appartiennent. À son habitude, l'élite de la FIFA décide de ne pas entrer en matière dans cette affaire qui concerne la politique interne des associations nationales.

Deuxièmement, les nouvelles associations membres issues de pays extra-européens sollicitent la FIFA afin qu'elle les aide à développer le football dans leur région. En effet, ces fédérations ne bénéficient pas des mêmes structures footballistiques que les associations européennes et les échanges avec leurs voisins restent peu développés. Il s'agit donc de tâches supplémentaires auxquelles l'élite de la FIFA doit faire face. Par ailleurs, quelques dirigeants de pays africains ${ }^{87}$ imaginent la création d'une entité continentale dans le but de favoriser l'établissement de relations plus fortes au niveau supranational entre les associations nationales du continent. En 1945, l'association égyptienne, active au sein de la FIFA depuis les années 1930, transmet une demande à la Fédération internationale en vue d'obtenir "l'autorisation de constituer un groupe de la FIFA au ProcheOrient ${ }^{88}$. Il ne s'agit pas d'aller contre son autorité puisque les dirigeants égyptiens indiquent que le groupement s'assurera que les règlements de la FIFA seront respectés. Ivo Schricker s'empresse de récolter des informations sur les actions entreprises par les dirigeants égyptiens à ce sujet. Outre le côté informatif, cette démarche du secrétaire général de la FIFA peut aussi être interprétée comme un rappel de l'autorité de la Fédération internationale sur le football mondial. En effet, Schricker indique aux Égyptiens que l'organisation de rencontres contre des associations qui ne sont pas membres de la FIFA doit préalablement être approuvée par elle $^{89}$. Finalement, le groupement ne voit pas le jour. Cependant, l'idée

86 Schricker I., Procès-verbal de l'assemblée générale de la FIFA des 25-26 juillet 1946, n.d. FIFA, comité exécutif (procès-verbaux 1940-1946).

87 Sur le développement du football en Afrique à cette période, voir : Dietschy P., « Le football africain, entre domination coloniale et émancipation ", dans Singaravélou P., Sorez J. (dir.), L'Empire des sports. Une histoire de la mondialisation culturelle, Paris, Belin, 2010, pp. 53-69.

88 Schricker I., Procès-verbal de la réunion du comité exécutif de la FIFA des 10-12 novembre 1945, n.d. FIFA, comité exécutif (procès-verbaux 1940-1946).

89 Lettre de I. Schricker à l'Egyptian Football Association, 4 décembre 1945. FIFA, correspondance avec les associations nationales : Égypte (1932-1994), dossier : 22 Egypt 1932-1950. 
de fonder un tel organisme régional témoigne d'une volonté chez les nouveaux arrivants de rechercher de nouvelles manières de développer le jeu dans leur région par la création d'organismes supranationaux, procédé qui pourrait, à terme, déboucher sur une refonte de l'organisation même de la FIFA. À la fin des années 1940, alors que le contexte est de plus en plus favorable aux idées de réunir les peuples africains au sein d'organisation commune ${ }^{90}$, une proposition émane cette fois d'un groupe de pays d'Afrique subsaharienne. Soutenu devant le congrès de la FIFA de 1950 par l'association de la Gold Coast, le projet vise à la création d'une "United African Football Association " qui rassemblerait les associations d'Afrique du Sud, de la Côte d'Ivoire, de la Gold Coast, du Nigeria, de la Sierra Leone et du Togo. Le but de cette Union serait " de créer une liaison plus étroite entre les associations d'Afrique, d'échanger des vues, de régler les contributions financières, d'organiser régulièrement des matchs intercoloniaux et finalement d'instituer une compétition annuelle intercoloniale $"{ }^{91}$. Les dirigeants du comité exécutif de la FIFA refusent néanmoins d'entrer en matière sur la question, évoquant qu' " il est nécessaire que les organisations respectives soient affiliées à la FIFA ${ }^{92}$, ce qui n'est pas le cas puisque la plupart de ces pays ont encore un statut de colonie. En conséquence, leurs activités footballistiques sont gérées par la fédération de la métropole. Signe tout de même d'une tendance à prendre davantage en compte les demandes des associations extraeuropéennes, le comité de la FIFA place la question à l'ordre du jour de l'assemblée générale qui se déroule les deux jours suivants. La proposition fait l'objet d'un débat entre plusieurs congressistes, mais aucun pays africain n'est présent pour la défendre, ce qui laisse le champ libre aux dirigeants des puissances coloniales pour faire entendre leurs voix. En fait, les déclarations des dirigeants qui interviennent sur la question révèlent bien la position de leur pays face à la situation coloniale. Ainsi, le Français Henri Delaunay souligne que deux organisations nommées par la Gold Coast dépendent de la Fédération française - aucun nom n'est mentionné dans le procès-verbal, mais nous pouvons en déduire qu'il s'agit de la Côte d'Ivoire et du Togo, qui font alors partie du territoire de l'Afrique

90 C'est en particulier la volonté du mouvement panafricaniste. Sur celui-ci, voir : Boukari-Yabara A., Africa unite! : une histoire du panafricanisme, Paris, La Découverte, 2014.

91 Anonyme, "Annexe à l'ordre du jour du XXVII congrès à tenir à Rio de Janeiro les 22 et 23 juin 1950 ", n.d. FIFA, XXV-XXVII congrès ordinaires (1946-1952, rapport d'activité).

92 Schricker I., Procès-verbal de la réunion du comité exécutif de la FIFA du 21 juin 1950, n.d. FIFA, comité exécutif (procès-verbaux 1947-1950). 
occidentale française (AOF). Selon Delaunay, ces deux organisations ne demandent ni ne désirent se constituer en Union africaine. Au contraire du déni exprimé par le dirigeant français, qui rappelle bien les difficultés que connaît la métropole française à se séparer de ses colonies ${ }^{93}$, l'Anglais Arthur Drewry mentionne que les autres associations citées sont certes affiliées à la Football Association, mais qu'elles «sont en état de prendre les mesures et décisions à leur convenance $"{ }^{94}$. Cette position plus ouverte correspond à la politique anglaise en matière de décolonisation, qui tend à progressivement laisser de plus en plus de latitude à ses colonies, voire à les soutenir dans leur développement ${ }^{95}$. Cette stratégie vise en fait à conserver des liens étroits avec l'Empire, alors en dislocation, au sein d'un "nouveau Commonwealth ». Malgré les propos de Drewry, la discussion en reste là et le président Jules Rimet - français rappelons-le - conclut les débats en mentionnant qu'il faut suivre les recommandations du comité exécutif qui sont elles-mêmes basées sur les statuts de la FIFA ${ }^{96}$.

Les requêtes pour la création d'un groupement africain ou du ProcheOrient rappellent celles déjà proposées par les dirigeants sud-américains durant les années 1930. Or, en mai 1949, soit en marge de la Copa America, de nouvelles discussions ont lieu au sein de la Confédération sud-américaine en vue de proposer une décentralisation de la FIFA. Les neuf associations membres de l'organisme y envoient des représentants ${ }^{97}$, ce qui constitue la participation la plus élevée de l'histoire de l'organisation. Cette situation souligne l'importance des sujets que les congressistes vont avoir à traiter. Outre deux sujets d'actualité, à savoir la problématique des éliminatoires de la prochaine Coupe du monde de 1950 ainsi que la

93 Sur le rapport entre la France et ses colonies en matière sportive, voir : Charitas P., «A More Flexible Domination. Franco-African Sport Diplomacy during Decolonization, 1945-1966 ", dans Dichter H., John A. (eds.), Diplomatic games. sport, statecraft, and international relations since 1945, Kentucky, Kentucky University Press, 2014, pp. 183-214.

94 Anonyme, Procès-verbal de l'assemblée générale de la FIFA des 22-23 juin 1950, n.d. FIFA, XXV-XXVII congrès ordinaires (1946-1952, rapport d'activité).

95 Charitas P., «Imperialisms in the Olympics of the colonization in the postcolonization. Africa into the International olympic committee, 1910-1965 ", The International Journal of the History of Sport, vol. 32, $\mathrm{n}^{\circ} 7,2015$, pp. 909-922.

96 "Les associations établies dans une Colonie ou un Dominion peuvent, en accord avec l'association nationale de leur métropole, rester un groupement subordonné à celle-ci ou s'affilier directement à la Fédération ». Anonyme, Statuts de la FIFA [édition de 1948], art. 1 [des statuts]. FIFA, statuts, 1904-1981.

97 Caballero M., Correa Meyer R., Procès-verbal de l'assemblée générale de la Confédération sud-américaine de mars-mai 1949, n.d. FIFA, correspondance avec les confédérations continentales : CONMEBOL (1941-1961), dossier:-1941-31-12,1950. 
situation du football en Colombie ${ }^{98}$, une longue discussion s'engage sur la réforme des statuts de la FIFA. À ce sujet, c'est notamment l'association d'Argentine, soutenue par son homologue uruguayenne, qui mène les débats.

Le but recherché par les dirigeants argentins est de convaincre la FIFA d'attribuer des places supplémentaires au sein de son comité exécutif aux dirigeants sud-américains. Mais des idées plus ambitieuses sont également formulées, en particulier une refonte générale de la structure de la FIFA. Les congressistes souhaitent porter la question devant le prochain congrès de la Fédération internationale et ils chargent une commission de rédiger un document de synthèse devant permettre d'arrêter une position commune à défendre au sein de la FIFA. Si les dirigeants présents au congrès de la Confédération sud-américaine s'attaquent toujours au monopole des Européens, il s'agit aussi pour eux de s'assurer désormais une place privilégiée au sein de l'organisation internationale. En effet, à la vue de l'extension du nombre de membres à la FIFA, la position des associations sud-américaines au sein de la Fédération internationale risque à terme d'être minimisée puisque, comme nous l'a rappelé en entretien Hans Bangerter, secrétaire adjoint de la FIFA dès 1953, "il ne faut pas oublier que la CONMEBOL compte [seulement] dix associations, dont certaines petites $"{ }^{99}$. En conséquence, l'idée de créer des organismes continentaux au sein de la FIFA dont l'une des tâches serait d'élire les dirigeants de son comité exécutif parait être la solution à défendre dans le futur. Les dirigeants sudaméricains sont néanmoins conscients que ces idées impliquent de revisiter l'architecture de la FIFA. De fait, afin d'éviter de possibles tensions au sein même de leur entité continentale, comme ce fut le cas dix ans plus tôt ${ }^{100}$, l'assemblée se donne un temps de réflexion de trente jours durant lequel les associations membres de la Confédération sud-américaine ont la possibilité de faire parvenir leurs commentaires sur le document de synthèse.

Dans les mois qui suivent, les associations sud-américaines transmettent deux propositions au secrétaire général de la FIFA, ce qui montre que si, dans l'esprit, elles s'accordent pour entreprendre des réformes de

98 Le conflit consiste en une scission entre la fédération et la ligue professionnelle (ligue Dimayor). Il impacte tout le football sud-américain car la ligue Dimayor propose de hauts salaires aux joueurs. En raison de certaines décisions prises, comme le fait de ne verser aucune indemnité pour les transferts des joueurs et le refus de libérer les joueurs pour les rencontres des équipes nationales, elle se met en porte-à-faux par rapport aux autorités du football sud-américaine.

99 Entretien avec Hans Bangerter réalisé le $1^{\text {er }}$ octobre 2012 à Bollingen.

100 Supra 1.3.2. 
l'architecture de la Fédération internationale, dans les faits, des divergences existent encore entre elles sur la manière de procéder. La première proposition émane de l'association d'Argentine, également soutenue par le Paraguay et l'Uruguay ${ }^{101}$. Ces fédérations proposent que le comité exécutif respecte davantage les représentations des différents continents au sein de la FIFA. Ainsi, le président de la FIFA serait toujours élu par le congrès, par contre chaque groupe continental aurait droit à un vice-président nommé pour quatre ans, qu'il élirait lui-même. Élément novateur, si le dirigeant choisi devait quitter son poste avant la fin de son mandat, il serait remplacé par un autre dirigeant issu de son groupe. De cette manière, la fonction deviendrait plus importante que le représentant. De plus, il s'agirait que la FIFA reconnaisse formellement, dans ses statuts, l'existence de confédérations continentales, ambition affichée par les dirigeants de la Confédération sud-américaine depuis les années 1920, mais qui a toujours été refusée par l'élite de la FIFA. Dans le projet présenté, une confédération n'existerait que si elle réussissait à réunir plus de "trois quarts des associations affiliées du continent en question " ${ }^{102}$. Cette mesure favoriserait indéniablement les Sud-Américains, car leur continent n'est composé que d'une dizaine de pays, qui sont alors déjà tous - hormis le Venezuela - affiliés à la Confédération. A contrario, ce procédé risquerait d'être très compliqué à réaliser pour les Européens, qui sont désormais divisés par la Guerre froide. La proposition de l'association argentine porte donc clairement une atteinte à leur hégémonie. Mais il s'agit là aussi pour leurs dirigeants de défendre au mieux leurs intérêts au sein de la FIFA, car cette mesure rend difficile la création de groupements continentaux en Asie et éventuellement en Afrique - encore sous le joug colonial -, deux continents immenses et qui risquent de compter à terme de très nombreuses fédérations. Enfin, un dernier souhait est émis, à savoir celui de changer l'article 22 des statuts de la FIFA qui préciserait dès lors que chaque confédération continentale aurait le droit et la compétence de régler les affaires footballistiques concernant les associations nationales de son continent. Certes, le pouvoir suprême de la FIFA n'est pas remis en question par la proposition argentine et, si son congrès le jugeait nécessaire, il aurait le droit de rejeter les décisions prises par les confédérations continentales. Cependant, il s'agit tout de même d'une transformation fondamentale de l'architecture et du mode de gouvernance de la FIFA

101 Rappelons que, pour déposer une modification de statuts durant le congrès, il est nécessaire que la proposition soit émise par trois associations nationales.

102 Anonyme, "Annexe à l'ordre du jour du XXVII congrès à tenir à Rio de Janeiro les 22 et 23 juin 1950 », n.d. FIFA, XXV-XXVII congrès ordinaires (1946-1952, rapport d'activité). 
qui est envisagé. De plus, il est possible d'y voir une manière de limiter l'influence des autres continents permettant ainsi de préserver une place plus importante aux Sud-Américains au sein de la FIFA.

Le second projet émane de l'association chilienne, à laquelle se joignent le Pérou et la Bolivie. Si ces fédérations soutiennent en partie les idées de leurs homologues liées au projet argentin, elles proposent une vision différente du comité exécutif de la Fédération internationale. Celui-ci serait composé d'un président, de cinq vice-présidents et de huit membres élus par le congrès. Toutefois, un "vice-président » serait élu par les quatre associations britanniques, un par l'Organisation centrale du sport en Russie (section football de l'URSS) et un par les associations d'Amérique du Sud. Le congrès ne garderait la main que sur les deux dernières places. De même, sur les huit membres restants à désigner, un serait élu par la Confédération sud-américaine et un autre par la Confédération de l'Amérique centrale et du Nord. Ce mode d'élection n'est pas très novateur et est similaire à celui qui existe déjà au sein de la FIFA. Le seul changement de taille est de conférer une place supplémentaire dans le comité exécutif aux Confédérations d'Amérique centrale et du Nord. En outre, il est aussi question dans ce projet de créer à terme des organismes continentaux prenant le modèle sud-américain comme exemple - avec pour objectif de leur conférer la responsabilité de l'administration du football sur leur continent. Cette proposition vise clairement à la division de la FIFA en différents groupements, qui disposeraient d'une grande autonomie visà-vis de l'organisation centrale. En ce sens, elle est peut-être considérée comme plus ambitieuse que la proposition de l'association d'Argentine, ce qui peut s'expliquer par le fait que des pays comme le Chili et le Pérou remettent régulièrement en cause, depuis l'entre-deux-guerres, la position suprême de la FIFA sur le football mondial.

À l'approche du congrès de Rio, les associations sud-américaines transmettent donc des propositions concrètes en vue de restructurer l'architecture de la FIFA. Premièrement, il s'agit de préserver, et d'étendre quelque peu, leur position au sein de la Fédération internationale. Deuxièmement, l'idée est aussi de continuer à discuter de l'hégémonie des Européens sur la FIFA. Si les souhaits des associations africaines n'ont pas été entendus durant le congrès de 1950, ceux des associations sudaméricaines sont par contre objet d'attention. À cet égard, un journaliste de L'Équipe note, quelques heures avant le congrès, que les propositions faites par les dirigeants sud-américains peuvent « être le prélude à l'organisation 
de confédérations continentales, ainsi que cela existe déjà en Amérique du Sud $"{ }^{103}$.

Le contexte semble donc propice à une discussion sur une réforme de la FIFA, et ce d'autant plus que les associations britanniques - comme nous le verrons plus loin - ont également comme idée de discuter de l'architecture de la FIFA et souhaitent en discuter avec leur homologue argentine ${ }^{104}$. Au passage, signalons qu'à l'occasion de la participation de l'équipe nationale anglaise à la Coupe du monde brésilienne, les deux dirigeants anglais Arthur Drewry et Stanley Rous font, au préalable, un détour par Buenos Aires afin de discuter avec leurs homologues argentins de la possible réforme des statuts de la FIFA. Le congrès de Rio s'annonce donc important car les délégués vont devoir décider s'ils entament des démarches à cet effet et, si c'est le cas, de quelle manière ils doivent s'y prendre.

\subsubsection{S'accorder sur une réorganisation}

À la veille de l'assemblée de 1950, Maurice Pefferkorn, journaliste expérimenté, note que la FIFA " est à la veille de réformes de [sa] structure $»^{105}$. Dans son allocution, le président Rimet confirme cette vision et n'hésite pas à souligner que les délégués présents font face à un tournant dans l'histoire du football. Il ajoute que son développement pose effectivement des problèmes qui doivent être discutés. Mais s'il reconnaît que des changements doivent être envisagés, en particulier dans la structure de la FIFA, il met en garde contre de trop grandes modifications des statuts :

«Est-ce à dire, s'exclame-t-il, que la FIFA doive rester figée dans le conformisme intangible au milieu d'un monde en continuelle évolution ? Assurément non. Mais il importe à sa mission que soit maintenue intégralement la notion de solidarité entre les associations nationales qui a inspiré ses fondateurs, que rien ne soit tenté pour diminuer son autorité faite de l'accord de tous et qui sera utile à la protection de chacun, qu'aucune modification ne soit apportée

103 « 22 et 23 juin : congrès de la FIFA. La FIFA envisagera-t-elle aussi des réformes de structure? ", L'Équipe, 21 juin 1950.

104 Anonyme, Procès-verbal de la commission de selection de l'équipe nationale du 7 novembre 1949, n.d., Football Association, FA minutes 1949-1950. L’Association d'Argentine entretient une relation étroite avec la FA, puisque, dès sa création durant les années 1880, elle demande à être incorporée au sein de l'Association anglaise.

105 "M. Pefferkorn qui succédera au docteur Schricker au poste de secrétaire général de la FIFA ? ", France football, 12 juillet 1950 
à sa structure ou à son fonctionnement qui n'ait été laborieusement étudiée et débattue. L'improvisation est la ressource des étourdis ${ }^{106}$. »

Par ces mots, Jules Rimet invite les délégués à ne pas entreprendre de réformes trop importantes, et lorsque la discussion sur la réorganisation s'apprête à commencer, il se permet de repréciser sa pensée en soulignant que la FIFA est l'unique organisation qui a réussi à grouper toutes les associations du monde. De fait, si une réforme est nécessaire, il faut l'entreprendre avec grande précaution afin de ne pas entraver des statuts qui ont fait leur preuve dans le temps et qui ont permis le succès de l'organisation. Le président indique donc qu'il ne souhaite pas que la structure de la FIFA soit modifiée et profite de son discours pour rappeler la position universaliste d'une organisation mondiale et indivisible qu'il a toujours défendue. En fait, la crainte de Rimet est que la Fédération internationale perde du pouvoir vis-à-vis d'organismes régionaux mais aussi qu'elle perde son rôle de garante "des intérêts supérieurs du football mondial $"{ }^{107}$. Signe que l'aura de Rimet est moindre au sein de la Fédération internationale, les congressistes ne vont néanmoins suivre que modérément les propositions du président. Il faut également signaler que des débats existent au sein du comité exécutif de la FIFA et que la position de Rimet n'est pas partagée par tous ses collègues. Comme signalé ci-dessus, l'élite de la FIFA est en plein renouvellement et certains de ses membres sont enclins à commencer un travail de réorganisation avec la création d'une commission ad hoc ${ }^{108}$.

Lors des discussions, il ressort tout d'abord qu'aucune réforme ne pourra être décidée à Rio de Janeiro car le quorum minimum pour modifier les statuts n'est pas atteint. En effet, pour réaliser ce travail, un congrès doit "réunir la moitié au moins des associations affiliées " ${ }^{109}$. Ce n’est pas le cas dans la ville carioca puisque trente-cinq associations sont présentes sur les près de soixante-dix membres que compte l'organisation. L'assemblée de 1950 n'a donc pas le pouvoir de modifier l'ensemble des statuts de la FIFA. La proposition du comité exécutif de créer une commission de réorganisation a pour avantage, en outre, de permettre des discussions

106 Anonyme, Procès-verbal de l'assemblée générale de la FIFA des 22-23 juin 1950, n.d. FIFA, XXV-XXVII congrès ordinaires (1946-1952, rapport d'activité).

107 Gassmann K., Procès-verbal de l'assemblée générale de la FIFA du 21 juin 1954. FIFA, XXIX-XXX congrès ordinaires (1953-1959, rapport d'activité).

108 Schricker I., Procès-verbal de la réunion du comité exécutif de la FIFA du 21 juin 1950, n.d., FIFA, comité exécutif (procès-verbaux 1947-1950).

109 Anonyme, Statuts de la FIFA [édition de 1948], art. 11 [des statuts]. FIFA, statuts, 1904-1981. 
entre toutes les forces de la Fédération internationale dans un petit comité. Ainsi, ce procédé pourra permettre de limiter les éventuels conflits. Arthur Drewry, président de la Football Association et vice-président de la FIFA, est l'un des principaux promoteurs de cette solution. Durant les débats, il réaffirme l'opportunité de créer une commission d'étude sur la réorganisation de la FIFA et propose à l'assemblée que le futur organe soit composé d'un représentant issu de : l'Europe du Nord, l'Espagne, la Yougoslavie, les associations britanniques, l'Argentine et le Chili, ainsi que d'un délégué du comité exécutif. Les congressistes vont finalement suivre cette proposition, discussion qui révèle qu'une majorité des associations nationales soutiennent une réforme des statuts de la FIFA.

Tableau 11. Composition de la commission de réorganisation de la FIFA

\begin{tabular}{|l|l|l|l|}
\hline Nom & Fonction & Pays représenté & Bloc représenté \\
\hline Seeldrayers R. & Président & Belgique & Aucun \\
\hline Andrejevic M. & Membre & Yougoslavie & Aucun \\
\hline Drewry A. & Membre & Angleterre & Britannique \\
\hline Pujol A. & Membre & Espagne & Latin \\
\hline Russo J./Ramirez A. & Membre & Argentine & Amérique du Sud \\
\hline Schwartz E. & Membre & Danemark & Scandinavie \\
\hline $\begin{array}{l}\text { Valenzuela L./ } \\
\text { Alveal E. }\end{array}$ & Membre & Chili & Amérique du Sud \\
\hline Gassman K. & Secrétaire général* & Suisse & Aucun \\
\hline Barassi O. & Secrétaire* & Italie & Aucun** (Latin) \\
\hline Rous S. & Secrétaire* & Angleterre & $\begin{array}{l}\text { Aucun** } \\
\text { (Britannique) }\end{array}$ \\
\hline
\end{tabular}

Légende : ${ }^{*}$ : sans droit ${ }^{* *}$ : du moins officiellement parlant.

Si la présence de délégués de l'Angleterre, de l'Argentine et du Chili dans la commission de réorganisation s'explique par le fait que ces associations ont proposé des modifications devant l'assemblée générale, comment expliquer par contre celle des autres associations?

Le fait d'attribuer une place à la Yougoslavie dans cette commission présente plusieurs avantages. Tout d'abord, pour les congressistes, il s'agit de répondre aux possibles exigences des associations du bloc soviétique, les associations hongroises et tchèques ayant envoyé des propositions de modification des statuts, tout en limitant leurs capacités d'actions. À ce titre, 
la Yougoslavie constitue une bonne alternative aux pays du bloc soviétique, car si un régime communiste y est en place, elle est toujours en conflit avec l'URSS. En ce sens, elle ne peut pas être considérée comme le véritable porte-parole du bloc soviétique, par contre elle défend des idées relativement proches de celle-ci. De plus, le délégué yougoslave Andrejevic, présent dans les arcanes de la FIFA depuis l'entre-deux-guerres, peut aussi être reconnu comme un interlocuteur privilégié par les pays ayant fait partie de l'Europe centrale footballistique durant l'entre-deux-guerres, comme l'Autriche ou l'Italie. C'est du moins ce que suggère l'Italien Mauro lors d'une séance du comité exécutif du mois de mars 1951, dans laquelle il note que l'absence du délégué yougoslave aux séances de la commission de réorganisation a eu pour conséquence que " les pays de l'Europe centrale n'ont pas pu faire valoir leur point de vue ${ }^{110}$. La Fédération espagnole est également conviée à faire partie de la commission car il s'agit d'un pays pouvant faire le lien entre les pays d'Europe de l'Ouest et les pays latins ${ }^{111}$ non seulement d'Europe mais éventuellement aussi d'Amérique du Sud. La représentation espagnole peut également être interprétée comme un contrepoids à la présence yougoslave, le régime de Franco étant résolument anticommuniste - les deux pays n'entretiennent d'ailleurs pas de relations diplomatiques. Enfin, la place réservée aux pays scandinaves - qui sera occupée par le Danois Ebbe Schwartz - s'explique par le fait que, depuis l'entre-deux-guerres, les pays du Nord ont toujours disposé d'un représentant au comité exécutif de la FIFA. Stanley Rous le rappellera d'ailleurs quelques mois plus tard lorsqu'il s'agira de déterminer les futures places au comité exécutif de l'organisation ${ }^{112}$.

La composition de la commission a donc pour avantage de représenter les différentes forces au sein de la FIFA, ce qui illustre le souci constant de l'élite de la FIFA de réunir tous les acteurs importants sur un sujet dans le but de limiter les possibles conflits à l'intérieur de l'organisation. La représentation est complétée par la présence du secrétaire général et de deux secrétaires adjoints, qui n'auront pas de droit de vote. Ce sont Ottorino Barrasi et Stanley Rous qui vont officier dans ces fonctions. Comme nous l'avons indiqué, ces deux dirigeants souhaitent mener des réformes structurelles au sein de la Fédération internationale. Leur présence dans la commission leur

110 Gassmann K., Procès-verbal de la réunion du comité exécutif de la FIFA des 31 mars et 2 avril 1951, n.d. FIFA, comité exécutif (procès-verbaux 1951-1952).

111 Cavallaro M. E., "The Spanish European integration. The first steps of a long journey (1975-1976) ", dans Affinito M., Migani G., Wenkel C. (dir.), Les deux Europes. Actes du III colloque international RICHIE, Bruxelles, P.I.E. Peter Lang, 2009, pp. 149-153.

112 Anonyme, Procès-verbal de la réunion de la commission d'étude pour la réorganisation de la FIFA des 29, 30-31 mars, n.d. FIFA, réorganisation 1950-1953, 1. Commission d'étude et bureau, dossier : procès-verbayx des séances. 
permet dès lors assurément de jouer un grand rôle dans la réorganisation de la FIFA. En effet, ce sont eux, avec le concours du secrétaire général, qui vont réceptionner, trier, puis classer les propositions de modification des statuts transmises par les associations nationales.

Enfin, en décembre 1950, le comité exécutif de la FIFA discute de la nomination du président de la commission de réorganisation, qui doit être l'un de ses membres. Il est décidé que Rodolphe Seeldrayers dirigera les débats. S'il avait un temps espéré faire partie de la commission, le président Jules Rimet laisse la place à son homologue belge, car il ne peut contrer l'argument linguistique que lui oppose le Finlandais von Frenckell - il ne parle que le français. Ainsi, Rimet n'aura pas l'occasion de défendre sa position universaliste, qu'il avait rappelée dans son allocution du congrès de 1950 et qui entre en contradiction avec une refonte étendue des statuts de la FIFA, et en particulier la division de la Fédération en groupements continentaux. Lors de la séance du comité, il reconnaît que s'il avait été nommé président de la commission, il aurait essayé " d'empêcher que des modifications capitales soient apportées à la constitution de la FIFA, que celle-ci a montré l'excellence de son institution par cinquante années d'existence et de succès et qu'elle est le seul organisme international à avoir groupé dans une entente d'amitié toutes les Nations du monde »"${ }^{113}$. Seeldrayers fait certes, lui aussi, partie de la vieille garde de la FIFA. Cependant, contrairement à Jules Rimet, il se montre plus ouvert sur la question de la réorganisation. Durant les débats sur la nomination du président de la commission, il insiste d'ailleurs sur la question de la neutralité du représentant du comité exécutif, posture également relevée par le délégué finlandais von Frenckell qui note que le président de la commission ne devra pas venir dicter la conduite à adopter en son sein. Le choix de Seeldrayers paraît donc judicieux car, d'une part, le Belge est ouvert à des changements pour la Fédération ; d'autre part, il est aguerri aux travaux de la FIFA en raison de sa présence de longue date au sein de son comité exécutif. De fait, il saura sans doute également les limiter.

La commission ad hoc a devant elle une tâche fastidieuse. Il s'agit de revoir les 24 articles des statuts et les 39 articles du règlement de la FIFA, et ce dans un délai relativement court puisque le but est de présenter un projet devant la prochaine assemblée générale de la FIFA, en 1952. Dans le but de tenir ces délais, un calendrier précis est établi. Les associations nationales auront jusqu'en automne 1950 pour faire parvenir leurs propositions de modification des statuts. Puis il s'agira pour les membres

113 Anonyme, Procès-verbal de la réunion du comité exécutif de la FIFA du 2 décembre 1950 , n.d. FIFA, comité exécutif (procès-verbaux 1947-1950). 
de la commission de se réunir afin de discuter des propositions reçues et, enfin, d'établir un projet de nouveaux statuts qui sera soumis pour approbation au congrès de 1952 prévu à Helsinki.

Outre la charge de travail que cela représente, les dirigeants vont devoir s'accorder sur les réformes à entreprendre. Or une conciliation s'avère malaisée puisque différents positionnements sur la réorganisation existent au sein de la commission, et plus globalement dans la FIFA. C'est notamment le cas des associations du bloc soviétique qui, dans les mois qui suivent, vont essayer de faire entendre leur voix.

\subsubsection{Les revendications du bloc soviétique}

En ce début des années 1950, les associations du bloc de l'Est ont des difficultés à participer aux travaux de la FIFA, position illustrée par le fait que le vice-président soviétique n'est quasiment jamais présent aux réunions du comité exécutif. En effet, depuis son entrée officielle en 1947, Granatkine ne participe qu'aux séances des 15 et 16 avril 1948, où le président de la FIFA lui adresse une cordiale bienvenue ${ }^{114}$. Outre la situation politique qui pose des problèmes pour l'obtention de visas, dès 1949, il ne peut se rendre aux séances, pour des raisons de santé ${ }^{115}$. À une occasion, les Soviétiques tentent de le remplacer par le président de la Fédération soviétique de football, Konstantin Andrianov ${ }^{116}$. Cette solution est toutefois considérée comme non avenue par les membres du comité exécutif. Peutêtre que les dirigeants se méfient d'Andrianov, car ce n'est pas lui qui avait été préalablement présenté comme le président de la section soviétique à Schricker, mais un dénommé Kozlov ${ }^{117}$. Cependant, c'est surtout la manière de procéder qui n'est pas compatible avec la vision défendue par l'élite de la FIFA en matière de conditions de participation à une réunion du comité exécutif. Pour des dirigeants comme Lotsy, Mauro, Rimet, Rous, Schricker ou encore Seeldrayers, la seule personne pouvant y siéger doit être celle

114 Schricker I., Procès-verbal de la réunion du comité exécutif de la FIFA des 15-16 avril 1948, n.d. FIFA, comité exécutif (procès-verbaux 1947-1950).

115 Schricker I., Procès-verbal de la réunion du comité exécutif de la FIFA du 16 mai 1949, n.d. FIFA, comité exécutif (procès-verbaux 1947-1950).

116 Andrianov est un dirigeant très important du sport soviétique des années 1940 aux années 1980. Dufraisse S., "Konstantin Andrianov », papier présenté lors du congrès annuel «The President, the secretary and the minister. Biographies from international sports leaders ", Musée olympique de Barcelone, 14-15 juillet 2016.

117 Lettre de I Schricker au comité exécutif de la FIFA, 13 décembre 1946. FIFA, comité exécutif (circulaire aux membres 1946-1957.7). 
qui a été élue lors de l'assemblée générale. En 1950, Granatkine est finalement remplacé par Sergei Savin ${ }^{118}$, qui connaît lui aussi de nombreux problèmes pour se déplacer dans les pays où se tiennent les réunions $\mathrm{du}$ comité exécutif, comme c'est le cas en mars 1951 à Madrid ou en mars 1953 à Copenhague. Cette situation limite fortement l'établissement de relations de confiance entre le dirigeant soviétique et ses collègues du comité exécutif. Plus largement, elle crée un décalage entre les associations nationales de l'Europe de l'Ouest et de l'Est, ces dernières ne se sentant pas assez représentées au sein de l'élite de la FIFA

De plus, certains sujets mettent en opposition des associations de l'Est et de l'Ouest, tel celui des footballeurs ayant fui le bloc soviétique. Dès le début des années 1950, plusieurs athlètes des pays du bloc soviétique profitent de voyages à l'étranger pour quitter leur délégation et demander l'asile politique dans le pays dans lequel ils séjournent ${ }^{19}$. En football, c'est notamment le cas de plusieurs joueurs hongrois qui trouvent refuge en Espagne, pays qui se veut le chantre de l'anticommunisme. Là-bas, ils y forment une équipe nommée Hungaria qui dispute plusieurs rencontres, et ce malgré le fait que les joueurs la composant sont sous le coup d'une suspension par leur fédération d'origine. Le cas le plus connu de ces joueurs qui s'exilent, et sans doute aussi le plus discuté, est celui de László Kubala. Considéré comme l'un des meilleurs jeunes talents de l'équipe nationale hongroise, ce dernier va être l'objet d'un bras de fer entre la Fédération hongroise et l'association espagnole, Alors que le joueur a été suspendu par la FIFA durant une année pour avoir quitté son pays, la Fédération espagnole fait pression sur la Fédération internationale pour qu'elle accepte de lever sa suspension, en expliquant notamment que Kubala a quitté son pays pour éviter " une menace imminente de mort " ${ }^{120}$. Mais la Fédération hongroise ne l'entend pas de cette oreille et souhaite même suspendre Kubala de toute activité footballistique. Le cas de Kubala va mettre plusieurs années à se

118 Il ne semble pas que ce remplacement constitue une éviction mais plutôt une situation de circonstance - pour cause de maladie principalement - car Granatkine reste le président de la section de football de l'URSS. Il rependra son poste à la FIFA dès 1954.

119 Rider T., "Eastern Europe's unwanted: exiles athletes and the Olympic games, 1948-1964 ", Journal of Sport History, vol. 40, n 3, 2013, p. 445.

120 Propos de Manuel Valdes dans une lettre adressée à la FIFA le 24 septembre 1951 et qui est citée par Paul Dietschy. Dietschy P., Histoire du football, op. cit., p. 366. Kubala sert la propagande franquiste dans la lutte que le régime mène contre le communisme. En 1954, le Hongrois joue même son propre rôle au cinéma dans un film intitulé Los Ases Buscan La Paz (Les As cherchent la Paix). Pour un propos autour de ce film, voir : Simón J.A., " Fútbol y cine en el franquismo: la utilización política del héroe deportivo en la España de Franco ", Historia y compunicación social, vol 17, 2012 „pp 69-89-84. 
régler et va nécessiter plusieurs tentatives de médiation de la part du comité exécutif de la FIFA (le joueur reviendra finalement sur le terrain, avec succès, sous les couleurs du FC Barcelone dans la seconde partie de la décennie).

Nous avons vu qu'un bloc soviétique se dessine au sein de la FIFA dès les années 1947-1948 ${ }^{121}$. Comme dans d'autres organisations internationales, les tensions Est-Ouest qui s'opèrent sur la scène internationale au début des années 1950 marquent un renforcement des positionnements respectifs ${ }^{122}$. Cette posture est particulièrement visible lors du travail de réorganisation de la Fédération internationale. En effet, tout au long des discussions, les associations du bloc soviétique vont tenir une position ferme sur la manière de mener les réformes, posture qui les place en opposition avec la majorité des associations de l'Europe de l'Ouest.

Lors du congrès de 1950, la Fédération hongroise, soutenue par les associations de la Tchécoslovaquie et de la Pologne, envoie plusieurs propositions en vue de modifier les statuts de la FIFA. Tout d'abord, ces associations souhaitent davantage de représentativité au sein du comité exécutif et proposent « d'élire une personne des trois Fédérations de Hongrie, de la Tchécoslovaquie ou de la Pologne qui ne sont pas représentées dans la direction actuelle de la FIFA ${ }^{123}$. De même, elles considèrent que l'élite de la FIFA, hormis le président de l'organisation, ne devrait plus être composée de dirigeants spécifiques, mais de représentants d'une association nationale. Ainsi, c'est la fédération nationale qui devrait, à l'avenir, désigner le dirigeant qui la représenterait et qui pourrait, en tout temps, avoir " le droit de remplacer les titulaires durant leur mandat. Nous retrouvons ici l'idée défendue par les pays communistes au sein de la FIFA depuis quelques années selon laquelle la fonction dépasse l'individu. Ces propositions ne sont pas discutées par l'assemblée puisqu'aucun pays du bloc soviétique n’a fait le déplacement à Rio. En date du 5 décembre 1950, la Fédération hongroise s'offusque auprès du secrétariat de la FIFA de n'avoir pas été conviée à participer aux travaux de la commission de réorganisation. De

121 Ce renforcement au sein des pays du bloc soviétique se matérialise notamment dans les nombreux échanges sportifs qui sont développés à cette période. Pour un aperçu de cette situation, voir : Dufraisse S., "The emergence of Europe-wide collaboration and competition: Soviet sports interactions in Europe. 1945- mid-1960s ", dans Vonnard P., Sbetti N., Quin G. (eds.), Beyond Boycotts, op. cit., pp. 71-81.

122 C'est notamment le cas au CIO : Charitas P., « La Commission d'Aide Internationale Olympique (CAIO) : un instrument de propagande soviétique? (1951-1962) », Sport History Review, vol. 40, 2009, pp. 143-166.

123 Anonyme, "Annexe à l'ordre du jour du XXVII congrès à tenir à Rio de Janeiro les 22 et 23 juin 1950 », n.d. FIFA, classeur : XXV-XXVII congrès ordinaires (1946-1952, rapport d'activité). 
plus, le courrier mentionne que les représentants élus dans la commission ne sont pas légitimes, car leurs associations sont représentées dans le comité exécutif de la FIFA. La rancœur est forte puisque la lettre mentionne encore :

"Nous trouvons [que le] traitement que nous devons subir dans ces derniers temps est d'autant plus inexplicable, parce que notre fédération qui est un membre notable de longue date de votre Association ne saurait souffrir encore davantage des pareilles relégations continuelles et tendancieuses au second plan et elle va chercher tous les moyens en son pouvoir pour faire changer l'attitude partiale de la direction actuelle de la FIFA que nous estimons nuisible à la cause commune du football universel ${ }^{124}$.»

En outre, l'association hongroise précise aussi qu'elle est fermement opposée à l'idée de régionaliser la FIFA par la création d'organismes continentaux, ce qui aurait pour conséquence de diminuer le pouvoir de l'organisation en faveur des différentes confédérations. Cette posture doit se comprendre car pour peser sur la gouvernance de la FIFA, il est plus aisé pour le bloc soviétique de créer des alliances avec des associations nationales, une tactique déjà utilisée au sein du $\mathrm{CIO}^{125}$. Il faut ajouter qu'en raison du contexte politique international, la création de groupements continentaux obligerait sans doute les pays du bloc soviétique à créer leur propre groupement. À cette même période, c'est d'ailleurs ce qui se produit dans cerains domaines, tel celui des communications avec la création de l'Union européenne de radio (UER) par les pays du bloc de l'Ouest et l'Organisation internationale de radio (OIR) par les pays du bloc de l'Est ${ }^{126}$. Une telle décision ne serait pas sans conséquence sur la place du bloc soviétique au sein de la FIFA. En effet, en raison du petit nombre d'associations qui en font partie (une dizaine), celui-ci ne disposerait probablement pas de beaucoup de sièges au sein du comité exécutif et ne pourrait donc pas véritablement peser sur la gouvernance de la FIFA, voire risquerait d'être isolé.

124 Lettre du secrétaire de la Fédération hongroise au secrétaire général de la FIFA, 5 décembre 1950. FIFA, Réorganisation 50-53, 3. Propositions et projets, dossier : correspondance générale.

125 Parks J., "Welcoming the "Third World”. Soviet sport diplomacy, developing nations and the Olympic games ", dans Dichter H., John A., Diplomatic games, op. cit., pp. 85-114.

126 Heinrich Franke C., "Curtains in the European ether: broadcasting and the Cold War ", dans Badenoch A., Fickers A., Heinrich-Franke C. (eds.), Airy Curtains in the European Ether: broadcasting and the Cold War, Baden-Baden, Nomos, 2013, pp. 183-219. 
Dans sa stratégie visant à ne pas attiser les tensions au sein de la FIFA, le comité exécutif ne répond pas aux reproches de la Fédération hongroise et préfère laisser le temps agir. Cependant, la Guerre froide va directement impacter le travail de la commission de réorganisation. Lors de la première réunion qui se déroule en mars 1951 à Madrid, et alors que le Yougoslave Andrejevic est absent ${ }^{127}$ en raison du refus de son gouvernement de lui délivrer l'autorisation de se rendre dans la capitale ibérique, l'Espagnol Augustin Pujol remet en question le poste de vice-président réservé à l'URSS. Selon lui, le peu de participation de l'Union soviétique aux travaux de la FIFA ne devrait pas permettre à cette association de disposer d'un poste privilégié au comité exécutif. Certes, à cette période, l'URSS reste effectivement en retrait en matière de gestion de l'organisation et le football soviétique n'est pas très actif au niveau international. Toutefois, plus que l'argument footballistique, le propos de Pujol ne peut être dissocié d'ambitions plus politiques et rappelle, une fois encore, les tensions qui existent entre l'Espagne franquiste et le bloc soviétique. Aucune décision n'est cependant prise sur le sujet, les autres délégués présents décidant de finalement botter en touche la proposition espagnole. Lors de la deuxième réunion de la commission de réorganisation qui se déroule en septembre 1951 à Londres, Pujol remet le sujet sur la table ${ }^{128}$. Malgré une intervention du président de la commission, Rodolphe Seeldrayers, qui rappelle que la discussion a déjà été préalablement traitée à Madrid, un long échanges s'engage sur la question. Afin de régler le cas, le président est même obligé de déclarer un vote. Par trois voix contre deux et une abstention, la proposition de la Fédération espagnole est refusée de justesse, signe que, malgré la politique de neutralité menée par le comité exécutif de la FIFA depuis l'entre-deux-guerres, la politique n'est jamais très loin des discussions.

Ces échanges au sein de la commission de réorganisation sont exploités, quelques heures plus tard, par le vice-président soviétique, Serguei Savin, lors d'une réunion du comité exécutif. Présent pour la première dois depuis sa nomination en 1950, il réagit aux propos qui ont été tenus contre son pays par le représentant espagnol. Il les critique vivement et estime que la proposition d'annuler le poste de vice-président dédié à

127 Même s'il ne représente pas les intérêts du bloc soviétique en raison des tensions toujours fortes entre Belgrade et Moscou, Andrejevic défend tout de même des positions relativement proches de celle des pays du bloc de l'Est.

128 Anonyme, Procès-verbal de la réunion de la commission d'étude pour la réorganisation de la FIFA des 4-5 octobre 1951, n.d. FIFA, réorganisation 1950-1953, 1. Commission d'étude et bureau, dossier : procès-verbayx des séances. 
l'Union soviétique ne rime pas avec les principes fédérateurs portés par la FIFA. De plus, il rappelle que s'il n'était pas présent au congrès de Rio de 1950 et lors de la dernière séance du comité exécutif qui a été organisée à Madrid, c'est en raison de l'absence de relations diplomatiques entre l'URSS et les pays d'accueil de ces assemblées (respectivement, le Brésil et l'Espagne). Au passage, il demande de tenir compte de cette situation à l'avenir afin de préserver "l'unité de la FIFA " ${ }^{129}$. Ce message s'inscrit dans la doctrine du régime soviétique sur la scène internationale, qui prône une rhétorique de paix, message devant permettre de répondre avantageusement à ce qui est considéré comme une agressivité impérialiste du bloc capitaliste ${ }^{130}$. Seeldrayers tente alors une entreprise diplomatique et relativise le propos qu’a tenu le délégué espagnol lors des séances de la commission de réorganisation en indiquant que la discussion portait avant tout sur les groupements d'associations nationales qui pouvaient prétendre à un siège de vice-président. Il ajoute qu'il n'y avait aucune intention contre l'URSS de la part d'Augustin Pujol. Les autres dirigeants présents interviennent également dans ce sens, tentant de désamorcer une possible situation de crise. Sentant, peut-être, que les discussions risquent de se retourner contre son association nationale, le délégué espagnol Armando Munoz Calero - farouchement anticommuniste puisqu'il est membre de la Phalange, le parti de Franco, et ancien volontaire de la division bleue lors de la Deuxième Guerre mondiale ${ }^{131}$ - essaie finalement de dédramatiser l'affaire et souhaite la bienvenue à Serguei Savin. En outre, il insiste sur le fait qu'il ne faut parler que de sport au sein de la Fédération internationale et que les propositions de Pujol devaient être considérées uniquement sous un angle sportif.

Ce cas rappelle, une fois encore, combien l'élite de la FIFA prône une politique visant à neutraliser les conflits au sein de la Fédération et surtout tente d'éluder les questions d'ordre politique qui pourraient créer de fortes tensions entre les associations nationales. Le dirigeant espagnol est donc obligé de se contraindre à cette manière de procéder et de revenir

129 Gassmann K., Procès-verbal du comité exécutif de la FIFA des 6-7 octobre 1951, n.d. FIFA, comité exécutif (procès-verbaux 1951-1952).

130 La rhétorique de la paix est une constante tout au long du récit de la thèse de Sylvain Dufraisse. Ce dernier note que le nom même des compétitions organisées entre les pays du bloc de l'Est doit servir cette politique (par exemple, il existe une " course cycliste de la paix "). Dufraisse S., Les " Héros du sport ", op. cit., p. 227.

131 Division de volontaires espagnoles qui a combattu sur le front de l'Est en compagnie des Allemands. Viuda-Serrano A., "A diplomatic mission: Spain and the 1948 London Olympics ", The International Journal of the History of Sport, vol. 27, $\mathrm{n}^{\circ}$ 6, 2010, p. 1085 . 
sur la posture défendue par son collègue Pujol. Finalement, la place de l'URSS n'est pas remise en cause dans le nouveau projet de statut préparé par la commission de réorganisation au printemps 1952. Cependant, les tensions Est-Ouest ne sont pas terminées et vont se prolonger dans les mois qui suivent.

Tout d'abord, le bloc soviétique se montre très critique face au projet qui est soumis en vue d'une discussion lors du congrès de la FIFA de 1952 à Helsinki. Dans un courrier daté du 31 mai 1952, Serguei Savin fustige le contenu du projet de réforme et note que celui-ci doit être nettement revu car " il est rédigé de telle façon que les droits des sportifs des pays coloniaux et dépendants sont blessés [puisqu’une situation a été créée qui privilégie les] sportifs de la Grande-Bretagne, des USA et de l'Amérique du Sud envers les autres pays " ${ }^{132}$. Savin souligne le manque de place laissé aux associations asiatiques et africaines dans le comité exécutif. Cette position confirme la volonté de l'URSS de s'attirer la sympathie des pays extraeuropéens afin de créer une alliance avec eux, tactique devant in fine de prendre le contrôle de l'organisation. En guise de conclusion, le dirigeant soviétique souhaite que le projet soit réexaminé et que la composition de la commission soit revue afin d'y inclure des représentants de pays coloniaux, mais aussi de la Chine populaire ou des pays de l'Est. Finalement, en raison d'autres critiques adressées par différentes associations (scandinaves ${ }^{133}$ et sud-américaines ${ }^{134}$ ), les dirigeants du comité exécutif décident de repousser les discussions sur la réforme de la FIFA à une assemblée spécialement réunie pour l'occasion, ce qui est accepté par le congrès de 1952.

Cette décision n'empêche néanmoins pas de nouvelles discussions sur le sujet. Durant celles-ci, Serguei Savin soumet aux délégués la proposition que la commission de réorganisation soit élargie et comprenne des représentants des pays africains et asiatiques mais aussi ceux " des associations de l'Est et de la Chine $"{ }^{135}$. Si cette demande paraît excessive aux dirigeants du comité exécutif, un compromis se dessine par contre avec l'incorporation du vice-président soviétique dans la commission de réorganisation. Cette proposition est en particulier soutenue par le

132 Anonyme, Traduction d'une lettre de S. Savin à K. Gassmann, 31 mai 1952. FIFA, Réorganisation 1950-1953, 3. Réorganisation 50-52, dossier : réorganisation et contreprojet.

133 Lettre de E. Schwartz à K. Gassmann, 29 mai 1952. FIFA, Réorganisation 1950-1953, 3. Proposition et projets, dossier : réorganisation contre-proposition, etc.

134 Voir infra 3.3.1.

135 Gassmann K., Procès-verbal de la réunion du comité exécutif de la FIFA des 20, 21, 22

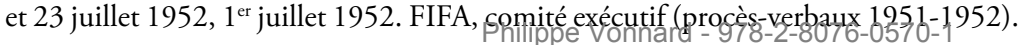


président Jules Rimet et elle est acceptée par les congressistes qui élisent Savin à une bonne majorité (22 voix contre 11$)$. La décision prise par les congressistes est importante, car elle permet au bloc soviétique de faire davantage entendre sa voix au sein de la commission de réorganisation. Lors de ce même congrès, un autre fait marquant va dans le sens d'une neutralisation des problèmes politiques issus de la Guerre froide : l'adhésion de la République démocratique allemande (RDA) à la FIFA. L'acceptation de la RDA, dont l'État a été créé quelques mois plus tôt, par une très grande majorité - seule l'Allemagne de l'Ouest s'abstient de voter - est à souligner car l'adhésion de ce pays est refusée dans beaucoup d'autres organisations sportives, comme la Fédération internationale de ski (FIS) ${ }^{136}$ ou la Fédération internationale de gymnastique $(\mathrm{FIG})^{137}$. De même, le CIO n'accepte pas la partition des deux Allemagnes et oblige la formation d'une délégation commune, ce qui est effectif à partir de $1956^{138}$. La FIFA prend ici une décision forte, car de nombreux pays ne reconnaissent pas l'existence de la RDA sur la scène diplomatique. Ladhésion de l'Allemagne de l'Est se fait dans un lieu symbolique puisqu'elle est acceptée lors du congrès qui se déroule à Helsinki, ville issue d'un pays à la croisée de l'Est et de l'Ouest, et qui se trouve alors être hôte de Jeux olympiques dont la principale attraction consiste en la première participation d'une importante délégation soviétique ${ }^{139}$.

Malgré ces décisions, les mois qui suivent sont encore marqués par le sceau du conflit Est-Ouest. Tout d'abord, la présence de Savin dans la commission de réorganisation est remise en question, son élection lors du congrès d'Helsinki ne s'étant pas déroulée selon l'ordre préalablement établi par le président, ce qui l'annule de facto. En bon allié de la cause anticommuniste, c'est l'Espagnol Munoz Calero qui relève le vice de forme

136 Dichter H., "We have allowed our decisions to be determined by political considerations": the Cold War in the International Ski Federation ", Sport in History, vol. 37, n 3, pp. 290-308.

137 Cervin G. et al., "Gymnastics' centre of gravity. The Fédération internationale de Gymnastique, its governance and the Cold War 1956-1976 ", Sport in History, vol. 37, $\mathrm{n}^{\circ} 3$, pp. 309-331.

138 La première participation de la RDA et de la RFA aux Jeux olympiques date de 1968. Sur l'équipe unifiée qui a concouru de 1956 à 1964, voir : Lanz J., Zwischen Politik, Protokoll und Pragmatismus. Die deutsche Olympiageschichte von 1952 bis 1972, Berlin, wvb Wiss. Verlag, 2011.

139 Dufraisse S., "Les Soviétiques, finalistes à Helsinki (1952). Anatomie et résonance d'une performance ", dans Archambault F., Artiaga L., Bosc G. (dir.), Le continent basket, op. cit., pp. 141-158. 
au secrétaire général de la FIFA $^{140}$. Après plusieurs échanges avec le comité d'urgence, ce dernier est obligé de reconnaître qu'il y a effectivement eu un problème. Finalement, Serge Savin n'est pas autorisé à participer aux séances ${ }^{141}$. Par contre, en raison des risques de conflit qu'engendre cette décision, le vice-président soviétique est invité par les dirigeants du comité exécutif à participer aux discussions informelles qui entoureront les séances. Le délégué soviétique n'accepte toutefois pas ce compromis et n'assiste dès lors pas aux discussions, situation qui renforce la position à la marge du bloc soviétique dans le cadre de la réorganisation de la FIFA. La non-participation de Savin paraît toutefois arranger les membres de la commission de réorganisation car le délégué soviétique se serait sans doute montré critique sur plusieurs points de la réforme et aurait probablement contesté l'idée de régionaliser la FIFA ${ }^{142}$.

Alors qu'un nouveau projet est finalement proposé pour être discuté lors d'un congrès extraordinaire à Paris, le bloc soviétique est toujours aussi hostile à tout changement de structure de la FIFA. Durant l'assemblée qui se déroule en novembre 1953 dans la capitale française, les délégués des associations du bloc soviétique reviennent à la charge contre le projet de réorganisation. Tout d'abord, le délégué yougoslave Pleic se permet de rappeler la nécessité de respecter l'égalité des droits entre les membres au sein de la FIFA. Il se réfère notamment à une étude effectuée par un professeur de l'école de droit de Limoges, le docteur Paroutaud, parue quelques mois plus tôt dans le Bulletin $M G O-O N G, \mathrm{n}^{\text {os }} 8$ et 9 (numéros d'août et septembre) et intitulée "Sport et droit international ". Ce juriste estime que la structure de la FIFA est " antidémocratique " car ses associations membres n'ont pas toutes les mêmes droits, citant par exemple le cas des fédérations de l'Amérique du Nord et de l'Asie qui ne disposent

140 Lettre de A. Munoz Calero à K. Gassmann, 3 septembre 1952. FIFA, réorganisation 1950-1953, 2. Commission d'études et bureau, dossier : séance Paris.

141 Gassmann K., Procès-verbal de la réunion du comité exécutif de la FIFA des 8-9 septembre, 17 septembre 1952. FIFA, comité exécutif (procès-verbaux 1951-1952).

142 Dans une lettre écrite en mars 1953, Seeldrayers se fend d'une confidence personnelle au secrétaire général Kurt Gassmann à propos du délégué yougoslave Andrejevic qui, certes, tient des positions moins tranchées que son homologue soviétique, mais s'en approche par son idée de défendre une plus grande égalité entre les membres de la FIFA : "S’il continue [à procéder de la sorte], il se fera appeler Gromyko tant il s'entête à dire : "niet". " Lettre de R.W. Seeldrayers à K. Gassmann, 10 mars 1953. FIFA, Réorganisation 1950-1953, 2. Commission d'étude et bureau, dossier : séance du 6/7.3.1953 à Paris. Seeldrayers fait ici référence à Andrei Gromyko, diplomate russe, ambassadeur aux États-Unis de 1943 à 1946, puis vice-ministre des Affaires étrangères. Il fut baptisé "Monsieur Niet " en raison de sa capacité à tenir tête aux Occidentaux et à défendre la politique spviétique vonnard - 978-2-8076-0570-1 
pas de représentants au sein du comité exécutif. Reprenant ce constat, le dirigeant yougoslave propose d'une part d'abolir tous les privilèges au sein de la Fédération internationale, notamment celui de disposer d'une place réservée au sein du comité exécutif; d'autre part d'établir une nomination directe de tous les membres de ce comité par le congrès. Dans le même temps, il propose la création d'organes régionaux qui œuvreraient au développement du football dans leurs continents respectifs, mais en aucun cas ne les représenteraient dans le comité exécutif de la FIFA.

À la suite de Pleic, c'est le délégué soviétique Serge Savin qui prend la parole. Il se veut plus véhément que son collègue yougoslave. Pour lui, il est impératif que toutes les associations disposent des mêmes droits, ce que la proposition yougoslave ne garantit pas ${ }^{143}$. Au contraire, il affirme que ce sont les pouvoirs de l'assemblée générale qui doivent être renforcés. Le représentant tchécoslovaque, Joseph Vogl, insiste lui aussi sur l'aspect démocratique de la question. Il demande en particulier la nomination directe par le congrès du président, des vice-présidents et des membres du comité exécutif. Cependant, contrairement à Savin, il est prêt à faire quelques concessions puisqu'il accepte que les associations britanniques, sud-américaines et soviétiques puissent élire un viceprésident. Pourquoi cette prise de parole differe-t-elle de celle de son homologue soviétique ? Après le propos très ferme de Savin, comment celui un peu plus ouvert de Vogl peut-il être interprété ? S'agit-il d'une tactique visant à permettre des alliances avec d'autres associations ou y a-t-il quelques divergences au sein du bloc soviétique lui-même ? Cette dernière proposition va dans le sens de l'analyse de Xavier Breuil, qui souligne qu'en football, les pays satellites ne sont pas toujours en accord avec le "grand frère " soviétique ${ }^{144}$.

$\mathrm{Si}$, à la vue de la documentation récoltée, il est difficile de répondre à ces questions, en tous les cas constatons que les prises de position du bloc soviétique ne sont pas très efficaces. En effet, dans la soirée qui suit le premier jour du congrès, les associations de l'Europe de l'Ouest et les

143 Les deux pays sont toujours divisés sur la scène internationale Sur les relations entre la Yougoslavie et l'Union soviétique à cette période, voir : Rajak S., Yugoslavia and the Soviet Union in the early Cold War: reconciliation, comradeship, confrontation, 1953-1957, London, Routledge, 2011.

144 Breuil X., "Football and the construction of a European area in the East: Ruptures and Continuities after 1945 ", dans Vonnard P., Quin G., Bancel N., Building Europe with the ball, op. cit., pp. 121-136. Rappelons qu'en 1953, le bloc soviétique connaît un moment de trouble avec la révolte des ouvriers de Berlin-Est. De plus, les dirigeants à la tête de l'Union soviétique sont alors eux-mêmes en pleine "guerre politique ", puisqu'il s'agit d'assurer la succession de Staline, décédé en mars de la mêmeannée. 
Sud-Américains ont tenu une réunion qui a permis de créer une entente entre leurs associations nationales sur la question de la réorganisation. Ce consensus a été long à dessiner et, pour le comprendre, il s'agit de revenir sur les discussions qui ont lieu entre 1950 et 1953 entre les dirigeants de la Confédération sud-américaine et la nouvelle génération de dirigeants qui émergent dans plusieurs associations nationales européennes.

\subsection{Suivre le modèle sud-américain}

Dès la fin des années 1940, le contexte de la Guerre froide fonde certes une opposition entre les pays d'Europe de l'Est et ceux d'Europe de l'Ouest au sein de la FIFA. Toutefois, depuis l'entre-deux-guerres, ce sont surtout les divergences qui existent entre les associations européennes et leurs homologues sud-américaines qui sont l'objet de vifs débats au sein de la FIFA. La période qui va de 1950 à 1953 va encore les amplifier, en particulier parce que les associations sud-américaines militent ouvertement en vue d'une décentralisation de la FIFA. C'est la position que vont défendre leurs deux représentants qui siègent dans la commission de réorganisation.

\subsubsection{Un match Europe-Amérique du Sud}

Lors de la première séance qui se déroule à Madrid en mars 1951, le Chilien Luis Valenzuela mentionne, dès le début des discussions, qu'il y a eu une confusion dans les documents présentés aux délégués car une proposition de la Confédération sud-américaine est mentionnée comme étant celle de l'Uruguay ${ }^{145}$. Par ce commentaire, il souligne que les deux délégués représentent la voix de l'Amérique latine dans son entier au sein de la commission et espèrent que celle-ci sera entendue par leurs collègues. À ce titre, les deux Sud-Américains proposent rapidement de fixer statutairement les sièges qu'occupent déjà l'Amérique du Nord et l'Amérique du Sud au sein du comité exécutif. L’Argentin Juan Russo justifie cette proposition en relevant qu'il est nécessaire "d'assurer la participation de toutes les associations, en proportion de leur importance

145 Lettre de R.W. Seeldrayers à K. Gassmann, 3 mars 1951. FIFA, réorganisation 1950-1953, 1. Commission d'étude et bureau, dossier : réorganisation séance $29 / 30.03$. 
et de leur activité, au pouvoir directeur de la FIFA ${ }^{146}$. Il montre ainsi que les associations sud-américaines sont en faveur d'une ouverture du comité exécutif de la FIFA aux associations des pays extra-européens, mais pas forcément à n'importe quelles conditions. En effet, l'idée de conférer des places en fonction de la force des associations nationales favorise les SudAméricains au détriment des autres associations extra-européennes car ce procédé ne correspond pas au système selon lequel un pays est égal à une voix en vigueur lors des congrès de la FIFA.

Malgré un fort activisme, la position des deux Sud-Américains reste cependant minoritaire car ils font face à cinq dirigeants européens qui sont globalement opposés à leur proposition. En effet, les délégués qui proviennent du Vieux Continent ne souhaitent pas pour l'heure décentraliser la FIFA. Ils préfèrent défendre le statu quo ou alors, comme le Yougoslave Andrejevic, prônent une vision qui se rapproche sous certaines formes du bloc soviétique ${ }^{147}$. Deux raisons principales expliquent cette volonté de ne pas trop réformer la structure de la FIFA, qui sera à nouveau exprimée à plusieurs reprises tout au long de la réforme. La première est que les associations européennes ne souhaitent pas conférer des places au sein du comité exécutif aux associations d'Afrique, d'Amérique centrale et d'Asie, estimant que le football n'a pas encore atteint assez de maturité dans ces régions. Dès lors, ils pensent qu'il faut tout d'abord que les associations nationales de ces continents se développent avant que leurs dirigeants puissent intégrer le comité exécutif de la FIFA. La deuxième doit être reliée au contexte de la Guerre froide. En effet, il paraît difficilement envisageable de créer une entité européenne qui réunirait en son sein les pays des deux blocs.

Ces deux aspects se retrouvent dans la proposition de réforme des statuts présentée au congrès de 1950 par les associations britanniques, qui propose de diviser la FIFA en huit groupes géographiques déléguant chacun un représentant au comité exécutif ${ }^{148}$. Relevons que si les petites nations sont effectivement davantage représentées dans le projet britannique, il n'est cependant pas question d'égalité entre tous les membres. En effet, l'Europe se taille toujours la part du lion puisque sa trentaine de fédérations est

146 Anonyme, Procès-verbal de la réunion de la commission d'étude pour la réorganisation de la FIFA des 29, 30 et 31 mars 1951, n.d. FIFA, réorganisation 1950-1953, 1. Commission d'étude et bureau, dossier : procès-verbaux des séances.

147 À savoir, renforcer le pouvoir des associations nationales au sein de la FIFA.

148 Anonyme, "Annexe à l'ordre du jour du XXVII congrès à tenir à Rio de Janeiro les 22 et 23 juin 1950 », n.d. FIFA, XXV-XXVII congrès ordinaires (1946-1952, rapport d'activité). 
répartie en cinq groupes. Par ailleurs, trois autres groupes réunissent celles d'Amérique centrale, du Nord et du Sud. Par contre, les autres continents ne sont que peu pris en compte puisque le dernier groupement convoque les dix-sept associations restantes, soit celles provenant d'Afrique et $\mathrm{d}^{\prime} \mathrm{Asie}^{149}$. Outre cet européocentrisme, la proposition anglaise reste globalement conservatrice car les groupements continentaux préconisés n'auront pas vraiment de pouvoir, hormis celui d'élire leur représentant à la FIFA. Enfin, le projet tient compte du contexte politique international, l'Europe étant divisée en cinq entités géographiques :

- Europe orientale (Albanie, Bulgarie, Hongrie, Pologne, Roumanie, Tchécoslovaquie et Russie) ;

- Europe méridionale (Autriche, Chypre, Espagne, Grèce, Italie, Portugal et Yougoslavie) ;

- Europe septentrionale (Danemark, Finlande, Islande, Norvège et Suède) ;

- Europe de l'Ouest (Belgique, France, Irlande, Luxembourg, PaysBas, Suisse, voire l'Allemagne pour autant que sa réaffiliation soit confirmée par le congrès) ;

- un dernier groupe composé des quatre associations britanniques.

Drewry et Rous font partie de la commission de réorganisation et, en raison de leur écoute auprès des autres dirigeants des associations nationales d'Europe de l'Ouest, nous pouvons penser que les idées qu'ils défendent sont écoutées par leurs collègues.

À la suite des discussions des deux séances de la commission, respectivement organisées à Madrid en mars 1951, puis à Londres en octobre de la même année, le bureau de la commission élabore un projet de nouveau statut qui est présenté au comité exécutif en mars 1952. Celui-ci ne prône pas de régionaliser la FIFA. En fait, comme le souligne le président de la commission de réorganisation Rodolphe Seeldrayers, le seul changement important dans les statuts concerne la représentation au comité exécutif ${ }^{150}$. Le projet de nouveaux statuts prévoit, en effet, d'augmenter de trois le nombre de "membres " dans le comité. Sur ces

149 Anonyme, "Mémorandum. Propositions soumises par la "Football Association" (anglaise) à la Fédération internationale de Football Association visant à modifier les articles 8 et 36 et le Statut 10 », n.d. FIFA, réorganisation 1950-1953, 3. Propositions et projets, dossier : réorganisation 1950/52.

150 Anonyme, Procès-verbal de la réunion du comité exécutif de la FIFA des 9-10 mars 1952, 3 avril 1952. FIFA, comité exécutif (procès-verbaux 1951-1952) 
places, des postes fixes seront attribués à l'Amérique centrale, du Nord et du Sud ainsi qu'aux associations africaines et asiatiques ${ }^{151}$.

\section{Tableau 12. Composition du comité exécutif selon le nouveau projet de statuts de la FIFA}

\begin{tabular}{|l|c|l|c|l|}
\hline $\begin{array}{l}\text { Fonctions au } \\
\text { sein du comité }\end{array}$ & $\begin{array}{l}\text { Actuel } \\
\text { (nombre) }\end{array}$ & $\begin{array}{l}\text { Actuel (Organe } \\
\text { électeur) }\end{array}$ & Projet & Organe (Organe électeur) \\
\hline Président & 1 & Congrès & 1 & Congrès \\
\hline Vice-présidents & 5 & $\begin{array}{l}\text { Confédération } \\
\text { d'Amérique } \\
\text { du Sud (1)*, } \\
\text { Associations } \\
\text { britanniques (1), } \\
\text { Union soviétique } \\
\text { (1), Congrès (2) }\end{array}$ & 5 & $\begin{array}{l}\text { Confédération d'Amérique } \\
\text { du Sud (1), Associations } \\
\text { britanniques (1), Union } \\
\text { soviétique (1), Congrès (2) }\end{array}$ \\
\hline Membres & 6 & $\begin{array}{l}\text { Congrès } \\
\text { (n) }\end{array}$ & 9 & $\begin{array}{l}\text { Confédération d'Amérique } \\
\text { du Sud (1), Confédération } \\
\text { d' Amérique centrale (1), } \\
\text { Confédération d'Amérique } \\
\text { du Nord (1), Associations } \\
\text { des pays africains (1), } \\
\text { Associations des pays } \\
\text { asiatiques (1), Congrès (4) }\end{array}$ \\
\hline
\end{tabular}

Légende : ${ }^{*}$ nombre de places attribuées.

Les membres européens de la commission ont donc été d'accord de faire quelques concessions et de conférer une place dans le comité exécutif respectivement aux associations africaines et asiatiques. Mais cette proposition ne satisfait pas les fédérations sud-américaines qui souhaitent renforcer les prérogatives de leur entité continentale. En conséquence, elles militent en faveur d'une décentralisation de la FIFA, avec la création d'organismes continentaux (sur le modèle des confédérations existant dans les Amériques). Dès lors, celles-ci décident d'envoyer de nouvelles propositions au secrétaire général de la FIFA en vue d'une discussion lors du congrès ordinaire de l'été

151 Anonyme, «Projet pour les statuts, le règlement et le règlement du congrès de la FIFA », Article 17 (des statuts), 1952. FIFA, 3. Réorganisation 1950-1953, 3. Proposition et projets, dossier : 80 réorganisation 1950-1952. 80.8 projets pour les statuts et règlement. 
$1952^{152}$. Lors de l'assemblée générale qui se tient à Helsinki, les délégués sud-américains vont se montrer particulièrement offensifs et se confronter aux dirigeants européens. Il s'agit autant de manifester leur mécontentement sur la façon dont s'élabore la réforme de la FIFA que d'allonger les débats, en vue de ne pas statuer sur la réforme lors de ce congrès.

Dès son ouverture, un dirigeant uruguayen, Celestino Mibelli, donne le ton. "Au nom des associations de l'Amérique du Sud ", ce dernier attaque le Finlandais von Frenckell qui, dans son discours inaugural, aurait rappelé un incident survenu à Helsinki en 1927, lorsque les associations britanniques ont quitté la FIFA. Se sentant comparé aux Britanniques, Mibelli indique que les Sud-Américains sont venus dans un esprit de bonne entente. Malgré les tentatives d'apaisement de Jules Rimet et un déni de von Frenckell, les débats débutent dans un climat pour le moins houleux. Cette pique constitue une sorte de mise en bouche qui sert à montrer le mécontentement des SudAméricains. Elle va être suivie de plusieurs autres. Mibelli s'en prend ensuite au secrétaire général de la FIFA, Kurt Gassmann, mentionnant qu'aucun délégué sud-américain n’a été convié aux discussions sur la future Coupe du monde et pose d'autres questions diverses (par exemple sur la manière de se procurer les procès-verbaux des réunions des organes de la FIFA). Finalement, leur stratégie fonctionne puisque les congressistes décident de ne pas statuer sur la question et d'organiser un congrès extraordinaire l'année suivante, qui aura pour unique but de traiter de cette question. Malgré tout, un débat s'engage sur la composition de la commission de réorganisation. En effet, comme le bloc soviétique, les Sud-américains souhaiteraient que des représentants des continents africains, arabes et asiatiques soient élus dans cette commission et leur requête vise sans doute à fortifier des alliances chez d'autres associations extra-européennes, ce qui permettrait de contrebalancer les rapports de force au sein de la commission de réorganisation. Cette demande fait réagir plusieurs dirigeants européens des associations d'Europe de l'Ouest - qui ont tenu une réunion la vielle du congrès ${ }^{153}$-, dont Stanley Rous, qui trouve que la « discussion devient ridicule, car des heures ont déjà été passées à discuter " ${ }^{154}$, propos soutenus ensuite par Ernst Thommen. Un vote est malgré tout effectué quant à l'inclusion de représentants des autres

152 Anonyme, "Associación Uruguaya de Fútbol, Montevideo. Contre-proposition aux projets des Statuts, du Règlement et du Règlement du congrès de la FIFA ", 18 juin 1952. FIFA, 3. Réorganisation 1950-1953, 3. Proposition et projets, dossier : réorganisation, contre-proposition, etc.

153 Supra 3.1.3.

154 Gassmann K., Procès-verbal de la réunion du comité exécutif de la FIFA des 20-23 juillet 1952. Commentaire concernant l'ordre du jour, 12 août 1952. FIFA, comité exécutif (procès-verbaux 1951-1952). 
continents (Asie, Afrique). Nous ne disposons pas du détail des suffrages. Néanmoins, au regard des différents positionnements et des quelques suffrages explicités, nous pouvons imaginer que les associations d'Amérique du Sud et celles du bloc de l'Est ont voté en faveur de la proposition, au contraire des associations de l'Europe de l'Ouest et du bloc britannique. Malgré un vote favorable avec 23 voix pour la proposition sud-américaine et 21 voix contre, la requête est repoussée car, pour ce type de décision, il est nécessaire d'obtenir trois quarts des votes.

N'ayant pas réussi à modifier la composition de la commission de réorganisation, les associations d'Amérique du Sud lancent un nouveau défi aux associations européennes, qui va encore accroître la tension dans la salle. Alors que Rimet a été réélu sans encombre pour un dernier mandat de président, il s'agit désormais de statuer sur le cas des vice-présidents sortants, et en particulier pour le Belge Rodolphe Seeldrayers. Il devrait s'agir d'une formalité pour ce dirigeant qui officie à ce poste depuis plus de vingt ans, et ce d'autant plus que, par le passé, il a toujours été élu "par acclamation ». Mais les Sud-Américains, appuyés par leurs collègues d'Amérique centrale, ne l'entendent pas ainsi et opposent au Belge la candidature de l'Argentin Domingo Peluffo. Comme le souligne un dirigeant du Guatemala, ce procédé vise à ce que les pays d'Amérique latine soient davantage représentés au sein du comité exécutif. Ces propos confirment que, sur certaines questions, il existe bien un front panaméricain au sein de la FIFA. Ce procédé est très mal reçu par plusieurs dirigeants du Vieux Continent (excepté, là encore, les associations du bloc soviétique). Ainsi, Ernst Thommen rappelle qu'il est antistatutaire, l'Amérique du Sud ayant déjà désigné son représentant dans le comité exécutif. Ce point est aussi souligné par le Belge François Meert, qui demande aux délégués sud-américains d'abandonner leur proposition. Mais ces remarques ne font pas reculer les Sud-Américains qui, au contraire, persistent dans leur démarche. La tension monte et le Danois, Ebbe Schwartz, souligne que la discussion est "scandaleuse " tandis qu'Eric von Frenckell prédit un éventuel "scandale international " pour la FIFA si Seeldrayers n'est pas réélu. Au final, le vice-président sortant est tout de même reconduit dans ses fonctions à une forte majorité.

Quelques jours après la fin de ce congrès, un journaliste de France football indique que celui-ci a été le théâtre d'un "différend EuropeAmérique du Sud ${ }^{155}$. Cet affrontement n'est pas sans conséquence et va avoir un effet quasiment décisif sur la réorganisation de la FIFA. En

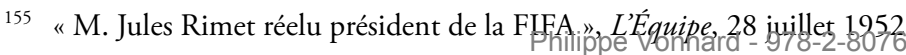


fait, deux constats généraux peuvent être portés sur les discussions lors du congrès d'Helsinki. Premièrement, si, comme le rapporte quelques jours après l'événement le Belge José Crahay à ses collègues du comité exécutif de l'Union belge, la « réunion s'est caractérisée par son désordre et par son manque total de travail constructif ${ }^{156}$, les congressistes n'ont toutefois pas remis en question la poursuite de l'étude de la réorganisation. Au contraire même, en décidant de l'organisation d'un futur congrès extraordinaire, ils soulignent bien qu'un consensus règne au sein de la FIFA sur le besoin de réformer la structure de l'organisation. Deuxièmement, Crahay relève aussi a posteriori dans le livre des vingt-cinq ans de l'UEFA que l'unité sudaméricaine semble avoir été une source d'inspiration pour les dirigeants du football européen, car "sur chacun des sujets, un délégué de l'Amérique du Sud, pas toujours le même, prit la parole, afin de discuter la politique générale. On sentait très bien que chaque point avait été étudié, et que des délégués avaient vraisemblablement été désignés pour défendre un point de vue ${ }^{157}$. " Le modus operandi mis en place par les Sud-Américains, qui consiste à se réunir régulièrement pour traiter de sujets relatifs au football continental, confirme aux Européens la nécessité de continuer les démarches entreprises dès la fin mai en vue de se réunir plus souvent ${ }^{158}$.

Lors du congrès d'Helsinki, les délégués présents décident de lancer une nouvelle série de concertations sur la réforme des statuts de la FIFA. Ainsi, les associations nationales ont jusqu'au mois de septembre 1952 pour envoyer de nouvelles requêtes à ce sujet. 124 propositions sont finalement transmises au secrétariat de la FIFA. Certaines fédérations ont envoyé les mêmes doléances que deux ans plus tôt, d'autres ont fait de nouvelles demandes, ce qui témoigne du fait que de nombreuses fédérations nationales n'étaient pas satisfaites du projet initialement proposé par la commission de réorganisation.

Afin de faire le tri entre les nouvelles et anciennes propositions, mais aussi de les hiérarchiser, les membres du bureau de la commission, le président, Rodolphe Seeldrayers, le secrétaire général Kurt Gassmann et les deux secrétaires adjoints Ottorino Barassi et Stanley Rous se réunissent en novembre 1952 à Londres. Aucun Sud-Américain ne participe à ces discussions. De celles-ci, il ressort un document de synthèse accompagné d'un bref commentaire co-signé par les quatre dirigeants, qui doit permettre de préparer une nouvelle session de travail de la commission

156 Anonyme, Procès-verbal de la réunion du comité exécutif de l'Union belge du 9 août 1952, n.d. AGRB, URBSFA, dossier : comité exécutif (procès-verbaux 52-53).

157 Rothenbuehler R., Les 25 ans de l'UEFA, op. cit., p. 76.

158 Supra 3.1.3. 
de réorganisation ${ }^{159}$. Il y est en particulier indiqué que deux associations européennes, respectivement l'Allemagne et la Yougoslavie, ont envoyé des propositions - avec des divergences sur la forme - en vue de créer des entités continentales au sein de la FIFA. L'idée de régionaliser la FIFA, défendue par les dirigeants sud-américains, commence à être considérée comme une alternative par quelques fédérations européennes. Si les membres du bureau de la commission de réorganisation estiment aussi que la création d'entités régionales est désormais une possibilité à envisager dans un futur proche, ils pensent toutefois qu'il encore trop tôt pour entamer ce processus. Dès lors, ils s'emploient à contrer les projets considérés comme " révolutionnaires » des fédérations allemandes et yougoslaves. Ils avancent notamment un argument géographique. En effet, selon eux, la vision de l'Europe proposée par l'association allemande et yougoslave est erronée, l'Europe étant composée de trente-deux associations ${ }^{160}$. Or, dans les deux projets, l'Europe reste divisée par le clivage de la Guerre froide. Cette vision de l'Europe qui s'établit sur les échanges footballistiques européens tels qu' ils existaient durant l'entre-deux-guerres ${ }^{161}$ parait un argument implacable. En effet, si à cette période des associations de football des deux côtés du Rideau de fer commencent à rejouer les unes contre les autres, il semble par contre difficilement envisageable que tous les pays européens puissent se réunir au sein d'un même organisme. Le bureau de la commission d'études propose donc de conserver le statu quo en confirmant néanmoins les dispositions de l'année précédente, à savoir de réserver des places fixes au sein du comité exécutif aux associations africaines et asiatiques. Au mois de mars 1953, une nouvelle réunion de la commission de réorganisation se déroule à Paris, qui a pour but d'examiner le document de synthèse établi par son bureau.

Les dirigeants présents entérinent l'augmentation de trois places au sein du comité exécutif, qui doit notamment permettre aux associations africaines et asiatiques de disposer de représentants. Par ailleurs, le nouveau texte prévoit que l'élite de la FIFA soit élue par une association nationale

159 Seeldrayers R., Barassi O., Rous S., Gassmann K., " Note préliminaire à l'examen des 124 propositions que le congrès d'Helsinki a renvoyées devant la Commission de révision des statuts et règlements de la FIFA nommée en 1950 au congrès de Rio de Janeiro ", 19 décembre 1952. FIFA, Réorganisation 1950-1953, 2. Commission d'étude et bureau, dossier : séance Paris.

160 Respectivement (par ordre alphabétique) : Albanie, Allemagne de l'Est et Allemagne de l'Ouest, Angleterre, Autriche, Belgique, Bulgarie, Danemark, Écosse, Espagne, France, Finlande, Grèce, Hongrie, Irlande, Irlande du Nord, Islande, Italie, la Sarre, Luxembourg, Norvège, Pays de Galles, Pays-Bas, Pologne, Portugal, Roumanie, Suède, Suisse, Tchécoslovaquie, "Turquie d'Europe », Union soviétique et Yougoslavie.

161 Supra 1.1.2. 
(pour le vice-président soviétique), par un groupe d'associations nationales (pour le vice-président britannique, le vice-président et le membre choisi par les Sud-Américains, les membres choisis par les associations d'Amérique centrale, d'Amérique du Nord, d'Afrique et d'Asie) ou " au congrès par le reste des autres associations nationales " (pour tous les autres dirigeants) ${ }^{162}$. C'est alors que, dans le but de confirmer la régionalisation de la FIFA, mais aussi de faire un pas en avant dans cette direction, les deux délégués sud-américains proposent que "le reste des autres associations nationales " soit remplacé par le terme "Europe ". Nous pouvons supposer que ce procédé recèle plusieurs avantages pour les associations sud-américaines. Premièrement, il permet de ne pas trop remettre en cause la domination européenne sur la FIFA et pourrait donc avoir comme effet de convaincre les associations du Vieux Continent de finalement accepter de créer des organismes régionaux au sein de la FIFA. Deuxièmement, en réservant des places à l'Europe, cela limiterait les places au sein du comité exécutif des autres pays extra-européens. L'influence de l'Amérique latine au sein de la FIFA serait dès lors renforcée. En effet, en conservant sa place de vice-président et en obtenant une place fixe de membre, ce continent sécurise sa position en tant que deuxième force au sein de la Fédération internationale après l'Europe, et ce d'autant plus que ses représentants pourront aisément former des alliances à l'échelle panaméricaine avec les deux places réservées aux associations d'Amérique centrale et du Nord. Ce souhait de ne pas donner trop de place dans le comité exécutif aux associations africaines et asiatiques est toujours partagé par les associations d'Europe de l'Ouest. Troisièmement, la proposition de réserver des places aux Européens oblige quasiment ceux-ci à créer un organisme continental. Or, en raison du contexte de Guerre froide, celui-ci risque d'avoir des difficultés à bien fonctionner, ce qui laisserait des possibilités d'action au sein de la FIFA aux Sud-Américains qui, comme le montre le congrès de 1952, arrivent souvent à défendre une position commune.

La proposition des Sud-Américains n'est pas suivie par la majorité des autres dirigeants présents. Ce manque de soutien en vue de leur requête ne doit pas se comprendre uniquement en raison de divergences sur la manière de conduire la réforme, mais aussi à cause de la difficulté des délégués sud-américains à créer des alliances avec leurs homologues européens. Cette situation s'explique peut-être par le fait que, contrairement aux

162 Gassmann K., Procès-verbal de la réunion du bureau de la commission d'étude pour la réorganisation des 24, 25 et 26 novembre, 9 décembre 1952. FIFA, Réorganisation 1950-1953, 1. Commission d'étude et bureau/révision, dossier : Procès-verbaux des séances. 
autres membres de la commission, les délégués sud-américains sont novices et participent pour la première fois à une réunion de la commission de réorganisation. En effet, en 1952, Ernesto Alveal remplace Luis Valenzuela alors qu'Alvaro Ramirez succède à Juan Russo ${ }^{163}$. Ce manque de continuité est pénalisant et empêche sans doute la création d'un climat de confiance entre les deux Sud-Américains et les dirigeants du Vieux Continent.

Malgré le refus de la commission d'études de soutenir la proposition des deux délégués sud-américains, dans une lettre adressée au secrétaire général de la FIFA, Kurt Gassmann, quelques jours après la réunion, Rodolphe Seeldrayers reconnait que celle-ci fait sens. De plus, il se permet de sortir de sa réserve habituelle et écrit : "Après tout c'est peut-être la meilleure méthode. Ainsi, l'Europe, du moment que le vice-président britannique vote avec ses délégués et que le président est européen, aura la majorité au sein du comité [exécutif de la FIFA] et, par le président, la voix prépondérante ${ }^{164}$. " À la fin du mois de mars, Seeldrayers indique à ses collègues du comité exécutif que les changements apportés aux statuts ne vont pas réformer l'architecture de la FIFA et que « les craintes qu'une Confédération européenne pourrait être formée comme contrepoids à la Confédération sud-américaine ont vite été dissipées " ${ }^{165}$. Il s'agit désormais de convaincre la majorité des associations nationales d'accepter le nouveau projet de statuts.

À cet effet, une nouvelle réunion du bureau de la commission est prévue à la fin juin pour finaliser le travail. Celle-ci se déroule au domicile d'Ernst Thommen ${ }^{166}$, avec la participation du représentant des pays scandinaves, Ebbe Schwartz. Ce dernier est justement présent à Bâle car l'équipe nationale danoise affronte la Suisse le soir même dans la cité rhénane. Sa présence est troublante puisqu’il ne fait pas partie du bureau de la commission. La participation du dirigeant danois semble montrer qu'avant de soumettre le projet, les membres du bureau de la commission de réorganisation tentent de recueillir le plus d'avis possible

163 Lettre de E. Morreno Allendes et J. Pinto Duran à K. Gassmann, $1^{\text {er }}$ juin 1953. FIFA, correspondance avec les associations nationales : Chili (1932-1972), dossier : 1.1.1951-31.12.1955.

164 Lettre de R.W. Seeldrayers à K. Gassmann, 10 mars 1953. FIFA, réorganisation 1950-1953, 2. Commission d'étude et bureau, dossier : séance du 6/7.3.1953 à Paris.

165 Gassmann, K., Procès-verbal de la réunion du comité exécutif des 27-28 mars 1953, 21 avril 1953. FIFA, comité exécutif (procès-verbaux 1953-1954).

166 Gassmann K., Procès-verbal de la réunion du bureau de la commission d'étude pour la réorganisation de la FIFA du 27 juin 1953, 2 juillet 1953. FIFA, réorganisation de la FIFA, 2. Commission d'étude et bureau, dossier : 80. 6. Bureau de la Commission d'étude, Séance 27.6 1953 à Bâle. 
sur la question, et en particulier ceux des associations européennes d'Europe de l'Ouest. À Bâle, Rous peut parler au nom des Britanniques, Barassi - et Thommen, qui participe sans doute aux discussions en dehors des réunions officielles - au nom de la vingtaine d'associations européennes qui se sont réunies en $1952^{167}$ et Schwartz représente les intérêts des associations scandinaves. À noter encore que, dans une lettre datant du 10 juin, l'association suisse de football - dont Thommen est président - invite tout le bureau de la commission à assister au banquet qui suit la rencontre internationale. Il est fait également mention de la présence de Lotsy et de Rimet. En raison des pratiques qui existent au sein de la FIFA depuis l'entre-deux-guerres, nous pouvons en déduire que des discussions informelles s'engagent entre tous ces dirigeants. En juin 1953, ce sont donc les principaux leaders du football d'Europe de l'Ouest qui sont réunis à Bâle, de manière formelle ou non, pour discuter des ultimes étapes du projet de nouveaux statuts.

Parallèlement à ces démarches, d'autres discussions ont lieu dans les semaines qui suivent. Par exemple, l'association yougoslave organise une conférence à Split les 7 et 8 août 1953 dans le but de discuter de l'amélioration $\mathrm{du}$ " niveau du football européen " ${ }^{168}$, mais aussi de créer une compétition européenne pour les juniors. Les associations suivantes répondent à l'appel (par ordre alphabétique) : Autriche, Allemagne de l'Ouest, Angleterre, Suisse, Grèce, Turquie et Yougoslavie. Rous et Thommen participent à l'événement ${ }^{169}$, et nous pouvons penser que celui-ci constitue une occasion supplémentaire pour ces dirigeants de discuter de la réforme de la FIFA, notamment de la demande de création de groupements continentaux transmise par l'association yougoslave. Ainsi, dans le courant de l'été, plusieurs discussions ont lieu entre les dirigeants de la vingtaine d'associations européennes qui ont co-signé, au printemps 1952, une proposition de réforme des statuts de la FIFA.

Dans le projet qui est finalement transmis aux associations nationales en vue d'une discussion lors d'un congrès extraordinaire fixé en novembre 1953 à Paris, il n'est pas fait mention de la proposition des dirigeants sudaméricains. De plus, aucune place n'est formellement réservée à l'Europe dans le comité exécutif de la FIFA. En fait, le projet de nouveaux statuts ne

167 Supra 3.1.3.

168 Lettre de K. Popovic à K. Gassmann, $1^{\text {er }}$ août 1953. FIFA, correspondance avec les associations nationales, Yougoslavie (1939-1974), dossier : 1.1.1951-31.12.1955.

169 Lettre de S. Rous à K. Gassmann, 4 août 1953. FIFA, correspondance avec les associations nationales : Angleterre (1927-1955) dossier: 1.1.53-31 12.55 
propose toujours pas vraiment une réforme de la structure de la Fédération internationale, mais plutôt une adaptation de ses statuts.

En novembre 1953, soit à la veille du congrès extraordinaire de la FIFA qui doit prendre une décision sur la future structure de l'organisation, dans quel état d'esprit sont les délégués qui convergent vers la capitale française? Lors de la séance du comité exécutif qui doit préparer l'assemblée, Ernst Thommen mentionne à ses collègues qu'il n'est pas souhaitable de régionaliser la FIFA. Cependant, il indique aussi qu'il devrait être permis à des associations nationales d'un continent de se mettre ensemble afin "de créer un organisme leur permettant de sauvegarder leurs intérêts " ${ }^{170}$. Sa proposition témoigne de l'incertitude qui règne chez plusieurs dirigeants du football européen, ces derniers semblant se préparer à éventuellement devoir négocier une réforme plus conséquente de la FIFA. Thommen se permet d'exposer l'idée de la création d'une entité européenne à ses collègues du comité exécutif, démarche qu'il n’a jamais réalisée auparavant. Même si aucune proposition fondamentale contraire au projet de nouveaux statuts n'a été annoncée, la tension est palpable et, selon des journalistes français, "une joute oratoire Europe-Amérique latine " ${ }^{171}$ est attendue lors du congrès extraordinaire. Dans le même temps, et afin d'aborder les travaux, la confédération sud-américaine se réunit préalablement dans le but de définir une ligne de conduite commune. De même, vingthuit associations européennes tiennent une réunion la veille du congrès, nombre qui semble indiquer que, pour la première fois, des associations $\mathrm{du}$ bloc soviétique participent également aux discussions. Il ressort de celles-ci qu'une majorité d'associations européennes prône de ne rien changer car, si elles concèdent qu'il est nécessaire de réformer la structure de la FIFA, elles demandent de continuer à étudier le sujet et surtout ne souhaitent pas donner des places fixes au sein du comité exécutif aux associations d'Amérique du Nord, d'Afrique et d'Asie. Elles argumentent pour cela que le football n'est pas encore suffisamment développé dans ces régions.

La future formation du comité exécutif (article 17 du projet de réforme) constitue le point le plus important des séances du congrès extraordinaire qui s'ouvre le 12 novembre $1953^{172}$. Dès le début des discussions, le délégué uruguayen et nouveau secrétaire de la Confédération d'Amérique

170 Gassmann K., Procès-verbal de la réunion du comité exécutif de la FIFA des 12-13 novembre 1953, 14 décembre 1953. FIFA, comité exécutif (procès-verbaux 1953-1954).

171 "Mais dès aujourd'hui au congrès de la FIFA joute oratoire Europe-Amérique latine ", L'Équipe, 14-15 novembre 1955.

172 Dix des dix-huit pages du procès-verbal sont consacrés à ce point. 
du Sud, Rotili, intervient : "Les associations [sud-américaines] désirent prendre part au congrès, conscientes de leur force et ayant donné de multiples preuves de leur puissante organisation et administration et de leur volonté de travailler pour le développement du football ${ }^{173}$. " Cette intervention annonce la couleur et confirme les ambitions des associations qui proviennent d'Amérique latine, à savoir d'obtenir davantage de places fixes au sein du comité exécutif de la FIFA. À sa suite, le président de l'Union belge, George Hermesse, prend la parole et - fait totalement nouveau - s'exprime au nom "d'un groupement d'associations européennes". Il indique que les Européens souhaitent conserver le statu quo et qu'ils proposent de reporter la décision finale à un prochain congrès. Les associations européennes tentent donc de faire obstruction à une réorganisation de la FIFA, tactique qui leur permet en fait de jouer la montre. En effet, cette manière de procéder a pour avantage de jauger les réactions des dirigeants sud-américains et, le cas échéant, de rediscuter en dehors des sessions afin de trouver un possible terrain d'entente avec eux.

C'est en fait "dans la coulisse " ${ }^{174}$ et en marge des réunions officielles que la réorganisation de la FIFA va se jouer lors d'une assemblée informelle organisée entre les dirigeants sud-américains et européens le premier soir du congrès.

\subsubsection{Le " compromis Thommen "}

La réunion entre Sud-Américains et Européens ${ }^{175}$ se déroule dans la soirée du premier jour de l'assemblée générale et fait suite à une proposition de compromis soumise en fin d'après-midi par Ernst Thommen. Afin de sortir de l'impasse, le dirigeant helvétique propose d'aller dans le sens des associations sud-américaines et de réserver des places au sein du comité exécutif aux associations européennes. Ernst Thommen semble avoir préparé le terrain puisqu'il s'est préalablement entretenu à ce sujet avec Barassi et Seeldrayers ainsi qu'avec l'Uruguayen Rotili et le Brésilien Sotero Cosme. Dans cette recherche de consensus, il

173 Gassmann K., Procès-verbal du congrès extraordinaire de la FIFA des 14-15 novembre $1953,1^{\text {er }}$ mai 1954. FIFA, XXIX-XXX congrès ordinaires (1953-1959, rapport d'activité).

174 "Au congrès extraordinaire de la FIFA (Samedi et dimanche) », L'Équipe, 16 novembre 1953.

175 D’après les déclarations faites par le délégué soviétique, Savin, le lendemain de cette réunion, il semble que des associations du bloc soviétique ont aussi participé à ces discussions. 
peut aussi compter sur le soutien de l'Espagnol Munoz Calero, qui essaie d'établir un lien entre les Européens et les Sud-Américains. Alors qu'il est à la même période en train d'essayer d'organiser un match "EuropeAmérique du Sud " à Madrid en 1954 pour fêter le cinquantenaire de la FIFA ${ }^{176}$, Munoz Calero recommande de suivre la proposition de Thommen. Il rappelle que " les délégués de l'Amérique du Sud sont venus pour collaborer et ils se sont longuement préparés pour ce travail. Un pas en avant a été fait au congrès de Luxembourg [de 1946] en accordant une vice-présidence aux associations sud-américaines et il faut continuer à aller de l'avant ${ }^{177}$."

Le lendemain, Ernst Thommen expose devant l'assemblée les conclusions de la réunion entre les dirigeants européens et sud-américains, qui a abouti à l'élaboration d'une nouvelle rédaction de l'article 17. Désormais, les associations européennes reconnaissent le droit à l'Afrique et à l'Asie de disposer d'un siège chacune au sein du comité exécutif de la FIFA. Par ailleurs, elles acceptent de s'y réserver deux places de vice-président et quatre places de membres. Thommen explique que l'abandon de l'élection directe du comité exécutif de la FIFA est, pour lui et plusieurs de ses collègues dirigeants des associations européennes, inévitable. La pression constante des dirigeants sud-américains qui risquent, à terme, de perpétuer les conflits au sein de la FIFA semble donc avoir pesé de tout son poids dans la balance et a finalement eu raison des dernières résistances des dirigeants européens. Par ailleurs, cette proposition correspond finalement également aux volontés d'adapter la structure de la FIFA au contexte du football international portées par la nouvelle génération de dirigeants du football européen, dont Thommen est, avec Barassi et Rous, le porte-parole. Il s'agit désormais pour lui de convaincre le reste de l'assemblée de se rallier à cette proposition. Cette décision n'est pas sans conséquence pour les associations européennes car, comme le rappelle le dirigeant suisse, elle implique que celles-ci devront prochainement se réunir afin de créer une organisation. Or cela signifie que les Européens de l'Ouest et le bloc soviétique devront se réunir, ce qui constitue alors une exception : à cette époque, seule la Commission économique pour le développement de l'Europe des

176 Gassmann K., Procès-verbal de la réunion du comité exécutif de la FIFA des 12-13 novembre 1953, 14 décembre 1953. FIFA, comité exécutif (procès-verbaux 1953-1954).

177 Gassmann K., Procès-verbal du congrès extraordinaire de la FIFA des 14-15 novembre $1953,1^{\text {er }}$ mai 1954. FIFA, XXIX-XXX congrès ordinaires (1953-1959, rapport d'activité). 
Nations unies (UNECE) réunit ces pays. Au sujet de la géographie du futur regroupement, Thommen ajoute encore que l'invitation pour la réunion "sera également adressée aux associations du Proche-Orient et de l'Afrique du Nord qui décideront si elles veulent y donner suite ${ }^{178}$. Ces territoires restent encore largement sous domination coloniale, ce qui explique leur intégration éventuelle à l'espace footballistique européen. Alors qu'il était l'un des premiers congressistes à s'exprimer, George Hermesse reprend la parole en toute fin de congrès. Se faisant une nouvelle fois le porte-parole des associations européennes, il encourage les congressistes à accepter la proposition de son collègue suisse. Il souligne aussi que les fédérations nationales européennes (en tout cas de l'Europe de l'Ouest) acceptent de "faire un sacrifice " visà-vis de leurs homologues africaines et asiatiques en leur laissant des places au sein du comité exécutif de la FIFA. Le terme " sacrifice " nous interpelle puisque la solution préconisée favorise encore largement les fédérations du Vieux Continent qui vont disposer de deux viceprésidents et de quatre membres, soit la plus grande représentation au comité exécutif. Ce vocabulaire révèle l'européocentrisme qui prédomine encore chez plusieurs dirigeants européens, qui considèrent que la FIFA doit avant tout être dirigée par les associations de leur continent. Mais les Européens ont décidé, fidèles à la politique de médiation des conflits qui existe au sein de la FIFA et afin d'éviter que des problèmes plus graves n'éclatent au sein de la Fédération internationale, d'accorder un peu de leur pouvoir aux dirigeants des associations extra-européennes. Dans cette optique, le terme "sacrifice " sert à souligner devant ces dirigeants que les Européens font un pas dans leur sens.

La proposition d'Ernst Thommen est bien accueillie par la majorité des associations et notamment par les représentants africains et asiatiques. Un délégué égyptien, dont l'intervention est vivement applaudie, indique qu'elle répond aux attentes des pays de son continent. Les statuts de la FIFA, ajoute-t-il, doivent être adaptés au contexte mondial et sauvegarder les intérêts de tous. Ce point de vue est soutenu par les délégués du Vietnam, Luong-Van-Hoa, et du Laos, Oudong Sananikone. Ces réactions montrent autant le succès de la tactique des dirigeants européens de l'Ouest que l'échec de la stratégie de séduction conduite par les Soviétiques vis-à-vis des associations extra-européennes. Par l'intermédiaire de cette alliance entre les Européens de l'Ouest et les Sud-Américains, la continentalisation de la FIFA semble en bonne voie. Le président Rimet met au vote la question de savoir si les associations

178 Ibid. 
souhaitent, oui ou non, la création d'organismes continentaux, dont la tâche principale serait d'élire les membres du comité exécutif de la FIFA (article 17 des nouveaux statuts). Le délégué sud-américain Rotili, en faveur de la réforme, et le Soviétique Savin, qui y est opposé, mettent alors une ultime pression sur les congressistes en demandant que le vote soit réalisé par appel nominal. Ce fait est rarissime et montre qu'une certaine tension est encore palpable et que les différents acteurs essaient par tous les moyens possibles de faire passer leurs idées. Ce procédé ne change pas la donne, le résultat final étant, sans équivoque, en faveur $\mathrm{du}$ " compromis Thommen ». La proposition sur le changement des statuts est largement ratifiée par 39 voix contre 6 , ce qui montre qu' une coalition entre les associations d'Europe de l'Ouest, les pays d'Amérique latine et les autres pays extra-européens présents a été conclue. En fait, les refus proviennent uniquement des pays du bloc soviétique. Ainsi, leurs tentatives de créer des alliances avec les dirigeants des pays africains et asiatiques se soldent par un échec. Quant à la Yougoslavie, elle s'est abstenue.

Après trois ans de travail et de multiples discussions formelles et informelles, les congressistes s'accordent pour réformer l'élection des dirigeants du comité exécutif. Désormais, ses membres ne seront plus élus lors de l'assemblée générale, mais indirectement par des groupements continentaux. Conscient de l'importance de la décision qui vient d'être prise, Jules Rimet, qui vit son dernier congrès en tant que président, se permet de prendre la parole. Il souligne, une nouvelle fois, son attachement à l'unité de la FIFA, car il est conscient du risque pris avec la création de groupements continentaux, ces derniers pouvant à terme créer des divisions au sein de la Fédération internationale. Toutefois, il s'accorde avec la décision prise par ses collègues et, en bon joueur, mentionne que "tous ceux qui auront l'honneur d'être placés à la tête de la Fédération internationale, désigné chacun par leurs régions, y apporteront un sentiment d'unité, un sentiment d'harmonie, un sentiment d'équité qui permettra à votre Fédération, après avoir existé depuis cinquante années déjà, de vivre encore longtemps ${ }^{179}$. 


\section{Tableau 13. Composition du comité exécutif selon le nouveau projet de statuts de la FIFA}

\begin{tabular}{|l|c|l|}
\hline $\begin{array}{l}\text { Fonctions au sein } \\
\text { du comité }\end{array}$ & $\begin{array}{l}\text { Nombre de } \\
\text { dirigeants }\end{array}$ & Organe électeur \\
\hline Président & 1 & Congrès \\
\hline Vice-présidents & 5 & $\begin{array}{l}\text { Groupe des associations européennes }(2)^{*}, \\
\text { Confédération d'Amérique du Sud }(1), \text { Associations } \\
\text { britanniques }(1)^{* *}, \text { Union soviétique }(1)^{* *}\end{array}$ \\
\hline Membres & 8 & $\begin{array}{l}\text { Groupe des associations européennes }(4)^{*}, \\
\text { Confédération d'Amérique du Sud }(1), \\
\text { Confédération centrale (1), Groupe des associations } \\
\text { africaines }(1)^{*} ; \text { Groupe des associations asiatiques } \\
(1)^{*}\end{array}$ \\
\hline
\end{tabular}

Légende : ${ }^{*}$ : groupe à constituer d'ici le prochain congrès de la FIFA de juin 1954. Si le groupe n'est pas constitué, le congrès élira les représentants de ces associations ; ** : ces associations ne prennent pas part aux élections des représentants du groupe des associations européennes au comité exécutif de la FIFA.

Ce vote ne signifie cependant pas la fin du congrès, beaucoup de sujets restant encore à aborder. Leur traitement ne pose pas de véritables problèmes et la vitesse à laquelle les travaux avancent étonne même certains délégués comme l'Argentin Carrioli, qui « est surpris par la rapidité des débats et par les marques d'impatience des délégués venus de pays peu éloignés alors que d'autres viennent de régions très éloignées " ${ }^{180}$. Les journalistes de France football, Max Urbini et Jean-Philippe Réthaker, précisent - sur un ton un peu sarcastique - que les 42 derniers articles ont été traités en deux heures, contrastant avec les neuf heures passées uniquement sur l'article $17^{181}$. Les discussions touchent finalement à leur terme et une commission de rédaction est nommée, composée de Seeldrayers, Gassmann, Rous - qui se chargera du texte en anglais -, Delaunay - qui révisera le texte en français - et l'Espagnol Ramirez - qui traduira le document en espagnol. Force est de constater que ce sont des Européens qui se chargent de finaliser le travail, confirmant ainsi qu'ils conservent la mainmise sur l'organisation.

Quelques jours après le congrès, l'un des principaux acteurs de celui-ci, le Belge George Hermesse, indique à ses collègues de l'Union belge qu'une

180 Ibid.

181 «Quand la FIFA passe un week-end à l'UNESCO ou l'article 17 revu, corrigé et... adopté ", France football, 17 novembre 1953i 
" formule de compromis présentée par les associations européennes a été admise en ce qui concerne la composition du comité exécutif $"{ }^{182}$. Par contre, il ne fait aucunement mention du groupement que les Européens doivent désormais fonder. Rodolphe Seeldrayers se montre plus enthousiaste et n'hésite pas à écrire à Kurt Gassmann que l'assemblée a été un "triomphe " ${ }^{183}$, soulignant que les propositions de modifier totalement l'architecture de la FIFA - en particulier l'idée de créer des groupements continentaux qui s'occuperaient de la gestion du football sur leur continent - n'ont finalement pas été acceptées.

En fait, plus qu'un simple changement de modalité d'élection des dirigeants du comité exécutif de la FIFA, les décisions prises à Paris ouvrent une ère nouvelle de son histoire. Comme nous allons le développer dans le chapitre suivant, elles vont mener à sa régionalisation, ce qui va entraîner un changement fondamental de son fonctionnement ainsi qu'à une nouvelle répartition des tâches en matière de gestion du football international. Cette décision ouvre donc en grand la porte à la création d'une entité européenne de football.

182 Anonyme, Procès-verbal de la séance du comité exécutif de l'Union belge du 28 novembre 1953, n.d. AGRB, URBSFA, dossier : comité exécutif (procès-verbaux 53-54).

183 Lettre de R.W. Seeldrayers à K. Gassmann, 25 novembre 1953. FIFA, membres du comité exécutif, dossier individuel : correspondance R.W. Seeldrayers (1939-1950), dossier : $1^{\text {er }}$ janvier 1951-7 octobre 1955 
Philippe Vonnard - 978-2-8076-0570-1

Téléchargé de PubFactory à01/07/2021 08:14:02PM

via free access 


\section{CHAPITRE 4}

\section{La création de l'UEFA (1954-1960)}

\section{Introduction du chapitre}

Ce chapitre va de 1954 à 1960 et traite spécifiquement de la formation et des premiers développements de l'UEFA. Durant ces six années, les bases en vue de conférer à l'Union le statut d'organe régulateur du football européen vont être posées.

Premièrement, nous décrivons les étapes qui s'opèrent du printemps 1954, moment où ont lieu les premières discussions sur la création d'un Groupement des associations européennes de football au sein de la FIFA, à la fin des années 1950, lorsque l'élite de l'Union envisage la création d'un siège propre et l'engagement d'un secrétaire fixe. Une fois ces jalons posés, nous nous interrogeons sur les frontières de l'organisation, et en ce sens nous focalisons sur le cas de la Turquie et d'Israël. Les décisions prises quant à ces deux fédérations sont importantes car elles déterminent ce qui est considéré comme le territoire européen du football (vision qui va rester en place jusqu'à la fin de la Guerre froide). Si, comme indiqué dans le chapitre précédent, le football européen entre dans une nouvelle phase de développement depuis le début des années 1950, la création de l'UEFA renforce très clairement cette dynamique. C'est en particulier la création de la Coupe des clubs champions européens - lancée lors de la saison 1955-1956 - puis de la Coupe d'Europe des nations - créée en 1958 - qu'il faut souligner ici, même si, pour cette dernière, des grandes associations européennes se montrent résistantes face au projet.

Deuxièmement, nous étudions les conséquences de la création de ce nouvel acteur continental sur la scène footballistique européenne. Tout d'abord, il est nécessaire de comprendre comment son élite dirigeante arrive à faire face au contexte de Guerre froide, car en dépit des tensions régulières qui existent entre l'Est et l'Ouest, l'UEFA se développe rapidement. Ici, son comité exécutif s'appuie sur certaines stratégies développées au sein de la FIFA - tout en les modifiant quelque peu - afin de neutraliser les conflits internes. En outre, durant ses premières années d'existence, l'UEFA se détache de la tutelle de la FIFA. Cette situation ne va pas sans poser des 
problèmes, comme le montre l'exemple de la reprise de l'organisation du tournoi international des juniors par l'UEFA, et implique une médiation entre l'élite dirigeante des deux organisations, qui s'opère finalement à la fin des années 1950 : à l'UEFA la gestion du football européen, à la FIFA celle du football mondial. Cette monopolisation croissante de l'administration du football à l'échelle européenne par l'UEFA confronte rapidement l'organisation à d'autres acteurs qui se montrent intéressés à réaliser des projets continentaux. À l'intérieur du monde footballistique, c'est tout d'abord au Comité international de liaison des ligues, fondé en 1959, que l'UEFA doit faire face. À l'extérieur, l'Union entreprend des discussions avec l'Union européenne de radio qui, par l'entremise de son réseau Eurovision - lancé en 1954 -, souhaite retransmettre des rencontres de la Coupe des champions. Les négociations avec ces deux organismes renforcent la position de l'UEFA et la profilent comme l'organe régulateur du football continental. À noter que son action dépasse largement le cadre footballistique et que l'organisme peut être vu comme un acteur dynamique de la coopération européenne, au sens large du terme. En effet, au travers de ses compétitions, l'UEFA propose des échanges réguliers et officiels entre l'Est et l'Ouest qui lui confèrent assurément une place à part dans ce processus.

En quelques années, l'Union se profile comme la principale confédération continentale de la FIFA. C'est le troisième point que nous abordons dans ce chapitre. En effet, à la suite des décisions prises lors du congrès extraordinaire de 1953 à Paris, des organismes continentaux vont se créer en Europe, mais aussi en Afrique et en Asie. Dans ce cadre, les confédérations du continent américain (Amérique centrale, du Nord et surtout du Sud) sont prises comme modèles par les promoteurs de ces nouvelles entités. Mais le développement de ces organismes implique une redistribution des cartes entre eux et la FIFA. Sous cet angle, l'UEFA joue un rôle central puisqu'elle milite, dans les années 1955-1956, pour l'obtention d'une somme financière de la Fédération internationale sur la recette qu'elle prélève lors des matchs internationaux (requête qui doit permettre d'obtenir les mêmes droits que la Confédération sudaméricaine). La décision en ce sens, finalement prise lors du congrès de la FIFA de 1956 - en raison notamment d'alliances tissées de manière informelle entre les élites des confédérations -, permet aux entités continentales de pérenniser leur existence. Dans les dernières années de la décennie, l'UEFA va commencer à se profiler comme la principale confédération continentale, notamment lorsqu'elle porte la requête novatrice de demander une rétrocession sur les recettes perçues par la FIFA lors de la Coupe du monde. En fait, si les autres organismes ne se 
calquent pas forcément sur la même structure que l'UEFA, elles semblent néanmoins grandement influencées par les actions de cette dernière en vue de développer le football européen. Ainsi, en 1959, la Confédération sud-américaine va mettre en place une compétition continentale pour les clubs, qui s'inspire de celle qu'organise son homologue européenne.

\subsection{Dynamiser le football européen}

La seconde partie des années 1950 marque le début d'un tournant dans le développement du football européen. On constate un renouveau des matchs Est-Ouest, matérialisé par la Coupe du monde de 1954 en Suisse - avec une finale Allemagne de l'Ouest-Hongrie - ainsi que par l'édition, cette même année, du tournoi international des juniors, dont la participation se monte à 18 équipes qui proviennent des deux côtés du Rideau de fer. En parallèle émerge l'idée de compétitions pour les clubs convoquant la majorité des pays européens, telle celle lancée dans les colonnes du journal L'Équipe en décembre 1954. Enfin, et surtout, il y a la fondation d'une organisation européenne en football, qui va largement supporter cette nouvelle phase d'européanisation du jeu.

\subsubsection{Un organe faîtier pour le football européen}

À la suite de la réorganisation de la FIFA qui a été décidée en novembre 1953 et qui entre formellement en vigueur avec les nouveaux statuts de l'organisation promulgués en février $1954^{1}$, les associations européennes sont obligées de mettre sur pied une nouvelle réunion entre elles. Le but principal de celle-ci consiste à choisir leurs six représentants (deux viceprésidents et quatre membres) au sein du comité exécutif de la FIFA. Mais il pourrait aussi sagir de constituer une organisation plus formelle, comme le suggérait déjà Ottorino Barassi au printemps $1952^{2}$, au sein de laquelle les associations nationales pourraient discuter de différentes thématiques sur le football européen.

Les trois membres de la commission permanente - pour rappel nommés par les associations européennes en mai 1952 à Zurich -, à savoir Ottorino Barassi, José Crahay et Henri Delaunay, entament

1 Rimet J., Gassmann K., Statuts de la FIFA [édition de 1953], 15 février 1954. FIFA, statuts, 1904-1981.

2 Supra 3.1.3. 
donc des démarches en vue d'organiser cette discussion ${ }^{3}$. En tant que secrétaire de cette commission, Delaunay prend contact avec la trentaine d'associations considérées comme européennes par la FIFA 4 . À ce titre, il se demande où s'arrêtent les frontières de l'Europe footballistique et transmet une requête au secrétaire de la Fédération internationale, Kurt Gassmann, en vue de savoir si la Turquie peut participer à la future réunion. En date du 19 mars 1954, le secrétaire général de la FIFA lui indique - après consultations auprès de l'élite de la FIFA - que ce pays est à placer dans le futur groupement de l'Asie, car la Fédération turque a son siège dans la capitale Ankara, ville qui se trouve sur le continent asiatique ${ }^{5}$. Delaunay n'invite donc pas la Turquie à la réunion entre les associations européennes qui est fixée, par les trois membres de la commission, au 12 avril 1954 à Paris, en marge d'un match entre la France et l'Italie.

Vingt-deux associations sont présentes à Paris ${ }^{6}$. Par ailleurs, les associations de l'Albanie, de la Bulgarie, de la Grèce, de l'Irlande du Nord, de l'Islande, du Pays de Galles, de la Pologne, de la Roumanie et de l'Union soviétique se sont excusées. Si les dirigeants britanniques (des associations anglaise et écossaise) sont bel et bien présents, signe de leur ralliement progressif à l'idée de créer davantage de synergie entre les associations du Vieux Continent, a contrario les pays du bloc soviétique se montrent toujours globalement réticents à participer aux discussions. Seules la Hongrie et la Tchécoslovaquie participent à celles-ci. Si les deux associations supportent la candidature de Gustav Sebes pour un poste de vice-président de la FIFA, elles se montrent par contre, par la voix du délégué tchèque, Josef Vogl, opposées à la formation d'un groupe européen. Face à cette remarque, Henri Delaunay lui rappelle que cette question a

Anonyme, Procès-verbal de la réunion du comité exécutif de l'Union belge de football du 3 avril 1954, 10 avril 1954. AGRB, URBSFA, dossier : comité exécutif (procèsverbaux 51-52).

4 Delaunay H., Procès-verbal de la réunion des associations européennes de football du 12 avril 1954, n.d. Bundesarchiv (BA), DY 12 Deutscher Turn und Sportbund (DTSB), dossier : 2.081 Zusammenarbeit mit der FIFA, microfiche 03, $\mathrm{n}^{\circ}$ 169-171. Contrairement à ce qu'annonçait Ernst Thommen durant le congrès extraordinaire de la FIFA de 1953, il ne semble pas que Delaunay prenne contact avec les associations d'Afrique du Nord et du Proche-Orient.

5 Lettre de K. Gassmann à H. Delaunay, 19 mars 1954. FIFA, correspondance avec les associations nationales : France (1937-1954), dossier : 1.1.1951-53.

6 Par ordre alphabétique : Allemagne de l'Est, Allemagne de l'Ouest, Angleterre, Autriche, Belgique, Danemark, Espagne, Écosse, Finlande, France, Hongrie, Irlande, Italie, Luxembourg, Norvège, Pays-Bas, Portugal, Sarre, Suède, Suisse, Tchécoslovaquie et Yougoslavie. 
déjà été tranchée dans les réunions initiales de Zurich, Paris et Helsinki. Cela n'est toutefois pas totalement correct, puisque, comme nous l'avons $\mathrm{vu}$, les réunions précitées ont certes permis des discussions mais n’ont pas vraiment débouché sur la volonté de nommer des représentants communs au sein du comité exécutif de la FIFA. D'ailleurs, signe que la constitution d'un organisme est sujet à débat, la réunion de Paris ne débouche pas sur un accord en la matière, comme le confirme, quelques jours plus tard, Ernst Thommen dans une lettre à Jules Rimet ${ }^{7}$. En outre, les délégués n'arrivent pas non plus à se mettre d'accord sur les onze candidatures (issues de onze associations nationales différentes) qui ont été envoyées à Delaunay pour les postes à pourvoir au comité exécutif de la FIFA. Il faut dire que le sujet est délicat, car seules six places sont réservées aux Européens ; en conséquence, cinq candidats ne seront pas choisis. Afin de minimiser le possible impact négatif de cette situation sur les relations entre les associations nationales européennes, Stanley Rous propose de continuer à réfléchir sur la question et de fixer une nouvelle réunion à la veille du prochain congrès de la FIFA, qui doit se dérouler au mois de juin en Suisse. Cette proposition a pour avantage de laisser le temps de mener des discussions informelles sur le sujet, démarche qui pourrait permettre de créer des alliances, voire de trouver des compromis entre les associations nationales du continent, et qui rappelle les manières de faire des dirigeants européens au sein de la FIFA depuis l'entre-deux-guerres. Les délégués acceptent cette proposition.

De plus, en toute fin de réunion, ils acceptent également une autre proposition d'Ottorino Barassi. En effet, ce dernier propose de permettre, à lui-même et à ses deux collègues de la commission permanente José Crahay et Henri Delaunay, d'élaborer le projet de statuts d'une future entité européenne ${ }^{8}$. L’idée est de le discuter lors de la prochaine assemblée. Il s'agit d'un pas important puisque, par l'entremise de cette décision, les congressistes acceptent l'éventualité de créer dans un futur proche un organisme continental. Afin de déterminer les contours de celui-ci, Henri Delaunay envoie, en date du 24 avril, un questionnaire (voir ci-dessous) à toutes les fédérations européennes?

Lettre de E. Thommen à J. Rimet, 25 avril 1954. FIFA, membres du comité exécutif, dossier individuel : correspondance J. Rimet (1945-1950), dossier : 1951-1954.

8 Delaunay H., Procès-verbal de la réunion des associations européennes de football du 12 avril 1954, n.d. BA, DY 12 DTSB, dossier : 2.081 Zusammenarbeit mit der FIFA, microfiche 03, $\mathrm{n}^{\circ}$ 169-171

9 Anonyme, Procès-verbal de la réunion du comité exécutif de l'Union belge du 24 abril 1954, n.d. AGRB, URBSFA, dossier : comité exécutif (procès-verbaux 51-52), 
Figure 4. Questionnaire envoyé aux associations européennes en mai 1954

1) Le Groupe européen doit-il se réunir seulement tous les deux ou quatre ans, pour élire deux vice-présidents et quatre membres du comité exécutif de la FIFA ?

2) Le Groupe européen doit-il être une "Entente européenne " ayant un caractère consultatif, se réunissant une ou deux fois par an?

3) Dans ce cas, les associations européennes doivent-elles élire un bureau comportant un président et un secrétaire ou plusieurs membres?

4) Les associations doivent-elles fixer un siège social ou seulement se réunir alternativement dans différentes villes?

5) Le Groupe européen doit-il se constituer sous une forme juridique, avoir des statuts, un budget?

6) Le Groupe ainsi constitué doit-il élire un comité exécutif chaque année ou toutes les deux années?

7) Le Groupe, qui pourrait être dénommé « Fédération européenne des associations de football ", devrait-il résoudre les questions concernant particulièrement le football en Europe?

8) Devrait-il étudier les ordres du jour des congrès de la FIFA en vue d'adopter une position collective sur les problèmes qui lui sont soumis?

9) Dans le cas de la création d'une telle Fédération, seriez-vous d'accord pour demander à la FIFA de ristourner au Groupement $1 \%$ des pourcentages qu'elle prélève sur les matchs internationaux, comme elle le fait pour la Confédération sud-américaine?

10) Êtes-vous partisan d'une Coupe de l'Europe [des sélections nationales] qu'organiserait le Groupe ou Fédération européenne tous les quatre ans, dans l'intervalle de la Coupe du monde?

Dans sa lettre d'accompagnement, le secrétaire de la commission permanente indique les trois options qui s'offrent aux dirigeants européens. Premièrement, les associations décident de créer un organisme dont le but principal serait l'élection des membres européens au comité exécutif de la FIFA, comme le préconise l'article 17 des nouveaux statuts de la Fédération internationale. Deuxièmement, les associations souhaitent se montrer plus ambitieuses en mettant sur pied une "entente" consultative ayant des réunions occasionnelles pour procéder à des échanges de vues et formuler des vœux ${ }^{10}$. Troisièmement, les associations décident - il s'agirait de la forme la plus avancée de coopération - de créer un groupement ayant une forme juridique s'inspirant des autres entités continentales déjà existantes. Dans ce dernier cas, Delaunay fait explicitement référence à la

10 Lettre de H. Delaunay au secrétaire général de la Section de football de la RDA, 20 avril 1954. BA, DY 12 DTSB, dossier : 2.081 Zusammenarbeit mit der FIFA, microfiche $03, \mathrm{n}^{\circ} 182-183$. 
Confédération sud-américaine. Quelle que soit l'option choisie, il rappelle néanmoins que toutes les actions entreprises devront rester subordonnées à la FIFA.

Constatons que le questionnaire est assidûment rempli puisque le secrétaire reçoit vingt-deux réponses sur ses trente et un envois. Quatre fédérations nationales indiquent qu'elles préferrent encore attendre avant de donner leur réponse (Allemagne de l'Est, Bulgarie, Islande et Union soviétique) alors que cinq n'accusent tout simplement pas réception du document (Albanie, Hongrie, Pologne, Pays de Galles, Roumanie).

À la suite des réponses, un document de synthèse est établi par la commission permanente, qui doit permettre de dégager les principales tendances sur les différentes questions ${ }^{11}$. Il ressort de ce travail que la majorité des associations consultées se montrent finalement favorables à créer une entité formelle. Elles optent pour la voie médiane proposée par Delaunay, à savoir un organisme dont la tâche principale sera d'élire ses représentants au sein du comité exécutif de la FIFA et qui pourra également se réunir une fois par année pour discuter de thématiques relatives au football européen. Dans cette perspective, il est préconisé de nommer un organe exécutif et de créer un siège qui serait placé au domicile de son secrétaire général. Les rencontres du comité et les assemblées générales annuelles se dérouleraient alternativement dans différentes villes européennes, stratégie permettant d'impliquer le maximum d'associations. En ce printemps 1954, plusieurs associations nationales européennes décident donc de franchir le Rubicon et de former une entité continentale.

À partir des réponses au questionnaire, la commission permanente poursuit ses démarches et élabore un projet de statuts pour le futur groupement ${ }^{12}$. En date du $1^{\text {er }}$ juin 1954, Henry Delaunay envoie une nouvelle lettre aux associations nationales contenant cette fois le procès-verbal de la réunion de Paris, une brève synthèse des réponses au questionnaire ainsi qu'un projet de statuts pour le futur Groupement européen. Celui-ci témoigne du caractère souple de la future entité. Ainsi, l'Entente européenne de football, telle qu'elle est nommée, « ne se prévaut

11 Anonyme, "Groupe des associations européennes de football. Analyse des réponses au questionnaire relatif à la forme constitutionnelle du groupe ». BA, DY 12 DTSB, dossier : 2.081 Zusammenarbeit mit der FIFA, microfiche 03, $\mathrm{n}^{\circ} 176$.

12 Anonyme, Procès-verbal de la réunion du comité exécutif de l'Union belge de football du 29 mai 1954, n.d. AGRB, URBSFA, dossier : comité exécutif (procès-verbaux 51-52). 
provisoirement d'aucun caractère officiel ${ }^{13}$ et reste subordonné à la FIFA. Dans l'en-tête du document se trouve d'ailleurs l'inscription "FIFA » et le document est envoyé pour information à son comité exécutif ${ }^{14}$. Ces démarches soulignent que la création d'une entité européenne ne se fait pas contre la Fédération internationale. La future entité s'assigne comme buts de :

a) Résoudre toutes les questions concernant le football en Europe.

b) Étudier les ordres du jour des congrès de la FIFA.

c) Rapprocher les divers points de vue de ses membres au sujet des problèmes figurant à l'ordre du jour des congrès de la FIFA et arrêter, si possible, une attitude commune à leur égard.

d) Procéder à la nomination des deux vice-présidents - sans la participation des associations britanniques ni de l'URSS - et des quatre membres du comité exécutif de la FIFA qui, en vertu de l'article 17 des statuts de cet organisme, sont éligibles par les associations européennes ${ }^{15}$.

Si le premier point montre que le futur groupement se donne le droit de traiter de plusieurs prérogatives du football européen, les trois autres restent très liés à la FIFA et rappellent que les actions des associations européennes s'opèrent avant tout en réaction aux changements de statuts de la Fédération internationale. Soulignons tout de même que l'éventualité de mettre sur pied un tournoi européen pour les équipes nationales est évoquée à l'article 4. C'est donc le projet d'un organisme aux prérogatives limitées qui est proposé aux associations nationales européennes.

Leur nouvelle assemblée se déroule le 15 juin 1954 à Bâle, avec cette fois la présence de vingt-cinq associations nationales ${ }^{16}$. Rapidement, les délégués s'accordent sur la création d'un Groupement européen des associations de football. Puis, ils discutent au sujet des élections des

13 Anonyme, "Entente europenne de football, projet de règlement ", n.d. BA, DY 12, DTSB, dossier : 2.081 Zusammenarbeit mit der FIFA, fiche 03, ${ }^{\circ} 173-175$.

14 Gassmann K., Procès-verbal de la réunion du comité exécutif de la FIFA des 12-13 juin 1954, 7 juillet 1954. FIFA, comité exécutif (procès-verbaux 1953-1954).

15 Anonyme, Procès-verbal de la réunion du comité exécutif de l'Union belge du 29 mai 1954, n.d. AGRB, URBSFA, dossier : comité exécutif (procès-verbaux 1953-1954).

16 Par ordre alphabétique : Allemagne de l'Est, Allemagne de l'Ouest, Angleterre, Autriche, Belgique, Bulgarie, Danemark, Écosse, Espagne, Finlande, France, Hongrie, Irlande, Irlande du Nord, Italie, Luxembourg, Norvège, Pays-Bas, Portugal, Sarre, Suède, Suisse, Tchécoslovaquie, Union spviétique, et Yougoslavie.-2-8076-0570-1 
dirigeants européens qui les représenteront dans le comité exécutif de la FIFA. Le délai demandé par Stanley Rous lors de la réunion du mois d'avril semble avoir porté ses fruits puisque les candidats sont choisis soit comme représentants au sein du comité exécutif de la FIFA, soit au sein de celui du groupement européen. Les dirigeants choisis pour composer ce dernier sont (par ordre alphabétique) : José Crahay, Henri Delaunay, Joseph Gerö, George Graham, Ebbe Schwartz et Gustav Sebes. L'assemblée bâloise, qui se déroule dans " une atmosphère plus satisfaisante que la réunion de Paris [du 12 avril] " ${ }^{17}$, dixit un dirigeant de l'Union belge de football, officialise donc la création d'une organisation européenne. Celle-ci est officiellement reconnue en date du 21 juin 1954 par le comité exécutif de la FIFA ${ }^{18}$.

Il s'agit désormais de pérenniser les décisions prises et en particulier que les associations nationales s'accordent sur le projet de statuts présenté par la commission permanente. À ce titre, durant la réunion, décharge a été faite au comité exécutif pour élaborer un projet définitif qui devra être approuvé lors de la première assemblée générale du Groupement européen qui se déroulera en 1955. Une réunion initiale du comité exécutif, qui est organisée dans la foulée du congrès, permet à l'élite de l'UEFA de nommer son président, Ebbe Schwartz, ainsi que son secrétaire général, Henri Delaunay ${ }^{19}$. De même, un calendrier est établi afin de mener à bien la nouvelle rédaction des statuts. Enfin, les dirigeants présents décident de fixer une future rencontre à la fin octobre 1954 à Copenhague dans le but de continuer les discussions. Durant l'été, Henri Delaunay échange plusieurs courriers avec les associations nationales européennes afin de poursuivre l'élaboration du projet de statuts ${ }^{20}$. À la suite de ces démarches, le comité exécutif se réunit effectivement les 29 et 30 octobre, dans la capitale danoise.

17 Anonyme, Procès-verbal de la réunion du comité exécutif de l'Union belge du 2 juillet 1954 n.d. AGRB, URBSFA, dossier : comité exécutif (procès-verbaux 1953-1954).

18 Gassmann K., Procès-verbal de l'assemblée générale de la FIFA du 21 juin 1954, décembre 1954. FIFA, dossier : XXIX-XXX congrès ordinaires (1953-1959, rapport d'activité).

19 Delaunay H., Procès-verbal de la réunion du comité exécutif du Groupement des associations européennes de football du 22 juin 1954, n.d. Archives de l'Union des associations européennes de football (UEFA), RM00000749 (réunions du comité exécutif, 1954-1959), document relié : procès-verbaux des comités exécutifs et comités d'urgence 1954-1959).

20 Lettre de H. Delaunay au secrétaire général de la Section de football de la RDA, 19 juillet 1954. BA, DY 12 DTSB, dossier : 2.085 Zusammenarbeit mit der UEFA, fiche $05, \mathrm{n}^{\circ} 489$. 
À Copenhague, les dirigeants présents rediscutent du projet de statuts et arrêtent des décisions en vue de pérenniser l'existence de l'entité. Tout d'abord, ils lui donnent un nom. La dénomination retenue est celle d'Union des associations européennes de football, dont l'abrégé en anglais - celui choisi - donne : UEFA. À la suite de William Gasparini, insistons sur le terme convoquée ${ }^{21}$. Le terme d'Union confère deux avantages. Premièrement, par rapport à celui de Groupement, il est juridiquement plus contraignant et permet de renforcer les liens préalablement établis. Deuxièmement, il offre aussi l'opportunité de respecter le principe d'une entité reconnaissant les associations nationales et non d'une organisation dans laquelle les associations délégueraient leur pouvoir à l'autorité centrale. Ce dernier point est important, car il suit les dispositions prises au sein de la FIFA durant les années 1930, à savoir que l'organisme supranational n'intervient pas dans les affaires internes des fédérations nationales ${ }^{22}$. Toutefois, tous les dirigeants du football européens ainsi que les journalistes de l'époque ne sont pas forcément toujours rigoureux sur l'appellation de l'entité et il est possible de trouver des documents dans lesquels ils emploient le terme "Union européenne de football ». Puis, le comité exécutif ôte la phrase du projet de statuts qui indique que l'organisation « ne se prévaut provisoirement d'aucun caractère officiel » et décide que sa forme juridique sera réalisée "dans le pays où sera fixé le siège social du Groupement " ${ }^{23}$. Enfin, les dirigeants présents fixent une cotisation annuelle de 250 francs suisses - montant qui se calque sur les cotisations que les associations versent chaque année à la FIFA (260 francs suisses $\left.{ }^{24}\right)$ - et optent pour l'envoi d'un formulaire d'inscription aux associations. Toutes ces décisions, qui devront être discutées lors de l'assemblée générale de l'UEFA fixée en mars 1955 à Vienne, indiquent que son comité exécutif prend des décisions rapides en vue d'ancrer l'existence de l'entité.

Par ailleurs, l'élite de l'UEFA se montre également proactive et témoigne d'une volonté de développer le football européen. Le comité exécutif décide ainsi d'élaborer le projet d'une compétition européenne pour les équipes nationales. En effet, l'organisation de ce tournoi pourrait

21 Gasparini W., "Un sport européen ? Genèse et enjeux d'une catégorie européenne ", Savoir/Agir, vol. 15, 2011, p. 53.

22 Supra 1.2.4.

23 Delaunay H., Procès-verbal de la réunion du comité exécutif du Groupement des associations européennes de football des 29 et 30 octobre 1954, n.d. UEFA, RM00000749 (réunions du comité exécutif, 1954-1959), dossier : CE 29-6-1957. Copenhague.

24 Rimet J., Gassmann K., Statuts de la FIFA [éditions 1953], article 30 [des statuts], 15 février 1954. FIFA, statuts, 1904-1981 
permettre de légitimer davantage l'existence de l'entité européenne. Par ailleurs, cela aurait aussi comme avantage de supporter les coûts relatifs aux réunions du comité exécutif, voire de participer au financement des voyages et séjours des délégués lors des assemblées générales du Groupement. L'UEFA prélèverait donc une petite somme sur la recette des matchs internationaux, comme le fait la FIFA avec la Coupe du monde.

$\mathrm{Si}$, comme nous l'aborderons plus loin ${ }^{25}$, les congressistes présents lors de l'assemblée générale de l'UEFA de mars 1955 n'acceptent pas de lancer une compétition pour les équipes nationales, ils soutiennent par contre les volontés affichées par le comité de développer l'organisation. Ainsi, la nouvelle version des statuts proposée par le comité exécutif est acceptée à l'unanimité par les délégués et quasiment sans modification. Par ailleurs, ils décident également d'augmenter le nombre de dirigeants présents dans le comité exécutif, de six à huit. De même, ils acceptent que l'UEFA parraine, en été 1955, un match entre la Grande-Bretagne et le reste de l'Europe dans le but de célébrer les 75 ans de l'association d'Irlande du Nord. Durant les discussions, des sujets divers qui concernent les associations européennes de football - les concours de pronostics, la télédiffusion des matchs ou encore l'éventuel établissement d'un calendrier pour les rencontres internationales - sont également abordés. Le congrès de l'UEFA se profile donc comme un lieu propice de discussions sur différentes thématiques liées au jeu.

En mai 1955, le comité exécutif poursuit ses démarches en vue de structurer l'UEFA et décide d'ouvrir un compte bancaire à Paris ainsi que de créer un papier à lettres avec les abréviations "UEFA ${ }^{26}$. Puis, il s'agit d'organiser la rencontre de l'été 1955. Ce match recèle plusieurs avantages pour l'Union. Premièrement, il lui offre un apport financier puisque l'entité européenne touche un petit pourcentage sur les recettes. Deuxièmement, la rencontre constitue un bon moyen pour renforcer les liens entre les associations nationales, car, sur le modèle des matchs de la FIFA de 1938, 1947 et 1953, il s'agit de mettre sur pied une sélection européenne - le "Reste de l'Europe »-contre une sélection britannique. La rencontre connaît un certain succès avec 58000 spectateurs et est relayée par plusieurs quotidiens sportifs européens. Sur le terrain, si toutes les associations membres de l'UEFA ne sont pas représentées sont présents (par ordre alphabétique) : Autriche, Danemark, Belgique,

\section{Infra 4.1.4.}

26 Delaunay P., Procès-verbal de la réunion du comité d'urgence de l'UEFA des 6-7 mai 1955, n.d. UEFA, RM00005974 (réunion du comité exécutif, 1954-1959), document relié : procès-verbaux des comités exécutifs et comités d'urgenge 1954-1959 
France, Italie, Portugal, Suède, Yougoslavie et les quatre associations britanniques -, il semble néanmoins que cette situation ne soit pas due à la volonté du comité exécutif de l'UEFA mais à d'autres circonstances. En effet, un journaliste de L'Équipe écrit que les Britanniques ont été déçus des forfaits qui "se sont produits depuis un mois et regrettent l'absence des Hongrois, surtout des Russes, des Allemands et des Espagnols ${ }^{27}$. En convoquant une nouvelle fois les membres de la communauté du football européen, la rencontre permet de continuer les rapprochements entre les pays européens, et la volonté affichée de créer une représentation large témoigne du caractère paneuropéen de l'organisme.

L'année 1956 voit la promulgation des statuts officiels de l'UEFA ainsi que le lancement d'un bulletin trimestriel qui contient, dans les trois langues officielles de l'Union (allemand, anglais et français), autant des résumés des décisions prises par le comité exécutif de l'Union que des résultats des rencontres organisées dans le cadre de compétitions de l'entité. En cette même année, il est également question de professionnaliser le secrétariat de l'UEFA. Suite au décès, en novembre 1955, du premier secrétaire de l'Union, Henri Delaunay ${ }^{28}$, l'intérim est assuré par son fils, Pierre. Lors de l'assemblée générale de 1956, qui se déroule en été à Lisbonne, les congressistes discutent du poste de secrétaire et, plus largement, de la possibilité de créer un secrétariat permanent. Il faut dire que, jusque-là, l'UEFA est hébergée dans des locaux mis à sa disposition par la Fédération française. Si la majorité des associations membres ne se montrent pas prêtes ni à créer un siège pour l'entité ni à engager un secrétaire rémunéré à plein temps, sur proposition du comité exécutifif ${ }^{29}$, elles confirment Pierre Delaunay à la fonction de secrétaire général, néanmoins en ôtant de la fonction la possibilité de disposer d'un droit de vote au sein du comité exécutif. Ainsi, comme à la FIFA, le secrétaire général supervise le travail mais reste dans une fonction de type administratif. Lorsque nous l'avons interrogé au sujet de sa nomination, Pierre Delaunay s'est montré évasif et nous a simplement indiqué que son père avait "obtenu [qu'il] occupe sa place ${ }^{30}$. Delaunay parle et écrit dans plusieurs langues (allemand, anglais et français) et est déjà doté d'une expérience certaine

27 "À pied d'œuvre depuis la veille les "Continentaux" s'entraînent sous la direction de Pierre Pibarot ", L'Équipe, 12 août 1955.

28 Pour cause de maladie. "Henri Delaunay n'est plus... ", L'Équipe, 10 novembre 1955.

29 Delaunay P., Procès-verbal de la réunion du comité exécutif de l'UEFA du 8 juin 1956, n.d. UEFA, RM00005984 (congrès de l'UEFA, procès-verbaux 1954-1994), document relié : procès-verbaux des assemblées générales 1954-1959.

30 Entretien avec Pierre Delaunay réalisé le 18 septembre 2012 à Versailles. 
en matière d'administration du football puisqu'il est entré au service du Groupement des clubs autorisés (GCA) - organisme qui s'occupe du football professionnel en France - après la Deuxième Guerre mondiale, puis a été embauché à la Fédération française de football. S'il suit les traces de son père en cumulant le poste à l'UEFA avec celui de secrétaire général de la FFF, Pierre Delaunay est toutefois moins reconnu dans les cercles du football européen de l'époque. Or, à l'orée des années 1958-1959, ce cumul de fonctions et la moindre autorité dont fait preuve Pierre Delaunay va amener à des questionnements sur sa place en tant que secrétaire général de l'Union.

Il faut souligner que l'organisation continue en effet sa croissance et compte désormais sept commissions permanentes (commission des finances, commission des juniors, commission d'études des problèmes de la télévision, commission d'organisation de la Coupe des clubs champions européens, commission de la Coupe d'Europe, commission des amateurs, commission d'appel de la Coupe des clubs champions européens) ${ }^{31}$ auxquelles il faut ajouter le comité exécutif.

Tableau 14. Commissions permanentes de l'UEFA (début 1959)

\begin{tabular}{|l|l|c|}
\hline Commissions & Date de création & Nombre de membres* \\
\hline Exécutive & 1954 & 9 \\
\hline Coupe des champions & 1956 & 5 \\
\hline Appel & 1956 & 3 \\
\hline Finance & 1957 & 4 \\
\hline Juniors & 1957 & 5 \\
\hline Coupe des nations** & 1956 & 5 \\
\hline Télévision & 1958 & 3 \\
\hline
\end{tabular}

Légende : * : secrétaire général non inclus ; ${ }^{* *}$ : une commission provisoire existe déjà depuis 1955.

Le travail de ces commissions implique une tâche de coordination considérable pour le secrétaire général de l'UEFA, et ce d'autant plus qu'afin d'être tenus au courant de l'avancée des travaux, les dirigeants du comité exécutif exigent, à partir d'octobre 1958, qu'un exemplaire du procès-verbal

31 Delaunay P., Rapport du secrétaire général de l'UEFA (1958-1959), n.d. UEFA, RM00000917 (publications : rapport dusecrétaire général 1954-1985), po-10-1 
de chaque commission leur soit envoyé ${ }^{32}$. S'ajoute à ce travail le traitement de divers sujets (projet de compétition, établissement d'un calendrier international, questions relatives à l'homogénéisation de l'arbitrage ou encore relations avec les autres confédérations continentales). En outre, le Bulletin de l'UEFA devient plus conséquent et comprend désormais des articles divers sur le football européen, ce qui amplifie encore les tâches du secrétariat. À la veille du congrès de 1958, les dirigeants du comité exécutif cherchent à trouver des solutions en vue de répondre à cette augmentation des tâches du secrétaire général. En l'absence de Delaunay - les dirigeants lui ayant demandé de ne pas assister à la séance ${ }^{33}$-, des solutions sont préconisées en particulier par José Crahay - lui-même secrétaire général de l'Union belge et du Comité olympique belge. Ce dernier se montre compréhensif envers la situation du secrétaire général et insiste sur le fait qu'il a besoin d'aide. Selon lui, il est nécessaire que Pierre Delaunay puisse davantage déléguer le travail à un secrétaire administratif qui serait luimême " assisté du personnel subalterne indispensable à la bonne marche de l'UEFA " ${ }^{34}$. Durant le congrès qui suit ces discussions, des délégués estiment que le temps est venu d'établir un secrétariat fixe et d'engager un secrétaire employé à $100 \%$ par l'UEFA. En ce sens, il est décidé qu'une discussion devra avoir lieu avec la Fédération française dans la perspective que celle-ci mette à la disposition de l'Union de nouveaux bureaux ${ }^{35}$. Suivant ces recommandations, le comité exécutif de l'UEFA adresse, dans le courant de l'automne, une demande à la FFF afin qu' elle lui réserve trois bureaux dans ses locaux. Si cette requête est acceptée par la Fédération française, la solution que cette dernière propose ne convient néanmoins pas à l'élite dirigeante de l'Union, car les travaux d'agrandissement des

32 Delaunay P., Procès-verbal de la réunion du comité exécutif de l'UEFA du 28 octobre 1958, n.d. UEFA, RM00000749 (réunions du comité exécutif, 1954-1959), document relié : procès-verbaux des comités exécutifs et comités d'urgence 1954-1959.

33 Le sujet le touche de près et des reproches pourraient possiblement être adressés contre son travail. Des lettres échangées - conservées dans les archives la Fédération française entre novembre 1955 et mars 1956 entre un dirigeant du Groupement des clubs autorisés, Jean Dennis et Stanley Rous, soulignent cet aspect. En effet, le premier aurait indiqué au second que son fils ne serait pas l'égal de son père et que sa succession aurait du mal à être acceptée au sein de la Fédération française. Nous remercions Kevin Tallec Marston pour cette information.

34 Crahay J., Procès-verbal de la réunion du comité exécutif de l'UEFA du 3 juin 1958, n.d. UEFA, RM00000749 (réunions du comité exécutif, 1954-1959), document relié : procès-verbaux des comités exécutifs et comités d'urgence 1954-1959.

35 Delaunay P., Procès-verbal de l'assemblée générale de l'UEFA du 4 juin 1958, n.d. UEFA, RM00005986 (congrès fondateur, 1954. I-III congrès ordinaire, 1955-1957), document relié : procès-verbaux des assemblées générales 1954-19597 
locaux sont trop onéreux à son goût ${ }^{36}$. En date du 5 mars 1959, une souscommission, composée des membres de la commission des finances de l'UEFA et de son président, Ebbe Schwartz, rencontre le président de la Fédération française, Pierre Pochonnet. Cette réunion est l'occasion pour les dirigeants de l'Union d'indiquer au président de la Fédération française que l'organisation souhaite finalement quitter Paris afin de s'installer dans un siège unique.

Le comité exécutif se met donc en quête d'un nouveau lieu de résidence pour l'UEFA et s'accorde finalement sur l'établissement du siège en Suisse. Ce pays recèle d'indéniables qualités au regard des activités de l'Union. Sa neutralité ${ }^{37}$ offre des opportunités d'entretenir des relations avec la majeure partie des pays européens. De plus, grâce à son système bancaire développé, il sera possible de gérer au mieux les finances de l'Union. Il semble en effet que l'organisation européenne ait des difficultés avec son compte bancaire à Paris et, dès 1957, l'Union dispose déjà d'un compte en Suisse, situation qui semble faciliter les échanges financiers avec les associations nationales ${ }^{38}$. Enfin, nous pouvons supposer que la présence de la FIFA, mais aussi d'autres organisations comme l'Union européenne de radio ${ }^{39}$, sur le sol helvétique plaide également en faveur de ce choix ${ }^{40}$.

Le déménagement de l'UEFA en Suisse condamne le futur de Delaunay en tant que secrétaire général car, comme il nous l'a indiqué, il n'a pas envie de déménager, en particulier en raison de sa situation familiale (il a

36 Traduction d'une lettre de E. Schwartz aux associations européennes, n.d. UEFA, RM00005987 (IV Congrès ordinaire, 1958. I Congrès extraordinaire, 1959), dossier : assemblée générale extraordinaire de l'UEFA.

37 À cette période, la Suisse est toutefois plus proche du camp occidental, le communisme étant combattu par l'élite politique et économique du pays. Pour un propos général sur le positionnement du pays durant la Guerre froide, voir : Bott S. et al., "Le rôle international de la Suisse dans la Guerre froide globale : un équilibre précaire ", Relations internationales, vol. 163, n 3, 2015, pp. 3-14.

38 Delaunay P., Procès-verbal de la réunion du comité exécutif de l'UEFA des 7-8 novembre 1957, n.d. UEFA, RM00005974 (réunion du comité exécutif, 1954-1959), document relié : procès-verbaux des comités exécutifs et comités d'urgence 1954-1959.

39 Infra 4.2.4.

40 Il ne semble pas que la Confédération helvétique joue un rôle dans l'établissement du siège de l'UEFA sur son territoire. Ce n'est qu'à partir des années 1980 que le pays développera une véritable " diplomatie par le sport ", avec notamment comme but l'accueil d'organisations internationales sportives. À ce sujet, nous attendons les conclusions de la thèse de doctorat que prépare actuellement Quentin Tonnerre sous la direction de Patrick Clastres et Janick Marina Schaufelbuehl à l'Université de Lausanne. 
alors deux enfants en bas âge $)^{41}$. Dans une discussion sur le sujet, Jacques Ferran nous a précisé que "Pierre Delaunay n'avait pas l'envergure ni le courage de laisser tomber le football français pour aller là-bas, donc on savait à l'avance qu'il dirait [non], qu'il [préférerait] garder [son poste à] la Fédération française ${ }^{42}$. Il semble que la nomination d'un nouveau secrétaire entre aussi dans la balance pour le choix de la Suisse. En effet, dès le printemps, le secrétaire adjoint de la FIFA, Hans Bangerter, paraît avoir la cote pour occuper le poste de secrétaire général de l'UEFA. Or ce dernier souhaite rester en Suisse ${ }^{43}$. Dans son autobiographie, l'influent dirigeant anglais Stanley Rous indique qu'il connait Bangerter depuis plusieurs années et l'estime beaucoup. Certes, ce dernier souhaite plutôt succéder au secrétaire général de la FIFA, Kurt Gassmann, dont l'âge très avancé laisse présager une retraite prochaine (qui interviendra en 1961). Toutefois, selon Rous, ses chances d'obtenir ce poste sont minces ${ }^{44}$ : le jeune âge de Bangerter lui cause du tort puisque la plupart de ses prédécesseurs n'ont obtenu ce genre de consécration qu'après une longue carrière dans les organes dirigeants du football. Par contre, Rous comprend que le dynamisme du Bernois peut constituer un sérieux atout pour la jeune UEFA. Du haut de sa trentaine, Bangerter est déjà un administrateur disposant d'une certaine expérience en matière d'administration du sport. Après des études dans une école technique de Berne dans laquelle il est formé à un travail dans l'administration, il a travaillé au centre fédéral de gymnastique de Macolin où il est notamment chargé d'accueillir les visiteurs étrangers ou les participants à des cours. C'est d'ailleurs sur les hauts de la ville de Bienne qu'il a rencontré Stanley Rous. Puis, à partir de 1953, il est engagé comme secrétaire adjoint de la FIFA où il collabore notamment avec l'expérimenté Kurt Gassmann et étoffe ses relations avec les plus influents dirigeants du football européen, tels Barassi ou Thommen. De plus, Hans Bangerter détient trois autres qualités indispensables pour le poste de secrétaire général d'une organisation internationale. Premièrement, sa nationalité suisse plaide pour lui. Faisant partie d'un pays neutre, il sera difficilement possible de le taxer d'avoir des sympathies politiques pour l'un ou l'autre camp. En outre, il ne lui sera pas trop compliqué de se déplacer dans les différents pays européens. Deuxièmement, il a un sens aigu de la diplomatie, disposition clé pour ce type de poste, qu'il a notamment cultivé lors de ses fonctions à Macolin et au sein de la FIFA. Troisièmement, il parle et écrit très aisément plusieurs

\footnotetext{
41 Entretien avec Pierre Delaunay, réalisé le 18 septembre 2012 à Versailles.

42 Entretien avec Jacques Ferran, réalisé le 19 septembre 2012 à Paris.

43 Entretien avec Hans Bangerter, réalisé le $1^{\text {er }}$ octobre 2012 à Bollingen.

44 Rous S., Football worlds, op. cit., pp. 134-135.
} 
langues et notamment les trois langues officielles de l'Union (allemand, anglais et français).

Durant l'été 1959, l'avenir de l'UEFA s'inscrit loin de Paris et l'engagement définitif de Bangerter au poste de secrétaire général semble s'effectuer à ce moment-là. Par ailleurs, il s'agit de trouver un siège pour l'Union. Après de nombreuses démarches ${ }^{45}$, Bangerter arrive, avec l'aide d'Ernst Thommen, à réserver une place pour l'UEFA dans la Maison des sports qui se construit dans la banlieue de Berne et qui doit héberger le nouveau siège de l'Association suisse de football.

Afin de ne pas froisser Pierre Delaunay et la Fédération française et d'assurer au mieux la transition avec le nouveau secrétaire, le comité exécutif de l'UEFA envisage d'augmenter d'une place le nombre de dirigeants en son sein, procédé qui donnera " la possibilité d'élire Pierre Delaunay au sein du comité exécutif en qualité de Membre " ${ }^{46}$. Cette vision est acceptée lors d'un congrès extraordinaire de l'UEFA qui se déroule en décembre 1959. En outre, les délégués acceptent d'établir le siège en Suisse par 16 voix contre 9 et 3 abstentions. Si le procès-verbal de l'assemblée générale ne donne pas davantage de détails sur le résultat du vote, Jacques Ferran précise, dans un article sur le sujet paru dans le journal L'Equipe, que les pays de l'Est, la Grèce et le Portugal ont soutenu le maintien du siège à Paris ${ }^{47}$. Les griefs contre la décision du comité exécutif sont explicités notamment par le Yougoslave Andrejevic, qui souligne que le sujet n'a pas formellement été débattu entre les associations nationales, mais qưil est principalement le fruit d'une démarche du comité exécutif. Les décisions prises à Paris en matière d'administration pérennisent davantage l'existence de l'association. De plus, sous l'impulsion de Bangerter, le secrétariat connaît un rapide développement avec l'engagement de trois secrétaires administratives, respectivement Ilse Schmidlin, Suzanne Otth et Ursula Krayenbuehl, qui vont assister le secrétaire général dans ses tâches. Les documents officiels de I'UEFA reflètent cette professionnalisation du secrétariat : ils sont nettement plus formalisés (avec des rubriques précises et numérotées) et comportent désormais systématiquement des dates de rédaction et des signatures.

45 La FIFA est même contactée à ce sujet mais refuse d'héberger le siège de l'UEFA. Gassmann K., Procès-verbal de la réunion du comité exécutif de la FIFA du 24 avril 1959, 20 mai 1959. FIFA, comité exécutif (procès-verbaux 1959).

46 Delaunay P. Procès-verbal de la réunion du comité exécutif de l'UEFA du 30 octobre 1959 , n.d. Document numérisé que nous a transmis l'archiviste de l'UEFA, Nicolas Bouchet.

47 «Incroyable mais vrai. La France n'a pas voté pour la France! », L'Équipe, 15 décembre 1959. 
Durant ces premières années, l'UEFA se profile donc comme une organisation permettant des échanges sur des thématiques relatives au football européen. Outre le lancement de plusieurs compétitions ${ }^{48}$, de nombreux sujets sont discutés lors des séances du comité exécutif et des assemblées générales de l'Union, par exemple (liste non exhaustive) :

- les concours de pronostics sur les matchs internationaux ;

- un calendrier des matchs internationaux;

- un stage pour les entraîneurs ;

- la définition d'une catégorie de jeu pour les espoirs ;

- la télédiffusion des matchs.

En outre, les congrès annuels de l'Union constituent assurément une plateforme de rencontres pour la soixantaine de dirigeants qui proviennent en moyenne d'une trentaine de pays. Comme lors des congrès de la FIFA, ces assemblées sont le théâtre de moments de sociabilité qui doivent permettre de fortifier les liens entre les dirigeants présents. Par exemple, en mars 1955 à Vienne, tous les congressistes se déplacent sur la tombe du premier vice-président de l'Union, l'Autrichien Joseph Gerö, décédé à la fin de l'année 1954. En outre, il offre l'image d'une organisation européenne unie commémorant ses morts, ce qui ressort fortement de l'allocution faite sur la tombe du défunt ${ }^{49}$. Enfin, dès ses premières années, l'UEFA commence à avoir comme vocation d'aider les associations nationales à participer aux échanges internationaux. Cette aide peut prendre la forme d'un soutien financier dans le déplacement des équipes, en particulier pour le tournoi international des juniors ou d'un soutien à l'organisation même de la joute, l'Union acceptant de se porter garante en cas de déficit (comme c'est le cas en 1958 où la joute est organisée par le Luxembourg, une petite association qui dispose de ressources limitées $)^{50}$. Par ailleurs, dans cette volonté de participer aux développements du football en Europe, en

48 Infra 4.1.3. et 4.1.4.

49 Dont le discours a été retrouvé dans les archives nationales allemandes. Par ailleurs, dans la salle de réunion du siège de la Fédération autrichienne dans laquelle se déroule le congrès - ce qui montre au passage que l'Union reste alors une entité modeste - trône une photo du dirigeant disparu. "Ils n'ont pas voulu du Championnat d'Europe !... ", France football, 8 mars 1955.

50 Anonyme, " $4^{\mathrm{e}}$ Assemblée générale de l'UEFA à Stockholm. 10. Règlement du tournoi international juniors », n.d. UEFA, RM00005987 (IV Congrès ordinaire, 1958. I Congrès extraordinaire, 1959), dossier : assemblée générale de Stockholm 4/6/1958/ textes complets des délibérations. 
mars 1960, les dirigeants du comité exécutif de l'UEFA imaginent la mise sur pied d'un cours pour entraîneurs et coachs, qui s'effectuerait sous la direction de Gustav Sebes, membre du comité et ancien sélectionneur de l'équipe nationale de Hongrie ${ }^{51}$.

Durant ses cinq premières années d'existence, l'UEFA s'affirme donc rapidement comme un acteur majeur du développement du football européen. Par ailleurs, dès ses premières années, elle renforce aussi la délimitation des frontières du territoire européen du jeu.

\subsubsection{Quelles sont les frontières du football européen ?}

Les qualifications de la Coupe du monde ont, depuis l'entre-deuxguerres, délimité le territoire du football européen. La création du Groupement européen entraîne de nouvelles discussions sur le sujet. La première question qui se pose aux dirigeants est celui du cas de la Turquie car, en 1955, l'Association turque fait part de son souhait d'être incorporée à l'entité européenne.

Cette volonté s'explique par le faible développement du football chez ses voisins asiatiques qui font montre d'un niveau footballistique plutôt faible. Aussi les dirigeants turcs estiment-ils préférable, pour la dynamisation de leur football, de se tourner vers les pays européens. En outre, ce souhait de faire partie de l'UEFA doit également se comprendre en raison des relations historiques que la Turquie entretient en matière de football avec plusieurs pays européens. Affiliée depuis 1923 à la FIFA, la Turquie rencontre régulièrement, durant l'entre-deux-guerres, les pays du Sud-Est du continent et participe à la Coupe des Balkans ${ }^{52}$. À partir du début des années 1950, l'équipe nationale élargit ses échanges et rencontre des pays plus à l'ouest de l'Europe, comme l'Allemagne de l'Ouest, l'Espagne, la Suède ou encore la Suisse, et participe aux qualifications pour la Coupe du monde de la zone Europe. Notons encore que la sélection turque junior prend en effet part aux tournois internationaux des jeunes de 1953 et 1954. En septembre 1955, Kurt Gassmann fait d'ailleurs le constat que l'équipe nationale turque joue «la plupart [de ses] matchs internationaux

51 Schmidlin I., Procès-verbal de la réunion du comité exécutif de l'UEFA du 10 mars 1960, 8 avril 1960. UEFA, RM00000750 (séances du comité exécutif, 10 mars-8 juillet 1960).

52 Breuil X., Constantin P.N., "The Balkan cups as a vector of European integration ", op. cit. 
[...] contre des associations européennes $»^{53}$. Enfin, la structure de l'association turque et les décisions prises par ses dirigeants, en particulier concernant la légalisation de la pratique du football professionnel en 1952, se rapprochent de celles de leurs homologues européennes.

À la vue de ces différents éléments, il est possible de considérer que la Turquie est intégrée dans $l^{\prime}$ « Europe du football ». Nous souscrivons donc aux propos de Özgehan Senyuva et Tunç Sevecen qui indiquent que faire partie de l'UEFA pour la Turquie parait alors " une chose naturelle ${ }^{54}$. Plus largement, cette participation aux activités footballistiques européennes s'inscrit dans la ligne du gouvernement turc, qui se tourne vers l'Europe en construction. Le pays est membre du Conseil de l'Europe depuis 1949 et vise à terme à participer au développement de l'Europe économique ${ }^{55}$. L'adhésion de la Turquie à l'entité européenne est formellement discutée lors de son premier congrès officiel qui se déroule à Vienne en 1955.

À la veille de l'assemblée générale, le comité exécutif de l'UEFA engage un débat au sujet de la requête transmise par les dirigeants turcs. Après discussions, l'élite de l'UEFA décide de faire voter la demande d'affiliation au congrès, avec un préavis favorable, « afin que l'Association turque soit provisoirement inscrite dans le Groupement européen, dans l'attente d'une homologation de la FIFA " $"$. Lors des discussions, l'Islande, la Grèce et la Pologne se joignent préalablement au cortège des associations déjà membres de l'UEFA. Trente et une fédérations sont désormais réunies au sein de l'organisme. Le cas de la Turquie est certes plus épineux mais est plutôt bien accueilli par les associations membres de l'UEFA, ce qui révèle que plusieurs dirigeants considèrent le pays comme étant effectivement intégré dans le territoire footballistique européen. À l'entame de la discussion sur la question de savoir si la Turquie peut être incorporée à l'Union, son président, Ebbe Schwartz, se permet d'appuyer la requête turque et lit une communication signée

53 Gassmann K., Rapport relatif à l'ordre du jour de la réunion du comité exécutif de la FIFA des 17-18 septembre 1955, 17 août 1955. FIFA, comité exécutif (procès-verbaux 1955-1957).

54 Senyuva Ö., Tunç S., "Turkey and the European Football ", Sport in History, vol. 35, $\mathrm{n}^{\circ} 4,2015$, p. 575.

55 Vaner S., "La Turquie et l'Union européenne. L'altérité commune », dans Dumoulin M., Duchenne G. (dir.), L'Europe et la Méditerranée. Actes de la VI Chaire Glaverbel d'études européennes 2000-2001, Bruxelles, P.I.E. Peter Lang, 2001, pp. 107-124.

56 Delaunay P., Procès-verbal de la réunion du comité exécutif de l'UEFA du $1^{\text {er }}$ mars 1955, n.d. UEFA, RM00005974 (réunion du comité exécutif, 1954-1959), document relié : procès-verbaux des comités exécutifs et comités d'urgenge 1954-1959 
du Yougoslave Miahilo Andrejevic et du Grec Constantin Constantaras, qui plaident en faveur de l'adhésion de la Turquie. Ce support doit se comprendre en raison des liens footballistiques étroits qui unissent ces pays depuis les années 1920. De plus, le contexte géopolitique facilite ces rapprochements, la Turquie ayant signé une alliance politico-économicomilitaire avec les deux pays en août $1954^{57}$. La note des deux délégués insiste sur le fait que l'activité sportive de l'association nationale turque "s'est toujours exercée dans le cadre du continent européen ${ }^{58}$. Ce point est l'un des arguments majeurs des dirigeants turcs, qui ajoutent qu'ils n'ont d'ailleurs jamais participé aux activités du football asiatique. Toutes les associations membres de l'UEFA ne semblent toutefois pas être en total accord avec l'adhésion de la Turquie. Dans le livre commémoratif du vingt-cinquième anniversaire de l'UEFA, Sir Stanley Rous revient brièvement sur les débats à ce sujet ${ }^{59}$. Il est difficile de savoir exactement qui prend position contre la Turquie ainsi que la teneur de ces oppositions. Malgré tout, le cas turc reçoit finalement le soutien de la part de la majorité des dirigeants présents. En effet, le procès-verbal de la réunion indique que l'assemblée a tenu compte des recommandations du comité exécutif et demande donc à la FIFA de procéder à l'affiliation de l'association nationale turque. Quelques mois plus tard, le président de la Fédération turque, Hasan Polat, adresse une lettre à la FIFA pour appuyer la position de son association, soulignant que le congrès de l'UEFA a décidé que "la Fédération turque devrait être considérée comme une Association faisant partie de cette Union ${ }^{60}$. C'est donc finalement à la FIFA de trancher sur cette décision. Laisser la décision finale à la FIFA semble un moyen pour les associations membres de UEFA de se délester d'un sujet encombrant, et ce d'autant plus que, parallèlement à la requête turque, une autre association demande à faire partie de l'organisation, la Fédération israélienne ${ }^{61}$.

57 Oikonomidis P., Le jeu mondial dans les Balkans. Les relations gréco-yougoslaves de la Seconde Guerre mondiales à la Guerre froide, Paris, L'Harmattan, 2011, p. 506.

58 Delaunay P., Procès-verbal de l'assemblée générale de l'UEFA du 2 mars, n.d. UEFA, RM00005974 (réunion du comité exécutif, 1954-1959), document relié : procèsverbaux des comités exécutifs et comités d'urgence 1954-1959.

59 Rous S. "Quelques souvenirs ", dans Rothenbuehler R., Les 25 ans de l'UEFA, op. cit., p. 79.

60 Lettre de H. Polat à R.W. Seeldrayers, 14 septembre 1955. FIFA, correspondance avec les associations nationales : Turquie (1932-1970), dossier : 1.1.1951-31.12.1955.

61 Gassmann K., Procès-verbal de la réunion du comité exécutif de la FIFA du 9 mai 1955, 13 mai 1955. FIFA, comité d'urgsnce (procès-verbaux 1951-1957) 
Pour l'élite de l'UEFA, la situation de ce pays paraît néanmoins plus délicate à traiter que celle de la Turquie ${ }^{62}$. Pourtant, certains arguments des dirigeants israéliens sont les mêmes que ceux de leurs collègues turcs. Le cas israélien diverge toutefois sur trois points. Premièrement, la position d'Israël sur la scène internationale est problématique. En effet, suite à la guerre israélo-arabe de 1948-1949, qui débouche sur l'indépendance israélienne, Israël n'entretient aucune relation diplomatique avec ses voisins arabes et, au contraire, se trouve même en état d'alerte constant, comme le rappellera l'éclatement de la crise de Suez quelques semaines plus tard. Cette situation empêche le pays « d'avoir des relations de sport avec les associations asiatiques les plus proches " ${ }^{63}$. Ce n'est donc pas uniquement pour des raisons sportives qu'Israël souhaite entamer des échanges avec les pays européens, mais également parce qu'il ne trouve pas d'adversaires dans sa région en raison de problèmes politiques. De plus, des tensions existent aussi avec certains pays européens puisqu'Israël n'entretient aucune relation diplomatique avec certains d'entre eux, en particulier avec l'Allemagne. Par ailleurs, le fait que le pays soit soutenu par les États-Unis ${ }^{64}$ l'oppose de facto aux pays du bloc de l'Est. C'est pourquoi, comme l'a étudié Haggai Harrif, les deux rencontres jouées dans le cadre des qualifications pour les Jeux olympiques de 1956 entre Israël et l'Union soviétique sont marquées par un fort investissement politique de l'État hébreu $^{65}$. Dès lors, l'entrée de ce pays dans l'UEFA ne risquerait-elle pas de créer de graves problèmes à l'intérieur même de l'organisation ? Le fait qu'Israël est un pays jeune, créé seulement en 1948, constitue un deuxième élément en défaveur de son adhésion à l'Union. Malgré un positionnement rapide sur la scène internationale sportive ${ }^{66}$, le pays n'entretient pas de traditions footballistiques fortes avec les associations européennes. Dès lors,

62 Delaunay P., Procès-verbal de la réunion du comité exécutif de l'UEFA des 6-7 mai 1955, n.d. UEFA, RM00005974 (réunion du comité exécutif, 1954-1959), document relié : procès-verbaux des comités exécutifs et comités d'urgence 1954-1959.

63 Gassmann K., Rapport relatif à l'ordre du jour de la réunion du comité exécutif de la FIFA des 17-18 septembre 1955, 17 août 1955. FIFA, comité exécutif (procès-verbaux 1955-1957).

64 Claude G., «Israël-États-Unis, de la reconnaissance historique à l’alliance stratégique. Histoire des relations stratégiques et diplomatiques, 1948-2004 ", Revue historique des armées, vol. 252, 2008, pp. 2-11.

65 Harrif H., " "It is important that we beat the gentiles": the national significance of Israel's soccer matches against the USSR, Summer 1956 ", Sport in Society, vol. 12, $\mathrm{n}^{\circ}$ 8, 2009, pp. 1038-1053.

66 C'est au début des années 1950 que le pays est officiellement reconnu au sein de la FIFA et du CIO : Alperovich, A., Israel in der olympischen Bewegung, Sank Augustin, Academia Verlag, 2012. 
au contraire de la Turquie, il ne peut compter sur aucun soutien fort au sein de l'UEFA. Troisièmement, Israël peut-il être considéré comme faisant partie de l'Europe ? Certes, les frontières du continent sont discutables et découlent d'une conception formellement établie au XIX ${ }^{\mathrm{e}}$ siècle $^{67}$. Selon celle-ci, Israël n'est pas incorporé au sein du continent européen. Ce sont ces conceptions géographiques que retiennent les dirigeants du comité exécutif de l'UEFA. Par exemple, la Turquie peut être intégrée dans le continent européen puisqu'une (petite) partie de son territoire y est rattaché, à savoir la ville d'Istanbul. Au contraire, le territoire israélien n'a que peu d'attaches directes avec le Vieux Continent et doit donc être considéré comme un territoire du Proche-Orient. Le contexte politique, le peu de traditions footballistiques du pays avec les associations européennes ainsi que la représentation géographique du continent de l'élite de l'UEFA sont différents du cas de la Turquie et ont pour conséquence de limiter fortement la probabilité d'une adhésion d'Israël à l'Union.

Le 14 août 1955, le comité exécutif de l'UEFA statue finalement sur la question de ce pays et indique qu'il " n'est pas d'avis de retenir [la candidature d'Israël], mais décide, avant de se prononcer définitivement, de recueillir l'avis de la FIFA ${ }^{68}$. Aucun argument n'est avancé dans le procès-verbal, mais les discussions qui s'opèrent, dans les mois qui suivent, entre la FIFA et l'UEFA, éclairent ce positionnement. C'est lors des sessions du comité exécutif de la FIFA, qui se déroulent les 17 et 18 septembre 1955, que les dirigeants de la Fédération internationale délibèrent sur les demandes d'Israël, de la Turquie (et aussi de Chypre qui a également posé sa candidature pour entrer dans l'UEFA). Dans son commentaire relatif à l'ordre du jour, Kurt Gassmann note qu'il est temps pour le comité exécutif de la FIFA de prendre une décision sur ces points. Pour lui, la question est sans équivoque, ces associations sont " géographiquement et politiquement parlant, des associations appartenant de facto et de jure au continent asiatique. Les deux fédérations ont leur siège dans la capitale de leur pays. Vouloir les considérer comme des associations européennes serait nier l'évidence ${ }^{69}$."

67 Sur cette question, voir en particulier le numéro spécial de la revue Monde(s), "Inventions des continents ", coordonné par Isabelle Surun et Hughes Tertrais en 2013. Et pour un propos plus général : Grataloup C., L’invention des continents : comment l'Europe a découpé le monde, Paris, Larousse, 2009.

68 Delaunay P., Procès-verbal de la réunion du comité exécutif de l'UEFA du 14 août 1955, n.d. UEFA, RM00005974 (réunion du comité exécutif, 1954-1959), document relié : procès-verbaux des comités exécutifs et comités d'urgence 1954-1959.

69 Gassmann K. Rapport relatif à l'ordre du jour de la réunion du comité exécutif de la FIFA des 17-18 septembre 1955. FIFA, somité exécutif (procès-verbaux 1955-1957). 
Par "géographiquement », le secrétaire général veut souligner le fait que le siège de la fédération nationale se trouve en dehors du continent européen. À cette date, la Fédération turque est effectivement basée à Ankara, c'est-à-dire sur un territoire considéré comme asiatique. Par contre, qu'entend-il par "politiquement parlant " ? Un indice pourrait être qu'il considère que le gouvernement turc siégeant également à Ankara, donc sur territoire asiatique, le pays est " politiquant parlant " en Asie. C'est du moins ce que le secrétaire Gassmann avait déjà signalé en avril 1954 à Henri Delaunay, lorsque ce dernier lui avait demandé si la Turquie pouvait être invitée aux discussions sur la création du Groupement européen ${ }^{70}$. En outre, des arguments footballistiques, que Gassmann ne mentionne pas, peuvent expliquer sa position. En effet, une organisation asiatique existe désormais. De fait, la participation des associations turques et israéliennes, qui se montrent particulièrement dynamiques dans l'établissement d'échanges footballistiques internationaux, est peutêtre perçue comme une aubaine par la FIFA en vue de développer les relations à l'intérieur de la Confédération asiatique. De fait, dépouiller cette dernière des fédérations turques et israéliennes paraît contraire à l'idée de dynamiser le jeu au Proche et au Moyen-Orient. Toutefois, la porte de l'UEFA ne leur est pas totalement fermée, le secrétaire général de la FIFA mentionnant que si l'Union le souhaite, elle pourra permettre aux associations turques et israéliennes de disputer ses compétitions. De plus, des autorisations exceptionnelles peuvent être délivrées par la FIFA, comme pour le tournoi international des juniors, vu qu'une telle épreuve n'existe pas sur le continent asiatique. Gassmann rappelle aussi que, concernant la Coupe du monde, la répartition des groupes de qualification ne dépend pas uniquement de l'aspect géographique mais aussi des considérations économiques et sportives, ce qui sous-entend qu'il pourrait arriver que ces pays soient intégrés dans les groupes de la zone européenne.

Le comité exécutif de la FIFA suit les principes développés par le secrétaire général Gassmann et décide ne pas "donner suite à ces demandes vu qu'indubitablement les pays de ces trois associations géographiquement-politiquement font partie du continent asiatique ${ }^{71}$. En date du 20 septembre 1955, les trois associations concernées reçoivent

70 Lettre de K. Gassmann à H. Delaunay, 19 mars 1954. FIFA, correspondance avec les associations nationales : France (1937-1954), dossier : 1.1.1951-53.

71 Gassmann K., Procès-verbal de l'assemblée générale de la FIFA du 17 septembre 1955, 22 novembre 1955. FIFA, comité exécutiff.(procès-verbaux 1955-1957):0570-1 
un courrier leur indiquant que, sans doute possible, leur fédération nationale appartient au continent asiatique ${ }^{72}$.

Réuni le 18 mars 1956, le comité exécutif de l'UEFA prend note de cette décision. Si l'élite dirigeante de l'Union se conforme à celle-ci pour ce qui est d'Israël, elle n'est par contre pas en accord avec la vision de la Fédération internationale vis-à-vis des requêtes chypriote et turque. Dès lors, elle souhaite donc porter cette question devant le prochain congrès de la FIFA afin que la Fédération internationale statue "clairement sur la situation de ces pays vis-à-vis de l'Union européenne " ${ }^{73}$. Cette requête confirme qu'au sein de l'UEFA, le cas turc est traité différemment du cas israélien. Lors du congrès de l'UEFA de 1956, le délégué portugais Figueira insiste - considération qui semble suivie par la grande majorité des autres dirigeants - sur la différenciation qui doit être faite entre la Turquie et les deux autres pays. Pour lui, l'association turque devrait pouvoir s'affilier à la confédération de son choix, car son territoire chevauche deux continents. Suivant ce raisonnement, le président et le secrétaire général de l'UEFA font « la proposition que soit confirmée la reconnaissance de l'Association nationale de la Turquie dans le cadre de l'Union européenne, étant entendu que l'attention de la FIFA sera fortement attirée en vue d'obtenir que cette fédération puisse jouir de tous ses droits comme membre affilié à l'UEFA ${ }^{74}$. Malgré cette motion, la Fédération internationale décide de ne pas revoir sa politique sur le sujet.

Afin de la contourner, la Turquie va être, au fil des mois, de plus en plus intégrée aux actions de l'UEFA, l'association nationale turque prenant régulièrement part à ses assemblées générales et le vainqueur de son championnat national participant, dès l'année 1958-1959, à la Coupe des clubs champions créée en 1955. De même, l'équipe nationale turque fait partie des dix-sept équipes qui participent à la première édition de la Coupe d'Europe des nations qui est organisée en 1958. Enfin, une année plus tard, le comité exécutif de la FIFA accepte la requête de la Fédération turque d'être placée dans le groupe qualificatif de la zone Europe en vue de

72 Lettre de K. Gassmann à H. Polat, 20 septembre 1955. FIFA, correspondance avec les associations nationales : Turquie (1932-1970), dossier : 1.1.1951-31.12.1955. Une lettre analogue et datant de la même période peut être retrouvée dans la correspondance de la fédération israélienne.

73 Delaunay P., Procès-verbal de la réunion du comité exécutif de l'UEFA du 18 mars 1956, n.d. UEFA, RM00005974 (réunion du comité exécutif, 1954-1959), document relié : procès-verbaux des comités exécutifs et comités d'urgence 1954-1959.

74 Delaunay P., Procès-verbal de l'assemblée générale de l'UEFA du 8 juin 1956 à Lisbonne, n.d. UEFA, RM00005984 (congrès de l'UEFA, procès-verbaux 1954-1994), document relié : procès-verbaux des assemblées générales 1954-1959 
la Coupe du monde de $1962^{75}$. Au regard de ces différentes démarches, il est possible de considérer le pays comme un « membre virtuel » de l'UEFA, pour reprendre l'expression de Peter Beck sur la position des associations britanniques vis-à-vis de la FIFA dans les années 1930.

Selon Senyuva et Tunç, le principal lobbyiste contre l'adhésion de la Turquie au sein de l'UEFA est le secrétaire général de la FIFA, Kurt Gassmann ${ }^{76}$. Certes, ce dernier s'est effectivement montré réticent, toutefois, au regard de nos analyses, ce n'est pas un argument de type personnel qui semble être décisif mais plutôt celui qui a trait à la vision géographique du comité exécutif de la FIFA. En effet, la fédération turque est finalement autorisée à être incorporée au sein de l'UEFA lorsqu'elle déplace son siège d'Ankara à Istanbul en $1962^{77}$. En revanche, le cas israélien ne connaît pas d'avancement. En 1958, le comité exécutif de la FIFA refuse d'entrer en matière sur une nouvelle requête de la Fédération israélienne, la demande étant arrivée après le délai stipulé dans les statuts pour être traitée lors du congrès. Dès lors, le pays reste considéré comme faisant partie du continent asiatique. Deux ans plus tard, ce sont les dirigeants du comité exécutif de l'UEFA qui refusent la participation du champion israélien à la Coupe des champions, invoquant, à nouveau, la " situation géographique ${ }^{78}$ du pays pour motiver leur refus.

Les demandes d'Israël et de la Turquie ${ }^{79}$ sont intéressantes à étudier car elles permettent de dessiner la conception du territoire européen chez les dirigeants de l'UEFA. Pour eux, les frontières de "l'Europe du football " correspondent au territoire géographique européen tel qu'il a été défini par les géographes dès le XIX ${ }^{e}$ siècle ${ }^{80}$. Or, si la Turquie peut intégrer cet ensemble, il paraît nettement plus difficile pour eux d'imaginer qu'Israël puisse être véritablement considéré comme un pays européen. C'est donc dans le cadre de ce territoire que le football européen va se développer et

75 Gassmann K., Procès-verbal de la réunion du comité exécutif de la FIFA du 27 octobre 1959, 9 décembre 1959. FIFA, comité exécutif (procès-verbaux 1959).

76 Ces deux auteurs se basent essentiellement sur des sources provenant de la presse turque. Senyuva Ö., Tunç S., "Turkey and the European Football », op. cit., p. 575.

77 Käser K., Procès-verbal de la réunion du comité exécutif de la FIFA des 8-9 février 1962, $1^{\text {er }}$ mars 1962 (version française). FIFA, comité exécutif (procès-verbaux 1962).

78 Schmidlin I., Procès-verbal de la réunion du comité exécutif de l'UEFA du 10 mars 1960, 8 avril 1960. UEFA, RM00000750 (séances du comité exécutif : 10 mars-8 juillet 1960).

79 Auxquelles il faut ajouter le cas chypriote, qui se rapproche de celui de la Turquie. Finalement, l'association de Chypre est affiliée à l'UEFA en 1964.

80 Pécout G., "Jusqu'où va l'Europe au XIX" siècle ? ", dans Pécout G., Penser les frontières de l'Europe, op. cit., pp. 97-117. 
que l'UEFA va commencer à administrer des compétitions, et en premier lieu un tournoi pour les clubs : la Coupe des clubs champions européens.

\subsubsection{Le succès de l'Europe des clubs}

Dans un texte paru en 1998, le secrétaire général adjoint de l'UEFA, Markus Studer, mentionnait que l'Union a été créée pour organiser des compétitions $^{81}$. En fait, la mise sur pied d'une organisation internationale sportive n'implique pas forcément la création de compétitions. Rappelons que la FIFA a par exemple attendu près de vingt-cinq ans avant d'organiser la première édition de son propre tournoi. De même, dans le projet de statuts qui est présenté aux délégués présents lors de la première assemblée générale de l'UEFA à Vienne, sur les six buts de l'Union, un seul traite explicitement de l'aspect compétitif en indiquant qu'elle se réserve le droit " d'organiser à sa convenance et au moins tous les quatre ans un Championnat d'Europe dont elle sera seule compétente pour fixer les règlements et conditions $"{ }^{82}$. De plus, durant ce congrès, créer une compétition ne paraît pas être une priorité des congressistes puisqu'ils ne soutiennent pas le projet de Coupe d'Europe des nations qui leur est présenté. Pour autant, il faut concéder à Markus Studer que, très rapidement, l'organisation de compétitions va devenir la tâche principale de l'UEFA. Dès lors, comment expliquer ce retournement ?

Il faut tout d'abord mentionner que de nombreuses compétitions européennes sont imaginées pour différents sports dans la seconde moitié du XX ${ }^{\mathrm{e}}$ siècle. En effet, si, depuis l'entre-deux-guerres, des championnats européens d'athlétisme et de boxe existent déjà, au milieu des années 1950, de nouveaux projets de compétitions européennes sont évoqués comme celui d'une coupe intervilles de basket ${ }^{83}$. Dans le domaine footballistique, plusieurs acteurs du jeu (dirigeants des associations nationales, dirigeants de clubs ou encore journalistes) souhaitent désormais créer des compétitions d'envergure, notamment pour les clubs. Au milieu des années 1950, deux ambitieux projets sont ainsi lancés quasiment de manière parallèle.

81 Studer M., "Le développement du football au sein de l'UEFA », dans Bizzini L., Hauert C.-A., Piffaretti M. (dir.), Le football : éléments théoriques pour une meilleure compréhension, Genève, Médecine et Hygiène, 1998, p. 98.

82 Anonyme, "Union des associations européenne de football. Projet de statuts ", 18 février 1955. FIFA, correspondance avec les confédérations continentales : UEFA (1955-1958), dossier : correspondance générale 01.01.1955-31.12.1958.

83 "La Coupe d'Europe intervilles de jeu à sept verra le jour ce soir ", L'Équipe, 19 octobre 1956. 
Le premier émane du trio Barassi, Rous et Thommen et consiste en la création d'un tournoi joué entre des équipes de villes ("scratch team ») qui organisent de grandes foires internationales ${ }^{84}$. Par ce biais, il s'agirait de créer de nouvelles synergies entre des acteurs du football européen et des acteurs économiques. Dans ses mémoires, Stanley Rous note également que, dans ces décennies d'après-guerre, cette épreuve est aussi l'occasion de concrétiser un nouvel esprit de coopération au travers du football, médium permettant de dépasser les anciennes rivalités et de créer de nouvelles amitiés ${ }^{85}$. L'épreuve est officiellement lancée le 4 juin 1955 avec la première rencontre qui se joue entre Bâle XI et Londres XI. Les équipes suivantes s'inscrivent (par ordre alphabétique) : Bâle XI, FC Barcelone, Birmingham City, Cologne XI, Francfort XI, Leipzig XI, Londres XI, FC Lausanne-sport, Inter Milan, Staevnet, Vienne XI et Zagreb XI ${ }^{86}$. Malgré les difficultés pour fixer les matchs, la première épreuve se déroulant jusqu'en 1958 , le tournoi connaît un certain succès ${ }^{87}$. Par ailleurs, signe de son importance, son assemblée générale annuelle réunit de nombreux dirigeants d'associations nationales ou de clubs influents dans le football européen. Connaissant bien l'organisation du football, les trois dirigeants ont pris le soin de ne pas affronter les organisations garantes du football européen, en premier lieu la FIFA mais aussi la jeune UEFA. En effet, les équipes de villes ne sont pas des entités officielles en tant que telles et n'ont donc pas à se référer aux organismes officiels du football (associations nationales et internationales). Cette précaution n'a pas été prise par les promoteurs d'un autre projet, beaucoup plus ambitieux au regard du nombre d'équipes envisagées : la Coupe d'Europe des journalistes de L'Équipe. Projet désormais bien étudié dans l'histoire du football ${ }^{88}$, cette idée est lancée par l'un des journalistes piliers de la rubrique football,

84 La Coupe des villes de foires n'a pas fait jusqu'ici l'objet d'études spécifiques. Quelques éléments peuvent être trouvés dans : Vonnard P., « How did UEFA govern the European turning point in football? ", op. cit.

85 Rous S., Football worlds, op. cit., p. 145.

86 Les villes de Cologne et Vienne annulent finalement leur participation. De même, nous constatons que contrairement aux vœux initiaux des organisateurs, quelques clubs - comme FC Barcelone et Lausanne-sport -participent au tournoi.

87 Avec environ 20000 spectateurs de moyenne par match selon le rapport du secrétaire général de l'UEFA 1954-1955. Delaunay P., Rapport du secrétaire de l'UEFA (1954-1955), n.d. UEFA, RM00000917 (publications : rapport du secrétaire général 1954-1985).

88 Pour davantage de détails sur la création de l'épreuve, nous nous permettons de renvoyer à notre livre : Vonnard P., La genèse de la Coupe des champigns ach-cit. 
Gabriel Hanot, en date du 15 décembre $1954^{89}$. Il s'agirait de créer une coupe disputée à l'échelle européenne entre seize clubs issus de seize pays différents. Ce projet tient compte des nouvelles possibilités offertes par le transport aérien et par le début de l'éclairage dans les stades, qui permet une pratique hivernale du football les jours de semaine. Il tient également compte de la recherche constante de gains des dirigeants de clubs pour financer le football professionnel mais aussi des journaux sportifs toujours avides de nouvelles informations ${ }^{90}$. En ce sens, il obtient rapidement plusieurs supports de la part de présidents de grands clubs européens ainsi que de journaux sportifs influents (Bola au Portugal, La Gazzetta dello Sport en Italie, Les Sports en Belgique, Marca en Espagne).

Après l'élaboration d'un premier règlement, deux journalistes de L'Équipe, Jacques Ferran et Gabriel Hanot, viennent plaider la cause du projet lors de l'assemblée générale de l'UEFA de mars 1955. Cependant, comme pour la Coupe des nations, les délégués présents ne vont pas soutenir l'idée. Non découragés par ce refus, les journalistes convoquent une assemblée à Paris au mois d'avril à laquelle quinze grands clubs européens qu'ils ont préalablement sélectionnés en raison de leur prestige - sont représentés ${ }^{91}$. Des deux jours de discussion il ressort l'élaboration d'un règlement pour une compétition inter-clubs qui se déroulera dès le mois de septembre ainsi que la nomination d'un comité exécutif de l'épreuve, avec à sa tête l'Espagnol Santiago Bernabeu (président du Real Madrid) et le Hongrois Gustav Sebes (représentant des deux clubs de Budapest : Honved et Voros Lobogos) ${ }^{92}$. Dans le but de concrétiser définitivement le lancement de l'épreuve, les délégués fixent les matchs du premier tour. Ainsi, l'UEFA se voit mise devant le fait accompli et, selon son secrétaire général, Henri Delaunay, va devoir réagir puisque, comme il le note dans une lettre au nouveau président de la FIFA, Rodolphe Seeldrayers :

89 "Non, Wolverhampton n'est pas encore le "champion du monde des clubs"! ", L'Équipe, 15 décembre 1954.

90 Montérémal G., "L'Équipe: médiateur et producteur de spectacle sportif(1946-1967) », Le Temps des Médias, vol. 9, n² 2, 2007, pp. 107-120.

91 Anderlecht (Belgique), Partizan Belgrade (Yougoslavie), Chelsea (Angleterre), FC Copenhague (Danemark), Djugaarden (Suède), Rot Weiss Essen (Allemagne), Servette Genève (Suisse), Hibernian (Écosse), Holland Sport (Pays-Bas), Sporting Lisbonne (Portugal), Real Madrid (Espagne), AC Milan (Italie), Stade de Reims (France), Sarrebruck (Sarre), Stade de Reims (France), Rapid Vienne (Autriche) et Voros Lobogos (Hongrie).

92 Anonyme, "Projet d'une Coupe d'Europe proposé par le journal L'Équipe et d'autres journaux européens ", n.d. FIFA, correspondance avec les confédérations continentales : UEFA (1955-1958), dossier : correspondance générale 01 01_1955-31 12 1958. 
"Si des clubs, des journaux, éventuellement des Ligues nationales ou professionnelles peuvent ainsi passer outre au contrôle et à l'autorité des associations nationales, de la FIFA et éventuellement des groupes statutaires (Europe) qu'elle a institués, la vie même des associations nationales peut être mise en péril, surtout lorsqu'il s'agit d'un tel titre et d'une telle épreuve ${ }^{93}$. »

En mai 1955, le comité exécutif de l'Union transmet une motion à son homologue de la FIFA afin de pouvoir récupérer l'organisation de l'épreuve. De même, il lui demande que "le titre "Europe" soit réservé à l'UEFA " ${ }^{94}$. Cette requête constitue un geste fort en vue de l'affirmation du monopole de l'Union sur le football à l'échelle européenne puisque celle-ci souhaite se réapproprier, pour elle seule, le droit de nommer un tournoi portant le terme "Europe ». Le comité exécutif de la FIFA va suivre cette demande et émet trois conditions à respecter en vue de l'organisation de l'épreuve. Premièrement, les clubs engagés doivent avoir le consentement de leur association nationale. Deuxièmement, le nom " Europe " ne doit être utilisé que pour des joutes concernant les sélections nationales ${ }^{95}$. Troisièmement, il est décidé que la compétition doit être gérée par l'UEFA. Ce point est très important, car il ôte l'autorité de l'épreuve au comité d'organisation déjà constitué, et donc aux clubs et aux journalistes.

La passation de témoin entre le comité créé par les clubs et les journalistes et l'UEFA s'effectue au mois de juin 1955. Le comité exécutif de l'Union assoit de suite son autorité sur l'épreuve et décide de renommer le tournoi sous l'appellation de Coupe des clubs champions européens. En outre, si, pour la première édition, ce sont les clubs choisis par les journalistes de L'Équipe qui sont conservés - le court laps de temps avant le début de l'épreuve ne permettant pas de convoquer d'autres équipes -, il est décidé qu'à l'avenir l'épreuve opposera les champions de tous les championnats nationaux des associations membres de l'UEFA.

La création de cette épreuve, dont le premier match se déroule en septembre 1955, est cruciale dans le développement de l'UEFA. Premièrement, la Coupe des champions confère de facto une nouvelle prérogative à l'UEFA, avec l'organisation d'un premier tournoi européen. Lors de sa séance des 17 et 18 septembre 1955, le comité exécutif de

93 Lettre de H. Delaunay à R.W. Seeldrayers, 28 avril. FFF, Euro 60, dossier : Coupe de l'Europe 1955.

94 Delaunay P., Procès-verbal de la réunion du comité exécutif de l'UEFA des 6-7 mai 1955, n.d. UEFA, RM00005974 (réunion du comité exécutif, 1954-1959), document relié : procès-verbaux des comités exécutifs et comités d'urgence 1954-1959.

95 Gassmann K., Procès-verbal de la réunion du comité d'urgence de la FIFA du 9[8] mai 1955, 13 mai 1955. FIFA, comité d'urgence (procès-verbaux 1951-1957) 
la FIFA accepte le règlement de la Coupe des champions transmis par l'UEFA. L'élite dirigeante de la Fédération internationale confie aussi le soin à l'Union de s'occuper de la Coupe des villes de foires dont la première édition bat dorénavant son plein ${ }^{96}$. Cette décision montre que l'entité européenne devient progressivement la référence en ce qui concerne l'organisation de compétitions à l'échelle continentale. L'organisation de la Coupe des champions confere donc du poids aux dirigeants du comité exécutif de l'UEFA, comme José Crahay, Henri Delaunay ou Ebbe Schwartz, qui militent pour que l'Union organise des compétitions (et en particulier la Coupe d'Europe des nations). En outre, l'épreuve offre une légitimité supplémentaire à l'UEFA auprès de ses associations membres. Ainsi, des associations qui n'avaient pas été invitées par les journalistes parisiens initiateurs de la Coupe se manifestent très rapidement afin de participer à l'épreuve. C'est le cas du CDNA Sofia (Bulgarie), de Dudelange (Luxembourg), de Gwardia Varsovie (Pologne), du Dinamo Bucarest (Roumanie), du Spartak Sokolovo Prague (Tchécoslovaquie) et de la formation turque de Galatasaray Istanbul ${ }^{97}$.

Deuxièmement, le tournoi - dont le succès de la première édition assure sa reconduction l'année suivante - permet aussi de financer les activités de l'UEFA. En effet, dans le règlement de la Coupe, établi formellement pour la deuxième édition qui se déroule en 1956-1957, il est indiqué que l'Union reçoit $1 \%$ de la recette brute de chaque match. Elle touche également $5 \%$ de la recette sur la finale ${ }^{98}$. Dans son rapport pour les années 1954-1955, le secrétaire de l'UEFA indique avec satisfaction que plus de 800000 spectateurs ont assisté aux vingt-neuf matchs de la Coupe des champions, soit une moyenne de 28000 spectateurs par rencontre ${ }^{99}$. L’engouement pour les grands matchs dépasse largement la capacité des stades, comme le montre l'exemple de la rencontre qui oppose le CDNA Sofia à l'Étoile Rouge de Belgrade pour les quarts de finale de l'édition 1956-1957. En effet, 400000 demandes de billets sont soumises au club

96 Gassmann K., Procès-verbal de la réunion du comité exécutif de la FIFA du 17 septembre 1955, 22 novembre 1955. FIFA, comité exécutif (procès-verbaux 1955-1957).

97 Delaunay P., Procès-verbal de la réunion du comité d'urgence de la FIFA du 17 juillet 1955, n.d. UEFA, RM00005974 (réunion du comité exécutif, 1954-1959), document relié : procès-verbaux des comités exécutifs et comités d'urgence 1954-1959.

98 Anonyme, Règlement de la Coupe des champions [saison 1956-57], art. 16, n.d. UEFA, RM00005391 (publications : commission de la Coupe des clubs champions européens, dossier : ECCC règlements 1956-1957).

99 Delaunay P., Rapport du secrétaire général de l'UEFA (1954-1955), n.d. UEFA, RM00000917 (publications : rapport dy secrétaire général 1954-1985) 
de la capitale bulgare alors que son stade ne compte que 40000 places $^{100}$. Selon un article de France football du 5 juillet 1960, plus de deux millions de spectateurs se rendent dans les stades pour la saison 1959-1960, soit une moyenne de près de 41000 personnes par match. L'auteur de l'article ajoute que seulement six matchs se sont déroulés devant moins de 10000 spectateurs et indique que "partout, maintenant, [la Coupe des champions] est connue et convoitée. Partout, elle aimante les foules » ${ }^{101}$. En conséquence, ces fonds supplémentaires vont permettre à l'UEFA de développer ses activités, notamment en organisant, à partir de la fin des années 1950, différents cours et formations (pour arbitres ou entraîneurs).

Troisièmement, le tournoi participe à la structuration de l'Union. En effet, après une première édition gérée par son comité exécutif, dès la deuxième édition de 1956-1957, une commission permanente est mise sur pied pour l'organisation de la Coupe des champions. C'est l'un des premiers organes permanents de l'UEFA à être créé. Il est intéressant de souligner que cette commission est composée de dirigeants très actifs en matière de développement de l'Union, à savoir José Crahay, Sir George Graham et Augustin Pujol. La commission joue un rôle avant tout technique et administratif, effectuant les tirages au sort, discutant du calendrier, des dates et lieux des finales ou encore répondant aux questions provenant des clubs. Parallèlement à la mise sur pied de cet organe, le règlement initial de l'épreuve est largement remodelé. Désormais, il compte 16 articles qui traitent des droits et obligations des participants, des bornes saisonnières de la compétition et qui donnent des indications concernant l'arbitrage des rencontres.

La création de la Coupe des champions conforte donc l'existence de l'UEFA, mais plus largement, marque un tournant dans l'histoire du football européen, car il s'agit de la première épreuve véritablement européenne pour les clubs. Certes des tournois supranationaux d'importance existent dès l'entre-deux-guerres, telle par exemple la Mitropa Cup. Mais trois différences majeures sont à relever entre cette épreuve et la Coupe des champions. En premier lieu, la Coupe des champions convoque beaucoup plus de pays. Si seize équipes provenant de seize pays différents prennent part à la première édition en 1955-1956, vingt-deux clubs - cette fois, tous des champions nationaux - participent à l'épreuve lors de la saison 1956-1957 et une trentaine de formations s'inscrivent au tournoi à la fin de la décennie.

100 Finalement des aménagements seront faits et 50000 personnes assisteront au match. Voir «Bojkov s'arrache les cheveux et pleure : Sofia ne jouera pas les demi-finales ! ", France football, 26 février 1957.

101 «La balle au bond. Pas sympathique », Erance football, 5 juillet 1960 
Cette participation implique un nombre de matchs conséquent et amorce de nouveaux échanges entre les associations de football en Europe. Alors qu'au pic de sa popularité, au milieu des années 1930, la Mitropa Cup était le théâtre de trente-deux matchs ${ }^{102}$, durant la saison 1958-1959, 55 matchs sont disputés dans le cadre de la Coupe des champions. En second lieu, la Coupe des champions se dispute tout au long de l'année footballistique, ce qui n'était pas le cas de la Mitropa Cup qui se jouait au plus durant quatre à cinq mois. Ainsi, le tournoi se superpose aux championnats nationaux, ce qui constitue assurément une nouveauté. De cette manière, la Coupe des champions permet de dynamiser les épreuves nationales puisque, désormais, la première place au championnat national équivaut à une qualification pour cette "Coupe d'Europe " dont les journaux sont de plus en plus friands. Au fil des années, des rubriques spéciales sont créées pour traiter de cette actualité et aussi aborder les matchs quelques semaines en amont. Il s'agit par exemple de jauger l'adversaire d'un des clubs du pays et les journalistes n'hésitent pas à considérer les matchs de championnat précédant l'affrontement européen comme des rencontres de préparation à la Coupe ${ }^{103}$. En troisième lieu, en convoquant uniquement les champions nationaux, ce sont rarement les mêmes équipes qui participent à la Coupe. Lors de la saison 1958-1959, seules 7 équipes sur les 26 engagées ont déjà pris part au tournoi préalablement. Cette hétérogénéité permet d'établir de nouveaux contacts entre tous les acteurs de la communauté footballistique européenne, et ce pour deux raisons principales. En premier lieu, lorsqu'une équipe se déplace, la délégation n'est pas seulement composée de joueurs, mais aussi de dirigeants du club, de membres de la fédération nationale et de journalistes de la presse locale et nationale. Par exemple, lors du crash aérien qui touche l'équipe de Manchester à son retour d'un match joué à Belgrade en février 1958, ce sont des joueurs et des dirigeants du club, mais aussi une dizaine de journalistes anglais (de la presse locale et nationale). En deuxième lieu, les voyages à l'étranger sont l'occasion pour les clubs de conclure des matchs internationaux supplémentaires. Par exemple, lorsque l'équipe hongroise de Voros Lobogos se déplace en France, en décembre 1955, pour joueur contre le Stade de Reims, ses dirigeants concluent trois matchs amicaux. Les deux premiers seront joués à Grenoble et Nice dans la foulée de la rencontre disputée contre l'équipe champenoise. La troisième se disputera au début janvier à Lyon et nécessitera donc un nouveau voyage d'une délégation

102 Comme indiqué dans le chapitre 2, elle s'arrête en 1939. Le tournoi est malgré tout relancé en 1955 mais reste, jusqu’à sa disparition au début des années 1990, un tournoi secondaire qui se dispute en été.

103 Comme le montre une lecture générale de La Semaine sportive des années 1950 aux années 1970. 
hongroise dans l'Hexagone ${ }^{104}$. Au vu de tous ces éléments, la Coupe des champions fait rupture avec les tournois supranationaux organisés par le passé et engage une nouvelle phase de l'histoire des compétitions européennes. Par ailleurs, en offrant la possibilité aux clubs de disputer une compétition supplémentaire, elle dynamise encore plus la lutte pour le titre de champion national. Ainsi, l'échelle géographique européenne influe sur le développement du jeu à l'échelon national.

Inspirés par le succès de la Coupe des champions, des acteurs du football européen voient cette épreuve comme un premier pas vers l'établissement d'autres compétitions continentales. Le 18 mars 1956, le comité exécutif de l'UEFA « prend connaissance d'une proposition du Dr Frey, tendant à doubler la Coupe des champions européens par une épreuve similaire jouée entre les vainqueurs des Coupes nationales " ${ }^{105}$. Aucune décision n’est prise en la matière, mais cette proposition crée un débat sur la question. En marge du congrès annuel qui se déroule au mois de juin à Lisbonne, le journaliste français Gabriel Hanot s'enthousiasme pour l'idée et n’hésite pas à écrire que "L'Équipe" provoquera [les dirigeants de l'Union à ce sujet], comme elle l'a déjà fait pour la Coupe des clubs ${ }^{106}$. Cette pression de L'Équipe en vue de la réalisation du projet n'est pas à négliger puisque ce journal a fortement contribué au développement de la Coupe des champions. De plus, en octobre de la même année, des journalistes de sa rubrique «Basket » participent activement à la création d'une compétition européenne de clubs pour ce sport ${ }^{107}$, ce qui révèle la volonté du journal de développer les échanges sportifs à l'échelle continentale mais aussi le réseau dont il dispose au sein du monde sportif.

Après un premier temps de latence, c'est la Fédération espagnole qui reprend le flambeau en vue de l'établissement d'une compétition pour les vainqueurs des coupes nationales. En novembre 1957, Augustin Pujol détaille devant ses collègues du comité exécutif de l'Union un projet de tournoi qui convoquerait les vainqueurs des coupes nationales. Selon

104 "Voros Lobogos jouera à Grenoble le 19 décembre à Nice, le 22 ", L'Équipe, 14 décembre 1955.

105 Delaunay P., Procès-verbal de la réunion du comité exécutif de l'UEFA du 18 mars 1956, n.d. UEFA, RM00005974 (réunion du comité exécutif, 1954-1959), document relié : procès-verbaux des comités exécutifs et comités d'urgence 1954-1959. Les coupes nationales sont des épreuves disputées en parallèle des championnats, en match à élimination directe. Elles mettent aux prises autant les clubs de l'élite que les clubs amateurs. À cette période, cette épreuve n'existe pas dans tous les pays européens.

106 "À Lisbonne, UEFA et FIFA prêtes à siéger », L'Équipe, 8 juin 1956.

107 "La Coupe d'Europe intervilles de jeu à sept verra le jour ce soir », L'Équipe, 19 octobre 1956. 
lui, « cette épreuve pourrait intéresser dès cette année les vainqueurs de Coupe d'Angleterre, d'Espagne, de France et du Portugal ${ }^{108}$. Quelques heures avant le début du congrès annuel de 1958, Pujol transmet un projet remanié au comité exécutif. Ceux-ci se montrent réceptifs et décident " de former une commission chargée d'élaborer le règlement, composée de MM. Crahay, Graham, Frey, Pujol, qui sera soumis, s'il y a lieu, au prochain Congrès, en vue d'une réalisation pour la saison 1959-1960 $»^{109}$.

En raison du temps restreint, le projet n'est finalement pas présenté lors du congrès de l'UEFA en 1958 et les dirigeants du comité exécutif entament une autre démarche avec la consultation de toutes les associations membres de l'UEFA. Il est convenu « de donner suite à l'étude de cette question, si, au moins, dix d'entre elles se déclarent intéressées par ce projet ${ }^{110}$. Les résultats de la consultation sont discutés en mars 1959 par les dirigeants du comité exécutif. Ils se présentent comme suit :

Associations qui refusent de participer : Albanie, Allemagne (Ouest), Angleterre, Danemark, Belgique, Espagne, Islande, Pays-Bas, Suède, Suisse et Union soviétique.

Associations qui réservent encore leur réponse : France, Italie, Irlande du Nord et Luxembourg.

Associations qui acceptent de participer : Allemagne (Est), Autriche, Écosse, Irlande, Roumanie et Turquie.

Sur les trente et une associations membres, vingt et une ont répondu, ce qui souligne que les communications transmises par l'UEFA sont prises au sérieux par la majorité des associations nationales européennes. Cependant, le soutien pour la compétition est en deçà des espérances de l'élite de l'Union puisque onze associations ne souhaitent pas inscrire d'équipes dans la future compétition. Comme il avait été décidé qu'il fallait a minima dix associations favorables pour concrétiser le projet, le comité exécutif ne donne pas suite à l'idée.

108 Delaunay P., Procès-verbal de la réunion du comité exécutif de l'UEFA des 7-8 novembre 1957, n.d. UEFA, RM00005974 (réunion du comité exécutif, 1954-1959), document relié : procès-verbaux des comités exécutifs et comités d'urgence 1954-1959.

109 Delaunay P., Procès-verbal de l'assemblée générale de l'UEFA des 2-3 juin 1958, n.d. UEFA, RM00005974 (réunion du comité exécutif, 1954-1959), document relié : procès-verbaux des comités exécutifs et comités d'urgence 1954-1959.

110 Delaunay P., Procès-verbal de la réunion du comité exécutif de l'UEFA du 28 octobre 1958, n.d. UEFA, RM00005974 (réunion du comité exécutif, 1954-1959), document relié : procès-verbaux des comités exécutifs et comités d'urgenge 1954-1959 
Le projet de la Coupe des coupes est intéressant à étudier puisqu'il souligne la croissance des activités de l'Union. Néanmoins, si son comité exécutif souhaite dynamiser les échanges footballistiques en Europe par le biais de la Coupe des champions, une partie des associations membres de l'UEFA se montrent encore résistantes face à une trop grande extension de ce processus. Cette posture se perçoit dans les difficultés qui entourent le projet de Coupe d'Europe des nations.

\subsubsection{La difficile émergence de l'Europe des nations}

Dans un texte se focalisant sur le développement du football européen des années 1950, Fabien Archambault souligne que celui-ci est marqué par le sceau de la difficulté ${ }^{111}$. Les propos développés dans les lignes précédentes nous amènent à plus de nuances, car nous avons vu que l'UEFA développe rapidement de nombreuses activités. Cependant, l'argument d'Archambault s'accole bien au projet de Coupe d'Europe des nations.

Suite au refus de l'assemblée générale de 1955 de soutenir le projet de compétition pour les équipes nationales européennes, de nouvelles discussions ont lieu sur le sujet au sein d'une commission spéciale du comité exécutif ${ }^{12}$. Malgré ces avancées, les délégués réunis lors de l'assemblée générale de l'UEFA à Lisbonne en 1956 rejettent la création d'une telle compétition $^{113}$. Paul Dietschy résume bien les principaux griefs qui sont alors portés au projet, à savoir " les divergences de vue sur la dimension géographique que doit revêtir l'internationalisme du ballon rond [et] les turbulences de la géopolitique européenne [ainsi] que les rivalités divisant le cercle des dirigeants du football européen " ${ }^{114}$. Ses promoteurs réussissent néanmoins à préserver le travail de la commission d'étude sur le projet, qui est reconduite et même renforcée puisqu'elle passe de trois à cinq membres.

111 Archambault F., " " La difficile gestation d'une Europe du football », op. cit.

112 Une réunion a par exemple lieu à Bologne en février 1956. Delaunay P., Procèsverbal de la réunion du comité exécutif de l'UEFA du 22 février 1956, n.d. UEFA, RM00005974 (réunion du comité exécutif, 1954-1959), document relié : procèsverbaux des comités exécutifs et comités d'urgence 1954-1959.

113 Delaunay P., Procès-verbal de la réunion du comité exécutif de l'UEFA du 8 juin 1956 à Lisbonne, n.d. UEFA, RM00005984 (congrès de l'UEFA, procès-verbaux 1954-1994), document relié : procès-verbaux des assemblées générales 1954-1959.

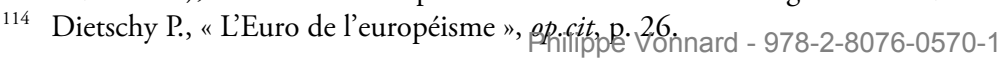


Cet élargissement doit permettre de fédérer davantage les opinions des différentes forces existantes au sein de l'Union autour du projet et, à terme, de trouver des solutions de compromis permettant de créer la compétition. Parmi les nouveaux dirigeants qui y officient, il faut mentionner la présence du Polonais Lyzek Rylski. Ainsi, deux dirigeants du bloc soviétique - le Polonais rejoint le Hongrois Gustav Sebes - participent aux travaux. Cette situation témoigne du rapprochement Est-Ouest qui est en train de se produire. Sur la scène politique internationale, le rapport Khrouchtchev de février 1956, dans lequel le premier secrétaire du parti communiste soviétique reconnaît les crimes commis sous le règne de Staline ${ }^{115}$, permet d'entrevoir de nouvelles coopérations. Dans un texte d'un livre consacré à l'année 1956 qui serait, selon ses coordinateurs, "une date européenne ", René Rémond note que le contexte est alors marqué par le début de discussions significatives entre des dirigeants politiques des deux camps ${ }^{116}$. Autre dirigeant coopté dans la commission d'étude pour l'organisation de la Coupe d'Europe, l'Espagnol Augustin Pujol. Ce dirigeant s'est montré favorable au développement de l'UEFA puisque, lors du congrès de 1956, il défend l'idée de la création d'un poste fixe de secrétaire ${ }^{117}$ et que, comme signalé, il soutient le projet d'une Coupe des vainqueurs de coupes, démarche à laquelle a également participé l'Autrichien Alfred Frey, qui est lui aussi choisi pour siéger dans la commission. Enfin, la représentation est complétée par le Grec Constantin Constantaras.

Ainsi, les délégués présents ont choisi des représentants des différentes forces existant au sein de l'UEFA, et ce afin de pouvoir faire avancer au mieux les discussions. Mais ils ont aussi opté pour des dirigeants issus d'associations nationales favorables au développement de l'Union. Sous cet aspect, il est intéressant de relever que les pays dont ils proviennent sont globalement absents des organisations européennes qui ont émergé depuis le début des années 1950. Or Juan Antonio Simón a par exemple montré que, dès la seconde partie des années 1950, le régime franquiste

115 Sur cette période, voir : Carrère d'Encausse H., La deuxième mort de Staline, Bruxelles, Complexe, 2006.

116 Rémond R., "La rencontre des deux Europe, octobre 1956 », dans Mink G., Lazar M.,Sielksi M.-J. (dir.), 1956 : une date européenne, Lausanne, Éditions Noir sur Blanc, p. 351. Ce contexte général favorable permet notamment une "réunion officieuse » à Helsinki, du 6 au 9 février 1957, entre les délégués techniques de l'Union européenne de radio et télévision (Est) et leurs homologues de l'Union internationale de radio (Ouest). Anonyme, "Activités de l'UER ", Bulletin de l'UER, vol. 42, mars-avril 1957.

117 Delaunay P., Procès-verbal de la réunion du comité exécutif de l'UEFA du 8 juin 1956 à Lisbonne ", n.d. UEFA, RM00005974 (réunion du comité exécutif, 1954-1959), document relié : procès-verbaux des comités exécutifs et comités d'urgence 1954-1959-1959. 
déploie un activisme grandissant sur la scène internationale, en investissant en particulier le basket-ball et le football ${ }^{118}$. Sous cet angle, le football peut-il constituer un moyen pour les gouvernements franquistes et soviétiques de ne pas être totalement exclus des entreprises de coopération européennes ${ }^{119}$ ?

À côté de ces décisions prises au sein de l'UEFA, des acteurs influents du football continental militent désormais activement en faveur de la création d'un tournoi pour les équipes nationales européennes et tentent désormais de mettre une certaine pression sur l'élite de l'UEFA afin qu'elle statue définitivement sur la question. Nous retrouvons ici notamment les journalistes de L'Équipe. Ainsi, Gabriel Hanot, envoyé spécial au congrès de Lisbonne de 1956, écrit que l'assemblée a décidé de créer une Coupe d'Europe des nations ${ }^{120}$, alors que, comme nous l'avons indiqué, les congressistes n'ont en fait pas pris de décision à ce sujet. Quelques mois plus tard, c'est Jacques Ferran qui prend la plume - il écrit depuis plusieurs mois sur le sujet en espérant que les choses bougen ${ }^{121}$ - et n'hésite pas à marteler que l'absence d'une épreuve européenne regroupant les nations nuit au prestige du football européen. Il ajoute que « les idées les plus simples, les plus évidentes, se heurtent à mille obstacles inattendus lorsqu'elles sont confrontées avec les hommes chargés de les mettre en pratique. Depuis 1954, l'Union européenne a louvoyé, tergiversé, tourné autour du pot ${ }^{122}$. "Ce commentaire est bien entendu intéressé, une compétition supplémentaire signifiant pour le journal davantage d'informations et donc potentiellement plus de ventes. Mais les propos de Ferran doivent sans doute aussi servir à appuyer les actions de Pierre Delaunay qui, au sein de l'UEFA, a repris le flambeau de son père et se

118 Simón J.A., "La diplomacia del Balón. Deporte y relaciones internacionales durante el franquismo ", História e Cultura, vol. 4, n²1, 2012, pp. 165-189,

119 La question mérite d'être posée car, comme l'a montré Johaness Grossmann, des représentants de l'Espagne franquiste jouent des rôles dans des organisations européennes pouvant être considérées comme de second plan, tel le Centre européen de documentation et d'information (CEDI) : Grossmann J., "Élites conservatrices et politique extérieure privée en Europe de l'Ouest après la Seconde Guerre mondiale », dans Osmont M. et al. (dir.), Européanisation au XXe siècle. Un regard historique, Bruxelles, P.I.E. Peter Lang, 2012, pp. 47-58. Pour le régime soviétique, voir les nombreux travaux de Marie-Pierre Rey, en particulier : Rey M.-P., « Le retour à l'Europe ? Les décideurs soviétiques face à l'intégration européenne, 1957-1991 ", Journal of European Integration History, vol. 11, n 1, 2005, pp. 7-27.

120 "Lisbonne, confluent du football européen et mondial ", L'Équipe, 9-10 juin 1956.

121 Déjà en mars 1955, au sujet du rejet du projet lors de la première Assemblée générale de l'Union, il n'avait pas hesité à écrire (en comparant le cas européen à celui de l'Amérique du Sud) : "Pauvre vieille Europe, comme tu retardes ! ", "Ils n'ont pas voulu du Championnat d'Europe !... ", France football, 8 mars 1955.

122 "L'Allemagne contre l'Europe ", L'Équipe 3 mars 1957. 
démène pour réaliser le tournoi. En date du 25 avril 1957, après de nouvelles discussions au sein de la commission d'étude, une nouvelle mouture du projet de tournoi est envoyée aux associations nationales. Dans sa lettre d'accompagnement, le secrétaire général explique que les membres de la commission ont tenté de répondre aux éventuelles critiques, notamment en réduisant "au maximum le nombre de matchs susceptibles d'être joués par les pays engagés, afin de ne pas nuire à l'établissement de leur propre calendrier international $"{ }^{123}$. Par ailleurs, le projet comprend aussi davantage de détails sur la répartition financière des gains de la compétition.

Calendrier limité, répartition des recettes entre les différentes instances du jeu (UEFA, FIFA, associations nationales) et indépendance de l'épreuve visà-vis de la Coupe du monde ; la commission a donc répondu aux principaux griefs qui leur étaient adressés depuis deux ans. En outre, quelques heures avant l'ouverture du congrès de l'UEFA de 1957, le comité exécutif de l'Union ajoute à l'article 1 du projet de compétition un amendement stipulant que celle-ci se disputera "sous réserve d'approbation du comité exécutif de la FIFA ${ }^{124}$ afin de répondre à une ultime remarque des dirigeants européens de la Fédération internationale ${ }^{125}$. Les promoteurs du tournoi ont donc fait preuve de mesure et, comme de coutume, recherchent le compromis et le dialogue. Malgré ces avancées, des résistances persistent, en particulier de la part des membres du comité exécutif de la FIFA, notamment Barassi et Rous, qui émettent de sérieuses réserves et soulignent soit que l'UEFA souhaite aller trop rapidement en besogne, soit qu'il y a déjà trop de compétitions existantes et que la Coupe des nations est de trop. Ils affirment même qu'elle pourrait risquer de nuire aux rencontres amicales, alors très importantes pour les finances des fédérations nationales ${ }^{126}$.

Malgré ces réticences, le projet de tournoi européen est finalement accepté : quinze associations s'expriment en faveur du projet, sept s'y

123 Lettre de P. Delaunay aux associations nationales affiliées à l'UEFA, 25 avril 1957. UEFA, RM00000749 (réunions du comité exécutif, 1954-1959), dossier : 1957.06.26-27.

124 Delaunay P., Procès-verbal de la réunion du comité exécutif de l'UEFA des 26-27 juin 1957 à Copenhague, n.d. UEFA, RM00000749 (réunions du comité exécutif, 1954-1959), dossier : 1957.06.26-27.

125 Gassmann K., Procès-verbal de la réunion du comité d'urgence de la FIFA 15 mars 1957, 31 mars 1957. FIFA, comité d'urgence (procès-verbaux, 1951-1957).

126 Un document avec toutes les prises de parole a été conservé aux archives de l'UEFA. Anonyme, "Projet de création d'une Coupe d'Europe des Nations (présenté par MM. Augustin Pujol et Pierre Delaunay) », n.d., UEFA, RM00005986 (congrès fondateur, 1954. I-III congrès ordinaire, 1955-1957), dossier : Coupe d'Europe des Nations). 
opposent et quatre s'abstiennent ${ }^{127}$. Une majorité de fédérations souhaite donc que l'étude en vue de l'organisation du tournoi se poursuive et soit rediscutée à la prochaine assemblée générale, en vue, cette fois, d'une acceptation définitive. Dans l'année qui suit, si les promoteurs du tournoi continuent à réfléchir au projet, leur but principal est d'essayer de convaincre un maximum d'associations de participer à la future épreuve. Ainsi, le congrès de 1958 s'apparente pour eux à une heure de vérité : soit le projet est accepté par une majorité d'associations et, dans la foulée, la compétition peut démarrer, soit il est rejeté et l'idée du tournoi sera abandonnée.

Les discussions de 1958 sur la question sont âpres, mais vont finalement déboucher sur la création de l'organisation, d'autant que grâce aux actions des membres de la commission d'étude dix-sept associations indiquent désormais qu'elles sont prêtes à participer à la future épreuve. Toutefois, les plus farouches opposants à la création de l'épreuve, et en premier lieu le trio Barassi, Rous, Thommen, continuent dans leur tactique visant à, une nouvelle fois, la repousser, argumentant qu'il est nécessaire de continuer à réfléchir sur la question. En ce sens, ils n'hésitent pas à souligner que l'UEFA s'approprie un droit détenu par les associations nationales, celui de pouvoir choisir son adversaire pour les matchs internationaux. Ces tentatives d'obstruction n'aboutissent pas et le projet de tournoi européen est finalement accepté par l'assemblée de l'UEFA. Il faut dire que le bloc soviétique s'est désormais totalement rallié à l'idée de cette compétition. La doctrine défendue par l'Union soviétique sur la scène internationale, la " coexistence pacifique ", semble se refléter dans le football. En effet, sa nouvelle politique ne consiste plus à faire chuter de manière frontale le capitalisme, mais à le dépasser dans tous les domaines. Sous cet angle, une participation active aux grandes joutes sportives et aux travaux des organisations internationales sportives est dorénavant activement promue par les dirigeants de l'URSS. Sous cet angle, Jenifer Parks souligne que, désormais, les délégués soviétiques qui officient dans les organisations internationales sportives doivent étudier les langues étrangères afin de participer plus activement aux débats ${ }^{128}$. La Coupe d'Europe des nations s'offre comme une opportunité pour conduire cette politique, car elle permettrait de rencontrer des pays du bloc capitaliste. Désormais sûr de

127 Delaunay P., Procès-verbal de l'assemblée générale de l'UEFA des 28-29 juin 1957 à Copenhague ", n.d. UEFA, RM00005984 (Congrès de l'UEFA, procès-verbaux 1954-1994), document relié : procès-verbaux des assemblées générales 1954-1959.

128 Parks J., Red Sport, Red Tape: the Olympic Games, the Soviet Sports Bureaucracy, and the Cold War, 1952-1980, thèse de doctorat réalisée sous la direction de Donald Raleigh, University of North Carolina, 2009, p. 141 
la valeur footballistique de son équipe - l'équipe soviétique est médaille d'or au tournoi de football des Jeux olympiques de 1956 et atteint les quarts de finale de la Coupe du monde de 1958 -, le régime soviétique pourrait, par l'entremise des rencontres de l'équipe nationale organisées dans le cadre du tournoi, montrer la vigueur du système communiste ${ }^{129}$.

Alors que le congrès accepte finalement le lancement de l'épreuve, le tirage au sort est organisé déjà quelques heures après la fin du congrès. Cette rapidité d'exécution s'explique autant au regard des délais impartis, la compétition devant débuter dès le mois suivant, que pour éviter un possible retour en arrière, voire de nouvelles tensions au sein de l'UEFA. Dix-sept pays prennent part à la première épreuve (par ordre alphabétique) : Allemagne de l'Est, Autriche, Bulgarie, Danemark, Espagne, France, Grèce, Hongrie, Irlande, Norvège, Pologne, Portugal, Roumanie, Tchécoslovaquie, Turquie, Union soviétique, Yougoslavie. Constatons que les fédérations anglaises, ouest-allemandes et italiennes, qui se sont farouchement opposées à la mise en place de la compétition, manquent donc à l'appel. De même, de petites nations influentes dans le domaine du ballon rond européen comme la Belgique, le Pays de Galles, la Suède et la Suisse refusent d'y participer. Par contre, l'Espagne, qui a fortement soutenu le projet, la France - d'où vient le secrétaire de l'UEFA - et le Danemark - d'où provient le président - s'engagent dans l'épreuve. Dès lors, sans l'inscription de tous les pays du bloc soviétique (ils sont huit en comptant la Yougoslavie), le tournoi n'aurait pas vu le jour.

Lépreuve va permettre de continuer l'accroissement des échanges à l'échelle européenne depuis l'entre-deux-guerres. En effet, les premiers tours de l'édition inaugurale de la Coupe d'Europe des nations proposent des confrontations tout à fait inédites. Ainsi, l'Espagne rencontre notamment la Pologne. Outre le fait que cette rencontre oppose deux régimes politiquement divisés, à savoir le régime franquiste et un pays sous obédience communiste, c'est aussi une nouveauté sur le plan footballistique, car les deux associations nationales ne se sont jamais rencontrées par le passé. Un constat analogue peut être fait au sujet de la partie entre l'Allemagne de l'Est et le Portugal. Par ailleurs, la Tchécoslovaquie est opposée à l'Irlande, contre laquelle elle n'a joué qu'une seule fois jusqu'alors. Cette remarque est aussi valable pour le match Autriche-Norvège.

Le tournoi final (demi-finale et finale), organisé en France, ne connaît toutefois qu'un engouement relatif. Il a lieu au début juillet, sous l'insistance, semble-t-il, des pays du bloc soviétique, c'est-à-dire au même

129 Des études sont à mener sur cet aspect. 
moment qu'une autre compétition extrêmement populaire, le Tour de France. Par ailleurs, la date n'est que peu favorable, car elle fait suite à la saison de plus en plus longue des championnats nationaux, qui se terminent à la mi-juin et qui est encore suivie de matchs amicaux de clubs. Cette situation perturbe la préparation des équipes dont certaines ne peuvent pas compter sur leurs meilleurs joueurs ${ }^{130}$. Ces deux éléments pénalisent indéniablement le succès populaire de la joute. Ainsi, si respectivement 30000 et 28000 spectateurs assistent aux demi-finales, seulement 18000 personnes bravent la pluie pour assister à la finale entre l'Union soviétique et la Yougoslavie qui se déroule au Parc des Princes à Paris ${ }^{131}$. Constatons néanmoins qu'au début des années 1960, l'organisation de compétitions à l'échelle européenne paraît de plus en plus acceptée par les membres de la communauté footballistique européenne, et en particulier par les dirigeants des associations nationales qui s'étaient opposées à leur développement. Ainsi s'ajoute à l'indéniable succès de la Coupe des champions la création d'une Coupe des vainqueurs de coupes européennes en 1961. De même, pour la seconde édition de la Coupe d'Europe des nations, la très grande majorité des associations membres de l'UEFA prennent part à l'épreuve. Enfin, la Coupe des villes de foires - qui reste encore en dehors du giron de l'Union - voit son nombre de participants largement augmenter et des discussions commencent au sein de l'UEFA pour savoir si l'organisation ne devrait pas reprendre son organisation ${ }^{132}$.

Ces compétitions permettent donc de fortifier l'existence de l'UEFA et renforcent les échanges au sein de la communauté du football européen. Elles confortent également ses dirigeants du comité exécutif dans leur volonté de développer un cadre footballistique continental.

\subsection{Un nouvel acteur européen}

Lors de notre entretien avec Hans Bangerter, celui-ci nous a indiqué que, dans les années 1960, il dut faire face à de gros problèmes qui

130 C'est en particulier le cas de l'équipe nationale française qui ne peut, en outre, disposer de ses meilleurs éléments (en particulier Raymond Kopa qui est blessé et doit renoncer au tournoi). "France football répond aux questions que vous vous posez à propos de la Coupe d'Europe des nations ", France football, 5 juillet 1960.

131 La rencontre est télévisée en direct, ce qui peut aussi avoir un impact sur ce chiffre plutôt faible, le Parc des Princes pouvant accueillir jusqu'à 45000 spectateurs. " La Coupe d'Europe sous tous ses aspects ", France football, 12 juillet 1960.

132 Décision prise en 1966 et qui sera effective en 1971, la Coupe étant renommé Coupe UEFA. 
découlaient de la Guerre froide, en insistant en particulier sur l'obtention de visas pour les joueurs de l'Allemagne de l'Est ${ }^{133}$. L'UEFA, composée de pays issus des deux blocs, paraît en effet particulièrement exposée à ce que le contexte politique international rejaillisse en son sein. Pour éviter cela, les promoteurs de l'Union vont reprendre, mais aussi adapter, les stratégies créées au sein de la FIFA durant les années 1930.

\subsubsection{L'ombre de la Guerre froide}

Lors du congrès constitutif de l'UEFA - entité qui, pour rappel, s'appelle alors, le Groupement européen -, le 15 juin 1954 à Bâle, l'assemblée est composée d'associations qui proviennent des deux côtés du Rideau de fer, comme le montre la carte ci-dessous.

Figure 5. Pays présents lors de l'assemblée constitutive du Groupement européen

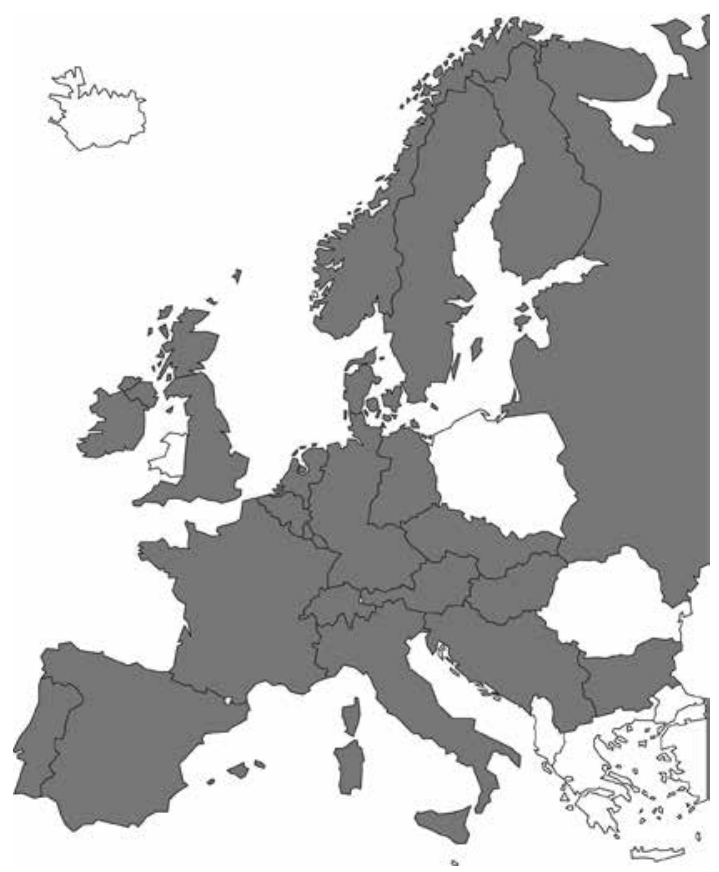

Légende : en gris, associations nationales présentes.

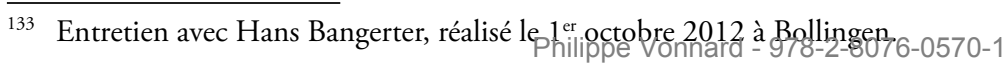


Ces associations s'accordent rapidement sur la création d'un organisme paneuropéen, ce qui contraste avec la majorité des organisations européennes créés dans d'autres domaines dès le début des années 1950, aux niveaux économique - la Communauté européenne du charbon et de l'acier (CECA) $)^{134}$ et l'Association européenne de libre échange $(\mathrm{AELE})^{135}$-, culturel - le Centre européen de la culture établi à Genève, la Communauté européenne des écrivains (COMES) ${ }^{136}$ ou encore la Société européenne de culture $(\mathrm{SEC})^{137}$-, technique - l'Union européenne de radio (UER) ${ }^{138}$, la Conférence européenne des administrations des postes et des télécommunications (CEPT) ${ }^{139}$ - et scientifique - la Communauté européenne de recherche nucléaire $(\mathrm{CERN})^{140}$. Or ce processus, que l'historien Robert Frank a nommé "l'Europe-organisation " ${ }^{141}$, concerne avant tout le bloc de l'Ouest et ne transcende jamais le Rideau de fer.

Cette coexistence Est-Ouest au sein de l'UEFA, qui témoigne d'une ambition portée par plusieurs dirigeants du football européens de trouver une entente commune en vue de développer le football continental, ne va toutefois pas sans poser problème. Tout d'abord, elle met aux prises des délégués qui défendent des conceptions du football différentes ${ }^{142}$ ainsi que des associations nationales qui proviennent de pays farouchement opposés sur la scène internationale et qui, parfois, n'entretiennent aucune relation footballistique. C'est notamment le cas entre l'Espagne, le Portugal et les pays du bloc soviétique; de même que des deux Allemagne. Pour faire face à cette situation, des dirigeants expérimentés qui participent à la réunion

134 Bitsch M.-T., La construction européenne, op. cit.

135 Kaiser K., "A Better Europe? EFTA, the EFTA Secretariat, and the European Identities of the "Outer Seven", 1958-1972", dans Bitsch M.-T., Loth W., Poidevin R. (dir.), Institutions européennes et identités européennes, Bruxelles, Bruylant, 1998, pp. 165-183.

136 Racine N., " La COMES (1958-1969). Une association d'écrivains dans la Guerre froide », dans Sirinelli J.-F., Soutou G.-H. (dir.), Culture et Guerre froide, Paris, Presses universitaires de la Sorbonne, 2008, pp. 139-151.

137 Guinnard S., "La Société européenne de culture et le dialogue Est-Ouest jusqu'en 1956 ", dans Fleury A., Jilek L., Une Europe malgré tout, op. cit., pp. 125-137.

138 Alvès P., «L’Union européenne de radiodiffusion (1950-1969), dans Lévy M.-F., Sicard M.-N. (dir.), Les lucarnes de l'Europe. Télévisions, cultures, identités, 1945-2000, Paris, Publications de la Sorbonne, 2008, pp. 47-69.

139 Laborie L., L'Europe mise en réseaux, op. cit., pp. 347-390.

140 Strasser B., Joye F., "Une science "neutre" dans la Guerre froide ? La Suisse et la coopération scientifique européenne (1951-1969) ", Revue suisse d'histoire, vol. 55, $\mathrm{n}^{\circ} 1,2005$, pp. 95-112.

141 Frank R., "Les débats sur l'élargissement de l'Europe », op. cit., pp. 180-181.

142 Par exemple vis-à-vis du professionnalisme, du football des jeunes, du rapport aux médias, etc. 
constitutive du groupement européen, tels Ottorino Barassi, José Crahay, Henri Delaunay, Karel Lotsy, Stanley Rous, Ebbe Schwartz ou Ernst Thommen, vont essayer de pallier les difficultés liées à cette situation. Tout d'abord, des discours visent à célébrer l' «Europe unie " ${ }^{143}$, comme dans l'allocation du Suisse Ernst Thommen qui ouvre les débats du congrès. De même, il s'agit de tenir compte de la particularité de l'assemblée, comme le suggère Ottorino Barassi - qui préside les débats - lors de la discussion sur la représentation des associations nationales absentes par une autre fédération.

N'ayant pu venir en raison de la non-attribution des visas à ses représentants par la légation suisse présente à Bucarest, l'association roumaine demande officiellement à l'assemblée d'être représentée par la Tchécoslovaquie. Barassi rappelle que, selon les statuts de la FIFA, une telle représentation n'est pas possible. Il se déclare néanmoins personnellement favorable à la demande, sans toutefois accorder le droit d'un report des votes de la délégation roumaine en faveur d'une autre association pour les élections des membres européens au comité exécutif de la FIFA. Après une assez longue discussion, la représentation de la Roumanie par la Tchécoslovaquie est mise au vote. Par 14 voix contre 10 et 2 abstentions, les délégués acceptent de suivre la proposition du président de séance. Le vote est serré et il est difficile de connaître la position de chaque pays puisque nous n'avons pas le détail du scrutin. Nous pouvons cependant penser que les suffrages suivent les lignes de fracture imposées par la Guerre froide. Les discussions sur un autre cas traité dans la foulée, celui de la représentation du Pays de Galles, tendent à confirmer cette hypothèse. En effet, Stanley Rous mentionne que cette association, également absente, lui a demandé de la représenter. Cette requête est appuyée par Ernst Thommen et Ottorino Barassi, qui la considèrent comme analogue à celle de la Roumanie. Ils sentent que le sujet peut être une source de conflit et essaient dès lors de limiter son impact. Les dirigeants du bloc de l'Est objectent toutefois contre cette proposition. Sans doute s'agit-il ici d'une réponse aux dix associations qui ont rejeté l'idée de conférer une représentation à la Roumanie. Selon le représentant soviétique, les deux cas ne sont pas analogues, le Pays de Galles n'ayant pas fait parvenir - au contraire de l'association roumaine - une demande officielle en la matière. Malgré cette requête et sans doute pour respecter une certaine égalité de traitement qui permet d'éviter que le conflit ne s'étende, Barassi décide

143 Delaunay H., Procès-verbal de l'assemblée constitutive du Groupement européen du 15 juin 1954 à Bâle, n.d. UEFA, RM00005984 (congrès de l'UEFA, procès-verbaux 1954-1994), document relié : procès-verbaux des assemblées générales 1954-1959. 
de faire également voter la proposition. Celle-ci est acceptée par 12 voix contre 9 et 4 abstentions. Là encore, le résultat du vote témoigne bien des rapports de force Est-Ouest qui existent au sein de l'assemblée et qui risquent de compliquer la bonne entente au sein du Groupement. Face à cette situation, des dirigeants expérimentés comme Barassi, Rous ou encore Thommen se rendent sans doute compte qu'il est nécessaire de prendre quelques libertés face aux règlements de la FIFA et de les adapter au regard du contexte politique particulier dans lequel se trouve le continent européen.

Cet aspect se perçoit également dans la discussion concernant les élections au comité exécutif de la FIFA, qui constituent l'une des principales tâches du nouvel organisme et donc un des moments forts de l'assemblée. Tout d'abord, les congressistes décident d'élire Ernst Thommen et Karel Lotsy aux postes de vice-présidents de la Fédération internationale. Dans ce cas, les délégués ont privilégié la continuité puisque Lotsy et Thommen occupaient déjà ce poste depuis plusieurs années - depuis 1934 pour le premier et 1950 pour le second - et sont, en outre, très bien insérés dans l'élite qui dirige la FIFA. En ce sens, ils sont perçus comme étant les mieux à même de porter les intérêts du Groupement européen sur la scène internationale. De plus, pour ces postes importants, les représentants du congrès ont choisi des dirigeants provenant de petits pays. Ce procédé a l'avantage de neutraliser le possible poids des plus fortes associations footballistiques et est une tactique souvent utilisée sur la scène internationale. En effet, comme l'a souligné Antoine Fleury, les petits États européens comme la Belgique, la Suisse et les Pays-Bas ont souvent servi de tampon pour modérer les ambitions des grandes puissances ${ }^{144}$. En ce qui concerne les quatre membres du comité exécutif, sont élus : le Yougoslave Andrejevic (20 voix), l'Italien Barassi (18 voix), le Suédois Lange (15 voix). Le Français Lafarge vient compléter l'effectif après un second tour de scrutin remporté au détriment du Hongrois Sebes. Comme pour les deux postes de vice-présidents, les congressistes optent pour la continuité puisque Barassi est déjà membre du comité exécutif de la FIFA depuis 1952 et qu'Andrejevic a déjà occupé ce poste par le passé entre 1938 à 1948. Par ailleurs, les représentations régionales ont été respectées puisqu'un

144 Fleury A., "Les petits États dans la politique européenne au $\mathrm{XX}^{\mathrm{e}}$ siècle ", dans Dumoulin M., Duchenne G. (dir.), Les petits États et la construction européenne. Actes de la VII' Chaire Glaverbel d'études européennes 2000-2001, Bruxelles, P.I.E. Peter Lang, 2002, pp. 15-46. 
Scandinave, un représentant des pays latins et un délégué pouvant être considéré comme proche des pays du bloc balkaniques sont élus ${ }^{145}$.

S'ajoutent à cette délégation du Groupement européen les deux viceprésidents désignés respectivement par les quatre associations britanniques et par l'organe central du sport soviétique. $S$ 'ils sont élus de manière différente, ces deux dirigeants, en l'occurrence Arthur Drewry et Valentin Granatkine, entretiennent toutefois des liens étroits - surtout pour le premier nommé - avec leurs collègues européens. Dès lors, il est possible que, sur certains sujets, ils pourront s'accorder avec leurs collègues élus par le Groupement européen et ainsi porter également la voix de l'Europe au sein de la FIFA.

Tableau 15. Représentants du Groupement européen élus à la FIFA

\begin{tabular}{|l|l|l|l|l|}
\hline Dirigeants & Pays & Fonction & $\begin{array}{l}\text { Entrée au Comité } \\
\text { exécutif de la } \\
\text { FIFA }\end{array}$ & Représentation \\
\hline Drewry & Angleterre & vice-président & 1946 & Britannique* $^{*}$ \\
\hline Granatkine & Union soviétique & vice-président & 1948 & $\begin{array}{l}\text { Union } \\
\text { soviétique* }\end{array}$ \\
\hline Thommen & Suisse & vice-président & $1950-$ & Aucun$^{* *}$ \\
\hline Lotsy & Pays-Bas & vice-président & $1934-$ & Aucun** \\
\hline Andrejevic & Yougoslavie & membre & $1938-1948 / 1954-$ & Balkans \\
\hline Barassi & Italie & membre & $1952-$ & Latins \\
\hline Lafarge & France & membre & $1954-$ & Aucun \\
\hline Lange & Suède & membre & $1954-$ & Scandinave \\
\hline
\end{tabular}

Légende : ${ }^{*}$ dirigeant non élu par le Groupement européen (Drewry est choisi par les quatre associations britanniques ; Granatkine est désigné par l'organe central qui dirige le sport en URSS) ; ${ }^{*}$ dirigeant d'un pays ne faisant pas partie d'un bloc régional.

Mais un problème se pose à la suite de ces élections, à savoir que la non-élection des quatre autres candidats qui s'étaient aussi présentés aux élections crée des tensions entre les associations nationales européennes. C’est pourquoi Stanley Rous défend une solution de compromis qui

145 Pour rappel, ces dirigeants s'ajoutent aux deux vice-présidents nommés par les associations britanniques et soviétiques, qui n'avaient pas de droit de vote sur ce scrutin. 
pourrait permettre de les minimiser. Il propose à l'assemblée de ne pas procéder à des élections, mais de nommer les quatre dirigeants non élus aux places du comité exécutif de la FIFA, à savoir l'Allemand Bauwens, l'Autrichien Gerö, l'Espagnol Munoz Calero et le Hongrois Sebes, dans le comité exécutif du Groupement européen. Pour les accompagner dans cette tâche, Rous ajoute les noms des deux autres membres de la commission permanente, à savoir le Belge José Crahay et le Français Henri Delaunay, présence qui paraît logique vu leur important travail préliminaire. Pour finir, il mentionne le Danois Ebbe Schwartz et l'Écossais George Graham ${ }^{146}$, deux dirigeants ayant participé aux travaux de réforme de la FIFA. Composée de dirigeants expérimentés qui ont leur entrée au sein de la FIFA et qui entretiennent des liens autant avec les représentants européens qui viennent d'être choisis au sein de son comité exécutif qu'avec des dirigeants sud-américains, cette représentation permettra de défendre au mieux les intérêts du Groupement. En outre, là encore, les différentes forces du football européen sont convoquées. La désignation de ces dirigeants peut donc servir à neutraliser les possibles conflits au sein du Groupement européen, contexte d'autant plus nécessaire que l'entité est très jeune et donc peu solide. En ce sens, les dirigeants ont suivi les pratiques existant au sein de la FIFA depuis l'entre-deux-guerres.

La proposition de l'Anglais convient aux autres congressistes. Toutefois pour que celle-ci soit effective, il est nécessaire de s'arrêter sur une modification dans le projet de statut. En effet, celui-ci prévoit que le comité exécutif de l'organisation continentale soit composé uniquement de six membres ${ }^{147}$, or le dirigeant anglais en a proposé huit. Ce changement n'est toutefois pas nécessaire, Bauwens et Munoz Calero déclarant ne pas être candidats. Nous pouvons supposer que leur refus s'explique par leur déception de ne pas avoir été élus comme représentants dans le comité exécutif de la FIFA, considérant sans doute que la meilleure manière de défendre les intérêts de leur association était d'être nommés au sein du comité exécutif de la Fédération internationale et non pas au Groupement européen ${ }^{148}$.

146 Si les associations britanniques ne peuvent pas prendre part à la nomination des délégués du Groupement européen au sein du comité exécutif de la FIFA, elles peuvent par contre participer à la gestion de l'entité continentale. Cette remarque vaut également pour l'URSS.

147 Anonyme, "Entente europenne de football, Projet de règlement ", Article 11, n.d. BA, DY 12 DTSB, dossier : 2.081 Zusammenarbeit mit der FIFA, fiche 03, $\mathrm{n}^{\circ}$ 173-175.

148 Dans une lettre écrite quelques mois plus tard à Jules Rimet, Peco Bauwens mentionne explicitement que son but est que l'Allemagne retrouve sa place au sein du comité exécutif de la FIFA, " comme cela a toujours été le cas ». Lettre de P. Bauwens à J. Rimet, 10 février 1955. DFB, Korrespondenz P. Bauwens, dossier : Korresponenzen [28] 
Réunis le lendemain du congrès, les membres du comité exécutif du Groupement européen choisissent d'élire Ebbe Schwartz comme président. Nous avons interrogé Hans Bangerter - secrétaire de l'UEFA de 1969 à 1989 - sur les raisons de la nomination du dirigeant danois. Il nous a tout d'abord donné un argument de type social, à savoir qu'Ebbe Schwartz était quelqu'un d'agréable qui était bien accepté par ses collègues. Mais, dans la suite de l'entretien, Hans Bangerter a ajouté un autre point qui nous parait crucial dans ce choix : «Il y avait aussi peut-être, je ne sais pas, entre les grandes personnalités que nous avons citées tout à l'heure [Barassi, Rous et Thommen en particulier], ils ne voulaient pas qu'un pays puisse avoir trop d'influence [...]. C'est la raison pour laquelle, je pense, ils ont choisi un président d'un petit pays ${ }^{149}$. "Provenant d'un pays modérément influent sur la scène footballistique et qui oscille politiquement parlant entre neutralisme et proximité avec le camp capitaliste - un "Western neutral » selon le concept développé par Jussi Hänhimaki ${ }^{150}$-, la nomination de Schwartz offre la possibilité de minimiser les conflits à l'intérieur du Groupement européen. Les dirigeants ont donc choisi un dirigeant qui symbolise le consensus. Autre élément plaidant pour le Danois : les connexions qu'il entretient avec d'autres acteurs influents du football européen, et en particulier Sir Stanley Rous ${ }^{151}$. Enfin, Schwartz a activement participé à la récente réforme de la FIFA et a donc eu de nombreux échanges avec les acteurs majeurs du comité exécutif de la Fédération internationale, mais aussi avec les dirigeants sud-américains. Sous cet angle, il apparaît donc comme un interlocuteur précieux pour l'entité continentale sur la scène footballistique internationale. Par ailleurs, les six dirigeants décident de confier la responsabilité du secrétariat à Henri Delaunay ${ }^{152}$. Cette nomination paraît logique, car c'est lui qui tenait déjà ce poste au sein de la commission permanente. De plus, Delaunay est aguerri au rôle d'administrateur, car il officie en tant que secrétaire de

149 Entretien réalisé avec Hans Bangerter le $1^{\text {er }}$ octobre 2012 à Bollingen.

150 Le Danermark fait par exemple partie de l'OTAN depuis sa création en 1949. Hanhimäki J., "Non-aligned to what? European neutrality and the Cold War ", dans Bott S. et al. (eds.), Neutrality and neutralism in the global war. Between or within the blocs?, London, Routledge, 2015, pp. 17-32.

151 Rous S., Football worlds, op. cit., p. 115. D'ailleurs, anecdote qui pourrait corroborer cette proximité, lors du premier congrès de l'UEFA qui se déroule à Vienne en mars 1955, dans l'hôtel qu'ils occupent, les deux dirigeants disposent d'une porte reliant leurs deux chambres.

152 Delaunay H., Procès-verbal de la réunion du comité exécutif du Groupement des associations européennes du 22 juin 1954, n.d., UEFA, RM00005974 (réunion du comité exécutif, 1954-1959), document relié : procès-verbaux des comités exécutifs et comités d'urgence 1954-1959. 
la Fédération française depuis 1919 ainsi que de la commission des Lois du jeu de la FIFA. C'est donc un acteur reconnu et expérimenté et qui connaît la majeure partie des principaux dirigeants du football continental en raison des démarches de consultation des associations européennes préalablement entamées depuis 1952.

Dans les années qui suivent, la représentation des différentes forces au sein du comité exécutif de ce qui est désormais appelé l'UEFA va être consolidée. En 1955, l'organe est élargi avec l'entrée de l'Allemand Bauwens et du Grec Constantaras. Cette élection, qui s'effectue lors de la première assemblée générale de l'Union au mois de mars 1955, permet de compter sur un représentant des pays balkaniques au sein du comité exécutif et de confier une tâche à la grande fédération d'Allemagne de l'Ouest. De plus, l'Autrichien Frey remplace son compatriote, Gerö, décédé quelques semaines plus tôt. Lors de ces élections complémentaires, les candidatures de l'Espagnol Pujol et du Tchèque Vogl sont par contre rejetées. Sebes étant déjà membre du comité exécutif, les pays de l'Est auraient disposé de deux membres sur cinq si Vogl avait été élu, et auraient ainsi été surreprésentés par rapport aux autres forces régionales au sein de l'Union. De même, les congressistes ont cherché à consolider l'entente de l'organisation et, à ce titre, la présence de l'Espagnol Pujol, en raison de la position encore délicate du franquisme sur la scène internationale, aurait pu être une source de tensions au sein de la jeune UEFA.

En 1958, une nouvelle réorganisation du comité exécutif est nécessaire en raison de l'augmentation progressive des tâches de l'Union. L'organe est désormais composé de neuf dirigeants représentant toujours les différentes forces au sein de l'Union (bloc britannique, bloc scandinave et bloc soviétique ainsi que des représentants des pays du Benelux et des pays latins) qui accompagnent le secrétaire général. Cette fois, le dirigeant espagnol, Pujol, est choisi, avec toutefois une contrebalance puisqu'un deuxième représentant du bloc soviétique est également élu.

Tableau 16. Membres du comité exécutif de l'UEFA en 1958

\begin{tabular}{|l|l|l|l|l|}
\hline Nom & Pays & $\begin{array}{l}\text { Représentation } \\
(\text { bloc })\end{array}$ & Fonction & $\begin{array}{l}\text { Entrée au } \\
\text { comité }\end{array}$ \\
\hline Schwartz & Danemark & Scandinavie & Président & 1954 \\
\hline Sebes & Hongrie & Soviétique & Vice-président & 1954 \\
\hline Crahay & Belgique & Benelux & Membre & 1954 \\
\hline Frey & Autriche & Aucun & Membre & 1955 \\
\hline
\end{tabular}




\begin{tabular}{|l|l|l|l|l|}
\hline Nom & Pays & $\begin{array}{l}\text { Représentation } \\
\text { (bloc) }\end{array}$ & Fonction & $\begin{array}{l}\text { Entrée au } \\
\text { comité }\end{array}$ \\
\hline Bauwens & Allemagne & Aucun & Membre & 1955 \\
\hline Constantaras & Grèce & Balkans & Membre & 1955 \\
\hline Rylski & Pologne & Soviétique & Membre & 1956 \\
\hline Pujol & Espagne & Latin & Membre & 1956 \\
\hline Rous & Anglais & Britannique & Membre & 1958 \\
\hline Delaunay & France & Aucun & $\begin{array}{l}\text { Secrétaire } \\
\text { général }\end{array}$ & 1956 \\
\hline
\end{tabular}

Cette volonté de minimiser l'impact du conflit Est-Ouest sur l'UEFA se révèle aussi au travers des lieux choisis pour les congrès annuels de l'organisation. Sur les six assemblées générales qui se déroulent entre 1955 et 1960 , trois $(1956,1958$ et 1960) sont organisées dans les mêmes villes que les congrès de la FIFA, ce qui a pour avantage que les associations nationales de l'UEFA n'ont pas à discuter du choix du lieu. De plus, ce type de procédé devrait garantir aux ressortissants des pays de l'Est, et en particulier de la $\mathrm{RDA}^{153}$, d'obtenir plus facilement des visas. En outre, la réunion de 1955 est organisée à Vienne. Cité phare du football européen de l'entre-deuxguerres ${ }^{154}$, la capitale autrichienne a l'avantage d'être géographiquement au centre de l'Europe du continent, mais aussi d'occuper une place à part puisqu'elle est à cette époque un reliquat de la "grande alliance " qui a prévalu durant la Deuxième Guerre mondiale ${ }^{155}$. Deux ans lus tard, c'est le pays du président de l'UEFA, en l'occurrence le Danemark, qui accueille la manifestation tandis que le congrès extraordinaire de 1959 est organisé dans le pays du secrétaire, à savoir la France.

Le souci de permettre un dialogue entre les blocs de l'Est et de l'Ouest est illustré non seulement pas le choix des pays d'accueil des congrès mais également par l'élection à l'interne de personnalités à même de favoriser

153 À la fin des années 1950, la RDA n'est toujours pas officiellement reconnue par plusieurs pays européens.

154 Sur cet " âge d'or " du football viennois, voir : Horak R., Maderthaner W., Mehr als ein Spiel. Fussball und populare Kulturen im Wien der Moderne, Wien, Löcker Verlag, 1997.

155 En effet, elle est toujours divisée en quatre zones administrées par les forces américaines, anglaises, françaises et soviétiques. Ainsi, que ce soit d'un point de vue politique, géographique ou footballistique, Vienne est un lieu qui rassemble l'Est et l'Ouest de l'Europe. 
un tel dialogue. Au début des années 1960, le Bulgare Michel Daphinov est ainsi engagé au poste de secrétaire adjoint. De même, une des toutes premières secrétaires, Ursula Krayenbuehl, est capable de dialoguer dans différentes langues slaves ${ }^{156}$.

Trois autres éléments témoignent de cette volonté de l'élite de l'UEFA de faire face au mieux au contexte de la Guerre froide. Premièrement, comme nous l'avons explicité dans une recherche conduite en compagnie de Jürgen Mittag, les rapports annuels tenus par le secrétaire général ainsi que les articles du Bulletin de l'UEFA insistent non seulement sur les réalisations de l'organisation, mais aussi sur l'harmonie entre ses associations membres tout en passant sous silence, ou en minimisant, les possibles conflits en son sein ${ }^{157}$. Cette manière de faire a l'avantage de montrer à ses associations membres mais aussi aux autres acteurs du football européen (en particulier la presse) le visage d'une organisation unie, qui se soucie de créer une harmonie entre ses membres. Deuxièmement, l'UEFA va appliquer une règle informelle qui existe au sein de la FIFA depuis l'entredeux-guerres : ne pas intervenir dans les affaires des associations nationales. C'est notamment le cas lors de la Révolution hongroise de 1956 qui se déroule au début de l'existence de l'UEFA. Cet événement implique le départ de Hongrie de nouveaux joueurs, cas qui sont dénoncés par la Fédération hongroise auprès de la FIFA dès janvier $1956^{158}$. Si les Hongrois se tournent vers la Fédération internationale, le sujet est également discuté au sein du comité exécutif de l'UEFA. Celui-ci prend une décision à la veille du congrès de l'UEFA de 1956 et indique se déclarer incompétent en la matière. De fait, il transmet "l'étude de cette affaire à la FIFA en la priant de bien vouloir apporter toute son attention sur l'attitude de ce joueur, afin de répondre utilement à la question posée ${ }^{159}$. Lors de l'assemblée générale de l'Union, suite à une demande de clarification d'un délégué norvégien, la parole est donnée au Yougoslave Andrejevic qui, en tant que représentant de la FIFA, donne des précisions sur le sujet ${ }^{160}$.

156 Information qui nous a été donnée par Gerhard Aigner.

157 Mittag J., Vonnard P., "The role of societal actors in shaping a pan-European consciousness ", op. cit.

158 Lettre de la G. Honti à la FIFA, 21 janvier 1956. FIFA, correspondance avec les associations nationales : Hongrie (1937-1965), dossier : 1.1.1951-31.12.57

159 Delaunay P., Procès-verbal de la réunion du comité exécutif de l'UEFA des 6 et 7 juin 1956, n.d. UEFA, RM00005974 (réunion du comité exécutif, 1954-1959), document relié : procès-verbaux des comités exécutifs et comités d'urgence 1954-1959.

160 Delaunay P., Procès-verbal de l'assemblée générale de l'UEFA du 8 juin 1956, n.d. UEFA, RM00005986 (congrès fondateur, 1954. I-III congrès ordinaire, 1955-1957), document relié : procès-verbaux des assemblées générales 1954-1958 
Ainsi, les dirigeants de l'UEFA estiment ne pas être compétents pour traiter de cette affaire, une manière pour eux d'éluder une question d'ordre politique. À ce titre, renvoyer la question à la Fédération internationale semble être une solution adéquate pour éviter le déclenchement d'un problème interne. Mais les événements de Hongrie valent également au pays d'être mis au ban de la scène internationale par plusieurs pays européens qui condamnent l'intervention soviétique et le nouveau régime politique hongrois et acceptent sur leur territoire des milliers de réfugiés. Dans le domaine sportif, des échanges avec la Hongrie sont remis en question, comme le montre le boycott des Jeux olympiques de Melbourne en novembre 1956. Ainsi, l'Espagne franquiste refuse de se rendre en Australie pour protester sur la situation en Hongrie tandis que la Suisse, après de multiples tergiversations au sein des différentes associations sportives pour savoir s'il faut, ou non, participer à ces Jeux, ne peut finalement y prendre part ${ }^{161}$. Suivant la position de leur gouvernement, des équipes nationales refusent de jouer contre la Hongrie. Le délégué hongrois du comité exécutif de l'UEFA, Gustav Sebes, demande donc à ses collègues si l'UEFA peut intervenir face à cette situation. Cependant, ceux-ci ne s'estiment, là encore, pas compétents pour juger du cas et suggèrent que la Fédération hongroise transmette la requête à la FIFA ${ }^{162}$.

Troisièmement, les dirigeants du comité exécutif de l'UEFA vont s'atteler à faire respecter leurs statuts lorsque la Guerre froide perturbe le bon déroulement des activités de l'organisation. Ce procédé leur permet de se baser sur des arguments qui ne peuvent être considérés comme arbitraires par les parties lésées. C'est notamment le cas lors de la Coupe d'Europe des nations de 1960, quand l'Espagne décide de renoncer à affronter l'Union soviétique lors des quarts de finale. En effet, les deux pays n'entretiennent toujours pas de relations diplomatiques sur la scène internationale. Or, deux ans auparavant, le régime franquiste avait interdit à la section de basket-ball du Real Madrid de faire le déplacement de Riga dans le cadre de la Coupe d'Europe des clubs. Pour les autorités franquistes, la seule possibilité de rencontrer les Soviétiques consiste à disputer le

161 Lorsque la décision est prise, il est finalement trop tard pour affréter des avions en vue du déplacement. Quin G., Tonnerre Q., « "Les Suisses n’iront pas à Melbourne pour n'avoir pas trouvé d'avion convenable". Histoire d'une non-participation olympique (1948-1956) ", Revue suisse d'histoire, vol. 17, n² 2, pp. 343-360.

162 Delaunay P., Procès-verbal de la réunion du comité exécutif de l'UEFA du 28 février 1957, n.d., UEFA, RM00005974 (réunion du comité exécutif, 1954-1959), document relié : procès-verbaux des comités exécutifs et comités d'urgenge 1954-1959 
match sur terrain neutre, une requête rejetée par ces derniers ${ }^{163}$. Conscient des difficultés inhérentes à l'organisation de cette opposition, le comité exécutif de l'UEFA prend des mesures quelques semaines avant la partie. Il est décidé que le président de l'Union, Ebbe Schwartz, la représentera officiellement durant le premier match qui doit se dérouler à Moscou ${ }^{164}$. Cette présence doit favoriser le bon déroulement de la rencontre et empêcher de possibles attitudes négatives de la part des dirigeants espagnols et soviétiques. En outre, c'est un geste fort qui doit permettre de montrer que l'UEFA réussit là où d'autres organisations échouent, à savoir dans le rapprochement Est-Ouest. Mais en dépit de ces tentatives d'apaisement, le match est finalement annulé, l'Espagne franquiste refusant de se rendre, au dernier moment, en Union soviétique. Face à cette décision, le comité exécutif de l'Union joue la voie de l'apolitisme sportif. Après avoir entendu des responsables espagnols et soviétiques, l'UEFA applique à la lettre le règlement de l'épreuve et décide que la Fédération espagnole est fautive, car elle s'est retirée de la compétition sans motif valable. Dès lors, elle devra verser un dédommagement financier à son homologue soviétique afin de combler le préjudice subi. Par ailleurs, l'Union demande que les deux équipes jouent prochainement un match amical "pour démontrer leur bonne volonté $"{ }^{165}$.

Face au contexte de la Guerre froide, les principaux dirigeants du comité exécutif de l'UEFA, en particulier Schwartz, Crahay et le secrétaire Delaunay, poursuivent une politique de l'apolitisme en reprenant, modifiant ou adaptant les stratégies employées au sein de la FIFA pour ce qui est de la gestion des conflits. Parfois, lorsque le cas semble trop compliqué, ils n'hésitent pas à le transmettre à la Fédération internationale. Cependant, l'harmonie n'est pas totale entre les deux entités et le rapide développement de l'UEFA suscite certaines oppositions, notamment de la part des représentants élus par l'Union dans le comité exécutif de la FIFA.

163 Simón J.A., "L'homme de l'ombre Raimundo Saporta et le basket espagnol et européen ", dans Archambault F., Artiaga L., Bosc G. (dir.), Le continent basket, op. cit., p. 180.

164 Schmidlin I., Procès-verbal de la réunion du comité exécutif de l'UEFA du jeudi 10 mars 1960, 8 avril 1960. UEFA, RM00000750 (Séances du comité exécutif, 10 mars-8 juillet 1960), dossier : ExKo 10.03.1960.

165 Bangerter H., Procès-verbal de la réunion du comité exécutif de l'UEFA du 3 octobre 1962, 18 octobre 1962. UEFA, RM00000754 (séance du comité exécutif, 3 octobre 1962), dossier : 03.10.1962. F. 


\subsection{2. “ Accord et désaccord ${ }^{166}$ avec la FIFA}

Entre 1955 et 1960, l'élite de l'UEFA prend différentes décisions qui permettent de dynamiser le football européen. Progressivement, l'Union se profile comme l'organe principal du football européen, ce qui crée des tensions avec les dirigeants européens du comité exécutif de la Fédération internationale de football. En effet, si ceux-ci ont œuvré à la création de l'entité européenne, ils estiment que si elle peut se développer, l'organisation doit néanmoins rester subordonnée à la FIFA. Or, dans les années 1956 et 1957, des décisions prises par le comité exécutif de l'UEFA remettent en cause ce statut supérieur de la Fédération internationale, ce qui attise les tensions entre l'élite dirigeante des deux organisations.

Dès la création du groupement européen, ses dirigeants prennent une décision qui peut créer, à terme, une distance entre cette organisation et la FIFA : ils introduisent une clause dans les statuts qui stipule que les dirigeants élus au comité exécutif de la FIFA ne peuvent siéger au bureau du Groupement européen ${ }^{167}$. En conséquence, deux groupes de dirigeants représentent désormais les intérêts du football continental, comme le montre le schéma ci-dessous. D’une part, ceux élus par le Groupement au comité exécutif de la FIFA, dont la tâche principale est de représenter les intérêts de l'Europe dans la Fédération internationale ; d'autre part, les dirigeants du comité exécutif de l'organisation européenne qui auront pour but de développer l'organisation et surtout de s'occuper du football européen. Comme nous l'avons vu dans le cas de la création de la Coupe des champions ou avec la question de la délimitation du territoire géographique de l'UEFA ${ }^{168}$, tous ces dirigeants arrivent à s'accorder.

166 Titre d'un film de Woody Allen sorti en 1999 sur un jazzman imaginaire des années 1930, Emmet Ray, qui s'inspire de celui qu'il estime être le plus grand guitariste de jazz de l'époque, Django Reinhardt, et se mesure régulièrement à lui.

167 Delaunay H., Procès-verbal de l'assemblée constitutive du Groupement des associations européennes du 15 juin, n.d. UEFA, RM00005986 (congrès fondateur, 1954. I-III congrès ordinaire), 1955-1957, document relié : procès-verbaux des assemblées générales 1954-1959. 
Figure 6. Instances footballistiques du football européen en juin 1954

Organisation internationale (organe suprême)
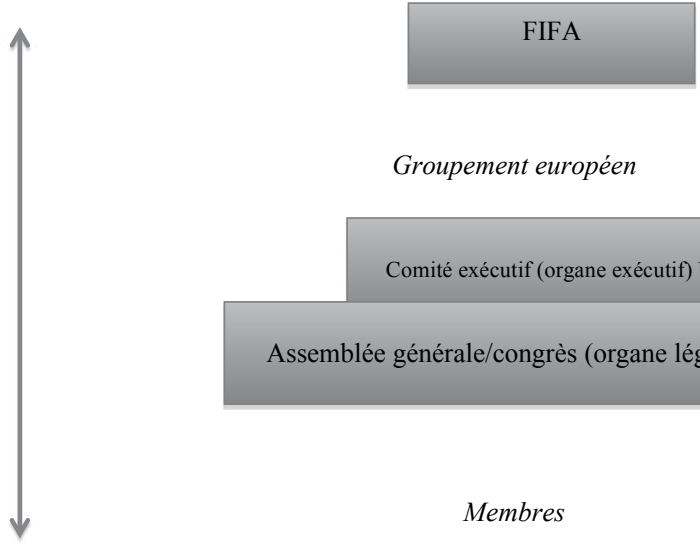

Groupement européen
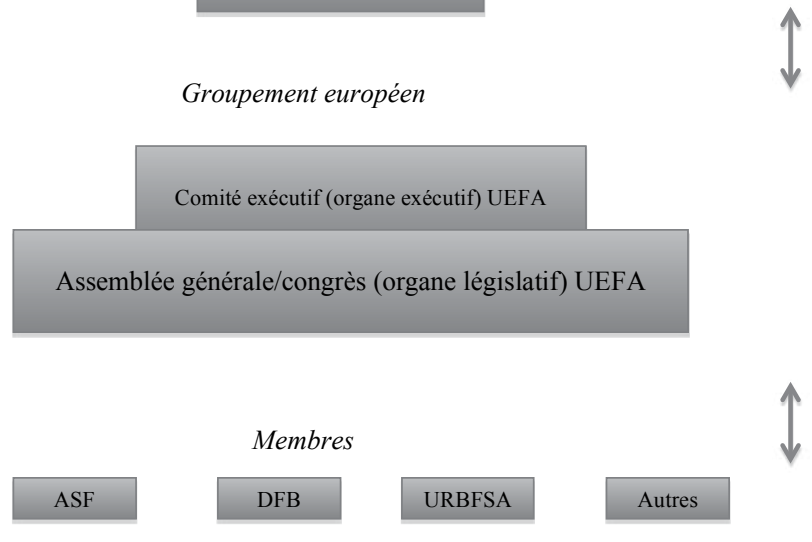

Légende : ASF (Association suisse de football), DFB (Deutsche Fussball Bund), URBSFSA (Union royale belge des sociétés de football association)

Des premiers désaccords surgissent néanmoins à partir de 1955 , qui concernent, en premier lieu, la reprise de l'organisation du tournoi international des juniors par l'UEFA, gérée par la FIFA depuis 1949. Au milieu des années 1950, l'idée est émise de confier la responsabilité de cette joute aux entités continentales. Plusieurs raisons expliquent cette volonté. En raison du fait qu'aucune commission spécifique aux tournois juniors n'existe au sein de la Fédération internationale, c'est le secrétariat qui doit s'occuper de la gestion du tournoi, en coopération avec le comité d'organisation du pays qui accueille la manifestation. Outre le travail fastidieux que cela représente, des difficultés se font sentir dans le suivi de l'épreuve, ce qui agace le secrétaire Gassmann. Ainsi, en septembre 1955, il écrit : "Une fois de plus, nous avons dû rappeler à plusieurs reprises aux associations de nous adresser leurs remarques et suggestions. Douze des dix-neuf ont donné suite à notre invitation. C'est avec regret que nous constatons cette carence et ce manque de collaboration ${ }^{169}$. " Au regard du contexte politique tendu entre l'Est et l'Ouest en Europe, la mise en

169 Gassmann K., Rapport relatif à l'ordre du jour de la réunion du comité exécutif de la FIFA des 17-18 septembre 1955, 17 août 1955. FIFA, comité exécutif (procès-verbaux 1955-1957). 
place du tournoi nécessite un fort engagement de la part de la FIFA, que son secrétariat n'a ni le temps ni l'énergie d'investir. Par exemple, pour l'édition de 1955, la Fédération internationale est prise à partie quant au forfait de l'association d'Allemagne de l'Est, qui n'a pu obtenir les visas à temps de la part du gouvernement italien. Cette intrusion de la politique dans les affaires footballistiques soulève un véritable tollé, le secrétariat de la FIFA accusant réception de près de quatre-vingts télégrammes et lettres de protestation de la part de divers acteurs du football européen. Enfin, le souhait des dirigeants sud-américains de développer leur propre tournoi renforce la nécessité de confier l'épreuve aux nouvelles organisations continentales $^{170}$.

En raison de ces différents éléments, dès septembre de la même année, il est acté que l'organisation des tournois internationaux des juniors sera donnée aux confédérations continentales concernées. Toutefois, pour la Fédération internationale, la transmission de cette tâche ne s'apparente pas à une perte d'autorité totale sur les tournois juniors. En effet, le comité exécutif de la FIFA précise :

« Ces tournois devront être mis sur pied conformément aux décisions prises et aux dispositions générales édictées par le comité exécutif et contenues dans un règlement, valables pour tous les tournois des juniors. Le comité exécutif exercera la haute surveillance et le contrôle sur ces tournois et déléguera, selon les nécessités, un ou plusieurs membres pour surveiller l'application des dispositions réglementaires générales ${ }^{171}$."

Le 5 janvier 1956, Kurt Gassmann contacte le secrétaire général de l'UEFA, Pierre Delaunay, pour lui demander si l'Union serait disposée à se charger dès 1957 de l'organisation de la joute en Europe. Dans le courrier, il précise qu'il ne s'agirait que d'une délégation de la Fédération internationale à l'UEFA. En conséquence, « le comité exécutif [de l'UEFA] ne s'occuperait dans ce cas que du règlement général régissant ce tournoi et qui en constituerait la base. Il devra être le même pour tous les tournois de juniors, n’importe où ils auront lieu ${ }^{172}$. » Delaunay lui répond rapidement

170 Gassmann K., Procès-verbal de la réunion du comité exécutif de la FIFA du 18 novembre 1954, 29 novembre 1954. FIFA, comité exécutif (procès-verbaux 1953-1954).

171 Gassmann K., Procès-verbal de la réunion du comité exécutif de la FIFA du 17 septembre 1955, 22 novembre 1955. FIFA, comité exécutif (procès-verbaux 1955-1957).

172 Lettre de K. Gassmann à P. Delaunay, 5 janvier 1956. FIFA, correspondance avec les confédérations continentales : UEFA (1955-1958), dossier : correspondance générale 01.01.1955-31.12.1958. 
et lui indique qu'il portera la question à l'ordre du jour de la prochaine réunion du comité exécutif de l'UEFA, prévue au mois de mars ${ }^{173}$.

La reprise de l'épreuve par l'UEFA se précise au printemps 1956. En effet, dans son rapport pour les années 1954-1955, qui paraît au mois de mars 1956, le secrétaire général de la FIFA mentionne qu' " à l'avenir - c'est-à-dire à partir de 1957 - le tournoi en Europe devra être mis sur pied par l'Union des associations européennes de football $"{ }^{174}$. Il rappelle toutefois qu'il faudra que l'UEFA respecte le règlement établi par la Fédération internationale et précise que le tournoi reste sous le contrôle du comité exécutif de la FIFA. En date du 18 mars 1956, l'affaire semble conclue puisque son homologue de l'UEFA décide de donner son approbation à cette proposition ${ }^{175}$, provocant la satisfaction de l'élite de la FIFA.

$\mathrm{Si}$, pour les dirigeants de la Fédération internationale, la reprise de l'organisation du tournoi par l'Union est considérée comme un simple passage de témoin, pour leurs homologues de l'UEFA, elle implique au contraire de rediscuter le règlement de l'épreuve. Le comité exécutif de l'entité européenne souhaite en particulier revenir sur le manque d'esprit compétitif. En effet, depuis l'édition de 1955 qui s'était déroulée en Italie, le tournoi ne désigne plus de vainqueur. Cette décision avait été prise sous l'impulsion d'Ottorino Barassi, président du comité d'organisation de l'épreuve. Il faut souligner qu'une année plus tôt, le Néerlandais Karel Lotsy s'était montré très critique face au développement du tournoi, l'esprit de fraternité de la joute étant, selon lui, sur le déclin ${ }^{176}$. En conséquence, la décision de ne plus désigner de vainqueur a été prise afin de renforcer l'aspect de convivialité de la manifestation qui, par ailleurs, compte dans son programme d'autres activités culturelles que le tournoi de football. La proposition des dirigeants de l'UEFA, qui vise à réinstaurer la désignation d'un vainqueur, est donc mal reçue par les dirigeants du comité exécutif de la FIFA et surtout par ceux élus par l'UEFA qui ont, dans un passé récent, œuvré aux modifications du règlement de la joute.

173 Lettre de P. Delaunay à K. Gassmann, 7 janvier 1956. FIFA, correspondance avec les confédérations continentales : UEFA (1955-1958), dossier : correspondance générale 01.01.1955-31.12.1958.

174 Gassmann K., Rapport du secrétaire général de la FIFA (1954 et 1955), mars 1956. FIFA, comité exécutif (procès-verbaux 1955-1957).

175 Delaunay P., Procès-verbal de la réunion du comité exécutif de l'UEFA du 18 mars 1956, n.d. UEFA, RM00005984 (congrès de l'UEFA, procès-verbaux 1954-1994), document relié : procès-verbaux des assemblées générales 1954-1959.

176 Marston K.T., "Sincère camaraderie" "Phplippépe pronnár 
Afin d'assurer au mieux cette transmission, lors de l'assemblée générale de l'UEFA de 1956, les congressistes acceptent la création d'une commission pour discuter du football des juniors, qui soit composée de dirigeants expérimentés dans ce domaine. Ainsi, il est envisagé que le futur organe compte dans ses rangs ${ }^{177}$ : l'Anglais Stanley Rous, initiateur du premier tournoi de 1948 et grand défenseur du football junior ; l'Allemand Karl Zimmermann, qui a été particulièrement actif lors de l'édition du tournoi de 1953 en Allemagne ; le Français Louis Pelletier, qui dirige la commission des juniors de la Fédération française ; le Tchèque Joseph Vogl, également actif dans le football junior dans son pays. Le représentant du comité exécutif de l'UEFA dans cette commission est José Crahay, un fervent partisan du développement des compétitions au sein de l'Union. La commission est donc composée de dirigeants expérimentés et souhaitant développer le football chez les jeunes. De plus, elle a l'avantage de représenter les différentes forces actives au sein de l'Union. Si nous exceptons les associations scandinaves, les blocs britanniques et soviétiques ainsi que les pays du Benelux et les pays latins (avec la présence du Français Pelletier) sont en effet tous représentés. La création de cette commission va permettre de rendre effective la reprise de l'organisation du tournoi par l'UEFA. Dès l'été 1956, des correspondances ont lieu sur le sujet entre les secrétariats de la FIFA et de l'UEFA. Le 6 juillet, Gassmann se permet de rappeler à Delaunay dans quelle perspective le comité exécutif de la Fédération internationale a confié l'organisation du tournoi en Europe à l'Union ${ }^{178}$. Afin de le guider, il lui fait parvenir de la documentation et se montre même disponible pour un éventuel entretien. Cette démarche constitue autant une aide qu'un moyen de contrôle du secrétaire de la FIFA sur celui de l'UEFA. En réponse, Pierre Delaunay indique à Gassmann que toutes les dispositions ont été prévues par le Comité exécutif de l'Union ${ }^{179}$. Quelques semaines plus tard, Delaunay informe par courrier Gassmann de l'avancée de l'organisation du tournoi. Il lui indique que la commission de l'UEFA, créée pour gérer le tournoi, se réunira les 28 et 29 septembre et que cette réunion sera suivie d'une discussion au

177 Delaunay P., «Union des associations européennes de football. Comité éxécutif restreint. Réunion du 13 juin 1956 à Paris ", n.d. UEFA, RM00005984 (congrès de l'UEFA, procès-verbaux 1954-1994), document relié : procès-verbaux des assemblées générales 1954-1959.

178 Lettre de K. Gassmann à P. Delaunay, 6 juillet 1956. FIFA, correspondance avec les confédérations continentales : UEFA (1955-1958), dossier : correspondance générale 01.01.1955-31.12.1958.

179 Lettre de P. Delaunay à K. Gassmann, 11 juillet 1956. FIFA, correspondance avec les confédérations continentales : UEFA (1955-1958), dossier : correspondance générale 01.01.1955-31.12.1958. 
sein du comité d'urgence de l'Union sur la compétition. En outre, il ajoute que des changements de règlement sont à envisager puisque les dirigeants s'occupant de la question au sein de l'UEFA n'ont globalement pas « la même opinion sur les conditions d'organisation du tournoi junior " ${ }^{180}$ que leurs collègues de la FIFA. Il s'agit ici d'un premier tournant, face auquel Gassmann réagit rapidement. En effet, quelques jours plus tard, il rappelle à son homologue de l'UEFA que "le tournoi doit être organisé selon les lignes directrices établies par le comité exécutif de la FIFA ${ }^{181}$. De fait, l'organisation européenne n'a pas pour mission de modifier les règles du tournoi. Sentant que la FIFA est en train de perdre de l'influence vis-à-vis des actions de l'Union, Gassmann écrit parallèlement au nouveau président de la Fédération internationale, Arthur Drewry - élu lors du congrès de 1956 en remplacement de Rodolphe Seeldrayers, décédé en cours de mandat pour lui faire part de la situation. Ce dernier espère contrer les possibles réformes grâce à la présence de Stanley Rous, qui partage des idées proches des dirigeants européens du comité exécutif de la FIFA, dans la commission des juniors de l'UEFA. Cette tentative s'avère cependant infructueuse, Rous étant minoritaire au sein de la commission ${ }^{182}$.

Constatant que l'UEFA organise la compétition sans tenir compte des décisions et des recommandations de la Fédération internationale, son comité exécutif comprend qu'il ne pourra plus faire plier les dirigeants de l'organisation européenne. Afin de marquer sa désapprobation sur la nouvelle manière de gérer l'épreuve par l'UEFA, la FIFA refuse la requête de l'Union de pouvoir utiliser le trophée des tournois précédents. L'argument avancé se base certes sur un aspect géographique, la Coupe " n'étant pas destinée pour le tournoi des juniors d'un seul continent ${ }^{183}$. Cependant, ce refus doit être perçu comme un symbole du mécontentement des dirigeants du comité exécutif de la Fédération internationale vis-à-vis de leurs collègues de l'UEFA.

180 Lettre de P. Delaunay à K. Gassmann, 12 septembre 1956. FIFA, correspondance avec les confédérations continentales : UEFA (1955-1958), dossier : correspondance générale 01.01.1955-31.12.1958.

181 Lettre de K. Gassmann à P. Delaunay, 19 septembre 1956. FIFA, correspondance avec les confédérations continentales : UEFA (1955-1958), dossier : correspondance générale 01.01.1955-31.12.1958.

182 Lettre de A. Drewry à K. Gassmann, 5 octobre 1956. FIFA, correspondance avec les confédérations continentales : UEFA (1955-1958), dossier : correspondance générale 01.01.1955-31.12.1958.

183 Gassmann K., Procès-verbal de la réunion du comité d'urgence de la FIFA du 15 mars 1957, 31 mars 1957. FIFA, comité d'urgence (procès-verbayx 1951-1957) 
En avril 1957, soit quelques semaines après la première édition de l'épreuve sous l'égide de l'UEFA, José Crahay souligne que les modifications apportées au règlement de l'épreuve ont été réalisées en vue $d^{\prime}$ ' augmenter le succès [du tournoi] tant au point de vue du sport que du spectacle ${ }^{184}$. Le principal changement tient dans le renforcement de l'aspect compétitif avec la réinstauration d'un vainqueur de l'épreuve. En effet, même si les membres de la commission pour le tournoi considèrent que l'idée de minimiser l'esprit de compétition était une bonne initiative de la FIFA, ils constatent que, dans les faits, les équipes cherchent tout de même à jouer les premières places. L'épisode de la reprise du tournoi des juniors se clôt finalement en juin 1957, le comité exécutif de la FIFA prenant définitivement acte " du fait que l'organisation de ce tournoi a entièrement passé dans les mains de l'Union des associations européennes de football ${ }^{185}$. Outre la prise d'indépendance progressive de l'UEFA vis-à-vis de la tutelle de la FIFA, la manière dont s'opère la transition de l'organisation du tournoi des juniors entre la FIFA et l'UEFA souligne la différence de conception dans la gestion des affaires footballistiques qui existent entre leurs dirigeants européens du comité exécutif de la Fédération internationale, Barassi, Lotsy ou encore Thommen, et leurs homologues de l'UEFA. Cette différence ne constitue pas une rupture totale mais plutôt, comme le note Kevin Marston, un hybride entre une poursuite des objectifs plus fraternels du football souhaitée par les dirigeants de la FIFA et une accentuation de l'aspect compétitif du jeu du côté de l'UEFA ${ }^{186}$. Pourtant, au premier abord, le profil sociologique des dirigeants du comité exécutif de l'UEFA ne semble pas très différent de celui de leurs collègues européens qui officient à la FIFA ${ }^{187}$. S'il a été difficile d'obtenir des informations à leur sujet, nous pouvons néanmoins remarquer qu'ils ont eux aussi une longue trajectoire dans les arcanes footballistiques, tout d'abord à l'échelle nationale. De plus, les nombreux congrès de la FIFA auxquels ils ont participé leur offrent l'opportunité d'être aguerris à l'échelle internationale ainsi que la possibilité de découvrir plusieurs villes du Vieux Continent. De même, ils disposent d'un capital cosmopolite développé car, en raison de leurs fonctions préalables dans le football, ils voyagent énormément depuis de nombreuses années. Souvent, en qualité de secrétaire ou de président de leur fédération nationale, ils ont

184 Crahay J., "Le tournoi international de juniors 1957 », Bulletin de l'UEFA, n 4, avril 1957.

185 Gassmann K., Procès-verbal de la réunion du comité exécutif de la FIFA des 20-21 juin 1957, 22 juillet 1957. FIFA, comité exécutif (procès-verbaux 1955-1957).

186 Marston K.T., "Sincère camaraderie" ", op. cit. p. 152.

187 Supra 1.2.2. 
accompagné les équipes nationales dans leurs voyages à l'étranger. Enfin, la plupart officient dans des professions de type libéral et semblent venir de la petite et moyenne bourgeoisie. Nous ne pouvons pas connaître avec certitude leurs niveaux d'études, mais nous pouvons supposer, au regard de leurs activités professionnelles respectives, qu'ils disposent, pour la plupart, d'une formation d'études supérieures. Leur capital culturel n'est donc pas très différent de celui de leurs collègues de la FIFA. La majorité d'entre eux sont capables de parler ou d'écrire dans deux ou trois langues européennes. Certains ont aussi vécu dans un pays étranger par le passé. C'est le cas de Delaunay qui a vécu à Londres lorsqu'il était âgé d'une vingtaine d'années. De même, Sebes a séjourné plusieurs années en France pendant les années 1930 .

Si le profil et le parcours des dirigeants du Groupement européen et de la FIFA sont similaires sur certains aspects, des différences de taille existent néanmoins. En effet, les individus à la tête de l'UEFA incarnent une nouvelle tendance chez les dirigeants du football européen avec le fait de n'avoir pas forcément été joueurs ou arbitres de haut niveau - sauf quelques exceptions comme Gustav Sebes qui a eu une brève carrière de joueur en France ${ }^{188}$ et a entraîné l'équipe de Hongrie lors de la Coupe du monde de 1954, et comme Henry Delaunay qui est un ancien arbitre de niveau national. A contrario, les autres dirigeants ont joué au football dans leur jeunesse mais n'ont jamais pratiqué ce sport à un haut niveau. Sans doute que cette situation change quelque peu leur rapport au jeu. Autre distinction, trois des six membres du comité exécutif de l'UEFA, à savoir Crahay, Delaunay et Graham (puis, dès 1958, Stanley Rous qui peut être perçu comme le remplaçant de Graham), officient comme secrétaire de leur association nationale. Or les statuts de la Fédération internationale n'autorisent pas la présence de dirigeants rémunérés pour leurs activités dans le football au sein de son comité exécutif ${ }^{189}$. Ainsi, la nomination de ces acteurs montre que, dès la création de l'UEFA, les dirigeants du football européen souhaitent se détacher quelque peu des us et coutumes de la FIFA et créer leur propre Sonderweg. La présence de secrétaires d'associations nationales dans l'élite de l'UEFA est importante, car leurs profils d'administrateur du jeu les placent plus du côté technocratique que du côté des idéaux, défendus en général par les présidents. En ce

188 Hadas M., "Stratégie politique et tactique sportive ", op. cit.

189 L'article 17, alinéa 14, des statuts de la FIFA stipule : « Les fonctionnaires rémunérés ne sont pas autorisés à faire partie du Comité Exécutif ». Rimet J., Gassmann K., Statuts de la FIFA [éditions 1953], article 17 [des statuts], 15 février 1954. FIFA, statuts, 1904-1981. 
sens, ils peuvent être amenés à favoriser davantage le développement du football, et en particulier du football professionnel, au détriment d'idéaux plus généraux - comme l'utilité sociale du football - qui concernent plutôt le football amateur. Cette présence des secrétaires témoigne de la professionnalisation progressive du football sur le Vieux Continent. En effet, l'intensification des échanges et l'accroissement des tâches en matière de football à l'échelle européenne nécessitent d'avoir des dirigeants capables de répondre de manière administrative à ces développements.

Parallèlement aux discussions sur le mode d'organisation du tournoi des juniors, l'UEFA adresse également une requête financière à la FIFA en vue de récupérer un pourcentage sur la recette brute des matchs internationaux disputés entre les équipes nationales européennes. Pour le comité exécutif de l'Union, il s'agit ici de suivre le modèle de la Confédération sudaméricaine. Cette action, qui se concrétise finalement en $1956^{190}$, marque un nouveau pas dans la distinction qui se crée entre les dirigeants du comité exécutif de la FIFA et le comité exécutif de l'UEFA. Deux ans plus tard, une nouvelle demande financière, qui touche les rencontres disputées dans le cadre de la Coupe du monde, amplifie encore les tensions. L'apport financier finalement octroyé à l'UEFA par la FIFA est très important pour l'Union, car il lui permet de continuer à développer ses activités ainsi que de se réserver une autonomie sur la scène internationale. Enfin, il confirme que l'entité se détache de la tutelle de la FIFA, comme le confirme la décision prise, en octobre 1958, par les dirigeants de son comité exécutif d'ôter de leur en-tête de correspondance la mention "FIFA » encore présente dans l'imprimé des statuts de l'Union ${ }^{191}$.

Mais, à terme, cette situation risque de porter préjudice aux Européens, qui en raison de l'internationalisation continue de la FIFA se retrouvent désormais en position minoritaire. Ainsi, au début de l'année 1959, les dirigeants européens du comité exécutif et l'élite de la FIFA souhaitent recréer un climat plus favorable. Peut-être que l'élection de Stanley Rous, proche de Barassi et Thommen, au comité exécutif de l'UEFA permetelle de favoriser ce dialogue. En tout cas, le 5 mars 1959, le président de l'Union Ebbe Schwartz note avec satisfaction que les rapports entre les deux organisations s'améliorent ${ }^{192}$. Dans le but de créer une meilleure

190 Infra 4.3.1.

191 Delaunay P., Procès-verbal de la réunion du comité exécutif de l'UEFA du 28 octobre 1958, n.d. UEFA, RM00000749 (comité exécutif 1954-1959), dossier : 1958.10.28.

192 Delaunay P., Procès-verbal de la réunion du comité exécutif de l'UEFA du 5 mars 1959, n.d. UEFA, RM00005984 (congrès de l'UEFA, procès-verbaux 1954-1994), document relié : procès-verbaux des assemblées générales 1954-1959 
synergie entre les dirigeants du comité exécutif de la FIFA d'une part et celui de l'UEFA d'autre part, Ernst Thommen propose, en décembre de la même année, la création d'une commission consultative FIFA-UEFA. Après la première réunion de cette commission, qui a lieu à Paris, le dirigeant helvétique se montre très satisfait de cette manière de procéder et indique, dans une lettre adressée au comité exécutif de l'UEFA, qu'il s'agit d'un pas important en vue d'une bonne entente entre la FIFA et l'UEFA ${ }^{193}$. Signe de ce rapprochement, et surtout d'une meilleure acceptation des tâches respectives de chaque entité, le comité d'urgence de la FIFA indique à l'association d'Union soviétique, en mai 1960, qu'il ne rentre pas en matière sur le forfait de l'équipe d'Espagne dans le cadre de la Coupe d'Europe des nations. Pour cet organe, il s'agit d'un match d'une compétition organisée par l'Union et " par conséquent le comité exécutif de l'UEFA est compétent pour décider du litige " 194 .

Les premières années de l'Union sont donc marquées par une prise d'indépendance vis-à-vis de la FIFA, qui lui permet de se réserver progressivement un monopole en matière d'organisation du football européen. Parallèlement, l'UEFA se montre également attentive aux actions d'autres acteurs du domaine footballistique qui pourraient éventuellement remettre en question ce monopole naissant.

\subsubsection{Neutraliser les concurrences}

Comme nous l'avons déjà évoqué à plusieurs reprises dans cet ouvrage, de multiples acteurs souhaitent développer les échanges footballistiques européens, notamment en créant des compétitions continentales. C’est notamment le cas des journalistes de L'Équipe avec le projet de compétition inter-clubs qu'ils développent dans la première partie de l'année $1954^{195}$. Les dirigeants du comité exécutif de l'UEFA vont devoir s'atteler à neutraliser ces possibles concurrences, démarche qui va in fine renforcer le monopole de l'Union en matière d'administration du jeu à l'échelle européenne.

Tout d'abord, il faut bien souligner à nouveau le tournant qu'implique la création de la Coupe des champions ainsi que de la Coupe des villes de foires sur le football européen. En effet, ces épreuves concurrencent

193 Lettre de E. Thommen au comité exécutif de l'UEFA, 27 juillet 1960. UEFA, RM0000949 (Séances du comité de consultatif UEFA-FIFA 1959-1962), dossier : 1960.08.17.

194 Gassmann K., Procès-verbal de la réunion du comité exécutif de la FIFA du 7 juillet 1960, 12 juillet 1960, comité exécutif (procès-verbaux 1960).

195 Supra 4.1.3. 
les tournois régionaux comme la Coupe des Grasshopper, la Coupe latine ou la Mitropa Cup - relancée en 1955. Si la dernière subsiste, les deux premières sont finalement abandonnées en $1957^{196}$. Malgré cette situation, qui tend à renforcer l'attractivité de la Coupe des champions, l'UEFA n'a pas le monopole en matière d'organisation de compétitions continentales. En effet, même si le comité exécutif de la FIFA émet le souhait, dès septembre 1955, que l'UEFA s'empare de l'organisation de la Coupe des villes de foires ${ }^{197}$, celle-ci reste gérée par un comité privé. En 1958, une deuxième édition de l'épreuve est lancée. L'épreuve se veut désormais plus ambitieuse et voit s'opposer seize équipes sous la forme d'une coupe en match aller et retour. Les formations qui participent à ce second tournoi sont :

Bâle XI (Suisse), FC Barcelone (Espagne) ; Belgrade XI (Yougoslavie) ; Birmingham City (Angleterre) ; Cologne XI (Allemagne) ; Copenhague XI (Danemark), Chelsea (Angleterre) ; Ujpesti Dozsa (Hongrie) ; Hanovre 96 (Allemagne) ; Lausanne-sports (Suisse) ; Leipzig XI (Allemagne) ; Olympique Lyonnais (France) ; Inter Milan (Italie) ; AS Roma (Italie) ; Union St-Gilloise (Belgique) ; Zagreb XI (Yougoslavie).

Le format de l'épreuve est donc modifié afin de la dynamiser et se calque désormais sur celui de la Coupe des champions. Avec cette nouvelle formule, la compétition devient plus attractive et se profile comme une sérieuse concurrence à l'épreuve phare de l'UEFA, et ce d'autant qu'une différenciation entre les deux tournois n'est pas forcément établie. Par exemple lors de la saison 1959-1960, le FC Barcelone dispute simultanément la Coupe des champions et la Coupe des foires. Dans sa volonté de s'approprier davantage de prérogatives en matière de football européen, le comité exécutif de l'UEFA émet le souhait de contrôler davantage la Coupe des foires et, plus largement, les tournois se disputant à l'échelle européenne.

196 Au sujet de la disparition de la Coupe latine, Stéphane Mourlane note que l'épreuve « n’a pas résisté à la dynamique propre du football, véhiculée par ses dirigeants au sein de la FIFA ou de l'UEFA et ses commentateurs médiatiques, fondée sur une double logique d'expansion géographique et de rentabilité financière ». Mourlane S., "La Coupe latine : aspects sportifs, culturels et politiques (1949-1957) ", dans Rey D. (dir.), Football en Méditerranée occidentale de 1900 à 1975, Ajaccio, Alain Piazzola, 2010, pp. 53-66.

197 Gassmann K., Procès-verbal de la réunion du comité exécutif de la FIFA du 17 septembre 1955, 22 novembre 1955. FIFA, comité exécutif (procès-verbaux 1955-1957). 
En date du 4 juin 1958, l'élite de l'organisation européenne décide d'introduire "dans [ses] statuts un alinéa identique en tous points à celui figurant dans les règlements de la FIFA, rendant nécessaire l'approbation de l'UEFA pour les tournois de plus de trois équipes ${ }^{198}$. Toutefois, après discussions lors du congrès annuel qui se déroule quelques heures plus tard, cette idée est abandonnée. En effet, pour une majorité des dirigeants présents, une telle mesure parait trop contraignante pour les associations nationales. Le comité exécutif poursuit néanmoins ses démarches en vue d'avoir davantage de contrôle sur l'organisation des compétitions européennes et, quelques mois plus tard, soumet une requête aux fédérations membres de l'UEFA dans le but d'établir un formulaire de demande d'autorisation pour l'organisation de compétitions européennes. La procédure serait la suivante. Les organisateurs de telles compétitions devraient transmettre au secrétariat de l'UEFA « les noms des membres de leur Comité, la liste des équipes prenant part à la compétition, ainsi que le règlement de cette dernière " ${ }^{199}$. Les demandes seraient ensuite étudiées par le comité exécutif qui donnerait son aval, ou non, à l'organisation du tournoi. Selon l'élite de l'UEFA, cette disposition permettrait de coordonner les différentes actions entreprises à l'échelle européenne et de limiter ainsi le nombre de matchs. De nombreux projets de compétition sont effectivement en latence, le journaliste Jacques Ferran n'hésitant pas à titrer dans France football "Il pleut des idées " ${ }^{200}$, en évoquant différents projets de compétitions européennes en cours. Nous pouvons faire l'hypothèse que cette mesure permettrait également au comité exécutif de l'UEFA d'avoir plus de contrôle sur le football continental et d'éviter de possibles concurrences.

Quelques mois plus tard, le comité exécutif de l'UEFA émet un autre souhait, à savoir qu'un questionnaire soit envoyé aux associations nationales avec pour objectif "d'établir un tableau complet des compétitions " ${ }^{201}$ prévues en Europe. Cette demande n'émane pas uniquement de l'élite de l'UEFA mais aussi de quelques associations membres de l'Union,

198 Delaunay P., Procès-verbal de l'assemblée générale de l'UEFA du 4 juin 1958, n.d. UEFA, RM00005986 (congrès fondateur, 1954. I-III congrès ordinaire, 1955-1957), document relié : procès-verbaux des assemblées générales 1954-1959.

199 Delaunay P., Procès-verbal de la réunion du comité exécutif de l'UEFA du 28 octobre, n.d. UEFA, RM00005984 (congrès de l'UEFA, procès-verbaux 1954-1994), document relié : procès-verbaux des assemblées générales 1954-1959.

200 "Il pleut des idées ", France football, 26 février 1957.

201 Delaunay P., Procès-verbal de la réunion du comité exécutif de l'UEFA du 5 mars 1959, n.d., UEFA, RM00005984 (congrès de l'UEFA, procès-verbaux 1954-1994), document relié : procès-verbaux des assemblées générales 1954-1959 
qui demandent à ce que l'entité intervienne afin de régulariser certaines situations. Par exemple, en mars 1959, Stanley Rous transmet au comité exécutif une lettre de la Fédération espagnole au sujet de la Coupe des villes de foires. Le courrier dénonce en particulier le côté arbitraire de la sélection des équipes participantes et le fait qu'aucun représentant espagnol ne figure au sein du comité d'organisation. Enfin, la Fédération espagnole souligne que, pour elle, les rencontres de la compétition relèvent d'un caractère amical puisque, pour être officielle, " cette coupe devrait de toute nécessité être organisée sous l'égide de l'UEFA et non pas par un Comité échappant à l'autorité et à la discipline de cette dernière " ${ }^{202}$. Le comité exécutif de l'Union se montre en accord avec les remarques de la Fédération ibérique. S’il ne s'agit pas de reprendre formellement l'organisation de la compétition, l'UEFA souhaite que, dorénavant, les engagements des clubs dans la Coupe des villes de foires devront recevoir l'accord de leur fédération nationale. Cette décision n'est pas anodine car elle relie davantage les participants du tournoi aux associations nationales et permet in fine un meilleur contrôle de l'UEFA sur le déroulement de l'épreuve.

À la fin des années 1950, l'Union commence donc à s'enquérir des compétitions organisées, ou en projet, à l'échelle européenne. Dans les années qui suivent, elle va prendre d'autres mesures, d'une part en s'octroyant le seul droit d'organiser des épreuves englobant tous les pays européens, d'autre part en n'autorisant pas les clubs participant à ses épreuves à disputer, en parallèle, des compétitions non administrées par l'UEFA.

Leurs réactions face à la création d'un Comité international de liaison des ligues confirment la volonté de l'élite de l'UEFA d'affirmer leur monopole sur la gestion du football à l'échelle européenne. En avril 1959, le procès-verbal d'une réunion du comité exécutif de la FIFA fait état de l'organisation prochaine d'une conférence entre des dirigeants provenant de plusieurs ligues nationales ${ }^{203}$. Celle-ci se déroule effectivement en date du 4 mai dans la capitale française et concerne des représentants des ligues professionnelles de football anglaise, française et italienne. Si ces entités, dont certaines ont été créées durant l'entre-deux-guerres, reconnaissent la suprématie de leur fédération nationale sur le football

202 Lettre de A. de la Fuente à la Coupe internationale des Villes de Foires, 19 janvier 1959. UEFA, RM0000749 (séances du comité exécutif, 1954-1959), dossier : comité éxécutif de l'UEFA. Séance du 11 Xbre 1959 à Paris.

203 Gassmann K., Procès-verbal de la réunion du comité exécutif de la FIFA du 24 avril 1959, 20 mai 1959. FIFA, comité exécutif.(procès-verbaux 1959) 
de leur pays, elles ont néanmoins l'autonomie nécessaire pour gérer les catégories professionnelles du championnat national. Dorénavant, les ligues professionnelles projettent de créer des tournois supranationaux, comme en témoigne l'organisation, dès 1958, de la Coupe d'amitié francoitalienne. Cette épreuve réunit une quinzaine de clubs de première et deuxième division qui s'affrontent sur trois dimanches au mois de juin dans une rencontre aller et retour. À la fin de tous les matchs, un classement est établi ${ }^{204}$ et le pays qui totalise le plus de points est désigné vainqueur. Il semble qu'après la deuxième édition, des discussions ont lieu entre les organismes français et italiens pour ouvrir l'épreuve aux équipes anglaises et suisses ${ }^{205}$. C'est dans ce même esprit de créer davantage de synergies à l'échelle européenne que les représentants de ligues professionnelles se rencontrent. Deux buts principaux sont recherchés par les promoteurs de ces échanges. Premièrement, il s'agit de défendre davantage leurs intérêts, notamment face aux fédérations nationales. En effet, certains clubs voient d'un mauvais œil la multiplication des rencontres des équipes nationales, car ils mettent gratuitement leurs joueurs à la disposition des fédérations avec le risque que ceux-ci reviennent fatigués, voire blessés ${ }^{206}$. Deuxièmement, l'idée est de créer de nouvelles compétitions entre clubs de manière à augmenter le nombre de rencontres internationales afin de réaliser un gain supplémentaire leur permettant de financer un professionnalisme qui coûte de plus en plus cher. Ces perspectives peuvent donc constituer une sérieuse menace contre le pouvoir des associations nationales et, in fine, de l'UEFA.

À la suite de la première réunion des ligues professionnelles en mai 1959, un secrétaire est désigné en la personne de l'Italien Luigi Scarambone, déjà secrétaire de la Ligue italienne de football. Celui-ci contacte plusieurs fédérations qui n'ont pas participé à la première réunion afin de les convier à une nouvelle assemblée. Il semble qu’à cette période, les échanges soient établis uniquement avec les pays disposant de ligues professionnelles ou semi-professionnelles, ce qui exclut de fait les pays scandinaves et soviétiques, où le football est officiellement considéré comme amateur $^{207}$. Dans certains cas, comme celui de l'Espagne où il n'existe pas

204 Selon le barème suivant : une victoire équivaut à deux points, un match nul à un point et une défaite à zéro point.

205 "La balle au bond. Saison à rallonge ", France football, 7 juin 1960.

206 "Le Comité et l'Union ", France football, 3 novembre 1959.

207 Si cette affirmation semble correcte pour les pays scandinaves, en revanche elle est infondée pour ceux du bloc soviétique. En effet, les joueurs d'élite de football qui évoluent dans ces pays ont certes un statut d' " employés ", de " travailleurs ", des fonctions dans l'armée, mais dans les faits ils consacrent leur tempsprincipalement à 
d'organisme spécifique gérant le football professionnel, Scarambone prend directement contact avec la Fédération nationale ${ }^{208}$, car c'est elle qui gère le championnat d'élite. Cela permet à l'UEFA d'être tenue au courant des actions du comité des ligues, la Fédération espagnole faisant part au secrétaire, Pierre Delaunay, des actions entreprises par Scarambone. Les Espagnols en profitent aussi pour indiquer au secrétaire général de l'UEFA leur non-participation aux discussions car ils estiment que celui-ci va à l'encontre des actions de l'UEFA. Si la Fédération espagnole refuse de s'engager dans le mouvement, le Comité des ligues poursuit ses démarches initiales et une nouvelle réunion est finalement agencée à Londres, le 26 octobre 1959.

Lors de cette réunion, le Comité international de liaisons des ligues est fondé officiellement. Signe de l'élargissement envisagé envers des ligues semi-professionnelles, des dirigeants autrichiens et suisses participent également aux débats, mais en qualité d'observateurs. Selon Jacques Ferran, ce changement de cap s'explique par le fait que ces démarches sont suivies avec "attention par des pays comme la Grèce, la Suède, la Hollande, la Belgique, voire l'Espagne où pourtant les clubs professionnels ne disposent d'aucune organisation autonome. Il semble même que les pays de l'Est regardent avec intérêt du côté de ce nouvel organisme ${ }^{209}$." Ce commentaire souligne bien l'hétérogénéité des acteurs qui agissent dans le football européen, car même en Espagne des dirigeants de grands clubs, tels ceux du Real Madrid ou du FC Barcelone, peuvent se montrer intéressés par ce type de démarche. Quelques jours après la réunion de Londres, le secrétaire de l'UEFA reçoit les statuts du Comité des ligues de la part de son secrétaire, Luigi Scarambone ${ }^{210}$. Cet organisme se donne trois buts. Il s'agit premièrement d'étudier les problèmes relatifs aux ligues professionnelles; deuxièmement, « de faciliter les relations entre les Ligues et les Clubs qui en font partie dans le cadre de leur fédération respective

la pratique du football. De plus, ils bénéficient de privilèges (financiers et en nature) réservés aux élites du régime et, pour les meilleurs d'entre eux, ont l'opportunité de pouvoir voyager (notamment en Occident).

208 Lettre de A. de la Fuente à L. Scarambone, 23 mars 1959. UEFA, RM0000749 (Séances du comité exécutif, 1954-1959), dossier : comité éxécutif de l'UEFA. Séance du 11Xbre 1959 à Paris.

209 "Le Comité et l'Union ", France football, 3 novembre 1959.

210 Lettre de L. Scarambone à P. Delaunay, 23 novembre 1959. UEFA, RM0000749 (séances du comité exécutif, 1954-1959), dossier : Comité éxécutif de l'UEFA. Séance du 11Xbre 1959 à Paris. 
et de la FIFA ${ }^{211}$; troisièmement, de soutenir activement et de défendre les accords pris en son sein. Les objectifs du nouvel organisme restent donc modestes et il n'est pas fait mention dans ses statuts de créer des compétitions.

En automne 1959, c'est donc un nouvel organisme du football qui est créé à l'échelle européenne. Celui-ci est par ailleurs déjà relativement bien structuré : il dispose d'un bureau - formé du Français Jean-Bernard Dancausse, de l'Anglais Joseph Richard, de l'Italien Giuseppe Pasquale et d'un dirigeant écossais qui n'est pas encore désigné à cette période -, organise une assemblée générale annuelle et dispose d'un petit budget composé, dans un premier temps, des cotisations de ses membres. Dès lors, si le Comité des ligues indique qu'il agit en conformité avec les règlements de la FIFA, de l'UEFA et des fédérations nationales qui y sont affiliées, cet organisme constitue tout de même une possible menace pour le monopole que s'est récemment construit et réservé l'UEFA en matière de gestion du football européen. Dans un premier temps, son comité exécutif accepte l'existence du Comité des ligues et ce tant qu'il « ne contrariera d'aucune manière l'autorité et la compétence de l'UEFA » ${ }^{212}$. Cette position d'attente correspond à celle prise préalablement par la FIFA. En effet, son " comité exécutif a pris connaissance du projet de statuts des Ligues et estime qu'aussi longtemps qu'elles respectent leurs associations nationales respectives comme étant la seule et suprême autorité pour les relations internationales et aussi longtemps qu'elles observent les statuts et règlements de leurs associations nationales ainsi que ceux de la FIFA, il n'est pas nécessaire d'intervenir ${ }^{213}$.

Le Comité des ligues va toutefois se montrer rapidement actif, notamment en créant des compétitions, telle la Coupe des Alpes qui réunit, dès l'été 1960, des sélections de joueurs nationaux suisses et italiennes. Cette activité va entraîner une réaction des dirigeants de l'UEFA. Au mois d'août, son comité exécutif discute du fait « que certaines ligues nationales, membres du Comité international de liaison des ligues de football essayent

211 Relevons que le Comité des ligues ne fait pas mention de l'UEFA, ce qui à la vue du développement récent et croissant de l'Union paraît tout de même curieux. Anonyme, Statuts du Comité internationale de liaison des ligues de football [édition de 1959], Article 4, 26 octobre 1959. UEFA, RM0000749 (séances du comité exécutif, 1954-1959), dossier : Comité éxécutif de l'UEFA. Séance du 11 Xbre 1959 à Paris.

212 Delaunay P., Procès-verbal de la réunion du comité exécutif de l'UEFA du 11 décembre 1959. Document numérisé que nous a transmis l'archiviste de l'UEFA, Nicolas Bouchet.

213 Gassmann K., Procès-verbal de la réunion du comité exécutif de la FIFA du 27 octobre 1959, 9 décembre 1959. FIFA, comité exécutif (procès-verbayx 1959) 
de s'emparer des devoirs et droits des associations nationales ${ }^{214}$. Afin de faire la lumière sur cette affaire, les dirigeants présents décident de créer une commission composée de Bauwens, Crahay, Schwartz et Pujol (suppléant) dans le but d'obtenir des éclairages sur la question. En fait, à partir de cette période, l'UEFA commence à surveiller étroitement les actions du Comité des ligues. Après une nouvelle discussion au sein du comité exécutif de la FIFA, Ernst Thommen souligne aussi qu'il a pris contact avec le nouvel organisme, "l'invitant à se mettre en rapport avec l'UEFA et de ne pas aller trop loin en ne respectant pas les intérêts des fédérations internationales $»^{215}$. Finalement, à la suite de nouvelles discussions, l'UEFA intervient et il sera même décidé d'incorporer le Comité des ligues au sein de l'Union ${ }^{216}$.

Au début des années 1960, l'UEFA prend progressivement la place de garante organisationnelle du football à l'échelle continentale en Europe et limite, voire annihile, les actions d'autres acteurs du football. Mais l'intérêt pour le jeu ne provient pas uniquement d'acteurs du domaine footballistique. En effet, en raison de sa popularité, le football intéresse également d'autres organisations européennes, dont les prérogatives se développent en même temps que celles de l'UEFA. C'est en particulier le cas de l'Union européenne de radio, qui s'intéresse rapidement au football.

\subsubsection{Interagir avec d'autres organisations européennes}

Créée au début des années 1950 sur les ruines de l'Union internationale de radio (UIR), l'Union européenne de radio (UER) se veut une organisation de défense des intérêts des chaînes de télévision nationales ainsi qu'un forum de discussion sur les problèmes ou enjeux liés à la télévision ${ }^{217}$. Avec l'accroissement constant du nombre de ventes

214 Bangerter H., Procès-verbal de l'assemblée générale de l'UEFA du 19 août 1960, 10 octobre 1960. UEFA, RM00000751 (séances du comité exécutif, 1960-1961), dossier : ExKo 19.08.1960.

215 Gassmann K., Procès-verbal de la réunion du comité exécutif de la FIFA du 19 août 1960, 5 octobre 1960. FIFA, comité exécutif (procès-verbaux 1960).

216 Cette décision est effective en 1963 avec la création de commission du football professionnel et non amateur, qui lors de sa première législature est formée pour moitié de dirigeants représentants l'UEFA et pour l'autre moitié d'anciens dirigeants du Comité des ligues.

217 Heinrich-Franke C., "Creating transnationality through an international organization? The European broadcasting union's (EBU) television programme activities ", dans Fickers A., Johnson C. (eds.), Transnational television history. A comparative approach, London, Routledge, 2012, p. 35. 
de récepteurs, la télévision, qui a fait ses premiers pas dans les années 1930 , se profile comme un média important ${ }^{218}$. Pour la développer, ses promoteurs ont l'ambition de s'emparer de nombreux sujets sociétaux, dont le football, qui recèle plusieurs avantages. Outre sa popularité et le contenu relativement limité de son message politique ${ }^{219}$, le jeu est bien adapté à une diffusion télévisuelle. En effet, contrairement à d'autres sports (comme le base-ball par exemple), le terrain peut aisément être capté avec une ou deux caméras postées en haut du stade. Par ailleurs, par rapport au basket-ball ou au hockey sur glace, le football est moins rapide et plus facile à filmer. Enfin, la régularité des rencontres et les nombreux échanges internationaux offrent un terreau favorable pour réaliser le miracle de la télédiffusion. Dès 1953, les téléspectateurs britanniques plus de deux millions de récepteurs sont alors en circulation au RoyaumeUni - ont l'occasion d'assister en direct à la première finale de la Coupe d'Angleterre $^{220}$. Au niveau international, la rencontre entre la France et l'Allemagne de 1952 peut également être vue en direct. Ce premier match entre les deux pays depuis la fin de la guerre suscita un grand intérêt du public. Il semble même qu'il permit la vente de plusieurs milliers de récepteurs de télévision peu avant la rencontre.

En matière d'échanges de programmes internationaux de télévision idée émise dès 1951 par l'un des promoteurs de l'UER, le Suisse Marcel Bezençon -, une avancée se produit avec le couronnement de la reine Élisabeth II au printemps 1953, retransmis simultanément en Allemagne, Belgique, France, Italie, Pays-Bas et Suisse. À la suite de ce premier test, l'UER envisage, dès juillet de la même année, la mise sur pied d'un programme de coopération pour l'été 1954. Dans le cadre du lancement de ce qui sera renommé a posteriori Eurovision, la Coupe du monde de 1954 apparaît comme une thématique phare de ces échanges ${ }^{221}$. Ce positionnement est confirmé quelques mois plus tard puisque la toute nouvelle commission des programmes de l'UER confère une place importante au tournoi dans

218 Sur le dévéloppement des télévisions nationales en Europe, voir : Bignell J., Fickers A. (eds.), A European Television History, Maiden, Wiley-Blackwell, 2008.

219 Ce qui en fait un produit de divertissement tout à fait acceptable pour les télévisions dont la grande majorité reste sous la coupe étatique ainsi qu'un programme de divertissement particulièrement apprécié d'une grande partie du public.

220 Haynes R., "A pageant of sound and vision: Football's relationship with television, 1936-60 ", The International Journal of the History of Sport, vol. 15, $\mathrm{n}^{\circ}$ 1, 2008, pp. 211-226.

221 "Activités de l'UER ", Bulletin de documentation et d'information, vol. 4, n 20, juillet 1953, p. 503. 
une "Saison d'été d'échanges européens de télévision »"22. Sept pays choisissent de diffuser dix rencontres et en particulier les demi-finales et les finales de la compétition ${ }^{223}$, ce qui implique que près d'un tiers des matchs sont retransmis en direct. Notons que le football n'est pas le seul sport à connaître un tel engouement télévisuel international. Le cyclisme, par exemple, fait l'objet de programmes en Eurovision durant l'été 1954, avec des reportages durant le Tour de France ${ }^{224}$. Au sortir de la Coupe du monde de 1954, le président de la commission des programmes de l'UER, Marcel Bezençon, insiste cependant sur l'importance de l'événement footballistique dans le cadre des échanges télévisuels internationaux. Il indique en effet que si le mois "de juin fut choisi, ce fut [en] raison des matchs de la Coupe du monde de football qui se jouaient alors en Suisse, et qui constituaient, on le devine, des spectacles populaires du plus vif intérêt ${ }^{225}$. Mais Bezençon souligne aussi les difficultés rencontrées dans l'entreprise : les problèmes techniques liés à la transmission de l'information et du son ou encore les différences d'expériences entre les télévisions nationales participant à l'aventure. En outre, il s'est avéré que les négociations entre l'UER et la FIFA étaient également délicates.

En effet, les organes footballistiques se montrent alors réticents à une trop grande télédiffusion des matchs et portent deux griefs principaux au petit écran. Premièrement, la télévision risque de provoquer une désaffection du public et notamment en cas de mauvais temps ou de période d'hiver, les amateurs de football pouvant préférer regarder le match chez eux plutôt que de se rendre au stade. Deuxièmement, elle risque de créer "une fâcheuse concurrence pour les matchs de compétitions nationales, lorsqu'il s'agit de la retransmission d'une rencontre internationale dans un autre pays, ou de la finale d'une Coupe nationale ${ }^{226}$. C'est pourquoi les dirigeants du football n'hésitent pas à interdire, ou du moins à limiter fortement, les retransmissions des rencontres. Un autre aspect peut également être ajouté : la télévision pourrait inciter les jeunes à devenir

222 "Activités de l'UER ", Bulletin de documentation et d'information, vol. 5, n 24, marsavril 1954, p. 285.

223 Dietschy P., Histoire du football, op. cit., p. 540.

224 "Le tour en Eurovision", Télé-Magazine, n 24, 8-24 avril 1955.

225 Bezençon M., "L'Eurovision est-elle un mythe ? ", Bulletin de documentation et d'information, vol. 5, $\mathrm{n}^{\circ} 27$, septembre-octobre 1954, p. 590.

226 Delaunay P., Procès-verbal de l'assemblée générale de l'UEFA du 2 mars 1955, n.d. UEFA, RM00005984 (congrès de l'UEFA, procès-verbaux 1954-1994), document relié : procès-verbaux des assemblées générales 1954-1959. 
plus spectateurs qu'acteurs du sport ${ }^{227}$. Cette inquiétude est notamment formulée par Ottorino Barrasi et confirme que certains acteurs du football recherchent aussi, par l'entremise de cette pratique, à promouvoir des objectifs moraux. Ce sont donc des aspects commerciaux mais aussi moraux qui sont évoqués par les dirigeants pour limiter, en partie, les retransmissions des matchs à la télévision. Lors de l'assemblée générale de l'UEFA de 1955, le cas de la télévision retient fortement l'attention des congressistes. Après une assez longue discussion, un consensus est trouvé parmi les délégués dans le but de limiter la concurrence induite par la télévision. Les trois principes suivants sont édictés au sujet de la retransmission des matchs par la télévision :

- Une association nationale ne pourra permettre la [retransmission] d'un match international que si elle a l'autorisation de l'association qu'elle reçoit.

- L'association nationale organisatrice devra s'assurer que la retransmission de la rencontre n'est [diffusée] qu'à l'intérieur des frontières de son pays.

- Elle ne pourra notamment permettre la [retransmission] du match dans un autre pays qu'avec le consentement de l'association nationale de ce dernier ${ }^{228}$.

Ces décisions, nommées par le comité exécutif de l'UEFA les «Accords de Vienne ", confirment que l'organisation est bien un forum de discussion entre les associations nationales. Toutefois, l'une des limites de l'Union réside dans le fait qu'elle n'a pas la possibilité de contraindre ses associations membres à appliquer les dispositions prises et les décisions que prend son comité exécutif ne font office que de recommandations ${ }^{229}$. Malgré cela, il semble que les mesures préconisées par l'UEFA au sujet de la télévision sont globalement suivies par les associations nationales. En effet, le président de l'Union peut se féliciter durant l'assemblée générale de 1956 des " grands services rendus par la bonne application [des décisions prises]

227 Delaunay P., Procès-verbal de l'assemblée générale de l'UEFA des 28-29 juin 1957, n.d. UEFA, RM00005984 (congrès de l'UEFA, procès-verbaux 1954-1994), document relié : procès-verbaux des assemblées générales 1954-1959.

228 Delaunay P., Procès-verbal de l'assemblée générale de l'UEFA du 2 mars 1955, n.d. UEFA, RM00005984 (congrès de l'UEFA, procès-verbaux 1954-1994), document relié : procès-verbaux des assemblées générales 1954-1959.

229 L'article 4, alinéa C, des statuts indique que le but est d' " arrêter si possible une attitude commune à leur égard ». Anonyme, Statuts de l'UEFA [édition 1956], article 4, n.d. UEFA, RM00005779 (Statuts de UEFA, 1954-1976). 
à Vienne ${ }^{230}$. Cette remarque signale que l'UEFA jouit d'une certaine reconnaissance auprès de ses associations membres.

Jusqu'à l'hiver 1956, la thématique de la télévision concerne surtout le rapport entre les associations nationales et les organismes de télévision de leur pays. Mais, à partir de cette même année, une nouvelle problématique en matière de télévision interpelle les dirigeants de l'UEFA, qui sont contactés par les dirigeants de l'UER et de la télévision. En effet, ces derniers souhaitent pouvoir retransmettre des matchs de la Coupe des champions européens. Il faut souligner ici la rapidité d'action de l'UER, signe que les membres de sa commission des programmes sont attentifs au développement du football. Trois enjeux expliquent la démarche entreprise par l'UER. Premièrement, ses dirigeants souhaitent poursuivre, et pérenniser, le développement du réseau Eurovision. En effet, ce type d'échanges a comme avantage de pouvoir proposer des programmes aux télévisions qui disposent de peu de moyens et donc de limiter les coûts. Sous cet angle, les promoteurs de ces échanges envisagent de retransmettre des programmes sportifs ${ }^{231}$, comme les parties de la Coupe des champions, qui en raison de leur popularité constituent indéniablement une possibilité de toucher un grand public. Deuxièmement, il s'agit aussi pour les dirigeants de l'UER de défendre les intérêts de leur organisme. En effet, l'édition de janvier et février 1956 du Bulletin de l'UER souligne la nécessité de s'intéresser " aux tentatives que semblent vouloir développer certains organismes privés pour s'assurer l'exclusivité des droits de télévision de certaines manifestations sportives de caractère international ${ }^{232}$. En d'autres termes, l'organe directeur de l'UER souhaite consolider le droit de retransmission sur les joutes sportives à l'échelle européenne. Pour répondre à ce défi, il s'agit pour eux de prendre contact avec les organismes sportifs internationaux. Troisièmement, les principaux dirigeants de la commission des programmes de l'Union de radio, et en premier lieu son président, le Suisse Marcel Bezençon, ne sont pas insensibles à l'idée d'établir des liens plus fermes entre les peuples au travers des échanges télévisuels internationaux. Ainsi, nous pouvons émettre l'hypothèse que

230 Delaunay P., Procès-verbal de l'assemblée générale de l'UEFA du 8 juin 1956, n.d. UEFA, RM00005984 (congrès de l'UEFA, procès-verbaux 1954-1994), document relié : procès-verbaux des assemblées générales 1954-1959.

231 Dans le volume $35 \mathrm{du}$ Bulletin de l'UER, un article indique qu'il faut que l'organisme se concentre "sur les possibilités d'exploitation "maximum" de grandes manifestations d'intérêt international comme les Jeux olympiques, les Championnats du monde ou d'Europe de divers sports, etc. " Anonyme, "Les activités de l'UER », Bulletin de l'UER, vol. 35, janvier-février 1956.

232 Anonyme, "Les activités de l'UER », Bulletin de l'UER vol.35, janyier-féyrier 1956. 
retransmettre des parties de la Coupe des champions est un bon vecteur de cette ambition politique de leur point de vue.

En date du 19 mars 1956, une délégation composée de dirigeants importants de l'organisme de télévision - en particulier Bezençon et le conseiller technique du réseau Eurovision, Georges Straschnov - rencontre le comité exécutif de l'UEFA. Après discussions, les dirigeants présents s'entendent sur l'idée d'une collaboration entre les deux entités " compte tenu de leurs intérêts respectifs ${ }^{233}$. Il est notamment décidé que l'Union de football tiendra au courant l'UER au sujet des rencontres des équipes nationales qui pourraient l'intéresser, mais que sur ce point celle-ci devra ensuite s'entendre directement avec les associations nationales concernées. En outre, le sujet sur lequel les deux organisations semblent pouvoir engager une véritable collaboration est la Coupe des champions. Une procédure est arrêtée, l'UER s'engageant à informer l'Union de football de l'intérêt sur les rencontres et c'est l'UEFA, en sa qualité d'organisatrice, qui traitera ensuite de la question avec les associations-membres concernées. La mise en œuvre de cet accord de principe semble néanmoins délicate. Dans le Bulletin de l'UER des mois de mai et juin, Marcel Bezençon note que l'Eurovision a encore passablement de soucis, en particulier dans les discussions avec les dirigeants du football « avec [lesquels] on peut arriver petit à petit à une bonne entente. Cela sera lent. Mais pourquoi vouloir brûler les étapes? "234. En outre, lors du congrès de l'UEFA de 1956 certains délégués présents indiquent que le petit écran est assurément un bon moyen de publicité, et les accords de Vienne sont reconduits ${ }^{235}$. En ce qui concerne la Coupe des champions, il est alors décidé que les organismes de télévision devront payer un dédommagement en raison de l'éventuel manque à gagner dû à la perte de spectateurs. Une répartition est arrêtée : deux tiers du montant versés par la télévision seront répartis entre les clubs participant au match et un tiers ira dans les caisses de l'UEFA. En ce sens, les dirigeants de l'Union prennent conscience que la télédiffusion des rencontres peut aussi servir à soutenir les activités de leur organisme.

Quelques jours après le congrès de l'UEFA, la retransmission de la finale de la première édition de la Coupe des champions, qui se dispute

233 Delaunay P., Procès-verbal de la réunion du comité exécutif de l'UEFA du 19 mars 1956, n.d., UEFA, RM00005974 (réunion du comité exécutif, 1954-1959), document relié : procès-verbaux des comités exécutifs et comités d'urgence 1954-1959.

234 "L'Eurovision à l'auscultation ", Bulletin de l'UER, vol. 7, n³7, mai-juin 1956, p. 361

235 Delaunay P., Procès-verbal de l'assemblée générale de l'UEFA du 8 juin 1956, n.d. UEFA, RM00005986 (congrès fondateur, 1954. I-III congrès ordinaire, 1955-1957), document relié : procès-verbaux des assemblées générales 1954-19597 
à Paris entre Reims et Real Madrid, donne un bon aperçu du rôle que pourrait jouer la télévision dans les années suivantes. L'événement est en effet retransmis par le réseau Eurovision dans plusieurs pays (en intégralité en France, la seconde mi-temps en Allemagne et en Suisse). Dans l'Hexagone, près de deux millions de téléspectateurs assistent à la diffusion de la rencontre ${ }^{236}$, ce qui enthousiasme des journalistes comme Marcel Leclerc, directeur de Télé-programme magazine, qui écrit : " En un mot, la télévision a eu ce soir-là droit de cité. Répétons-le : plusieurs millions de personnes ont applaudi à la fois aux vainqueurs et, inconsciemment peutêtre, à l'incroyable magie, à la puissance démesurée de la télévision ${ }^{237}$. " Malgré cet engouement et cette première diffusion à succès, la proposition de dédommagement financier présentée par l'UEFA n'est pas acceptée par l'UER, son Bulletin des mois de juillet-août 1956 indiquant qu'aucun accord n'a été trouvé avec l'Union de football. En fait, s'ajoutent à ces considérations financières, des problèmes techniques dans la télédiffusion des matchs. Pendant plusieurs mois, les deux organisations n'entretiennent plus véritablement d'échanges. Cette distance ne signifie toutefois pas la non-diffusion des rencontres de la Coupe des champions sur les télévisions nationales puisque jusqu'à la finale, les clubs peuvent - en accord avec leur fédération nationale - conclure des contrats avec la télévision. C'est pourquoi le règlement du tournoi pour l'année 1957-1958 prend en compte la possible télédiffusion des rencontres dans sa partie financière et suit les dispositions prises à Lisbonne quelques mois plus tôt ${ }^{238}$.

Comme en 1954, c'est la Coupe du monde qui va donner une nouvelle impulsion à la thématique de la télévision. En effet, après d'âpres négociations FIFA-UER, l'épreuve de 1958 qui se joue en Suède est retransmise sur le réseau Eurovision. Cette retransmission n'est pas sans poser des problèmes, car un relais est placé au Danemark, pays qui n'est pas qualifié pour l'épreuve finale. Sa fédération de football a dès lors refusé que des matchs de la compétition soient retransmis sur son territoire afin de ne pas concurrencer les parties amicales disputées à la même période par son équipe nationale. Le cas de la télédiffusion des matchs de football est réexaminé durant l'assemblée générale de l'UEFA qui est organisée à Stockholm pendant le tournoi mondial. Après une longue discussion sur la question, les dirigeants prennent deux décisions majeures. Premièrement,

236 "Apothéose de la première Coupe d'Europe des clubs ", L'Équipe, 13 juin 1956.

237 Leclerc M., "Une fenêtre ouverte sur le monde! ", Télévision programme magazine, $\mathrm{n}^{\circ} 35,24-30$ juin 1956.

238 Anonyme, Règlement de la Coupe des clubs champion [saison 1957-58], n.d. UEFA, RM00000749 (réunions du comité exécutif 1954-1959), dossier-CF 08 04.1958. 
estimant que les éventuels fonds issus de la télévision peuvent soutenir les activités de l'Union, ils décident de créer un fond financier pour supporter les déplacements des équipes lors du tournoi international des juniors organisés annuellement par l'UEFA ${ }^{239}$. Deuxièmement, ils décident d'officialiser la mise sur pied d'une « commission d'étude pour les problèmes de la télévision ${ }^{240}$. Celle-ci est composée de dirigeants expérimentés, à savoir le Belge José Crahay, l'Anglais Stanley Rous, accompagnés du secrétaire général, Pierre Delaunay. L'organe est créé afin de représenter au mieux les intérêts de l'UEFA auprès des organisations de télévision. Cette situation s'inscrit elle-même dans la volonté générale de structurer l'UEFA. Ces dispositions non seulement favorisent le suivi de possibles négociations avec les organes de télévision, mais montrent également que l'Union se profile comme le référent du football européen vis-à-vis d'acteurs extérieurs à ce sport.

Dans le même temps, les dirigeants de l'UER font également des démarches visant à améliorer les liens avec les organismes sportifs. À cet effet, des juristes sont interrogés sur la question d'offrir une rémunération financière aux organismes sportifs pour les retransmissions des compétitions dont elles sont les dépositaires. Selon ceux-ci, il semblerait qu'une telle compensation, lorsque l'événement est organisé dans un endroit fermé et avec le paiement d'un ticket pour assister au spectacle, se justifie ${ }^{241}$. De plus, en 1959, la commission des programmes demande au Britannique Peter Dimmock, qui œuvre au sein de l'UER quasiment depuis ses débuts, de bien vouloir endosser le costume de "conseiller sportif ${ }^{242}$. Alors que le réseau Eurovision est désormais bien établi avec un peu moins de 300 programmes pour l'année $1959^{243}$, l'UER paraît mieux armée pour discuter avec l'élite de l'UEFA.

239 Delaunay P., Procès-verbal de l'assemblée générale de l'UEFA du 4 juin 1958, n.d. UEFA, RM00005986 (congrès fondateur, 1954. I-III congrès ordinaire, 1955-1957), document relié : procès-verbaux des assemblées générales 1954-1959.

240 Cette commission a déjà tenue séance, notamment en octobre 1957, suivant en cela l'idée émise par l'Italien Barassi - lors du congrès de l'UEFA organisé quelques mois plus tôt à Copenhague - de créer une commission au sujet de la télévision. Cependant, c'est la décision prise lors du congrès de 1958 qui permet de lancer véritablement ses activités.

241 "L'Eurovision et ses problèmes juridiques ", Revue de l'UER. Cahier B, vol. 55, juin 1959, pp. 25-28.

${ }^{242}$ Dimmock P., « Le sport télévisé à l'UER - passé, présent et avenir. Et notes sur la télévision sportive en Grande-Bretagne ", Revue de l'UER. Cahier B, vol. 110, juillet 1968, p. 13.

243 Le réseau bénéficie de l'augmentation croissante du nombre de récepteurs de télévision en service dans les pays affiliés à l'UER (environ 3200000 en 1954 contre 14200000 en 1959). 
En cette fin des années 1950, les deux entités semblent désormais prêtes à trouver un terrain d'entente sur la télédiffusion des rencontres européennes de football. À ce titre, l'édition 1959-1960 de la Coupe des champions témoigne de cette situation puisque douze matchs sur les cinquante-deux du tournoi sont retransmis en direct ${ }^{244}$. Après la télédiffusion à succès de la finale du tournoi de 1960, notamment en Allemagne, en Belgique et en France ${ }^{245}$, un premier accord UEFA-UER est finalement signé en 1961 en vue de la retransmission des finales ${ }^{246}$.

Comme l'avaient déjà suggéré Jürgen Mittag et Jörg-Uwe Nieland dans un article retraçant les grandes étapes de la collaboration l'entre l'UEFA et l'UER des années 1950 aux années $1990^{247}$, les discussions entre les deux organisations soulignent que les actions de l'Union dépassent le cadre footballistique et s'inscrivent plus globalement dans le cadre de la coopération européenne. En administrant un domaine très populaire, marqué par des échanges réguliers et étendus géographiquement notamment transcendant le Rideau de fer -, l'UEFA se profile rapidement comme un acteur des relations entre les pays européens.

\subsubsection{Un acteur « atypique » de la coopération européenne}

Dans un texte paru en 2010 et qui résume les apports de sa thèse de doctorat, Gabriel Bernasconi souligne que, depuis 1945, le Comité international olympique est devenu un acteur " atypique $»^{248}$ des relations internationales, notamment parce qu'il a la capacité de susciter des discussions avec les États et de créer des conditions de rencontre entre des pays politiquement divisés. Dans les lignes qui suivent, nous souhaitons reprendre à notre compte cette idée et l'accoler au cas de l'UEFA. Nous affirmons que l'Union, en particulier par l'entremise de la Coupe des champions, a aussi pu tenir ce rôle et se profiler ainsi comme un acteur atypique de la coopération européenne.

\footnotetext{
244 «La balle au bond. Pas sympathique », France football, 5 juillet 1960.

245 Information donnée dans le $\mathrm{n}^{\circ} 238$ de Télé-Magazine.

246 Bangerter H., Rapport sur la deuxième Conférence des secrétaires généraux des 9-10 septembre 1965 à Hambourg, septembre 1965. UEFA, RM00010067 (rapport de la conférence des secrétaires généraux de 1965), pp. 8-9.

247 Mittag J., Nieland J.-U., "Auf der Suche nach Gesamteuropa », op. cit.

248 Bernasconi G., «De l'universalisme au transnational : le Comité international olympique, acteur atypique des relations internationales ", Bulletin de l'Institut Pierre Renouvin, vol. 31, n 1, 2010, pp. 151-1591 
Dès son lancement par les journalistes de L'Équipe, la Coupe des champions est pensée comme une épreuve devant dépasser les clivages Est-Ouest. En effet, outre les objectifs économiques (cette nouvelle information devant permettre une augmentation du nombre de ventes) et footballistiques (en particulier l'amélioration du niveau du football français grâce aux confrontations avec des clubs étrangers) visés par les journalistes, nous pouvons aussi émettre l'hypothèse qu'ils ne sont pas dénués d'intérêts plus politiques. Le football pourrait ainsi permettre de rapprocher les peuples européens divisés. Mentionnons qu'a posteriori, Jacques Goddet et Jacques de Ryswick reviennent, dans leur autobiographie respective, sur cet aspect ${ }^{249}$. De plus, lors des différents échanges que nous avons eus avec lui, Jacques Ferran a également insisté sur ce point. Cette hypothèse est également émise par Antoine Maumon de Longevialle, qui a eu l'occasion de rencontrer Jacques Ferran ${ }^{250}$. Dans le premier projet de statuts de la Coupe datant de février 1955, des pays issus des quatre coins de l'Europe et des deux blocs se côtoient ${ }^{251}$.

Cette volonté de dépasser le clivage Est-Ouest au travers de la compétition est poursuivie par le comité exécutif de l'UEFA qui, comme nous l'avons indiqué, reprend l'organisation de l'épreuve dès le mois de juin $1955^{252}$. En effet, les participants présélectionnés par le journal parisien sont reconduits, avec seulement quelques changements dus principalement à des forfaits de dernière minute.

Le tout premier match de l'épreuve, qui se joue en septembre 1955, témoigne de cette possibilité offerte par le tournoi de créer des

249 De Ryswick J., 100000 heures de football, Paris, La Table Ronde ; Goddet J., L'Équipée belle, Paris, Robert Lafont-Stock, 1962 ; Ferran J., Le football. Aventure d'hommes, Paris, La Table Ronde.

250 "L'étonnement dont a témoigné Jacques Ferran lorsque nous lui avons demandé si la présence de fédérations de l'Est à la Coupe des champions avait toujours été évidente est révélatrice de cette volonté naturelle d'ouverture à l'Est ", écrit-il dans son travail. Maumon de Longevialle A., La construction de l'Europe du football, op. cit., p. 42.

251 Les équipes sélectionnées sont les suivantes : Allemagne de l'Ouest (Rot Weiss Essen) ; Angleterre (Chelsea) ; Autriche (Rapid Vienne) ; Belgique (Anderlecht) ; Danemark (Copenhague) ; Écosse (Hibernian) ; Espagne (Real Madrid) ; France (Stade de Reims) ; Hongrie (Hondved) ; Italie (AC Milan) ; Portugal (Sporting Lisbonne) ; Pays-Bas (Holland Sport) ; Sarre (Sarrebruck) ; Suède (Malmö) ; Suisse (Servette FC) ; Tchécoslovaquie (Sparta Prague) ; Union soviétique (Dynamo Moscou) ; Yougoslavie (Partizan Belgrade). FIFA, "Projet d'une Coupe d'Europe proposé par le journal L'Équipe et d'autres journaux européens ", n.d. FIFA, correspondance avec les confédérations continentales : UEFA (1955-1958), dossier : correspondance générale 01.01.1955-31.12.1958.

252 Supra 4.1.1. 
connexions entre des pays européens divisés sur la scène internationale puisqu'il oppose Partizan Belgrade au Sporting du Portugal. Or le Portugal, dirigé par le dictateur Salazar, prône traditionnellement une politique résolument anticommuniste ${ }^{253}$, et la Yougoslavie du maréchal Tito considère les régimes ibériques espagnols et portugais comme fascistes. Au premier abord, l'organisation de la rencontre risque de s'avérer délicate. Toutefois, en ce milieu des années 1950, un accord entre les deux pays ne semble pas impossible. Déjà en janvier 1951, lorsque le délégué yougoslave Andrejevic n'avait pu se rendre à la réunion de la commission de réorganisation de la FIFA qui devait se dérouler à Madrid - en raison d'une interdiction de son gouvernement de séjourner en Espagne -, il avait suggéré que le lieu de la rencontre soit déplacé à Lisbonne ${ }^{254}$. Il faut dire que le Portugal salazariste n'est pas isolé internationalement parlant et prend une part active aux travaux des organisations internationales et européennes (il intègre l'OTAN puis, en 1958, fait partie des membres fondateurs de l'AELE). De plus, sous un angle footballistique, Yves Léonard indique que l'essor du football n'est pas un véritable enjeu pour Salazar et qu'il se réalise à contrecœur des volontés du régime ${ }^{255}$. Dès lors, si une victoire est toujours bonne à prendre en termes de propagande politique, le club du Sporting Lisbonne ne peut toutefois pas être considéré par le régime salazariste comme un porte-parole ni comme un emblème représentant la force du régime ${ }^{256}$. Signe de ce contexte, cette première confrontation n'a pas été décidée par tirage au sort, mais par consentement entre les représentants des deux équipes lors de la réunion d'avril 1955 organisée à Paris entre les journalistes de L'Équipe dans le but de créer l'épreuve ${ }^{257}$. Cette double

253 Pour des propos de synthèse sur le salazarisme et en particulier une comparaison avec d'autres régimes fascistes, voir : Pinto, A.C., "Le salazarisme et le fascisme européen ", Vingtième Siècle. Revue d'histoire, vol. 62, 1999, pp. 15-25.

254 Indication donnée par Seeldrayers dans un courrier au secrétaire Gassmann. Le dirigeant belge montre néanmoins son étonnement face à cette requête : «Personnellement, je ne vois pas comment, dans ces conditions, la Yougoslavie pourrait lui permettre d'aller au Portugal où il y a aussi, du point de vue soviétique, le Gouvernement d'un dictateur. " Lettre de R.W. Seeldrayers à K. Gassmann, 30 janvier 1951. FIFA, réorganisation 50-53, 1. Commission d'étude et bureau, dossier : réorganisation séance des 29/30.03.

255 Léonard Y., "Le sport dans le Portugal de Salazar, "instructeur social” plus qu' un outil de propagande ", dans Bensoussan G. et al., Sport, corps et sociétés de masse, op. cit., p. 251.

256 Pereira V., "La Selecção portugaise, entre dictature, propagande coloniale et horizon européen ", dans Archambault F., Beaud S., Gasparini W., Le football des nations, op. cit., pp. 51-74.

257 Vonnard P., La genèse de la Coupe des champions, op. cit.. p. 119.2-8076-0570-1 
confrontation permet donc à l'Union de confirmer son statut de forum entre les associations nationales de football européennes, voire de se poser en véritable promotrice du rapprochement Est-Ouest.

Ce positionnement se confirme quelques semaines plus tard, et de manière beaucoup plus nette, car cette fois le Partizan doit affronter le Real Madrid dans le cadre des quarts de finale. Cette opposition met aux prises l'équipe phare du régime de Tito à une formation madrilène pouvant être considérée comme l'emblème du franquisme ${ }^{258}$. Jacques Ferran, qui a effectué le tirage au sort, n’hésite pas à écrire qu'il s'agit là " d'un match explosif et un peu inquiétant ${ }^{259}$. En effet, le football est utilisé par le régime franquiste comme un lieu symbolique pour mener la lutte contre le communisme car, comme nous l'avons déjà indiqué, plusieurs joueurs ayant fui les régimes communistes au début des années 1950 ont trouvé refuge en Espagne. Signe de la position du gouvernement ibérique vis-à-vis des pays du bloc soviétique, l'équipe nationale espagnole n'a encore jamais affronté une équipe provenant de l'autre côté du Rideau de fer. En ce milieu des années 1950, le climat entre l'Espagne et la Yougoslavie n'est donc que peu propice à la réalisation d'échanges footballistiques et les deux pays n'entretiennent aucune relation diplomatique sur la scène internationale. Au moment du tirage au sort, il n'est donc pas possible de savoir si la partie va se dérouler correctement. Afin que la partie puisse s'organiser, l'Union s'active auprès des deux associations nationales. Le secrétaire général de l'UEFA, Pierre Delaunay, propose notamment aux délégués du Real de venir à Paris lors du match France-Yougoslavie qui doit se disputer le 11 novembre 1955 afin qu'ils entrent en relation avec Andrejevic ${ }^{260}$. Cette rencontre sert autant à déterminer les dates des deux parties - il n'y avait pas assez de dirigeants présents lors du tirage au sort du 4 novembre à Paris pour entamer des discussions à ce sujet - que de discuter du bon déroulement de la rencontre. Finalement - les sources nous manquent pour étayer le propos -, un terrain d'entente semble être trouvé entre les dirigeants des deux pays.

258 Gonzalez Calleja E., "Le Real Madrid, “équipe du regime” ? Football et enjeux politiques pendant la dictature de Franco ", dans Mourlane S., Gastaud Y. (dir.), Le football dans nos sociétés, op. cit., pp. 66-82.

259 "J'ai tiré un France Hongrie des clubs (Reims-Voros Lobogo) et un match explosif et un peu inquiétant : Real Madrid-Partizan de Belgrade ", L'Équipe, 5-6 novembre 1955. Jacques Ferran insiste sur ces difficultés, arguant que la Yougoslavie a, dans un passé récent, toujours refusé de jouer contre des équipes espagnoles, notamment dans les compétitions de basket.

260 Delaunay P., Procès-verbal de la réunion du comité d'urgence de l'UEFA du 4 novembre 1955, n.d. UEFA, RM00005974 (réunion du comité exécutif, 1954-1959), document relié : procès-verbaux des comités exécutifs et comités d'urgenge 1954-1959 
L'un des principaux problèmes consiste dans l'obtention des visas pour les membres des deux clubs. Finalement, une solution est trouvée : il s'agira de passer par les légations des deux pays à Paris. Suite à cet accord, le journaliste de L'Équipe, Jean-Philippe Réthacker n'hésite pas à écrire : "On se réjouira, dans le monde entier, d'apprendre que le sport a réussi là où tout le monde avait échouée ${ }^{261}$. " La double confrontation se déroule sans encombre et permet même à des dirigeants politiques des deux pays de se rencontrer. Un journaliste de France football relate ainsi, à la suite du premier match : "Dans l'euphorie de la discussion, le président yougoslave alla même jusqu’à dire au représentant espagnol : "Je crois même qu'il y a un consulat de Yougoslavie à Madrid, mais depuis le temps qu'il est inutilisé il faudra bien prévoir sa réfection" ${ }^{\text {"62 }}$. "Si ce commentaire est à prendre avec des précautions, il confirme, comme l'ont déjà montré de nombreux auteurs, que l'arène sportive est un endroit propice aux discussions d'ordre politique ${ }^{263}$. Le match retour à Belgrade est l'occasion de poursuivre ces échanges. En effet, après négociations, les autorités yougoslaves acceptent de recevoir l'importante délégation espagnole qui est composée des joueurs et d'une soixante de membres du Real présentés par la presse sportive française comme des supporters du onze madrilène ${ }^{264}$.

Dans les années qui suivent, plusieurs autres confrontations Est-Ouest vont se dérouler lors des épreuves continentales de clubs. Le tournoi confirme la large étendue du territoire des échanges footballistiques, comme le montre la carte ci-dessous relative aux clubs participant à sa deuxième édition. De 1955 à 1960, soixante-sept matchs sur un total de deux cent vingt-huit opposent des équipes de l'Est et de l'Ouest, soit un peu moins d'un tiers des rencontres. Une véritable habitude est donc prise de jouer contre des équipes de l'autre bloc. En outre, des lieux paraissent particulièrement à la pointe de ces échanges Est-Ouest, comme Belgrade ou Budapest, qui accueillent respectivement neuf et six rencontres. Ces deux villes disposent de plusieurs clubs de haut niveau qui se relaient d'une année à l'autre dans ces premières années de compétitions.

261 "Real Madrid-Partizan conclu le 11 décembre. Le match retour ayant lieu à Belgrade le 8 ou le 15 ou le 25 janvier ", L'Équipe, 11-12 novembre 1956.

262 "Quand Tito rime avec Franco ", France football, 27 décembre 1955.

263 Sur ce sujet, voir en particulier : Gounot A., Jallat D., Carithey B. (dir.), Les politiques au stade : étude comparée des manifestations sportives du XIX $X^{e}$ au XXI siècle, Rennes, Presses universitaires de Rennes, 2007.

264 Il serait toutefois intéressant de connaître plus précisément l'identité de ces individus et en particulier leur fonction dans le régime franguiste. 
Dans un texte sur le trésorier du Real Madrid et pilier de la Fédération internationale de basket-ball Raimundo Saporta, Juan Antonio Simón indique que lors du premier match de l'histoire du Real Madrid à Moscou en 1962 - ce qui constitue alors la première visite officielle d'une délégation espagnole en Union soviétique -, Saporta écrit un rapport au gouvernement franquiste sur les conditions de vie en Union soviétique ${ }^{265}$. Nous pouvons supposer que, dans le cadre des nombreux échanges EstOuest qui s'opèrent au travers de la Coupe des champions, d'autres démarches de ce type ont été conduites.

\section{Figure 7. Clubs participant à la deuxième édition de la Coupe des champions ${ }^{266}$}

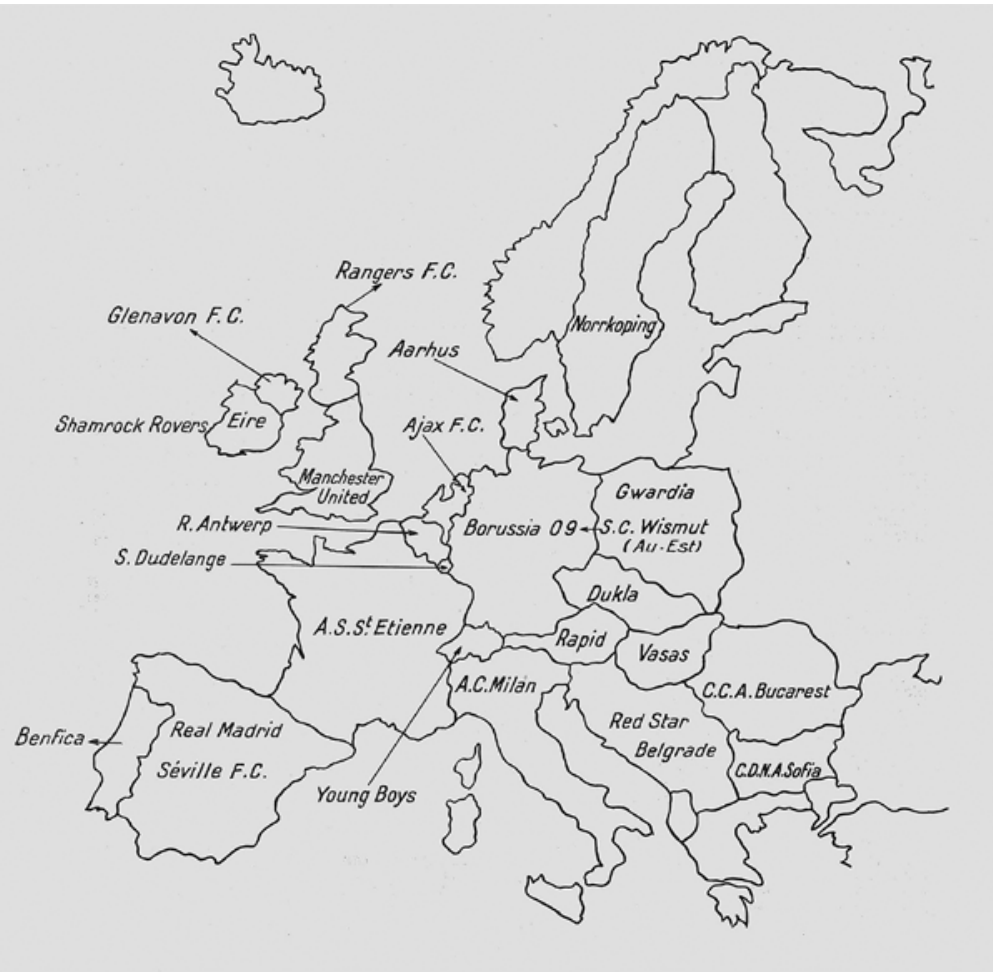

265 Simón J.A, " L'homme de l'ombre. Raimundo Saporta et le basket espagnol et européen ", dans Archambault F., Artiaga L., Bosc G., Le continent basket, op. cit, p. 26.

266 Au passage, soulignons que la frontière de l'Allemagne de l'Est n'est pas dessinée sur cette photo. Erreur ou représentation de p'hépogue de la part du secrétaire de l'Union? 
En outre, ces nombreux échanges permettent d'offrir des lieux officiels de rencontre à des pays n'ayant pas de relations diplomatiques sur la scène internationale. Autour de ces matchs, des discussions informelles se déroulent durant les festivités (visites, dîner) qui sont organisées autour des rencontres. En ce sens, la Coupe des champions doit être évaluée à l'aune du renouvellement de l'historiographie de la Guerre froide qui s'opère depuis quelques années et tend à montrer que les « deux blocs étaient certes divisés, mais pas déconnectés ${ }^{267}$. En d'autres termes, il s'agit de scruter les coopérations (encore largement sous-estimées) qui ont existé entre les deux blocs tout au long de la Guerre froide. À l'échelle européenne, l'UEFA semble être à la pointe de ces échanges. En effet, la Coupe des champions - suivie ensuite par les autres compétitions de l'UEFA - offre un terrain d'échanges régulier entre l'Est et l'Ouest.

Durant ces cinq premières années d'existence, l'UEFA connaît un élargissement croissant de ses tâches, dont la rapidité n'avait sans doute pas été imaginée au départ par ses principaux promoteurs. En ce sens, elle va rapidement se profiler comme un modèle à suivre pour les autres confédérations continentales de la FIFA.

\subsection{Un modèle pour les autres groupements continentaux?}

À la suite des décisions prises en matière de décentralisation de la FIFA lors du congrès extraordinaire de Paris en novembre 1953, les associations nationales des continents africain et asiatique entreprennent - comme les associations européennes - des démarches en vue de créer une organisation continentale. Ainsi, dans la seconde partie des années 1950, ce que nous pouvons nommer la continentalisation de la FIFA devient effective. Cette situation n'est pas sans conséquence pour le comité exécutif de la Fédération internationale car elle influe sur sa manière de gérer l'organisation. En effet, les confédérations continentales vont présenter des demandes afin que la FIFA soutienne leur développement, démarche qui remet in fine en cause la position dominante de cette entité sur le football mondial.

Delaunay P., «L'Union européenne au travail ». UEFA, Bulletin de l'UEFA, ${ }^{\circ} 6$, novembre 1957.

267 Voir par exemple : Hochscherf T., Laucht C., Plowman A. (eds.), Divided, but not Disconnected: German Experiences of the Gold War, New York, Berghahn Book, 2010. 


\subsubsection{La continentalisation effective de la FIFA}

À la veille du congrès de 1954, l'élite de la FIFA fait le point sur la réforme de l'organisation. Si, lors du congrès extraordinaire de Paris de novembre 1953, sa recomposition a été discutée, les actions entreprises par les associations asiatiques et européennes donnent à penser que, sur ces deux continents, des confédérations continentales vont être créées. Ainsi, elles viendraient compléter celles déjà existantes dans les Amériques (Confédération d'Amérique centrale, du Nord et du Sud).

En ce qui concerne l'Europe, le comité exécutif de la FIFA estime qu'il existe désormais un groupe des associations européennes, se basant " sur la lecture du procès-verbal de l'assemblée du 12 avril à Paris de cet organisme $»^{268}$. Pourtant, comme nous l'avons indiqué ${ }^{269}$, aucun groupement européen n'existe encore formellement, même s'il est vrai qu'un projet de statuts est en cours d'élaboration et qu'une nouvelle réunion est agendée deux jours plus tard, soit le 15 juin 1954. Par contre, au sujet des démarches entreprises par des associations asiatiques, l'élite de la FIFA se montre plus réservée. Selon les informations reçues par son secrétariat, une réunion a en effet eu lieu à Manille en mai 1955 entre 12 des 24 associations asiatiques affiliées à la FIFA. Cependant, l'assemblée qui s'est tenue dans la capitale des Philippines n’a pas concerné toutes les associations du continent membres de la FIFA. Par ailleurs, le comité exécutif note quaucune action ne semble avoir été entreprise par les associations africaines. En fait, la discussion reflète plus globalement des réserves chez les dirigeants du comité exécutif quant aux places à attribuer aux associations asiatiques et africaines dans l'élite de la FIFA et témoigne encore et toujours de leur vision européocentrée $e^{270}$. De plus, il semble que les associations de l'Amérique du Sud remettent en question la manière dont les discussions du congrès extraordinaire de Paris ont été relatées dans le procès-verbal, en particulier " par rapport à la nomination des membres du comité exécutif pour l'Afrique et pour l'Asie $»^{271}$, comme le note le secrétaire général dans son commentaire relatif à l’ordre du jour de la réunion.

268 Gassmann K., Procès-verbal de la réunion du comité exécutif de la FIFA des 12-13 juin 1954, 7 juillet 1954. FIFA, comité exécutif (procès-verbaux 1953-1954).

269 Supra 4.1.1.

270 Encore composé en grande majorité de dirigeants européens puisque la nouvelle composition inscrite dans les statuts de la FIFA n'entre en vigueur que lors du congrès de 1954.

271 Gassmann K., Commentaire relatif à l'ordre du jour de la réunion du comité exécutif de la FIFA des 12-13 juin 1954, 3 juin 1954, FIFA : comité exécutif (procès-verbaux 1953-1954). 
Les discussions sur le nouvel agencement du comité exécutif de la FIFA vont alimenter les débats lors de son congrès qui se déroule le 21 juin 1954. Tout d'abord, à l'occasion de la dernière allocution de sa carrière en tant que président de la FIFA, le président Rimet met, une dernière fois, ses collègues en garde en indiquant qu'il est indispensable de conserver l'unité de la FIFA afin d'assurer son développement, et que la briser serait une grave erreur. À la suite de ce discours, une discussion s'engage sur la tonalité à donner aux décisions prises lors du congrès extraordinaire de 1953. Seeldrayers tente de s'expliquer sur ce fait. Effectivement, il concède qu'après coup, le comité exécutif a décidé d'interpréter le compromis proposé par Thommen un peu différemment de ce qui avait été décidé à Paris. Sans véritablement le dire comme tel, il indique que pour bénéficier de places au sein du comité exécutif, il faut dorénavant disposer d'une organisation continentale. En conséquence, il s'agit pour le congrès de 1954 de statuer sur l'existence, ou non, d'une organisation continentale en Afrique et en Asie. Dans l'esprit du comité exécutif de la FIFA, tant que ce ne sera pas le cas, ce sera toujours l'assemblée générale qui élira leurs deux membres. La discussion en reste là mais reprend au moment des élections. En fait, le seul poste pour lequel les congressistes doivent voter est celui de président. Ils font le choix de la continuité puisqu'ils élisent Rodolphe Seeldarayers, qui officie depuis les années 1920 au sein du comité exécutif, en remplacement de Jules Rimet. Puis, l'assemblée enregistre le choix des représentants proposés pour les postes de vice-présidents par les associations britanniques (1 représentant), l'Union soviétique (1), la Confédération sud-américaine (1) et les associations européennes (2 représentants). Pour les membres, les Confédérations d'Amérique du Nord, centrale et du Sud proposent chacune un représentant, de même que les associations européennes, qui ont élu leurs quatre membres lors du congrès constitutif du Groupement européen tenu quelques jours plus tôt. C'est à ce moment que le débat sur les places attribuées aux associations africaines et asiatiques reprend de plus belle. Le délégué du Soudan, Halim, reconnaît qu’aucune organisation n'existe en Afrique, mais il affirme que " le moment est venu pour que les associations africaines et asiatiques désignent ellesmêmes leurs propres représentants ${ }^{272}$. Ses propos sont appuyés par son collègue égyptien, Salem, ainsi que par le Yougoslave Andrejevic. Il y a très clairement un clivage qui se dessine entre d'une part les Européens (du bloc de l'Ouest) et les Sud-Américains, qui soulignent qu'au regard des statuts, les associations africaines et asiatiques doivent d'abord constituer

272 Gassmann K., Procès-verbal de l'assemblée générale de la FIFA du 21 juin 1954. FIFA, XXIX-XXX congrès ordinaires (1953-1959 Papport d'activité) 
des organisations avant d'obtenir leur place au sein du comité exécutif ; d'autre part les délégués de ces deux continents, appuyés par ceux du bloc soviétique, qui militent en faveur de davantage de reconnaissance au sein de l'organisation. Pour sortir de l'impasse, un vote est finalement organisé.

Les congressistes décident de ne pas suivre les recommandations du comité exécutif et se prononcent affirmativement, par 23 voix contre 17 , en faveur de la requête des délégués africains. Ceux-ci sont donc aptes à choisir leur représentant. Dans la foulée, l'organisme créé en mai à Manille en avril 1954 est officiellement reconnu et un représentant asiatique entre également au comité exécutif. Un délégué chinois proteste, estimant que l'organisation asiatique ne concerne pas toutes les associations de ce continent, sa propre fédération n'ayant pas participé aux débats. Rimet clôt la discussion, indiquant que cette affaire n'est pas du ressort de la FIFA, mais doit être discutée au sein même de la Confédération asiatique. Il s'aligne ainsi sur la stratégie qui consiste dans la non-intervention de la Fédération internationale dans les affaires internes des associations.

Les décisions prises par le congrès de 1954 confirment donc l'internationalisation croissante de l'organisation. En effet, sur les cinquante-deux associations présentes, près de la moitié ne proviennent pas d'Europe. Cette situation est perçue lors du vote, où les associations européennes du bloc de l'Ouest ont été placées en minorité. Ainsi, l'hégémonie du Vieux Continent commence à être véritablement remise en question au sein de la Fédération internationale, et ce malgré le fait que les associations européennes disposent encore du plus grand nombre de représentants dans le comité exécutif.

Tableau 17. Nouvelle composition du comité exécutif de la FIFA selon les statuts de $\mathbf{1 9 5 4}$

\begin{tabular}{|l|l|}
\hline Fonctions & Organe électeur \\
\hline Président & Congrès \\
\hline Vice-président & URSS \\
\hline Vice-président & 4 associations britanniques \\
\hline Vice-président (2) & Associations européennes \\
\hline Vice-président (1) & Confédération sud-américaine \\
\hline Membre (4) & Associations européennes \\
\hline Membre (1) & Confédération sud-américaine \\
\hline Membre (1) & Confédération d'Amérique centrale \\
\hline
\end{tabular}




\begin{tabular}{|l|l|}
\hline Fonctions & Organe électeur \\
\hline Membre (1) & Confédération d'Amérique du Nord \\
\hline Membre (1) & Associations africaines \\
\hline Membre (1) & Associations asiatiques \\
\hline
\end{tabular}

Dans les mois qui suivent, les associations nationales africaines, asiatiques et européennes entreprennent des démarches en vue de créer formellement leurs organismes continentaux et transmettent des statuts provisoires à la $\mathrm{FIFA}^{273}$. À partir de 1956, les congrès de la Fédération internationale sont donc aussi le théâtre de réunions préliminaires entre ces différentes organisations continentales. Ces assemblées permettent de discuter autant des questions relatives à l'organisation que de préparer l'ordre du jour du congrès de la FIFA. La structure de ces organismes continentaux se calque à la fois sur celle de la FIFA et sur celle de la Confédération sud-américaine. À noter que, comme cette dernière, les nouvelles entités imaginent rapidement la création d'une compétition pour les nations. Sur le continent africain, un premier tournoi est d'ailleurs organisé au Soudan en février $1957^{274}$.

Issus de pays récemment décolonisés et gouvernés par des dirigeants souhaitant discuter la géopolitique mondiale, les leaders des associations nationales de ces continents sont très souvent politisés. En conséquence, ces confédérations continentales vont placer le curseur sur des questions d'ordre politique au sein de la FIFA. Un cas révèle bien cette posture : celui de l'Afrique du Sud. En effet, la Fédération sud-africaine exclut les joueurs noirs de son association et, en conséquence, deux fédérations coexistent dans le pays. Face à cette situation, les dirigeants asiatiques et africains demandent à la FIFA d'agir en excluant l'Afrique du Sud tant qu'elle n'accepte pas d'incorporer les joueurs de couleur. Contrairement aux Européens, il ne s'agit pas de botter en touche, en attendant que la

273 Dans la boîte de la correspondance FIFA-Confédération africaine de football (1954-1967), il est possible de trouver le projet de statuts, non daté mais qui porte un accusé de réception du secrétariat de la FIFA du 15 février 1956. Au sujet de la Confédération asiatique, la correspondance ne commence qu’à partir des années 1960. Cependant, dans sa séance du 15 mars 1957, le comité exécutif discute de la réception d'un projet de statuts.

274 Mohamed Y., Rapport du secrétaire general de la Confédération africaine de football (1956-1958), 27 mai 1958 [date de réception du document]. FIFA, correspondance avec les confédérations continentales, CAF (1954-1967) dossier : correspondance générale. 1954-1958. 
situation interne se règle. Au contraire, il s'agit que la FIFA pèse de tout son poids sur l'association sud-africaine afin que la situation évolue en faveur de l'égalité entre Blancs et Noirs. À la fin des années 1950, aucune décision n'est toutefois prise par l'élite de la FIFA sur le sujet ${ }^{275}$.

Mais les organismes continentaux se profilent également comme des acteurs pouvant dynamiser le football dans leur région. À ce titre, elles demandent du soutien logistique et financier à la FIFA. Par exemple, en octobre 1957, le délégué asiatique au sein du comité exécutif de la Fédération, Skinner, fait part de son souhait d'organiser un cours d'arbitrage lors des $3^{\text {es }}$ Jeux asiatiques organisés du 20 mai au $1^{\text {er }}$ juin 1958 à Tokyo. Ses collègues acceptent la requête en allouant un crédit pour les frais de voyage et pour le séjour de Stanley Rous, qui officiera comme directeur du cours ${ }^{276}$. Requête plus importante, celle portée sur la rétrocession d'une partie des pourcentages que touche la FIFA sur la recette brute des rencontres internationales de football. Cette demande se calque sur le statut privilégié dont dispose la Confédération sud-américaine. En effet, l'article 31, alinéa 5, des statuts de la FIFA stipule que les associations affiliées à la Confédération sud-américaine " ne paient que $1 \%$ [sur la recette brute du match] à la FIFA pour les matchs joués entre elles tandis que l'autre $1 \%$ revient à [leur entité continentale] $»{ }^{277}$. Ce vou est en particulier ardemment porté par l'élite de l'UEFA et, dès 1955, celle-ci envisage de "demander à la Fédération internationale de Football Association de porter à l'ordre du jour de son prochain Congrès une proposition tendant à obtenir qu'il ne soit versé à la FIFA qu'un pourcentage de $1 \%$ sur la recette brute des matchs internations joués entre pays européens ; l'autre $1 \%$ étant versé à l'Union européenne ${ }^{278}$. Toutefois, les principaux dirigeants européens du comité exécutif de la Fédération internationale, en premier lieu Barassi et Thommen, ne se montrent guère enchantés par la requête de leurs homologues européens de l'UEFA. Lors de la réunion du 3 décembre

275 Dans la décennie suivante, ce cas va opposer de plus en plus les dirigeants extraeuropéens à leurs collègues européens, voir Darby P., "Stanley Rous "own goal" : football politics, South Africa and the contest for the FIFA presidency in 1974 ", Soccer and Society, vol. 9, n 2, 2008, pp. 259-272.

276 Gassmann K., Procès-verbal de la réunion du comité d'urgence de la FIFA du 13 octobre, 18 octobre 1957. FIFA (comité d'urgence : 1951-1957).

277 Rimet, J., Gassmann K., Statuts de la FIFA [éditions 1953], article 31 [des statuts], 15 février 1954. FIFA, statuts, 1904-1981.

278 Delaunay P., Procès-verbal de la réunion du comité exécutif de l'UEFA du 14 août 1955, n.d. UEFA, RM00005974 (réunion du comité exécutif, 1954-1959), document relié : procès-verbaux des comités exécutifs et comités d'urgenge 1954-1959 
1955 du comité d'urgence de la FIFA - composé de Drewry, Lotsy et Thommen -, il est signalé qu' " une diminution de ce pourcentage serait d'un effet désastreux pour la situation financière de la FIFA ${ }^{279}$. Il faut effectivement souligner que, pour l'année 1954 , les pourcentages reçus s'élèvent à 158878,28 francs suisses, soit près de $71 \%$ des recettes totales de la FIFA (sans compter les recettes de la Coupe du monde) ${ }^{280}$. Si le détail des paiements ne nous est pas connu, nous pouvons tout de même indiquer que les rencontres entre les associations nationales européennes représentent une grande partie de ce pourcentage. Dès lors, le fait de rétrocéder une partie du pourcentage perçu sur la recette des matchs internationaux risque de largement impacter les finances de la Fédération internationale. Conscients néanmoins qu'il est nécessaire de soutenir l'UEFA - et plus largement les confédérations continentales - d'un point de vue financier, les trois membres du comité d'urgence envisagent quelques solutions (comme celle d'abolir le privilège des associations britanniques qui, depuis leur retour à la FIFA en 1946, sont exonérées du paiement des pourcentages sur les rencontres annuelles des championnats britannique), toutefois sans succès. Cette position d'attente ne fait pas reculer le comité exécutif de l'UEFA dans ses démarches, et ce d'autant plus qu'il semble que sa volonté soit désormais également officiellement soutenue par d'autres confédérations continentales. En effet, dans son projet de statuts qui est envoyé à la FIFA au début de l'année 1956, la Confédération africaine de football (CAF) envisage pour se financer « de partager avec la FIFA la recette des matchs internationaux joués entre les membres de la Confédération africaine de football ${ }^{281}$. Par ailleurs, nous pouvons supposer que l'élite de l'UEFA estime que la FIFA peut produire un effort financier car elle connaît une situation comptable de plus en plus favorable, comme l'illustre la création de son siège sur les hauts de Zurich, qui ne correspond pas avec l'image d'une organisation ayant des difficultés financières. Enfin, les dirigeants de l'UEFA sont sans doute déçus du peu de soutien de la part des dirigeants européens du comité exécutif de la FIFA qui sont censés représenter, voire défendre, les intérêts de l'UEFA au sein de celui-ci. C'est pourquoi, au mois de

279 Gassmann K., Procès-verbal de la réunion du comité d'urgence de la FIFA du 3 décembre 1955, 15 décembre 1955. FIFA (comité d'urgence : 1951-1957).

280 Thommen E., "Tableau récapitulatif des recettes de la FIFA [1946-1954] ", 13 septembre 1955. FIFA, commission des finances, dossier : 1955-1962.

281 Anonyme, "Constitution and By-Laws of the African Football Confederation ", 15 février 1956 [date de réception du document par la FIFA]. FIFA, correspondance avec les confédérations continentales : CAF (1954-1967) dossier : correspondance générale. 1954-1958. 
mars 1956, l'élite de l'Union décide de maintenir ses propositions en vue d'une discussion lors du prochain congrès de la FIFA ${ }^{282}$.

Dans les semaines qui suivent, plusieurs démarches sont entreprises afin de régler le problème. José Crahay et Pierre Delaunay font une visite officieuse au secrétaire de la FIFA afin de discuter avec lui de plusieurs points de l'ordre du jour du futur congrès de la FIFA, et donc en particulier de la requête supportée par l'UEFA en vue d'une rétrocession d'une partie du pourcentage sur les rencontres internationales ${ }^{283}$. En outre, Ernst Thommen propose une médiation. Lors d'une séance du comité exécutif de la FIFA qui se déroule à Lisbonne quelques jours avant le congrès de la FIFA de 1956, durant lequel doit avoir lieu une discussion sur le sujet, le dirigeant suisse propose d'augmenter d'une manière générale le pourcentage des recettes perçues par la FIFA à $2 \%$. Sur ce pourcentage, $1,5 \%$ lui reviendrait et $0,5 \%$ irait à la confédération continentale concernée par la rencontre. Afin de convaincre les entités continentales d'accepter cette proposition, il recommande que les dirigeants du comité exécutif soient actifs et entreprennent des pourparlers avec chacune d'entre elles. Mais cette proposition ne fait pas l'unanimité au sein de l'élite de la FIFA puisque les représentants africains, asiatiques et sudaméricains se rallient à la proposition de l'UEFA. Durant les discussions, Jack Skinner, le membre élu par la Confédération asiatique, souligne que son entité continentale soutient la demande de l'organisme européen ${ }^{284}$. Parallèlement, lors de la réunion préparatoire qui précède le congrès de l'UEFA de 1956 - qui doit se dérouler quelques jours avant celui de la FIFA -, le comité exécutif de l'Union reçoit la visite du nouveau président de la Confédération sud-américaine, Carlos Dittborn. Ce dernier vient apporter l'appui de l'Amérique du Sud sur différents sujets, notamment la question des pourcentages sur les matchs internationaux. Quelques heures plus tard, le congrès de l'UEFA décide à l'unanimité de maintenir la proposition préalablement faite par la Fédération française - déposée au nom de l'UEFA - au congrès de la FIFA sur cette question ${ }^{285}$. Lors

282 Delaunay P., Procès-verbal de la réunion du comité exécutif de l'UEFA du 18 mars 1956, n.d. UEFA, RM00005974 (réunion du comité exécutif, 1954-1959), document relié : procès-verbaux des comités exécutifs et comités d'urgence 1954-1959.

283 Gassmann K., Procès-verbal de la réunion du comité d'urgence de la FIFA du 10 mai 1956, 18 mai 1956. FIFA, classeur : Emergency Commitee Meeting, Agenda Minutes, 1951-1957.

284 Gassmann K., Procès-verbal de la réunion du comité exécutif de la FIFA des 6-7 juin 1956, 18 juillet 1956. FIFA, comité exécutif (procès-verbaux 1955-1957).

285 Delaunay P., Procès-verbal de l'assemblée générale de l'UEFA du 8 juin 1956 à Lisbonne, n.d. UEFA, RM00005986 (copgrè̀ fondateur 1954 I-LILcongrès ordinaire, 
de l'assemblée générale de la Fédération internationale, le soutien à la requête de l'UEFA de la part des autres confédérations continentales est confirmé par la décision des congressistes, à " une grande majorité " ${ }^{286}$, d'opter pour la proposition qui consiste à modifier les articles des statuts de la Fédération internationale au sujet des pourcentages prélevés par la FIFA. Désormais, les confédérations continentales toucheront la moitié du pourcentage perçu par la FIFA (soit $2 \%$ ) sur les rencontres internationales qui concernent leur continent. À noter que les matchs qui se jouent dans le cadre de la Coupe du monde ne sont pas touchés par cette mesure. Les décisions prises dans la capitale portugaise constituent une étape en vue d'une indépendance des confédérations continentales vis-à-vis de l'autorité de la FIFA. Tout en leur assurant une assise financière, ces décisions montrent que les confédérations sont capables de porter des sujets au sein de la FIFA, voire de créer des alliances entre elles.

Tous ces éléments rendent la gestion de la FIFA plus délicate et compliquent, en particulier, les relations entre les dirigeantes qui officient au sein de son comité exécutif. En effet, ces derniers risquent de faire passer les intérêts de leurs continents avant ceux de la FIFA et de remettre ainsi en question la collégialité à la tête de l'organisation, si importante pour les plus anciens dirigeants qui officient dans l'élite de la FIFA. En date du 22 juillet 1957, Karel Losty, membre très expérimenté du comité exécutif dans lequel il est actif depuis les années 1930, rappelle que, lors des congrès, les dirigeants doivent parler au nom du comité exécutif et donc tenir une position commune ${ }^{287}$. Cependant, sans doute conscients que trop de divergences existent sur certains sujets, il est finalement décidé de réaliser un compromis en acceptant, quelques mois plus tard, que «le président pourra [autoriser un dirigeant] du comité exécutif de parler au nom de la minorité $»^{288}$.

Cette prise d'importance des confédérations donne l'idée à leur élite dirigeante qu'il faudrait demander qu'elles puissent être considérées comme des membres à part entière de la FIFA. Ce procédé aurait pour avantage

1955-1957), document relié : procès-verbaux des assemblées générales 1954-1959. Les confédérations continentales n'étant pas reconnues comme membres de la FIFA, elles ne peuvent soumettre directement des requêtes devant le congrès de la FIFA et sont donc obligées de passer par leurs associations membres.

286 Gassmann K., Procès-verbal de l'assemblée générale de la FIFA des 9-10 juin, juillet 1956. FIFA, XXIX-XXX congrès ordinaires (1953-1959, rapport d'activité).

287 Gassmann K., Procès-verbal de la réunion du comité exécutif de la FIFA des 20-21 juin 1957, 22 juillet 1957. FIFA, FIFA, comité exécutif (procès-verbaux 1955-1957).

288 Gassmann K., Procès-verbal de la réunion du comité exécutif de la FIFA du 2 juin 1958, 12 juin 1958, FIFA, comité exécutifif (procès-verbaux 1955-1957) $0570-1$ 
qu'elles pourraient présenter elles-mêmes des modifications de statuts de la Fédération internationale. Une première idée de ce type est discutée au sein du comité exécutif de l'UEFA à la veille du congrès de la FIFA de 1956, sans toutefois que la proposition soit portée devant l'assemblée. À la fin de la décennie, c'est cette fois le président de la Confédération sud-américaine de football, Ramon De Freitas, qui se fait le porte-parole de plusieurs de ses collègues sud-américains ${ }^{289}$. Afin de traiter ce sujet qui risque de revenir à l'avenir, le comité exécutif de la FIFA décide finalement de créer une commission spéciale qui traitera de la question qui sera traitée lors d'un nouveau congrès extraordinaire de la FIFA en 1961.

Les confédérations continentales prennent donc rapidement d'importantes prérogatives. Si, jusqu'au milieu de la décennie, c'était surtout la Confédération sud-américaine qui faisait office de modèle à suivre, le dynamisme de l'UEFA fait d'elle la principale confédération continentale à la fin des années 1950. Désormais, ce sont également les Sud-Américains qui peuvent s’inspirer, voire copier, les Européens.

\subsubsection{Un " effet retour » sur la Confédération sud-américaine}

Jusqu’au milieu des années 1950, la Confédération sud-américaine constitue un modèle pour les entités continentales existantes et celles en construction. En effet, les Européens s'inspirent de son organisation lors des discussions préliminaires à la création du Groupement européen, puis se calquent sur l'exemple sud-américain en demandant à la FIFA de rétrocéder à l'UEFA une partie des pourcentages sur les matchs internationaux. Par ailleurs, les Sud-Américains peuvent également être perçus comme modèle en matière d'organisation de compétitions continentales, avec la Copa America créée en 1915, le tournoi des juniors sud-américains, organisé pour la première fois en 1954 ou encore le Championnat panaméricain qui est organisé par la Confédération panaméricaine dès $1952^{290}$. Avec le rapide développement de l'UEFA, un nouveau modèle commence à émerger, qui va influencer les autres confédérations et même l'entité sudaméricaine.

289 Gassmann K., Procès-verbal de la réunion du comité exécutif de la FIFA du 24 avril 1959, 20 mai 1959. FIFA, comité exécutif (procès-verbaux 1959).

290 Au stade de nos recherches, il est difficile de véritablement comprendre le rôle de la Confédération panaméricaine qui, comme nous l'avons vu, a été créée en 1948. Si elle organise ce championnat - auquel peu d'équipes du continent participent - et édite un bulletin officiel, elle ne semble toutefois pas avoir une très grande influence. 
Dans un texte publié en 2003, qui traite de la thématique de l'histoire croisée, Michael Werner et Bénédicte Zimmermann notaient : "Quand on étudie des sociétés en contact, on constate fréquemment que les objets et les pratiques sont non seulement en situation d'interrelation, mais encore se modifient réciproquement sous l'effet de leur mise en relation ${ }^{291}$. " En nous inspirant de cette réflexion, nous pouvons supposer que des interrelations s'opèrent au sein de la FIFA entre les dirigeants des différentes confédérations, qui ont pu jouer en faveur de leur structuration. À ce titre, en raison de son rapide développement et du fait qu'elle est composée des associations nationales les plus structurées, on peut imaginer que l'UEFA exerce une influence sur les actions des dirigeants extra-européens, en particulier ceux de la Confédération sud-américaine.

Un premier exemple de cette influence concerne, à nouveau, une question financière. En effet, avec l'accroissement de ses activités, les charges de l'UEFA ne cessent d'augmenter. De plus, l'Union n'hésite pas à se porter garante de l'organisation du tournoi international des juniors ${ }^{292}$ compétition confiée par la FIFA, faut-il le rappeler. En conséquence, le comité exécutif de l'UEFA, outre des mesures d'économies, s'attelle aussi à chercher des fonds supplémentaires. Dans cette perspective, il s'adresse à nouveau à la FIFA. Il s'agit cette fois d'obtenir une partie du pourcentage que la Fédération internationale perçoit sur les rencontres disputées entre les associations européennes dans le cadre des matchs éliminatoires de la Coupe du monde. Ce sujet, qui va être débattu en 1957-1958 au sein du comité exécutif de la FIFA, révèle le leadership que commence à prendre l'UEFA dans la Fédération internationale. En effet, la requête portée préalablement sur la rétrocession d'un pourcentage sur la recette des rencontres internationales entre les équipes nationales européennes se fondait sur l'exemple de la Confédération sud-américaine. Or, ici, il s'agit d'une nouvelle demande dont ne bénéficie aucune autre confédération continentale. Cette action confirme l'activité du comité exécutif de l'UEFA et aussi le fait que l'organisation européenne devient assez solide pour porter de nouvelles questions au sein de la FIFA. En date du 28 février 1957, une lettre est adressée à la FIFA dans le but de sonder le comité exécutif de la FIFA. Premièrement, il est demandé s'il

291 Werner M., Zimmermann B., "Penser l'histoire croisée : entre empirie et réflexivité ", Annales. Histoire, Sciences Sociales, vol. 58, n 1, 2003, p. 12.

292 C'est notamment le cas en 1958, le tournoi étant organisé par le Luxembourg, une fédération ayant peu de moyens. UEFA, « $4^{\mathrm{e}}$ Assemblée générale de l'UEFA à Stockholm. 10. Règlement du tournoi international juniors ", n.d. UEFA, RM00005987 (IV Congrès ordinaire, 1958. I Congrès extraordinaire, 1959), dossier : assemblée générale extraordinaire de l'UEFA, le vendredi 11 décembre 1959 à 14 h 30 à Paris 
est envisageable de recevoir $1 \%$ des $5 \%$ de recettes brutes perçues par celle-ci sur les matchs du Championnat du monde ${ }^{293}$. Deuxièmement, si des confédérations disposent déjà d'un tel privilège. Par la voix de son secrétaire général, Kurt Gassmann, la Fédération internationale répond à l'UEFA que " les $5 \%$ des recettes brutes des matchs préliminaires du Championnat du monde - Coupe Jules Rimet 1958 reviennent entièrement à la FIFA » ${ }^{294}$ et que cette disposition n'existe pas pour d'autres confédérations continentales et n'est pas envisagée par le comité exécutif. Non découragée par cette réponse, l'élite de l'UEFA décide alors de passer à l'offensive et de porter l'inscription de la question au prochain congrès de la Fédération internationale ${ }^{295}$, portant ainsi une nouvelle charge contre l'autorité du comité exécutif de la FIFA.

Si l'élite de l'UEFA transmet cette requête à la FIFA, c'est aussi que la situation financière de cette dernière lui paraît favorable pour soutenir la proposition de l'organisation européenne. En effet, en 1956, la FIFA a réalisé un excédent de 21 171,86 francs suisses. Certes, le chiffre peut paraître peu élevé, mais ce bénéfice est encore un fait rare à cette époque (notamment lors d'une année sans Coupe du monde) et il révèle la bonne santé des finances de l'organisation qui compte tout de même déjà sur un avoir de plus de deux millions en réserve ${ }^{296}$. Une année plus tard, l'excédent augmente - il s'élève à 74671 francs suisses ${ }^{297}$ - et confirme ainsi la bonne santé financière de la Fédération internationale. Malgré ce contexte a priori favorable, la FIFA ne se montre que peu coopérative vis-à-vis de la demande de l'UEFA. Dans son rapport d'activité pour les années 1956 et 1957, son secrétaire général indique que le comité exécutif ne partage pas le point de vue de certaines associations qui estiment que $1 \%$ des $5 \%$ des recettes des rencontres de la Coupe du monde devrait

293 Delaunay P., Procès-verbal de la réunion du comité exécutif de l'UEFA du 28 février 1957, n.d. UEFA, RM00005974 (réunion du comité exécutif, 1954-1959), document relié : procès-verbaux des comités exécutifs et comités d'urgence 1954-1959.

294 Lettre de K. Gassmann à P. Delaunay, 24 avril 1957. FIFA, correspondance avec les confédérations continentales : UEFA (1955-1958), pochette : correspondance générale 01.01.1955-31.12.1958.

295 Delaunay P., Procès-verbal de la réunion du comité exécutif de l'UEFA des 26 et 27 juin, n.d. UEFA, RM00005974 (réunion du comité exécutif, 1954-1959), document relié : procès-verbaux des comités exécutifs et comités d'urgence 1954-1959.

296 Gassmann K., Procès-verbal de la réunion du comité d'urgence de la FIFA du 15 mars 1957, 31 mars 1957. FIFA, classeur : Emergency Commitee Meeting, Agenda Minutes, 1951-1957.

297 Gassmann K., Rapport financier de la FIFA (1957), 21 janvier 1958. FIFA, Commission des finances, 1955-1962. 
être retourné à la confédération continentale concernée ${ }^{298}$ - il ne fait pas référence aux vœux des entités continentales, qui ne sont toujours pas considérées comme associations membres de la Fédération internationale. Sans doute dans le but d'éviter de nouveaux conflits, il est malgré tout envisagé de discuter lors du prochain congrès de la FIFA ${ }^{299}$.

Alors que des échanges ont lieu entre les deux organisations dans les premiers mois de l'année $1958^{300}$, une médiation est tentée par Thommen et Barassi. À la suite des discussions entre les deux dirigeants et une délégation de la commission des finances de l'UEFA, un compromis est trouvé : il s'agirait de laisser les dispositions existantes pour la compétition de 1958 et de les modifier dans le sens de la requête de l'UEFA pour celle de 1962.

Comment expliquer ce changement d'attitude de l'élite dirigeante de la FIFA et en particulier de Barassi et Thommen ? En fait, la requête portée par l'UEFA a reçu le soutien d'autres confédérations continentales, et en particulier de celle d'Amérique du Sud. En effet, l'association brésilienne développe une requête qui va dans le même sens, déposée vraisemblablement après celle de l'UEFA, car les dirigeants du comité exécutif de la FIFA n'en ont jamais fait mention. De même, nous pouvons supposer qu'une alliance se met en place entre les confédérations continentales en marge du congrès de la FIFA. Il ne s'agit que d'hypothèses. En tous les cas, durant le congrès annuel de l'UEFA de 1958, le président de la commission des finances de l'UEFA, Peco Bauwens, "se félicite qu'un accord avec la FIFA semble intervenir sur ce point " ${ }^{301}$. Ce souhait semble partagé par les associations nationales membres de l'UEFA puisque les congressistes acceptent la proposition. Quelques jours plus tard, c'est au tour de l'assemblée générale de la FIFA de décider, " à une grande

298 Il faut souligner qu'au même moment la FIFA essaie de négocier une décision (qualifiée d'inattendue par son secrétaire général) de l'Office cantonal des impôts de Zurich, qui exige que la Fédération internationale paie des impôts cantonaux et communaux dont elle était pourtant exonérée depuis plus de vingt-cinq ans. Malgré différentes négociations, la requête de la FIFA n'est pas prise en compte par les autorités.

299 Gassmann K., Rapport du secrétaire général de la FIFA (1956-1957), janvier 1958. FIFA, comité exécutif (procès-verbaux 1958).

300 Delaunay P., Procès-verbal de la réunion de la commission des finances du 28 février, n.d. UEFA, RM0000990 (séances de la comission des finances, 1957-1978), document relié : commission des finances 1957-1959.

301 Delaunay P., Procès-verbal de l'assemblée générale de l'UEFA du 4 juin 1958, n.d. UEFA, RM00005986 (congrès fondateur, 1954. I-III congrès ordinaire, 1955-1957), dossier : document relié : procès-verbaux des assemblées générales 1954-1959-1 
majorité ${ }^{302}$, que les confédérations obtiendront désormais $1 \%$ des $5 \%$ des recettes brutes des rencontres de la Coupe du monde. Le règlement de cette question permet non seulement de renforcer la base financière de l'UEFA et des autres confédérations, mais offre aussi aux acteurs principaux de l'Union de se profiler comme des acteurs particulièrement actifs dans le développement de leur confédération. Dès lors, les Européens commencent à devenir une source de questionnement, voire d'inspiration, pour les autres entités continentales.

Relevons par exemple que, quelques semaines après le congrès de 1958, le secrétaire de la FIFA, Kurt Gassmann, reçoit une lettre du nouveau président de la Confédération sud-américaine, José Ramos de Freitas. Ce dernier demande de lui remettre des documents relatifs aux activités de l'UEFA et ce dans "l'intérêt du sport sud-américain " ${ }^{303}$. Il s'agit des documents suivants :

- les statuts de l'UEFA,

- le règlement de la Coupe des champions,

- le règlement de la commission d'arbitrage continentale,

- le règlement du tournoi international des juniors.

Cette lettre est intéressante sur deux points au moins. Premièrement, pourquoi les dirigeants sud-américains s'adressent-ils à la FIFA plutôt qu'à l'UEFA ? Estiment-ils que l'Union reste subordonnée à la FIFA et, en conséquence, que c'est cette dernière qu'il s'agit de contacter en premier lieu ? Deuxièmement, pourquoi la Confédération sud-américaine a-t-elle besoin de ces documents ? Y a-t-il des discussions, au même moment, en son sein au sujet d'une possible réforme de sa structure ? Dans la correspondance FIFA-Confédération sud-américaine nous n'avons rien trouvé qui puisse nous permettre à l'heure actuelle de véritablement répondre à ces questions.

En ce qui concerne la Coupe des champions, la situation est plus claire : les Sud-Américains sont à la recherche d'un modèle puisque, à la même période, des discussions ont lieu au sein de leur Confédération à ce sujet. En raison du succès croissant de la Coupe des clubs champions,

302 Gassmann K., Procès-verbal de l'assemblée générale de la FIFA du 5 juin 1958, juillet 1958. FIFA, XXXI-XXXII congrès ordinaires (1958-1961, rapport d'activité).

303 Lettre de J. Ramos de la Freitas à Kurt Gassmann, 28 juillet 1958. FIFA : correspondance avec les confédérations continentales : CONMEBOL (1941-1961), pochette : 1.1.1951-31.12.58. 
des dirigeants sud-américains semblent en effet vouloir transposer cette compétition sur leur continent. Durant l'été 1959, le journal L'Équipe indique que des discussions ont lieu en Amérique du Sud dans le but d'imiter l'Europe ${ }^{304}$. Le premier tournoi, intitulé Copa Libertadores, est finalement organisé dès la saison 1959-1960, les rencontres se déroulant principalement au printemps. Certes, le format de la Copa Libertadores ne va pas forcément se calquer sur celui de la Coupe des champions ${ }^{305}$. Cependant, dans l'idée, les Sud-Américains semblent s'inspirer de ce qui se fait en Europe.

Au vu de ces éléments, qui nécessiteraient assurément d'être étoffés, nous postulons que, à partir des années 1958-1959, le développement de l'UEFA commence à être une source d'inspiration non seulement pour les dirigeants sud-américains, mais aussi pour ceux d'autres confédérations puisque, dans la décennie suivante, celles-ci mettent également en place des compétitions continentales pour les clubs.

304 « 1960 : An I de la Coupe du monde des clubs car l'Amérique du Sud va imiter l'Europe ", L'Équipe, 19 août 1959.

305 Il existe de petites différences entre les deux coupes. Par exemple, afin de garder le suspens, les Sud-Américains décident de ne pas tenir compte du goal-average et ainsi en cas de victoire des deux équipes, un troisième match d'appui est automatiquement organisé. Puis, à partir de 1962, une phase de groupe doit déterminer les places en demi-finale, ce qui contraste avec l'épreuve européenne, disputée sous la forme d'une coupe à élimination directe. 
Philippe Vonnard - 978-2-8076-0570-1

Téléchargé de PubFactory à01/07/2021 08:14:02PM

via free access 


\section{Conclusion de la partie}

Dans cette partie, nous avons d'abord étudié la formation de l'UEFA. Nous avons vu que les actions de ses promoteurs s'insèrent dans un contexte propice aux développements de rencontres entre les clubs et les équipes nationales européennes. Plus largement, ces actions correspondent aux volontés de certains dirigeants d'associations nationales de créer un groupement s'attelant à discuter de sujets relatifs au football continental mais aussi de poursuivre et d'amplifier cette dynamique d'échanges européens en football (en particulier par le biais de l'établissement de compétitions continentales). Par ailleurs, s'ils ne remettent pas en cause le pouvoir de la FIFA, des acteurs importants du football européen, comme Ottorino Barassi, Ernst Thommen et Stanley Rous, estiment que la structure de la Fédération internationale doit évoluer et que des groupements continentaux doivent émerger en son sein.

L'entité européenne de football est donc une émanation de la FIFA, puisqu'un groupe européen est créé suite à sa réorganisation dans la première moitié de 1954. Nous avons souligné que les dirigeants sudaméricains jouent un rôle non négligeable dans la création de ce groupement continental. Premièrement, tout au long de la réforme de la Fédération internationale, ils défendent des positions visant à continentaliser la FIFA. Deuxièmement, dès que le groupement européen est créé, en juin 1954, la Confédération sud-américaine apparaît comme une sorte de modèle à suivre.

Au départ, les prérogatives du groupement européen - renommé UEFA en octobre 1954 - sont très modestes. Par exemple, l'entité ne dispose ni de budget ni de siège propre. Toutefois, l'UEFA va rapidement se développer, en particulier par la reprise du projet de Coupe d'Europe porté par les journalistes français de L'Équipe. La Coupe des clubs champions - comme elle est renommée - va, en effet, apporter à l'UEFA des fonds financiers supplémentaires et donner du poids à son comité exécutif, qui souhaite notamment créer une épreuve pour les nations. En cinq ans, l'organisation connaît un rapide développement et s'autonomise rapidement de la tutelle de la FIFA. Ce processus ne va pas sans poser des problèmes avec la FIFA et souligne des différences dans la manière de gérer le développement du football entre l'élite de l'UEFA et les dirigeants européens qui officient dans le comité exécutif de la FIFA. 
Ce développement rapide est remarquable car, dès sa fondation, l'Union est composée de la majorité des pays européens. Ainsi, fait unique dans le cadre de la construction de l'Europe, elle transcende la Guerre froide. Afin de négocier au mieux cette situation, ses dirigeants reprennent les stratégies de gouvernance établies dans les années 1930 au sein de la FIFA. Durant les cinq premières années, l'UEFA renforce sa position et se construit progressivement un monopole en matière d'administration du football à l'échelle continentale. Elle prend des mesures vis-à-vis de possibles concurrents (comme le Comité international de liaison des ligues professionnelles). Elle entame des négociations avec des acteurs externes au domaine du football, comme l'Union internationale de radio au sujet de la télédiffusion des matchs de la Coupe des champions. Elle peut également faire infléchir des États car des régimes divisés sur la scène internationale sont obligés de trouver un compromis s'ils veulent que leurs clubs ou leurs équipes nationales participent aux épreuves de l'UEFA. En conséquence, il est possible de considérer l'Union comme un acteur de la coopération européenne, et ce d'autant plus que ses compétitions engagent des échanges réguliers entre les pays européens et connaissent un fort engouement populaire.

Enfin, nous avons vu que si la Confédération sud-américaine constitue une source d'inspiration pour les promoteurs de l'UEFA dans l'établissement de leur entité, les rôles peuvent, sur certains sujets, s'inverser vers la fin des années 1950. L'UEFA se profile alors comme le leader des confédérations continentales, s'attelant à demander que la FIFA octroie des ressources financières supplémentaires aux organismes continentaux, ce qui occasionne la création d'alliances entre eux. À la fin de la décennie, les dirigeants sud-américains s'inspirent des démarches des dirigeants de l'UEFA, en particulier lorsqu'ils créent leur propre compétition continentale de clubs, la Copa Libertadores. En moins de cinq années, l'UEFA est donc devenue la principale confédération continentale et une entité à part entière qui non seulement a pour tâche de réguler le football européen, mais joue également un rôle sur la scène internationale. 


\section{Conclusion générale}

4 septembre 1960. Suite à sa victoire cinq à un à domicile contre Peñarol de Montevideo ${ }^{1}$, le Real Madrid remporte la première Coupe intercontinentale. Cette épreuve oppose le vainqueur de la Coupe des clubs champions européens à celui de la Copa Libertadores, compétitions organisées respectivement par l'UEFA et la Confédération d'Amérique du Sud. Ici, l'échelle continentale prime et, pour certains chroniqueurs, le club madrilène représente ni plus ni moins que le continent européen tout entier ${ }^{2}$. Par ailleurs, il faut souligner le caractère transnational de l'épreuve, qui a été mise en place à la suite de discussions entre les dirigeants des deux organismes continentaux ${ }^{3}$ et, semble-t-il, avec le concours des journalistes de $L^{\prime} E q u i p e^{4}$. Elle s'est donc créée en dehors du giron de la FIFA, qui ne la reconnaît d'ailleurs pas officiellement ${ }^{5}$.

Cette opposition entre les deux champions continentaux illustre bien les changements qui se sont opérés en trente ans dans le football international. Premièrement, elle indique les liens qui existent entre les différents continents, qui ne sont certes pas nouveaux mais qui sont désormais davantage institutionnalisés avec la création de confédérations continentales dans la seconde moitié des années 1950. Deuxièmement, elle confirme que les confédérations continentales sont des actrices majeures du développement du jeu, que ce soit sur leur continent

1 Le match aller, disputé à Montevideo, s'est soldé par un nul 0 à 0.

2 "Le Real Madrid portera les insignes de l'Europe », France football, 28 juin 1960.

3 Après des discussions préalables en 1958 et 1959, une rencontre a lieu à Berne le 25 juin 1960 entre une délégation des deux organismes. Bangerter H., Procès-verbal de la réunion du comité exécutif de l'UEFA du 19 août 1960, 10 octobre 1960. UEFA, RM00000751 (réunions du comité exécutif 1960-1961).

4 "Les deux sœurs ", France football, 27 octobre 1959 ; "Havelange condamne les débordements de Maracanã ", L'Équipe, 19 novembre 1963.

5 Durant la séance du comité exécutif du 19 août 1960, Ernst Thommen rappelle que " toute compétition intercontinentale est de la compétence de la FIFA ». En signe de désaccord face aux actions des deux confédérations continentales, le comité exécutif de la Fédération internationale décide qu'aucun de ses membres ne se rendra de manière officielle à Madrid pour le match retour. Gassmann K., Procès-verbal de la réunion du comité exécutif du 19 août 1960, 5 octobre 1960. FIFA, classeur : comité exécutif (procès-verbaux 1960). 
respectif et plus largement à l'échelle internationale, où elles entrent en concurrence avec la FIFA ${ }^{6}$.

\section{De la FIFA à l'UEFA. Une brève synthèse}

Dans cet ouvrage, nous avons postulé que l'UEFA est un acteur clé dans l'établissement d'une dynamique européenne du jeu et qu'il est intéressant, à ce titre, de se focaliser sur ses premières années, durant lesquelles sont posées les bases du développement que connaît l'Union dans les décennies suivantes ${ }^{7}$. Outre de nous intéresser à la formation de l'organisation durant les années 1950, nous avons décidé de situer cette étude dans un plus long terme et de la faire débuter dès les années 1930. L'extension de la focale temporelle a permis non seulement de mieux saisir la rupture engendrée par la création de l'UEFA dans les échanges footballistiques européens mais également de comprendre la capacité de son élite dirigeante à créer puis faire évoluer l'organisation en dépit de la Guerre froide.

Trois axes de questionnement principaux, et complémentaires, ont présidé à la recherche. Le premier était relatif au rôle joué par la FIFA, puis par l'UEFA, dans l'établissement d'une dynamique européenne du jeu. Nous faisions l'hypothèse que la création de l'Union marque une nouvelle étape

6 Un économiste, Philippe Broda, a récemment publié un article dans The International Journal of the History of Sport sur la régulation des tensions entre les Européens et les dirigeants des autres continents au sein de la FIFA à partir des années 1960. Il pose une hypothèse intéressante, à savoir que pour régler les conflits ses dirigeants utilisent des stratégies de type « inflationnistes ». Nous pouvons toutefois regretter que pour la vérifier, ce chercheur n'emploie aucun matériel issu des riches archives de la FIFA ce qui limite fortement la portée explicative de son propos. De plus, la documentation de seconde main utilisée ne lui permet pas de véritablement comprendre les enjeux du développement de l'organisation, élément pourtant essentiel dans le cadre de sa réflexion. Broda P., «Europe Versus Emerging Countries Within FIFA: Using Inflation as a Conflict Regulation Mechanism ", The International Journal of the History of Sport, doi:10.1080/09523367.2017.1357546.

7 Le début d'une nouvelle phase de développement peut être repéré à partir des années 1990 avec le net accroissement du nombre d'employés de l'UEFA (qui passent d'une vingtaine à la fin des années 1970 à une centaine au début des années 1990). Ces changements résultent en particulier des modifications dans l'organisation du Championnat d'Europe des nations, du lancement de la Ligue des champions en 1991 et du développement des secteurs marketing et juridique. Pour un bref aperçu de ces changements : Olsson L.-C., "Decisive moments in UEFA », dans Gammelsaeter H., Senaux B. (eds.), The organisation and governance of top football across Europe, London, Routledge, 2011, pp. 17-31. 
de ce processus. Comme nous l'avons explicité, des échanges européens réguliers existent déjà durant l'entre-deux-guerres. Ici, c'est en particulier la FIFA qui joue un rôle important car elle permet de créer de nouvelles oppositions, par exemple par l'entremise de la Coupe du monde. De plus, ce n'est pas que sur le terrain que l'organisation œuvre aux rapprochements entre les associations nationales européennes. C'est pourquoi nous avons insisté sur d'autres éléments, tels les nombreux congrès annuels auxquels la plupart de ces dernières participent pendant les années 1930, ou encore les matchs de la FIFA de 1937 et 1938. En outre, la FIFA permet une homogénéisation du jeu en prenant des décisions sur certaines thématiques (transferts, arbitrage) et diffuse, par le biais de son Bulletin officiel, des informations générales sur le football européen. Ainsi, elle participe activement à l'ancrage du cadre continental en football. Toutefois, durant les années 1930, l'échelle géographique européenne reste encore limitée et les échanges les plus réguliers se font au niveau régional. Ainsi, les principales compétitions, telle la Mittel-Europa Cup, ne concernent au mieux que cinq ou six associations européennes - même si elles sont, parfois, relayées par la presse de pays n'y participant pas. En outre, des associations restent en dehors du giron de la FIFA, comme les associations britanniques, sorte de " membres virtuels ", et l'Union soviétique où le jeu commence à se développer et qui fait de timides incursions sur la scène footballistique internationale au milieu des années 1930 .

Cette situation change progressivement à partir de la seconde partie des années 1940, avec notamment le retour des associations britanniques dans le giron de la FIFA et l'entrée des Soviétiques au sein de l'organisation. Cet élargissement du territoire européen du football donne des idées à plusieurs acteurs du jeu. Ainsi, des projets en vue d'établir des compétitions plus ambitieuses sont lancés et l'idée de créer une confédération continentale est même évoquée dès 1949 dans la presse française par le président de la Fédération italienne, et dirigeant influent du football européen, l'Italien Ottorino Barassi. Finalement, une telle entité va voir le jour suite à la décentralisation de la FIFA qui s'opère en 1953. L'UEFA, créée une année plus tard, va renforcer considérablement la dynamique européenne du jeu. En créant des compétitions (la Coupe d'Europe des nations puis, plus tard, la Coupe des vainqueurs de coupe) ou en reprenant l'administration de compétitions existantes (comme la Coupe des clubs champions européens, le tournoi international des juniors), elle permet d'établir de nouveaux échanges entre les associations nationales sur un territoire qui s'étend de la Scandinavie à la Grèce, du Nord au Sud, et de la Turquie à l'Irlande, d'Est en Ouest. Par ailleurs, ces rencontres sont plus régulières que par le passé et se déroulent durant toute la saison footballistique, là 
où les compétitions de l'entre-deux-guerres se jouaient durant quelques mois seulement (principalement l'été). L'amélioration des conditions de transport (notamment avec l'utilisation de l'avion, qui permet aux équipes de jouer à l'étranger la semaine et de disputer le week-end ses rencontres du championnat national) ainsi que les infrastructures des stades (comme l'éclairage nocturne, qui offre l'opportunité de jouer lors des soirées hivernales) favorisent ce développement. C'est donc une communauté européenne du football qui se regroupe autour de l'UEFA. Certes, ce processus n'est pas linéaire et connaît, sur certains points, des résistances au sein des associations nationales, comme nous l'avons vu par exemple avec le projet de Coupe d'Europe des nations. Cependant, au début des années 1960, les échanges européens sont plus nombreux que par le passé et il est possible de considérer que l'échelle européenne s'est imposée comme un cadre important, voire même plus important, selon certains chroniqueurs, que l'échelle nationale ou locale (sans toutefois les faire disparaître).

Notre deuxième axe de questionnement portait sur la capacité des dirigeants de l'UEFA à créer une organisation qui transcende la Guerre froide, fait - rappelons-le une dernière fois - tout à fait unique au regard des autres entités continentales créées à la même période qui englobent uniquement des pays de l'Europe de l'Ouest. En fait, il s'agissait d'aborder la question de manière plus globale et de s'interroger sur les raisons expliquant que les dirigeants de l'UEFA sont parvenus à se créer une autonomie relative sur la scène internationale. Notre hypothèse était que les dirigeants de l'UEFA s'inspirent largement des stratégies de gouvernance développées, depuis les années 1930, au sein de la FIFA afin de réserver à l'organisation une autonomie relative sur la scène internationale. Nous avons questionné la construction de cette autonomie et avons notamment montré que, durant les années 1930 et 1940, le comité exécutif de la FIFA poursuit la volonté de créer une entité forte afin de poursuivre son but principal : développer le football à l'échelle internationale. En conséquence, les principaux dirigeants de la FIFA mettent en place des stratégies qui visent à neutraliser les conflits au sein de l'organisation et, en particulier, à limiter l'ingérence de la politique sur l'organisation (le football connaissant une politisation croissante depuis les années 1920). Premièrement, l'élite de la FIFA recherche une autonomie financière afin d'éviter au maximum toute ingérence extérieure de ce point de vue. Ainsi, son comité exécutif prend régulièrement des décisions en vue de préserver les finances de l'organisation (mesures d'économie, recherches de nouvelles mesures de financement). Deuxièmement, il poursuit une politique non interventionniste dans les affaires des associations nationales afin de ne pas introduire des sujets conflictuels au sein de l'organisation 
(c'est par exemple le cas lorsqu'ils décident de ne pas intervenir en faveur de l'une des deux organisations de football qui existent durant la Guerre d'Espagne, liées chacune à un camp politique). Troisièmement, l'élite de la FIFA négocie avec les différentes forces existantes dans l'organisation au sujet des places au sein de son comité exécutif. Quatrièmement, celle-ci est composée de dirigeants ayant un profil de diplomates - condition sine qua non pour le secrétaire général - qui ont un long vécu dans les arcanes footballistiques de leurs fédérations nationales respectives et, de préférence, qui n'ont pas de mandats politiques. Toutes ces décisions permettent de fortifier l'organisation et lui confèrent l'opportunité de s'imposer comme l'acteur principal en matière de football international et d'œuvrer à créer un monopole en la matière, vis-à-vis non seulement des autres acteurs du monde footballistique mais aussi de l'extérieur de celui-ci (par exemple vis-à-vis d'autres organisations internationales). La situation permet notamment à la FIFA de minimiser les soubresauts de la politique internationale, comme c'est le cas durant la Deuxième Guerre mondiale, et de minimiser ses conséquences (en particulier l'entrée progressive dans la Guerre froide). Cette politique est impulsée par le Français Jules Rimet, président de la FIFA de 1919 à 1954, qui affirme que le football peut participer au rapprochement des peuples.

Si nous nous sommes arrêtés assez longuement sur ces différents points, c'est qu'ils permettent de comprendre autant les raisons qui expliquent, d'une part, que l'UEFA est composée dès sa fondation d'association des blocs de l'Est et de l'Ouest; d'autre part, la façon dont l'élite dirigeante de l'UEFA va réussir à limiter l'impact de la Guerre froide sur l'organisation. En effet, en continuant la politique de neutralisation des conflits instaurée par les dirigeants de la FIFA, l'UEFA se développe rapidement, et ce en dépit de sa configuration particulière. De plus, en raison de cette situation, l'Union se profile comme un " acteur atypique " de la construction de l'Europe car elle a la capacité de rapprocher les pays européens. En effet, par l'entremise des différentes compétitions qu'elle organise mais aussi de ses congrès annuels, l'UEFA propose des possibilités de rencontres officielles entre les associations de pays n'entretenant parfois pas de relations diplomatiques, telles l'Espagne et l'Union soviétique. Toutes ces mesures vont donc permettre de créer un organisme qui se profile comme le régulateur du football européen et s'arroge, dès la fin des années 1950, le monopole en matière d'échanges à l'échelle continentale. Cette posture lui permet de limiter les actions d'acteurs internes au monde du football qui souhaitent développer des échanges footballistiques à l'échelle européenne (comme le Comité interliaison des ligues professionnelles créé en 1959). Elle permet également à cet organisme de se profiler 
comme l'interlocuteur privilégié du football vis-à-vis d'acteurs extérieurs qui s'intéressent à ces nouvelles connexions footballistiques européennes (telle l'Union européenne de radio). Ce développement ne va toutefois pas sans poser des problèmes, en particulier avec la FIFA, dont l'élite dirigeante voit d'un mauvais œil que certaines de ses prérogatives lui sont grignotées. Cette situation, qui se repère au travers de la gestion de certaines thématiques (telle la manière dont est gérée la reprise du tournoi international des juniors par l'UEFA), débouche finalement sur l'établissement d'une commission FIFA-UEFA dans le but de minimiser, voire d'éviter, les tensions entre les deux organisations.

La troisième question posée dans ce livre était la suivante : comment expliquer la création de l'UEFA au milieu des années 1950 ? Notre hypothèse était qu'il faut relier la création de l'Union aux changements intervenus dans la structure de la FIFA, ceux-ci étant impulsés par des associations nationales qui militent pour sa régionalisation. Nous avons montré que la volonté de décentraliser la Fédération internationale est ancienne et est discutée, depuis les années 1930, par les associations sud-américaines. En 1934 déjà, elles proposent au comité exécutif de la FIFA, par le biais de la Confédération sud-américaine (créée en 1916), de continentaliser la Fédération internationale. Cette volonté témoigne autant du souhait de jouer un plus grand rôle dans la gouvernance de la FIFA que d'une contestation envers l'hégémonie européenne qui existe à la tête de l'organisation. En effet, à cette période, le comité exécutif de la FIFA et ses différentes commissions permanentes sont, en très grande majorité, composés de dirigeants européens. En 1938, dans le but de limiter les tensions au sein de l'organisation, une place fixe au comité exécutif est réservée à un dirigeant sud-américain. Dans la seconde partie des années 1940, forts de leur alliance avec les associations d'Amérique centrale dans le cadre de la Confédération panaméricaine, créée en 1946, les dirigeants sud-américains vont formuler de nouvelles propositions concrètes en vue de décentraliser la FIFA. Leur but est d'acquérir des places supplémentaires dans le comité exécutif. Ces revendications bénéficient d'un contexte international qui leur est favorable : en raison de la décolonisation et de la perte de puissances des grandes nations européennes, les pays extra-européens prennent un rôle nouveau sur la scène internationale. Ainsi, parallèlement aux revendications sud-américaines, des associations africaines formulent également le vou de créer un groupement suprarégional. Ces idées trouvent une résonance chez de nouveaux dirigeants européens, en particulier le trio Barassi, Rous, Thommen, qui commencent à se profiler comme les futurs dirigeants principaux de la FIFA. Ces derniers pensent effectivement que la Fédération internationale 
doit être réorganisée, notamment en raison du développement du football dans le monde. Toutefois, ils ne sont pas totalement convaincus par les propositions sud-américaines. Ces différentes idées sont discutées lors du premier congrès organisé hors d'Europe, en 1950, à Rio. Finalement, les congressistes décident d'entamer un processus qui conduit à une réorganisation de la FIFA dans les années suivantes.

Après de longues discussions au sein de la FIFA, qui opposent différents blocs (sud-américain, britanniques et soviétique), la décision de créer des groupements continentaux est formellement prise lors du congrès de novembre 1953. En effet, le congrès extraordinaire organisé à Paris voit finalement l'établissement d'une alliance entre les Européens de l'Ouest et les Sud-Américains qui permet la réorganisation de la FIFA. Désormais, les Européens devront élire des représentants au sein du comité exécutif de la FIFA et, pour ce faire, créer un groupement continental. Force est donc de constater que les dirigeants sud-américains ont joué un rôle de premier plan dans la réorganisation de la FIFA. Mais leur influence est aussi importante dans la formation du groupement européen lui-même. En effet, la Confédération sud-américaine fait en quelque sorte office de modèle pour les promoteurs de l'entité européenne. Ainsi, dans les premiers mois de l'année 1954, les dirigeants européens s'inspirent de l'architecture organisationnelle de la Confédération sud-américaine pour créer leur propre groupement. Ils vont aussi suivre le modèle sud-américain lorsque, en 1955, l'UEFA émet le souhait d'obtenir une partie des pourcentages que versent les associations nationales européennes à la FIFA sur leurs matchs internationaux. La requête est notamment justifiée par le fait que les associations sud-américaines bénéficient de ce droit. Finalement, après plusieurs mois de discussions entre les dirigeants de la FIFA et de l'UEFA, la demande va être acceptée par l'instance internationale. Constatons que l'exemple sud-américain offre l'opportunité pour les dirigeants de l'UEFA de s'émanciper de la tutelle de la FIFA. À la fin de la décennie 1950, la structure de l'Union est en voie de consolidation et, cette fois, ce sont les Sud-Américains qui vont s'inspirer des Européens dans leurs démarches visant à créer une compétition continentale de clubs. En effet, leur compétition continentale, la Copa Libertadores, se calque en partie sur la Coupe des clubs champions de l'UEFA. À noter que des discussions voire des alliances - entre les deux confédérations s'opèrent également au sein de la FIFA, comme c'est le cas pour une requête qui vise à recevoir une partie des pourcentages que versent les associations nationales à la FIFA dans le cadre de la Coupe du monde de football.

Au début des années 1960, l'UEFA se profile comme l'organisme régulateur du football européen. Elle va conforter cette position dans les Philippe Vonnard - 978-2-8076-0570-1 
années 1960-1970, en particulier en élargissant ses compétences mais aussi en se réappropriant l'organisation en 1972 de la Coupe des villes de foires ${ }^{8}$. Tout au long de ces années, les actions de l'Union ont donc permis la pérennisation des échanges footballistiques continentaux et ont indéniablement joué un rôle crucial dans leur naturalité. Pour le dire autrement, les actions initiées par l'UEFA depuis sa fondation ont grandement permis au cadre footballistique européen de n'être quasiment jamais remis en question jusqu'à aujourd'hui, comme si finalement jouer à l'échelle européenne allait de soi.

\section{Quels apports pour l'histoire des coopérations européennes?}

Comme nous l'avons annoncé dans l'introduction, cet ouvrage s'inscrit dans la continuité des recherches souhaitant étendre la focale des études sur l'histoire des coopérations européennes et ainsi continuer à sortir d'une approche centrée principalement sur le cas de la Communauté économique européenne ou de l'Union européenne. Au travers de la mise en place de l'UEFA, cette étude confirme bien l'étendue de ces coopérations continentales. À ce titre, et pour élargir le cadre du présent livre tout en affinant, voire en traitant, des points laissés ici en suspens - par exemple, les raisons de l'engagement actif au sein de l'UEFA de pays comme l'URSS ou l'Espagne franquiste -, il sera nécessaire dans de futures recherches de se focaliser sur la diplomatie footballistique des États durant la Guerre froide? . Comme l'indiquait Tony Shaw en 2001, ce conflit a imprégné tous les domaines de la société ${ }^{10}$ et, sous cet angle, le football - comme d'autres domaines, telle la culture ${ }^{11}-\mathrm{a}$ pu être utilisé selon différentes formes d'investissement par les gouvernements.

8 Son nom est symboliquement changé en Coupe UEFA.

9 À ce jour, la diplomatie par le football pour la période de la Guerre froide n’a été que peu étudieé. Pour une réflexion sur l'emploi de ces archives : Dichter H., «Diplomatic and International History: Athletes and Ambassadors ", International Journal of the History of Sport, vol. 32, $\mathrm{n}^{\circ}$ 15, 2015, pp. 1741-1744. Et pour un bon exemple de ce type de démarche dans le domaine sportif, voir : Gygax J., Olympisme et Guerre froide culturelle. Le prix de la victoire américaine, Paris, L'Harmattan, 2012.

10 Shaw, T. "The politics of Cold War culture ", Journal of Cold War Studies, vol. 3, n 3, 2003, pp. 59-76.

11 Une riche littérature existe sur la culture durant la Guerre froide. Voir par exemple : Sirinelli J.-F., Soutou G.-H. (dir.), Culture et Guerre froide, Paris, PUPS, 2008 ; Mikkonen S., Suutari P., Music, Art and Piplomacwo op.cit. 978-2-8076-0570-1 
Arrivant au terme de ce livre, nous souhaitons revenir sur l'intérêt de cette étude pour l'histoire des coopérations européennes. Trois points peuvent être dégagés. Tout d'abord, et à la suite d'autres auteurs, nous voulons insister sur le bénéfice de choisir une perspective de longue durée. Pour l'étude d'une organisation internationale, cette démarche a pour avantage de considérer que cette dernière est parfois le fruit de devancières dont elle reprend des prérogatives, voire dont les dirigeants s'inspirent pour définir la structure. De plus, la longue durée offre l'opportunité de ne pas considérer les organisations comme des monolithes et permet de prendre en compte les différentes générations de dirigeants qui officient en leur sein. En d'autres termes de questionner les héritages et les nouveautés. Par ailleurs, l'emploi de la diachronie permet aussi d'interroger l'impact d'événements majeurs, comme la Deuxième Guerre mondiale ou la Guerre froide, sur la gouvernance des organisations ${ }^{12}$. Ainsi, nous avons vu qu'au sein des organisations du football européen, une sorte de continuité peut être repérée entre l'entre-deux-guerres et les premières années de la Guerre froide. Si elles ne sont certes pas insensibles au contexte international, les élites dirigeantes de la FIFA et de l'UEFA tentent de faire avec et de se créer un chemin par rapport à celui-ci. Enfin, l'avantage de cette prise en compte d'une temporalité longue amène à comprendre l'épaisseur historique d'un processus. Aussi, dans le cas du football, si l'Europe est une variable importante, c'est que cette échelle géographique se construit depuis le début du siècle dernier et, au fil des années et de son renforcement progressif - certes non linéaire, le processus connaissant parfois des arrêts, voire des reculs sur certains aspects -, devient une composante qui semble presque aller de pair avec le jeu lui-même.

Puis, nous avons montré qu'il s'agit de saisir les actions des dirigeants à l'aune de la politique de l'organisation. Or les études qui traitent des organisations européennes s'appuient encore peu sur la littérature qui existe en histoire et sociologie des organisations internationales. Notre recherche montre que l'élite dirigeante de la FIFA, puis de l'UEFA, ont par exemple développé des stratégies, constamment renégociées, permettant de neutraliser les conflits au sein de leur entité. Celles-ci leur ont donné l'opportunité d'outrepasser certaines barrières existantes dans le contexte

12 Par exemple : Kott S., " Par-delà la Guerre froide. Les organisations internationales et les circulations Est-Ouest (1947-1973) ", Vingtième Siècle. Revue d'histoire, vol. 109, $\mathrm{n}^{\circ}$ 1, 2011, pp. 143-154 ; Schot J., Kaiser W., Writing the Rules for Europe. Experts, Cartels, and International Organizations, Basingstoke, Palgrave Macmillan, 2014, Zakharova L., "Des techniques authentiquement socialistes ? Transferts et circulation dans les télécommunications entre l'URSS et l'Europe (années 1920-1960) ", Critique internationale, vol. 66, $\mathrm{n}^{\circ} 1,2015$, pp. 19-35. 
politique international - quoique lorsque la situation internationale est trop tendue, les échanges se limitent, voire s'estompent. Le chercheur se doit donc de saisir les ressorts de cette coopération et, sous cet angle, se focaliser sur la "boîte noire " des organisations. Par ailleurs, et afin de comprendre toute la complexité de l'entité étudiée, mais aussi ses spécificités, il paraît crucial d'établir davantage des comparaisons entre les organisations européennes ${ }^{13}$. En ce sens, le recours à de la littérature extérieure au domaine étudié, en l'occurrence ici le domaine sportif, mais aussi le croisement des approches discplinaires, s'avèrent très féconds, comme l'a suggéré Emmanuel MourlonDruol dans un texte paru en $2015^{14}$.

Enfin, nous souhaitons insister sur l'importance de décentrer le regard et de replacer la construction de l'Europe en adoptant une perspective globale. Dans le cadre de cet ouvrage, nous avons notamment souligné les liens qui existent entre la formation d'une organisation européenne et l'influence d'acteurs provenant d'autres continents. S'intéresser à ces interactions paraît crucial, que ce soit au travers des échanges mais aussi des luttes entre Européens et dirigeants des autres continents (ici en premier lieu les Sud-Américains), car cela a permis de mieux saisir différents éléments : les enjeux sous-jacents à la formation d'une entité continentale; les raisons de la temporalité dans laquelle s'effectue la création de l'UEFA; les options choisies par ses promoteurs en termes de structure. Certes, l'étude proposée dans cet ouvrage ne s'est pas faite "à parts égales " 15 et aurait dû, pour être plus complète, mobiliser des sources issues de fonds d'archives se trouvant dans des pays extra-européens (en particulier des pays sud-américains). Néanmoins, elle permet de penser davantage la construction de l'Europe vis-à-vis de pays n'ayant a priori pas de liens avec celle-ci.

En 2003, Bernard Hozé se demandait si le mouvement sportif avait une vision de l'Europe ${ }^{16}$. Ses conclusions étaient plutôt négatives. Or les recherches récentes - certes encore conduites principalement sur le football - semblent permettre de faire l'hypothèse qu'une vision de l'Europe existe bel et bien au sein du mouvement sportif. Dès lors,

13 Kaiser W., Patel K. K., " Multiple connections in European co-operation: international organizations, policy ideas, practices and transfers 1967-92 ", European Review of History. Revue européenne d'histoire, vol. 24, n 3, 2017, pp. 337-357.

14 Mourlon-Druol E., "Rich, Vivid, and Ignored. History in European studies ", Politique européenne, vol. 50, $\mathrm{n}^{\circ}$ 4, 2015, pp. 56-69.

15 Bertrand R., L'Histoire à parts égales. Récits d'une rencontre, Orient-Occident $\left(X V I^{e}-\right.$ XVII siècle), Paris, Seuil, 2011.

16 Hozé B., "Le mouvement sportif a-t-il une vision de l'Europe ? ", dans Schirmann S. (dir.), Organisations internationales et architectures européennes 1929-1939, Metz, Centre de recherche histoire et civilisation de l'Université de Metrz 2003 pp 163-177. 
continuer d'insister sur les (nombreuses) coopérations européennes en matière de sport permettrait de mettre au jour ces innombrables - et encore méconnus - échanges se réalisant au niveau continental et questionnerait véritablement à nouveaux frais les conclusions de Hozé. De futurs travaux sont donc nécessaires sur ces différents aspects et ce n'est qu'à leur suite qu'il sera possible de véritablement saisir la place du football - et plus largement du sport ${ }^{17}$ - dans l'histoire des coopérations européennes.

Plus globalement, une telle démarche permettrait d'amener de nouveaux éléments empiriques à ce que l'historien Gérard Bossuat a nommé l'" espace des relations intereuropéennes " ${ }^{18}$, dans lequel le domaine sportif joue sans doute un rôle encore sous-estimé. Outre leur intérêt heuristique, de telles études offriraient in fine la possibilité au domaine sportif de faire véritablement son entrée sur le terrain des études de l'histoire des coopérations européennes.

\section{... Du football à l'Europe!}

Dans le futur, il s'agira également de poursuivre l'étude de l'histoire de l'UEFA et de s'intéresser plus particulièrement aux décennies 1960 à 1980, durant lesquelles l'Union étend ses prérogatives en matière de football européen. Ainsi, loin de l'eurosclérose postulée par Anthony King ${ }^{19}$, les échanges footballistiques européens continuent ce qui, au fil du temps, a pour effet de renforcer leur apparente naturalité. C'est aussi durant ces décennies que des jalons sont posés pour les transformations importantes que connaît le football européen à partir des années 1990-2000. Dans cette optique, il s'agira notamment de questionner, dans une approche relationnelle ${ }^{20}$, l'impact qu'ont pu avoir les liens établis entre l'UEFA et

17 Peu d'études existent sur les autres organisations européennes. À notre connaissance, la seule entité qui a été abordée jusqu'ici - et encore de manière relativement brève puisqu'il s'agissait d'un livre réalisé pour un anniversaire - est la Fédération européenne d'athlétisme : Roger A., Terret T., European Athletics. Une histoire continentale de l'athlétisme, Stuttgart, Neuer Sportverlag, 2012.

18 Bossuat G., "Des identités européennes ", dans Frank R. (dir.), Pour l'histoire des relations internationales, op. cit., p. 664.

19 Certes, King a raison de souligner les problèmes, tel le hooliganisme, qui touche le football européen des années 1970-1980. Cependant, ceux-ci ne remettent nullement en cause la dynamique des échanges footballistiques européens. King A., The European ritual: football in the new Europe, Aldershot, Ashgate, 2004.

20 Patel K. K., «Provincialising European Union: Co-operation and integration in Europe in a Historical Perspective ", Contemporary European History, vol. 22, n 4, 2013, pp. 649-673 ; Mecchi L., Migani G., Petrini F. (eds.), Networks of glohalgoyernance: 
d'autres organisations européennes ${ }^{21}$. De même, d'étudier l'Europe dite des clubs et en particulier les actions des grandes formations européennes dans l'optique de créer un championnat d'Europe des clubs, démarche qui va aboutir à la transformation de la Coupe des clubs champions en Ligue des champions au début des années 1990.

Pour conclure cet ouvrage, et en prenant un peu de hauteur, nous pouvons affirmer que le football fait assurément partie des nombreux espaces fortement européanisés depuis fort longtemps et qui concernent les citoyens européens dans leur vie quotidienne ${ }^{22}$. Or, dans un temps où de nombreux discours remettent en cause l'existence même de l'Europe communautaire - sans doute, sur certains points le débat mérite d'être posé -, retracer les nombreux liens qui existent entre les Européens s'avère nécessaire pour nuancer les discours trop simplistes, voire démagogiques, contre l'unité européenne et qui risquent, en exacerbant les différences et en attisant le renfermement sur soi, de faire replonger, à terme, le continent dans l'abîme des guerres.

Aussi, et de manière somme toute paradoxale tant le jeu est perçu par de nombreux observateurs comme étant vecteur de nationalisme, de violences, voire comme un opium du peuple ${ }^{23}$, retracer l'histoire du football européen permet de mettre au jour les coopérations multiples souvent méconnues ou simplement ignorées - qui existent depuis des décennies entre les Européens. Si l'idée de rapprocher les peuples par le

International Organisations and European Integration in a historical perspective, Cambridge: Cambridge Scholar Press, 2014.

21 En effet, des études récentes montrent que la CEE ou le Conseil de l'Europe s'intéressent à partir des années 1970 au domaine du football. Voir en particulier Schotté M. (2016), " "To live is to live concealed". Confined relation between UEFA and the European community (1970s and 1980s) ", dans Vonnard P., Quin G., Bancel N., Building Europe with the ball, op. cit, pp. 187-199 ; Gasparini W., Heidmann M., «Les enjeux de l'européanisation du football. Débats et controverses entre les acteurs de l'Union européenne et du Conseil de l'Europe ", dans Robin G. (dir.), Football, Europe et régulations, Lille, Presses universitaires du Septentrion, 2011, pp. 111-123.

22 Voir par exemple des contributions dans : Bouvier Y., Laborie L. (dir.), L'Europe en transition. Énergie, mobilité, communication aux XVIII'-XXI siècles, Paris, Nouveau Monde Éditions, 2017.

23 C'est notamment le courant dit de la sociologie critique qui a passablement écrit sur ce sujet, voir par exemple : Brohm J.-M., Perelman M., Le football : une peste émotionnelle, Paris, Folio, 2006. Pour une vision critique mais moins catégorique et polémiste, voir le numéro spécial « Peut-on aimer le football ? " paru dans la revue Mouvements, vol. $78, n^{\circ} 2,2016$. Et pour un point de vue également critique, mais offert par des anarchistes passionnés de ballon rond, voir : Rosell W. (dir.), Eloge de la passe : changer le sport pour changer le monde, Saint-Georges-d'Oléron, Éditipgs_Libertaires 2012. 
football qu'a défendue en son temps le président de la FIFA, Jules Rimet, parait utopiste, une question persiste : ne s'apprécie-t-on pas davantage lorsque l'on se connaît ${ }^{24}$ ?

Interrogation pertinente car le football a indéniablement permis à plusieurs générations de suiveurs du jeu - tel le mendiant de football merveilleusement décrit par l'écrivain Eduardo Galleano ${ }^{25}$ - de s'instruire en matière de géographie de l'Europe, les matchs européens offrant de nombreuses occasions de voyager - physiquement ou par procuration via les médias. Le football fait donc vivre cette Europe, et ce indépendamment du statut social et culturel, du genre, de l'âge, de la nationalité et last but not least de la langue. Si Albert Camus avouait avoir compris beaucoup sur la morale au travers du ballon rond ${ }^{26}$, celui-ci a sans doute passablement appris au sujet de l'Europe à ses habitants.

24 Cautrès B., "Plus on se connaît, plus on s'aime?", Politique européenne, vol. 26, $\mathrm{n}^{\circ} 3$, 2008, pp. 165-190.

25 Galeano E., Football : ombre et lumière, Paris, Climats, 1997.

26 Confidence que l'écrivain fait dans le Bulletin du Racing Universitaire d'Alger - club pour lequel il a joué dans sa jeunesse - du 15 avril 1953. Merci à Gabriel Gonzalez pour le rappel de l'existence de ce texte. 
Philippe Vonnard - 978-2-8076-0570-1

Téléchargé de PubFactory à01/07/2021 08:14:02PM

via free access 


\section{Liste des tableaux}

Tableau 1. Ancienne et nouvelle composition du comité exécutif

Tableau 2. Matchs internationaux (1923-1930) des participants européens à la Coupe du monde 1934

Tableau 3. Composition du comité exécutif de la FIFA (1930-1938)

Tableau 4. Résumé des recettes et dépenses de la FIFA en 1938

Tableau 5. Répartition continentale lors des congrès de la FIFA entre 1930 et 1938

Tableau 6. Pays et dirigeants présents durant les congrès de la FIFA de 1930 à 1936

Tableau 7. Montant du pourcentage perçu par la FIFA sur les matchs internationaux de 1939 à 1944

Tableau 8. Comité exécutif de la FIFA en 1946

Tableau 9. Charges de la FIFA en 1938 et en 1942

Tableau 10. Pays européens aux tournois internationaux des juniors de 1949 à 1954

Tableau 11. Composition de la commission de réorganisation de la FIFA

Tableau 12. Composition du comité exécutif selon le nouveau projet de statuts de la FIFA

Tableau 13. Composition du comité exécutif selon le nouveau projet de statuts de la FIFA

Tableau 14. Commissions permanentes de l'UEFA (début 1959)

Tableau 15. Représentants du Groupement européen élus à la FIFA

Tableau 16. Membres du comité exécutif de l'UEFA en 1958

Tableau 17. Nouvelle composition du comité exécutif de la FIFA selon les statuts de 1954 
Philippe Vonnard - 978-2-8076-0570-1

Téléchargé de PubFactory à01/07/2021 08:14:02PM

via free access 


\section{Liste des figures}

Figure 1. Structure de la FIFA en 1932

Figure 2. Pays ayant ratifié la proposition de modification des statuts de la FIFA

Figure 3. Nombre d'associations membres de la FIFA de 1904 à 1950

Figure 4. Questionnaire envoyé aux associations européennes en mai 1954

Figure 5. Pays présents lors de l'assemblée constitutive du Groupement européen

Figure 6. Instances footballistiques du football européen en juin 1954

Figure 7. Clubs participant à la deuxième édition de la Coupe des champions 
Philippe Vonnard - 978-2-8076-0570-1

Téléchargé de PubFactory à01/07/2021 08:14:02PM

via free access 


\section{Sources}

\section{Sources primaires (fonds principaux)}

\section{Archives de l'UEFA (Nyon)}

Série RM00005779 : Statuts de l'UEFA

Série RM00005984- RM00005993 : assemblée générale (de 1954 à 1971)

Série RM00000749-RM00000777 : comité exécutif (de 1954 à 1971)

Série RM00000917 : rapport du secrétaire (de 1954 à 1985)

Série RM00000949 : commission UEFA-FIFA (de 1959 à 1962)

Série RM00000990 : commission des finances (de 1957 à 1978)

Série RM0000992 : Coupe d'Europe des nations (de 1958 à 1970)

Série RM00000987 : Coupe des clubs champions européens (de 1956 à 1972)

Série RM0002712 et RM0002713 : compétitions non organisées par l'UEFA

Série RM00010068 : rapport sur les cours et les conférences organisées par l'UEFA

\section{Archives de la FIFA (Zurich)}

Série : Statuts de la FIFA

Série : comité exécutif (de 1927 à 1970)

Série : comité d'urgence (de 1951 à 1964)

Série : assemblée générale (de 1904 à 1970)

Série : commission des finances (de 1955 à 1962)

Série : circulaire aux membres (de 1946 à 1957)

Série : réorganisation de la FIFA (de 1950 à 1953)

Série : correspondance des présidents et des membres du comité exécutif

M. Andrejevic (1938-1982) ; O. Barassi (1.1.61-31.12.63) ; S.E. M. Bianchi, (1946-31.12.1950); A. Drewry (1946-1955); V. Granatkine (1.7.54-31.12.63); K.J.J. Lotsy (1.1.49-31.12.50) ; G. Mauro (6.8.48-31.12.50) ; G.R. Manning (6.9.48-31.12.50) ; Jules Rimet (1946-1950) ; R.W. Seeldrayers (1939-1950); E. Thommen (22.6.50-31.12.50).

Série : correspondance avec les confédérations : CONMEBOL (1941-1961) ; CAF (1954-1967) ; UEFA (1955-1958) et (1959-1961) 
Série : correspondances avec les associations nationales : Allemagne (1938-1950); Allemagne de l'Ouest (1951-1954); Angleterre (1927-1948) et (1948-1957); Argentine (1934-1968) ; Autriche (1935-1963) ; Belgique (1939-1961) ; Brésil (1935-1950) et (1951-1967) ; Chili (1932-1972) ; Chypre (1947-1973) ; Danemark (1932-1974) ; Espagne (1935-1965) ; Égypte (1937-1954); France (1937-1954) et (1955-1965) ; Ghana (1953-1996) ; Hongrie (1938-1965) ; Italie (1939-1957) et (1958-1972) ; Israël (1950-1959) ; Pays-Bas (1935-1970); Roumanie (1935-1970); Suède (1939-1955); Suisse (1938-1950) et (1951 à 1961) ; Tchécoslovaquie (1938-1998); Turquie (1932-1970) ; Union soviétique (1923-1983) ; Uruguay (1934-1968) ; Yougoslavie (1938-1974).

\section{Sources primaires (fonds complémentaires)}

\section{BundesArchives (Berlin)}

Série: DY 12 Deutscher Turn und Sportbund (DTSB) ; (2.081) : Zusammenarbeit mit der FIFA (microfiches) ; (2.085) : Zusammenarbeit mit der UEFA (microfiches)

\section{Archives générales du Royaume de Belgique (Bruxelles)}

Série : Union Royale Belge des Sociétés de Football-Association (URBSFA) : livre des rapports du comité exécutif de l'URBSFA (de 1927 à 1962)

\section{Archives de la Football-Association (Londres)}

Série : livre des rapports du comité exécutif de la FA (de 1931 à 1960)

\section{Archives de la Fédération Française de Football (Paris)}

Série : livre des rapports du Bureau fédéral (de 1920 à 1960)

Classeur : Euro 1960 et Coupe de l'Europe 1955

\section{Archives du Deutsche Fussball Bund (Francfort s/Main)}

Série : Korrespondenz Peco Bauwens : Ausschluss Bauwens und des DFB aus der FIFA [27]/B.z.a.t)

Série: Wiederaufnahme des DFB in die FIFA [18] : pochette : B/ZA/T ; Aufbau des deutschen nach dem Zweiten Weltkrieg [27] ; Korrespondenzen [28] 


\section{Archives de l'Association Suisse de Football (Berne)}

Série : rapport annuel de l'ASF (de 1919 à 1962)

Série : 311 : Fédération Internationale de Football Association (FIFA), boîte : Wiederaufnahme Deutschlands in die FIFA : Korrespondenz, Protokolle, Pressebericht 1948-1950

\section{Archives de la Préfecture de Police de Paris (Paris)}

Série (32735P) : UEFA

\section{Archives de la Société des Nations (Genève)}

Série : 5A (International Bureaux Général Dossier, 1928-1932) : boîte (11713) : Union cycliste internationale : correspondances et documents divers

Série : 8A (Health General): boitte (39026) : Rapport of the Hygiene Organisation for the period January 1931 to September 1932 ; boîte (29252) : Physical Education. Correspondence with Federation International de Football Association

\section{Sources secondaires}

\section{A. Imprimés officiels}

Bulletin de la FIFA

Bulletin de l'UEFA

Bulletin de l'UER

Handbook de la FIFA (Édition 1927 ; 1928-1929 ; 1931 ; 1935 ; 1950 ; 1955 ; 1965)

Handbook de l'UEFA (Édition 1963-1964)

\section{B. Périodiques}

Journaux consultés de manière exhaustive (par ordre chronologique) :

Football-association (1920-1931) ; L'Auto (1930-1938) ; Le Sport suisse (1920-1942) ; L'Équipe (1946-1961) ; France football (1948-1961) ; La Semaine sportive (1948-1961)

Autres journaux consultés (par ordre alphabétique) : 
France-soir; Kickers ; L'Humanité; La Gazette de Lausanne ; Le Figaro ; Le Journal de Genève

\section{Principaux entretiens}

- Entretien avec Jacques Ferran, journaliste à L'Équipe (1949-1999), réalisé le 28 juin 2011 à Paris (au restaurant de la Rotonde) et le 19 septembre 2012 à Paris (au restaurant de la Rotonde).

- Entretien avec Pierre Delaunay, secrétaire de la Fédération française de football (1955-1969) et secrétaire général de l'UEFA (1955-1959), réalisé le 18 septembre 2012 à Versailles (chez lui).

- Entretien avec Hans Bangerter, secrétaire adjoint de la FIFA (1953-1959) puis secrétaire général de l'UEFA (1959-1989), réalisé le $1^{\text {er }}$ octobre 2012 à Bollingen (chez lui) 


\section{Bibliographie}

La bibliographie présentée ci-dessous regroupe une sélection des travaux utilisés dans cet ouvrage. Pour davantage de détails, nous renvoyons à la bibliographie de notre thèse de doctorat.

\section{A. Instruments de travail}

AGLAN A., FRANK R. (dir.), 1937-1947. La guerre-monde, tomes I et II, Paris, Gallimard, 2015.

BERTRAND R., L'Histoire à parts égales. Récits d'une rencontre, Orient-Occident (XVI'-XVII siècle), Paris, Seuil, 2011.

CONWAY M., PATEL K. K. (eds.), Europeanization in the twentieth Century: historical approaches, Basingstoke, Palgrave Macmillan, 2010.

DEVIN G., SMOUTS M.-C., Les organisations internationales, Paris, Armand Colin, 2011.

DIETSCHY P., Histoire du football, Paris, Perrin, 2010.

DULPHY A. et al. (dir.), Les relations culturelles internationales au $\mathrm{XX}^{\mathrm{e}}$ siècle, Bruxelles, P.I.E. Peter Lang, 2010.

DUMOULIN M., LANNEAU C. (dir.), La biographie individuelle et collective dans le champ des relations internationales, Bruxelles, P.I.E. Peter Lang, 2016.

EISENBERG C. et al., FIFA 1904-2004. Le siècle du football, Paris, Le Cherche Midi, 2004.

FRANK R. (dir.), Pour l'histoire des relations internationales, Paris, Presses universitaires de France, 2012.

HUGHSON J. et al. (eds.), Routledge Handbook of Football Studies, London, Routledge, 2017.

GRATALOUP C., Linvention des continents : comment l'Europe a découpé le monde, Paris, Larousse, 2009.

IRYE A., Global Community. The Role of international organizations in the making of the contemporary world, Berkeley, University of California Press, 2002.

MICHEL M., Décolonisations et émergence du tiers monde, Paris, Hachette, 1993.

OSMONT M. et al. (dir.), Européanisation au XXe siècle. Un regard historique, Bruxelles, P.I.E. Peter Lang, 2012. 
POPE S., NAURIGHT J. (eds.), Routledge Companion to Sports History, London \& New York, Routlege, 2010.

ROUSSELLIER N., L'Europe des traités. De Schuman à Delors, Paris, CNRS Éditions, 2007.

SINGARAVELOU P. (dir.), Les empires coloniaux, $X I X^{e}-X X^{e}$ siècle, Paris, Points, 2013.

SOUTOU G.-H., La guerre de cinquante ans : le conflit Est-Ouest 1943-1990, Paris, Fayard, 2001.

TERRET T., FROISSARD T. (dir.), Le sport, l'historien et l'histoire, Reims, Épure, 2011.

\section{B. Histoire générale (années 1930 - années 1960)}

ANCEAU E., BOUDON J.-O., DARD O. (dir.), Histoire des internationales. Europe, XIXe-XXe siècles, Paris, Nouveau Monde, 2017.

BERNASCONI G., «De l'universalisme au transnational : le Comité international olympique, acteur atypique des relations internationales ", Bulletin de l'Institut Pierre Renouvin, vol. 31, n 1, 2010, pp. 151-159.

BERSTEIN S., MILZA P. (dir.), L'année 1947, Paris, Presses de Sciences Po, 2000.

BERTRAND G., Le conflit helléno-turc : la confrontation des deux nationalismes à l'aube du XXI' siècle, Paris, Maisonneuve \& Larose, 2004.

BOLZ D., Les arènes totalitaires : fascisme, nazisme et propagande sportive : Hitler, Mussolini et les jeux du stade, Paris, CNRS Éditions, 2009.

BONDE H., Football with the foe. Danish sport under the swastika, Odense, University Press of Southern Denmark, 2008.

BOTT S. et al. (eds.), Neutrality and neutralism in the global Cold War: between or within the Blocs?, London, Routledge, 2015.

BOUKARI-YABARA A., Africa unite! Une histoire du panafricanisme, Paris, La Découverte, 2014.

CLAUDE G., « Israël-États-Unis, de la reconnaissance historique à l'alliance stratégique. Histoire des relations stratégiques et diplomatiques, 1948-2004", Revue historique des armées, vol. 252, 2008, pp. 2-11.

CLAVIN P., Securing the world economy. The reinvention of the League of Nations, 1920-1946, Oxford, Oxford University Press, 2013.

DECORZANT Y., La Société des Nations et la naissance d'une conception de la régulation économique internationale, Bruxelles, P.I.E. Peter Lang, 2011.

DEFRANCE J., « Lautonomisation du champ sportif. 1890-1970 », Sociologie et sociétés, vol. 27, $\mathrm{n}^{\circ} 1,1995$, pp. 15-31. 
CHARITAS P., « La Commission d'Aide Internationale Olympique (CAIO) : un instrument de propagande soviétique ? (1951-1962) ", Sport History Review, vol. 40, 2009, pp. 143-166.

CHARITAS P., "Imperialisms in the Olympics of the colonization in the postcolonization. Africa into the International olympic committee, 1910-1965 ", The International Journal of the History of Sport, vol. 32, n 7 , 2015, pp. 909-922.

DICHTER H., JOHN A. (eds.), Diplomatic Games. Sport starecraft and international relations since 1945, Lexington Kentucky, University Press of Kentucky, 2014.

DUFRAISSE S., MOMZIKOFF S., PEDEMONTE R., «Les Soviétiques hors d'URSS : quels voyages pour quelles expériences ", Les Cahiers Irice, vol. 16, $\mathrm{n}^{\circ}$ 2, 2016, pp. 11-18.

DULLIN S., "Des frontières s'ouvrent et se ferment. La mise en place d'un espace socialiste derrière le rideau de fer, 1953-1970 ", Relations internationales, vol. 147, n 3, 2011, pp. 35-48.

DURANT Y., Le nouvel ordre européen nazi (1938-1945), Bruxelles, Complexe, 1990.

DYRESON M., "The original Pan-American Games? The 1937 Dallas PanAmerican olympics ", The International Journal of the History of Sport, vol. 33, $n^{\circ} 1-2,2016$, pp. 6-28.

EGOROVA N., « La formation du bloc de l'Est comme frontière occidentale du système communiste (1947-1955) ", dans S. COEURE, S. DULLIN S. (dir.), Frontières du communisme. Mythologies et réalités de la division de l'Europe de la révolution d'Octobre au mur de Berlin, Paris, La Découverte, 2007, pp. 248-271.

FERNANDEZ L'HOESTE H., IRWIN R., POBLETE R. (eds.), Sports and nationalism in Latin/o America, Basingstoke, Palgrave MacMillan, 2015.

FICKERS A., JOHNSON C. (eds.), Transnational television history. A comparative approach, London, Routledge, 2012.

GAIDUK I.V., Divided together. The United States and the Soviet Union in the United Nations, 1945-1965, Washington, Woodrow Wilson Center Press, 2012.

GIRGINOV V., "Bulgarian sport policy 1945-1989: A strategic relations approach ", The International Journal of the History of Sport, vol. 26, $\mathrm{n}^{\circ} 4$, 2009, pp. 515-538.

GOUNOT A., Die Rote Sportinternationale, 1921-1937. Kommunistische Massenpolitik im europäischen Arbeitersport, Münster, Lit Verlag, 2002.

HAYNES R. " "Lobby" and the formative years of radio sports commentary, 1935-1952 ", Sport in History, vol. 29, n ${ }^{\circ}$ 1, 2009, pp. 25-48.

HELLEINER E., Forgotten Foundations of Bretton Woods. International Developments and the Making of the Postwar Order, Ithaca, Cornell University Press, 2014. 
HERREN M. (ed.), Networking the International System. Global Histories of International Organization, Cham, Springer, 2014.

HOCHSCHERF T., LAUCHT C., PLOWMAN A. (eds.), Divided, but not Disconnected: German Experiences of the Cold War, New York, Berghahn Book, 2010.

KEYS B., Globalizing sport. National rivalry and international community in the 1930s, London, Harvard University Press, 2006.

KOTT S., "Par-delà la Guerre froide. Les organisations internationales et les circulations Est-Ouest (1947-1973) ", Vingtième Siècle. Revue d'histoire, vol. 109, n 1, 2011, pp. 143-154.

KOTT S., «Les organisations internationales, terrains d'étude de la globalisation. Jalons pour une approche socio-historique ", Critique internationale, vol. 52, n 3, 2011, pp. 9-16.

KISSOUDI P., "Antidote to war: the Balkans Games ", dans J.A. MANGAN (ed.), Militarism, Sport, Europe. War Without Weapons, London, Frank Cass, 2003, pp. 142-165.

LABORIE L., " De quoi l'universel est-il fait ? L'Europe, les empires et les premières organisations internationales ", Les Cahiers Irice, vol. 9, $\mathrm{n}^{\circ}$ 1, 2012, pp. 11-22.

LAQUA D., "Internationalisme ou affirmation de la nation ? La Coopération intellectuelle transnationale dans l'entre-deux-guerres, Critique internationale, vol. 52, n 3, 2011, pp. 51-67.

LIPKIN M., "Avril 1952, la conférence économique de Moscou : changement de tactique ou innovation dans la politique extérieure stalinienne ?", Relations internationales, vol. 147, $\mathrm{n}^{\circ} 3,2011$, pp. 19-33.

LOUDCHER J.-F., DAY D., « The International Boxing Union (1913-1946): a European Sports and/or Political Failure ? ", The International Journal of the History of Sport, vol. 30, $\mathrm{n}^{\circ}$ 17, 2013, pp. 2016-2030.

MAUREL C., "L'Unesco : une plate-forme pour les circulations transnationales de savoirs et d'idées (1945-1980)", Histoire@Politique.Politique, culture, société, vol. 15, 2014, publié en ligne.

MONTEREMAL G., "L'Équipe : médiateur et producteur de spectacle sportif (1946-1967) ", Le Temps des médias, vol. 9, n 2, 2007, pp. 107-120.

OIKONOMIDIS P., Le jeu mondial dans les Balkans. Les relations gréco-yougoslaves de la Seconde Guerre mondiale à la Guerre froide, Paris, L'Harmattan, 2011.

OTTOGALLI-MAZZACAVALLO C., TERRET T., " La Fédération internationale d'escrime en guerre : de la spoliation à l'épuration (1939-1948) ", Sport History Review, vol. 42, n 1, 2011, pp. 1-16.

PARKS J., The Olympic Games, the Soviet Sports Bureaucracy, and the Cold War: Red Sport, Red Tape, Lanham, Lexington Books, 2017. 
PINTO A.C., "Le salazarisme et le fascisme européen », Vingtième Siècle. Revue d'histoire, vol. 62, 1999, pp. 15-25.

PONS S., The Global Revolution. A History of International Communism. 1917-1991, Oxford, Oxford University Press, 2014.

RAINIO-NIEMI J., The Ideological Cold War: the Politics of Neutrality in Austria and Finland, New York, Routledge, 2014.

RAJAK S., Yugoslavia and the Soviet Union in the early Cold War: Reconciliation, comradeship, confrontation, 1953-1957, London, Routledge, 2011.

RENOLIET J.-J., L'Unesco oubliée. La Société des Nations et la coopération intellectuelle (1919-1946), Paris, Publications de la Sorbonne, 1999.

REY M.-P., «Diplomatie et diplomates soviétiques à l’ère du dégel. 1953-1954 », Cahiers du monde russe, vol. 44, n 2, 2003, pp. 309-322.

RICHARD A.-I., "Competition and complementarity: civil society networks and the question of decentralizing the League of Nations ", Journal of Global History, vol. 7, n 2, 2012, pp. 233-256.

RIDER T., «Eastern Europe's unwanted: exiles athletes and the Olympic games, 1948-1964 ", Journal of Sport History, vol. 40, n 3, 2013, pp. 435-453.

RIORDAN J., Sport, politics and communism, Manchester, Manchester University Press, 1991.

ROMIJN P., SCOTT-SMITH G., SEGAL J. (eds.), Divided dreamworlds? The cultural Cold War in East and West, Amsterdam, Amsterdam University Press, 2012.

SHAW T. "The politics of Cold War culture », Journal of Cold War Studies, vol. 3 , $\mathrm{n}^{\circ} 3,2003$, pp. 59-76.

SIRINELLI J.-F., SOUTOU G.-H. (dir.), Culture et Guerre froide, Paris, PUPS, 2008.

VONNARD P., SBETTI N., QUIN G. (eds.), Beyond boycotts. Sport during the Cold War in Europe, Oldenburg, De Gruyter, 2017.

STUDENY C., Linvention de la vitesse. France, XVIII $-X X^{e}$ siècle, Paris, Gallimard, 1995.

TEICHLER H.-J., Internationale Sportpolitik im Dritten Reich, Schorndorf, K. Hofmann, 1991.

WAHL A., La seconde histoire du nazisme dans l'Allemagne fédérale depuis 1945, Paris, Armand Colin, 2006.

WAHLIG H., Sport im Abseits. Die Geschichte der jüdischen Sportbewegung im nationalsozialistischen Deutschland, Göttingen, Wallstein Verlag, 2015. 


\section{Histoire et sociologie de la coopération européenne}

AFFINITO M., MIGANI G., WENKEL C. (dir.), Les deux Europes. Actes du III colloque international RICHIE, Bruxelles, P.I.E. Peter Lang, 2009.

ARCHAMBAULT F., ARTIAGA L., BOSC G. (dir.), Le continent basket. L'Europe et le basket-ball au XXe siècle, Bruxelles, P.I.E. Peter Lang, 2015.

BADENOCH A., FICKERS A. (eds.), Materializing Europe. Transnational Infrastructure and the Project of Europe, Basingstoke, Palgrave Macmillan, 2010.

BADENOCH A., FICKERS A., HEINRICH-FRANKE C. (eds.), Airy Curtains in the European Ether: broadcasting and the Cold War, Baden-Baden, Nomos, 2013.

BITSCH M.-T., LOTH W., POIDEVIN R. (dir.), Institutions européennes et identités européennes, Bruxelles, Bruylant, 1998, pp. 165-83.

BITSCH M.-T., La construction européenne. Enjeuxpolitiques et choix institutionnels, Bruxelles, P.I.E. Peter Lang, 2007.

BOUVIER Y., LABORIE L. (dir.), L'Europe en transition. Énergie, mobilité, communication au XVIII ${ }^{e}-X X I^{e}$ siècles, Paris, Nouveau Monde, 2017.

BUSSIÈRE E., MORADIELLOS E. (eds.), Memorias y lugares de memoria de Europe - Mémoires et lieux de mémoire en Europe - Memories and places of memory of Europe, Bruxelles, P.I.E. Peter Lang, 2012.

CHABOT J.-L., Aux origines intellectuelles de l'Union européenne. L'idée d'Europe unie de 1919 à 1939, Grenoble, Presses universitaires de Grenoble, 2005.

DUCHESNE S., "L'identité européenne, entre science politique et sciencefiction ", Politique européenne, vol. 30, n 1, 2010, pp. 7-16.

FLEURY A., "Les petits États dans la politique européenne au XX $\mathrm{X}^{\mathrm{e}}$ siècle ", dans M. DUMOULIN, G. DUCHENNE (dir.), Les petits États et la construction européenne. Actes de la VII Chaire Glaverbel d'études européennes 2000-2001, Bruxelles, P.I.E. Peter Lang, 2009, pp. 15-46.

FLEURY A., JILEK L. (dir.), Une Europe malgré tout, 1945-1990, Bruxelles, P.I.E. Peter Lang, 2009.

GASPARINI W., "Un sport européen ? Genèse et enjeux d'une catégorie européenne ", Savoir/Agir, vol. 15, 2011, pp. 49-57.

KAISER W., PATEL K. K., "Multiple connections in European co-operation: international organizations, policy ideas, practices and transfers 1967-92", European Review of History. Revue européenne d'histoire, vol. 24, n 3, 2017, pp. 337-357.

KENT J., « British Postwar Planning for Europe 1942-45 ", dans A. VARSORI, E. CALANDRI (eds.), The failure of peace in Europe, 1943-48, Basingstoke, Palgrave Macmillan, 2002, pp. 40-48.

GAXIE D. et al. (dir.), L'Europe des Européens. Enquête comparative sur les perceptions de l'Europe, Paris, Economica, 2010. 
HOZÉ B., "Le mouvement sportif a-t-il une vision de l'Europe ?", dans S. SCHIRMANN (dir.), Organisations internationales et architectures européennes 1929-1939, Metz, Centre de recherche histoire et civilisation de l'Université de Metz, 2003, pp. 163-177.

LABORIE L., L'Europe mise en réseaux. La France et la coopération internationale dans les postes et les télécommunications (années 1850-années 1950), Bruxelles, P.I.E. Peter Lang, 2010.

LABORIE L., LOMMERS S., "Les concerts européens à la radio dans l'entredeux-guerres. Mise en onde d'une métaphore diplomatique ", Le Temps des médias, vol. 11, 2008, pp. 110-125.

LAPTOS J., "L'élargissement avant la lettre. La place de l'Europe centrale et orientale dans l'activité du Mouvement européen (1949-1952), dans C. HOREL (dir.), Nations, cultures et sociétés en Europe centrale [volume de mélanges offerts au professeur Bernard Michel pour son soixante-dixième anniversaire], Paris, Publications de la Sorbonne, 2006, pp. 123-135.

LÉVY M.-F., SICARD M.-N. (dir.), Les lucarnes de l'Europe. Télévisions, cultures, identités, 1945-2000, Paris, Publications de la Sorbonne, 2008.

LÉVY M.-F. (dir.), Jean d'Arcy, la communication au service des droits de l'homme, Paris, Presses de la Sorbonne, 2013.

MECCHI L., MIGANI G., PETRINI F. (eds.), Networks of global governance: International Organisations and European Integration in a historical perspective, Cambridge, Cambridge Scholar Press, 2014.

MOURLON-DRUOL E., "Rich, Vivid, and Ignored. History in European studies ", Politique européenne, vol. 50, n 4, 2015, pp. 56-69.

OLIVIER C., MAGNETTE P. (dir.), Une Europe des élites ? Réflexions sur la fracture démocratique de l'Union européenne, Bruxelles, IEE, 2007.

OSMONT M. et al. (dir.), Européanisation au XXe siècle. Un regard historique, Bruxelles, P.I.E. Peter Lang, 2012.

PATEL K. K., « Provincialising European Union: Co-operation and integration in Europe in a historical Perspective ", Contemporary European History, vol. 22, $n^{\circ}$ 4, 2013, pp. 649-673.

PECOUT G. (dir.), Penser les frontières de l'Europe du XIXe au XX siècle. Élargissement et union : approches historiques, Paris, PUF, 2004.

REY M.-P., «Le retour à l'Europe ? Les décideurs soviétiques face à l'intégration européenne, 1957-1991 ", Journal of European Integration History, vol. 11, n¹, 2005, pp. 7-27.

SCHOT J., LAGENDICK V., "Technocratic internationalism in the interwar years: building Europe on motorways and electricity networks ", Journal of Modern European History, vol. 6, n 2, 2008, pp. 196-217.

SCHOT J., KAISER W., Writing the Rules for Europe. Experts, Cartels, and International Organizations, Basingstoke, Palgrave Macmillan, 2014 
SOUTOU G.-H., ROBIN HIVERT E. (dir.), L'URSS et l'Europe de 1941 à 1957, Paris, Presses de l'Université Paris-Sorbonne, 2007.

SMITH A., La passion du sport : le football, le rugby et les appartenances en Europe, Rennes, Presses universitaires de Rennes, 2001.

ROGER A., TERRET T., European Athletics. Une histoire continentale de l'athlétisme, Stuttgart, Neuer Sportverlag, 2012.

TOKARSKI W. et al., A Perfect Match? Sport and the European Union, Aachen, Meyer \& Meyer Verlag, 2009.

VANER S., "La Turquie et l'Union européenne. L'altérité commune ", dans M. DUMOULIN, G. DUCHENNE (dir.), L'Europe et la Méditerranée. Actes de la VIe Chaire Glaverbel d'études européennes 2000-2001, Bruxelles, P.I.E. Peter Lang, 2001, pp. 107-124.

WAGNER A.-C., "Syndicalistes européens. Les conditions sociales et institutionnelles de l'internationalisme des militants syndicaux ", Actes de la recherche en sciences sociales, vol. $155, \mathrm{n}^{\circ} 5,2008$, p. 12-33.

WARLOUZET L., " Dépasser la crise de l'histoire de l'intégration européenne », Politique européenne, vol. 44, n 2, 2014, pp. 98-122.

WASSENBERG B., Histoire du Conseil de l'Europe (1949-2009), Bruxelles, P.I.E. Peter Lang, 2012.

WASSENBERG B., CLAVERT F., HAMMAN P. (dir.), Contre l'Europe? Antieuropéisme, euroscepticisme et alter-européisme dans la construction européenne de 1945 à nos jours : acteurs institutionnels, milieux politiques et société civile, Stuttgart, Franz Steiner Verlag, 2010.

ZAKHAROVA L., " Des techniques authentiquement socialistes ? Transferts et circulations dans les télécommunications entre l'URSS et l'Europe (années 1920 - années 1960) », Critique internationale, vol. 66, n 1, 2015, pp. 19-35.

\section{Histoire et sociologie du football en Europe et en Amérique du Sud}

ARCHAMBAULT F., "Le football à Trieste de 1945 à 1954 », Vingtième Siècle. Revue d'histoire, vol. 111, n³, 2011, pp. 49-58.

ARCHAMBAULT F., "Le continent du football », Cahiers des Amériques latines, vol. 74, 2014, pp. 15-35.

ARMUS D., RINKE S. (eds.), Del Football al Fútbol/Futebol: Historias Argentinas, Brasileras y Uruguayas en el Siglo XX. Frankfurt am Main, Vervuert, 2014.

BECK P., Scoring for Britain: international football and international politics, 1900-1939, London, F. Cass, 1999.

BERTHOUD J., QUIN G., VONNARD P., Le football en Suisse. Des pionniers aux professionnels, Lausanne, PPUR, 2016. 
BREUIL X., «Vichy et le football ", dans J.-F. LOUDCHER et al. (dir.), Sport et idéologie, Besançon, Université de Besançon, 2004, pp. 53-61.

BROWN T., The Football Association 1863-1883: A source book, Nottingham, SoccerData Publication, 2011.

CHARROIN P., WAQUET A., «Paris 1924 : L'universalisme professionnalisant du football contre l'amateur internationaliste des Jeux olympiques ", dans T. TERRET (dir.), Les Paris des Jeux olympiques de 1924, Biarritz, Atlantica, 2004, pp. 445-490.

CHISARI F., " "Une organisation parfaite" : la Coupe du monde de football de 1934 selon la presse européenne ", dans S. MOURLANE, Y. GASTAUD (dir.), Le football dans nos sociétés. Une culture populaire. 1914-1998, Paris, Autrement, 2006, pp. 174-189.

DICHTER H., « Kiking around international sport: West Germany's return to the international community through football ", The International Journal of the History of Sport, vol. 30, $\mathrm{n}^{\circ}$ 17, 2013, pp. 2031-2051.

DIETSCHY P., «Football et guerre totale : le cas de la Seconde Guerre mondiale », dans S. MOURLANE, Y. GASTAUD (dir.), Le football dans nos sociétés. Une culture populaire. 1914-1998, Paris, Autrement, 2006, pp. 159-173.

DIETSCHY P., "Le football africain, entre domination coloniale et émancipation », dans P. SINGAREVLOU, J. SOREZ (dir.), L'Empire des sports. Une histoire de la mondialisation culturelle, Paris, Belin, 2010, pp. 53-69.

EDELMAN R., Serious fun: a history of spectator sport in USSR, New York, Oxford University Press, 1993.

EDELMAN R., "Le football sous Staline. Le Spartak au Goulag, 1937-1945 ", dans G. BENSOUSSAN et al. (dir.), Sport, corps et sociétés de masse. Le projet d'un homme nouveau, Paris, Armand Colin, 2012, pp. 135-145.

GONZALEZ CALLEJA E., "Le Real Madrid, "équipe du régime” ? Football et enjeux politiques pendant la dictature de Franco ", dans Y. GASTAUD, S. MOURLANE (dir.), Le football dans nos sociétés. Une culture populaire. 1914-1998, Paris, Autrement, 2006, pp. 65-81.

HADAS M., "Stratégie politique et tactique sportive : esquisse d'une analyse socio-historique du style de jeu de "l'équipe d'or" hongroise des années cinquante ", dans H. HELAL, P. MIGNON (dir.), Football : jeu et société, Paris, Institut national du sport et de l'éducation physique, 1999, pp. 85-99.

HAYNES R., "A Pageant of Sound and Vision: Football's Relationship with Television, 1936-60 ", The International Journal of the History of Sport, vol. 15, $\mathrm{n}^{\circ}$ 1, 1998, pp. 211-226.

HARRIF H., " "It is important that we weat the gentiles": the national significance of Israel's soccer matches against the USSR, Summer 1956 ", Sport in Society, vol. 12, n 8, 2009, pp. 1038-1053. 
HAVEMANN N., Fußball unterm Hakenkreuz. Der DFB zwischen Sport, Politik und Kommerz, Frankfurt am Main, Campus-Verlag, 2005.

HAVEMANN N., "Le sport dans l'Allemagne nationale-socialiste en guerre ", Guerres mondiales et conflits contemporains, vol. 268, $\mathrm{n}^{\circ} 4$, 2017, pp. 67-68.

HEINRICH H., "Die Internationalen "Angelegenheiten” des DFB », dans L. PEIFFER, D. SCHULZE-MARMELING (eds.), Hakenkreuz und rundes Leder. Fussball im Nationalsozialismus, Göttingen, Verlag die Werkstatt 2008, pp. 190-197.

HERZOG M., "Blitzkrieg" im Fussballstadion. Der Spielsystemstreit zwischen dem NS-Sportfunktionär Karl Oberhuber und Reichstrainer Sepp Herberger, Stuttgart, Kohlhammer, 2012.

HERZOG M., BRÄNDLE F. (eds.), Europäischer Fussball im Zweiten Weltkrieg, Stuttgart, Kohlhammer, 2015.

HERZOG M., BAHRO B. (eds.), Die Gleischschaltung des Fussballsports im nationalsozalistischen Deutschland, Stuttgart, Kohlhammer, 2016.

KUIPER S., Ajax, the Dutch, the War. Football in Europe during the Second World War, London, Orion, 2003.

LANFRANCHI P., " Le football sarrois de 1947 à 1952. Un contre-pied aux actions diplomatiques ", Vingtième Siècle. Revue d'histoire, vol. 26, 1990, pp. 59-66.

MACON B., "The politization of football: the European game and the approach to the Second World War ", Soccer and Society, vol. 9, n 4, 2007, pp. 532-55.

MAJTÉNYI G., "Football et pouvoir dans la Hongrie communiste ", dans F. ARCHAMBAULT, S. BEAUD, W. GASPARINI (dir.), Le football des nations. Des territoires de jeu aux communautés imaginées, Paris, Publications de la Sorbonne, 2016, pp. 109-120.

MARTIN S., Football and Fascism. The National Game Under Mussolini, Berg, Oxford, 2004.

MASON T., Passion of the People? Football in South America, London, Verso, 1995.

MEYER J.-C., "La fondation du "Grand Stade". De la triomphale retransmission en direct de la Coupe du monde 1954 et de ses avatars dans les pays membres de l'Eurovision (1954-1958) ", Traverse. Revue d'histoire, vol. 23, n 1, 2016, pp. 49-59.

MURRAY B., The World's Game. A History of Soccer, Urbana, University of Illinois Press, 1996.

PEREIRA V., « La Selecção portugaise, entre dictature, propagande coloniale et horizon européen ", dans F. ARCHAMBAULT, S. BEAUD, W. GASPARINI (dir.), Le football des nations. Des territoires de jeu aux communautés imaginées, Paris, Publications de la Sorbonne, 2016, pp. 51-74. 
PORTER D., KOWALSKI R., " Cold War football: British-European encounters in the 1940s and 1950s ", dans S. WAGG, D. ANDREWS (eds.), East plays West: sport and the Cold War, London, Routledge, 2007, pp. 64-81.

QUIN G., "La Suisse face à la Grande Allemagne (1933-1942). Éléments pour une histoire du football helvétique ", dans M. ATTALI (dir.), Sports et médias, $X I X^{e}-X X^{e}$ siècles, Biarritz, Atlantica, 2010, pp. 761-770.

QUIN G., VONNARD P., "Switzerland, a stronghold in European football, 1930-1954? ", Sport in History, vol. 35, n 4, 2015, pp. 531-549.

PFEIL U., " Le football allemand sous le national-socialisme ", dans G. BENSOUSSAN et al. (dir.), Sport, corps et sociétés de masse. Le projet d'un homme nouveau, Paris, Armand Colin, 2012, pp. 117-133.

SBETTI N., "The Quest for Legitimacy. The Road to Redemption for Italian Football in Europe after the Second World War (1943-1949) ", dans P. VONNARD, G. QUIN, N. BANCEL (dir.), Building Europe with the ball. Turning points in the Europeanization of Football (1905-1995), Oxford, Peter Lang, 2016, pp. 101-119.

SIMON J. A., "Fútbol y cine en el franquismo: la utilización política del héroe deportivo en la España de Franco ", Historia y communicación social, vol. 17, 2012, pp. 69-84.

SCHOTTÉ M., « Monter en première division. Trajectoires de notabilisation des présidents de clubs de football professionnel (1960-1999) ", Politix, vol. 114, $\mathrm{n}^{\circ}$ 2, 2016, pp. 99-120.

TAYLOR M., «Four Nations against the World: Britain, "Britishness" and World Cup ", dans A. WAHL (dir.), Aspects de l'histoire de la Coupe du monde de football, Metz, Centre régional universitaire d'histoire, 2006, pp. 61-86.

TAYLOR M., " Football's Engineers? British football coaches, migration and intercultural transfer, c.1910-c.1950's ", Sport in History, vol. 30, n 1, 2010, pp. 138-163.

VIGARELLO G., "Les premières coupes du monde ou l'installation du sport moderne ", Vingtième Siècle, vol. 26, 1990, pp. 5-10.

WAHL A., Les archives du football. Sport et société en France (1880-1990), Paris, Gallimard, 1989.

WAHL A., Histoire de la Coupe du monde de football : une mondialisation réussie, Bruxelles : P.I.E. Peter Lang, 2012.

\section{E. Histoire et sociologie du football européen}

ARCHAMBAULT F., "La difficile gestation d'une Europe du football dans les années 1950 ", dans P. ANASTASIO, C. BOSSU (eds.), Facciamo l'Europa. Aspetti dell'integrazione culturale europea (1957-2007), Roma, Storia e Storia dell'Arte in Roma, 2012, pp. 85-96. 
BANCEL N., QUIN G., VONNARD P., " Introduction. Stuying the Europeanization of football in historical perspective ", dans P. VONNARD, G. QUIN, N. BANCEL (eds.), Building Europe with the ball. Turning points in the Europeanization of Football (1905-1995), Oxford, Peter Lang, 2016, pp. 1-18.

BREUIL X., "Football and the Construction of a European area in the East: Ruptures and Continuities after 1945 ", dans P. VONNARD, G. QUIN, N. BANCEL (eds.), Building Europe with the ball. Turning points in the Europeanization of Football (1905-1995), Oxford, Peter Lang, 2016, pp. 121-136.

BREUIL X., CONSTANTIN P.N., "The Balkan Cups as a Vector of European Integration ", Sport History, vol. 35, n 4, 2015, pp. 591-603.

DIETSCHY P., "Did a "Europe of football" exist in the 1930's? ", Sport in History, vol. 35, n 4, 2015, pp. 515-530.

DIETSCHY P., «L'Euro de l'européisme à la commercialisation de la Nation », Pôle Sud, vol. 47, n 4, 2018, pp. 25-39.

GASPARINI W., HEIDMANN M., «Les enjeux de l'européanisation du football. Débats et controverses entre les acteurs de l'Union européenne et du Conseil de l'Europe ", dans G. ROBIN (dir.), Football, Europe et régulations, Lille, Presses universitaires du Septentrion, 2011, pp. 111-123.

GASPARINI W., POLO J.-F., « L'espace européen du football. Dynamiques institutionnelles et constructions sociales ", Politique européenne, vol. $36, \mathrm{n}^{\circ} 1$, 2012, pp. 8-21.

GASPARINI W., "En guise de conclusion. Le football dans la construction européenne : de la nation à l'illusio européiste ", dans F. ARCHAMBAULT, S. BEAUD, W. GASPARINI (dir.), Le football des nations. Des territoires de jeu aux communautés imaginées, Paris, Publications de la Sorbonne, 2016, pp. 243-256.

GASPARINI W., «Sport et football "européens”. Genèse d'une nouvelle catégorie de l'action publique », dans W. GASPARINI (dir.), L'Europe du football. Sociohistoire d'une construction européenne, Strasbourg, Presses universitaires de Strasbourg, 2017, pp. 25-49.

KENNEDY P., "Using Habermas to crack the European Football Championships », Sport in Society, vol. 20, $\mathrm{n}^{\circ}$ 3, 2017, pp. 355-368.

KING A., The European ritual: football in the new Europe, Aldershot, Ashgate, 2004.

KOLLER C., " Einleitung: Europäischer Fussball im Zeitalter der Katastrophen », dans C. KOLLER, F. BRANDLE (eds.), Fussball zwischen den Kriegen, Zurich, Lit Verlag, 2010, pp. 1-22.

LANFRANCHI P., "Fussball in Europa 1920-1938: die Entwicklung eines internationalen netzwerkes", dans R. HORAK, W. REITER (eds.), Die kanten des runden leders. Beitrage zur europäischen fussballkultur, Vienna, Promedia, 1991, pp. 163-172. 
LANFRANCHI P., "Football, cosmopolitisme et nationalisme ", Pouvoir, vol. 101, 2002, pp. 15-25.

MARSCHICK M., " Mitropa: representations of "Central Europe" in football », International Review for the Sociology of Sport, vol. 36, $\mathrm{n}^{\circ}$ 7, 2001, pp. 7-23.

MARSTON K. T., " "Sincère camaraderie”: professionalization, politics and the pursuit of the European idea at the International Youth Tournament, 1948-57 ", dans P. VONNARD, G. QUIN, N. BANCEL (eds.), Building Europe with the ball. Turning points in the Europeanization of Football (1905-1995), Oxford, Peter Lang, 2016, pp. 137-161.

MITTAG J., "Europa und der Fussball. Die Europäische Dimension des Vereinsfussballs vom Mitropa-Cup bis zur Champions League ", dans J. MITTAG, H.-J. NIELAND (eds.), Das Spiel mit dem Fussball. Interessen, Projektionen und Vereinnahmungen, Essen, Klartext, 2007, pp. 155-176.

MITTAG J., LEGRAND B., «Towards a europeanization of football? Historical phases in the evolution of the UEFA football championship ", Soccer \& Society, vol. 11, n 6, 2010, pp. 709-722.

MOURLANE S., "A brief moment of latinity? France, Italy and the Latin Cup 1949-1957 ", Sport in History, 35, n 4, 2015, pp. 580-590.

NIEMANN A., GARCIA B., GRANT W. (eds.), The transformation of European football: Towards the europeanisation of the national game, Manchester, Manchester University Press, 2011.

POLI R., "L'Europe à travers le prisme du football. Nouvelles frontières circulatoires et redéfinition de la nation ", Cybergeo : European Journal of Geography, vol. 294, 2004, publié en ligne.

QUIN G., " La Coupe de l'Europe centrale (1927-1938), une compétition internationale oubliée ? ", Stadion. Revue internationale d'histoire du sport, vol. 37, n 2, 2013, pp. 285-304.

QUIN G., "Central Europe rules European Football. The "Golden Age" of Regional Connections in European Football (1926-38)", dans P. VONNARD, G. QUIN, N. BANCEL (eds.), Building Europe with the ball. Turning points in the Europeanization of Football (1905-1995), Oxford, Peter Lang, 2016, pp. 53-73.

RASK MADSEN M., " "Europe United”. La Ligue des champions comme construction européenne ", dans A. COHEN, Y. DEZALAY, D. MARCHETTI, "Esprits d'États, entrepreneurs d'Europe ", Actes de la recherche en sciences sociales, vol. 166-167, $\mathrm{n}^{\circ} 1-2,2007$, p. 9.

SENYUVA Ö., TUNC S., "Turkey and the European Football ", Sport in History, vol. 35, n 4, 2015, pp. 567-579.

SCHOTTÉ M., "La structuration du football professionnel européen. Les fondements sociaux de la prévalence de la "spécificité sportive" ", Revue française de socio-économie, vol. 13, $\mathrm{n}^{\circ}$ 1, 2014, pp. 85-106. 
SMITH A., "Conclusion. L'Europe, le football et la sociologie politique. Quelques remarques ", Politique européenne, vol. 36, 2012, pp. 149-157.

SONNTAG A., Les identités du football européen, Grenoble, Presses universitaires de Grenoble, 2008.

SONNTAG A., "Une passion partagée, des identités ambiguës. Enjeux européens du football contemporain ", Politique européenne, vol. 26, $\mathrm{n}^{\circ} 3$, 2008, p. 191-209.

SONNTAG A., "Grilles de perception et dynamiques identitaires dans l'espace européen du football. Le projet FREE (7 $7^{e}$ PCRD, 2012-2015) ", Politique européenne, vol. 36, $\mathrm{n}^{\circ}$ 1, 2012, pp. 185-192.

TAYLOR M., "England and the "Continent" reconsidered (1920-1960) », dans P. VONNARD, G. QUIN, N. BANCEL (eds.), Building Europe with the ball. Turning points in the Europeanization of Football (1905-1995), Oxford, Peter Lang, 2016, pp. 75-97.

VONNARD P., La genèse de la Coupe des clubs champions. Une histoire du football européen (1920-1960), Neuchâtel, Éditions du CIES, 2012.

VONNARD P., «A competition that shook European football: the origins of the European champion clubs' cup, 1954-1955 ", Sport in History, vol. 34, n 4, 2014, pp. 595-619.

VONNARD P., QUIN G., BANCEL N. (eds.), Building Europe with the ball. Turning points in the Europeanization of Football (1905-1995), Oxford, Peter Lang, 2016.

\section{F. Histoire et sociologie de la FIFA et de l'UEFA}

BARCELO L., "L'Europe des 52 : l'Union Européenne de Football Association (UEFA) ", Guerres mondiales et conflits contemporains, vol. 228, $\mathrm{n}^{\circ} 4,2007$, pp. 119-133.

BECK P.J., " Going to war, peaceful co-existence or virtual membership ? British football and FIFA, 1928-46 ", The International Journal of the History of Sport, vol. 17, n 1 1, 2000, pp. 113-134.

DIETSCHY P., "Une plongée dans les archives du football mondial : faire l'histoire de la Fédération Internationale de Football Association (FIFA) », dans F. BOSMAN, P. CLASTRES, P. DIETSCHY (dir.), Images de sport : de l'archive à l'histoire, Paris, Nouveau Monde, 2004, pp. 319-332.

DIETSCHY, P., « Making football global? FIFA, Europe, and the non-European football world, 1912-74 ", Journal of Global History, vol. 8, 2013, pp. 279-298.

EISENBERG C., "FIFA et politique. 1945-2000 ", dans Y. GASTAUD, S. MOURLANE (dir.), Le football dans nos sociétés. Une culture populaire. 1914-1998, Paris, Autrement, 2006, pp. 119-134. 
HOMBURG H., "Ernst Thommen, die Schweiz und der Weltfussball, 1946-1962 ", Basler Zeitschrift für Geschichte und Altertumskunde, vol. 107, 2007, pp. 69-102.

HOMBURG H., " Financial aspects of FIFA's world cup or the structural challenges of growth ", dans A. WAHL (dir.), Aspects de l'histoire de la Coupe du monde de football, Metz, Centre régional universitaire d'histoire, 2006, pp. 157-209.

GOUNOT A., "Vom "Rotsport" zur FIFA. Der Sowjetfußball und seine Internationalen Kontakte, 1922-1946 ", dans D. DAHLMANN, A. HILBRENNER, B. LENZ (eds.), Überall ist der Ball rund. Zur Geschichte und Gegenwart des Fußballs in Ost- und Südosteuropa, vol. 2, Essen, Klartext, 2007, pp. 269-286.

GROLL M., "UEFA Football competition as European site of memory - cups of identity ", dans W. PYTA, N. HAVEMANN (eds.), European Football and collective memory, Basingstoke, Palgrave Macmillan, 2014, pp. 63-84.

MITTAG J., " Negociating the Cold War? Perspectives in memory research on UEFA, the early European football competitions and the European Nations cups ", dans W. PYTA, N. HAVEMANN (eds.), European Football and collective memory, Basingstoke, Palgrave Macmillan, 2014, pp. 40-63.

MITTAG J., NIELAND J.-U., "Auf der Suche nach Gesamteuropa: UEFA und EBU als Impulsgeber der Europäisierung des Sports », dans C. BERTLING, E. MERTIN (eds.), Freunde oder Feinde? Sportberichterstattung in Ost und West während des Kalten Kriegs, Gütersloh, Medienfabrik Gütersloh, 2013, pp. 208229.

MITTAG J., VONNARD P., "The role of societal actors in shaping a panEuropean consciousness. UEFA and the overcoming of Cold War tensions, 1954-1959 ", Sport in History, vol. 37, n 3 2017, pp. 332-352.

QUIN G., " La reconstruction de la Fédération Internationale de Football Association (FIFA) après la Seconde Guerre mondiale (1944-1950). Jalons pour une histoire des relations sportives internationales ", STAPS, vol. 106, $\mathrm{n}^{\circ}$ 4, 2014, pp. 21-35.

QUIN G., VONNARD P., " La Présidence inamovible du football Jules Rimet (1873-1956) ", dans E. BAYLE (dir.), Les grands dirigeants du sport. 23 portraits et stratégies de management, Bruxelles, De Boeck, 2014, pp. 25-43.

SCHOTTÉ M., " "To live is to live concealed” confined relation between UEFA and the European community (1970s and 1980s)", dans P. VONNARD, G. QUIN, N. BANCEL (eds.), Building Europe with the ball. Turning points in the Europeanization of Football (1905-1995), Oxford, Peter Lang, 2016, pp. 187-199.

STUDER M., "Le développement du football au sein de l'UEFA ", dans L. BIZZINI, C.-A. HAUERT, M. PIFFARETTI (dir.), Le football, éléments 
théoriques pour une meilleure compréhension, Genève, Médecine et Hygiène, 1998, pp. 97-104.

SUDGEN J., TOMLINSON A., FIFA and the contest for world football: who rules the Peoples' Game?, Cambridge, Polity Press, 1998.

TOMLINSON A., «FIFA and the men who made It », Soccer and Society, vol. 1, $\mathrm{n}^{\circ} 1,2000$, pp. 55-71.

TOMLINSON A., SUDGEN J., "Global power struggles in world football: FIFA and UEFA, 1954-74, and their legacy ", International Journal of the History of Sport, vol. 14, ${ }^{\circ} 2$ 2, 1997, pp. 1-25.

VONNARD P., «How did UEFA govern the European turning point in Football ? UEFA, the European Champion Clubs' Cup and the Inter-Cities Fairs Cup Projects (1954-1959)", dans P. VONNARD, G. QUIN, N. BANCEL (eds.), Building Europe with the ball. Turning points in the Europeanization of Football (1905-1995), Oxford, Peter Lang, 2016, pp. 165-185.

VONNARD P., " Euvrer en faveur du football européen. Jalons biographiques sur les précurseurs de l'UEFA (1920-1960)", dans W. GASPARINI (dir.), L'Europe du football. Socio-histoire d'une construction européenne, Strasbourg, Presses universitaires de Strasbourg, 2017, pp. 107-121.

VONNARD P., QUIN G., " Did South America foster European Football ? Transnational influences on the continentalisation of FIFA and the creation of UEFA, 1926-1959 ", Sport in Society, vol. 20, n 10, 2017, pp. 1424-1439.

VONNARD P., MARSTON K., «Building bridges between separated Europeans: the role of UEFA's competitions in East-West exchanges (1955-1964) ", dans P. VONNARD, N. SBETTI, G. QUIN (eds.), Beyond boycotts. Sport during the cold war in Europe, Berlin Oldenbourg, De Gruyter, 2017, pp. 85-109.

WAHL A., "La Fédération internationale de football-association (1903-1930)", dans P. ARNAUD, A. WAHL (dir.), Sport et relations internationales, Metz, Centre de recherche "Histoire et Civilisation de l'Europe occidentale ", 1993, pp. 30-45.

WAHLIG H., « Dr. Ivo Schricker: Ein Deutscher in Diensten des Weltfussballs », dans L. PEIFFER, D. SCHULZE-MARMELING (eds.), Hakenkreuz und Rundes Leder. Fussball im Nationalsozialismus, Göttingen, Verlag die Werkstatt, 2008, pp. 197-206.

WAHLIG H., Ein Tor zur Welt. Der Deutsche Fußball und die FIFA 1945-1950, Göttingen, Verlag die Werkstatt, 2010.

WEILL P.-E., « "Plutôt l'UEFA que l'UE!" : (dés-)enchantement de l'identification à l'Europe des jeunes de milieux populaires issus de l'immigration ", Politique européenne, vol. 30, $\mathrm{n}^{\circ}$ 1, 2011, pp. 107-130. 


\section{G. Thèses de doctorat, mémoires de fin d'études, rapports}

DUFRAISSE S., Les " Héros du sport». La fabrique de l'élite sportive soviétique (1934-1980), thèse de doctorat réalisée sous la direction de Marie-Pierre Rey, Université Paris 1-Panthéon-Sorbonne, 2016.

JALABERT D'AMADO L., " “Montevideo 1930” ou l'amnésie européenne. Étude d'une Coupe du monde ignorée ", mémoire de master II réalisé sous la direction d'Olivier Compagnon, Université de Paris III, 2014.

LÜSCHER L., «La Coupe des nations 1930. Une compétition “européenne” dans la Genève Internationale ", mémoire de fin d'études réalisé sous la direction de Nicolas Bancel, Université de Lausanne, 2015.

MAUMON DE LONGEVIALLE A., " La Construction de l'Europe du football ", mémoire de $4^{\mathrm{e}}$ année d'I.E.P. réalisé sous la direction de Justine Faure, Université de Strasbourg, 2009.

PARKS J., Red Sport, Red Tape: the Olympic Games, the Soviet Sports Bureaucracy, and the Cold War, 1952-1980, thèse de doctorat réalisée sous la direction de Donald Raleigh, University of North Carolina, 2009.

QUIN G., Une première élite du football européen (1904-1956), ou les prémices d'un champ footballistique européen, dossier réalisé dans le cadre de l'UEFA Research Grant Programme 2011-2012.

SBETTI N., Giochi diplomatici. Sport e politica estera nell'Italia del secondo dopoguerra (1943-53), thèse de doctorat réalisée sous la direction de Giuliana Laschi, Université de Bologne, 2015.

\section{H. Littérature non académique}

ANONYME, Fédération internationale de football-association 1904-1929, Amsterdam, J.H. de Bussy-FIFA, 1929.

DE RYSWICK J., 100000 heures de football, Paris, La Table Ronde, 1962.

FERRAN J., Le football. Aventure d'hommes, Paris, La Table Ronde, 1964.

FERRAN J., Les Coupes d'Europe de football, Genève, Famot, 1978.

GODDET J., L'Équipée belle, Paris, Robert Lafont/Stock, 1962.

RIMET J., "Le football et le rapprochement des peuples ", Bulletin de la FIFA, édition spéciale, 1954.

RIMET J., Histoire merveilleuse de la Coupe du monde, Paris, Union Européenne d'Éditions, 1954.

ROUS S., Football words. A lifetime in Sport, London, Faber, 1978.

ROTHENBUEHLER R., Les 25 ans de l'UEFA, UEFA, 1979.

ROTHENBUEHLER R., UEFA. 50 ans, UEFA, Nyon, 2005. 
SCHAUB D., Ernst B. Thommen. Das bewegte Leben des grossen Schweizer sportforderers, Basel, Rotweiss, 2013.

VIELI A., Les 60 ans de l'UEFA, UEFA, Nyon, 2015. 


\section{Index des noms de personnes}

A

Alvéal Ernesto 231, 253

Andrejevic Mihailo 82, 102, 137, 139-140, 161, 164-165, 170, 210, 218, 231-232, 238, 242, 245, 279, 283, 308-309, 314, 343-344, 349

\section{B}

Bangerter Hans 40, 201, 206-207, 210, 226, 278-279, 304-305, 311, $316,333,341,346,365$

Barassi Ottorino 42, 78, 156-158, 189, 193, 201-221, 231, 250, 251, 254, 256, 257, 265, 267, 278, 290, 301, 302, 307-309, 311, 320, $323,325,340,352,359,363$, 367,370

Barreau Gaston 77, 198

Bauwens Joseph (Peco) 65, 68, 83, 87-88, 109, 147-148, 153, 155, 160-161, 163, 195, 210, 218, 310, 312-313, 333, 359

Bermudez 113-115, 120

Bernabeu Santiago 291

Bezençon Marcel 334-335, 337-338

Bianchi Manuel 140, 164-165

Bonnet Gabriel 87,

Briand Aristide 72

Brook Hirst Amos 133, 136, 179

Buero Enrique 57, 87, 97, 103, 109-110, 112-113, 119, 173
Cabot Ricardo 54

Camus Albert 377

Constantaras Constantin 211, 283, 299, 312-313

Crahay José 211, 213, 216-218, 250, 265, 267, 271, 276, 293-294, 297, $307,310,312,316,321,323-324$, $333,340,354$

Coudenhove-Kalergi Richard 72

\section{D}

Delaunay Henri 40, 54, 56, 65, 78, 81-82, 109, 210, 212, 217-218, 224-225, 260, 265-269, 271-274

Delaunay Pierre 274-279, 282-287, 290-293, 296-302, 307, 310-311, 313-317, 319-322, 324-325, 328, 331-332,335-338, 340, 344, 347, 352, 354, 358-359

De Ryswick Jacques 142, 201, 209, 342

Dimmock Peter 340

Dittborn Carlos 354

Do Reis Ribeiro Gilberto 54

Drewry Arthur 133, 135-136, 140, $163,165,202,225,229,231$, $246,309,322,353$

\section{$\mathbf{E}$}

Eberstaller Richard 54, 103, 109

Eicher Otto 154

Eie Daniel 54, 164, 166 


\section{$\mathbf{F}$}

Ferran Jacques 39, 198, 201,

278-279, 291, 300, 328, 331, 342, 344

Fodor 54

Frey Alfred 296, 297, 299, 312,

Fischer Mor 88-89, 91, 110, 164

Franco (General) 101, 232, 239, 345

Frederiksen Leo 143, 160, 164-165

\section{G}

Galeano Eduardo 377

Gassmann Kurt 54, 198, 204-207, 213-214, 222-223, 230-232, 239-240, 242, 244, 248, 250-257, 260-261, 265, 266, 270-272, 278-279, 281-288, 292-293, 301, 318-324, 326-327, 329, 332-333, 343, 348-349, 352-356, 358-360, 365

Gerö Joseph 161, 271, 280, 310, 312

Goddet Jacques 201, 342

Graham George 68, 136, 218, 271, 294, 297, 310, 324

Granatkine Valentin 141, 234-235, 309

Gromyko Andrei 242

\section{H}

Hanot Gabriel 201, 291, 296, 300

Havelange João 80, 365

Henninger Marcel 54

Herberger Joseph (Sepp) 77, 127,

Hermesse George 256, 258, 260

Hirschman Carl W. 47, 49-50, 55-56, $61,65,79,81,87,95-97,99,104$, 106, 108, 177

\section{K}

Kenyeres Arpad 54, 166-167

Khrouchtchev Nikita S. 299

Kips 54

Kopehel Karl 127

Krayenbuehl Ursula 279, 314

Krebs Jean 131, 140, 142-143, 164-165

Kubala László 198, 235

Kurmann 168, 203

\section{J}

Jacquemart Gustave 54, 78, 161

$\mathbf{L}$

Linnemann Félix 50, 95, 109, 145

Lotsy Johannes (Karel) 74-75, 87-88, 90-91, 110, 115-116, 140, 143, 161, 164-165, 198, 202, 207, 210, 218, 234, 254, 307-309, 320, 323, 353

Luchidy 102

\section{M}

Mallow 54, 167

Manning Randolph 170-171

Mauro Giovanni 49-52, 82, 87, 88, 103-104, 109, 148, 156-161, 163, $170,207,210,232,234$

Meert François 211, 218, 249

Meisl Hugo 49-50, 52, 54-56, 104, 110

Mibelli Celestino 248

Munoz Calero Armando 293, 241-242, 257, 310

Mussolini Benito 55, 156, 208 


\section{$\mathbf{N}$}

Neusch Walter 198

Nisot 97-98

\section{$\mathbf{O}$}

Oberhuter Karl 127

Oestrup Louis 54

Otth Suzanne 279

\section{$\mathbf{P}$}

Pascot Joseph (Jep) 160

Pefferkorn Maurice 201, 216, 229

Pelletier Louis 321

Pelikan Rudolf 50, 58, 70, 87-88, 91, 97, 110, 163-164

Peluffo Domingo 249

Pibarot Pierre 274

Pozzo Vittorio 77-78, 157

Przeworski 170

Pujol Augustin 231, 238-240, 294, 296-297, 299, 301, 312-313, 333

\section{$\mathbf{R}$}

Ramirez Alvaro 231, 253

Réthaker Jean-Philippe 260

Rijnink 128, 153

Rimet Jules 9, 38, 40, 45-46, 56-57, 70-71, 78,-88, 92, 95, 98-99, 103104, 117, 121-122, 124, 134-135, 138-142, 145, 148, 160-161, 164-169, 171, 183-185, 188, 199, 202, 206-207, 209, 210, 225, 229-230, 233-234, 241, 248-249, 254, 258-259, 265, 267, 272, 310, 324, 349-350, 352, 358, 369, 377

Roosevelt Franklin D. 114

Rotili Antonio 256, 259

Rous, Stanley 10, 38, 42, 66-67, 75-76, 78, 104, 134-136, 142,
189, 193, 199, 201-203, 205-211, 213-214, 216, 221, 229, 231-232, 234, 246, 248, 250-251, 254, 257, 260, 267, 271, 276, 278, 283, 290, 301-302, 307-311, 313, 321-322, 324-325, 339-340, 352, 363,370

Russo Juan 231, 244, 253

Rylski Lyzek 299, 313

\section{$S$}

Salazar António de Oliveira 343 Saporta Raimundo 346 Savin Serguei 235, 238-243, 256, 259 Schmidlin Ilse 279, 281, 288, 316 Schricker Ivo 46, 49, 51-52, 55, 61, 66-70, 74-78, 87-88, 91-96, 98-106, 112-113, 116, 118-121, 124-125, 128-129, 132, 134-135, $137-143,145,147-156,158-162$, 164-185, 199, 201-204, 223-224, 229-230, 234

Schwartz Ebbe 211, 231-232, 240, 249, 253-254, 271, 277, 282, 293, $307,310-312,316,325,333$

Sebes Gustav 266, 271, 281, 291, $299,308,310,312,315,324$

Seeldrayers William R. 50-51, 65, 77, 82, 87-88, 95, 97, 104, 115, 129, 134-135, 138-140, 143, 145, 147-156, 158-161, 164-165, 168-170, 177-178, 180-183, 199, 202, 205, 207-208, 210, 213-214, 231, 233-234, 238-239, 242, 244 , 246, 249-251, 253, 256, 260, 261, 283, 291-292, 322, 343, 349

Skinner Jack 352, 354, Spaak Paul-Henri 215

Staline Joseph 197, 243, 299 


\section{$\mathbf{T}$}

Tito (Maréchal) 343-345

Thommen Ernst 10, 11, 42, 189, 193-194, 201-211, 216, 218, 220-221, 248-249, 253-259, 266-267, 278-279, 290, 302, 307-309, 311, 323, 325-326, 333, $349,352-354,359,363,365,370$

$\mathrm{U}$

Urbini Max 260

V

Valousek Vaclav 140, 143, 164-165, 169-170

Valenzuela Luis 114, 179, 183-185, $231,244,253$
Vankesbeeck Oscar 161

Verdyck Alfred 54, 109, 207

Vogl Joseph 243, 266, 312, 321

Von Frenckell Eric 163-164, 233, 248-249

Von Mengden Guido 148

Von Tschammer und Osten Hans 146

W

Wiederkehr Gustave 211, 218

Willimosvki Ernest 128

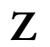

Zimmermann Karl 321 


\section{EUROCLIO - Titres parus}

№ 104 - The Two Sick Men of Europe? Britain and Italy between Crisis and Renaissance (1976-1983). Giulia Bentivoglıo, 2018.

№ 103 - Alcide De Gasperi: European Founding Father. Daniela PREDA, 2018.

№ 102 - Détente and Beyond. Anglo-Romanian Relations in the Aviation Industry (1966-1993). Mauro ElLI, 2018.

$\mathrm{N}^{\circ} 101$ - Experts and Expertise in Science and Technology in Europe since the 1960s Organized civil Society, Democracy and Political Decisionmaking. Christine Bouneau, David Burigana (eds.), 2018.

№ 100 - Jean Monnet et l'économie. Gérard Bossuat (dir.), 2018.

No 99 - The History of the European Monetary Union. Comparing Strategies amidst Prospects for Integration and National Resistance. Daniela PREDA, 2017.

N 098 - The European Union Approach Towards Western Sahara. Marco BALBONI and Giuliana LASCHI, 2016.

No 97 - Europe between Imperial Decline and Quest for Integration. Pro-European Groups and the French, Belgian and British Empires (19471957). Laura Koтtos, 2016.

№ 96 - Réinventer la diplomatie. Sociabilités, réseaux et pratiques diplomatiques en Europe depuis 1919 / Reshaping Diplomacy. Networks, Practices and Dynamics of Socialization in European Diplomacy since 1919. Vincent Genin, Matthieu Osmont and Thomas Raineau (eds.), 2016. No 95 - Sometimes Speaking with a Single Voice. The European Community as an International Actor, 1969-1979. Lorenzo FerRARI, 2016. No 94 - Competition Law Challenges in the Next Decade. Sofa OlivelRA PaIs (ed.), 2016.

№ 93 - The Borders of Schengen. Alice Cunha, Marta Silva, Rui Frederico (eds.), 2015.

№ 92 - Que dire à l'Espagne ? De l'isolement franquiste à la démocratie européiste, la France au défi, 1957-1979. Pablo Martin-Pañeda, 2015.

№ 91 - Francis Delaisi, du dreyfusisme à "l'Europe nouvelle ». Éric Bussière, Olivier Dard, Geneviève DuchenNe (dir.), 2015.

No 90 - European Parties and the European Integration Process, 19451992. Lucia Bonfreschi, Giovanni Orsina, Antonio Varsori (eds.), 2015. 
N 89 - Européanisation et démocratisation des États baltes dans la période de préadhésion à l'UE. Le rôle de la conditionnalité politique des organisations européennes. Anne-Sylvie PIGEONNIER, 2015.

№ 88 - Le Continent basket. L'Europe et le basket-ball au XXe siècle. Fabien Archambault, Loïc Artiaga, Gérard Bosc (dir.), 2015.

$N^{\circ} 87$ - The Convention on the Future of Europe. How States Behave in a New Institutional Context of Negotiation. Francesco MARCHI, 2015.

$\mathrm{N}^{\circ} 86$ - Christian Democrat Internationalism. Its Action in Europe and Worldwide from post World War II until the 1990s. Volume III. The European People's Party Continental and Social Cooperation. Jean-Dominique DuRAND (ed.), 2014.

№ 85 - Pela Paz! For Peace! Pour la paix ! (1849-1939). Maria Manuela Tavares Ribeiro, Maria Fernanda Rollo, Isabel Maria Freitas Valente, Alice CunHA (eds.), 2014.

No 84 - Economic Crisis and New Nationalisms. German Political Economy as Perceived by European Partners. Antonio VARSORI, Monika Poettinger (eds.), 2014.

$N^{\circ} 83$ - European Constitutionalism. Historical and Contemporary Perspectives. Alexandre Dupeyrix, Gérard Raulet (eds.), 2014.

$\mathrm{N}^{\circ} 82$ - Cross-Border Cooperation Structures in Europe. Learning from the Past, Looking to the Future. Luis Domínguez, Iva PIRES (eds.), 2014.

№ 81 - The European Community and the World. A Historical Perspective. Giuliana LASCHI (ed.), 2014.

$N^{\circ} 80$ - Christian Democrat Internationalism. Its Action in Europe and Worldwide from Post World War II until the 1990s. Volume II: The Development (1945-1979). The Role of Parties, Movements, People. JeanDominique Durand (ed.), 2013.

$N^{\circ} 79$ - Christian Democrat Internationalism. Its Action in Europe and Worldwide from Post World War II until the 1990s. Volume I: The Origins. Jean-Dominique Durand (ed.), 2013.

No 78 - Investment Banking History. National and Comparative Issues (19th-21st centuries). Hubert Bonin \& Carlo Brambilla (eds.), 2013.

$N^{\circ} 77$ - Citizenship and Solidarity in the European Union. From the Charter of Fundamental Rights to the Crisis, the State of the Art. Mariana CANOtILHO, Pedro Madeira Froufe \& Alessandra Silveira (eds.), 2013.

№ 76- The OSCE: Soft Security for a Hard World. Competing Theories for Understanding the OSCE. Roberto DomingueZ (ed.), 2013. 
$N^{\circ} 75$ - Euroscepticism, Europhobia and Eurocriticism. The Radical Parties of the Right and Left vis-à-vis the European Union. Cesáreo RodríGuezAguilera de Prat, 2013.

No 74 - Fermer les mines en CONSTRUisant L'Europe. Une histoire SOCIALE DE L'INTÉGRATION EUROPÉENNE. Nicolas Verschueren, 2012

№ 73 - Refletsde la construction européenne. Réflexions, références et refus du débat sur l'Europe. Bertrand VAYssière (dir.), 2012.

№ 72 - The International Relations of Local Authorities. From Institutional Twinning to the Committee of the Regions: Fifty Years of European Integration History. Fabio ZucCA, 2012.

No 71 - Histoire du Conseil de l'Europe (1949-2009). Birte WASSEnBERG, 2012.

№ 70 - The EU, Security and Transatlantic Relations. Finn LAURSEN (ed.), 2012.

No 69 - Européanisation au XXe siècle. Un regard historique / Europeanisation in the 20th Century. The Historical Lens. Matthieu Osmont, Émilia Robin-Hivert, Katja Seidel, Mark Spoerer \& Christian Wenkel (dir./ eds.), 2012. 
Philippe Vonnard - 978-2-8076-0570-1

Téléchargé de PubFactory à01/07/2021 08:14:02PM

via free access 


\title{
Réseau européen Euroclio
}

\author{
avec le réseau SEGEI
}

Coordination : Chaire Jean Monnet d'histoire de l'Europe contemporaine (Cehec)

Collège Erasme, 1, place Blaise-Pascal, B-1348 Louvain-la-Neuve

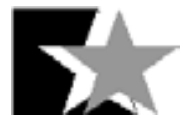

Allemagne
Jürgen Elvert
Wilfried Loth
Belgique
Julie Cailleau
Jocelyne Collonval
Yves Conrad
Gaëlle Courtois
Pascal Deloge
Geneviève Duchenne
Vincent Dujardin
Michel Dumoulin
Roch Hannecart
Pierre-Yves Plasman
Béatrice Roeh
Corine Schröder
Caroline Suzor
Pierre Tilly
Arthe Van Laer
Jérôme Wilson
Natacha Wittorski
Espagne
Enrique Moradiellos
Mercedes Samaniego Boneu

France
Françoise Berger
Marie-Thérèse Bitsch
Gérard Bossuat
Éric Bussière
Jean-François Eck
Catherine Horel
Philippe Mioche
Marine Moguen-Toursel
Sylvain Schirmann
Matthieu Trouvé
Laurent Warlouzet
Emilie Willaert

\section{Hongrie}

Gergely Fejérdy

\section{Italie}

David Burigana

Elena Calandri

Eleonora Guasconi

Luciano Segreto

Antonio Varsori

\section{Luxembourg}

Charles Barthel

Etienne Deschamps

Jean-Marie Kreins

René Leboutte

Robert Philippart

Corine Schröder

Gilbert Trausch

\section{Pays-Bas}

Anjo Harryvan

Jan W. Brouwer

Jan van der Herst

\section{Pologne}

Józef Laptos

Zdzisiaw Mach

\section{Suisse}

Antoine Fleury

Lubor Jilek 
www.peterlang.com

Philippe Vonnard - 978-2-8076-0570-1

Téléchargé de PubFactory à01/07/2021 08:14:02PM

via free access 